UNIVERSIDADE DE BRASÍLIA

FACULDADE DE TECNOLOGIA

DEPARTAMENTO DE ENGENHARIA CIVIL E AMBIENTAL

\section{MÉTODOS ANALÍTICOS E NUMÉRICOS PARA O ESTUDO DOS EFEITOS TERMOMECÂNICOS NO CONCRETO MASSA ORIENTADOS ÀS BARRAGENS DE GRAVIDADE}

NAILDE DE AMORIM COELHO

ORIENTADOR: LINEU JOSÉ PEDROSO

TESE DE DOUTORADO EM ESTRUTURAS E CONSTRUÇÃO CIVIL

PUBLICAÇÃO: E.TD - 007A/16

BRASÍLIA/DF: DEZEMBRO - 2016 
UNIVERSIDADE DE BRASÍLIA

FACULDADE DE TECNOLOGIA

DEPARTAMENTO DE ENGENHARIA CIVIL E AMBIENTAL

\section{MÉTODOS ANALÍTICOS E NUMÉRICOS PARA O ESTUDO DOS EFEITOS TERMOMECÂNICOS NO CONCRETO MASSA ORIENTADOS ÀS BARRAGENS DE GRAVIDADE}

NAILDE DE AMORIM COELHO

TESE SUBMETIDA AO DEPARTAMENTO DE ENGENHARIA CIVIL E AMBIENTAL DA FACULDADE DE TECNOLOGIA DA UNIVERSIDADE DE BRASÍLIA COMO PARTE DOS REQUISITOS NECESSÁRIOS PARA A OBTENÇÃO DO GRAU DE DOUTOR EM ESTRUTURAS E CONSTRUÇÃO CIVIL.

APROVADA POR:

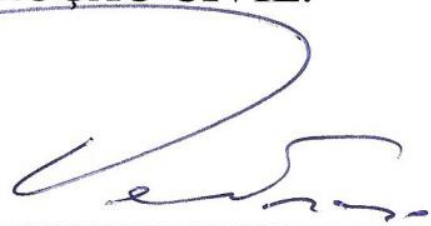

Prof. Lineu José Pedroso, Dr. Ing. (ENC-UnB)

(Orientador)

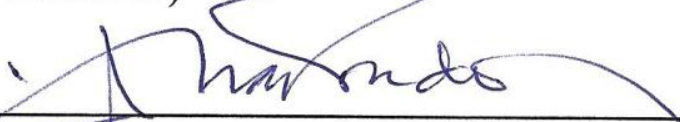

Prof. Roberto Dalledone Machado, DSd (UFPR)

(Examinador Externo)

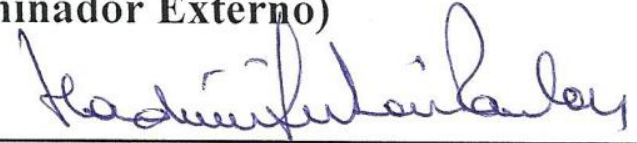

Prof. Vladimir Antonio Paulon, DSc. (UNICAMP)

(Examinador Externo)

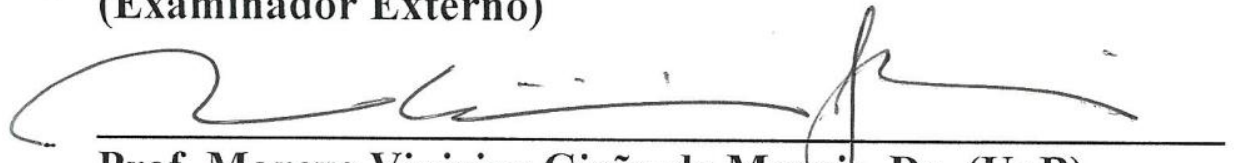

Prof. Marcus Vinicius Girão de Morais, Dr. (UnB)

(Examinador Externo)

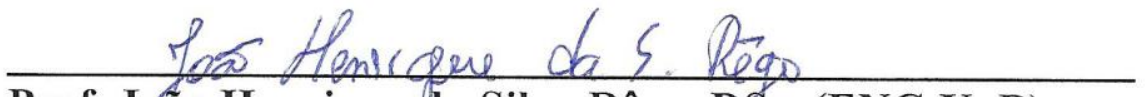

Prof. Jøâo Henrique da Silva Rêgo, DSc. (ENC-UnB)

(Examinador Interno)

BRASÍLIA/DF, 09 DE DEZEMBRO DE 2016 


\section{FICHA CATALOGRÁFICA}

\begin{tabular}{|c|c|}
\hline \multicolumn{2}{|c|}{$\begin{array}{l}\text { Métodos analíticos e numéricos para o estudo dos efeitos termomecânicos no concreto } \\
\text { massa orientados às barragens de gravidade. [Distrito Federal]. } 2016 . \\
\text { xxvii, 275p., } 210 \text { x } 297 \text { mm (ENC/FT/UnB, Doutor, Estruturas e Construção Civil, 2016). } \\
\text { Tese de Doutorado - Universidade de Brasília. Faculdade de Tecnologia. } \\
\text { Departamento de Engenharia Civil e Ambiental. }\end{array}$} \\
\hline 1. Concreto massa & 2. Temperatura \\
\hline 3. Método analíticos-numéricos & 4. Tensões termomecânicas \\
\hline 5. Barragens de gravidade & \\
\hline I. ENC/FT/UnB & $\mathrm{T}$ \\
\hline
\end{tabular}

\section{REFERÊNCIA BIBLIOGRÁFICA}

COELHO, N. A.; Métodos analíticos e numéricos para o estudo dos efeitos termomecânicos no concreto massa orientados às barragens de gravidade. Tese de Doutorado em Estruturas e Construção Civil. Publicação E.TD-007A/16, Departamento de Engenharia Civil e Ambiental. Universidade de Brasília. Brasília, DF, 275p.

\section{CESSÃO DE DIREITOS}

AUTOR: Nailde de Amorim Coelho.

TÍTULO: Métodos analíticos e numéricos para o estudo dos efeitos termomecânicos no concreto massa orientados as barragens de gravidade.

GRAU: Doutor

ANO: 2016

É concedida à Universidade de Brasília permissão para reproduzir cópias desta tese de doutorado e para emprestar ou vender tais cópias somente para propósitos acadêmicos e científicos. $\mathrm{O}$ autor reserva outros direitos de publicação e nenhuma parte dessa dissertação de mestrado pode ser reproduzida sem autorização por escrito do autor.

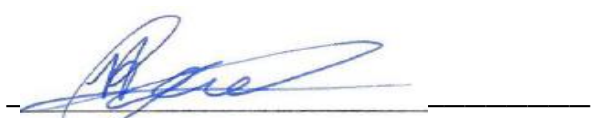

Nailde de Amorim Coelho CLN 407 Bloco C Apto 103, Asa Norte. 70.855-530 Brasília - DF - Brasil. 
Dedico aos meus pais, João Cincinato e Maria Alice, e à toda a minha família por todo apoio e incentivo, em especial aos meus irmãos Etevaldo, Erenita, Jobson, Elielton, e sobrinhos Isabela, Alícia, João Lucas e Luísa. 


\section{AGRADECIMENTOS}

Agradecer é uma simples forma de reconhecer àqueles que de alguma forma contribuíram para que o objetivo primordial fosse alcançado. Primeiramente, a minha gratidão à Deus, que me deu forças para enfrentar os desafios e obstáculos e não me deixou desistir no meio do caminho, mesmo diante das dificuldades.

Agradeço à Universidade de Brasília - UnB e ao Programa de Estruturas e Construção Civil - PECC pela oportunidade de poder me profissionalizar. Ao Conselho Nacional de Desenvolvimento Científico e Tecnológico - CNPq por conceder recursos que proporcionaram a permanência no curso e facilitaram o desenvolvimento da pesquisa e à Universidade Federal do Vale do São Francisco - UNIVASF por todo o apoio e liberação de atividades para conclusão do doutorado.

Aos meus professores do PECC o reconhecimento por todo o aprendizado, sobretudo, ao meu orientador Lineu José Pedroso, com o qual os estudos foram mais intensos, dignos de constante crescimento profissional. Agradeço também aos secretários do PECC Eva e Ricardo por todo apoio e suporte nessa jornada.

Aos meus amigos e companheiros do PECC, um imenso agradecimento por me ajudar e apoiar durante o percurso. Cito aqui àqueles que de algum modo contribuíram para o desenvolvimento desta tese: Divino, Eduardo, Eneida, Fabiano, Gelson, Matheus, Morgana e seu irmão Junior, Ramon, Sebastião, Virley, Wagner, Wallison, Wilber, e, especialmente, a Dyorgge e Nazaré grandes colaboradores em momentos decisivos dessa tese.

Aos meus pais, João Cincinato e Maria Alice, a minha eterna gratidão, sem eles eu nada seria. Obrigada também aos meus irmãos Etevaldo, Erenita, Jobson e Elielton, que acompanharam de perto a minha jornada e sempre me ajudaram. À minha avó, aos sobrinhos Isabela, Alicia, João Lucas e Luisa, e a toda a minha família, o meu sincero reconhecimento de que vocês são essenciais na minha vida.

Agradeço a Flávio Mamede, aluno do PECC e funcionário de Furnas, pessoa fundamental no desenvolvimento deste trabalho. Por fim, agradeço a todos que acreditaram, e também àqueles que duvidaram, que eu seria capaz. Agradeço àqueles que, mesmo com toda a minha ausência, puderam compreender e permanecem ao meu lado. A todos o meu muito obrigada! 
A persistência é o caminho do êxito.

Charles Chaplin 


\title{
RESUMO
}

\section{MÉTODOS ANALÍTICOS E NUMÉRICOS PARA O ESTUDO DOS EFEITOS TERMOMECÂNICOS NO CONCRETO MASSA ORIENTADOS AS BARRAGENS DE GRAVIDADE}

\author{
Autora: Nailde de Amorim Coelho \\ Orientador: Lineu José Pedroso, Dr. Ing. \\ Programa de Pós-graduação em Estruturas e Construção Civil \\ Brasília, dezembro de 2016
}

A construção de barragens de gravidade foi um marco para o desenvolvimento de estudos e controle tecnológico do concreto massa. A curva de geração de calor, devido ao calor de hidratação do concreto massa, é obtida experimentalmente, e seu ajuste pode ser feito pela função Hill. As restrições impostas às estruturas em conjunto com as variações térmicas podem gerar as fissuras de origem térmica, que, dependendo das proporções geométricas do corpo, se propagam até à superfície. A fim de evitar a deterioração das estruturas, algumas medidas de redução da temperatura devem ser tomadas. No entanto, é importante verificar o processo construtivo antes do início da execução das obras. O Método dos Elementos Finitos - MEF é uma alternativa para a simulação numérica dos problemas reais. Diante disso, este trabalho buscou analisar a construção de estruturas de concreto massa, abrangendo as metodologias aplicadas para a redução do gradiente térmico via MEF, como a construção em camadas. Porém, antes de utilizar o programa escolhido, o ANSYS, foram feitas validações com o Método das Diferenças Finitas - MDF e soluções analíticas para garantir o correto domínio da ferramenta. Após obterem-se a curvas de temperatura transiente, foram examinadas as tensões em alguns pontos da estrutura analiticamente, com o auxílio do MATLAB. Foram aplicadas as curvas de fluência do American Concrete Institute - ACI, European Committee for Concrete - CEB, United States Department of the Interior Bureau of Reclamation - USBR e Bazant-Panula. Todas se mostraram eficientes no cálculo de tensões. Posteriormente, analisou-se a influência da geometria dos corpos, verificando hipóteses da construção em camadas, da presença de furos com temperatura reduzida dentro de uma estrutura. Por fim, foi modelada a construção de uma barragem de gravidade hipotética levando-se em consideração todos os resultados simulados nas fases anteriores.

Palavras-chave: Concreto massa, Temperatura, Método analíticos-numéricos, Tensões termomecânicas, Barragens de gravidade 
ABSTRACT

ANALYTICAL AND NUMERICAL METHODS FOR THE STUDY OF THERMOMECHANICAL EFFECTS ON MASS CONCRETE ORIENTED TO GRAVITY DAMS

Author: Nailde de Amorim Coelho

Supervisor: Lineu José Pedroso

Postgraduate Program in Structural Engineering and Construction

Brasília, December of 2016

The construction of gravity dams was a landmark for the development of studies and mass concrete technology control. The heat generation curve, due to the heat of hydration of the mass concrete is obtained experimentally, and its fit can be done by the Hill function. The constraints imposed on the structures associated with thermal variations can generate the thermal origin cracks, which, depending on the geometric proportions of the body can propagate to the surface. In order to avoid structures deterioration, some measures of temperature reduction must be taken. However, it is important to check the construction process before the start of the construction. The Finite Element Method - FEM is an alternative for numerical simulation of real problems. Therefore, this thesis sought to analyze the construction of mass concrete structures, covering the methodologies applied for thermal gradient reduction by FEM, such as layered construction. However, before using the program chosen (ANSYS), validations were made with the Finite Difference Method - FDM and analytical solutions to ensure the correct mastery of the tool. After obtaining transient temperature curves, tensions at some points of the structure were examined analytically using MATLAB. The creep curves of the American Concrete Institute - ACI, European Committee for Concrete - CEB, United States Department of the Interior Bureau of Reclamation - USBR and Bazant-Panula were applied, and all were efficient in tension calculation. Afterwards, the influence of the geometry of the bodies was analyzed, verifying hypotheses of the construction in layers, presence of holes with reduced temperature inside the structure. UFinally, it was modeled the construction of a gravity dam taking into account all the simulated results in previous phases.

Keywords: Mass concrete, temperature, analytical-numerical method, thermomechanical Stresses, Gravity dams. 


\section{SUMÁRIO}

1 INTRODUÇ̃̃O

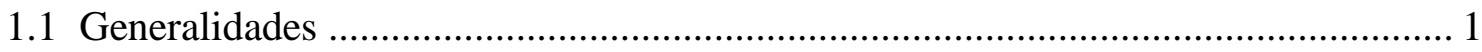

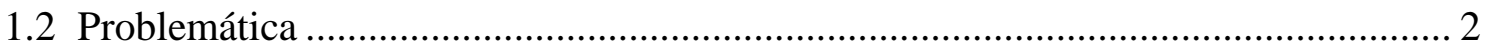

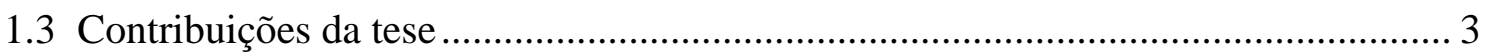

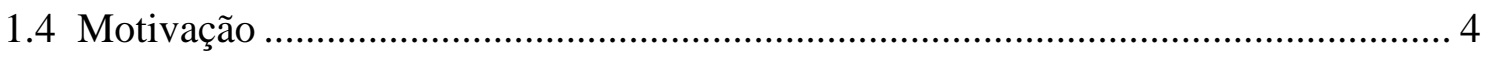

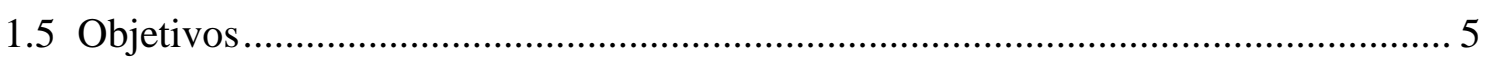

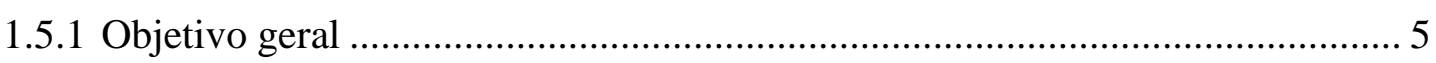

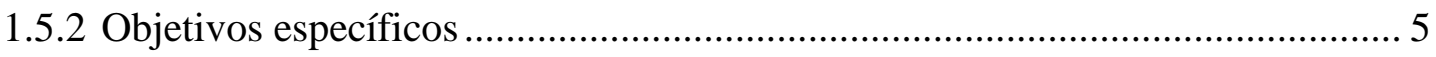

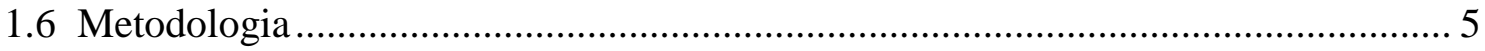

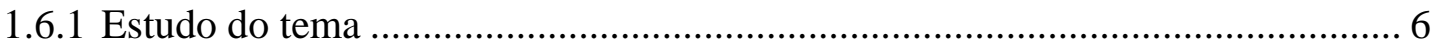

1.6.2 Estudo de equações.................................................................................... 6

1.6.3 Programas computacionais ...................................................................... 8

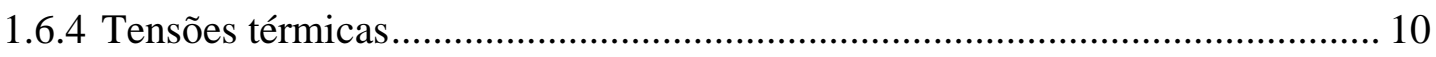

1.7 Abrangências e limitações ..................................................................................... 11

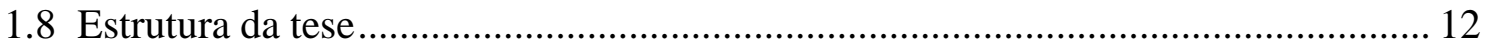

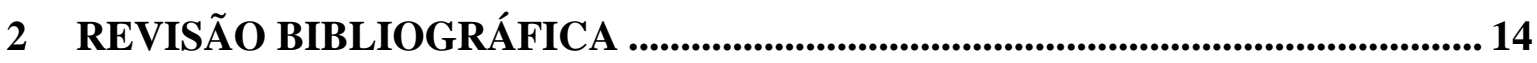

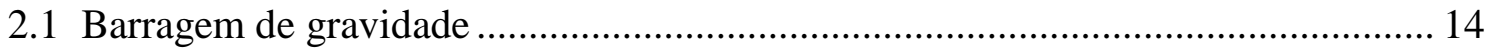

2.1.1 Breve histórico de barragens e perspectivas futuras........................................... 17

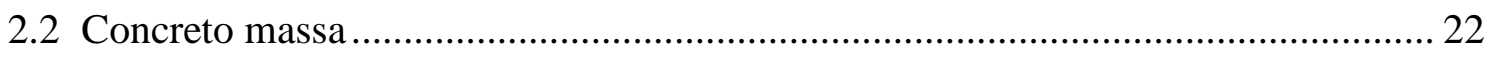

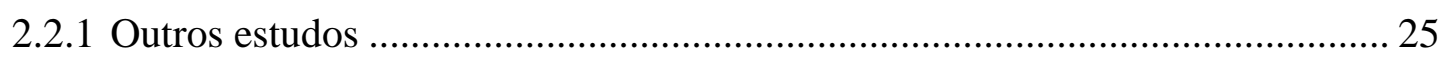

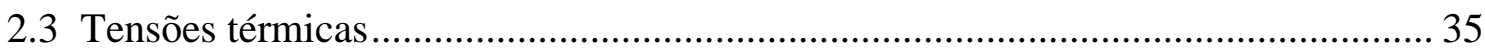

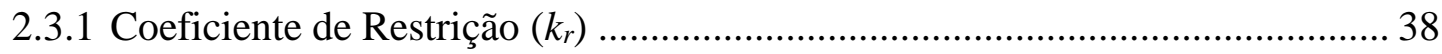

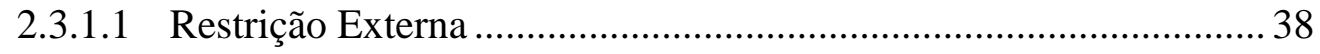

2.3.1.2 Restrição Interna ....................................................................... 44

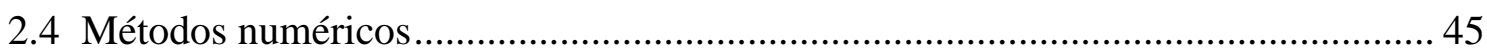

2.4.1 Solução pelo Método dos Elementos Finitos (MEF)......................................... 47

3 GENERALIDADES PARA UMA ANÁLISE TERMOMECÂNICA...................... 49

3.1 Propriedades térmicas do concreto ..................................................................... 49

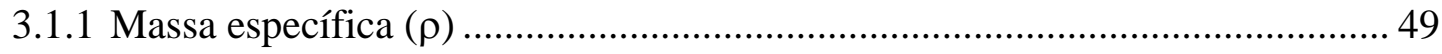

3.1.2 Condutividade térmica $(\mathrm{k})$...................................................................... 50

3.1.3 Calor Específico (c) …………………………………………………. 51 


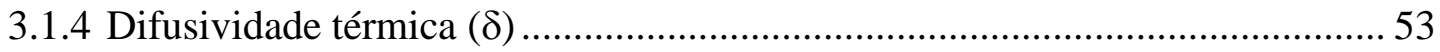

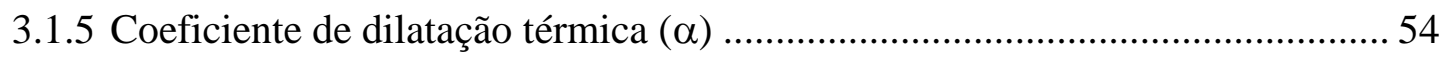

3.2 Propriedades Físicas e Mecânicas do Concreto ....................................................... 55

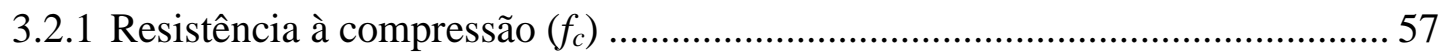

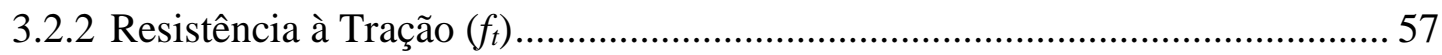

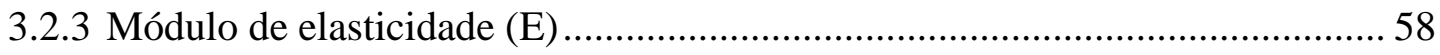

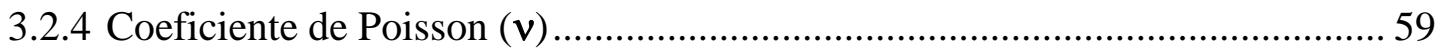

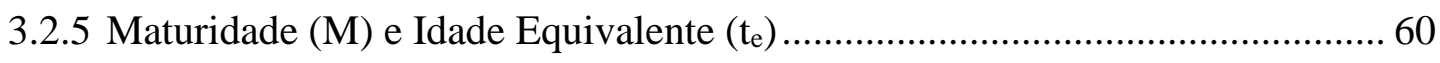

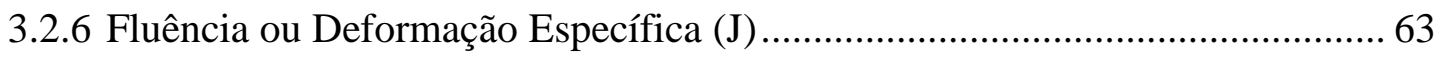

3.3 Transferência de calor em estruturas de concreto massa....................................... 73

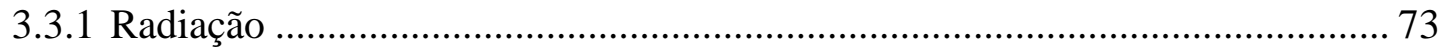

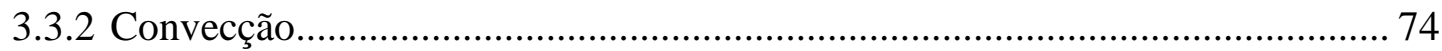

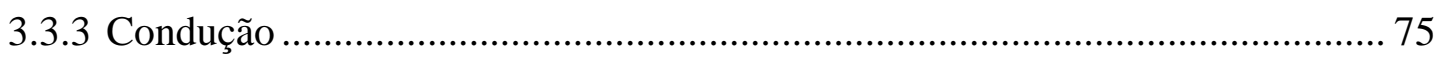

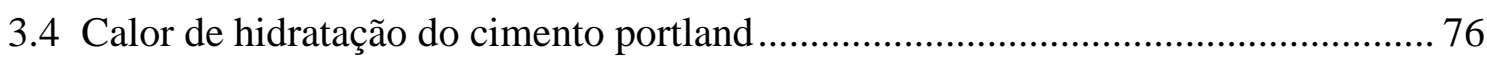

3.4.1 Valores numéricos para o calor de hidratação ............................................... 85

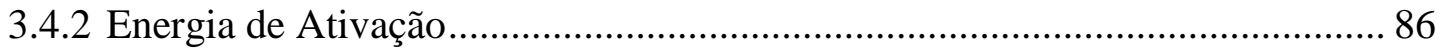

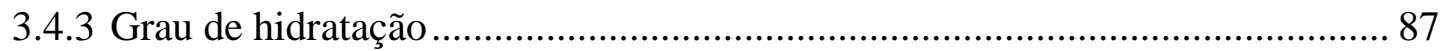

4 FUNDAMENTOS TEÓRICOS ....................................................................................... 89

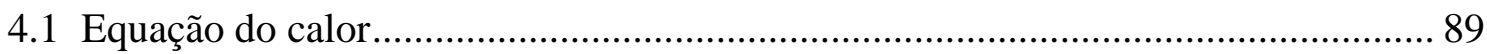

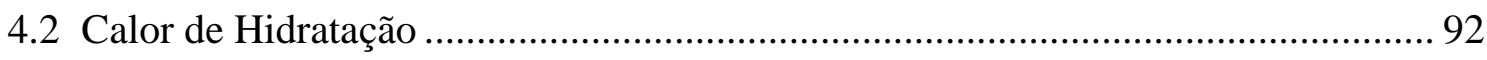

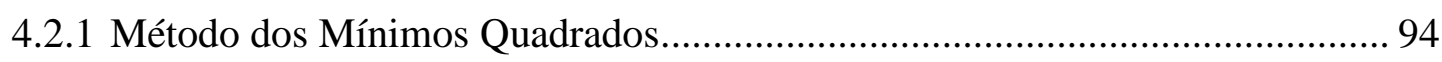

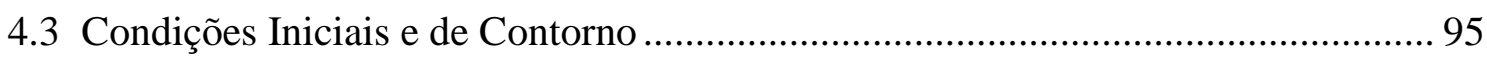

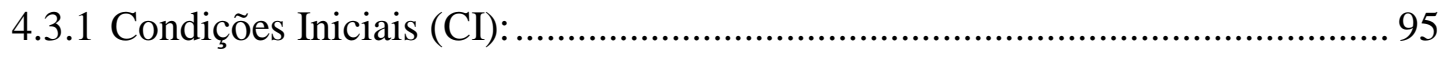

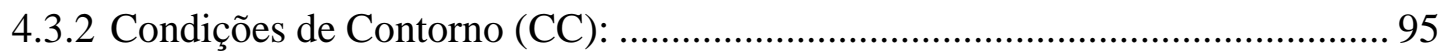

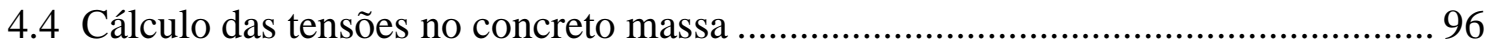

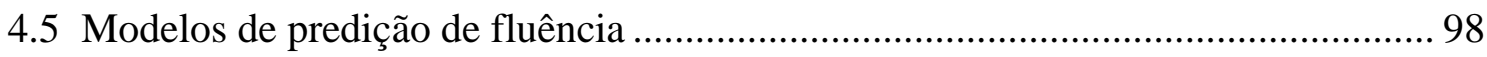

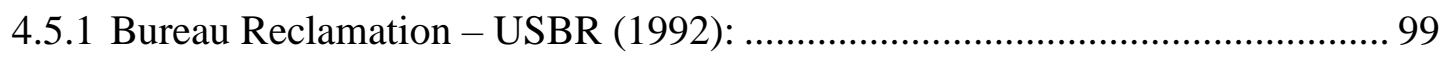

4.5.2 Dupla Potência - DP (Azenha, 2004):_......................................................... 99

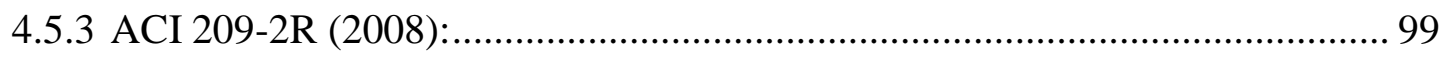

4.5.4 CEB MC90-99 (ACI 209-2R, 2008): ........................................................... 100

4.5.5 Comparação entre os métodos ....................................................................... 101

4.5.6 Comparação entre temperatura, geração de calor e tensão............................. 102 


\section{MÉTODOS DE SOLUÇÃO, ASPECTOS COMPUTACIONAIS e VALIDAÇÕES}

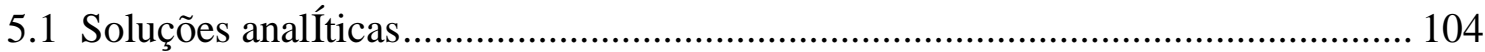

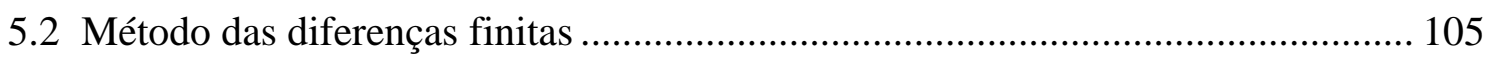

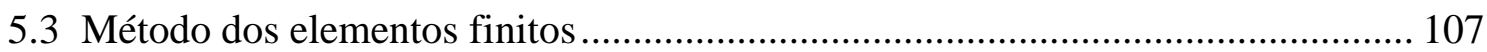

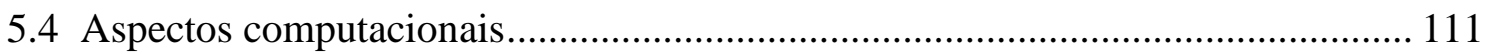

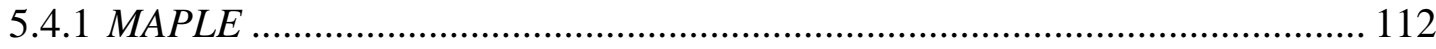

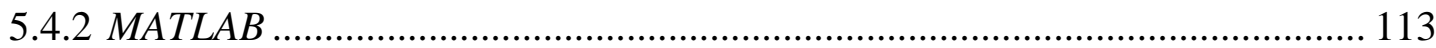

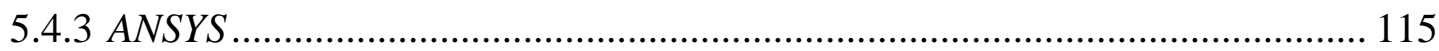

5.5 Testes preliminares de verificação de convergência.................................................. 120

5.6 Validação dos resultados numéricos.................................................................... 125

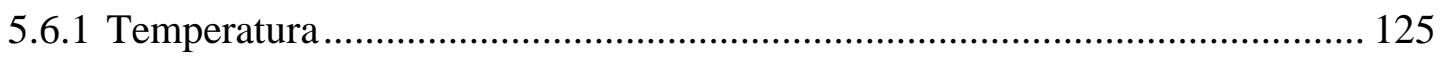

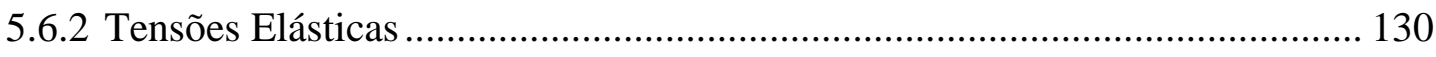

5.6.3 Tensões Viscoelásticas - problemas reais ....................................................... 132

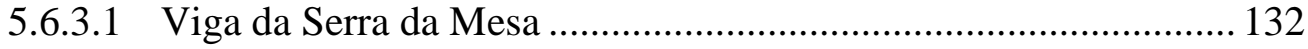

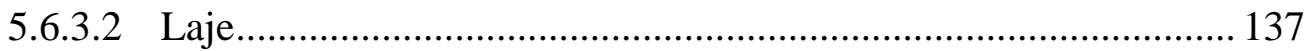

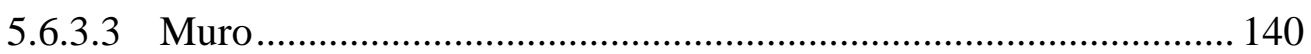

5.6.3.4 Sala de Radioterapia.................................................................... 145

6 RESULTADOS - ESTUDOS DE CASOS E SIMULAÇÕES ................................. 153

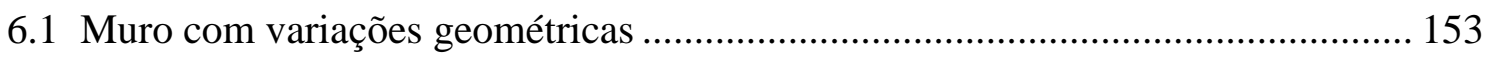

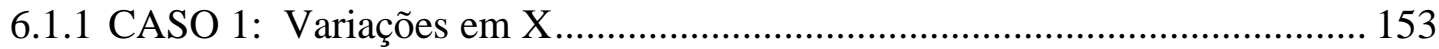

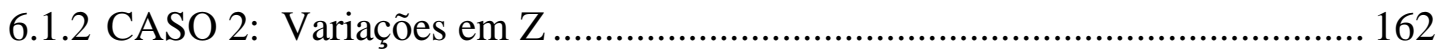

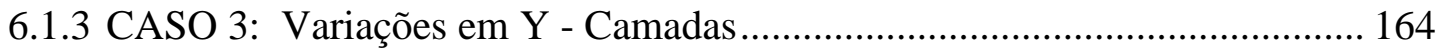

6.1.3.1 CASO 3.1 - Primeira Camada - C1 .............................................. 177

6.1.3.2 CASO 3.2 - Segunda Camada - C2 ………………………….. 182

6.1.3.3 CASO 3.3 - Camada com temperatura máxima - $\mathrm{C}_{\max }$.................. 188

6.2 CASO 4: Mesmo número de camadas com espessuras diferentes .......................... 198

6.3 CASO 5 - Influência de furos em uma estrutura ……………………………….... 208

6.3.1 CASO 5.1 - Bloco com um furo …………………………………………..... 208

6.3.2 CASO 5.2 - Bloco com quatro furos ……………………………………....... 215

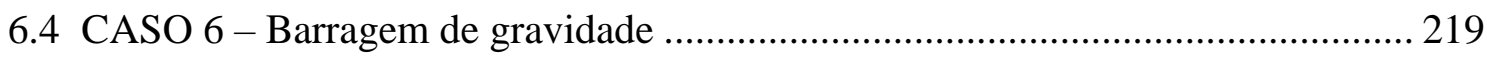

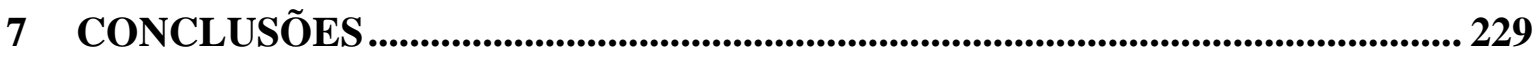

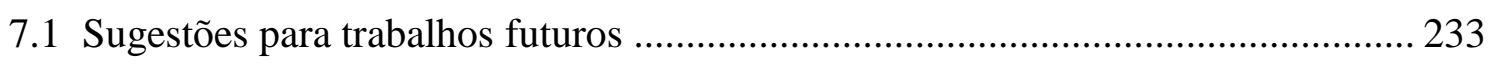

REFERÊNCIAS BIBLIOGRÁFICAS ..................................................................... 234 
APÊNDICE A - Soluções analíticas para a equação do calor 254

APÊNDICE B - Soluções pelo mdf para a equação do calor 256

APÊNDICE C - Efeito termomecânico 257

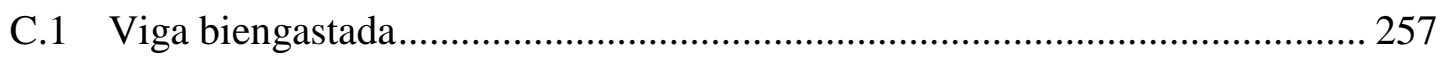

C.2 Viga com Geração de Calor Interno ......................................................... 260

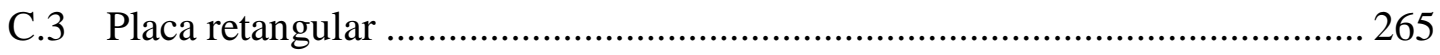

C.4 Placa retangular com módulo de elasticidade variando com a temperatura ... 269

APÊNDICE D - Coeficiente de restrição .................................................................. 270

APÊNDICE E - Influência do peso próprio no cálculo de tensões .............................. 272 


\section{LISTA DE TABELAS}

Tabela 2.1 - Potências hidrelétricas brasileiras (CBDB, 2016) 20

Tabela 2.2 - Potências a serem instaladas no Brasil até 2022 (Adaptado de Ministério de Minas e Energia, 2015)

Tabela 3.1 - Propriedades que influenciam na temperatura do concreto. Adaptado de Ranie

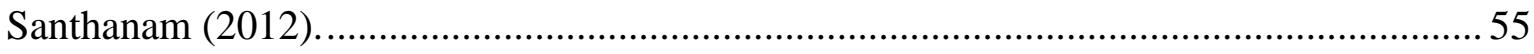

Tabela 3.2 - Valores de a e b para $f_{\mathrm{c}}($ ACI 209-2R, 2008).............................................. 57

Tabela 3.3 - Coeficiente de transmissão de calor superficial para diferentes ambientes de isolamento (Mehta e Monteiro, 2014).

Tabela 3.4 - Simbologia dos óxidos e compostos do cimento Portland (Carvalho, 2002).. 77

Tabela 3.5 - Formulações para o calor de hidratação do concreto massa............................. 85

Tabela 5.1 - Parâmetros térmicos utilizados na análise de convergência.......................... 124

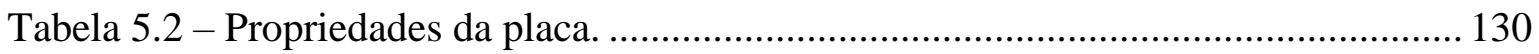

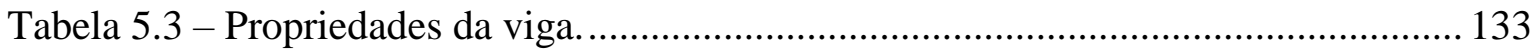

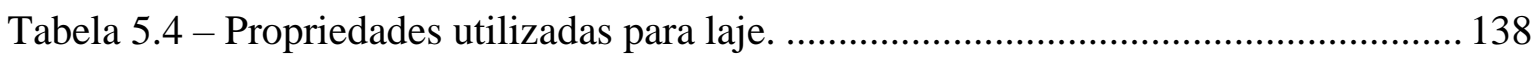

Tabela 5.5 - Propriedades térmicas utilizadas para o muro. ............................................ 141

Tabela 5.6 - Propriedades mecânicas para o muro. ......................................................... 143

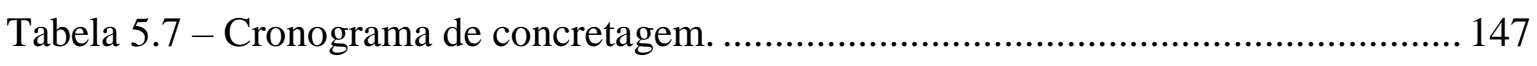

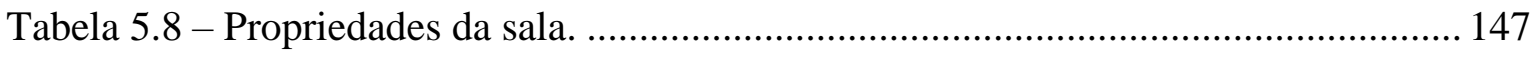

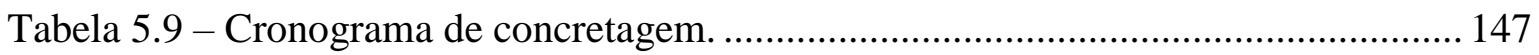

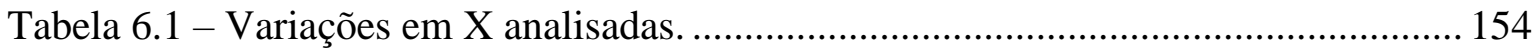

Tabela 6.2 - Máximas temperaturas para as variações em X........................................ 157

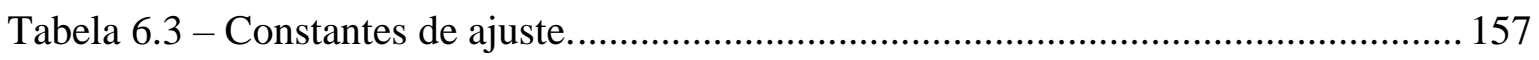

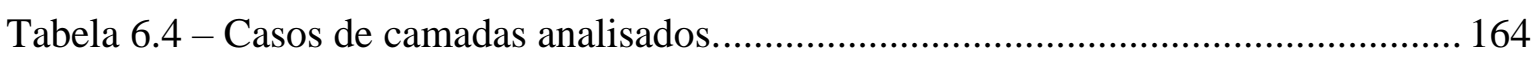

Tabela 6.5 - Resumo dos resultados para variações em X, Y e Z.................................... 194

Tabela 6.6 - Denominação dos Casos 4 analisados. ......................................................... 198

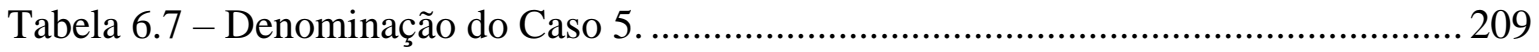

Tabela 6.8 - Relação entre diâmetros e áreas de influência............................................... 211

Tabela 6.9 - Distância do ponto P2 _..................................................................................... 213

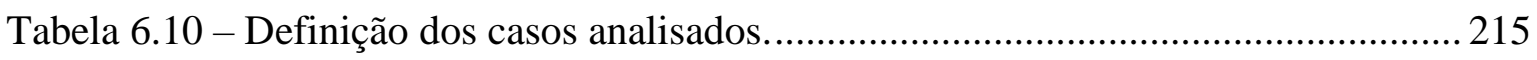

Tabela 6.11 - Casos de barragens analisados................................................................ 221

Tabela 6.12 - Coeficientes de restrição utilizados na barragem. ……............................. 223 
Tabela A.1 - Resumo das soluções analíticas. ............................................................. 254

Tabela B.1 - Soluções para as equações do calor via MDF. ........................................... 256

Tabela D.1 - Equações para $\mathrm{k}_{\mathrm{r}}$ com diferentes valores de L/H.................................... 270 


\section{LISTA DE FIGURAS}

Figura 1.1 - Etapas da metodologia.

Figura 1.2 - Método híbrido de solução do problema......................................................... 11

Figura 2.1 - a) Perfil de gravidade; b) Seção horizontal da base (Novak et al 2007)......... 15

Figura 2.2 - Barragem de gravidade aliviada (Bacaltchuk Sobrinho et al 2015). .............. 16

Figura 2.3 - Barragem e reservatório de Lajes, uma das duas grandes barragens mais antigas do Brasil (1906) (Mello, 2011b).

Figura 2.4 - a) UHE de Tucuruí em pleno funcionamento (Albuquerque, 2016a); b) uma de suas eclusas (Albuquerque, 2016b).

Figura 2.5 - Evolução da capacidade instalada de hidrelétricas indicativas (MW)

(Ministério de Minas e Energia, 2015).

Figura 2.6 - Relação entre a finura de cimento e o calor gerado para pasta de cimento

curada a $23.8^{\circ} \mathrm{C}$ (Adaptado de ACI 207.2R, 2007).

Figura 2.7 - Efeitos da temperatura de lançamento na temperatura adiabática no concreto massa contendo $223 \mathrm{~kg} / \mathrm{m}^{3}$ com o cimento Tipo I (ACI 207.2R, 2007). ........................... 25

Figura 2.8- Evolução de temperatura no interior de uma laje (Silvoso, 2002). 27

Figura 2.9 - a) Temperatura (36 h de concretagem); e b)tensões principais (18 e 144h de concretagem) para o tetrápode (Azenha et al 2011).....

Figura 2.10 - Plano de concretagem de bloco de fundação (Funahashi Júnior et al 2011). 30

Figura 2.11 - a) Captação; e b) imagem termográfica obtida.

Figura 2.12 - a) Localização dos pontos e b) Temperatura do concreto com presença de tubos de resfriamento (Ding e Chen, 2013).

Figura 2.13 - sistema de automação de cura (Adaptado de Ha et al 2014).

Figura 2.14 - Temperatura máxima atingida a partir da temperatura de lançamento

(Gambale e Traboulsi, 2015).

Figura 2.15 - Relação entre temperatura, tensão e umidade (Klemczak e Knoppik, 2015).

Figura 2.16 - Fissuras devido as restrições (Amin et al 2009). ........................................... 37

Figura 2.17 - Coeficiente de restrição (Adaptado de USBR, 1981)................................... 39

Figura 2.18 - Fissuras no concreto (Adaptado de Rostásy et al 1998)............................... 41

Figura 2.19 - Coeficiente de restrição calculado. ........................................................... 42 
Figura 2.20 - Fissuras com relação a rigidez da base a) base rígida; b) base flexível (Adaptado de CIRIA C660, 2007).

Figura 2.21 - Coeficiente de restrição pela variação horizontal (Adaptado de Schleech, 1962 apud CIRIA, 2007).

Figura 2.22 - Fissuras para superfícies com e sem restrição (Adaptado de CIRIA, 2007). 45

Figura 2.23 -O processo de Solução de problemas de engenharia (Adaptado de Chapra e Canale, 2015) 46

Figura 3.1 - Isotermas de temperatura para a) $\rho=2000 \mathrm{~kg} / \mathrm{m}^{3}$ e b) $\rho=3000 \mathrm{~kg} / \mathrm{m}^{3}$, respectivamente.

Figura 3.2 - Isotermas de temperatura para a) $\mathrm{k}=1 \mathrm{~W} / \mathrm{m} .{ }^{\circ} \mathrm{C}$ e b) $\mathrm{k}=4 \mathrm{~W} / \mathrm{m} .{ }^{\circ} \mathrm{C}$, respectivamente.

Figura 3.3 - Isotermas de temperatura para a) $\mathrm{c}=800 \mathrm{~J} / \mathrm{g}^{\circ} \mathrm{C} \mathrm{e} \mathrm{b}$ ) $\mathrm{c}=1300 \mathrm{~J} / \mathrm{g}^{\circ} \mathrm{C}$, respectivamente. 52

Figura 3.4 - Fases do concreto (Mehta e Monteiro, 2014)... 56

Figura 3.5 - Propagação de fissuras na zona de transição (Hanai, 2005 apud Andrade e Tutikian, 2011).

Figura 3.6 - Curva $\sigma-\varepsilon$ para os agregados, a pasta de cimento e o concreto (Andrade e

Tutikian, 2011). 58

Figura 3.7 - estágios da curva $\sigma-\varepsilon$ do concreto (Mehta e Monteiro, 2014). 59

Figura 3.8 - Representação da idade equivalente do concreto (Azenha, 2004). 63

Figura 3.9 - Representação da Fluência (Neville, 2016). 64

Figura 3.10 - a) Comportamento elástico e b) viscoelástico (Emborg, 1998a). 65

Figura 3.11 - Representação das propriedades para construção em camadas (Bofang, 2014) 65

Figura 3.12 - Deformação lenta de um concreto 66

Figura 3.13 - Influência do agregado na deformação lenta (Olliver e Vichot, 2014). 67

Figura 3.14 - Influência da umidade na fluência (Furnas, 1997)..... 67

Figura 3.15 - Influência da relação a/c na fluência (Furnas, 1997).................................... 68

Figura 3.16 - Influência da intensidade de carga na fluência (Furnas, 1997)...................... 68

Figura 3.17 - Influência das dimensões da peça na fluência (Furnas, 1997)....................... 69

Figura 3.18 - Influência do teor de pasta na fluência (Furnas, 1997)................................. 69

Figura 3.19 - Curva de tensão de um concreto (Neville, 2016) .70 
Figura 3.20 - a) Tensões arbitrárias; b) Tensões com influência da deformação de fluência;

c) Deformações arbitrárias d) Tensões com influência da relaxação. (Emborg, 1998b)..... 72

Figura 3.21 - Hidratação do $\mathrm{C}_{3} \mathrm{~S}$ (Julliand et al 2010 apud Cincotto 2011).

Figura 3.22- Calor desenvolvido por cada componente de cimento (Choktaweekarn e

Tangtermsirikul, 2010).

Figura 3.23 - Taxa de liberação de calor de um concreto (Neville, 2016).

Figura 3.24 - Influência da temperatura ambiente no processo de hidratação do cimento

(Cincotto, 2011).

Figura 3.25 - Temperatura adiabática para as diferentes misturas de concreto.

Figura 3.26 - a) Geração de calor e b) Calor acumulado para diferentes tipos de cimento (Cincotto, 2011).

Figura 3.27 - Temperatura na superfície de um bloco de concreto (modificado -

Choktaweekarn e Tangtermsirikul, 2010).

Figura 3.28 - Tubos de resfriamento no concreto (Liu et al 2015).................................... 85

Figura 3.29 - Evolução da reação de hidratação (Faria, 2004).

Figura 3.30 - Perfil de energia durante as reações (Brown et al 1991, apud Carvalho,

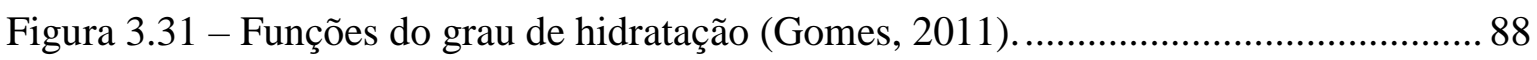

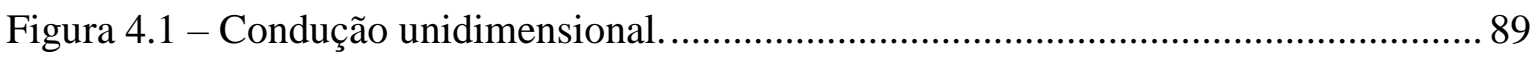

Figura 4.2 - Volume infinitesimal elementar de matéria................................................... 90

Figura 4.3 - Volume infinitesimal elementar de matéria. ................................................. 91

Figura 4.4 - Representação da curva de tensão pela soma das tensões individuais (Bofang,

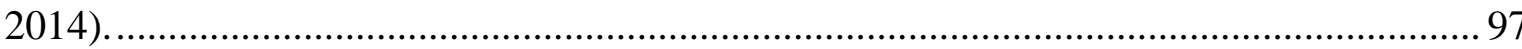

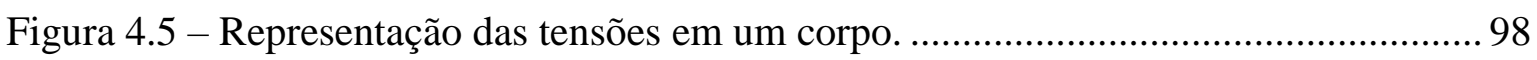

Figura 4.6 - Comparação dos modelos de fluência........................................................... 102

Figura 4.7 - Relação entre temperatura, calor gerado e tensões. ..................................... 103

Figura 5.1 - Metodologia de resolução da equação do calor. …….................................... 104

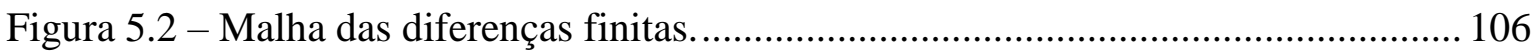

Figura 5.3 - Coordenadas para análise bidimensional de um ponto em MDF................. 107

Figura 5.4 - Representação das Condições de Contorno. ................................................... 108

Figura 5.5 - Fluxograma de solução das equações. ......................................................... 112

Figura 5.6 - Gráfico no MAPLE para a solução da equação completa do calor em 1D... 113

Figura 5.7 - Rotinas implementadas no MATLAB para solução do MDF. ........................ 114

Figura 5.8 - Forma de implementação de rotinas para solução das tensões térmicas....... 115 
Figura 5.9 - Solução em MEF.

Figura 5.10- Geometria do elemento PLANE55 (adaptado da biblioteca do ANSYS, 2013).

Figura 5.11- Geometria do elemento PLANE77 (biblioteca do ANSYS, 2013).

Figura 5.12- Geometria do elemento PLANE182 (adaptado da biblioteca do ANSYS, 2013).

Figura 5.13- Geometria do elemento PLANE183 (adaptado da biblioteca do ANSYS, 2013).

Figura 5.14- Geometria do elemento PLANE42 (adaptado da biblioteca do ANSYS, 2013).

Figura 5.15 - Geometria do elemento SOLID90 (adaptado da biblioteca do ANSYS, 2013).

Figura 5.16- Geometria do elemento CONTA174 (adaptado da biblioteca do ANSYS,

2013).

Figura 5.17 - Geometria do elemento TARGE170 (adaptado da biblioteca do ANSYS,

2013).

Figura 5.18 - Geometria do elemento SURF152 (adaptado da biblioteca do ANSYS, 2013).

Figura 5.19 - Corpo analisado na convergência estática. ............................................... 121

Figura 5.20 - Exemplo de malha com 4, 100, 400 elementos......................................... 122

Figura 5.21 - Convergência para o ponto central em Laplace. ......................................... 122

Figura 5.22 - Convergência da Equação de Laplace no eixo y......................................... 123

Figura 5.23 - Corpo unidimensional para verificação de convergência transiente............ 124

Figura 5.24 - Analise de convergência para fenômeno transiente.................................... 124

Figura 5.25 - Corpo e pontos analisados na equação completa 2D. ................................ 126

Figura 5.26 - Isotermas de temperatura ao final da análise 2D. ..................................... 126

Figura 5.27 - Temperatura ao longo do eixo x para equação completa 2D...................... 127

Figura 5.28 - Temperatura ao longo do eixo y para equação completa 2D...................... 128

Figura 5.29 - Análise de temperatura transiente do ponto P9 - Caso 4B........................ 129

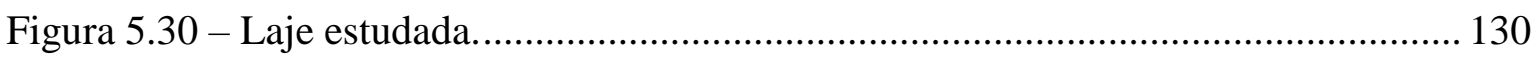

Figura 5.31 - a) Gradiente térmico e b) Tensões térmicas em x..................................... 131

Figura 5.32 - Comparação analítica-numérica para os pontos centrais em y. .................. 131

Figura 5.33 - Comparação analítico-numérica para um ponto em função do tempo......... 132

Figura 5.34 - Viga analisada (Furnas, 1997). ............................................................... 133 


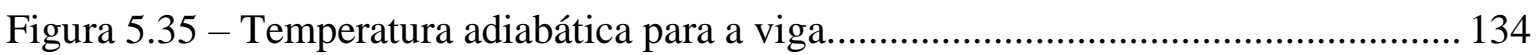

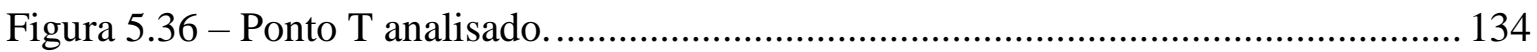

Figura 5.37 - Temperaturas para um ponto da viga.......................................................... 135

Figura 5.38 - Comparação das tensões para a viga........................................................ 136

Figura 5.39 - a) Isotermas com presença de tubos de resfriamento; b) Isotermas com tubos

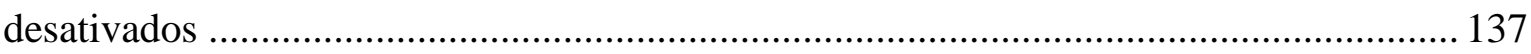

Figura 5.40 - Geometria e malha utilizadas na laje. ...................................................... 137

Figura 5.41 - Comparação das máximas temperaturas da laje.......................................... 139

Figura 5.42 - Isotermas de temperatura para a laje..................................................... 139

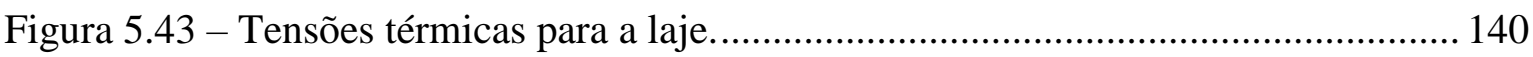

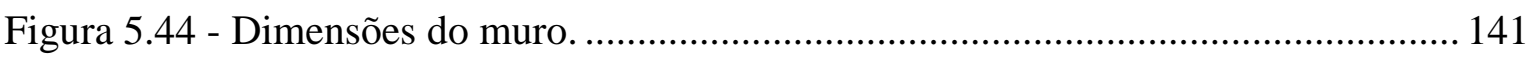

Figura 5.45 - Perfis de temperatura para o muro.......................................................... 142

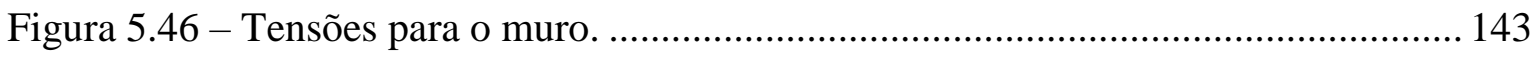

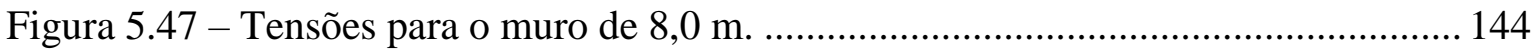

Figura 5.48 - Tensões para o muro de 16,0 m. ............................................................. 145

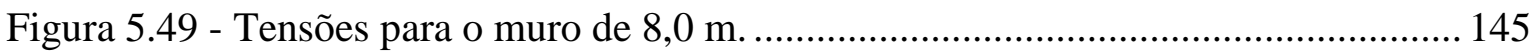

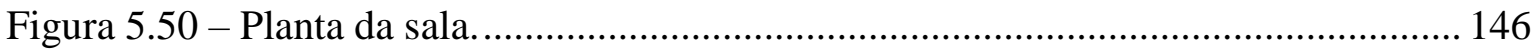

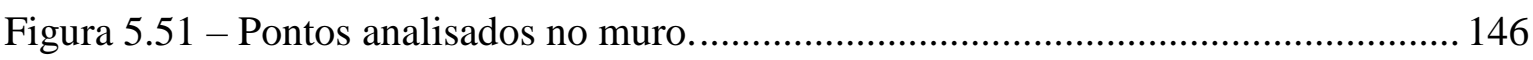

Figura 5.52 - Temperatura adiabática da sala. .............................................................. 148

Figura 5.53 - Malha utilizada para análise da sala........................................................ 148

Figura 5.54 - Isotermas para a sala em 22,12 dias..................................................... 149

Figura 5.55 - Isotermas para a sala em 72,40 dias................................................... 149

Figura 5.56 - Comparação de resultados numéricos e experimentais para três pontos da sala

Figura 5.57 - Perfis de temperatura para pontos nas diferentes camadas. ........................ 151

Figura 5.58 - Módulo de elasticidade em função do tempo para a sala............................ 151

Figura 5.59 - Tensões nos pontos de cada camada. ......................................................... 152

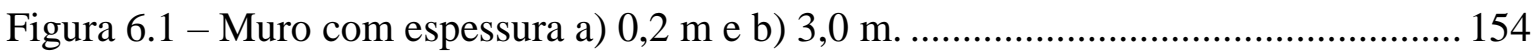

Figura 6.2 - Temperaturas em PC para variações em X............................................... 155

Figura 6.3 - - Temperaturas em PT para variações em X............................................. 156

Figura 6.4 - - Temperaturas em PB para variações em X............................................... 156

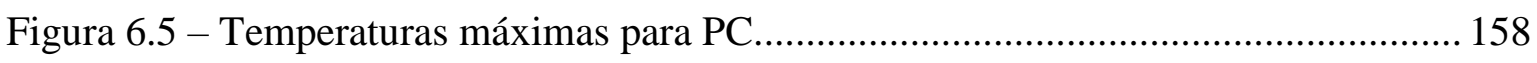

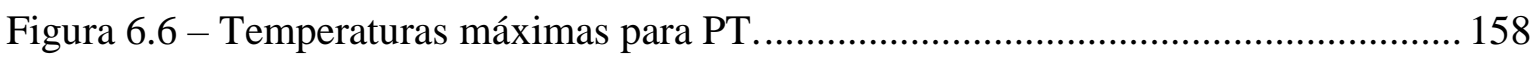

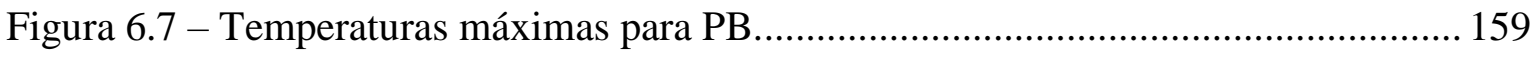


Figura 6.8 - Isotermas para $X=0,2 \mathrm{~m}$. 159

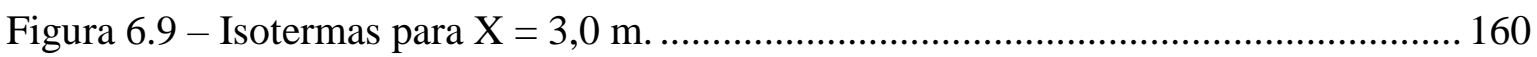

Figura 6.10 - Tensões pelo método DP para variações em X no muro. ............................. 161

Figura 6.11 - Tensões pelo método USBR para variações em X no muro. ........................ 162

Figura 6.12 - Tensões pelo método DP para variações em Z no muro.............................. 163

Figura 6.13 - Tensões pelo método USBR para variações em Z no muro......................... 163

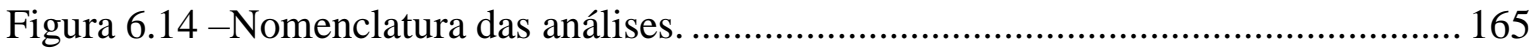

Figura 6.15 - Temperaturas para o Caso B com intervalo de lançamento de 12h............ 165

Figura 6.16 - Temperaturas para o Caso B com intervalo de lançamento de 24h........... 166

Figura 6.17 - Temperaturas para o Caso B com intervalo de lançamento de 48h............ 166

Figura 6.18 - Temperaturas para o Caso C com intervalo de lançamento de $12 \mathrm{~h}$............. 167

Figura 6.19 - Temperaturas para o Caso C com intervalo de lançamento de 24h............ 167

Figura 6.20 - Temperaturas para o Caso C com intervalo de lançamento de 48h............ 168

Figura 6.21 - Temperaturas para o Caso D com intervalo de lançamento de 12h............ 168

Figura 6.22 - Temperaturas para o Caso D com intervalo de lançamento de 24h........... 169

Figura 6.23 - Temperaturas para o Caso D com intervalo de lançamento de 48h............ 169

Figura 6.24 - Temperaturas para o Caso E com intervalo de lançamento de 12h. ........... 170

Figura 6.25 - Temperaturas para o Caso E com intervalo de lançamento de $24 \mathrm{~h}$. ............ 170

Figura 6.26 - Temperaturas para o Caso E com intervalo de lançamento de 48h. ........... 170

Figura 6.27 - Temperaturas para o Caso F com intervalo de lançamento de $12 \mathrm{~h}$.............. 171

Figura 6.28 - Temperaturas para o Caso F com intervalo de lançamento de 24h............ 171

Figura 6.29 - Temperaturas para o Caso F com intervalo de lançamento de 48h............. 172

Figura 6.30 - Temperaturas para o Caso G com intervalo de lançamento de 12h........... 172

Figura 6.31 - Temperaturas para o Caso G com intervalo de lançamento de 24h............ 173

Figura 6.32 - Temperaturas para o Caso G com intervalo de lançamento de 48h............ 173

Figura 6.33 - Temperaturas para o Caso H com intervalo de lançamento de $12 \mathrm{~h}$............ 174

Figura 6.34 - Temperaturas para o Caso H com intervalo de lançamento de 24h............ 174

Figura 6.35 - Temperaturas para o Caso H com intervalo de lançamento de 48h............ 174

Figura 6.36 - Temperaturas para o Caso I com intervalo de lançamento de $12 \mathrm{~h}$. ............. 175

Figura 6.37 - Temperaturas para o Caso I com intervalo de lançamento de 24h. ............ 175

Figura 6.38 - Temperaturas para o Caso I com intervalo de lançamento de 48h. ............ 176

Figura 6.39 - Temperaturas para TC1 com intervalo de lançamento de 12h................... 177

Figura 6.40 - Tensões para C1 pelo método DP com intervalo de lançamento de $12 \mathrm{~h}$.... 178 
Figura 6.41 - Tensões para C1 pelo método USBR com intervalo de lançamento de $12 \mathrm{~h}$.

Figura 6.42 - Temperaturas para TC1 com intervalo de lançamento de $24 \mathrm{~h}$.

Figura 6.43 - Tensões para C1 pelo método DP com intervalo de lançamento de 24h.... 179

Figura 6.44 - Tensões para C1 pelo método USBR com intervalo de lançamento de $24 \mathrm{~h}$.

Figura 6.45 - Temperaturas para TC1 com intervalo de lançamento de $48 \mathrm{~h}$. 180

Figura 6.46 - Tensões para C1 pelo método DP com intervalo de lançamento de 48h.... 181

Figura 6.47 - Tensões para C1 pelo método USBR com intervalo de lançamento de 48h.

Figura 6.48 - Módulo de elasticidade para diferentes camadas. ...................................... 182

Figura 6.49 - Tensões sob variação do módulo de elasticidade........................................ 183

Figura 6.50 - Temperaturas para TC2 com intervalo de lançamento de $12 \mathrm{~h}$.................... 184

Figura 6.51 - Tensões para C2 pelo método DP com intervalo de lançamento de 12h.... 184

Figura 6.52 - Tensões para C2 pelo método USBR com intervalo de lançamento de $12 \mathrm{~h}$.

Figura 6.53 - Temperaturas para TC2 com intervalo de lançamento de $24 \mathrm{~h}$.

Figura 6.54 - Tensões para C2 pelo método DP com intervalo de lançamento de 24h.... 186

Figura 6.55 - Tensões para C2 pelo método USBR com intervalo de lançamento de $24 \mathrm{~h}$.

Figura 6.56 - Temperaturas para TC2 com intervalo de lançamento de 48h.

Figura 6.57 - Tensões para C2 pelo método DP com intervalo de lançamento de 48h.... 187

Figura 6.58 - Tensões para C2 pelo método DP com intervalo de lançamento de 48h.... 188

Figura 6.59 - Temperaturas para $\mathrm{TC}_{\max }$ com intervalo de lançamento de $12 \mathrm{~h}$.

Figura 6.60 - Tensões para $\mathrm{C}_{\max }$ pelo método DP com intervalo de lançamento de $12 \mathrm{~h} .189$

Figura 6.61 - Tensões para $C_{\max }$ pelo método USBR com intervalo de lançamento de $12 \mathrm{~h}$.

Figura 6.62 - Temperaturas para $\mathrm{TC}_{\max }$ com intervalo de lançamento de $24 \mathrm{~h}$.

Figura 6.63 - Tensões para $\mathrm{C}_{\max }$ pelo método DP com intervalo de lançamento de $24 \mathrm{~h} .190$

Figura 6.64 - Tensões para $C_{\max }$ pelo método USBR com intervalo de lançamento de $24 \mathrm{~h}$.

Figura 6.65 - Temperaturas para $\mathrm{C}_{\max }$ com intervalo de lançamento de $48 \mathrm{~h}$.

Figura 6.66 - Tensões para $\mathrm{C}_{\max }$ pelo método DP com intervalo de lançamento de 48h. 192 
Figura 6.67 - Tensões para $C_{\max }$ pelo método USBR com intervalo de lançamento de $48 \mathrm{~h}$.

Figura 6.68 - Isotermas para diferentes alturas para construção com quatro camadas..... 199

Figura 6.69 - Temperaturas para o Caso 4-A..................................................................... 200

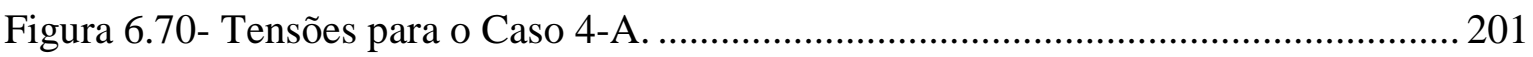

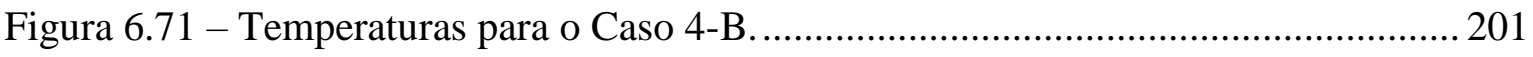

Figura 6.72 - Tensões para o Caso 4-B............................................................................ 202

Figura 6.73 - Temperaturas para o Caso 4-C................................................................... 202

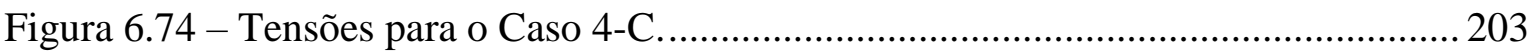

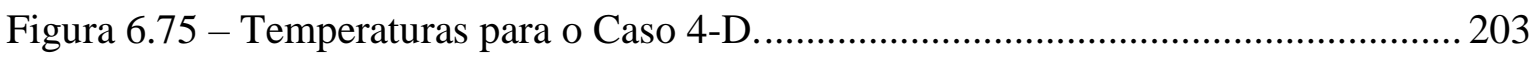

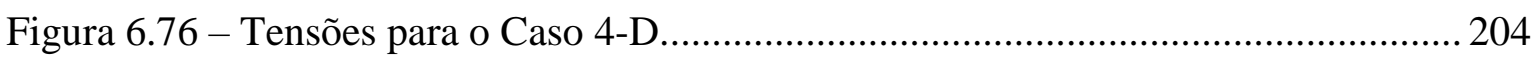

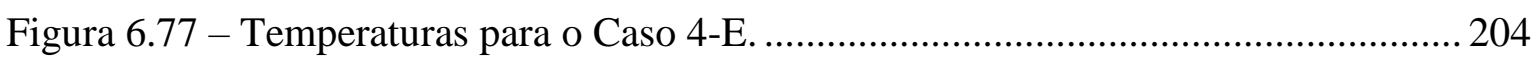

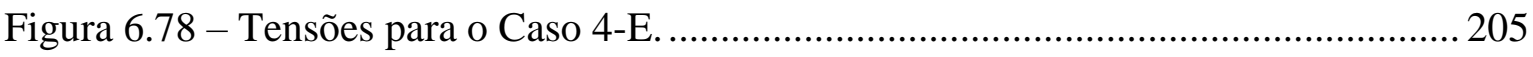

Figura 6.79 - Temperaturas para o Caso 4-F. .................................................................... 205

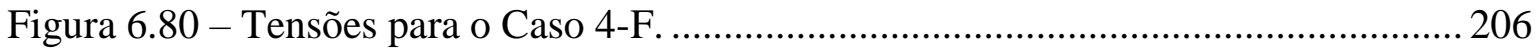

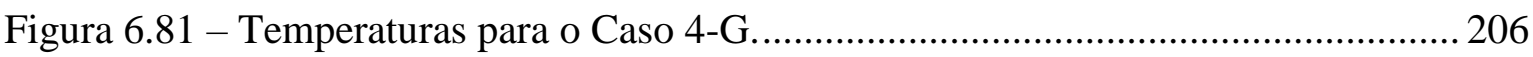

Figura 6.82 - Temperaturas para o Caso 4-G................................................................. 207

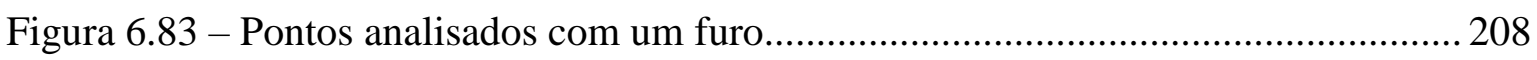

Figura 6.84 - Malha utilizada para análise com furo. .................................................... 209

Figura 6.85 - Isotermas para estrutura com um furo..................................................... 210

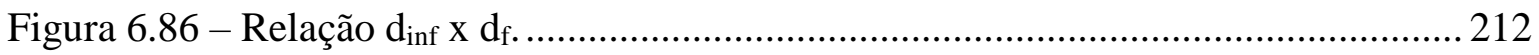

Figura 6.87 - Histórico de temperatura dos pontos P1 e P3 ............................................ 212

Figura 6.88 - Histórico de tensões dos pontos P1 e P3. ..................................................... 213

Figura 6.89 - Histórico de temperaturas do ponto P2 …................................................... 214

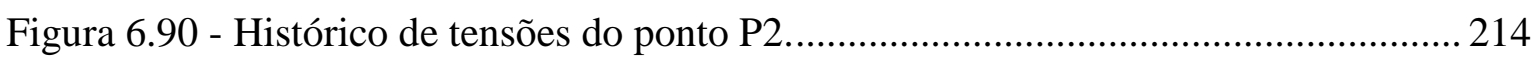

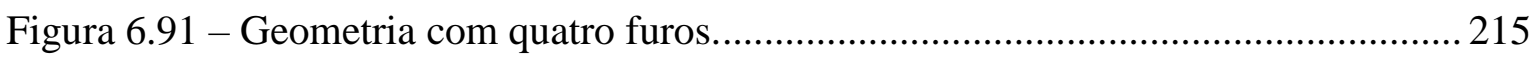

Figura 6.92 - Isotermas para estrutura com quatro furos............................................... 216

Figura 6.93 - Histórico de temperaturas para estrutura com quatros furos em P1........... 217

Figura 6.94 - Histórico de tensões para estrutura com quatros furos em P1. ................... 217

Figura 6.95 - Histórico de temperaturas para estrutura com quatros furos em P2 2........... 218

Figura 6.96 - Histórico de temperaturas para estrutura com quatros furos em P1............ 218

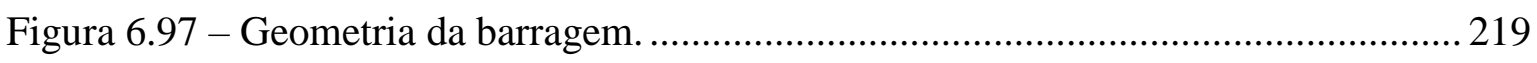

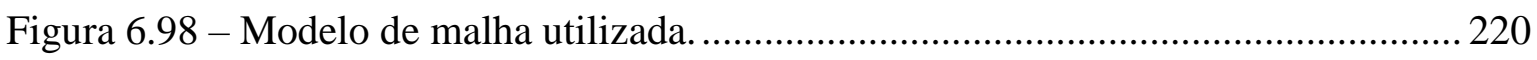

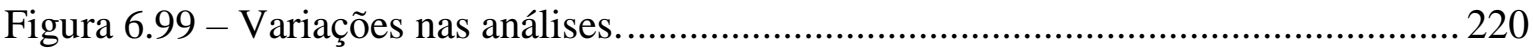


Figura 6.100 - Isotermas de temperatura para diferentes idades da barragem: a) 34,37 h; b)

$36,86 \mathrm{~h}$; c) $39,34 \mathrm{~h}$.

Figura 6.101 - Temperaturas para o Caso 6-A...................................................................... 223

Figura 6.102 - Tensões para C1 das estruturas analisadas............................................ 225

Figura 6.103 - Tensões termomecânicas para a barragem em C2, caso A. ...................... 227

Figura 6.104 - Tensões termomecânicas para a barragem em C11 ................................. 228

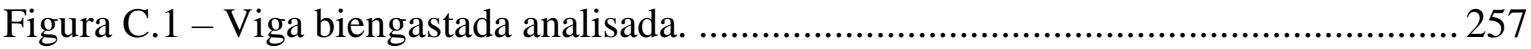

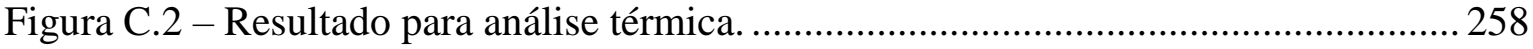

Figura C.3 - Comparação entre resultados analíticos e o ANSYS APDL para temperatura

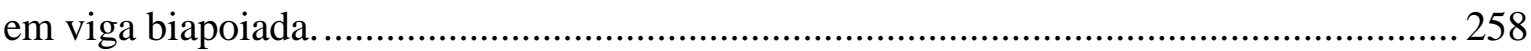

Figura C.4 - Análise termomecânica a partir do ANSYS.................................................. 259

Figura C.5 - Comparação entre resultados analíticos e o ANSYS para tensão em viga

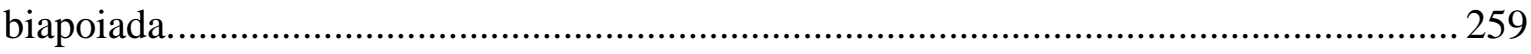

Figura C.6 - Viga retangular para análise térmica.......................................................... 260

Figura C.7 - Isotermas de temperatura para viga retangular pelo MEF (ANSYS)............ 260

Figura C.8 - Comparação dos resultados térmicos entre o método analítico e o MEF $(A N S Y S)$.

Figura C.9 - Viga com uma extremidade engastada e outra simplesmente apoiada (Hetnarski e Eslami, 2009).

Figura C.10 - Análise pelo MEF (ANSYS) dos resultados termomecânicos para a viga engastada-apoiada

Figura C.11 - Comparação dos resultados mecânicos para a viga engastada-apoiada..... 263

Figura C.12 - Viga biengastada (Hetnarski e Eslami, 2009).

Figura C.13 - Análise pelo MEF (ANSYS) dos resultados termomecânicos para a viga biengastada.

Figura C.14 - Comparação dos resultados mecânicos para a viga biengastada. 264

Figura C.15 - Análise pelo MEF (ANSYS) dos resultados termomecânicos para a viga engastada.

Figura C.16 - Comparação dos resultados mecânicos para a viga biengastada. 265

Figura C.17 - Comparação dos resultados mecânicos para a viga biengastada. 265

Figura C.18 - Resultados mecânicos para a viga biengastada. ......................................... 266

Figura C.19 - Comparação dos resultados mecânicos para a placa, Caso A. .................... 267

Figura C.20 - Resultados mecânicos para a placa engastada.......................................... 268

Figura C.21 - Comparação dos resultados mecânicos para a placa engastada, Caso B.... 268 
Figura C.22 - Comparação dos resultados mecânicos para a viga biengastada................ 269

Figura D.1 - Comparação dos resultados mecânicos para a viga biengastada................... 271

Figura E.1 - Tensões nas direções x, y e z para um elemento no interior de um volume. 272

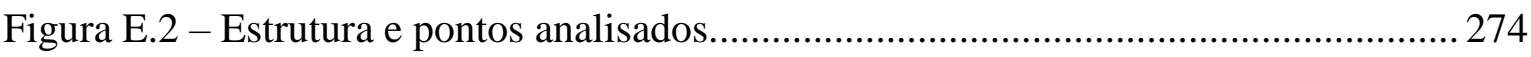

Figura E.3 - Temperaturas para os pontos PC1, PC2 e PC3 ......................................... 275

Figura E.4 - Tesões para os pontos PC1, PC2 e PC3 …................................................ 275 


\section{LISTA DE SÍMBOLOS, NOMENCLATURA E ABREVIAÇÕES}

$\begin{array}{ll}\rho & \text { Massa específica } \\ \delta & \text { Difusividade térmica } \\ \alpha & \text { Coeficiente de dilatação térmica } \\ \nu & \text { Coeficiente de Poisson } \\ \beta & \text { Energia de ativação } \\ \sigma & \text { Tensão } \\ \varepsilon & \text { Deformação } \\ \tau & \text { Idade } \\ \varepsilon^{\prime} & \text { Emissividade da superfície } \\ \Delta \mathrm{x} & \text { Elemento na direção } \mathrm{x}\end{array}$

$\Delta \mathrm{x} \Delta \mathrm{y} \Delta \mathrm{z} \quad$ Elemento de volume

$\Delta \mathrm{y} \quad$ Elemento na direção y

$\Delta \mathrm{z} \quad$ Elemento na direção $\mathrm{z}$

$\nabla^{2} T \quad$ Laplaciano da temperatura

$\mathrm{h}_{\mathrm{c}} \quad$ Coeficiente de convecção

$\mathrm{h}_{\mathrm{r}} \quad$ Coeficiente de transferência de calor por radiação

$\mathrm{Q}_{\mathrm{c}} \quad$ Quantidade de calor transmitida por convecção

$\mathrm{Q}_{\mathrm{r}} \quad$ Calor de radiação

$T_{a m b} \quad$ Temperatura ambiente

$\frac{d Q}{d t} \quad$ Quantidade de calor que atravessa a área A na unidade de tempo

$\frac{d T}{d n} \quad$ Gradiente térmico segundo a normal

$\frac{d T}{d x} \quad$ Gradiente térmico

$\dot{q} \quad$ Calor de hidratação

$q_{i} \quad$ Temperatura inicial do concreto

$q_{s} \quad$ Calor ganho devido à radiação solar

$\emptyset \quad$ Coeficiente de fluência

1D Uma dimensão

2D Duas dimensões 
Três dimensões

A

ACI

$a_{r}$

c

CBDB

CCR

CEB

CIGB

DP

E

F

$\mathrm{f}_{\mathrm{c}}$

$\mathrm{f}_{\mathrm{cm} 28}$

$\mathrm{f}_{\mathrm{t}}$

$\mathrm{h}$

J

k

$\mathrm{k}_{\mathrm{f}}$

$\mathrm{k}_{\mathrm{r}}$

M

MDF

MEF

MSV

$\mathrm{R}$

SMQ

$\mathrm{t}$

$t_{\mathrm{e}}$

USBR

$\xi$

$Q$

T

$\sigma^{\prime}$

Área da superfície

American Concrete Institute

Fator de absorção

Calor Específico

Comitê Brasileiro de Grandes Barragens

Concreto Compactado com Rolo

European Committee for Concrete

Comitê Internacional de Grandes Barragens

Dupla Potência

Módulo de elasticidade

Óxido de ferro

Resistência à compressão

Resistência média à compressão aos 28 dias

Resistência à tração

Coeficiente de transmissão de calor global

Fluência ou deformação específica

Condutividade térmica

Coeficiente da fundação

Coeficiente de restrição

Maturidade

Método das Diferenças Finitas

Método dos Elementos Finitos

Método de Separação de Variáveis

Relaxação

Soma dos mínimos quadrados

Tempo

Tempo equivalente

United States Department of the Interior Bureau of Reclamation

Grau de hidratação

Quantidade de calor

Temperatura

Constante de Stefan-Boltzmann 


\section{INTRODUÇÃO}

\subsection{GENERALIDADES}

O concreto massa é definido como um amplo volume de concreto que apresenta dimensões grandes o suficiente para exigir que algumas medidas sejam tomadas para reduzir a temperatura interna dessa estrutura, ou melhor, para reduzir o gradiente térmico entre as partes interna e externa do concreto (American Concrete Institute - ACI 116R, 2005).

Obras de concreto massa são muito importantes, onerosas e despertam um especial interesse com relação a segurança, eficácia e eficiência estrutural. É o caso de barragens de gravidade, fundações, pontes, entre outras.

Fissuras nessas estruturas são indesejáveis, pois afetam a permeabilidade, a durabilidade, aparência e suas tensões internas. As fissuras ocorrem, normalmente, quando as tensões de tração desenvolvidas excedem a resistência à tração do concreto. No entanto, uma modificação da temperatura altera o volume do concreto massa, principalmente, pela geração do calor de hidratação. O controle dessa temperatura é importante para que fissuras sejam evitadas (USBR, 1981).

Existem algumas técnicas de redução da geração de calor do concreto massa, assim como existem técnicas de pós-resfriamento e de construção que visam minimizar os efeitos térmicos nas estruturas. Entre eles, o método de construção em camadas, o método rampado, o processo de pré-resfriamento, pela redução da temperatura de lançamento do concreto e pós-resfriamento através da implementação de tubos no concreto massa por onde circula um fluido com uma temperatura inferior.

O aumento da temperatura modifica o módulo de elasticidade inicial de concreto. A taxa de fluência também aumenta com a temperatura mais elevada e a tensão de fluência é ampliada. Portanto, essas propriedades sofrem variações locais diferenciadas dentro das estruturas de concreto massa em uma função da temperatura e que, por sua vez, é uma função do tempo (Wu e Luna, 2001).

As propriedades em função da idade do concreto, módulo de elasticidade e fluência, devem ser consideradas nos cálculos das tensões térmicas do concreto massa. Existem várias funções de fluência, entre elas podemos citar os métodos do ACI, do European Committee 
for Concrete - CEB, do United States Department of the Interior Bureau of Reclamation USBR e o Bazant-Panula.

Para o estudo do concreto massa, este trabalho mostra a comparação entre distintos métodos na solução do problema. Serão utilizados o Método das Diferenças Finitas - MDF, o Método dos Elementos Finitos - MEF e a solução analítica, primeiramente para casos de validação, seguidos de análises de estruturas.

As soluções analíticas apresentam limitações. Nem todos os problemas podem ser resolvidos analiticamente, e quanto mais complexa a equação, mais complicada será a solução e mais difícil de se obterem os resultados. O MDF é um método simples (no escopo como foi utilizado neste trabalho), porém limitado quando se trata de geometrias mais sofisticadas. $\mathrm{O}$ MEF, por sua vez, em princípio, não tem muitas limitações, atendendo a todo tipo de geometria, por isso é amplamente utilizado, como é o caso dos programas computacionais.

Com base no exposto, a proposta deste trabalho é avançar nos estudos em concreto massa, utilizando os métodos numéricos, MDF e MEF, bem como o método analítico, para resolver a equação do calor, que governa o problema térmico do concreto massa, a fim de compreender o fenômeno, entender como cada termo da equação influencia no processo de evolução térmica e perceber a diferença existente em cada termo, simplificado ou não, da equação do calor.

A partir desse entendimento, prosseguir com análises termomecânicas do concreto massa, verificando as possibilidades de construção para redução dos efeitos indesejáveis, assim como a melhor equação para ajuste da curva de geração de calor. É também proposta uma sequência com as etapas as serem estudadas para este tipo de problema de modo a facilitar futuras pesquisas. Muitos pesquisadores da área não expõem todos os dados e forma de análise efetuada, o que dificulta a continuidade dos trabalhos por outras pessoas, que não estão inseridos no seu grupo de pesquisa. Dessa forma, pretende-se fazer desse trabalho uma referência de base aos estudos do concreto massa.

\subsection{PROBLEMÁTICA}

As estruturas com grande quantidade de concreto produzem uma elevação da temperatura interna do corpo, devido a liberação do calor de hidratação dos materiais cimentícios. Na 
prática, há uma dificuldade de determinar a curva de geração de calor, que parte de ensaios laboratoriais e deve ser implementada em simulações numéricas. Devido à baixa condutividade térmica do concreto, grandes volumes de concreto funcionarão como um corpo adiabático, ou seja, com dificuldade de dissipação do calor. Assim, internamente, o corpo possuirá um elevado tempo de resfriamento, enquanto na superfície o resfriamento é mais rápido, surgindo então gradientes térmicos. Com as restrições impostas, condições de apoio, normalmente na base da estrutura, enquanto há aquecimento, aparecerão tensões de compressão, relativamente baixas para a capacidade de resistência do concreto à compressão. No entanto, para um ponto no interior do domínio, com o resfriamento aparecem as tensões de tração e as tensões resistidas pelo concreto são aproximadamente $10 \%$ da resistência à compressão. Dessa forma, se não houver um controle e metodologia de construção adequados, poderão aparecer as fissuras térmicas, que, dependendo da relação entre o comprimento e a altura da estrutura, poderão se propagar até a superfície, deteriorando o corpo e reduzindo sua vida útil. Esse fenômeno é extremamente preocupante em obras de barragem, por exemplo.

\subsection{CONTRIBUIÇÕES DA TESE}

O principal questionamento que surge na construção de estruturas de concreto massa é se irão ou não fissurar. Diferentemente do concreto convencional, não existe uma norma brasileira que sintetize as etapas de cálculo, construção e verificação dos esforços quanto a sua capacidade resistiva para essas estruturas. As construções são feitas com base em experiências profissionais e normas de outros países.

A área é abrangente, mas pouco difundida. $\mathrm{Na}$ UnB é o primeiro trabalho que trata sobre o tema. Apresenta um nível elevado de dificuldade, pois deve-se entender tanto a parte dos materiais que os compõe quanto da parte mecânica, unindo as duas áreas do programa de pós-graduação, construção civil e estruturas.

Embora sejam encontrados na literatura trabalhos sobre o tema, algumas etapas para análise que são necessárias, as vezes são ocultadas ou não apresentam os parâmetros suficientes para se prosseguir com os estudos, fatores que colaboraram para não haver outros avanços nos resultados deste trabalho. 
Diante disso, o princípio básico desta tese é fornecer subsídios suficientes e necessários, assim como apresentar a sequência das etapas de análise para as estruturas de concreto massa, de modo que um pesquisador interessado pelo tema consiga assimilar os conhecimentos e avançar a partir dos resultados mostrados.

Este trabalho sintetiza a bibliografia difusa existente de forma a contribuir com as necessidades inerentes do tema e inspirar o desenvolvimento de guias e normas para o estudo e aplicação do concreto massa.

Além disso, apresenta uma compilação das informações encontradas isoladamente em outras pesquisas, como a metodologia para elaboração da curva de geração de calor, métodos de validação dos programas utilizados, construção em camadas, influência de furos na geometria, soluções analíticas e via MDF para problemas relacionados, não visto em nenhum trabalho da área. Tem-se ainda estudos numéricos das proporções geométricas, não enfatizado por outros autores, sempre buscando a implementação em problemas reais.

\subsection{MOTIVAÇÃO}

Muitas estruturas necessitam do concreto massa na sua construção, como é o caso de barragens, fundações, entre outros. Essas obras são, geralmente, onerosas e requerem uma análise prévia de possíveis problemas que possam vir a surgir, de modo a evitá-los.

Apesar da sua grande utilização, os estudos nessa área não são tão abrangentes, limitados a algumas universidades e a grandes empresas. Na UnB - Universidade de Brasília o assunto é pioneiro. Muitas informações são restritas e pouco divulgadas no âmbito das pesquisas cientificas. Vários questionamentos relativos ao concreto massa ainda precisam ser esclarecidos, tais como, a altura ideal de uma camada para redução de calor, qual a melhor posição para dispor os tubos de refrigeração, definição da equação de geração de calor, técnicas de redução das tensões.

O tema traz a proposta de uma pesquisa que envolve as duas áreas de atuação do programa de Pós-Graduação em Estruturas e Construção Civil, e os resultados da pesquisa são de interesse das equipes de Furnas e da Eletronorte. Propõe, não só aplicação, mas também um estudo mais abrangente das soluções numéricas, enfatizando as equações que governam o problema, comparando, resultados analíticos e numéricos. 
Dessa forma, procura-se desenvolver uma pesquisa de interesse acadêmico e da indústria, buscando também deixar claro todos os passos para soluções dos problemas pelos métodos numéricos, facilitando o entendimento, estudos e aplicações futuras do concreto massa, através de uma documentação progressiva e sistemática.

\subsection{OBJETIVOS}

\subsubsection{Objetivo geral}

Estudar os efeitos das tensões térmicas no concreto massa por métodos numéricos e analíticos, analisando as isotermas de temperatura e as tensões geradas, e verificando a possibilidade de eventuais danos às estruturas.

\subsubsection{Objetivos específicos}

- Rededuzir e analisar as várias formas da equação do calor e da equação de geração de calor do concreto massa entendendo o comportamento dos fenômenos envolvidos;

- Estudar, aplicar e comparar soluções analíticas com MDF e MEF para o problema do calor gerado;

- Analisar e aplicar os diferentes modelos de fluência do concreto;

- Avaliar a influência do comprimento, da altura e largura nas tensões termomecânicas. Assim como o efeito de camadas, a altura, o número, o intervalo de lançamento e a espessura das camadas nas tensões térmicas.

- Aferir os efeitos termomecânicos da presença de furos em estruturas de concreto massa.

- Simular o caso de uma barragem construída em camadas levando em consideração a temperatura e os modelos de fluência.

- Gerar um material de apoio que permita aos iniciantes o acesso a análise termomecânica do concreto massa.

\subsection{METODOLOGIA}

Este trabalho foi desenvolvido com base nos seguintes tópicos descritos de forma resumida pela Figura 1.1. 


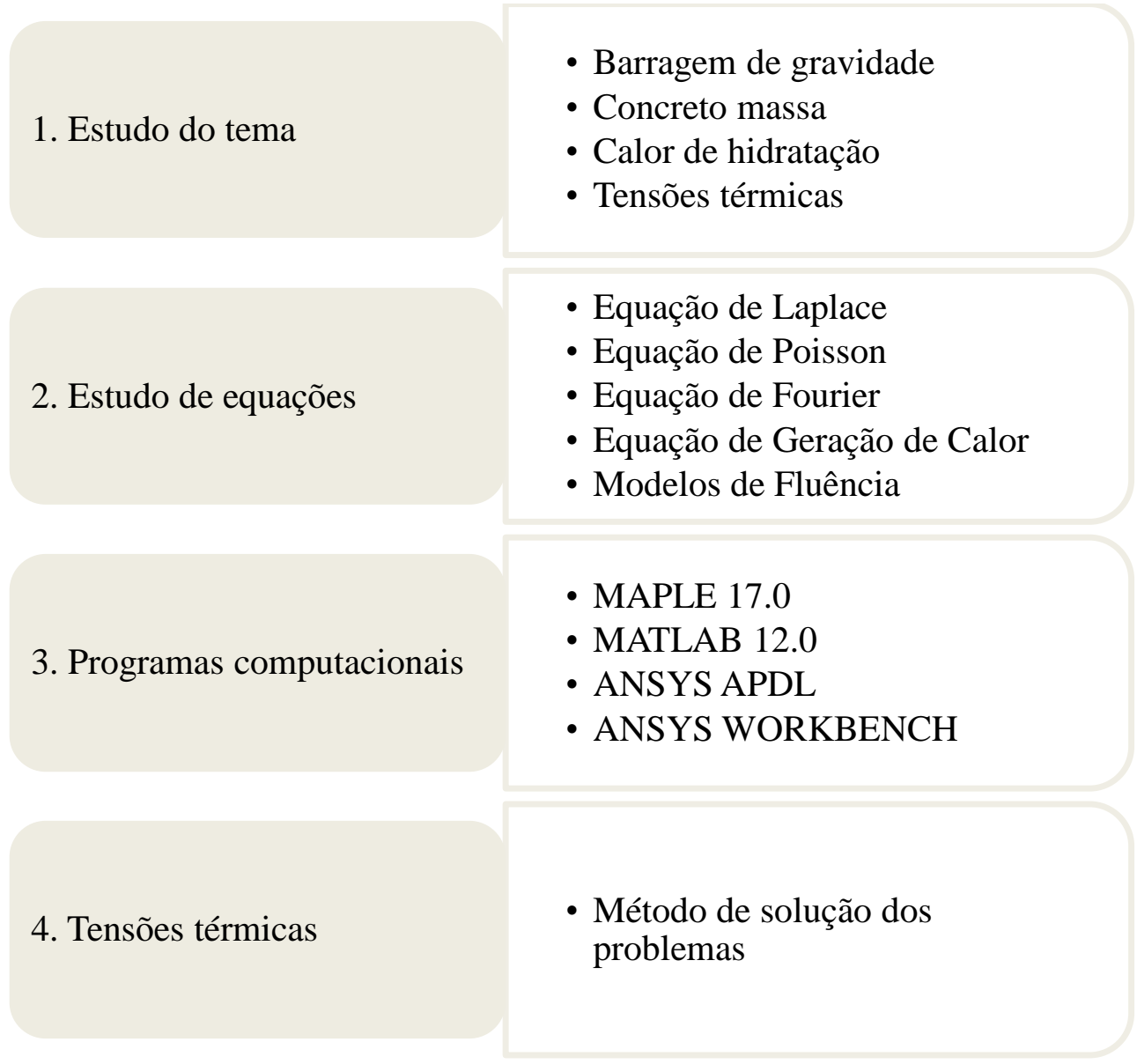

Figura 1.1 - Etapas da metodologia.

\subsubsection{Estudo do tema}

Conceitos básicos são fundamentais para o entendimento do problema. Desta forma, a primeira etapa do trabalho consiste em entender e definir os elementos necessários para o desenvolvimento de soluções analíticas e numéricas. Primeiro houve uma abordagem geral de barragem de gravidade, do concreto massa, assim como as propriedades físicas e mecânicas que estão relacionados aos casos em estudo. Devido à complexidade do tema, sentiu-se a necessidade de uma abordagem mais minuciosa do calor de hidratação, responsável pela elevação térmica do concreto massa.

\subsubsection{Estudo de equações}

Os fundamentos teóricos explicam qualquer problema desde que as equações sejam aplicadas e tratadas corretamente. Para o tratamento problema, primeiramente foram estudadas e rededuzidas analiticamente as equações do calor: Equação de Laplace, Equação de Poisson, Equação de Fourier com e sem geração de calor. Com as soluções analíticas para diversas situações pôde-se observar a influência das Condições de Contorno - CC e das 
Condições Iniciais - CI do problema. Para cada alteração há uma resposta diferente, mas todas são Séries de Fourier, ou seja, em termos de equações trigonométricas. As soluções analíticas foram obtidas utilizando-se o Método de Separação de Variáveis - MSV.

Simultaneamente, foram estudados o MDF e o MEF. As equações desenvolvidas analiticamente foram aplicadas aos métodos, através de um programa auxiliar, e os resultados comparados. Dessa forma, pôde-se ter confiança nas soluções apresentadas pelas três metodologias.

A equação do calor aplicada ao concreto massa apresenta o diferencial de possuir uma equação específica para o termo de geração de calor, pois neste caso, desenvolve o calor de hidratação. Diante disso, precisou-se estudar e conhecer o comportamento da temperatura adiabática, dada experimentalmente. Com os valores do experimento é necessário fazer ajustes a fim de descobrir sua equação. Num primeiro momento o ORIGIN 8.0 foi utilizado como ferramenta para isso, no entanto, numa análise de tensões posterior percebeu-se que com esse ajuste não era possível obter o perfil correto das tensões de compressão. Portanto para isso utilizou-se a função de Hill e o Excel para o ajuste das curvas de temperatura adiabática e, consequentemente, obter as curvas de geração de calor interno do concreto massa.

Com o intuito de utilizar o programa do MEF para encontrar as tensões termomecânicas em estruturas de concreto massa, foram simulados vigas e lajes e os resultados do acoplamento termomecânico comparados com os analíticos, evidenciando a credibilidade das análises para o estado plano de tensões. No entanto, para estruturas de concreto massa identificou-se a necessidade de inserção das funções de fluência.

Partindo do pressuposto, foram estudadas algumas funções de fluência: Método da Dupla Potência (DP), ou Bazant-Panula, Método USBR, Método do ACI e o Método do CEB. Primeiramente, essas foram comparadas entre si, para depois serem aplicadas aos problemas.

Nestes casos, o MATLAB também foi empregado como ferramenta de desenvolvimento das funções de fluência e para aplicação das equações analíticas nos problemas de concreto massa. 
O programa do MEF estudado nesta pesquisa possui uma função de fluência que se difere das quatro citadas, da qual a autora não tem conhecimento. Por isso, neste trabalho não foi possível mostrar as tensões tridimensionais das estruturas, e apenas em pontos específicos da estrutura. O programa do MEF foi utilizado para as soluções dos problemas térmicos, com esses resultados, alguns pontos tiveram seus históricos de temperatura no tempo coletados e foram aplicados nos códigos do $M A T L A B$ para obtenção analítica dos perfis de temperatura para esses pontos.

\subsubsection{Programas computacionais}

Para a expansão das séries das soluções analíticas utilizou-se o MAPLE 17.0. O MATLAB 12.0 foi utilizado para gerar códigos computacionais de desenvolvimento das equações do MDF. Essas duas ferramentas são utilizadas para soluções matemáticas e é possível verificar os gráficos das soluções obtidas. Com MATLAB foi possível montar e resolver matrizes de fluência para diferentes tempos e idades do concreto e, consequentemente, obter-se as tensões a partir da leitura das temperaturas obtidas com o MEF. Este também foi utilizado para implementação dos códigos do MDF utilizados na fase preliminar do trabalho.

Como ferramenta para o MEF o programa usado foi o ANSYS 15.0, adquirido pela Universidade Federal do Vale do São Francisco - UNIVASF, incialmente na sua versão APDL e, por fim, na interface WORKBENCH.

Por ser uma ferramenta mais complexa, serão definidas as sequências para as análises no ANSYS.

- ANSYS APDL - utilizado inicialmente, as programações eram feitas com códigos computacionais. Definindo-se:

a. Tipo de análise - térmica;

b. Tipo de elemento - Plane55 ou Plane77, para análise térmica bidimensional;

c. Geometria - pontos, linhas e áreas;

d. Malha - tamanho dos elementos;

e. CC e CI - definidos na etapa de solução para cada linha e área;

f. Tipo de análise - estática ou transiente;

g. Solução - após todas as condições impostas, o problema pode ser resolvido com o solver do ANSYS 15.0. 
No caso de análise em camadas, é necessário desativar as camadas inoperantes em um determinado intervalo de tempo, e ativá-las, assim como colocar/alterar as CC e CI, quando necessário. Um exemplo aplicado desta simulação pode ser encontrado em Coelho et al 2014a.

- $\quad$ ANSYS WORKBENCH - este possui uma interface mais amigável que o anterior, e uma maior facilidade de implementação e obtenção dos resultados, motivo pelo qual foi utilizado. No WORKBENCH não é necessário escolher o tipo de elemento, o programa define por default, a menos que se queira trabalhar com um elemento específico.

Os passos para a solução via ANSYS WORBENCH são:

a. Escolha do tipo de análise do sistema: STEADY-STATE THERMAL ou TRANSIENT THERMAL para análise térmica estática e transiente, respectivamente. No caso de análises termomecânicas acopladas, após os resultados térmicos, é feita a inserção dos sistemas STATIC STRUCTURAL ou TRANSIENT STRUCTURAL, para análises estáticas ou transientes, acoplada aos resultados térmicos, ou seja, aderindo à análise térmica como geometria, CC e CI.

b. Em ENGINEERING DATA são inseridas as propriedades térmicas e mecânicas dos materiais utilizados na análise.

c. No GEOMETRY é desenhada a geometria do corpo por meio de inclusão de blocos, cilindros ou desenhando a geometria base com o SCKETCH e fazendo a elevação do corpo com o EXTRUD. Esse último foi utilizado apenas para os casos de geometria irregular, como a barragem.

d. Em MODEL define-se malha, $\mathrm{CC}$ e CI dos elementos. Número de passos de tempo e subpassos, para análises transientes. São definidos também os pontos em que se deseja solução em função do tempo, em coordenadas.

No caso da construção em camadas, é necessário desativar todas as camadas e ativá-las a partir dos subpassos, com os comandos EKILL e EALIVE. Para isso, é preciso, anteriormente, nomear as camadas com o NAMED SELECT, e dizer na geometria que cada uma delas será modificada com o comando MATID.

O processo de construção em camadas requer um maior tempo de análise, pois para cada uma delas são inseridas duas CC laterais existentes a partir da 
sua construção, uma CC, na sua face superior que será desativada quando a camada seguinte for lançada, uma condição inicial, que é a temperatura de lançamento da camada e uma curva de geração de calor.

Para a geração de calor cabe uma observação. Embora, a equação seja a mesma, como a análise transiente é contínua, deve-se extrair para cada camada o tempo já decorrido nessa curva.

\subsubsection{Tensões térmicas}

Devido a curva de fluência existente no programa MEF não ser conhecida pela autora do trabalho, não foi possível encontrar as tensões termomecânicas para os casos viscoelásticos em 3D no programa.

Após as modelagens térmicas efetuadas, foram extraídos dos programas as temperaturas em cada intervalo de tempo correspondente para alguns pontos, os quais foram utilizados para obtenção analítica das tensões.

Essas tensões foram calculadas pelas fórmulas analíticas implementadas em códigos computacionais no MATLAB, para resolução das matrizes e geração da curva de tensões térmicas. Na programação foram criadas funções de fluência que levam em consideração o modulo de elasticidade em função da idade do concreto, bem como o coeficiente de fluência. Assim, chega-se a matriz de fluência, que multiplicada inversamente pela deformação térmica resulta nas variações de tensões.

Dessa forma, a solução final é obtida por um método híbrido, em que parte da solução é extraída do MEF e parte é calculada analiticamente, como mostra o esquema da Figura 1.2. Primeiramente, para a estrutura de barragem mostrada, são obtidas as isotermas de temperatura. Para o ponto central apresentando a máxima temperatura, seta vermelha, são extraídas as matrizes de variação térmica, $[\Delta \mathrm{T}]$, e temporal, [ $\Delta \mathrm{t}]$, as quais são implementadas em códigos computacionais no MATLAB.

Conhecendo-se a dilatação térmica do concreto utilizado, $\alpha$, encontra-se a matriz deformação, $[\Delta \varepsilon]$, com códigos computacionais, a partir da matriz temperatura, $[\Delta \mathrm{T}]$. Com a matriz de deformação multiplicada pela matriz de fluência $[\mathrm{J}]$, encontra-se a matriz de 
variação de tensões, $[\Delta \sigma]$. Dado o coeficiente de restrição, $k_{\mathrm{r}}$, obtido na seção média do comprimento longitudinal da estrutura, em função da sua altura em relação à base, e fazendo a soma dos incrementos de tensões, obtêm-se as matrizes e curvas de tensão em função do tempo.

A desvantagem da solução é não poder visualizar as tensões em 3D, entretanto, para análise das partes mais críticas da estrutura, como no caso da barragem mostrada, é possível fazer a modelagem numérica apenas da seção desejada ganhando tempo de processamento.

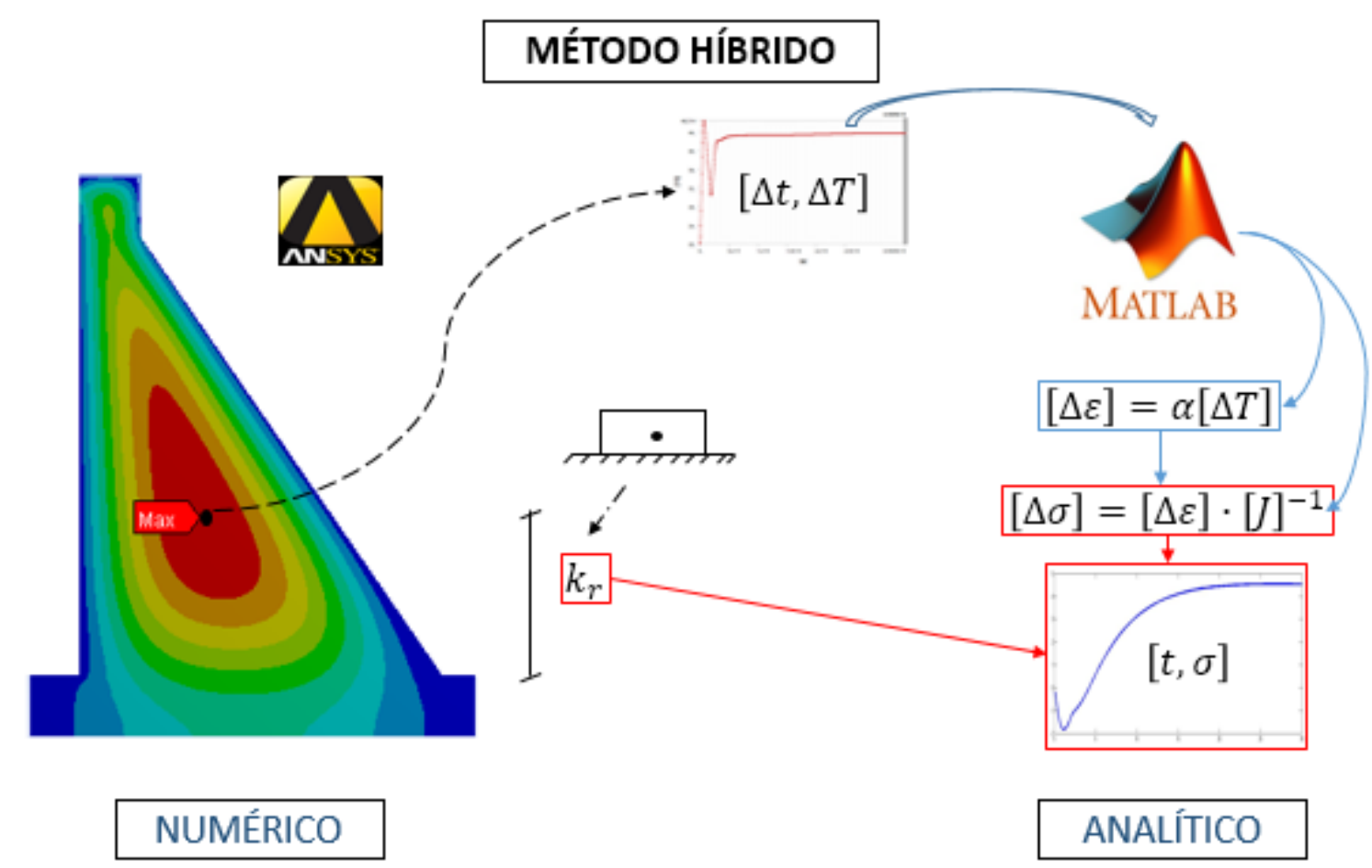

Figura 1.2 - Método híbrido de solução do problema.

\subsection{ABRANGÊNCIAS E LIMITAÇÕES}

- As tensões termomecânicas são calculadas com base em mais de um modelo de fluência;

- As temperaturas são calculadas em 3D pelo MEF, e as tensões analiticamente para pontos isolados da estrutura; 
- Nos problemas abordados não é levada em consideração a transferência de umidade;

- Não são calculados os efeitos de retração e relaxação do concreto, analisam-se apenas os efeitos de tensões térmicas com base nos modelos de fluência;

- Não se tem outros elementos internos no concreto, como o aço por exemplo;

- Os efeitos de radiação e convecção são simulados como uma única CC de convecção, assim como são descartados quaisquer efeitos do vento;

- É simulado o efeito da construção em camadas;

- Não é considerado o efeito da gravidade (peso próprio) do concreto nas análises de tensões.

\subsection{ESTRUTURA DA TESE}

Este trabalho foi desenvolvido em sete capítulos, conforme descritos abaixo.

O primeiro capítulo apresenta os aspectos iniciais do trabalho, fazendo uma introdução de alguns conceitos fundamentais, motivações, justificativa, objetivos e metodologia aplicados ao trabalho, buscando a compreensão do tema abordado pelo leitor.

O capítulo dois aborda uma revisão bibliográfica apresentando uma base teórica para o entendimento e desenvolvimento do tema. São mostrados conceitos importantes ao estudo sobre barragem de gravidade, concreto massa, tensões térmicas e métodos numéricos.

O capitulo três, traz uma abordagem das propriedades térmicas e mecânicas do concreto massa, assim como os fatores que influenciam na geração de calor e a teoria da energia de ativação. As formulações matemáticas, as equações que governam os problemas térmicos, as respectivas condições de contorno, assim como os métodos que podem ser utilizados para solução de problemas envolvendo os efeitos térmicos em estruturas de concreto massa são observados no capítulo quatro.

O capítulo cinco mostra a validação dos resultados com comparações analíticas e numéricas das soluções matemáticas por meio do MDF e MEF. Traz também comparações de temperaturas e tensões viscoelásticas em situações já estudadas por outros autores. 
O capítulo seis mostra algumas simulações fazendo-se uso de alterações de geometria, de construção em camadas, da presença de furos dentro de uma estrutura, verificando a influência de cada modificação nas temperaturas e tensões encontradas. Exibe também a simulação de tensões termomecânicas em uma barragem de gravidade aplicando as teorias já analisados.

As conclusões e perspectivas futuras são mostradas no capítulo sete. Nos apêndices encontram-se ainda as tabelas com algumas soluções analíticas e pelo MDF para e equação do calor. Apresenta também algumas verificações termomecânicas para casos elásticos em vigas e placas. 


\section{REVISÃO BIBLIOGRÁFICA}

As estruturas de concreto massa, grande volume de concreto, requerem uma atenção especial por parte dos pesquisadores e construtores devido a característica de produzir calor internamente, o qual é chamado de calor de hidratação. O calor gerado internamente pode atingir temperaturas bastante elevadas, gerando gradientes térmicos, que dependendo das proporções tenciona o concreto levando ao aparecimento de fissuras.

Segundo Fairbairn et al (2003) grandes estruturas de concreto, tais como barragens, blocos de fundação e lajes de pontes, podem estar sujeitas a fissurações em idades precoces devido às tensões térmicas e a indução da retração autógena. Do ponto de vista da engenharia, estas tensões podem ser minimizadas com algumas medidas preventivas que tentam reduzir os efeitos térmicos na reação de hidratação dos materiais cimentícios.

As obras que utilizam concreto massa apresentam, normalmente, um elevado custo e podem causar grandes desastres em caso de ruptura. Por isso, torna-se importante uma análise termomecânica a fim de prevenir as possíveis falhas na estrutura.

Dentre as utilizações do concreto massa destacam-se as barragens, blocos de fundação e as fundações para torres de energia eólica, que geralmente utilizam esse material. O Brasil tem previsão de construção de algumas grandes barragens, principalmente na região norte e está sendo amplamente difundido, principalmente no nordeste do país, a implementação de torres para captação de energia eólica. Além de que, nos centros urbanos é muito comum a utilização de blocos de fundação de grandes edifícios.

\subsection{BARRAGEM DE GRAVIDADE}

Segundo a Lei 12.334 (2010), barragem é qualquer estrutura em um curso permanente ou temporário de água para fins de contenção ou acumulação de substâncias líquidas ou de misturas de líquidos e sólidos, compreendendo o barramento e as estruturas associadas. Podem variar de pequenos maciços de terra a enormes estruturas de concreto, geralmente usadas para fornecimento de água, energia hidrelétrica e irrigação (Comitê Brasileiro de Grandes Barragens - CBDB, 2008). 
Pedroso (2002), afirma que as barragens é uma das formas mais tradicionais de armazenar água, em que barreiras são construídas em rios que apresentem potencial hidráulico, ou seja, vazão adequada que permita a acumulação de água.

As barragens são estruturas que requerem dispendiosos custos financeiros, grandes mobilizações sociais, ambientais e econômicas. Além de que, um acidente com barragens pode provocar danos desastrosos e pode pôr em risco inúmeras vidas humanas. Dessa forma, há uma necessidade de ações preventivas, visando à segurança dessas estruturas.

As barragens de gravidade são formadas por grandes maciços de concreto. São os tipos mais comuns e que requerem a menor manutenção, se adaptam em qualquer localidade, mas tem limitações de altura com relação à base e à fundação (Creager et al 1964).

A barragem de gravidade de concreto é totalmente dependente da sua própria massa para a estabilidade. O perfil de gravidade é essencialmente triangular, com a geometria do contorno indicado na Figura 2.1 a, para garantir a estabilidade e para evitar a sobrecarga da barragem ou a sua fundação (Novak et al 2007).
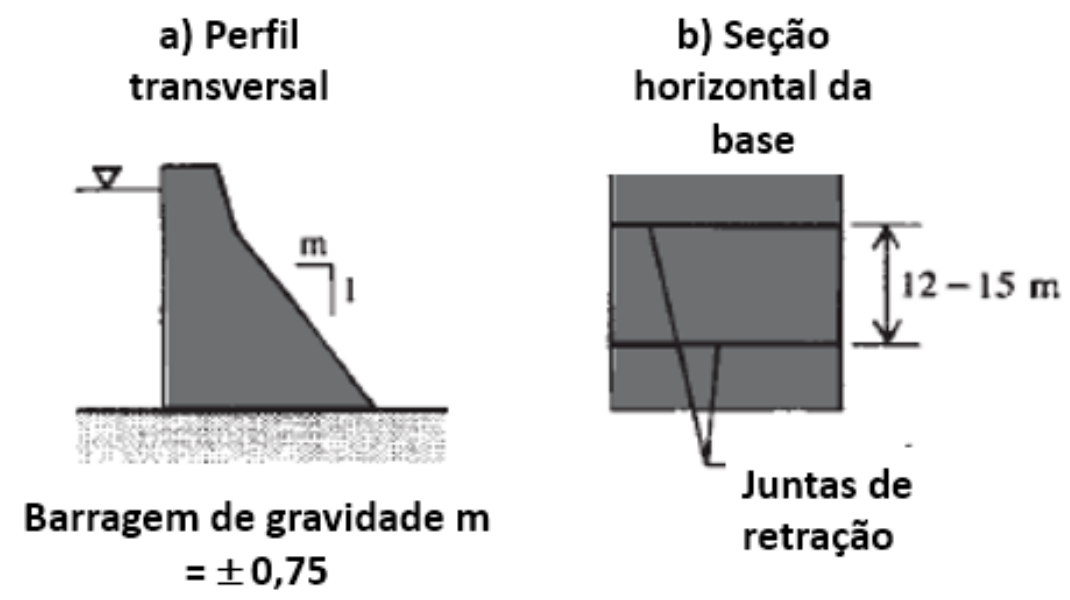

Figura 2.1 - a) Perfil de gravidade; b) Seção horizontal da base (Novak et al 2007).

O United States Department of the Interior Bureau of Reclamation - USBR (1977) afirma que as barragens de gravidade devem ser projetadas para todas as combinações de carga apropriadas, usando o fator de segurança adequado para cada um. Combinações de cargas transitórias, cada uma tendo apenas uma remota probabilidade de ocorrência, em qualquer dado momento, têm probabilidade negligenciável de ocorrência simultânea e não devem ser 
consideradas como uma combinação de cargas apropriada. Cargas de temperatura devem ser incluídos quando aplicável.

Embora com ampla experiência na construção de barragens, no Brasil não tem uma norma que regulamente a construção de barragens de concreto ou uma norma especifica para o concreto massa. Por isso, os pesquisadores e construtores se baseiam em normas de outros países ou experiências práticas.

A Eletrobrás (2003) lançou um manual com critérios de projetos para usinas hidrelétricas. Quando tratar-se de concreto massa, é conveniente a determinação das seguintes propriedades do concreto: resistência à tração na flexão; módulo de elasticidade; coeficiente de dilatação térmica; calor específico; difusividade térmica; elevação adiabática de temperatura; fluência; e o calor de hidratação do cimento. O material utiliza informações de FURNAS (1997) e do USBR (1981) para direcionar os cálculos. Ressalta ainda que é admissível uma abertura de fissuras de $0,3 \mathrm{~mm}$ para as estruturas em geral, e de 0,2 $\mathrm{mm}$ para as regiões em contato com a água, conforme a NBR 6118 (2014).

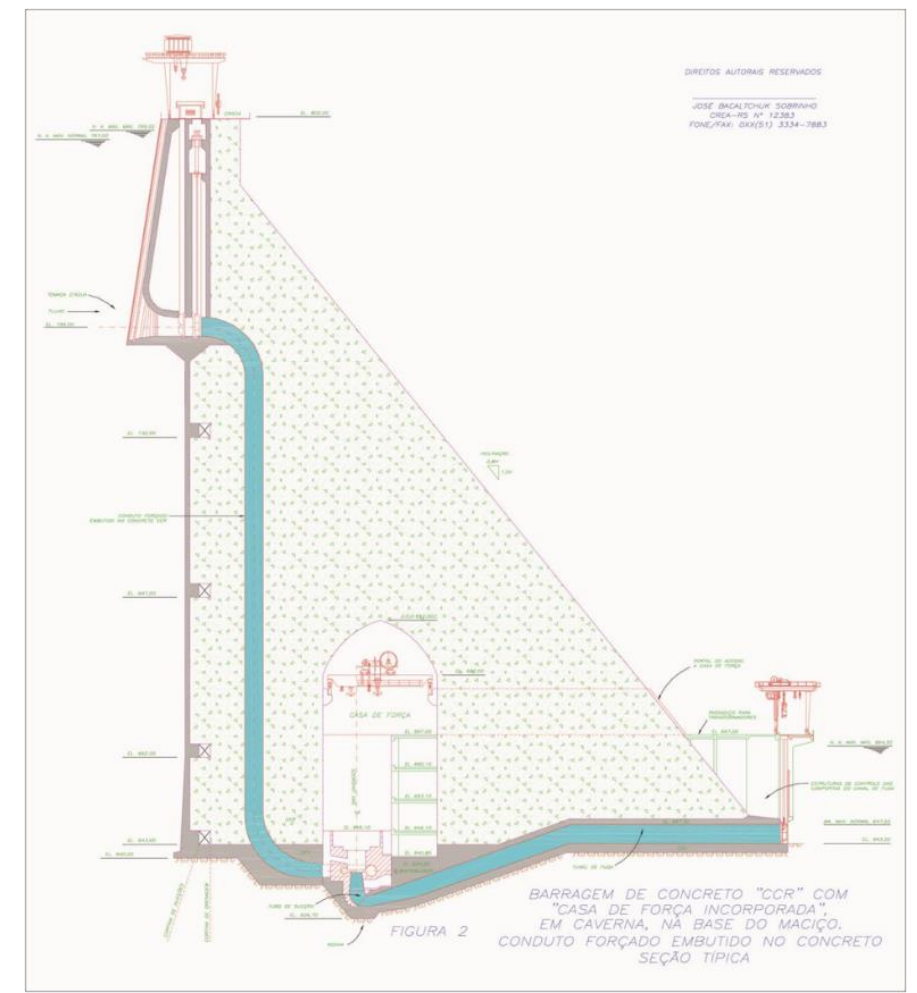

Figura 2.2 - Barragem de gravidade aliviada (Bacaltchuk Sobrinho et al 2015). 
Bacaltchuk Sobrinho, (1998) propôs a construção de barragens de Concreto Compactadas com Rolo - CCR com casa de força incorporada, em caverna, na base do maciço, Figura 2.2. Bacaltchuk Sobrinho et al (2015) ressaltaram ainda as vantagens desse tipo de construção, chamada "barragem aliviada", entre elas, uma redução no prazo de construção e uma economia no Custo de Implantação do Aproveitamento Hidrelétrico de até $20 \%$. O interessante é que a construção dessas aberturas se dá exatamente nas regiões de maiores temperaturas da barragem, fato que não foi avaliado pelos autores.

\subsubsection{Breve histórico de barragens e perspectivas futuras}

Data-se de antes de cristo as primeiras barragens de terra erguidas como reservatórios de água. Com o advento do concreto e do uso da energia hidrelétrica, as técnicas construtivas foram se aperfeiçoando e melhorando até os dias atuais. As primeiras barragens de terra foram construídas em 2000 a.C.; e a barragem de Sayamaike, uma das mais antigas do Japão, foi construída no início do século VII e, após várias modificações e um aumento de sua altura, continua em uso até hoje (INTERNATIONAL COMISSION ON LARGE DAMS ICOLD, 2008).

A mais antiga barragem que se tem notícia em território brasileiro foi construída onde hoje é área urbana do Recife, PE, possivelmente no final do Século XVI, antes mesmo da invasão holandesa. Conhecida presentemente como açude Apipucos, aparece em um mapa holandês de 1577 (Mello, 2011a).

O CBGB et al (1989) afirmam que os registros das primeiras barragens do Brasil são esparsos, sem divulgação, o que dificulta o retrospecto histórico dessas estruturas, estando a história associada às hidrelétricas. Comentam ainda que a primeira usina hidrelétrica instalada no país foi a de Ribeirão do Inferno, em Minas Gerais, em 1884.

Em 1887 foi posta em funcionamento a Hidrelétrica de Ribeirão dos Macacos e em 1889 a usina de Marmelos Zero, primeira a nível público, ambas em Minas Gerais. Esta última foi inaugurada sete anos após a instalação da primeira hidrelétrica do mundo, Appleto, nos EUA. Em 1901 foi inaugurada em São Paulo a usina Parnaíba com 2 MW instalados. De 1883 a 1900 a potência instalada no Brasil passou de $52 \mathrm{~kW}$ para $12085 \mathrm{~kW}$ (CBGB et al 1989). 
O ano de 1877 foi marcado por uma tragédia nacional devido à 'A Grande Seca no Nordeste'. O estado do Ceará perdeu mais de um terço da sua população de maneira trágica. Em 1880, logo após a Grande Seca, o Imperador D. Pedro II nomeou uma comissão para recomendar uma solução para o problema das secas no Nordeste e uma das principais recomendações foi a construção de barragens para suprimento de água e irrigação no Polígono das Secas. Isso marcou o início do planejamento e projeto de grandes barragens no Brasil. A primeira dessas barragens foi Cedros, de alvenaria de pedra, situada no Ceará e concluída em 1906 (Mello, 2011b).

No período anterior a 1900, o concreto utilizado em barragens não era controlado. O primeiro controle tecnológico registrado foi feito pelos EUA na barragem de Crystal Spring, na Califórnia, concluída em 1890. Posteriormente, o controle do concreto e o conceito de concreto massa foi se aprimorando nas barragens Elephant Butte, Arrowrock Dam - 1915, Big Dalton Dam -1920, Theodore Roosevelt Dam (ACI 207.1R, 1997).

De 1930 a 1970 houve um grande desenvolvimento na construção de barragens em concreto massa. Em 1930 foi organizado o ACI 207 que trata das informações e propriedades do concreto massa. A construção da Hoover Dam nos EUA nessa época, contribuiu para a evolução, devido ao seu tamanho, exigiu uma análise mais minuciosa dos materiais e técnicas construtivas, além de terem sido instalados tubos de pós-resfriamento do concreto. O uso de material pozolânico pode ser associado à construção de Big Dalton Dam e Bonneville Dam -1938. Após 1970 foi desenvolvido o CCR e suas técnicas são aprimoradas até hoje (ACI 207.1R, 1997).

As primeiras grandes barragens de gravidade do Brasil foram Cedros-CE e Lajes-RJ, Figura 2.3, que entraram em operação em 1906. A barragem de Lajes tinha o objetivo de derivar as águas do ribeirão das Lajes para da usina de Fontes no Rio de Janeiro, na época uma das maiores do mundo. 


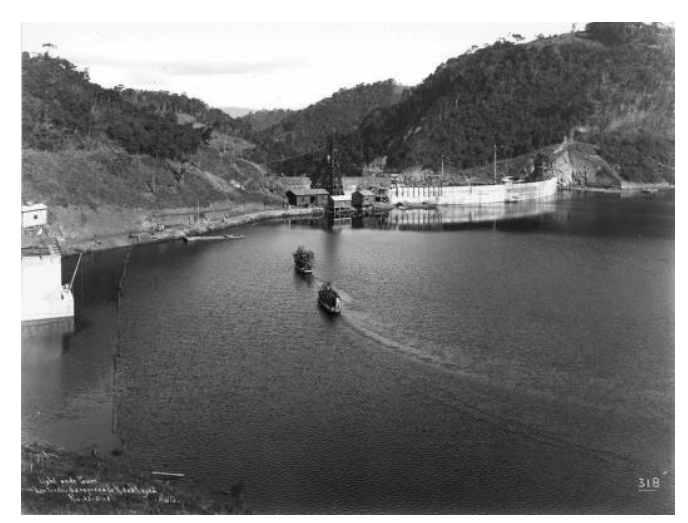

Figura 2.3 - Barragem e reservatório de Lajes, uma das duas grandes barragens mais antigas do Brasil (1906) (Mello, 2011b).

Nos últimos 30 anos, a oferta primária de energia hidráulica no mundo evoluiu concentradamente em duas regiões: Ásia, com destaque para a China, e América Latina, com destaque para o Brasil”. Em 1973 essas duas regiões respondiam por cerca de 10\% da produção mundial de hidroeletricidade, proporção que se elevou para pouco mais de $31 \%$ em 2003 (Plano Nacional de Energia, 2007). O Brasil tem o terceiro maior potencial de água para produção de energia elétrica, só superado pela China e pela Rússia (Santo Antônio Energia, 2012).

A partir dos anos 70 a construção de hidroelétricas no Brasil cresceu consideravelmente, e há ainda grande perspectiva de crescimento. Algumas ganham destaque no âmbito nacional, como é o caso de Itaipu, Furnas, Xingó, Sobradinho, Paulo Afonso, Tucuruí, Belo Monte, Santo Antônio, Complexo Tapajós. A Figura 2.4 mostra a Usina Hidrelétrica - UHE de Tucuruí em pleno funcionamento e uma de suas eclusas

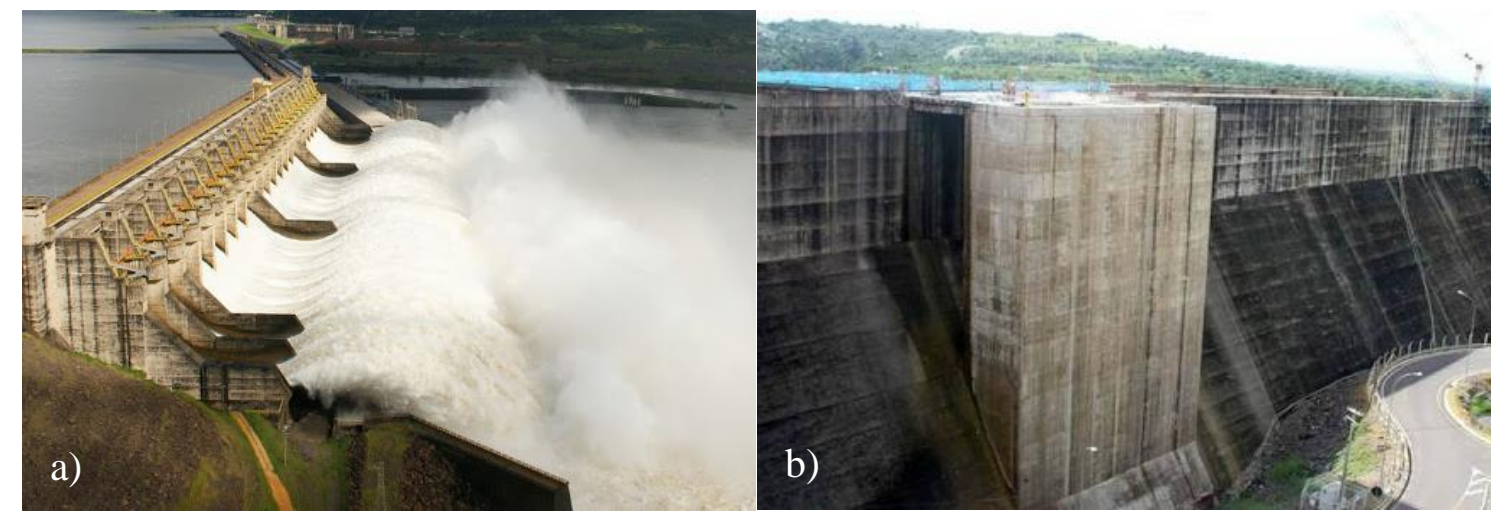

Figura 2.4 - a) UHE de Tucuruí em pleno funcionamento (Albuquerque, 2016a); b) uma de suas eclusas (Albuquerque, 2016b). 
O CBDB (2016), mostrou os maiores geradores de energia elétrica no Brasil em 2016, como mostra a Tabela 2.1.

Tabela 2.1 - Potências hidrelétricas brasileiras (CBDB, 2016)

\begin{tabular}{|l|l|l|l|l|l|}
\hline $\begin{array}{l}\text { Posição da } \\
\text { Hidrelétrica }\end{array}$ & $1^{\mathrm{a}}$ - Itaipu & $2^{\mathrm{a}}$ - Tucuruí & $3^{\mathrm{a}}$ - Jirau & $\begin{array}{l}4^{\mathrm{a}}-\text { Santo } \\
\text { Antônio }\end{array}$ & $5^{\mathrm{a}}$ - Xingó \\
\hline $\begin{array}{l}\text { Geração Média } \\
\text { Mensal em MWh }\end{array}$ & $8.906,05$ & $4.040,05$ & $1.293,93$ & $1.268,67$ & $1.126,01$ \\
\hline
\end{tabular}

O Ministério de Minas e Energia divulgou em 2015 o plano de expansão de energia hidrelétrica no Brasil até 2024. Na Tabela 2.2 observa-se que há uma probabilidade de construção/ampliação de Usinas Hidrelétricas (UHE) em todo o Brasil.

Tabela 2.2 - Potências a serem instaladas no Brasil até 2022 (Adaptado de Ministério de Minas e Energia, 2015).

\begin{tabular}{|c|c|c|c|c|}
\hline $\begin{array}{l}\text { Entrada em operação / } \\
\text { ano }\end{array}$ & Projeto & Rio & Potência & UF \\
\hline 2015 & $\begin{array}{l}\text { UHE Teles } \\
\text { Pires }\end{array}$ & Teles Pires & 1820 & PA \\
\hline \multirow{4}{*}{2016} & $\begin{array}{l}\text { UHE Belo } \\
\text { Monte }\end{array}$ & Xingu & 11233 & PA \\
\hline & UHE Colider & Teles Pires & 300 & MT \\
\hline & $\begin{array}{l}\text { UHE Salto } \\
\text { Apiacás }\end{array}$ & Apiacás & 45 & MT \\
\hline & $\begin{array}{l}\text { UHE São } \\
\text { Roque }\end{array}$ & Canoas & 135 & $\mathrm{SC}$ \\
\hline \multirow[t]{2}{*}{2017} & $\begin{array}{l}\text { UHE } \\
\text { Cachoeira } \\
\text { Caldeirão }\end{array}$ & Aráguari & 219 & $\mathrm{AP}$ \\
\hline & $\begin{array}{l}\text { UHE Baixo } \\
\text { Iguaçu }\end{array}$ & Iguaçu & 350 & PR \\
\hline \multirow[t]{2}{*}{2018} & $\begin{array}{l}\text { UHE São } \\
\text { Manoel }\end{array}$ & Teles Pires & 700 & PA \\
\hline & UHE Sinop & Teles Pires & 400 & MT \\
\hline 2019 & UHE Itaocara I & Paraíba do Sul & 150 & $\mathrm{RJ}$ \\
\hline \multirow{3}{*}{2021} & $\begin{array}{l}\text { UHE São Luiz } \\
\text { do Tapajós }\end{array}$ & Tapajós & 8040 & PA \\
\hline & UHE Tabajara & Jiparaná & 350 & $\mathrm{RO}$ \\
\hline & $\begin{array}{l}\text { UHE } \\
\text { Apertados }\end{array}$ & Piquiri & 139 & PR \\
\hline \multirow{2}{*}{2022} & $\begin{array}{l}\text { UHE Foz } \\
\text { Piquiri }\end{array}$ & Piquiri & 93 & PR \\
\hline & $\begin{array}{l}\text { UHE Telêmaco } \\
\text { Borba }\end{array}$ & Tibagi & 118 & PR \\
\hline
\end{tabular}




\begin{tabular}{|l|l|l|l|l|}
\hline \multirow{5}{*}{2023} & $\begin{array}{l}\text { UHE } \\
\text { Ercilândia }\end{array}$ & Piquiri & 87 & PR \\
\hline \multirow{5}{*}{2024} & $\begin{array}{l}\text { UHE } \\
\text { Comissário }\end{array}$ & Piquiri & 140 & PR \\
\cline { 2 - 5 } & UHE Paranhos & Chopim & 67 & PR \\
\cline { 2 - 5 } & UHE Jatobá & Tapajós & 2338 & PA \\
\hline \multirow{2}{*}{$\begin{array}{l}\text { UHE } \\
\text { Castanheira }\end{array}$} & Arinos & 192 & MT \\
\cline { 2 - 5 } & $\begin{array}{l}\text { UHE Bem } \\
\text { Querer }\end{array}$ & Branco & 708 & RR \\
\cline { 2 - 5 } & $\begin{array}{l}\text { UHE } \\
\text { Itapiranga }\end{array}$ & Uruguai & 725 & SC/RS \\
\hline
\end{tabular}

Na Figura 2.5, é possível verificar que até 2030, a expansão das UHE é ainda maior que o apresentado anteriormente. Diante disso, confirma-se a necessidade de ampliação de estudos e conhecimentos no âmbito da construção de grandes barragens, que ainda tem muita capacidade de exploração.

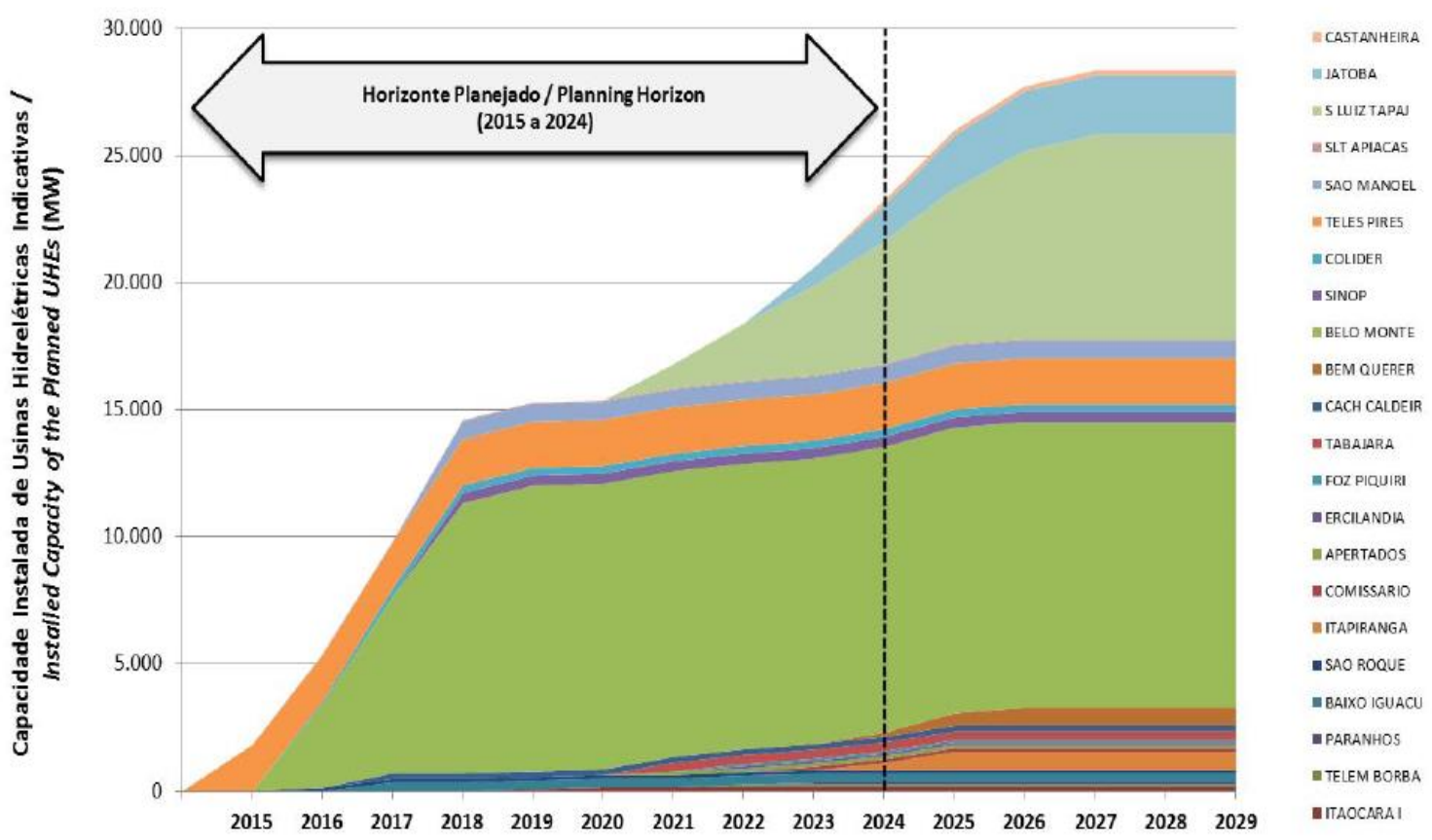

Figura 2.5 - Evolução da capacidade instalada de hidrelétricas indicativas (MW) (Ministério de Minas e Energia, 2015). 


\subsection{CONCRETO MASSA}

Antigamente, o termo "concreto massa" se aplicava somente a concretos de grandes dimensões, como barragens de gravidade, mas, atualmente, os aspectos tecnológicos do concreto massa são relevantes para qualquer elemento de concreto com dimensões tais que o comportamento térmico possa resultar em fissuração, caso não sejam tomadas medidas apropriadas (Neville, 2016).

Em peças volumosas, a temperatura se eleva no centro em razão da exotermicidade das reações de hidratação dos cimentos. Quando a espessura da peça é superior a um metro, o centro está praticamente em condições adiabáticas, porque o concreto é um fraco condutor de calor e a temperatura pode subir até $70^{\circ} \mathrm{C}$ ou acima. Um gradiente de temperatura aparece, assim, entre a superfície e o centro da estrutura (Olliver e Vichot, 2014).

O estudo da evolução do concreto nas primeiras idades está se tornando cada vez mais importante, pois a liberação do calor de hidratação e a retração do concreto, logo nas primeiras horas, podem gerar fissuras, aumentando a permeabilidade da estrutura e induzindo problemas de durabilidade e funcionalidade das mesmas (Aurich, 2008).

As duas principais causas de mudança de volume no concreto massa são a geração e dissipação de calor do concreto e ciclos periódicos da temperatura ambiente. Consequentemente, as medidas para a redução da variação do volume em concreto massa incluem, entre outras, a redução de calor gerado na hidratação dos materiais cimentícios e a redução da temperatura de lançamento do concreto. (ACI 116R, 2005).

Devido à pequena condutividade do concreto, pouco calor de hidratação se difunde a partir da superfície durante a construção. A camada seguinte não pode ser lançada até a camada anterior alcançar um nível de temperatura prescrita, o que muitas vezes atrasa o processo de construção (Yang et al 2012).

No entanto, Amin et al (2009) afirmam que o risco de fissuração térmica nas idades iniciais não deve ser baseada exclusivamente no critério da temperatura, a menos que os efeitos de outros parâmetros, tais como os valores de retração e as crescentes propriedades em idades iniciais do concreto estejam devidamente incorporadas ao prever o valor das tensões. Uma 
incorporação de melhores modelos de comportamento da evolução da rigidez e da deformação, assim como a análise da fluência é necessária.

Yunchuan et al (2012) propuseram três formas de controle de temperatura em concreto massa:

- A fórmula da temperatura adiabática do concreto precisa ser alterada para a Equação 2.1:

$$
T(t)=\frac{W Q\left(1-e^{-m t}\right)}{c \rho}
$$

sendo: W - teor de cimento; Q - calor de hidratação do cimento; m - taxa de aquecimento; c - calor específico o concreto; $\rho$-massa específica do concreto.

- A temperatura não deve ser tida como único parâmetro para fissuras em concreto massa, tampouco, deve-se limitar o gradiente que provoca fissuras em $25^{\circ} \mathrm{C}$, pois outros autores já relataram trabalhar com gradientes de $35^{\circ} \mathrm{C}$ sem fissuras.

Os autores fizeram ainda análise térmica com a implementação de tubos de resfriamento, no entanto, não explicaram de onde, nem o porquê de se utilizar a Equação 2.1.

Segundo Wu et al (2011), a temperatura ambiente afeta a tensão na superfície da parede de concreto, enquanto o calor de hidratação e temperatura de lançamento influenciam mais no centro da parede; a velocidade do vento aumenta o risco de fissuração durante os primeiros dois dias; e a redução da proporção altura-comprimento é uma boa maneira de evitar fissurações. Ha et al (2014), afirmam que as fissuras térmicas começam a ocorrer quando a tensão de tração atinge a resistência à tração do concreto.

A vida útil de serviço das estruturas de concreto depende do comportamento do concreto no ambiente e da mistura de concreto. Com efeito, a escolha do material cimentício, do tipo do agregado e da relação água/cimento tem grande influência no comportamento do concretomassa (Grondin et al 2011).

Wu e Luna (2001) fizeram o estudo de um bloco de concreto com dimensões de (4 x 4 x 30) $\mathrm{m}$ e encontraram os resultados térmicos e mecânicos para um ponto central do bloco. Concluíram que o ponto que concebe a máxima temperatura representa também a máxima tensão de compressão, e à medida que a temperatura varia, há modificação também na 
tensão. O estudo foi realizado apenas em um ponto, mais pontos deveriam ser analisados para se ter uma resposta mais precisa do fenômeno.

As adições minerais (cinzas volantes, argilas calcinadas e escória de alto forno) têm sido usados como uma medida eficaz para controlar a fissura térmica por seus efeitos sobre a redução da liberação de calor e redução do aumento da temperatura em materiais cimentícios (Liwu e Min, 2006).

Alhozaimy et al (2015) verificaram a influência de diferentes escórias de rochas pulverizadas sobre a redução do calor de hidratação, e observaram que foram tão eficazes quanto as cinzas volantes e argilas calcinadas na redução do calor de hidratação e da temperatura de pico. Han et al (2014) analisaram o calor de hidratação para o concreto com e sem adições minerais. O estudo mostrou que o concreto sem adições apresentou o maior calor de hidratação.

Já Poppe e De Schutter (2005) estudaram a influência do tipo de material de enchimento do concreto, calcário ou quartzito, na geração do calor de hidratação. Observaram que, em alguns casos, o mecanismo de reação do cimento Portland é claramente influenciado pela adição do material de enchimento calcário, o que não acontece quando o enchimento usado é o quartzito.

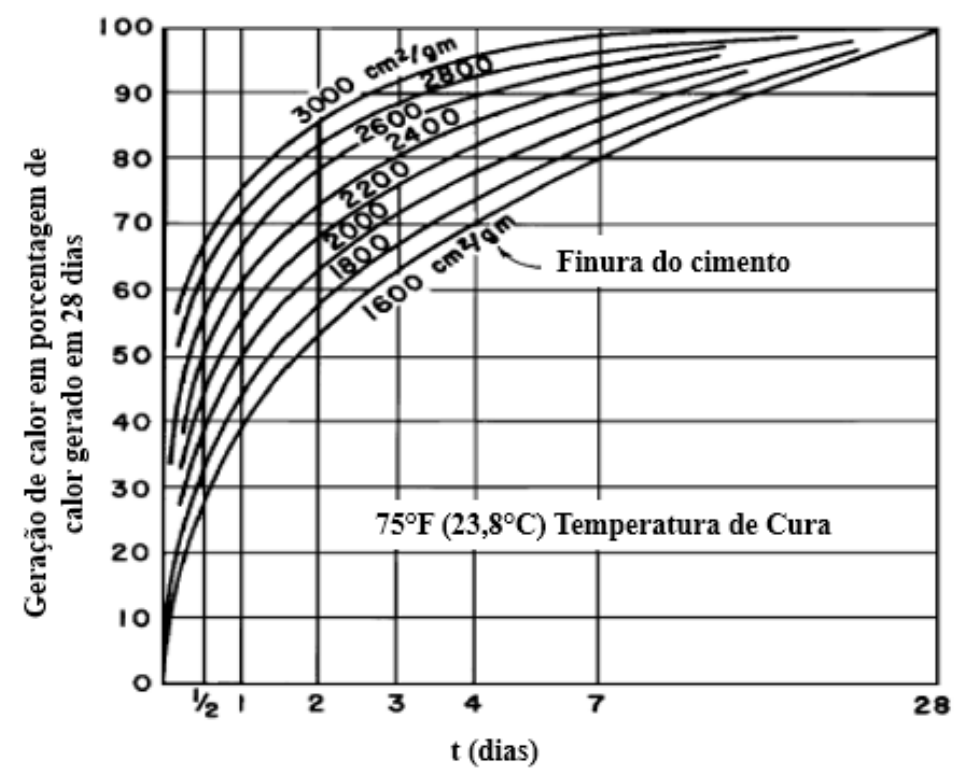

Figura 2.6 - Relação entre a finura de cimento e o calor gerado para pasta de cimento curada a $23.8^{\circ} \mathrm{C}$ (Adaptado de ACI 207.2R, 2007). 
Compreende-se da Figura 2.6 que quanto mais fino o cimento, há uma maior geração de calor, pois entende-se que há um menor diâmetro da partícula, o que resulta em maiores temperaturas máximas (ACI 207.2R, 2007).

Quanto à temperatura de lançamento, Figura 2.7, quanto mais elevada a temperatura inicial do concreto massa, maior a máxima temperatura de pico e mais rapidamente chega-se a esse valor. É notável ainda que se passa mais tempo com um pico de temperatura para maiores temperaturas de lançamento. Esse estudo foi realizado também por Coelho et al (2012a) de forma numérica e chegou-se às mesmas conclusões, isto é, maior a temperatura de lançamento, maior a temperatura atingida.

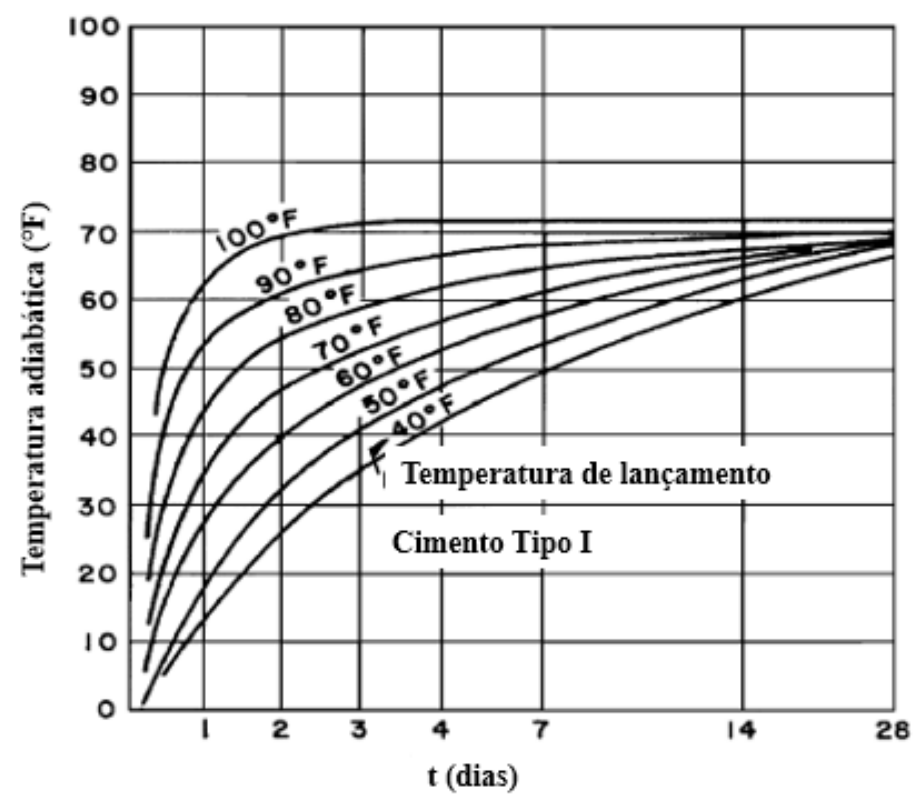

Figura 2.7 - Efeitos da temperatura de lançamento na temperatura adiabática no concreto massa contendo $223 \mathrm{~kg} / \mathrm{m}^{3}$ com o cimento Tipo I (ACI 207.2R, 2007).

\subsubsection{Outros estudos}

Borst e Boogaard (1994) estudaram o método dos elementos finitos aplicados à evolução da fissuração do concreto nas idades inicias. Apresentaram um tetrápode de concreto, utilizado como quebra mar, para evidenciar a evolução das fissuras com o passar do tempo.

Kim et al (2001) estudaram a presença de tubos de resfriamento em concreto massa através do MEF. Observaram que a temperatura do concreto com tubos de resfriamento diminui mais rapidamente do que nos que não possuem. Esta tendência é muito mais evidente nos pontos mais próximos desses tubos de refrigeração. Nos pontos próximos às extremidades, a redução de temperatura é relativamente menor, sendo atribuída à convecção atmosférica. Wu, Y. e Luna, R., (2001) apresentaram uma metodologia numérica para simular o processo 
de construção do concreto massa, considerando os efeitos da temperatura sobre o módulo de elasticidade e o comportamento de fluência do concreto.

Krüger (2001) analisou estruturas executadas por camadas, com a distribuição do campo de temperaturas no processo de construção, levando em conta a influência térmica de uma camada sobre as demais e sobre a estrutura como um todo. Dando continuidade, Silva (2003), estuda as tensões resultantes das temperaturas sem, no entanto, ressaltar a fluência. Posteriormente, Kavamura (2005) analisou o efeito termomecânico em barragens. Concluiu que à medida que se aumenta a altura das camadas a tensão final diminui, mas não apresentaram diferenças significativas, e que os valores das tensões diminuem consideravelmente a medida que o intervalo entre lançamentos de camadas é estendido.

Seguindo os avanços, Teixeira et al (2006), estudaram a modelagem por elementos finitos para análise das deformações por fluência em barragens em CCR e observaram que embora o nível das tensões tenha sido muito baixo para a barragem analisada, constatou-se uma diferença de $40 \%$ entre as tensões determinadas com a fluência e as obtidas sem esse efeito.

Batista et al (2002) utilizaram agregados de dimensões máximas de $50 \mathrm{~mm}$ em concreto bombeado a fim de acelerar o processo construtivo do vertedouro da UHE de Lajeado, afirmando que o uso de refrigeração ao concreto e o desenvolvimento de dosagens com baixos consumos de cimento foram decisivos para o sucesso da metodologia.

Gambale et al (2002) estudou um bloco de fundação da $3^{\text {a }}$ ponte do Lago Sul em Brasília de 4,0 m de altura e 10 de largura. Para o concreto utilizado e as alternativas estudadas, concluíram que para um coeficiente de restrição de $85 \%$, para não haver fissuração deveriam ser lançadas camadas de 0,5 m de altura em intervalos de sete dias. Sendo o coeficiente de restrição de $65 \%$, o intervalo de lançamento poderia ser reduzido para dois dias.

Carvalho (2002), estudou a determinação experimental da energia de ativação para concretos com diferentes composições. Silvoso (2002), simultaneamente com Carvalho (2002), implementou um programa numérico baseado no método dos elementos finitos, para o cálculo dos campos térmico, de hidratação e de tensões em um sólido de concreto, em modelo termo-químico-mecânico. Considerando a evolução da rigidez elástica do concreto e a presença de deformações decorrentes da variação de temperatura e da retração no cálculo 
de tensões. Como exemplo de resultados, apresenta-se a Figura 2.8 com a evolução térmica para uma estrutura de concreto.

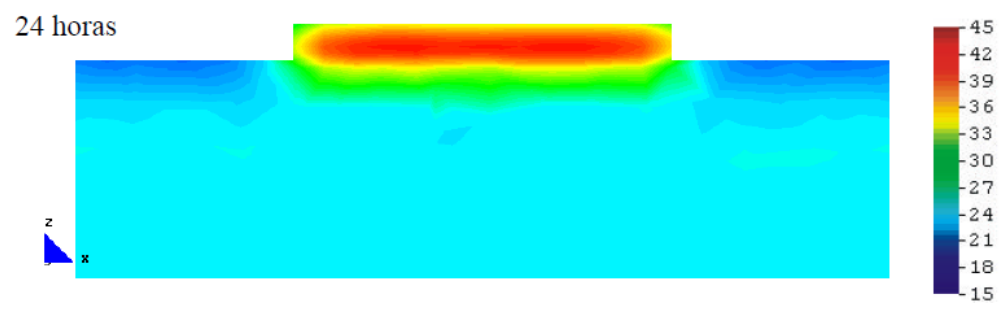

Figura 2.8- Evolução de temperatura no interior de uma laje (Silvoso, 2002).

Silvoso (2002) mostrou a otimização do processo construtivo de estruturas de concreto massa, considerando o processo de hidratação do concreto com a utilização de algoritmos genéticos. Em sequência, Faria (2004) pesquisou a predição das características da exotermia da reação de hidratação visando a determinação da elevação adiabática de temperatura dos concretos. Para isso, estudou dois modelos, o Modelo Multicomponente de Calor de Hidratação $(\mathrm{MCH})$ e a função de Hill estudada com de Redes Neurais (RNA), afirmando que a função Hill pode ser utilizada para todos os ensaios de elevação adiabática.

Milani Filho (2003) fez uma comparativo entre o CCR na sua forma tradicional por camadas e com o método rampado, sem, contudo, fazer análise numérica, inclusive da parte térmica. Confrontou produtividade com custos e apresentou algumas vantagens do CCR.

Calmon et al (2004) aplicam um programa em desenvolvimento, o PFEM_2DT, na análise de uma seção do muro de gravidade da barragem Cana Brava com bons resultados para a temperatura. $\mathrm{O}$ mesmo programa foi utilizado na obtenção de tensões para um bloco de concreto massa, com pequenas diferenças entre o experimental e o calculado, associadas aos valores aproximados dos parâmetros térmicos utilizados (Santos et al 2004a).

Ballin (2004) utilizou o MEF para representar um bloco de concreto massa usando, como entrada, os resultados de uma determinação da taxa de calor usando um calorímetro adiabático em conjunto com a função de maturidade de Arrhenius. Verificou a necessidade de uma melhor definição das condições de contorno do modelo, incluindo uma avaliação precisa de parâmetros, tais como o coeficiente de transferência de calor.

Santos (2004) desenvolveu um modelo computacional e um software para realizar análises termomecânicas de forma desacoplada em estruturas maciças de concreto construídas por 
etapas - camadas. Enfatizou que grande parte dos trabalhos com análises termomecânicas aplicadas à estruturas maciças não possuem todos os dados de entrada do problema, dificultando uma fiel representação das condições reais in loco. Como continuidade, Santos (2011) verificou o comportamento da fluência básica no concreto massa, variando o tipo de aditivos e adições no concreto. Concluiu que, há aumento da fluência básica com o uso de adições minerais e aditivos plastificantes na idade de início de carregamento de 1 dia.

Azenha (2004) estudou a modelagem e análise termomecânica de estruturas em concreto nas primeiras idades, com enfoque especial em problemas relacionados com a geração de calor de hidratação utilizando uma instrumentação real com a utilização do DIANA 8.1. Azenha (2009) prosseguiu os estudos sendo a geração do calor dada em função de calorímetro isotérmico, ao invés de calorímetro adiabático. O mesmo autor publicou ainda (Azenha et al 2011) um artigo mostrado a evolução termomecânica em tetrápodes de concreto em três dimensões. Enfatizou que o risco de fissuração é maior na superfície durante o aquecimento do concreto e nas áreas centrais, esse risco é muito pequeno, Figura 2.9 a, b.
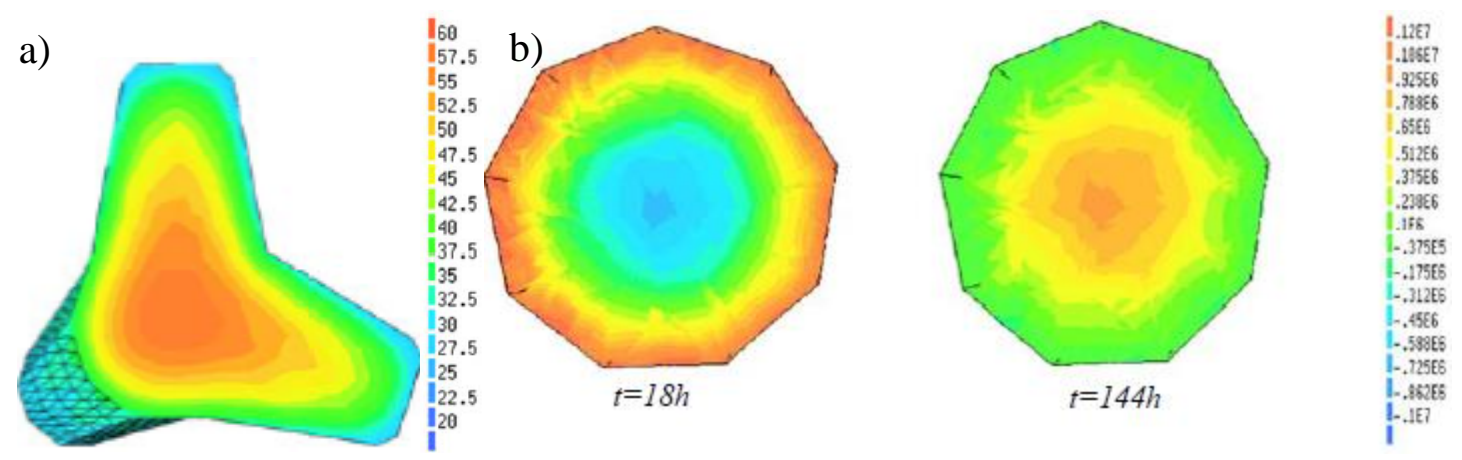

Figura 2.9 - a) Temperatura (36 h de concretagem); e b)tensões principais (18 e 144h de concretagem) para o tetrápode (Azenha et al 2011).

Marques Filho (2005) avaliou as propriedades do CCR nos estados fresco e endurecido utilizando resultados de maciços experimentais executados em laboratório, comparando-os com os resultados de uma barragem rampada, enfatizando que os resultados entre ambos foram semelhantes.

Cordeiro et al (2007) simularam a construção de uma barragem de gravidade utilizando concretos feitos de cimento puro e cimento misturado com dois resíduos agroindustriais: cinzas de bagaço de cana-de-açúcar e cinzas de casca de arroz. Os resultados indicam a 
redução térmica do concreto e a redução das emissões de $\mathrm{CO}_{2}$ na atmosfera causadas pela produção de cimento, já que há redução deste.

Aurich (2008) avaliou o risco de fissuração de uma estrutura de concreto nas primeiras idades com a análise da difusão de umidade. Analisou o comportamento de um tetrápode nas primeiras idades, elevação da temperatura no interior do mesmo, bem como da difusão da umidade e evolução das tensões. Afirmou que a temperatura cresce na região mais interna do tetrápode e, com o passar das horas, a temperatura decresce da superfície para o interior, alcançando o equilíbrio com o ambiente aos dez dias e que nesse período ainda existe uma diferença significativa da umidade na superfície e no interior do corpo, estando o valor mais elevado das tensões na superfície do tetrápode.

Ferreira (2008) defendeu o trabalho que traz uma metodologia de paralelização de um código de elementos finitos para a solução de um modelo termo-químico-mecânico, visando a simulação tridimensional da fase construtiva de uma barragem.

Gambale et al (2009a) afirmaram que o efeito da temperatura interna é mais controlável, uma vez que depende quase que exclusivamente da definição do traço de concreto e condições de lançamento in loco. Isso facilita a predição do efeito dando maior confiabilidade, apesar de que esse efeito pode ocorrer em conjunto com o efeito externo.

Albuquerque (2009), introduziu borracha de pneu no concreto massa em busca de melhores propriedades termomecânicas do concreto a fim de minimizar o risco do surgimento de fissuras de origem térmica.

Léger e Seydou (2009) estudaram os deslocamentos termomecânicos com um pêndulo em barragens de gravidade por meio de um modelo híbrido que compara uma barragem estrutural simplificada com elementos de viga a um modelo de deslocamento estatístico de tempo sazonal hidrostático. As comparações são primeiramente estabelecidas entre análises de transferência de calor 1D de seções típicas de barragens de gravidade e análises de elementos finitos 2D. Outros estudos do grupo podem ser observados em Javanmardi et al (2005) em avaliação da pressão da água na abertura de fissuras em barragens de gravidade; e em Roth et al (2016) em que é feita modelagem computacional 3D para analisar a propagação de fissuras de em uma simulação chamada de hidrofraturação. 
Funahashi Júnior e Kuperman (2010) verificaram que as fissuras ocorridas em uma pequena central hidrelétrica eram de origem térmica, e que para evitá-las seria necessário controlar as temperaturas máximas obtidas pelo concreto, e uma alternativa seria a refrigeração do concreto para concretagem.

Dolado e Breugeul (2011) enfatizaram que para o efeito da temperatura sobre a taxa de hidratação, há ainda uma procura de mais estudos sobre o parâmetro de controle da taxa. A crescente utilização de materiais cimentícios misturados e a necessidade de uma maior precisão dos dados disponíveis estão entre as razões mais importantes para o interesse contínuo em efeitos de temperatura.

Algumas análises de plano de lançamentos, estudos térmicos e mecânicos para elementos da UHE Santo Antônio podem ser encontradas em Gambale et al (2011a), Gambale et al (2011b), Gambale et al (2011c), Gambale et al (2011d).

Funahashi Júnior et al (2011) fizeram analise térmica de um bloco de fundação, antes da concretagem e o acompanhamento da construção para garantir que não fissurasse por tensões de origem térmica. Definiram a substituição de $80 \%$ da agua de amassamento por gelo e elaboraram um plano de concretagem, como mostra a Figura 2.10. Embora não houvesse intervalo entre o lançamento, as temperaturas dos lançamentos variaram, sendo a menor dela situada na região mais crítica. Dessa forma, garantiram a estabilidade da estrutura. Para as simulações térmicas e mecânicas utilizaram o programa B4cast.

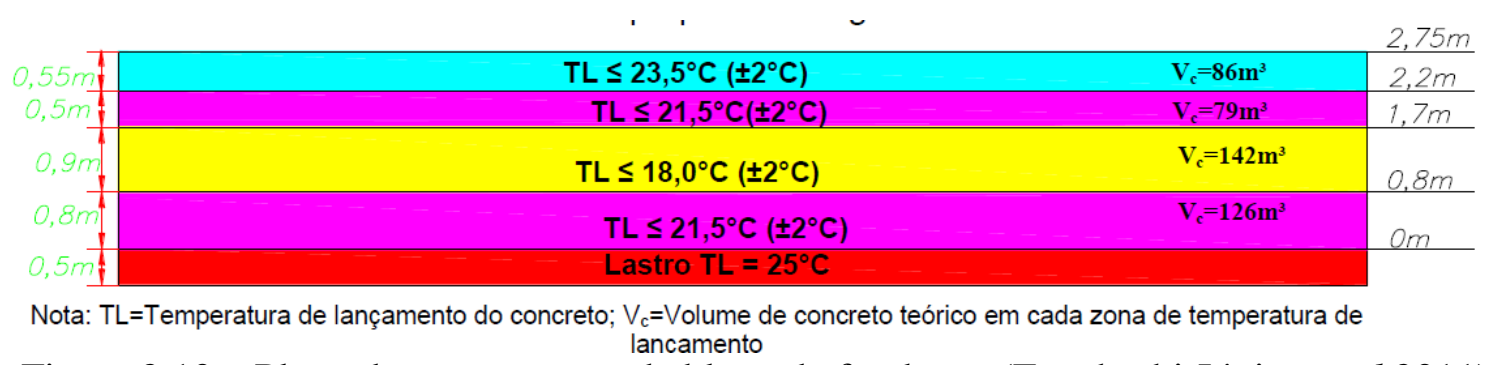

Figura 2.10 - Plano de concretagem de bloco de fundação (Funahashi Júnior et al 2011).

Gomes (2011) trabalhou com a modelagem numérico-computacional pelo método dos elementos finitos de estruturas de concreto nas primeiras idades com geometrias simples. 
Apresentou a influência da temperatura na elevação adiabática e nas tensões termomecânicas.

Khan (2011) fez uma análise termomecânica, com o ANSYS, de uma barragem de CCR na fase de construção como estudo de caso. Afirma que a construção pelo método rampado está sendo difundido, mas precisa ser analisado. E que os resultados da análise térmica em termos de temperaturas ou tensões são combinadas com os resultados da análise estrutural, a fim de avaliar o comportamento de corpo da barragem com todas as cargas.

Pettres (2011) utilizou RNA e técnicas de processamento de imagem para detectar anomalias subsuperficiais no interior de uma estrutura de concreto utilizando termografia. Para isso, moldou um bloco de concreto para verificar a temperatura alcançada, Figura 2.11 a, b. Em determinadas imagens, as simulações indicaram a existência de problemas no interior da estrutura, sua localização e suas dimensões aproximadas.
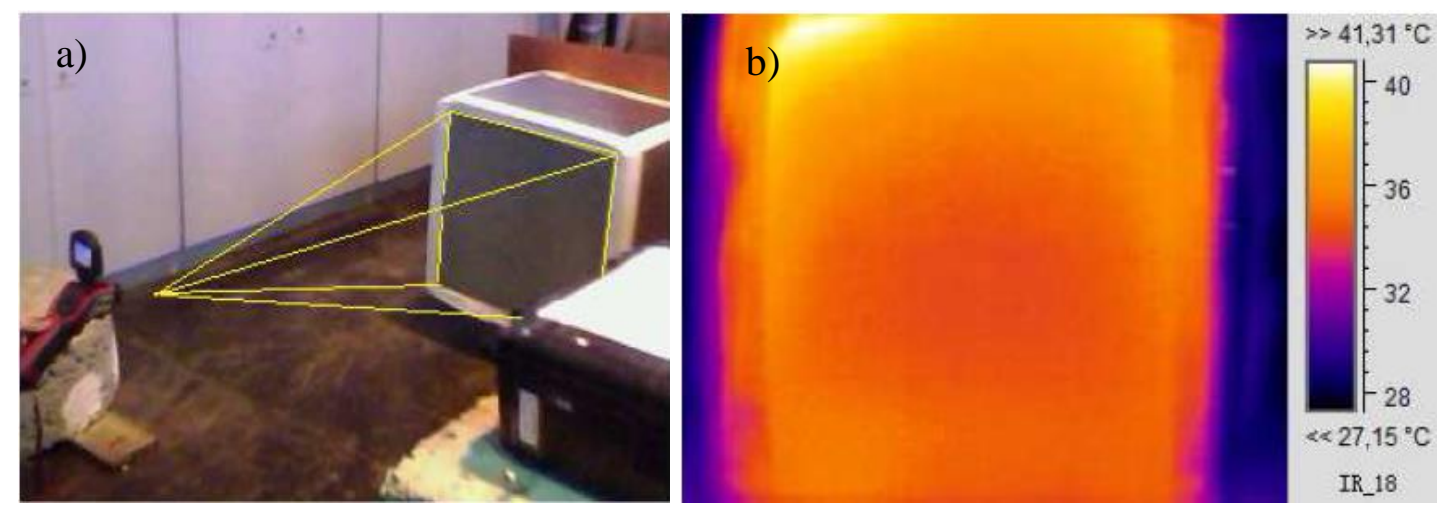

Figura 2.11 - a) Captação; e b) imagem termográfica obtida.

Wu et al (2011) simularam os comportamentos iniciais do concreto, avaliando o risco de fissuração com a análise termomecânica efetuando cálculo térmico com o ANSYS. Concluiu que a temperatura ambiente afeta a tensão na superfície da parede de concreto, enquanto o calor de hidratação e temperatura de lançamento influenciam mais no centro da parede. A velocidade do vento forte aumenta o risco de fissuração durante os primeiros dois dias. Uma menor retração reduz a tensão e que a redução da proporção altura-comprimento é uma boa maneira de evitar fissurações.

Yunchuan et al (2012) utilizaram o MIDAS, software de elementos finitos, para simular o campo de temperatura do concreto massa de uma determinada fundação de um edifício alto 
e o resultado da simulação foi verificado por meio de dados de medição de temperatura. Concluíram que deve-se ter o duplo controle de temperatura e de tensão térmica nessas estruturas e que a simulação pelo MEF ajuda a ter esse controle.

Lawrence et al (2012) afirmaram que é preciso um método eficiente que permita indicar a distribuição da temperatura no interior do concreto a fim de visualizar o gradiente térmico e assim prever o risco de fissuração.

Yang et al (2012) estudaram o processo de tubos de resfriamento via MEF. Disseram que, desde que os tubos de refrigeração sejam dispostos em intervalos regulares espaciais, o concreto pode ser considerado como uma série de células unitárias, com um tubo situado no centro da célula. Cada célula unitária pode ser simplificada como um cilindro circular oco longo com limite externo isolado. No entanto, esta abordagem é limitada pela sua incapacidade para as diferentes condições de construção, diferentes propriedades térmicas de concreto, e as variações do tempo arbitrárias em condições de água de resfriamento.

Qian e Gao (2012) estudaram o efeito de um bloco $(0,50 \times 0,50 \times 0,50) \mathrm{m}$ de concreto sem e com a presença de tubo de resfriamento no centro, sendo um modelo com resfriamento por água e outro com o uso de um fluido - SPCM. Verificaram que há diferença entre as três situações, as temperaturas e o efeito de resfriamento de SPCM mostrou-se melhor do que a água, o pico de temperatura de concreto resfriado por água e SPCM pode ser reduzida para $84,9 \%$ e $76,1 \%$, respectivamente.

Ding e Chen (2013) simularam a presença de tubos de resfriamento no concreto massa combinando o Método de Elemento Composto (CEM) com Algoritmo Genético (GA). O tubo de resfriamento começa a funcionar do $1^{\circ}$ ao $15^{\circ}$ dia após a concretagem, com isso, verificaram que, independentemente da posição dos pontos de análise, há uma queda da temperatura nesses pontos. Depois desse tempo, ainda há geração de calor, por isso sobe mais um pouco a temperatura, mas não tão intensamente, e começa a estabilizar de 30 a 150 dias após a concretagem, Figura 2.12. 

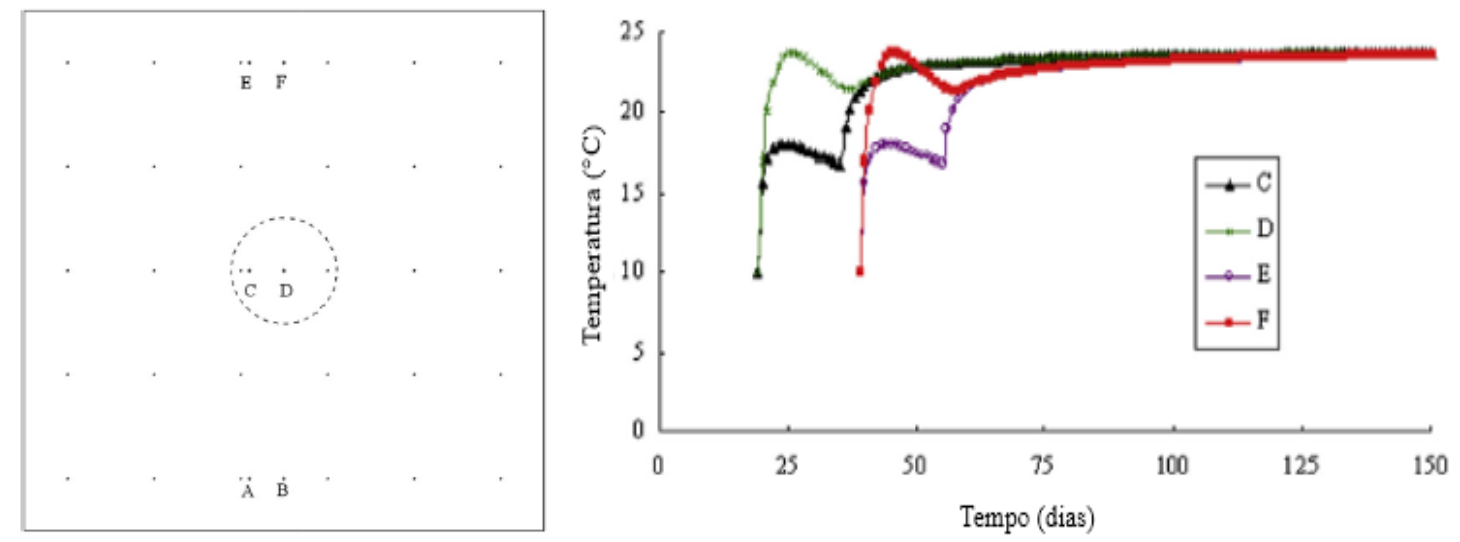

Figura 2.12 - a) Localização dos pontos e b) Temperatura do concreto com presença de tubos de resfriamento (Ding e Chen, 2013).

Tydlitát et al (2014) observaram que quanto maior a relação a/c, maior o calor de hidratação, o que pode ser explicado devido a maior presença de água hidratar mais rapidamente os compósitos de cimento, liberando maior quantidade de calor.

Vicente et al (2014) em análises termomecânicas do concreto massa afirmaram que as temperaturas máximas nos concretos aumentam proporcionalmente as dimensões dos blocos sendo que para uma mesma altura, os blocos com áreas da base superiores a 3x3 metros apresentam temperaturas máximas praticamente iguais. E que estas são maiores nos pontos localizados entre $30 \%$ e $50 \%$ da altura dos blocos e as tensões máximas de tração são maiores nos pontos localizados entre $10 \%$ e $40 \%$ da altura dos blocos a partir das fundações.

Ha et al (2014) criaram um sistema de automação de cura, como mostra a Figura 2.13, de forma que, quando a diferença entre o gradiente de temperaturas entre as partes interna e externa excedem $20^{\circ} \mathrm{C}$, a temperatura da água na superfície aumenta e, consequentemente, as tensões são reduzidas. Concluíram, o sistema é uma forma eficaz de controle de fissuração térmica por controlar a diferença de temperatura entre o centro e a superfície e, além disso, ele pode melhorar a resistência e a durabilidade do concreto. Portanto, pode ser muito útil em estruturas de concreto massa. 


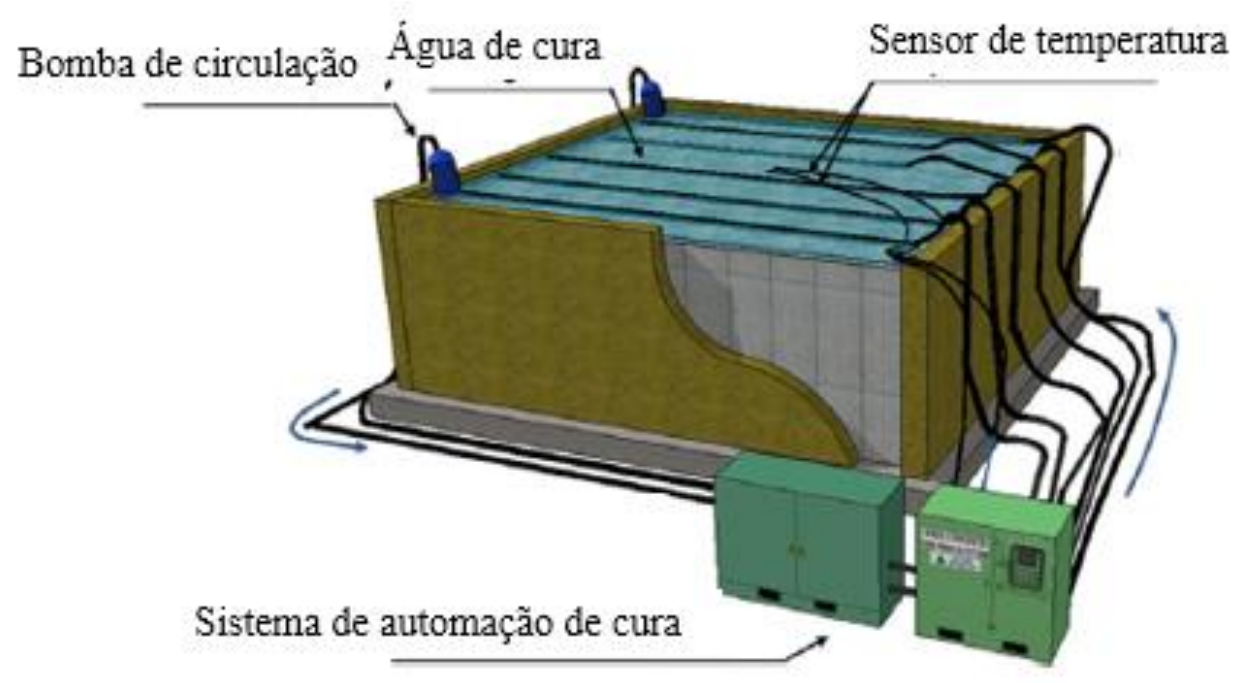

Figura 2.13 - sistema de automação de cura (Adaptado de Ha et al 2014).

Gambale e Traboulsi (2015) apresentaram um gráfico para estimar a temperatura máxima atingida na estrutura, dependendo da temperatura de lançamento e do consumo de cimento, como mostra o gráfico da Figura 2.14.

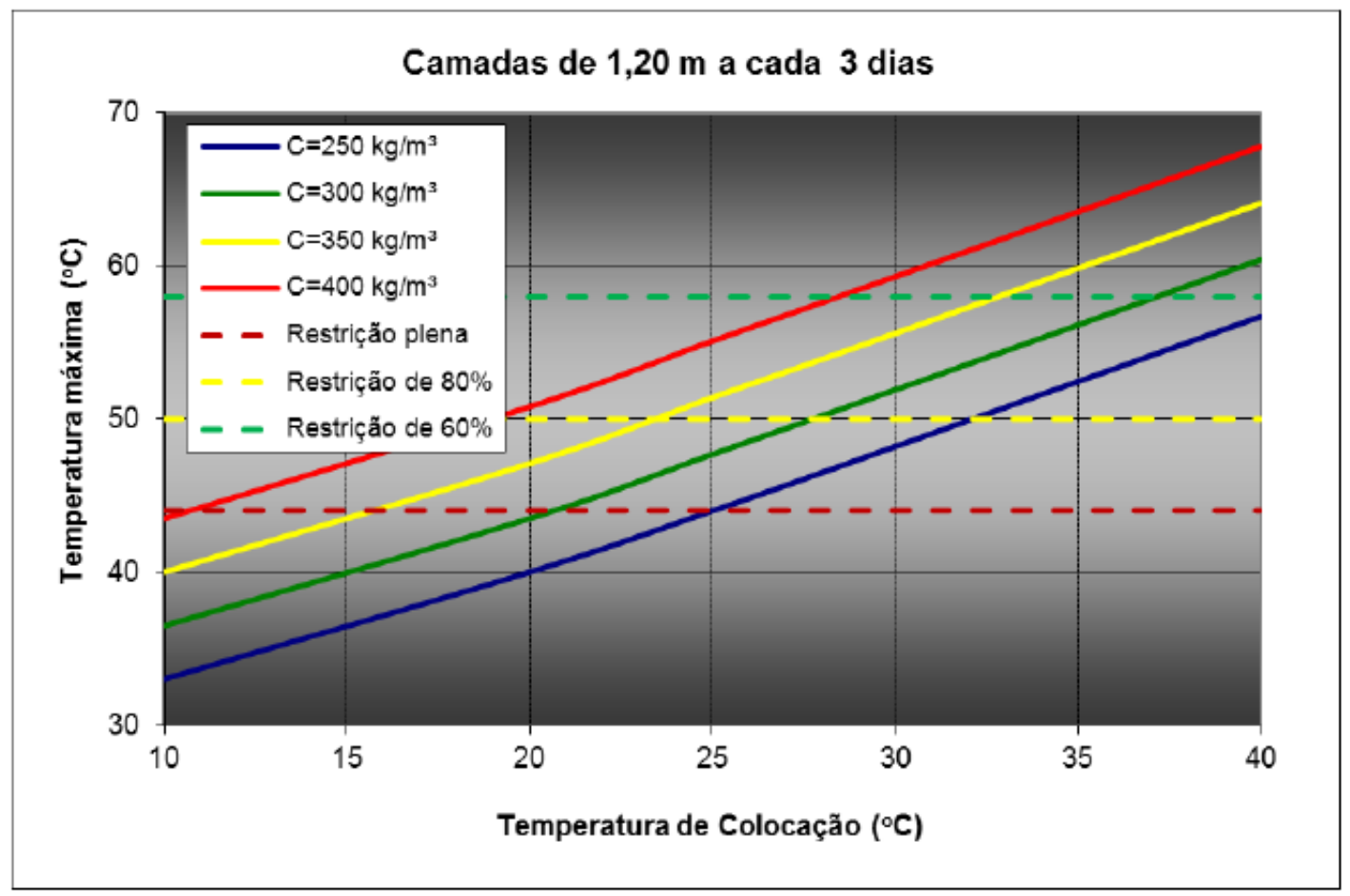

Figura 2.14 - Temperatura máxima atingida a partir da temperatura de lançamento (Gambale e Traboulsi, 2015).

O Brasil não tem uma Norma específica para concreto massa. Dessa forma, as construções baseiam-se em experiências de outras construções de barragens, estudos acadêmicos, normas de outros países ou avaliação por empresas. A empresa de Furnas no país também é referência a esses estudos, através de ensaios laboratoriais e de campo e do vasto 
conhecimento de sua equipe. Há ainda a necessidade de mais pesquisas na área, de forma que futuramente se possa obter uma Norma para subsidiar os profissionais e pesquisadores da área.

O Grupo de Dinâmica e Fluido Estrutura (GDFE) da UnB tem se devotado a várias pesquisas e estudos relativos aos efeitos térmicos em concreto massa, análise de tensões sob vária ações, e assuntos afins e correlatos, orientado ao problema de barragens, como pode ser visto em muitas publicações devotadas a esses assuntos: Almeida et al (2016); Coelho (2012); Coelho et al (2016a, 2016b); Coelho e Pedroso (2013, 2015, 2014); Gomes et al (2016a, 2016b); Pedroso, (2002, 2003, 2005, 2011, 2016); Martins e Pedroso (2016); Mendes e Pedroso (2016); Nascimento Junior (2016); Vasconcelos et al (2015); entre outros.

\subsection{TENSÕES TÉRMICAS}

Ao construir estruturas usando concreto massa, tensões térmicas produzidas devido ao calor de hidratação do cimento podem representar um problema grave para a integridade das estruturas. Portanto, a estimativa das tensões térmicas e das fissurações térmicas nessas estruturas torna-se inevitável (Kim et al 2002).

Para verificar a possibilidade de ocorrência de manifestações patológicas de origem térmica não basta conhecer apenas a geometria do bloco. Para reduzir a possibilidade de fissuração de origem térmica, recomenda-se a realização de estudos térmicos para determinar os procedimentos necessários para a minimização deste problema potencial (Vicente et al 2014).

Fissuração no concreto em idade precoce muitas vezes resulta de alteração de volume devido à mudança de temperatura durante a hidratação. $\mathrm{O}$ calor de hidratação propaga tensões no interior das estruturas induzidas pelas restrições internas e externas sob distribuição de temperatura não uniforme através da massa de concreto. Além disso, as condições ambientais têm efeitos sobre a distribuição de temperatura do concreto. Fluência e retração, que resultam em deformações complexas no concreto nas primeiras idades, também tem influências importantes sobre o desenvolvimento de estresse térmico (Wu et al 2011).

Barragens de gravidade, segundo o USBR (1977), devem cumprir os critérios de projeto para resistência, durabilidade, permeabilidade, e outras propriedades solicitadas. Por causa da 
carga sustentada geralmente associada com eles, para as análises de condições de carga estática deve incluir o estudo do efeito da fluência, pois as propriedades do concreto podem variar com a idade, o tipo de cimento, agregados, e outros componentes, bem como as suas proporções. Por isso, as medições devem ser feitas em amostras de idade suficiente para permitir a avaliação dos pontos críticos. Análises apropriadas devem ser feitas para determinar os valores de resistência à tração e ao cisalhamento.

Klemczak e Knoppik (2015) mostram graficamente, Figura 2.15, a relação entre a temperatura $(\mathrm{T})$, a umidade $(\mathrm{W})$ e as tensões $(\sigma)$ no decorrer tempo para um muro de concreto sobre uma fundação. Na Figura 2.15a, verifica-se que a temperatura da fundação é influenciada pelo aquecimento do concreto, ficando acima da temperatura ambiente até que a temperatura do concreto seja estabilizada. Na Figura 2.15c, observa-se que nas idades iniciais, quando o concreto está sendo aquecido, há apenas tensões de compressão, a partir do início do resfriamento do concreto, após um incremento de tempo, as tensões são zeradas e começa a haver tração devido ao resfriamento do concreto. Com o tempo há uma perda de umidade do concreto e da fundação, Figura 2.15b, e, segundo as autoras, esta característica também influenciará nas tensões de tração obtidas, conforme a Figura 2.15d.
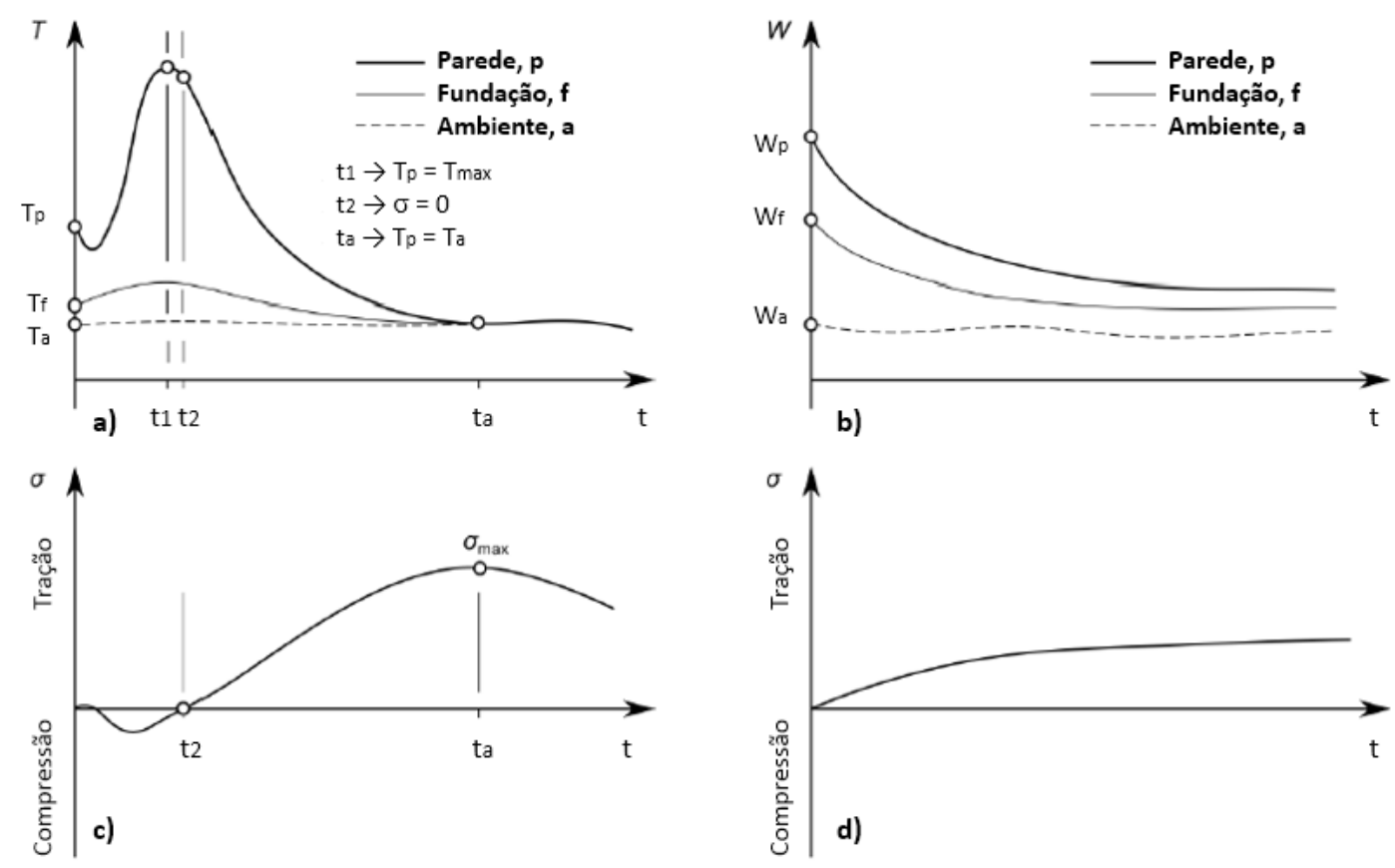

Figura 2.15 - Relação entre temperatura, tensão e umidade (Klemczak e Knoppik, 2015).

Quando uma parede é mantida na fôrma até que resfrie, tensões se desenvolvem no interior da parede, podendo dar início às fissuras internas. Quando a forma é removida nas fases 
iniciais da cura do concreto, um aumento da velocidade de resfriamento leva a maiores tensões na superfície (Klemczak eWróbel, 2014). Os autores afirmam ainda que a maior tensão térmica não ocorre na interface entre a parede e a de restrição, mas em algum nível acima dessa região, onde aparece a primeira fissuração. Esse fato resulta da distribuição não uniforme da temperatura e umidade dentro do elemento que se concentra em suas partes centrais.

Zhai et al (2016) estudaram a influencia do tipo de fôrma nas tensões térmicas, e observaram que entre uma forma de aço e uma de madeira, as tensões foram um pouco reduzidas para as formas de aço devido a alta condutividade térmica do material e sua pequena espessura, aumentando a dissipação do calor. No entanto, essa redução não foi suficiente para eliminar a fissuração.

Um elemento concreto, se livre para se movimentar, não terá nenhuma tensão. No entanto, os movimentos de concreto massa são quase sempre restritos, induzindo tensões térmicas normalmente devido a variações de temperatura. Essas tensões podem ser devido a restrições externas e/ou internas. A Figura 2.16 traz uma representação geométrica das ações combinadas de restrição que conduzem à fissuração por gradientes térmicos diferenciais em um concreto jovem entre o núcleo e as superfícies do volume de concreto e um elevado grau de restrição da base, que pode fazer com que o valor de tensão ultrapasse a resistência à tração do concreto (Amin et al 2009).

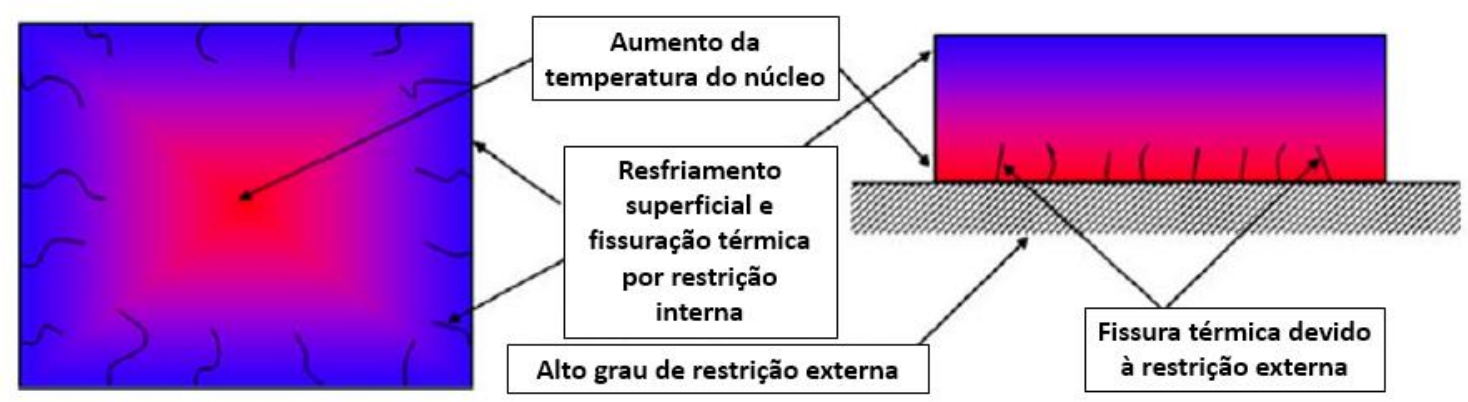

Figura 2.16 - Fissuras devido as restrições (Amin et al 2009).

Segundo Gambale et al 2011a, o comportamento térmico de superfícies com condição de contorno cuja vizinhança é rocha, concreto ou mesmo o ar não tem diferença significativa na temperatura máxima da estrutura. 
Lin e Chen (2016) afirmam ainda que o desenvolvimento da tensão de tração do concreto na superfície pode ser estimada usando o método da maturidade, e o risco de fissuração pode ser avaliada utilizando a relação tensão-deformação nos pontos críticos.

\subsubsection{Coeficiente de Restrição $\left(k_{r}\right)$}

As tensões térmicas são influenciadas pelas restrições externas e internas que apresentam. Neste trabalho, as restrições internas são desconsideradas, portanto, sua descrição será sintetizada. As restrições externas são levadas em consideração nos cálculos através de um coeficiente que relaciona a posição do ponto de análise com relação à largura e a altura da estrutura, conforme é exposto a seguir.

\subsubsection{Restrição Externa}

Quando uma estrutura sobre efeitos térmicos não está livre para se movimentar surgem as tensões oriundas das suas restrições.

O grau de restrição, $k_{r}$, é a razão entre a tensão real resultante da variação de volume e a tensão que resultaria se estivesse completamente restrito. Numericamente, a tensão é igual ao produto do grau de restrição existente no ponto em questão e a mudança no comprimento que ocorreria se o concreto não estivesse restringido (ACI 207.2R, 2007).

Segundo CIRIA C660 (2007) a tensão do concreto é diretamente proporcional ao coeficiente de restrição do concreto, de forma que uma diferença de 0,1 no seu valor, por exemplo, de 0,5 para 0,6 , irá resultar em um aumento de tensão em cerca de $20 \%$, que pode levar em uma diferença nas análises para afirmar se haverá ou não fissuração, e se serão ou não aceitáveis.

O concreto posto sobre uma base de rocha rígida sem juntas será essencialmente contido na interface concreto-rocha, mas o grau de restrição irá diminuir consideravelmente em localizações acima da rocha, como mostrado na Figura 2.17 (ACI 207.2R, 2007). O ACI traz apenas o gráfico do coeficiente de restrição para o ponto central, Figura 2.17a, baseado no USBR (1981), o qual apresenta também para os pontos a 1/4 e 1/10 do comprimento do corpo, exposto nas Figuras 2.17c e 2.17d, respectivamente.

Ressalta-se que não foi encontrada base científica para a elaboração dos ábacos mostrados. No entanto, sua utilização é uma forma consagrada na literatura, aplicada com êxito por 
vários autores, conduzindo a resultados coerentes. Em razão disso, a dedução dessas expressões deixa de ser efetuada neste trabalho, porque foge do escopo das nossas pesquisas.

Os valores do coeficiente de restrição apresentados na Figura 2.17 são para tensões uniaxiais. Tensões mais elevadas do que estas podem ocorrer sob condições de restrição biaxiais ou triaxiais. Levando em consideração estas restrições adicionais, os esforços máximos podem ser estimados multiplicando os resultados acima por 1/(1-v) para restrição biaxial e por 1/(12v) para restrição triaxial. Os valores do coeficiente de Poisson, v, para o concreto variam com a idade e com diferentes concretos, com a maioria dos valores variando entre $0,15-0,20$ à idade de 28 dias e 0,16-0,27 na idade de 1 ano (USBR, 1981). Devido as variações do modulo de elasticidade e coeficiente de dilatação térmica, é difícil calcular as tensões na fase de projeto para um bloco.

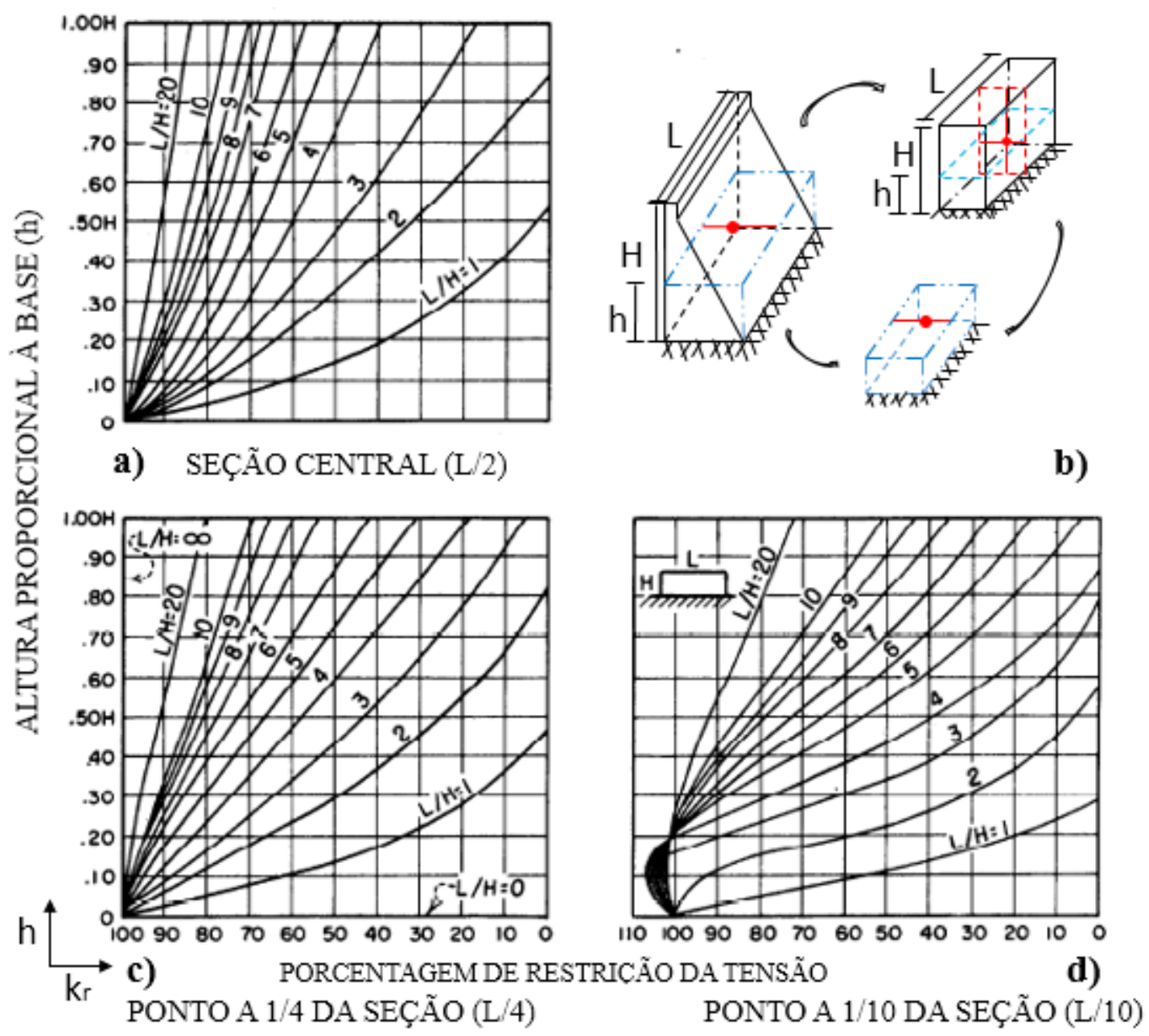

Figura 2.17 - Coeficiente de restrição (Adaptado de USBR, 1981). 
A Figura 2.17 mostra uma adaptação aos ábacos presente no USBR (1981) para determinação do coeficiente de restrição. No eixo das abscissas obtêm-se os coeficientes de restrição, $\mathrm{k}_{\mathrm{r}}$, em função da altura do ponto analisado com relação a altura total do corpo, $\mathrm{h}$, representado pelo eixo das ordenadas, para as diferentes relações entre o comprimento do corpo e sua altura, curvas de $\mathrm{L} / \mathrm{H}$. O ponto de cruzamento entre essas curvas e as linhas de h, para a altura do ponto estudado, determina o coeficiente de restrição nas abscissas.

O primeiro ábaco, Figura 2.17a, fornece os coeficientes de restrição para os pontos da seção central (L/2), como mostra as linhas tracejadas em vermelho, na representação da estrutura, Figura 2.17b. No contato entre a fundação e o corpo, $\mathrm{k}_{\mathrm{r}}$ será sempre igual a um. A medida que o ponto sobe, o valor de $\mathrm{k}_{\mathrm{r}}$ diminui, reduzindo assim as tensões obtidas. A linha azul no corpo mostrado, exemplifica um ponto na linha e seção central do corpo. Este é o único ábaco presente no ACI 207-2R (2007).

Ressalta-se também que as normas não trazem uma forma de determinação de $\mathrm{k}_{\mathrm{r}}$ diferente para o caso de uma estrutura de superfície irregular, como é o caso de uma barragem, que tem uma inclinação em uma de suas faces, portanto, é considerada como uma estrutura retangular, como representa a Figura 2.17b. Lembrando ainda que o USBR é uma norma voltada exclusivamente para o cálculo de barragens, apresentando apenas os ábacos para o cálculo dos coeficientes de restrição. As Figuras 2.17c e 2.17d mostram ainda os ábacos para pontos analisados em L/4 e L/10.

Quando a tensão no concreto devido à variação do volume atinge a resistência à tração do concreto, este será fissurado, dependendo do seu grau de confinamento. Se um membro de concreto está sujeito a uma redução uniforme do volume, mas é contido em sua base ou em uma extremidade, fissuras irão iniciar na base ou na borda restrita. Para L/H maior do que cerca de 2,5, a Figura 2.17 a indica que se houver tensão de tração suficiente para iniciar uma abertura, esta deve propagar para a altura total do bloco (ACI 207-2R, 2007).

De acordo com Rostásy et al (1988), Figura 2.18, as fissuras estão relacionadas com a razão $\mathrm{L} / \mathrm{H}$. Para $\mathrm{L} / \mathrm{H} \leq 1$ as fissuras concentram-se nas proximidades da base e as aberturas seriam bastante estreitas, menor ou igual a $0,1 \mathrm{~mm}$, as quais não são preocupantes. Enquanto para $\mathrm{L} / \mathrm{H} \geq 2$ para 2,5, as fissuras se propagariam até a altura do muro, que são as que realmente importam nas tensões termomecânicas. $\mathrm{O}$ autor não expõe o que aconteceria para $1<\mathrm{L} / \mathrm{H}<$ 
2, mas diante dos conceitos da literatura, nesse intervalo, surgiriam as tensões térmicas, as quais dificilmente conseguiriam subir até a superfície.

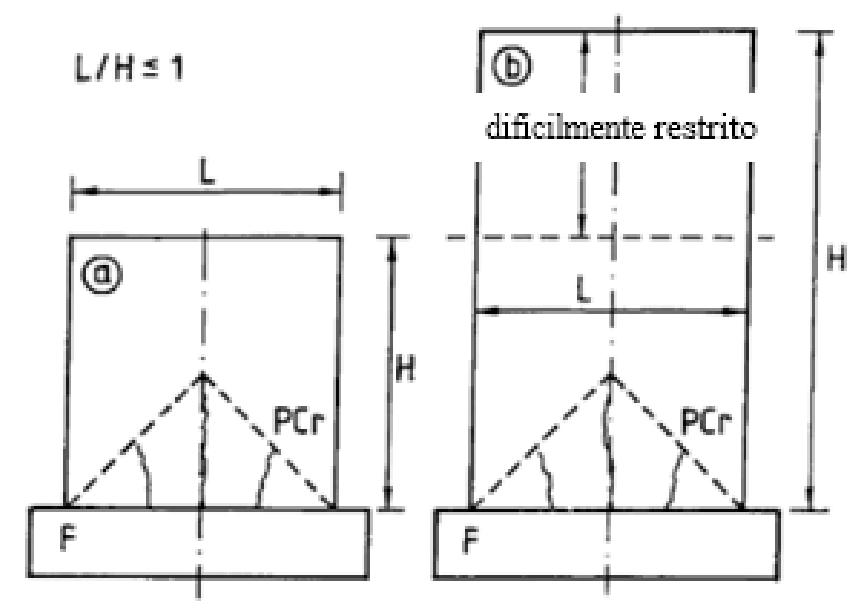

$\mathrm{L} / \mathrm{H} \geq 2$; Fissuras possiveis

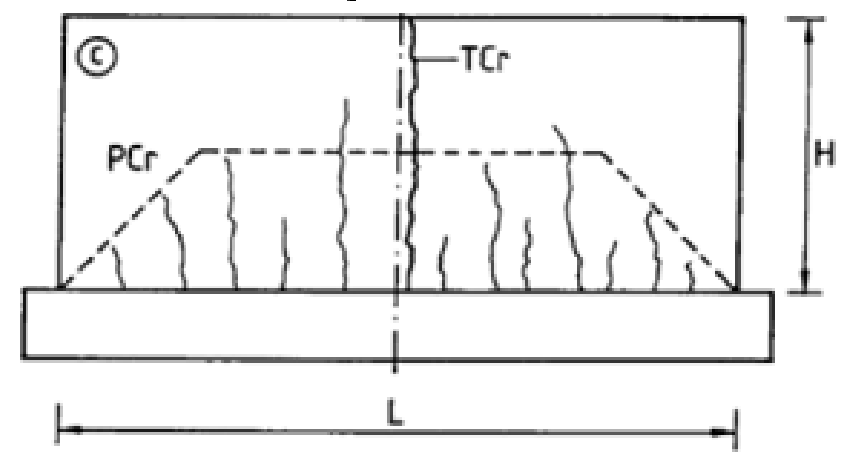

Figura 2.18 - Fissuras no concreto (Adaptado de Rostásy et al 1998).

Gambale et al (2009b) afirma que $K_{R}$ pode ser determinado pelas Equações 2.2 e 2.3:

$$
\begin{array}{lll}
k_{r}=\left(\frac{\frac{L}{H}-2}{\frac{L}{H}+1}\right)^{h / H} & \text { para } & \frac{L}{H}>2,5 \\
k_{r}=\left(\frac{\frac{L}{H}-1}{\frac{L}{H}+10}\right)^{h / H} & \text { para } & \frac{L}{H} \leq 2,5
\end{array}
$$

Para as formulações proposta pelo autor, foi elaborado o gráfico do coeficiente de restrição mostrado na Figura 2.19. No entanto, verifica-se que os valores são próximos aos do ACI, mas em alguns casos, como para $\mathrm{L} / \mathrm{H}=2$, a curva se diferencia da curva do ACI, que utiliza o USBR (1981). Também pela formulação 2.3, para $\mathrm{L} / \mathrm{H}=1, k_{r}$ seria sempre igual a zero, independente do valor de $\mathrm{h} / \mathrm{H}$. 


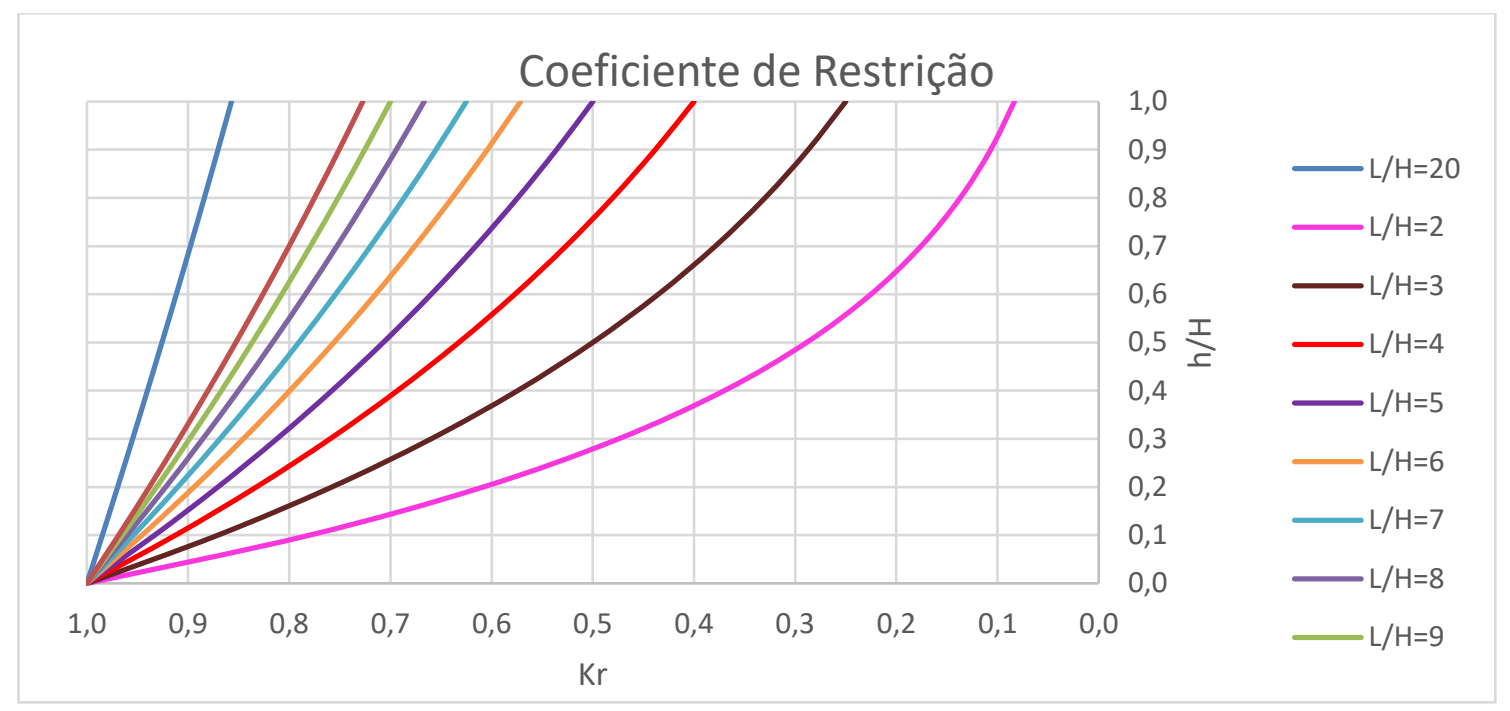

Figura 2.19 - Coeficiente de restrição calculado.

As expressões gráficas dadas pelos autores nas Equações 2.2 e 2.3 não representa o mesmo ábaco da literatura mostrada na Figura 2.17a. Aspecto que sugere a existência de outros parâmetros que não estão presentes nas referidas equações, tal como mostra o sucinto estudo empírico do apêndice D.

Quando o concreto é posto sobre uma base flexível, além do fator $k_{r}$, deve-se multiplicar as tensões também pelo coeficiente de fundação, $k_{f}$, que leva em consideração a sua deformação. O ACI 207.2R (2007) determina $k_{f}$ de acordo com a Equação 2.4.

$$
k_{f}=\frac{1}{1+\frac{A_{g} E_{c}}{A_{f} E_{f}}}
$$

Em que:

- $A_{g}=$ área total da seção do concreto em contato com a fundação;

- $A_{f}=$ área da fundação ou outro elemento restritivo;

- $\quad E_{f}=$ módulo de elasticidade da fundação ou outro elemento restritivo;

- $E_{c}=$ módulo de elasticidade do concreto. 
CIRIA C660 (2007) explica a diferença entre as fundações rígida e flexível. Considerando uma parede sobre uma fundação, sem restrição, a parede iria se movimentar livremente, mantendo a sua forma retangular. No entanto, ela deve permanecer ajustada à sua base, portanto se adequa à forma acabada tal como indicado nas Figuras $2.20 \mathrm{a}$ e b. As forças necessárias para a movimentação livre na forma real indicam as direções das principais tensões criadas no concreto e, portanto, do padrão de fissura provável. Por exemplo, na Figura 2.20a uma força horizontal é necessária para manter a compatibilidade de comprimento, mas isto tende a deformar a parede, de modo que uma força de tração vertical adicional é necessária para manter a compatibilidade vertical. Neste caso, o padrão de fissuração principal são fissuras verticais no meio do vão e aberturas espalhadas em direção às extremidades das paredes. Nas extremidades da parede, também é possível haver umas fendas horizontais na junção entre a parede e a base.

Quando a base é flexível, a parede pode se deformar e ambas as tensões horizontais e verticais são reduzidas. Entretanto a fissuração ainda pode ocorrer, neste caso, as aberturas serão menores e mais estreitas e há menos chance de uma fenda horizontal aparecer na articulação. Esses padrões de fissura são unicamente devidos à restrição, independente de armaduras. Todas essas rachaduras podem se estender completamente na seção, podendo, portanto, resultar em vazamento ou infiltração (CIRIA C660, 2007).
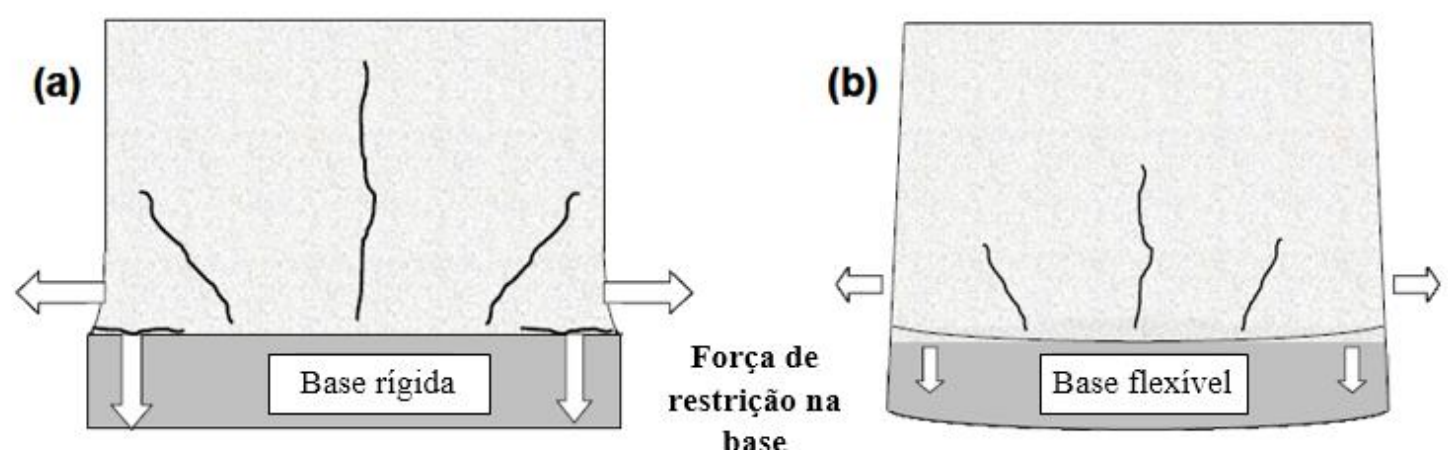

Figura 2.20 - Fissuras com relação a rigidez da base a) base rígida; b) base flexível (Adaptado de CIRIA C660, 2007).

Uma vez que existe uma fenda, a tensão necessária para propagar a fissura na zona de tensão de tração é menor do que a resistência à tração. Isto depende de vários fatores, tais como a forma da ponta da fissura, isto é, se é pontiaguda ou arredondada (ACI 207.2R, 2007). 
Para a variação horizontal também há uma variação no coeficiente de restrição. Segundo Schleech (1962) apud CIRIA C660 (2007) no centro da estrutura esse coeficiente é 1,0, o qual é reduzido até a extremidade conforme a Figura 2.21.

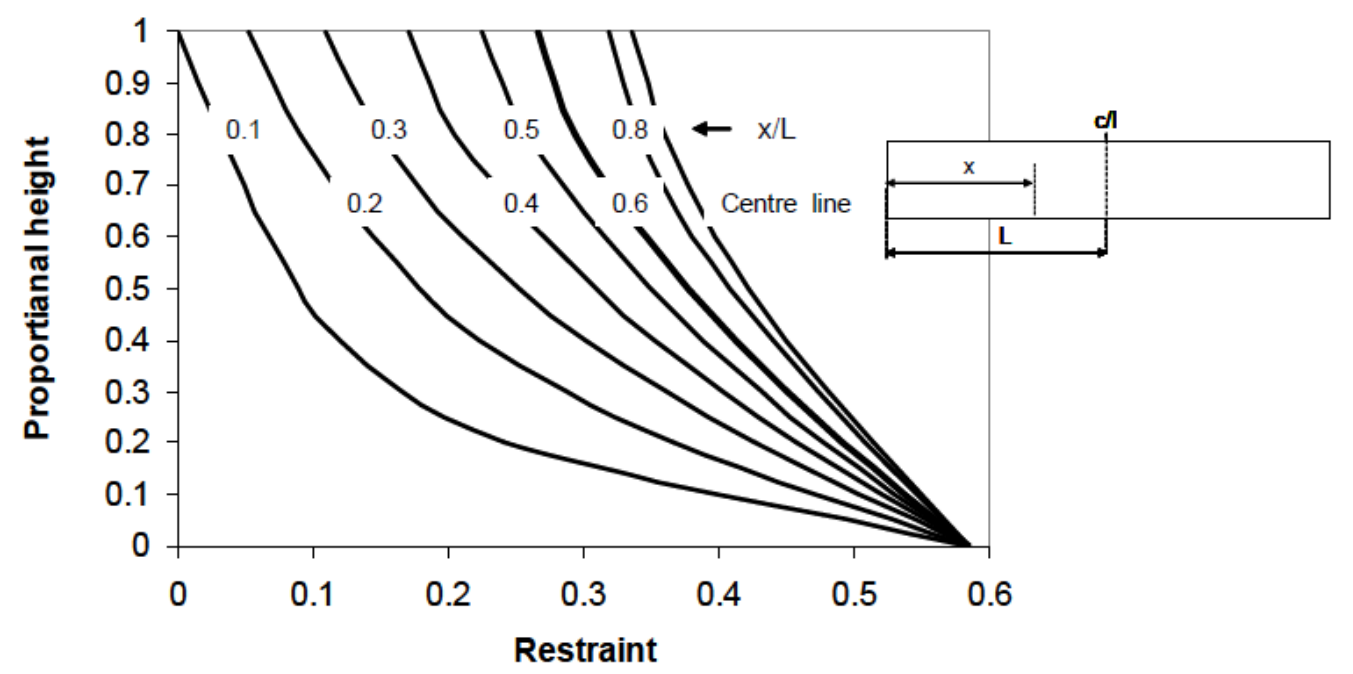

Figura 2.21 - Coeficiente de restrição pela variação horizontal (Adaptado de Schleech, 1962 apud CIRIA, 2007).

\subsubsection{Restrição Interna}

Restrição interna existe em membros com mudança de volume não uniforme em uma seção transversal, como é o caso do concreto massa com temperaturas interiores maiores do que as temperaturas de superfície. Os seus efeitos são adicionados algebricamente aos efeitos de restrição externa, mas sempre que existam condições de elevada restrição externa, os efeitos de restrição interna podem ser insignificantes. (ACI 207.2R, 2007)

Durante o aquecimento, como o núcleo de uma seção espessa aquece e se expande mais do que a superfície, tensões de tração só podem ser geradas na zona de superfície se o centro for livre para se expandir. Se a seção está restrita e a expansão total do núcleo é impedida, a tensão de tração desenvolvida na superfície será reduzida e também pode ser totalmente eliminada. Por isso o risco de fissuras superficiais pela restrição interna será reduzida quando existe restrição externa (CIRIA, 2007).

No centro da seção, quando a restrição interna for significativa, as restrições interna e externa serão somadas. Portanto, o risco de fissuras internas durante o resfriamento será maior e 
quaisquer fissuras que se formarem serão maiores, tal como mostrado na Figura 2.22 (CIRIA, 2007).

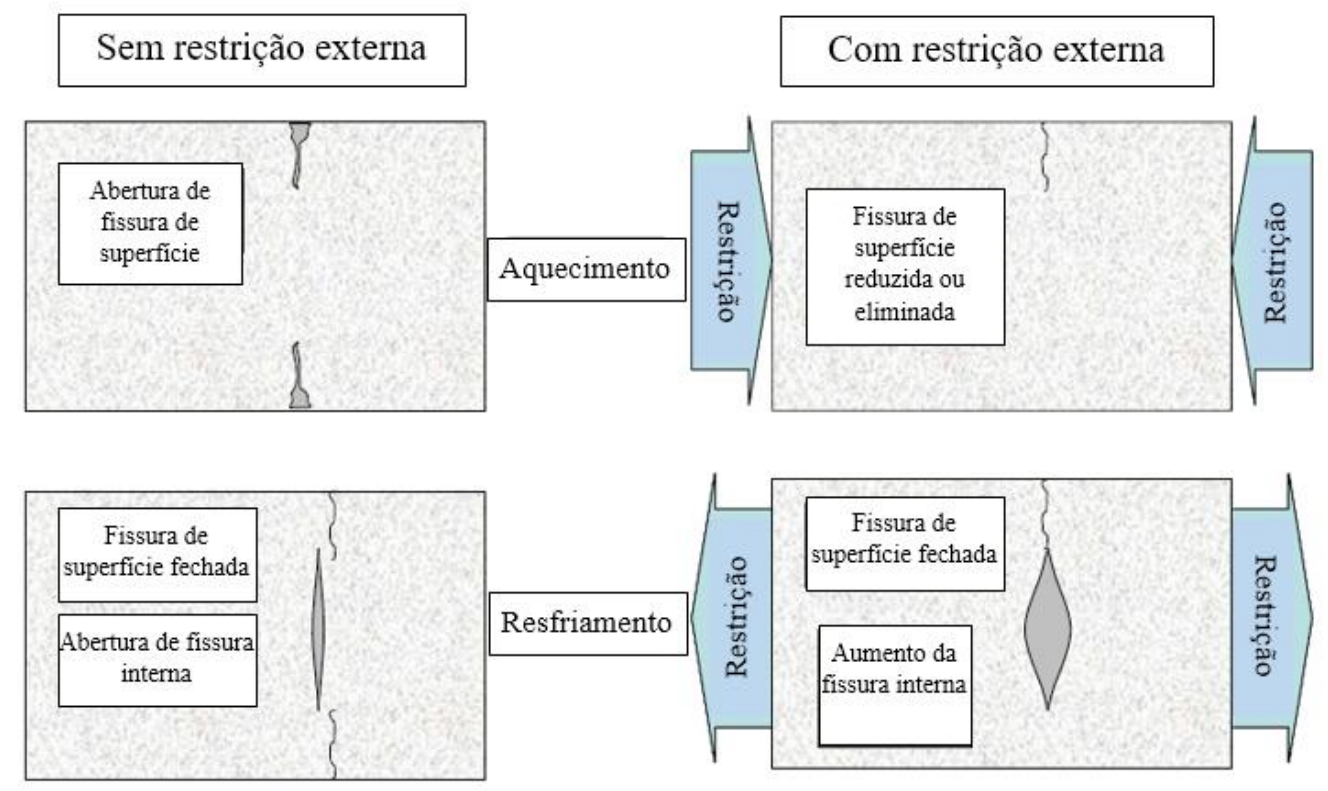

Figura 2.22 - Fissuras para superfícies com e sem restrição (Adaptado de CIRIA, 2007).

Diante do exposto, esse trabalho limita-se ao cálculo das tensões baseadas apenas nas restrições externas.

\subsection{MÉTODOS NUMÉRICOS}

A tecnologia nos permite fazer uso de equipamentos que facilitam a resolução de problemas complexos de engenharia, assim como de outras áreas da ciência. Existem softwares capazes de fornecer respostas precisas em um curto intervalo de tempo para esses problemas, porém o uso de métodos analíticos é indispensável para o entendimento e o uso dos programas computacionais (Coelho, 2012).

Ao se fazer a aproximação numérica da equação diferencial, espera-se obter o valor da variável dependente em um número finito de pontos no domínio, ou seja, de forma discreta. À medida que o número de pontos aumenta, é de se esperar que o valor numérico obtido se aproxime do valor exato da variável. O número de pontos do domínio deve ser escolhido de modo a haver um equilíbrio entre o erro numérico tolerado e o esforço computacional permitido (Silva Junior, 2012). 
Muitos dos problemas práticos de engenharia não têm solução exata, portanto faz-se uso de soluções aproximadas. Dentre os métodos numéricos mais utilizados tem-se o MDF, o MEF e o Método dos Elementos de Contorno (BEM). No primeiro a aproximação dos resultados é dada por equações diferenciais lineares e é de fácil aplicação em problemas de geometria simples. No entanto, a aplicação é complicada para problemas com complexa geometria e condições de contorno (Moaveni, 1999).

O MDF é simplesmente a substituição do operador diferencial pelo seu correspondente numérico. Tanto o MDF como o MEF não trabalham com volumes de controle e sim apenas com os pontos da malha, e, como consequência, não são conservativos em nível discreto (Maliska, 2004).

Segundo Moaveni (1999), o MEF utiliza a formulação integral criando sistemas de equações algébricas e proporcionando uma solução aproximada em cada elemento. A solução completa é dada com o somatório dos resultados individuais para cada elemento.

A resolução pelo MEF é dada dividindo-se o corpo contínuo em um número finito de partes (os elementos), conectados entre si por intermédio de pontos discretos, que são chamados de nós. A montagem de elementos, que constitui o Modelo Matemático, tem o seu comportamento especificado por um número finito de parâmetros (Alves Filho, 2000). Segundo Chapra e Canale (2015) o método de solução dos problemas via MEF pode ser dado conforme a Figura 2.23.

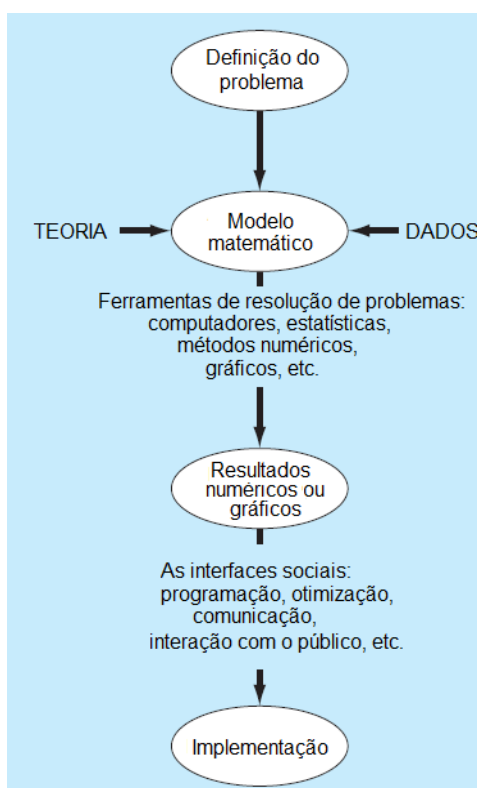

Figura 2.23 -O processo de Solução de problemas de engenharia (Adaptado de Chapra e Canale, 2015). 


\subsubsection{Solução pelo Método dos Elementos Finitos (MEF)}

A análise por elementos finitos pode integrar as medidas técnicas modernizadas e o projeto real, podendo fazer o controle da temperatura e da tensão térmica; é viável como método auxiliar de controle de temperatura e desfruta de ampla aplicação no projeto real (Yunchuan et al 2012).

Dessa forma, faz-se necessário a utilização de programas computacionais afim de se obter respostas para os diversos tipos de problemas. No entanto, é imprescindível que haja uma verificação da correta manipulação dos programas, garantido assim, a exatidão e confiança dos resultados obtidos. Isto é possível a partir da comparação dos resultados numéricos e analíticos obtidos de forma manual ou com softwares matemáticos mais simples com os programas mais rebuscados.

Diante disso, buscou-se um software para solução computacional do problema térmico utilizando o MEF. Existem vários programas para tal utilização, tais como ABAQUS, NASTRAN, ANSYS, ADINA, entre outros. A escolha do ANSYS para o trabalho foi motivada por este se tratar de uma ferramenta de análise versátil com uma boa aceitação e utilização no mercado.

Além do ANSYS, foram utilizados o MAPLE, o MATLAB e o Excel. O MAPLE e o MATLAB foram utilizados na elaboração de soluções analíticas e implementação de códigos para os resultados por diferenças finitas. Ambos são softwares que permitem a solução de equações matemáticas e códigos de programação, assim como a elaboração de gráficos. O Excel foi utilizado para a geração de gráficos comparativos.

A quantidade de elementos a ser utilizado deve ser estudada para cada caso, deve-se buscar sempre a convergência. Inicialmente faz-se a discretização de uma malha e analisa os seus resultados, posteriormente, refina-se a malha e observa se os valores estão próximos aos encontrados anteriormente. Caso isso aconteça, a primeira malha utilizada é suficiente para a análise dos resultados. Convém observar também que quanto mais refinada a malha, maior será o tempo de processamento do programa.

Dentre os métodos numéricos citados, o mais utilizado no estudo das estruturas de concreto massa é o MEF. Alguns autores utilizam dados experimentais e/ou de construções reais para 
fazer comparações entre eles, como mostrado no item 2.2.1. No entanto, não se constatou em nenhuma pesquisa um estudo mais aprofundado das equações que regem o problema de forma analítica ou utilizando o MDF. 


\section{GENERALIDADES PARA UMA ANÁLISE TERMOMECÂNICA}

Este capítulo completa o anterior de revisão bibliográfica, sendo voltado para o conhecimento de conceitos técnicos necessários para o aprendizado e modelagens numéricas em concreto massa. Serão abordadas as propriedades térmicas e mecânicas do concreto massa, assim como suas respectivas influências sobre o mesmo.

\subsection{PROPRIEDADES TÉRMICAS DO CONCRETO}

O estudo da massa e do calor específico, da condutividade e da difusividade térmica são importantes para o desenvolvimento de gradientes de temperatura, deformações térmicas, empenamento e fissuração nas primeiras idades do concreto.

As propriedades térmicas são de interesse por diversas razões, entre elas: a condutividade e a difusividade térmica são relevantes para o desenvolvimento de gradientes de temperatura, deformações térmicas, empenamento e fissuração nas idades inicias do concreto, como para o isolamento térmico do concreto em serviço; a dilatação térmica é necessária para o dimensionamento de juntas de dilatação e contração.

As propriedades do concreto irão depender das propriedades dos materiais utilizados, assim como o fluxo de calor é diretamente proporcional à condutividade térmica e ao gradiente térmico do material (Torquato, 2001).

A seguir apresentam-se as definições resumidas das propriedades térmicas do concreto:

\subsubsection{Massa específica ( $\rho)$}

A massa específica é a relação entre a massa de um corpo sobre o volume que esse mesmo corpo ocupa. Desta forma pode-se dizer que a densidade mede o grau de concentração de massa em determinado volume. É influenciada pelo teor de água e de finos, pelos agregados utilizados e pelo índice de vazios e pode ser um importante indicador das características que este apresentará no estado endurecido. $\mathrm{O}$ aumento de temperatura é dado com o aumento da massa específica do concreto.

Considerando os valores de $2000 \mathrm{~kg} / \mathrm{m}^{3} \mathrm{e} 3000 \mathrm{~kg} / \mathrm{m}^{3}$ como mínimo e máximo para a massa específica, foram analisadas as isotermas de temperatura, após dois dias de lançamento do concreto, para um bloco de dimensões $1 \mathrm{~m} \mathrm{x} 1 \mathrm{~m}$, considerando as demais propriedades 
constantes, obtendo-se os resultados mostrados na Figura $3.1 \mathrm{a}$, b (Coelho et al 2012b). Observa-se que há uma diferença na máxima temperatura final $\left(67,463^{\circ} \mathrm{C}\right.$ e $\left.59,976^{\circ} \mathrm{C}\right)$ e na distribuição das isotermas, o que evidencia que quanto maior a massa específica, menor a máxima temperatura obtida.

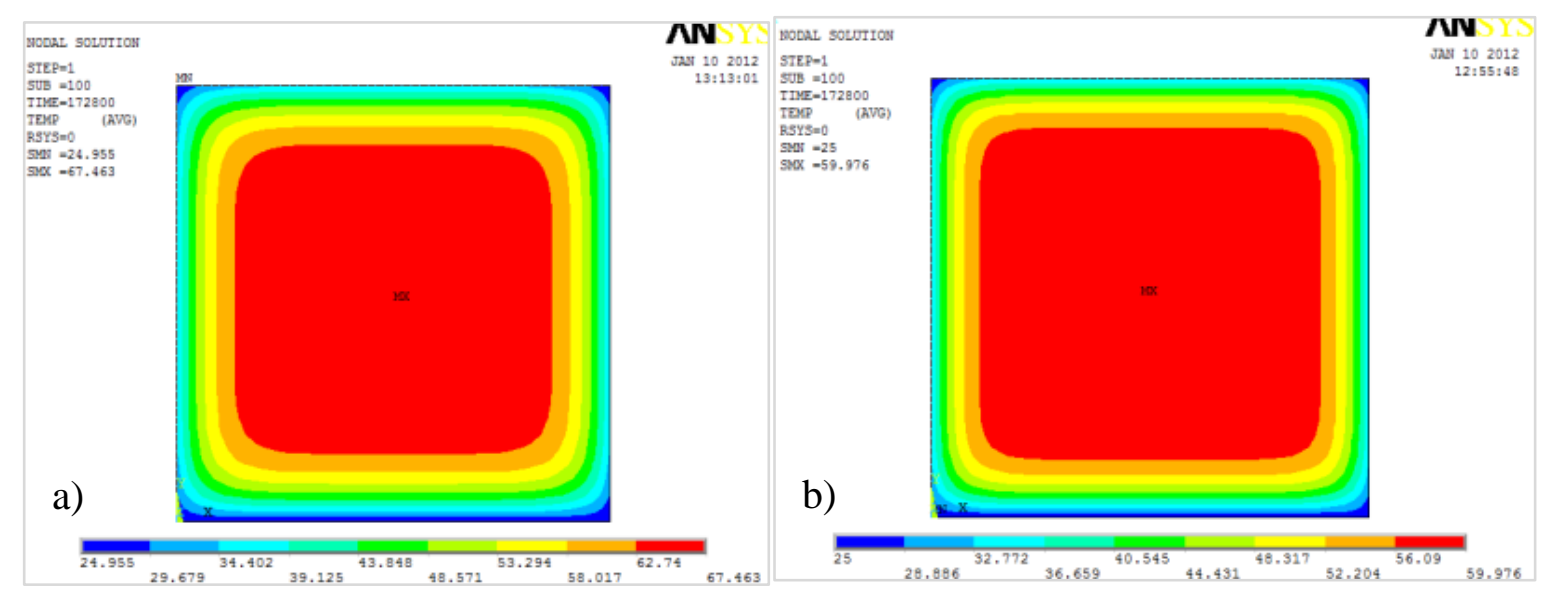

Figura 3.1 - Isotermas de temperatura para a) $\rho=2000 \mathrm{~kg} / \mathrm{m}^{3}$ e b) $\rho=3000 \mathrm{~kg} / \mathrm{m}^{3}$, respectivamente.

\subsubsection{Condutividade térmica $(\mathbf{k})$}

Definida como a capacidade do material conduzir calor, é a relação entre o fluxo de calor e o gradiente de temperatura. A condutividade térmica depende da composição do concreto e o aumento da umidade também eleva o seu valor (Neville, 2016).

Mehta e Monteiro (2014) dizem que a condutividade térmica fornece o fluxo de calor transmitido através de uma unidade de área de um material sob uma unidade de gradiente de temperatura unitária.

De acordo com Furnas (1997) e Neville (2016), essa condutividade tem valores que variam de 1,4 a 3,6 (W/m.K). Khan (2001) afirmou que quanto maior o teor de umidade e a condutividade térmica do agregado, maior será a condutividade térmica do concreto.

Avaliando a temperatura para variações da condutividade térmica do concreto de 1 e 4 $\mathrm{W} / \mathrm{m} .{ }^{\circ} \mathrm{C}$, valores considerados mínimo e máximo para o concreto, arredondados, para dois dias de concretagem, os resultados finais foram equivalentes $\left(64.534^{\circ} \mathrm{C}\right.$ e $64.460^{\circ} \mathrm{C}$, respectivamente). No entanto, as isotermas, ou seja, na segunda situação, o núcleo com máxima temperatura é relativamente menor, mostrando uma maior dissipação de calor para uma maior condutividade térmica, Figura 3.2 a, b (Coelho et al 2014b). É importante ressaltar que essa propriedade, normalmente assume valores baixos para o concreto massa. 


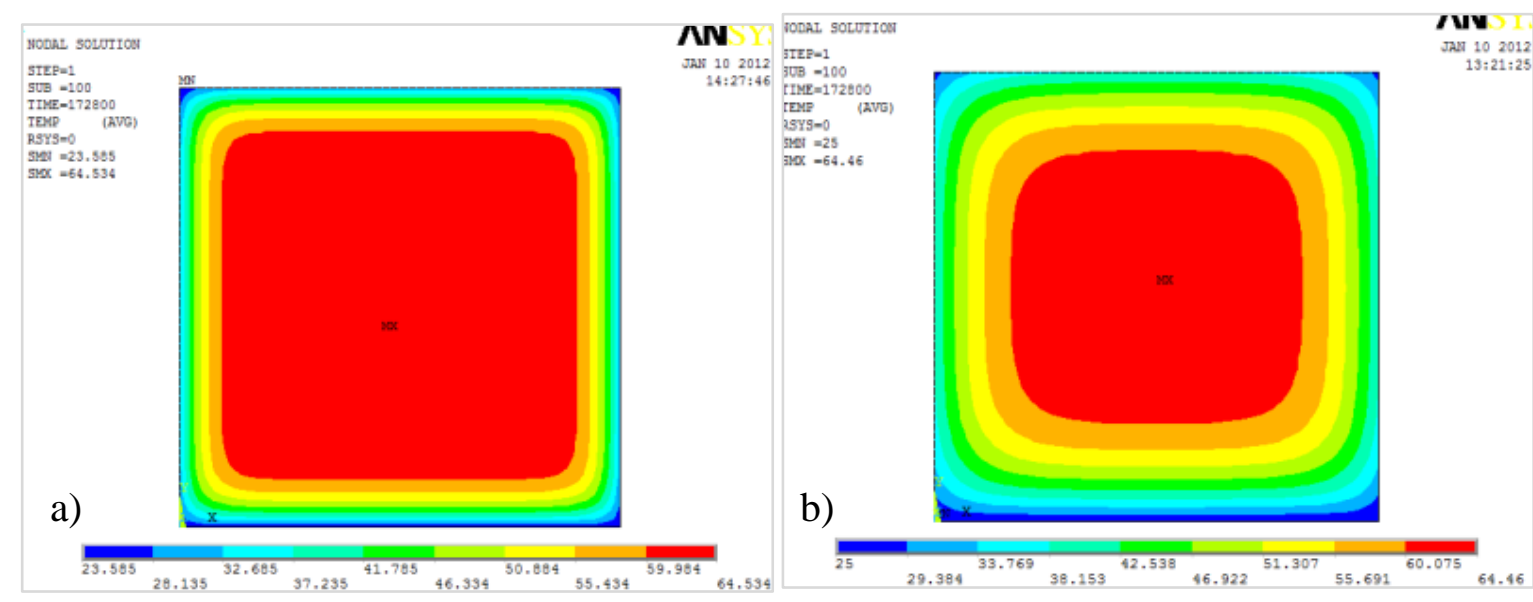

Figura 3.2 - Isotermas de temperatura para a) $\mathrm{k}=1 \mathrm{~W} / \mathrm{m} .{ }^{\circ} \mathrm{C}$ e b) $\mathrm{k}=4 \mathrm{~W} / \mathrm{m} .{ }^{\circ} \mathrm{C}$, respectivamente.

Lura e Breugel (2001) apud Azenha (2009) fornecem uma estimativa da condutividade térmica de concreto com base numa média ponderada das condutividades térmicas dos componentes da mistura, Equação 3.1:

$$
k=\frac{W_{c e m} k_{c e m}+W_{a g g} k_{a g g}+W_{w} k_{w}}{W_{c e m}+W_{a g g}+W_{w}}
$$

Sendo:

$k, k_{c e m}, k_{a g g}, k_{w}$ - condutividade térmica do concreto, condutividade térmica do cimento, condutividade térmica do agregado, condutividade térmica da agua, respectivamente.

$W_{c e m}, W_{a g g}, W_{w^{-}}$massa por metro cubico do cimento, do agregado e da agua, respectivamente.

Kim et al (2002) observaram que a idade do concreto praticamente não afeta a condutividade térmica do concreto, exceto para idade muito precoce, ou seja, cerca de 2 dias. No entanto, os experimentos não foram realizados em concreto massa.

\subsubsection{Calor Específico (c)}

É um parâmetro físico que expressa à capacidade de um material armazenar calor. Corresponde à quantidade de calor necessária para elevar em um grau a temperatura de uma unidade de massa. Valores típicos do calor específico para concretos normais estão entre 900 e $1000 \mathrm{~J} /\left(\mathrm{kg} \cdot{ }^{\circ} \mathrm{C}\right)$, segundo Mehta e Monteiro (2014) e entre 840 e $1170 \mathrm{~J} / \mathrm{kg}^{\circ} \mathrm{C}$ segundo Neville (2016).

Furnas (1997) afirma que o calor específico aumenta com o aumento da temperatura, com a diminuição da massa específica do concreto e com o acréscimo de umidade, atingindo um 
valor máximo para o concreto saturado, diminui com o aumento da dimensão máxima característica do agregado graúdo e é pouco alterado pela composição mineralógica do agregado.

Coelho et al (2014b), considerou o calor específico com valores extremos de 800 e 1300 $\mathrm{J} / \mathrm{g}^{\circ} \mathrm{C}$ para o concreto e analisou as isotermas de temperatura, os resultados encontrados são evidenciados na Figura 3.3 a, b. Nota-se uma diferença entre as isotermas e entre os valores finais obtidos $\left(69.416^{\circ} \mathrm{C}\right.$ e $\left.60.026^{\circ} \mathrm{C}\right)$ devido a alteração do calor específico, mas quanto menor esse valor, maior a máxima temperatura encontrada.

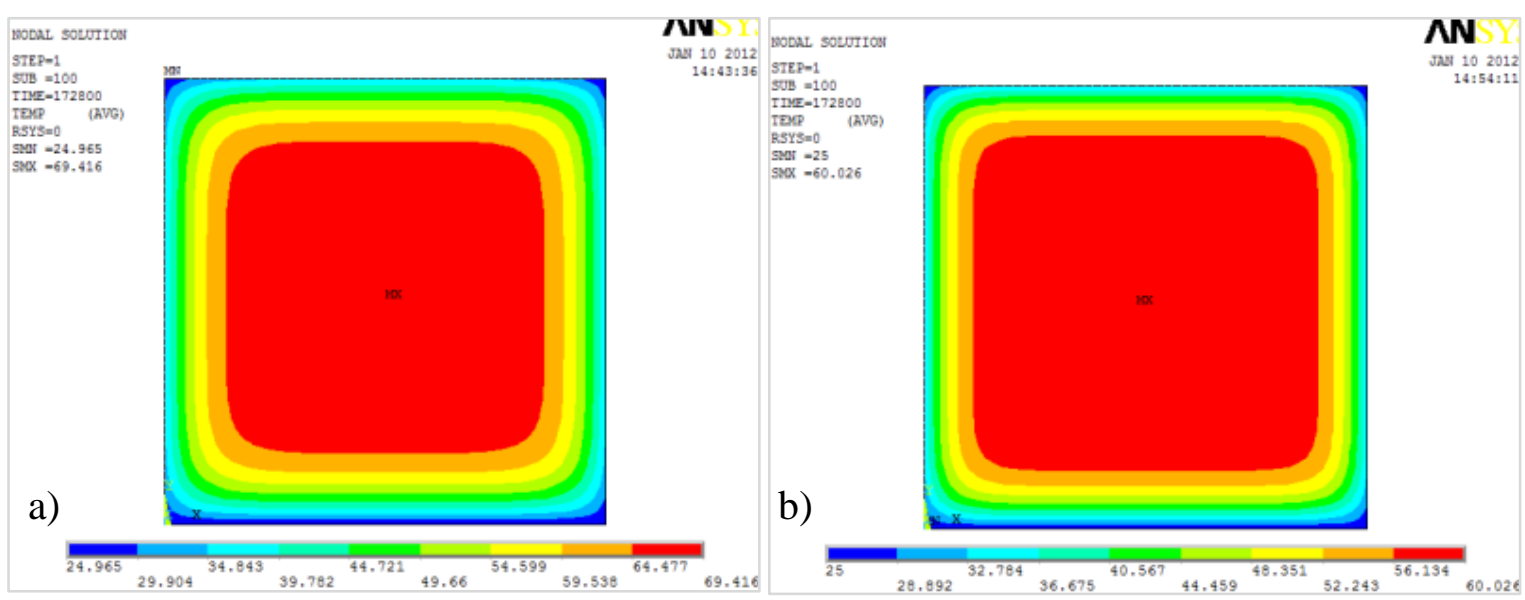

Figura 3.3 - Isotermas de temperatura para a) $\mathrm{c}=800 \mathrm{~J} / \mathrm{g}^{\circ} \mathrm{C} \mathrm{e} \mathrm{b}$ ) $\mathrm{c}=1300 \mathrm{~J} / \mathrm{g}^{\circ} \mathrm{C}$, respectivamente.

Segundo Azenha (2009), o calor específico pode ser definido segundo a Equação 3.2:

$$
c=\frac{W_{c e m} c_{c e m}+W_{a g g} c_{a g g}+W_{w} c_{w}-c_{b i n d} W_{c e m} \alpha c_{w}}{W_{c e m}+W_{a g g}+W_{w}}
$$

Sendo:

- $\quad W$ - peso: do cimento $\left(W_{c e m}\right)$, do agregado $\left(W_{a g g}\right)$ e da água $\left(W_{w}\right)$;

- $\quad c$-calor específico: do cimento $\left(c_{c e m}\right)$, do agregado $\left(c_{a g g}\right)$, da água $\left(c_{w}\right)$, e da reação físico-química da mistura $\left(c_{\text {bindW }}\right)$.

Em que:

$$
C_{c e m}=0.1812 T+2.618 T+431\left(\frac{\mathrm{J}}{\mathrm{kgK}}\right)
$$




$$
\begin{gathered}
C_{a g g}=0.0604 T+0.468 T+662\left(\frac{\mathrm{J}}{\mathrm{kgK}}\right) \\
C_{w}=4186\left(\frac{\mathrm{J}}{\mathrm{kgK}}\right)
\end{gathered}
$$

\subsubsection{Difusividade térmica $(\delta)$}

Representa a velocidade à qual a temperatura varia no interior de uma massa, sendo, portanto, um índice da facilidade com a qual o concreto pode sofrer variações de temperatura (Neville, 2016).

De acordo com a NBR 12818 (1993), é a propriedade que expressa a capacidade de difusão de calor em todas as direções e indica a facilidade com que o concreto tolera variações de temperatura.

É influenciada pelo teor de umidade do concreto, que depende do teor inicial de umidade da mistura, do grau de hidratação do cimento e da exposição à secagem. Os valores estão entre 2 a $6\left(10^{-3} \mathrm{~m}^{2} / \mathrm{h}\right)$. A difusividade térmica é calculada de acordo com a Equação 3.6.

$$
\delta=\frac{\mathrm{k}}{\mathrm{c} \rho}
$$

Onde:

- $\mathrm{k}=$ condutividade térmica;

- $\quad \mathrm{c}=$ calor específico;

- $\rho=$ massa específica do concreto - para efeito de cálculo pode-se adotar para o concreto simples valor $2400 \mathrm{~kg} / \mathrm{m}^{3}$ e para o concreto armado $2500 \mathrm{~kg} / \mathrm{m}^{3}$ (NBR $6118,2014)$.

A difusividade varia de acordo com os diferentes tipos de agregado, aumenta com o aumento da dimensão e do volume do agregado, aumenta com a redução da relação água/cimento (Furnas, 1997).

As propriedades térmicas dos materiais, notadamente o concreto, são importantes para descrever seu comportamento quanto à geração e difusão do calor. A difusividade térmica é pré-requisito essencial nas análises térmicas, pois relaciona-se com o tempo de resfriamento do material sujeito a determinadas condições iniciais e de contorno (Gomes et al 2016b). 


\subsubsection{Coeficiente de dilatação térmica $(\alpha)$}

Definido como a variação na unidade de comprimento por variação na unidade de temperatura. É controlado pelo coeficiente de dilatação térmica do agregado, portanto, a escolha do agregado é um fator crítico para prevenção de fissuras no concreto massa (Mehta e Monteiro, 2016). Os autores afirmam ainda que para o concreto, esse coeficiente pode variar de 6 a 18 x $10^{-6} /{ }^{\circ} \mathrm{C}$, enquanto Furnas (1997) diz que variam de 5 a 14 x $10^{-6} /{ }^{\circ} \mathrm{C}$.

Segundo Neville (2016), o coeficiente de dilatação térmica depende tanto da composição da mistura quanto do estado higroscópico do concreto no momento da variação de temperatura. Quando a pasta está seca ou saturada o valor é menor do que quando está parcialmente saturada.

Para Furnas (1997), é uma propriedade importante do ponto de vista de durabilidade, pois quando uma estrutura sofre gradientes de temperatura as variações volumétricas decorrentes são diretamente proporcionais a este coeficiente. Tem como fatores influentes o tipo litológico do agregado, com o coeficiente de dilatação da rocha, da pasta e da argamassa, o teor da pasta, a idade e a relação a/c.

Neville (2016) afirma que a reação de hidratação dos compostos do cimento é exotérmica, assim como muitas outras reações químicas, chegando a liberar energia de até $500 \mathrm{~J} / \mathrm{g}$ de cimento. A condutividade térmica do concreto é relativamente pequena. Sendo assim, ele pode comportar-se como um isolante e, no interior de grandes massas de concreto, a hidratação pode resultar em grandes elevações de temperatura. Enquanto o exterior da massa perde calor, resultando num significativo gradiente térmico que resulta em fissurações.

A variação da condutividade, difusividade e calor específico do concreto com a temperatura é pouco significativa em relação ao intervalo de temperaturas existentes no caso de barragem de concreto na fase de construção (Santos, 2004).

De uma forma geral, num estudo sobre a influência da temperatura nas propriedades do concreto usados em reatores nucleares, Rani e Santhanam (2012), definiram os principais fatores que afetam a mudança do comportamento do concreto com elevação de temperaturas até $100^{\circ} \mathrm{C}$, conforme a Tabela 3.1 . 
Tabela 3.1 - Propriedades que influenciam na temperatura do concreto. Adaptado de Ranie Santhanam (2012).

\begin{tabular}{|c|c|c|}
\hline $\begin{array}{l}\text { Propriedade do } \\
\text { concreto }\end{array}$ & $\begin{array}{l}\text { Influência da } \\
\text { temperatura }\end{array}$ & Observações \\
\hline Massa específica & Elevado & $\begin{array}{l}\text { A redução é menor para o concreto com agregados } \\
\text { grandes e amostras curadas ao ar. A densidade é } \\
\text { largamente influenciada pelo teor de umidade. }\end{array}$ \\
\hline Expansão térmica & Baixo & $\begin{array}{l}\text { A expansão aumenta com a proporção da pasta de } \\
\text { cimento, teor de umidade, relação água/cimento e tipo } \\
\text { de cimento a temperaturas moderadas. }\end{array}$ \\
\hline Calor específico & Baixo & Depende do conteúdo da pasta durante o aquecimento. \\
\hline $\begin{array}{l}\text { Condutividade } \\
\text { térmica }\end{array}$ & Baixo & $\begin{array}{l}\text { Condutividade varia linearmente com o teor de } \\
\text { umidade; misturas com mais finos têm maior } \\
\text { condutividade e maior variação na condutividade. }\end{array}$ \\
\hline $\begin{array}{l}\text { Tensão } \\
\text { compressão }\end{array}$ & Moderado & $\begin{array}{l}\text { Perda/ganho de resistência depende do teor de } \\
\text { umidade, do traço, da temperatura máxima, duração da } \\
\text { exposição, tipo de agregado, condições de cura, a idade } \\
\text { do concreto e das condições de ensaio. } \\
\text { Aumento/diminuição da resistência depende da } \\
\text { existência de umidade, de microfissuras e da } \\
\text { capacidade de deformação do concreto. }\end{array}$ \\
\hline $\begin{array}{l}\text { Resistência à } \\
\text { tração/flexão }\end{array}$ & Moderado & $\begin{array}{l}\text { Mais sensível do que a resistência à compressão e, } \\
\text { consequentemente, a redução percentual é maior. }\end{array}$ \\
\hline $\begin{array}{ll}\text { Módulo } & \mathrm{de} \\
\text { elasticidade }\end{array}$ & Moderado & $\begin{array}{l}\text { Para o concreto de resistência normal, o módulo } \\
\text { elástico diminui com a temperatura. É influenciado } \\
\text { pelo tipo de agregados e condições de cura. }\end{array}$ \\
\hline $\begin{array}{l}\text { Coeficiente de } \\
\text { Poisson }\end{array}$ & Baixo & $\begin{array}{l}\text { Não muito influenciado por temperaturas moderadas. } \\
\text { Permanece na faixa } 0,15-0,20\end{array}$ \\
\hline Deformação lenta & Moderado & $\begin{array}{l}\text { Tensões de fluência aumentam rapidamente até que um } \\
\text { teor de umidade estável seja atingido e é extremamente } \\
\text { afetada pela temperatura mais elevada. Fluência } \\
\text { aumenta com o aumento do nível de carga e vedação } \\
\text { das amostras, uma vez que afeta o transporte de } \\
\text { umidade. Amostras curadas com água têm maior } \\
\text { fluência }\end{array}$ \\
\hline
\end{tabular}

\subsection{PROPRIEDADES FÍSICAS E MECÂNICAS DO CONCRETO}

O concreto é formado por fases. O tipo, a quantidade, o tamanho, a forma e a distribuição das fases em um sólido constituem sua microestrutura, que é heterogênea, como mostra a Figura 3.4, e tem influência direta sobre as propriedades do concreto. Há três fases na microestrutura, as partículas de agregado e o meio ligante (pasta de cimento), facilmente distinguidas, e uma zona de transição, mais frágil situada próxima as partículas dos agregados (Mehta e Monteiro, 2014). 


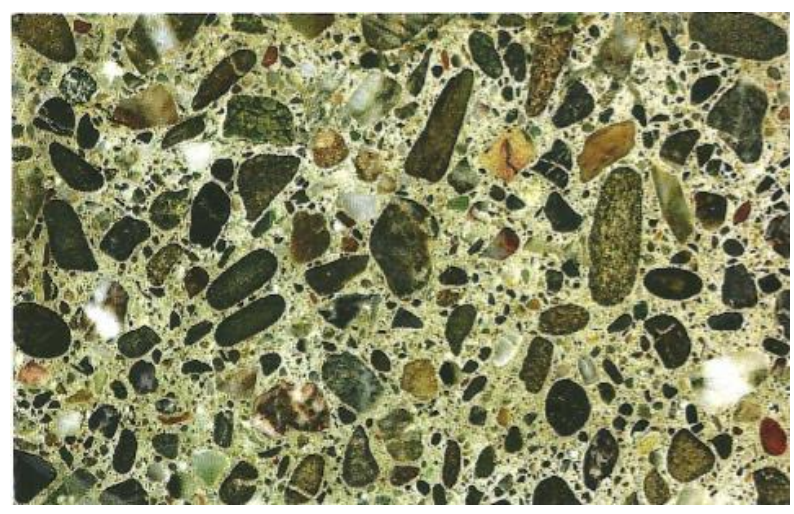

Figura 3.4 - Fases do concreto (Mehta e Monteiro, 2014).

Hanai (2005) apud Andrade e Tutikian (2011) ressaltam que o concreto convencional quando submetido a um esforço, seja de tração ou compressão, as fissurações aparecerão e se propagarão nas zonas de transição, onde já existem microfissuras, como representado pelas linhas vermelhas na Figura 3.5.

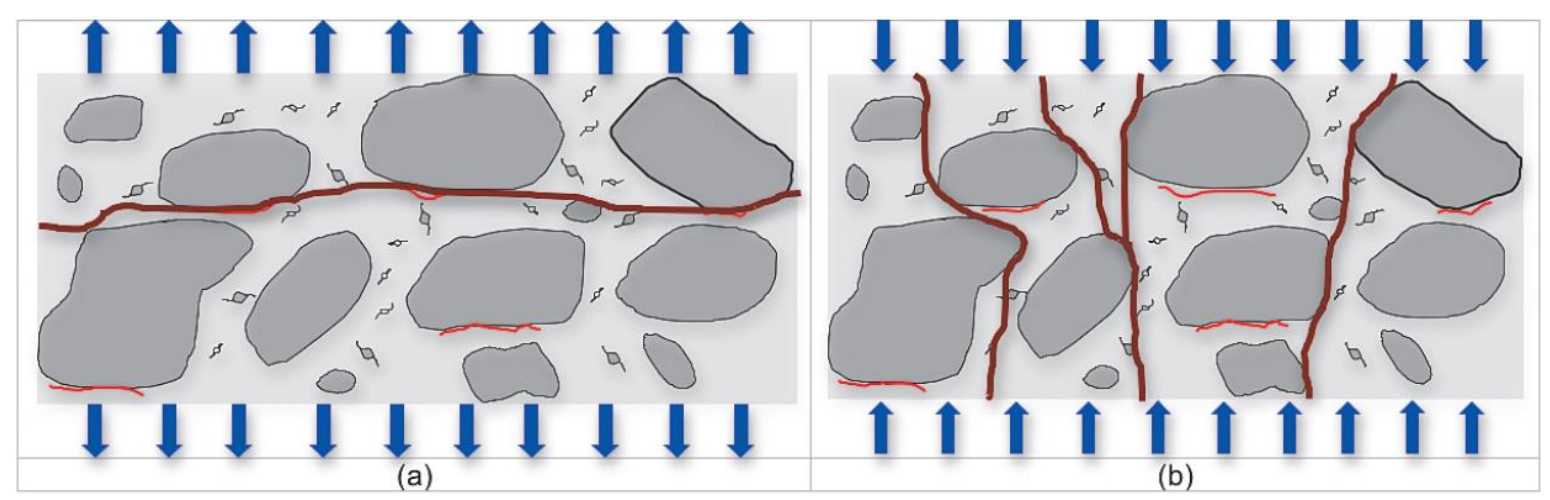

Figura 3.5 - Propagação de fissuras na zona de transição (Hanai, 2005 apud Andrade e Tutikian, 2011).

Abordagens numéricas parecem ser a melhor maneira de caracterizar as propriedades de falha do concreto em tensão a temperaturas elevadas. Em uma análise verificou-se que no caso da carga de tração com a temperatura, danos começam antes de $100^{\circ} \mathrm{C}$; a diferença dos resultados para diferentes geometrias não é significativa; a permeabilidade aumenta mais rapidamente, no caso de tração; a deformação total parece ser devida, principalmente, à expansão térmica, que contribui para a separação das camadas de C-S-H. E, a carga de tração leva à falha total do material (Grondin et al 2011).

As propriedades mecânicas do concreto devem ser analisadas a fim de examinar o seu comportamento, e poder ser verificado até que ponto ele pode resistir as solicitações 
empregadas. A seguir, apresenta-se uma descrição das propriedades importantes para o estudo do concreto massa.

\subsubsection{Resistência à compressão $\left(f_{c}\right)$}

Segundo Mehta e Monteiro (2014), a resistência à compressão do concreto depende de vários fatores que influenciam em sua porosidade. Esses fatores são a relação água/cimento, o teor de ar incorporado, o tipo de cimento utilizado, as características dos agregados, a qualidade da água de amassamento, o uso de aditivos e adições, as condições de cura, umidade e temperatura do concreto. Na compressão, é necessário um maior gasto de energia para gerar e aumentar fissuras existentes na matriz, tornando a ruptura menos frágil.

O ACI 209-2R (2000) traz como equação geral para prever a resistência à compressão em qualquer instante, $t$, a Equação 3.7:

$$
f_{c}=\left(\frac{t}{a+b t}\right) f_{c m 28}
$$

Onde $f_{c m 28}$ é resistência do concreto à compressão aos 28 dias em MPa ou psi, $a$ (em dias) e $b$ são constantes, e $t$ é a idade do concreto. Para os valores de a e b, recomenda que sejam utilizados os dados da Tabela 3.2. Os valores utilizados neste trabalho para fins de cálculos consideraram cura úmida para cimento tipo I, que corresponde aos cimentos brasileiros CPI ou CPI-S e o mais próximo dos cimentos utilizados (Battagin, 2011).

Tabela 3.2 - Valores de a e b para $\mathrm{f}_{\mathrm{c}}$ (ACI 209-2R, 2008).

\begin{tabular}{|c|l|l|l|l|}
\hline \multirow{2}{*}{ Tipo de cimento } & \multicolumn{2}{|l|}{ Cura úmida } & \multicolumn{2}{l|}{ Cura à vapor } \\
\cline { 2 - 5 } & $\mathrm{a}$ & $\mathrm{b}$ & $\mathrm{a}$ & $\mathrm{b}$ \\
\hline $\mathrm{I}$ & 4,00 & 0,85 & 1,00 & 0,95 \\
\hline II & 2,30 & 0,92 & 0,70 & 0,98 \\
\hline
\end{tabular}

\subsubsection{Resistência à Tração $\left(f_{t}\right)$}

A fissuração do concreto é frequentemente consequência de uma ruptura por tração; a retração geralmente ocorre devido à redução da temperatura do concreto ou à secagem do concreto úmido. Para estruturas de concreto geralmente se utiliza o aço para absorver as cargas de tração, no entanto, essa solução é impraticável em estruturas de concreto massa, tais como barragens (Mehta e Monteiro, 2014).

Os autores afirmam ainda que a relação entre a resistência à tração e à compressão é da ordem de 10 a $11 \%$ para concretos de baixa resistência - menos de $20 \mathrm{MPa}$, de 8 a $9 \%$ para concreto de média resistência - de $20 \mathrm{MPa} 40 \mathrm{MPa}$ e de $7 \%$ para o de alta resistência - acima 
de $40 \mathrm{MPa}$. É importante ressaltar também que no concreto massa a análise tensional devido ao problema térmico está relacionada com a resistência à tração. Deve-se lembrar ainda que os fatores que influenciam na resistência à compressão também influenciam a tração.

\subsubsection{Módulo de elasticidade (E)}

É uma medida da resistência à deformação elástica do material, seu conhecimento é fundamental na análise das deformações elásticas ou viscoelásticas das estruturas de concreto. Varia com o tipo de agregado, o teor da pasta e a proporção entre os dois (Furnas, 1997).

A partir de curvas tensão-deformação $(\sigma-\varepsilon)$ para os agregados, a pasta de cimento e o concreto, observa-se que este último não é linear, Figura 3.6. A tensão aplicada, não é proporcional à deformação para o concreto, nem é totalmente recuperada com o carregamento, comportamento viscoelástico (Mehta e Monteiro, 2014; Andrade e Tutikian, 2011; Neville, 2016).

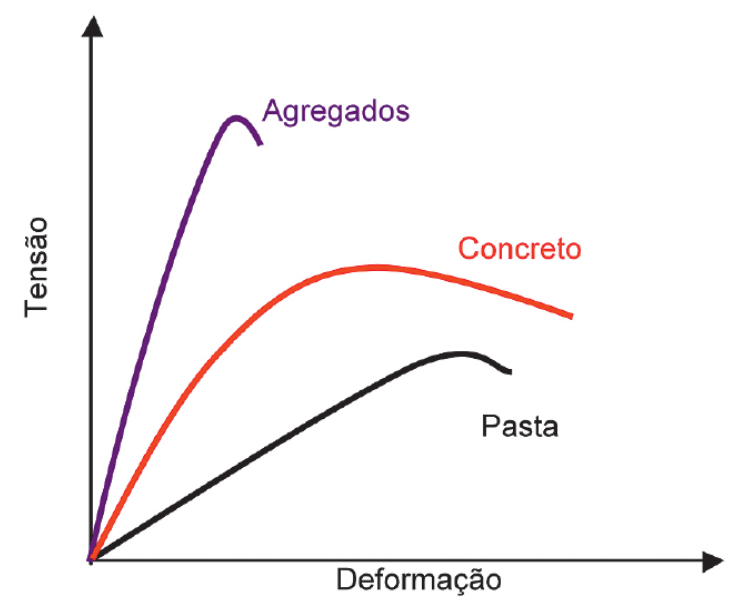

Figura 3.6 - Curva $\sigma-\varepsilon$ para os agregados, a pasta de cimento e o concreto (Andrade e Tutikian, 2011).

Ainda segundo Mehta e Monteiro (2014), a curva $\sigma-\varepsilon$ do concreto tem 4 estágios, conforme descrito a seguir e apresentado na Figura 3.7.

1. Abaixo de cerca de $30 \%$ da carga última do concreto já podem existir fissuras na zona de transição, mas ainda estáveis.

2. Acima dessa carga e abaixo de $50 \%$ da tensão última, as fissuras começam a aumentar, mas ainda são insignificantes. 
3. Entre 50 e $75 \%$ da carga última novas fissuras surgem na matriz tornando o sistema instável e a curva inclina-se consideravelmente para a horizontal.

4. Acima de $75 \%$ da carga última o material se deforma até romper.

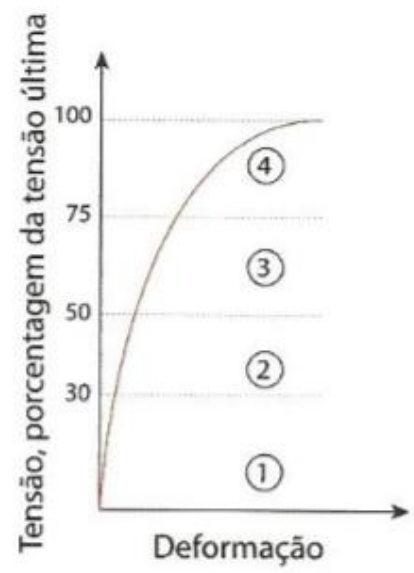

Figura 3.7 - estágios da curva $\sigma-\varepsilon$ do concreto (Mehta e Monteiro, 2014).

Para o cálculo da fluência, abordada no item 3.2.6, o módulo de elasticidade é determinado pela Equação 3.8 para o ACI 209-2R (2008) e pela Equação 3.9 para o CEB-90 (ACI 2092R, 2008), que leva em consideração a Equação 3.10.

$$
\begin{aligned}
& E=0,043 \rho^{1,5} \sqrt{f_{c}} \\
& E=E_{c 28} \exp \left[\frac{s}{2}\left(1-\sqrt{\frac{28}{t / t_{1}}}\right)\right] \\
& E_{c 28}=21500 \sqrt[3]{\frac{f_{c 28}}{f_{c}}}
\end{aligned}
$$

Sendo que $s$ depende do tipo de cimento e da resistência à compressão do concreto, $t_{1}=1$ dia e $f_{c 28}$ é a resistência à compressão do concreto aos 28 dias.

\subsubsection{Coeficiente de Poisson ( $v$ )}

Parâmetro também utilizado para caracterizar a deformação do concreto. Definido como a relação entre as deformações transversal e longitudinal, provocadas por carregamentos axiais dentro do limite elástico. Seus valores extremos se situam entre 0,11 e 0,27 e tende a diminuir à medida que se aumenta a dimensão máxima do agregado, sendo, portanto, para o concreto massa próximo ao seu limite inferior. Assim como o módulo de elasticidade, varia com o tipo de agregado, o teor da pasta e a proporção entre os dois (Furnas, 1997). 


\subsubsection{Maturidade (M) e Idade Equivalente ( $\left.t_{e}\right)$}

Um concreto com a mesma composição na mesma maturidade tem aproximadamente a mesma resistência em qualquer combinação de temperatura e idade (Bagheri-Zadeh et al 2007). A lógica por trás da técnica maturidade é que existe uma correlação entre a resistência do concreto e a sua temperatura nas fases iniciais após o lançamento (Rasmussen et al 2004 apud Bagheri-Zadeh et al 2007).

O AMERICAN SOCIETY FOR TESTING AND MATERIALS - ASTM C1074 (2000) a define como a extensão do desenvolvimento de uma propriedade de uma composição de concreto. Enquanto o termo é usado normalmente para descrever a extensão do desenvolvimento das resistências relativas, ela também pode ser aplicada para a evolução de outras propriedades que são dependentes das reações químicas que ocorrem num concreto. Em qualquer idade, a maturidade depende do histórico de cura.

Segundo Carino e Lew (2001) a função de maturidade está relacionada com a sensibilidade à temperatura no desenvolvimento da resistência inicial, e não há nenhuma função única de maturidade que seja aplicável a todas as composições de concreto. Esta função aplicável para um dado concreto pode ser obtida através da medição da variação da constante de velocidade com a temperatura de cura.

Métodos de maturidade são usados como um indicador mais confiável da resistência local do concreto durante a construção, em vez de análises de cilindros curado em campo (CONCRETE IN PRACTICE - CIP 39, 2006).

As principais limitações do método são: (1) o concreto deve ser mantida em condições que permite a hidratação do cimento; (2) o método não leva em conta o efeito da temperatura do concreto em idade precoce sobre a resistência a longo prazo; e (3) o método precisa ser complementado por outras indicações da tensão potencial da composição do concreto (ASTM C1074, 2000)

A função de maturidade é dada pela expressão 3.11 (ASTM C1074, 2000):

$$
M(t)=\sum\left(T-T_{r}\right) \Delta t
$$

Em que: 
- $M(t)=$ Maturidade - o fator de tempo-temperatura na idade $\mathrm{t}$, em graus-dias ou graus-horas.

- $\Delta t=$ Intervalo de tempo, em dias ou horas.

- $\quad T=$ Temperatura média do concreto durante o intervalo de tempo, $\Delta \mathrm{t}, \mathrm{em}{ }^{\circ} \mathrm{C}$.

- $T_{r}=$ Temperatura de referência, em ${ }^{\circ} \mathrm{C}$.

$\mathrm{Na}$ prática a Europa considera a temperatura de referência como $20^{\circ} \mathrm{C}$, enquanto que, na América do Norte utiliza-se $23^{\circ} \mathrm{C}$ (Carino e Lew, 2001).

Em duas décadas a experiência tem mostrado que o método da maturidade é perfeitamente adequado para prever a resistência à compressão do concreto em campo. Esta técnica foi ampliada com sucesso para o controle de fissuração em estruturas de concreto através da utilização de ferramentas numéricas tais como programas de elementos finitos. Esta abordagem fornece resultados que são razoavelmente precisos, desde que o concreto seja corretamente caracterizado e o método de construção adequadamente descrito (Waller et al 2004).

Outra função de maturidade é usada para calcular a idade equivalente, determinada como o número de dias ou de horas necessária para produzir uma maturidade igual à maturidade atingida por um período de cura a temperaturas diferentes a partir da temperatura específica, como mostra a Equação 3.12 (Hansen e Pederson, 1977 apud ASTM C1074 2000).

$$
t_{e}=\sum e^{-\beta\left(\frac{1}{T}-\frac{1}{T_{S}}\right) \Delta t}
$$

Onde:

- $t_{e}=$ Idade equivalente a uma dada temperatura $T_{s}$, em dias ou $\mathrm{h}$.

- $\beta=$ Energia de ativação, $E_{a}$, dividida pela constante dos gases, $R$, em K.

- $T=$ Temperatura média do concreto durante o intervalo de tempo $\Delta \mathrm{t}$, em K.

- $T_{r}=$ Temperatura de referência, em $\mathrm{K}$.

- $\Delta t=$ Intervalo de tempo, em dias ou horas.

De Schutter (2004) define a idade equivalente como o tempo durante o qual o concreto teria que ser curado a uma temperatura de referência constante para conseguir a mesma maturidade do concreto submetidos à cura real. 
Alguns autores chamam a Equação 3.11 de equação de Nurse-Saul e a Equação 3.12 como equação de Arrhenius (Abdel-Jawad, 2006; Bagheri-Zadeh et al 2007; Lee e Hover, 2016; Carino e Lew, 2001; De Schutter, 2004; Topçu e Toprak, 2004).

A resistência do concreto aumenta rapidamente após o tempo de pega na função da maturidade. Utilizando a função de Arrhenius, que leva em consideração os efeitos da temperatura há a diminuição das margens de erro da resistência do concreto em idades iniciais (Topçu et al 2007).

Carino e Lew (2001) afirmam que $E_{a}$ está relacionada com a relação água/cimento (a/c), sendo que, para a $/ \mathrm{c}=0,45$ tem-se $E_{a}=30-64 \mathrm{~kJ} / \mathrm{mol}$, para a $/ \mathrm{c}=0,60$ tem-se $E_{a}=31-56$ $\mathrm{kJ} / \mathrm{mol}$, dependendo também dos materiais cimentícios.

Embora ASTM C1074 (2000) sugere o valor padrão de $\mathrm{T}_{0}=0{ }^{\circ} \mathrm{C}$ para a temperatura do concreto até $40^{\circ} \mathrm{C}$; a esta temperatura o valor de $E_{a}$ compatível seria de aproximadamente $25 \mathrm{~kJ} / \mathrm{mol}$, em vez do padrão recomendado de 40 a 45 kJ/mol (Lee e Hover, 2016).

De forma mais sintetizada e considerando $\mathrm{R}=8.314 \mathrm{~J} / \mathrm{molK}$, Morabito (1998) define $\beta=$ $\frac{E_{a}}{R}$ como a Equação 3.13:

$$
\begin{cases}\beta=4000 & \text { para } T \geq 20^{\circ} \mathrm{C} \\ \beta=4000+175(20-T) & \text { para } T<20^{\circ} \mathrm{C}\end{cases}
$$

Para relacionar idade equivalente com maturidade Azenha (2004) afirma que a idade equivalente de um concreto com maturidade $\mathrm{M}$, e sob determinadas condições de cura em obra, corresponde à idade em que a referida maturidade $\mathrm{M}$ seria atingida para esse concreto num ensaio isotérmico conduzido a $20^{\circ} \mathrm{C}$.

Bagheri-Zadeh et al (2007) afirmam ainda que o método de maturidade do concreto pode produzir uma previsão confiável e precisa da resistência do concreto em campo em um tempo real contínuo durante a cura.

Conhecidas as curvas de evolução de resistência à compressão do concreto em função da sua idade para duas temperaturas de cura: temperatura de referência $\left(T_{r}=20^{\circ} \mathrm{C}\right)$ e temperatura 
arbitrária $\left(T_{a r b}>T_{r}\right)$. Se para o instante $\mathrm{t}_{1}$, à temperatura de referência, for determinada a resistência à compressão, e se se fizer a correspondência dessa resistência a um instante da curva $T_{a r b}$, obtém-se $t_{2}$. Diz-se então que a idade equivalente do concreto à temperatura $T_{a r b}$ no instante $t_{2}$ é $t_{1}$, Figura 3.8. Ou seja, uma vez que o concreto foi sujeito a temperaturas mais elevadas que no concreto de referência, o ganho de resistência deu-se mais rapidamente, assim, a idade equivalente é superior à sua idade real $\left(t_{1}>t_{2}\right)$ (Azenha, 2004).

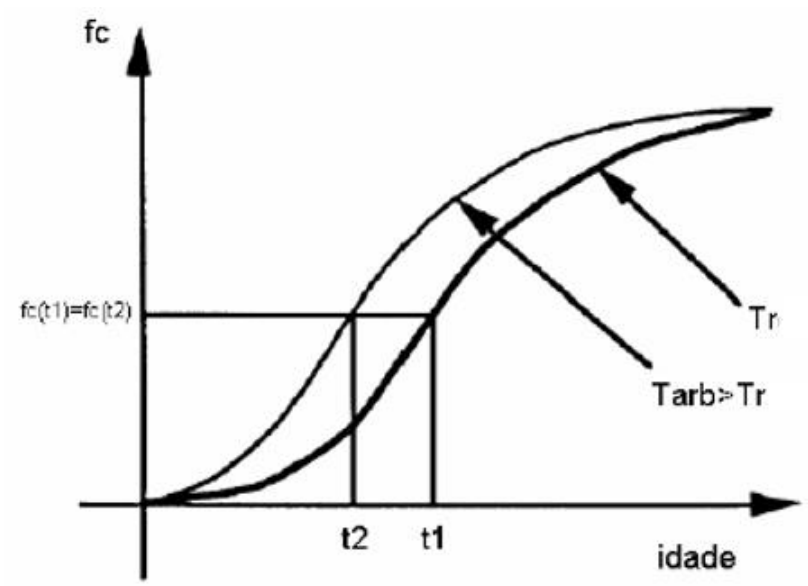

Figura 3.8 - Representação da idade equivalente do concreto (Azenha, 2004).

\subsubsection{Fluência ou Deformação Específica (J)}

O fenômeno do aumento gradual da deformação ao longo do tempo sob um dado tipo de tensão constante é chamado de fluência. Quando há redução gradual dessa deformação no tempo sob uma deformação constante acontece a relaxação do concreto. Essas manifestações acontecem em materiais viscoelásticos, estudados na reologia do concreto. (Mehta e Monteiro, 2014).

Devido ao comportamento do concreto massa, esta é, talvez, a propriedade mais importante, e também a mais complexa, para o entendimento e os cálculos de tensões. Portanto, este item procura descrever o fenômeno e entender sua teoria, de forma, que sua explicação é mais extensa que as demais neste trabalho.

A fluência é uma ação permanente indireta que cresce ao longo do tempo, devido a um certo nível de tensão, tendendo a um valor limite final constante. Evidentemente, quanto maior a tensão, maior a deformação para um certo tempo (Teixeira et al 2006). 
Neville (2016) define fluência como o aumento da deformação sob uma tensão mantida. Em condições normais de carregamento, a deformação instantânea depende da velocidade de aplicação da carga e inclui a deformação elástica e a fluência, Figura 3.9a, sendo que a deformação elástica é recuperável com o descarregamento. Considerando também o processo de secagem, a deformação por retração é adicionada. A fluência é ainda dividida em básica ou verdadeira, quando não há movimentação de umidade, e fluência por secagem, quando ocorre da secagem, Figura 3.9b. Neste trabalho é considerada apenas a primeira situação, Figura 3.9a.

a)

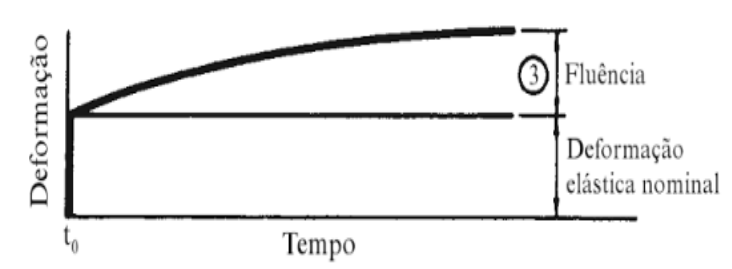

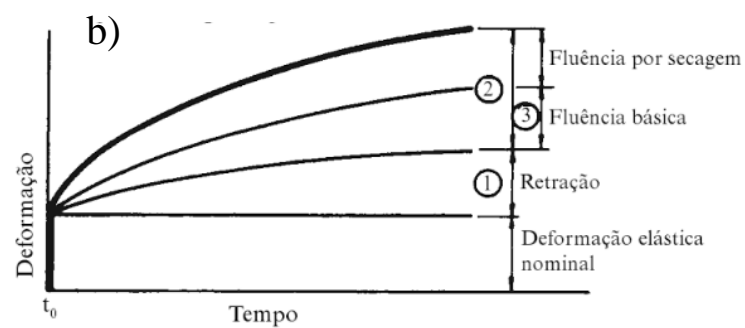

Figura 3.9 - Representação da Fluência (Neville, 2016).

Santos et al (2004b) observaram em simulações numéricas que as tensões normais geradas pelo efeito da retração por secagem do concreto foram pouco significativas em relação às tensões geradas pelo problema térmico. A sua expressividade pode ser elevada para situações em que a umidade relativa ambiente seja bem inferior à umidade interna do concreto, ou para um concreto com baixo fator a/c.

O concreto, quando submetido a solicitações de longa duração, sofre uma deformação imediata, seguida de uma deformação lenta, devido ao efeito de fluência (creep), que se desenvolve ao longo do tempo. Deste modo, mesmo sob tensões constantes, as deformações ocorridas no concreto aumentam no decorrer do tempo (Aurich, 2008).

Emborg (1998a) mostra através de gráficos, Figura 3.10, o comportamento elástico e viscoelástico, fluência, para o concreto em diferentes idades. Observa-se que no comportamento elástico as tensões são iguais em todas as idades, enquanto na fluência, quanto maior a idade, menor a deformação, confirmando os princípios enunciados. No entanto, o autor ressalta que, quando se trata de idades mais recentes do concreto, menor que cinco dias, ou de um a dois dias, os dados de deformação no tempo tornam-se escassos. 
a)

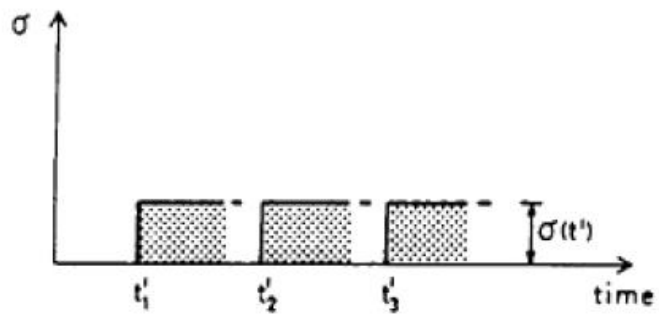

b)

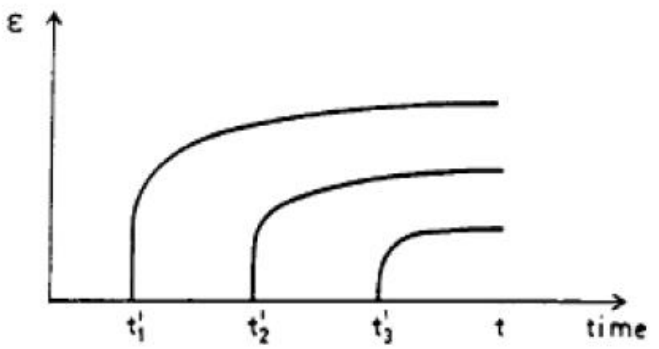

Figura 3.10 - a) Comportamento elástico e b) viscoelástico (Emborg, 1998a).

Bofang (2014) mostra esquematicamente, Figura 3.11, que o concreto com várias idades, como acontece com a construção em camadas, terá diferentes módulos de elasticidade, $E_{i}(\tau)$, coeficiente de fluência $C_{i}(t, \tau)$ e aumento da temperatura adiabática.

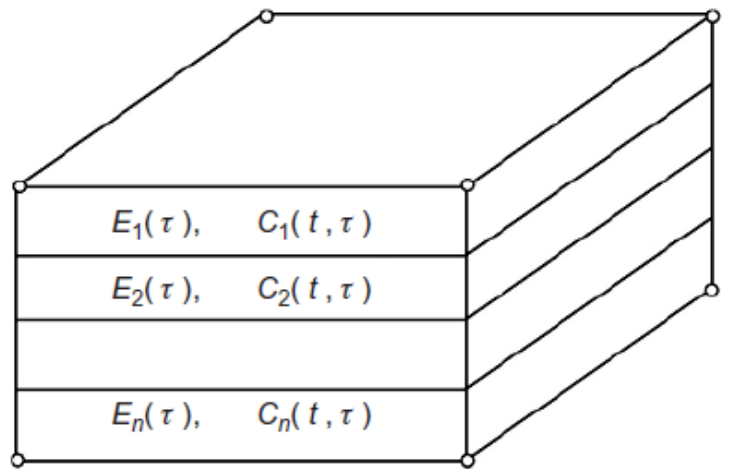

Figura 3.11 - Representação das propriedades para construção em camadas (Bofang, 2014).

Em ambientes em que é mantida a saturação de umidade do ambiente e a temperatura constante, a deformação que se desenvolve ao longo do tempo em uma peça de concreto submetida à tensão constante é chamada de fluência básica. Para concreto exposto a um ambiente com umidade relativa menor do que $100 \%$ é possível distinguir além da deformação elástica instantânea, da fluência básica e da deformação por secagem, uma deformação adicional, chamada de fluência por secagem Kalintzis e Kuperman (2001). 
No caso da fluência a migração da água é iniciada por uma carga externa aplicada, enquanto que na retração por secagem a mudança na umidade relativa seria a causa (Wittmann, 1982 apud Kalintzis e Kuperman, 2001).

Olivier e Vichot (2014) afirmam que o concreto tem um comportamento intermediário entre o elástico, com fluência nula, e o viscoso, em que a fluência tem velocidade constante, sendo chamado de viscoelástico. Enfatiza também que a fluência é uma deformação lenta influenciada por:

1. Carregamento - sob tensão permanente moderada, a deformação lenta de fluência é proporcional à tensão permanente aplicada - viscoelástico linear; se a idade aumenta, a deformação diminui - viscoelástico linear envelhecido. Se no instante $t_{0}$ aplica-se uma carga de compressão constante no concreto, o seu comportamento reológico muda e observa-se uma aceleração importante da deformação lenta, Figura 3.12.

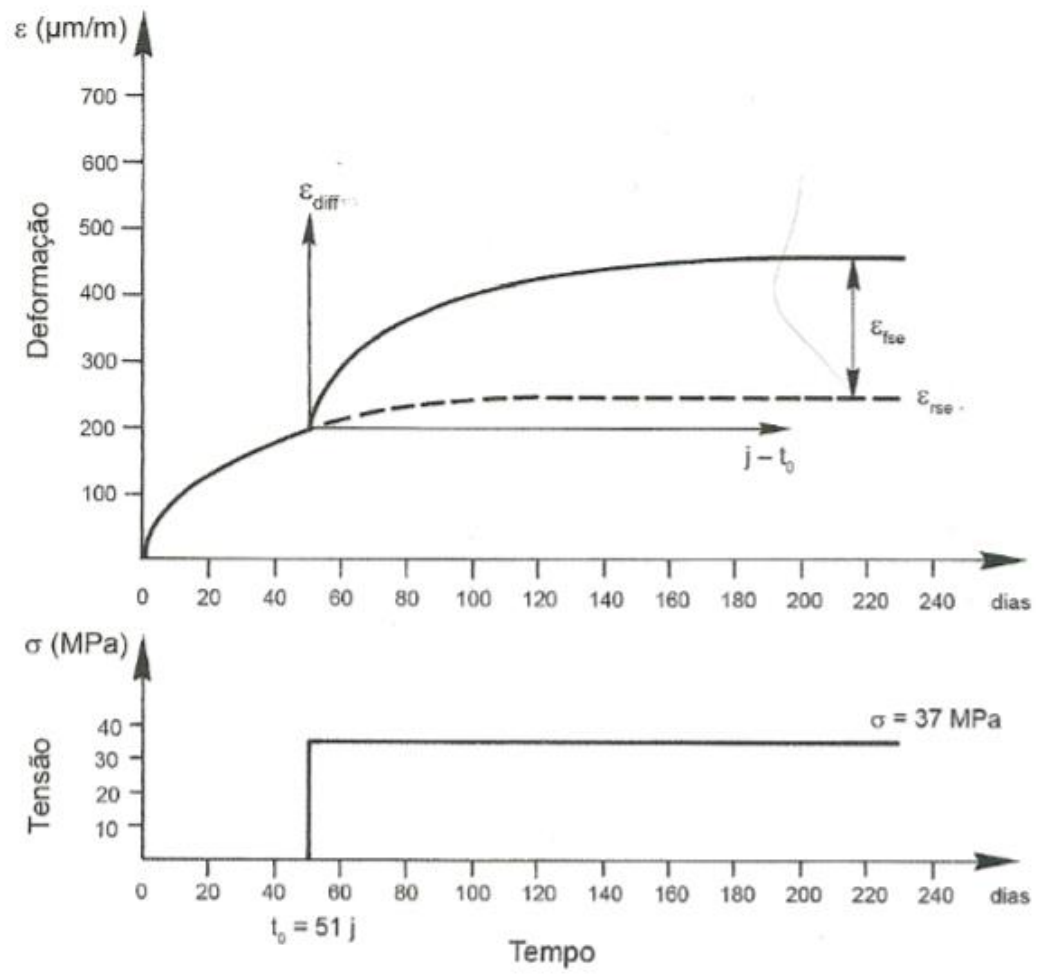

Figura 3.12 - Deformação lenta de um concreto.

2. Condições locais, ambientais e o efeito escala - no caso de temperaturas extremas (> $30^{\circ} \mathrm{C}$ ) deverá se levar em conta o poder amplificador da temperatura sobre a fluência. A umidade também interfere na deformação por fluência, uma umidade do concreto de $99-100 \%$ reduz fortemente a sua cinética. O efeito escala traduz a influência da 
dimensão da estrutura em relação às suas possibilidades de troca com o meio externo, a fluência será cada vez mais fraca à medida que a espessura for importante.

3. Os parâmetros da composição do concreto - o uso de certos agregados pode até triplicar a deformação lenta, Figura 3.13. E o tipo de cimento afeta o carregamento do concreto nas primeiras idades.

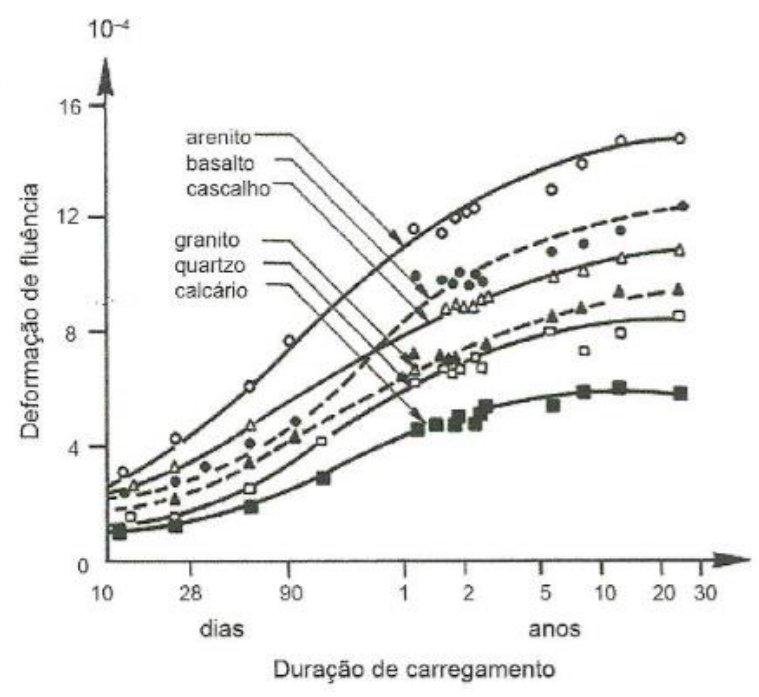

Figura 3.13 - Influência do agregado na deformação lenta (Olliver e Vichot, 2014).

Furnas (1997) traz como fatores influentes da fluência:

- Umidade do ar - a fluência é maior quanto menor for a umidade do ar, devido a maior evaporação da agua do concreto, Figura 3.14.

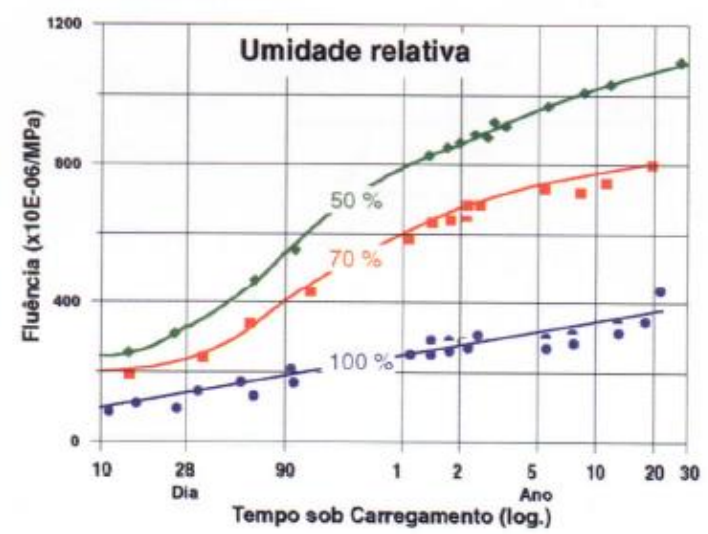

Figura 3.14 - Influência da umidade na fluência (Furnas, 1997).

- Resistência do concreto - a fluência é inversamente proporcional à resistência do concreto. 
- Idade de carregamento - quanto maior a idade de carregamento, menor a deformação. À medida que o concreto envelhece aumenta o modulo de elasticidade e sua resistência, diminuindo a fluência.

- Temperatura ambiente - a deformação é maior para temperaturas ambientes mais elevados.

- Tipo de cimento - na medida que há alteração na resistência, há modificação da fluência.

- Relação a/c - para reduzir a fluência deve-se ter uma menor relação a/c, como mostra a Figura 3.15.

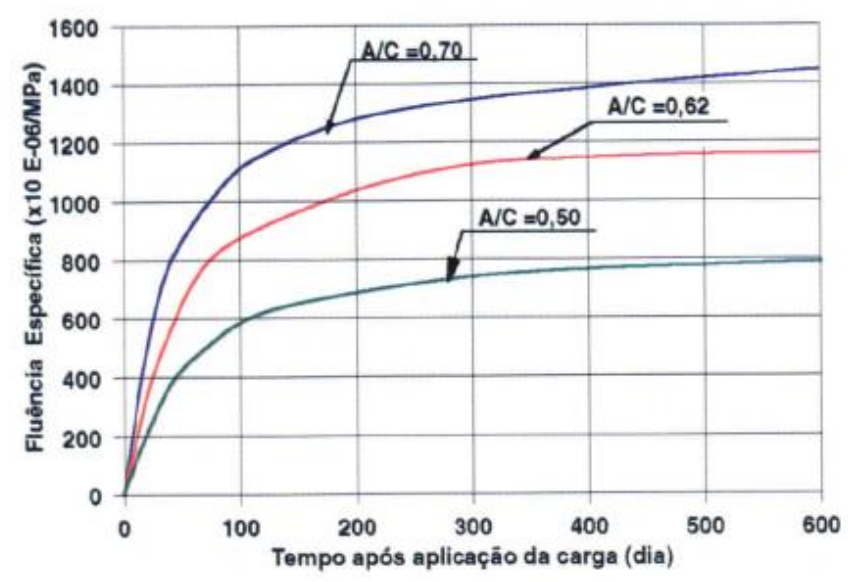

Figura 3.15 - Influência da relação a/c na fluência (Furnas, 1997).

- Intensidade de carga - diretamente proporcional à fluência, variando com o tempo de aplicação, Figura 3.16.

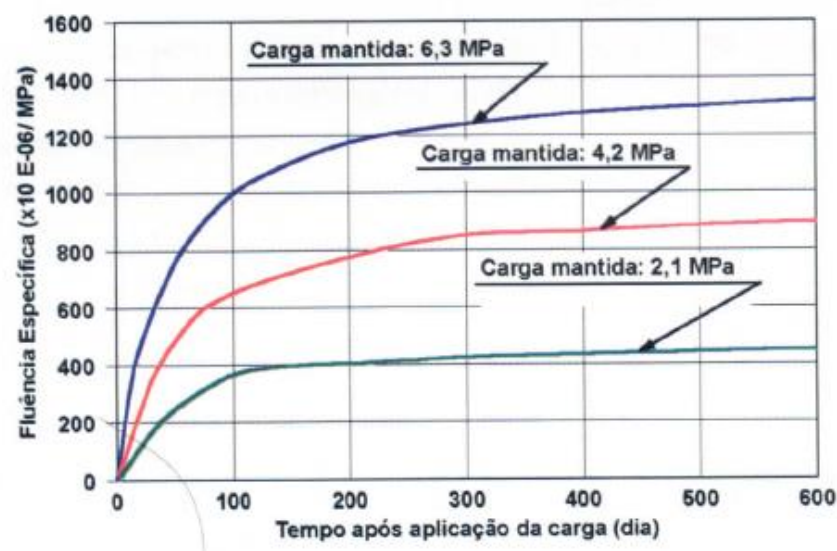

Figura 3.16 - Influência da intensidade de carga na fluência (Furnas, 1997).

- Aditivos - deve ser verificado quando a fluência é importante. Por exemplo, aceleradores de pega e redutores de agua podem aumentar a deformação. Santos 
(2011) verificou que há aumento substancial da fluência básica com o uso de adições minerais e aditivos plastificantes na idade de início de carregamento do concreto.

- Agregados - as propriedades dos agregados alteram a fluência do concreto, sendo o módulo de elasticidade o mais importante desses fatores.

- Dimensões da peça - peças espessas tem menor deformação devido a secagem interior ser mais demorada, Figura 3.17.

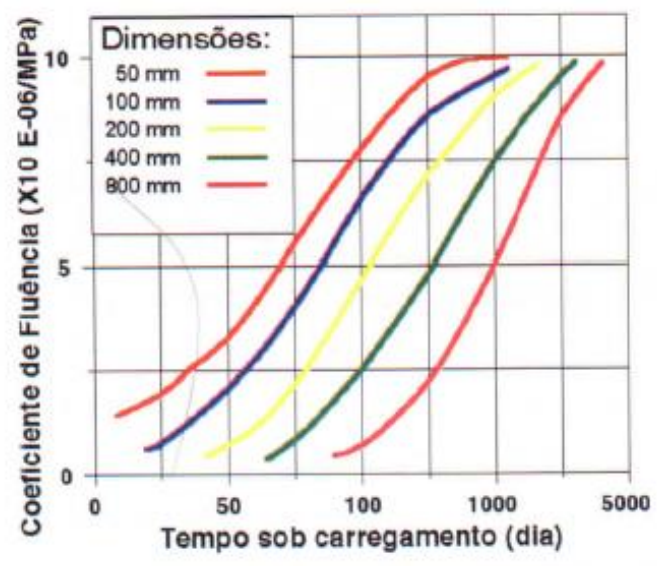

Figura 3.17 - Influência das dimensões da peça na fluência (Furnas, 1997).

- Porcentagem de pasta - constatou-se ao fim de 3, 7, 28, 90, 180 e 360 dias que a fluência se correlaciona linearmente com o teor de pasta, Figura 3.18.

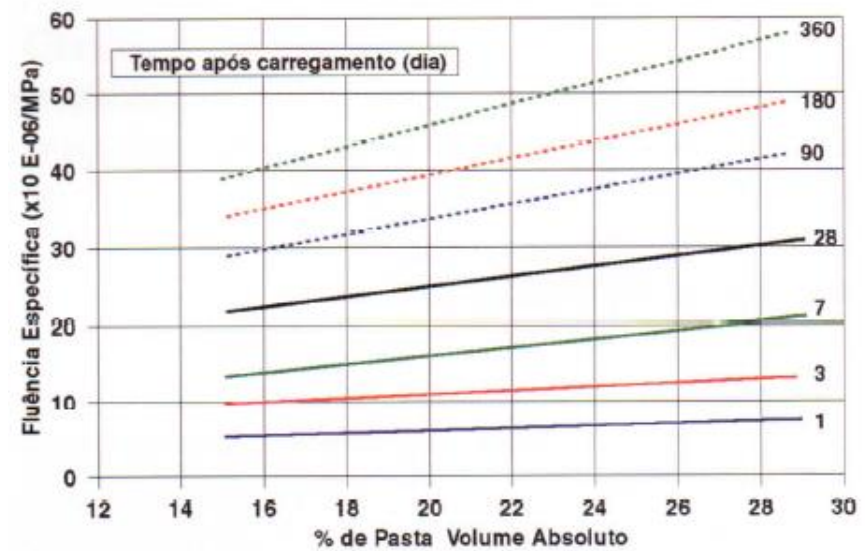

Figura 3.18 - Influência do teor de pasta na fluência (Furnas, 1997).

- Velocidade de carregamento - a deformação aumenta com o aumento da velocidade de carregamento.

Nas estruturas maciças de concreto é normal que o comportamento unidimensional em fluência do concreto se extrapole a três dimensões. Assim, na prática se emprega um único coeficiente de fluência correspondente a direção longitudinal para obter-se as seis deformações diferidas, em lugar de utilizar dois coeficientes de fluência. Isto é, não se 
considera a existência de uma fluência "cruzada" (Santos et al 2003). Em um estudo piloto para coeficientes de fluência direcionais, os autores afirmaram que a relação das deformações diferidas horizontais (transversais) com as verticais (longitudinais) na grande maioria dos instantes de análise, não ultrapassaram $10 \%$.

Botassi et al (2010) observaram, por meio de ensaios experimentais, que mudanças na dosagem do concreto, ainda que mantidos os mesmos materiais, é significativo na fluência. As variações no resultado de fluência básica alcançaram quase 30\% de diferença entre o concreto de maior relação a/c $(0,59)$ e o de menor $(0,50)$.

Em concreto massa, a fluência pode ser a causa de fissuração quando uma massa de concreto restringida sofre um ciclo de variação de temperatura devido á liberação de calor de hidratação e ao subsequente resfriamento. É induzida, então, uma tensão de compressão em função da rápida elevação da temperatura no interior do concreto, essa tensão é baixa em função do baixo módulo de elasticidade. A resistência desse concreto novo também é muito baixa, de forma que sua fluência é elevada. Isso causa um alivio de tensões de compressão, que vai desaparecendo à medida que o concreto resfria. Com a continuidade do resfriamento, são desenvolvidas tensões de tração, e, devido à velocidade de fluência ser reduzida com a idade, pode ocorrer fissuração mesmo antes da temperatura ter diminuído até o valor inicial no lançamento, Figura 3.19. Por essa razão, a elevação da temperatura em concreto massa deve ser controlada (Neville, 2016).

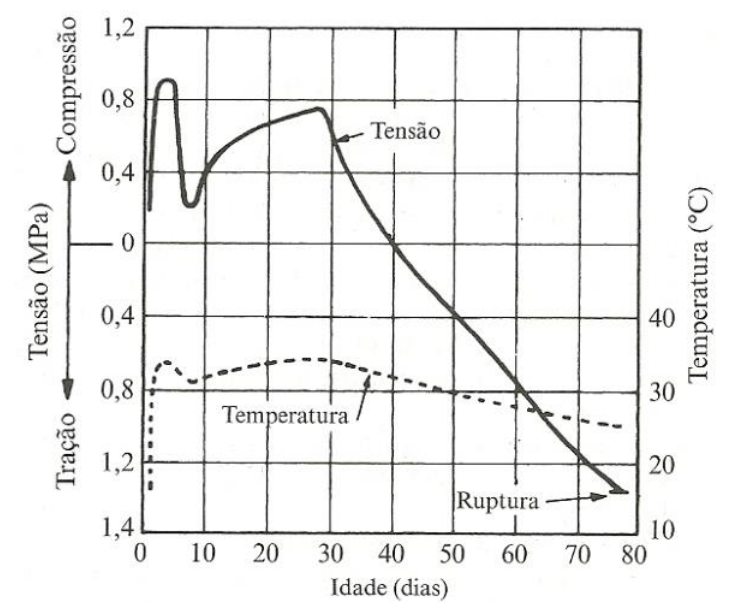

Figura 3.19 - Curva de tensão de um concreto (Neville, 2016). 
Para o cálculo da fluência, existem vários modelos, alguns serão apresentados no item 4.5. O ACI 209.2R (2008) traz alguns critérios a serem avaliados nos modelos de fluência e retração, os quais, resumidamente, são:

- Retração por secagem e fluência por secagem deve ser limitado. Isto é, eles não aumentam indefinidamente com o tempo;

- Equações de retração e fluência devem ser capaz de extrapolar o tempo e o tamanho;

- Modelos de retração e de deformação devem ser comparados com os dados na base de dados limitada pelas condições de aplicabilidade do modelo;

- As equações devem ser fáceis de usar e não altamente sensíveis a mudanças nos parâmetros de entrada;

- A forma das curvas individuais de retração e fluência em uma ampla faixa de tempo (minutos a anos) deve concordar com os resultados dos testes individuais;

- Expressões de retração e fluência devem ser capaz de acomodar concretos contendo adições;

- Os modelos devem permitir o efeito do tamanho da amostra; e

- Os modelos devem permitir mudanças na umidade relativa.

De forma geral, Emborg (1998b) traz como a lei da viscoelasticidade, a deformação total, como a integral da Equação 3.14:

$$
\varepsilon(t)=\int_{0}^{t} J(t, \tau) d \sigma(\tau)+\varepsilon^{0}(t)
$$

Sendo:

- $J(t, \tau)=$ É a função de fluência no tempo t para a idade de carregamento $z$.

- $d \sigma(\tau)=$ Incremento de tensão na idade $\mathrm{z}$.

- $\varepsilon^{0}(t)=$ É a tensão independente do tempo, retração.

$\mathrm{O}$ autor ainda afirma que o histórico de tensões no tempo, $\sigma(t)$, considerando a relaxação e o incremento de deformação pode ser escrito como a Equação 3.15.

$$
\sigma(t)=\int_{0}^{t} R(t, \tau)\left[d \varepsilon(\tau)-d \varepsilon^{0}(\tau)\right]
$$

Em que: 
- $R(t, \tau)=$ Função de relaxação para a deformação na idade $\tau$.

- $\quad d \varepsilon(\tau)=$ Incremento de tensões na idade $\tau$.

As equações 3.14 e 3.15 podem ser interpretadas a partir da Figura 3.20, utilizando o princípio da superposição. Na Figura 3.20 a, tem-se a representação de uma história de tensão arbitrária $\sigma(\mathrm{t})$ como uma soma de tensões infinitesimais $d \sigma(\mathrm{t})$. A Figura $3.20 \mathrm{~b}$ representa o histórico de deformações arbitrárias $\varepsilon(\mathrm{t})$ como resposta da superposição de dos diferentes perfis de tensões. $J\left(t, t_{1}\right)$ denota a função de fluência no tempo $t$ para um carregamento na idade $t_{1}$. A Figura $3.20 \mathrm{c}$ apresenta as deformações arbitrárias $\varepsilon(t)$ como uma soma de incrementos infinitesimais de deformação de. A Figura $3.20 \mathrm{~d}$ mostra as tensões pela superposição dos distintos históricos de deformação. $\mathrm{R}\left(\mathrm{t}, \mathrm{t}_{1}\right)$ indica a função de relaxamento no tempo t para um carregamento em $t_{1}$ (Emborg, 1998b).

a)

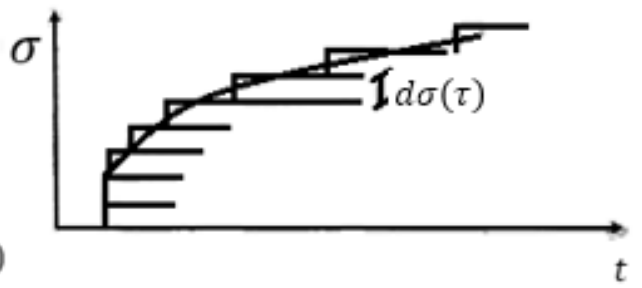

b)

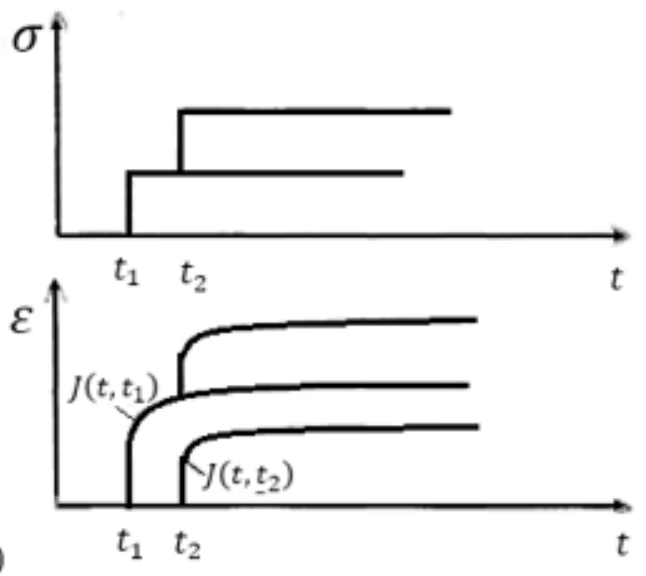

c)
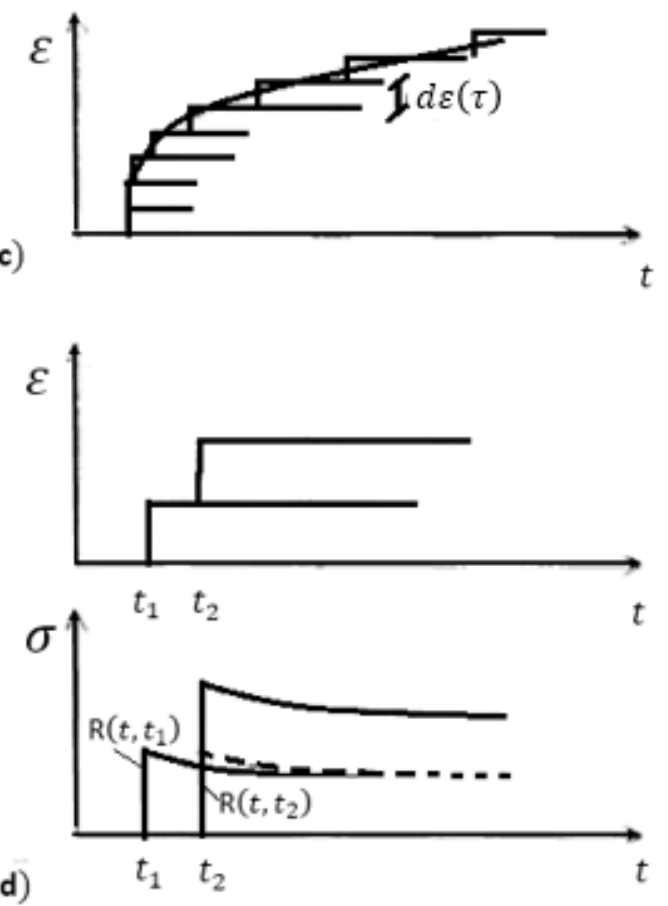

Figura 3.20 - a) Tensões arbitrárias; b) Tensões com influência da deformação de fluência;

c) Deformações arbitrárias d) Tensões com influência da relaxação. (Emborg, 1998b)

Ressalta-se que este trabalho se limita ao estudo das tensões do concreto devido às tensões térmicas, portanto, serão considerados os efeitos da fluência, mas não serão levados em conta a relaxação do concreto, nem a retração. Desta forma, aplica-se apenas a equação 3.14 e os gráficos da Figura 3.20 a e b. 


\subsection{TRANSFERÊNCIA DE CALOR EM ESTRUTURAS DE CONCRETO MASSA}

Calor é definido como a forma de energia que pode ser transferida de um sistema para outro em consequência da diferença de temperatura entre eles, a taxa de transferência é chamada transferência de calor, ou seja, a quantidade de calor transferida por unidade de tempo e para isso é necessário que haja uma diferença de temperatura (Çengel e Ghajar, 2012).

Existem três modos de transmissão de calor: a radiação, a convecção e a condução. Para um melhor entendimento, a seguir são estudados separadamente cada um desses processos, de forma que possa ficar mais claro a influência de cada um deles na alteração da temperatura no concreto massa.

\subsubsection{Radiação}

De acordo com Silveira (1961), radiação térmica é o processo de emissão, por um corpo, de energia radiante cuja quantidade depende da temperatura do corpo. $\mathrm{O}$ conhecimento da radiação solar é indispensável para determinar as temperaturas das superfícies das estruturas, ou melhor, a elevação da temperatura dessas superfícies em relação à temperatura do ar.

A radiação não exige a presença de um meio interveniente, é considerada superficial para os sólidos opacos, uma vez que a radiação emitida pelas regiões do interior desses materiais nunca chegará à superfície, e a radiação incidente sobre esses corpos normalmente é absorvida por alguns mícrons a partir da superfície (Çengel e Ghajar, 2012).

Quanto mais escura uma superfície maior será a absorção por ela adquirida sendo que a cor preta absorve totalmente a radiação imposta. Também influência na quantidade de calor absorvido a inclinação dos raios solares. De acordo com Incropera et al (2008) e Silva (2003), a equação que governa o fenômeno da energia de calorífica transmitida por um corpo negro com temperatura maior que o zero absoluto é dada pela lei de Stefan-Boltzmann, Equação 3.16:

$$
Q_{r}=\sigma^{\prime} \varepsilon^{\prime} A T^{4}
$$

Onde:

- $\mathrm{Q}_{\mathrm{r}}=$ é a quantidade de calor obtida por radiação;

- $\mathrm{A}=$ é a área da superfície; 
- $\mathrm{T}=$ é a temperatura;

- $\sigma^{\prime}=$ é a constante de Stefan-Boltzmann, sendo:

$$
\sigma^{\prime}=5,67 \times 10^{-8} \frac{W}{m^{2} K^{4}}
$$

- $\varepsilon^{\prime}=$ é a emissividade da superfície, $0 \leq \varepsilon^{\prime} \leq 1$. Para o concreto esse valor seria aproximadamente 0,90 (Gery, 1998).

Outra propriedade importante da radiação é a absortividade, $\alpha^{\prime}$, que é a fração de energia de radiação incidente sobre a superfície que a absorve, $0 \leq \alpha^{\prime} \leq 1$ (Çengel e Ghajar, 2012). Para o concreto esse valor seria aproximadamente 0,60 (Gery, 1998).

Analisando o concreto, como também outras estruturas expostas ao ambiente, durante as horas diurnas existe um ganho de energia calorífica. Tal fato é resultado da radiação solar incidente sobre as superfícies da mesma, a qual absorve parte desta energia. Contrariamente, no período noturno, ocorre uma perda de energia calorífica armazenada pela estrutura, devido, em parte, a re-radiação emitida por esta ao ambiente (Calmon, 1995 apud Santos, 2004).

\subsubsection{Convecção}

É a troca de calor através do movimento de um fluido. A quantidade de calor que passa de um sólido para um fluido ou que um fluido cede a um sólido é diretamente proporcional ao gradiente térmico da superfície do sólido. Para que ocorra a convecção é necessário que ocorra uma diferença de temperatura entre o fluido e o corpo. O fenômeno também é influenciado pela velocidade de deslocamento do fluido, pela densidade, viscosidade, calor específico e condutividade térmica do fluido, e ainda da natureza, forma, rugosidade, dimensões e orientação do corpo (Silveira, 1961).

Existem dois tipos de convecção: a natural e a forçada. A primeira acontece quando o movimento do fluido se dá unicamente pela diferença de densidade, motivada pela diferença de temperatura. No caso da convecção forçada, agentes externos provocam o movimento do fluido, independente do fenômeno térmico. No caso do estudo dos problemas térmicos relativos às barragens de concreto, observa-se convecção forçada sempre que correntes de ar devidas ao vento atuam sobre sua superfície (Santos, 2004). 
Supondo um corpo sólido mergulhado num fluido, em que $\mathrm{T}_{\mathrm{s}}$ é a temperatura da superfície e $\mathrm{T}_{\mathrm{f}, \infty}$ é a temperatura do fluido perturbado distante da superfície transmissora de calor, A é a área da superfície, e $\mathrm{h}_{\mathrm{c}}$ é o coeficiente de convecção, a quantidade de calor transmitida no tempo, $Q_{c}$, é dada pela Equação 3.17:

$$
Q_{c}=h_{c} A\left(T_{s}-T_{f, \infty}\right)
$$

Lembrando que o coeficiente $h_{c}$ é dado em função da velocidade do vento. Se $Q_{c}$ for dividido pela área superficial A encontra-se o fluxo de calor transferido por convecção $\mathrm{q}_{\mathrm{c}}$.

\subsubsection{Condução}

O processo de condução de calor ocorre através de um material, geralmente em sólido, podendo ocorrer também em fluidos. Na presença de qualquer movimento de massa do fluido, a transferência de calor entre o sólido e o fluido se dá por pura condução (Çengel e Ghajar, 2012).

A taxa de condução de calor, $Q_{c o n d}$, depende da geometria, área - $A$, da espessura, $d x$, do tipo de material, dado pela condutividade térmica - $k$, e da diferença de temperatura, $d T$, a que o meio está submetido, Equação 3.18 (Çengel e Ghajar, 2012).

$$
Q_{\text {cond }}=k A \frac{d T}{d x}
$$

De acordo com Santos (2004), o calor transferido unicamente por condução é muito pequeno e difícil de quantificar, sendo comum admitir que a transferência de calor por convecção e por condução seja analisada conjuntamente, assumindo um único coeficiente de transferência de calor, o qual dependerá das variáveis que intervém no fenômeno da convecção: velocidade do vento, temperatura na superfície e temperatura ambiente do ar. Assim, admitindo-se que os diferentes mecanismos de transferência de calor podem se agrupar assumindo um coeficiente de transmissão global, $h_{c}$, conforme a Equação 3.19:

$$
h_{c}=h_{c o n v}+h_{r}
$$

Mehta e Monteiro (2014) afirmam ainda que uma estrutura de concreto pode perder calor através de sua superfície, e a magnitude da perda de calor é uma função do tipo de ambiente 
em contato com a superfície do concreto. A Tabela 3.3 apresenta o coeficiente de transmissão de calor superficial para diferentes ambientes de isolamento.

Tabela 3.3 - Coeficiente de transmissão de calor superficial para diferentes ambientes de isolamento (Mehta e Monteiro, 2014).

\begin{tabular}{|l|l|}
\hline Tipo de isolamento & $\mathbf{h}_{\mathbf{c}}\left(\mathbf{k c a l} / \mathbf{m}^{2} \cdot \mathbf{h .}^{\circ} \mathbf{C}\right)$ \\
\hline Concreto-ar & 11,6 \\
\hline Concreto-água de cura & 300,0 \\
\hline Concreto-madeira-ar & 2,6 \\
\hline Concreto-metal-ar & 11,6 \\
\hline Concreto-isolante-ar & 2,0 \\
\hline
\end{tabular}

Nas modelagens de concreto massa é utilizado o coeficiente de convecção, $\mathrm{h}_{\mathfrak{c}}$, para uma superfície submetida a uma determinada temperatura ambiente como condição de contorno. Subtende-se que a radiação e a condução entre o concreto e o ambiente estão representadas por este único coeficiente.

\subsection{CALOR DE HIDRATAÇÃO DO CIMENTO PORTLAND}

O cimento Portland, na reação de hidratação, é responsável por uma liberação de calor, que muda de acordo com a idade do concreto, medido em calorias por grama. A quantidade de calor desenvolvida depende dos diferentes componentes do cimento e de outros fatores: a finura do cimento, a relação água/cimento, a temperatura inicial (Silveira, 1961).

Como a condutividade térmica do concreto é relativamente baixa, ele atua como um isolante, o que pode causar uma elevação da temperatura no concreto massa durante a hidratação. Ao mesmo tempo, o exterior da massa de concreto perde parte do calor, formando um significativo gradiente de temperatura, com posterior resfriamento, o que resulta em sérios problemas de fissuração. Esse comportamento, entretanto, é modificado pela fluência ou pelo isolamento superficial (Neville, 2016)

Carvalho (2002) declara que a reatividade dos compostos do cimento Portland com a água varia consideravelmente, sendo possível modificar as características de desenvolvimento de resistência, e por consequência o desenvolvimento de calor de hidratação, alterando-se as quantidades dos compostos do cimento, os quais são mostrados na Tabela 3.4; sendo o $\mathrm{C}_{3} \mathrm{~S}$, $\mathrm{C}_{2} \mathrm{~S}, \mathrm{C}_{3} \mathrm{~A}$ e $\mathrm{C}_{4} \mathrm{AF}$ os componentes mais importantes do cimento. Dessa forma, podem-se 
produzir cimentos com características diferentes, como os de alta resistência inicial, de baixo calor de hidratação, alta e moderada resistência a sulfatos, etc.

Tabela 3.4 - Simbologia dos óxidos e compostos do cimento Portland (Carvalho, 2002).

\begin{tabular}{|c|c|c|c|}
\hline Óxidos & Abreviação & Compostos & Abreviação \\
\hline $\mathrm{CaO}$ & $\mathrm{C}$ & $3 \mathrm{CaO} \cdot \mathrm{SiO}_{2}$ & $\mathrm{C}_{3} \mathrm{~S}$ \\
\hline $\mathrm{SiO}_{2}$ & $\mathrm{~S}$ & $2 \mathrm{CaO}_{2} \mathrm{SiO}_{2}$ & $\beta \mathrm{C}_{2} \mathrm{~S}$ \\
\hline $\mathrm{Al}_{2} \mathrm{O}_{3}$ & $\mathrm{~A}$ & $3 \mathrm{CaO} \cdot \mathrm{Al}_{2} \mathrm{O}_{3}$ & $\mathrm{C}_{3} \mathrm{~A}$ \\
\hline $\mathrm{Fe}_{2} \mathrm{O}_{3}$ & $\mathrm{~F}$ & $4 \mathrm{CaO} \cdot \mathrm{Al}_{2} \mathrm{O}_{3} \cdot \mathrm{Fe}_{2} \mathrm{O}_{3}$ & $\mathrm{C}_{4} \mathrm{AF}$ \\
\hline $\mathrm{MgO}$ & $\mathrm{M}$ & $4 \mathrm{CaO} \cdot 3 \mathrm{Al}_{2} \mathrm{O}_{3} \cdot \mathrm{SiO}_{3}$ & $\mathrm{C}_{4} \mathrm{~A}_{3} \mathrm{~S}$ \\
\hline $\mathrm{SO}_{4}$ & $\mathbf{S}$ & $3 \mathrm{CaO} \cdot 2 \mathrm{SiO}_{2} .3 \mathrm{H}_{2} \mathrm{O}$ & $\mathrm{C}_{3} \mathrm{~S}_{2} \mathrm{H}_{3}$ \\
\hline $\mathrm{H}_{2} \mathrm{O}$ & $\mathrm{H}$ & $\mathrm{CaSO}_{4} \cdot 2 \mathrm{H}_{2} \mathrm{O}$ & $\mathrm{CS} \mathrm{H}_{2}$ \\
\hline
\end{tabular}

Faria (2004), afirma que a reação de hidratação é na realidade a composição de diversas reações de hidratação, podendo ser apresentadas, esquematicamente, sob a forma das Equações 3.20 a 3.23 abaixo:

$$
\begin{gathered}
\mathrm{C}_{3} \mathrm{~S}+\mathrm{H} \rightarrow \mathrm{C}-\mathrm{S}-\mathrm{H}+\mathrm{CH}+\text { calor } \\
\mathrm{C}_{2} \mathrm{~S}+\mathrm{H} \rightarrow \mathrm{C}-\mathrm{S}-\mathrm{H}+\mathrm{CH}+\text { calor } \\
\mathrm{C}_{3} \mathrm{~A}+\mathrm{CSH}_{2}+\mathrm{H} \rightarrow \mathrm{AF}+\text { calor } \\
\mathrm{C}_{4} \mathrm{AF}+\mathrm{CSH}_{2}+\mathrm{H} \rightarrow \mathrm{AF}_{t}+\mathrm{CH}+\mathrm{FH}_{3}+\text { calor }
\end{gathered}
$$

Onde o $H$ representa a água; o $C-S$ - $H$ os hidratos de silicato de cálcio hidratado; o $C H$, o hidróxido de cálcio ou Portlandita; e o $A F_{t}$ simboliza a etringita.

Com a introdução da água, os componentes do cimento começam a se hidratar. Os produtos formados em sua maioria são os silicatos de cálcio hidratado (CSH). A medida em que se desenvolvem mais CSH a mistura ganha resistência. Imediatamente após a introdução da água na mistura de cimento, um pequeno período de intensa atividade química ocorre. Esta atividade química corresponde à dissolução dos íons, reação da água com o $\mathrm{C}_{3} \mathrm{~A}$, na qual ocorre a liberação de uma grande quantidade de calor (Carvalho, 2002).

Neville (2016) ressalta que a hidratação do $\mathrm{C}_{3} \mathrm{~S}$ caracteriza o comportamento do cimento. Sua hidratação não ocorre a uma velocidade ou taxa de velocidade constante. A rápida hidratação do hidróxido de cálcio na solução forma uma camada externa de silicato de cálcio 
hidratado que impede a hidratação subsequente, de modo que, por algum tempo, praticamente não ocorre hidratação. $\mathrm{O}$ fenômeno pode ser visto na Figura 3.21 e explica o primeiro pico de calor na hidratação do cimento Portland.

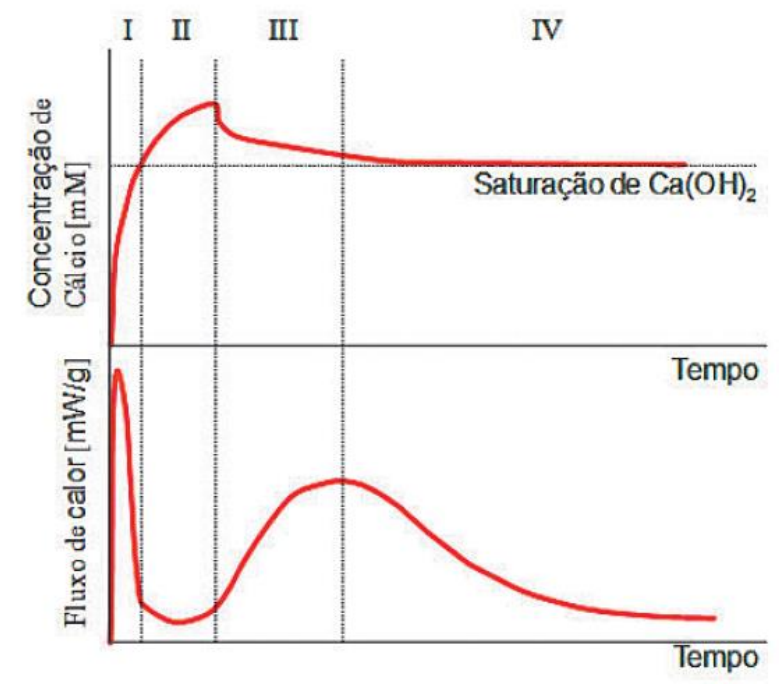

Figura 3.21 - Hidratação do $\mathrm{C}_{3} \mathrm{~S}$ (Julliand et al 2010 apud Cincotto 2011).

A relação água/cimento desempenha um papel definitivo na cinética da velocidade da reação de hidratação do cimento e, consequentemente, na formação dos produtos de hidratação (Neves Junior et al 2012).

O grau de dependência entre as reações dos minerais de clínquer ainda deixa muitos fatos inexplicados e, até agora, é difícil avaliar quantitativamente as possíveis causas e seus graus de influência. Apesar disso, é de consenso que concretos com cimentos de altos teores de $\mathrm{C}_{3} \mathrm{~S}$ e $\mathrm{C}_{3} \mathrm{~A}$ terão alta resistência inicial somada a uma grande liberação de calor durante a sua hidratação. Por outro lado, um concreto com alto teor de $\mathrm{C}_{2} \mathrm{~S}$ irá promover uma baixa resistência inicial, alta resistência a longo prazo e, ainda, baixa liberação de calor (Maekawa, 1999 apud Faria, 2004). Assim seria mais indicado o uso do CP III ou CP IV nas construções com concreto massa.

A Figura 3.22 mostra a quantidade de calor desenvolvida por cada componente do cimento segundo estudos de Choktaweekarn e Tangtermsirikul (2010), evidenciando a alta produção de calor pelo $\mathrm{C}_{3} \mathrm{~A}$ e $\mathrm{C}_{3} \mathrm{~S}$ e um baixo calor para o $\mathrm{C}_{2} \mathrm{~S}$. 


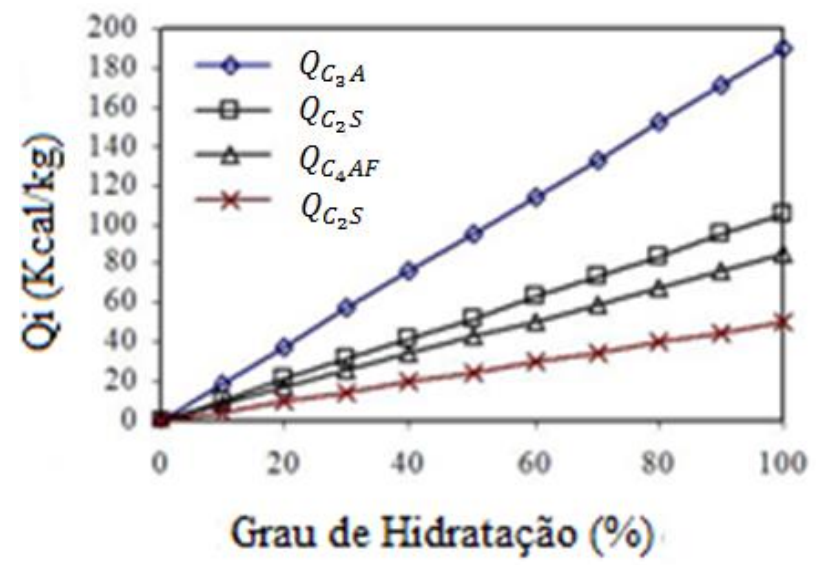

Figura 3.22- Calor desenvolvido por cada componente de cimento (Choktaweekarn e Tangtermsirikul, 2010).

Como a hidratação do cimento é uma reação exotérmica, a taxa de liberação de calor é um indicativo da velocidade de hidratação. A Figura 3.23 mostra que há três picos durante a hidratação do cimento Portland. O primeiro, bastante elevado, corresponde a hidratação inicial da superfície dos grãos de cimento e envolve principalmente o $\mathrm{C}_{3} \mathrm{~A}$. A duração deste pico é bem curta, seguida de um período de dormência, com velocidade bastante baixa, dura entre uma e duas horas, sendo formada uma camada superficial nos grãos de cimento. Posteriormente, a camada superficial é rompida, aumentando a velocidade de hidratação e a liberação de calor lentamente até atingir o segundo pico, em cerca de $10 \mathrm{~h}$, podendo ser atingido até em $4 \mathrm{~h}$. Nesse intervalo ocorre a pega. Após o segundo pico, a velocidade de hidratação diminui por um longo período. Na maioria dos cimentos, ocorre um terceiro pico, menor que os anteriores, entre 18 e $30 \mathrm{~h}$, associado à retomada da reação do $\mathrm{C}_{3} \mathrm{~A}$ após o esgotamento do sulfato de cálcio (Neville, 2016).

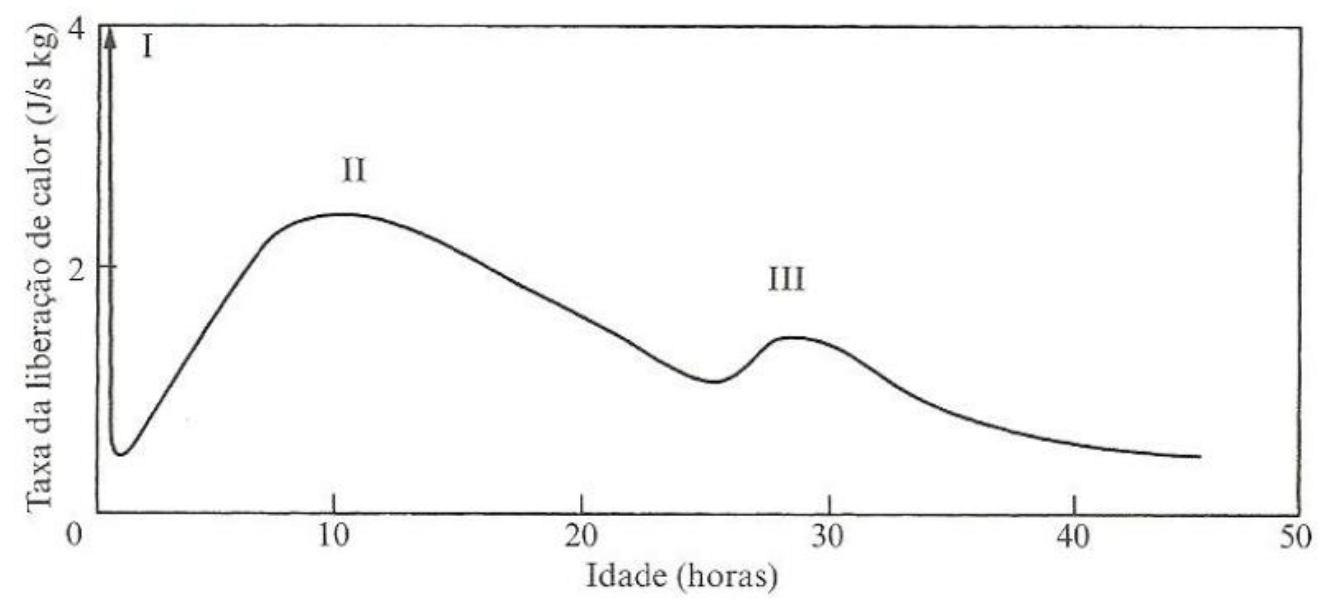

Figura 3.23 - Taxa de liberação de calor de um concreto (Neville, 2016). 
De Schutter e Taerwe (1995) afirmam que o primeiro pico pode ser desconsiderado, pois acontece no primeiro minuto, do primeiro contato da agua com o cimento. Constatando a teoria dos autores, normalmente, para fins de cálculo, o primeiro pico não é considerado.

Observa-se uma semelhança entre os gráficos das Figuras 3.21 e 3.23, que mostram a liberação de calor do silicato tricálcico e do cimento Portland, sendo possível dizer que esse tem grande influência nas reações de hidratação do cimento. Taylor (1997) também mostra esta similaridade.

Bogue (1955) apud Neville (2016) observou que para cimentos Portland comuns cerca de metade do calor total é liberado entre um e três dias, cerca de $75 \%$ em sete dias e entre 83 a 91\% em seis meses. Assim, nota-se que a liberação de calor, mesmo que pequena, se estende por um longo período após a construção quando se trata de concreto massa. As leis de transferência de calor demonstram que em sistemas com fonte interna de calor, este pode fluir de um corpo, inversamente ao quadrado de sua menor dimensão.

Inoue (1986) considerando algumas paredes feitas com concreto normal e exposta ao ar em ambas as faces, afirmou que: para uma parede de $15 \mathrm{~cm}$ de espessura $95 \%$ do calor no concreto será perdido para o ar em 1 h e $30 \mathrm{~min}$. Para uma parede de 1,5 m de espessura, esta mesma proporção de calor seria perdida em uma semana. Para uma parede de $15 \mathrm{~m}$ de espessura, que poderia representar a espessura de uma barragem tipo arco, levaria 2 anos para dissipar 95\% do calor armazenado, enquanto que para uma barragem de $152 \mathrm{~m}$ de espessura levaria 200 anos.

Cincotto (2011) mostrou ainda que a temperatura ambiente afeta o processo de hidratação do cimento, havendo um deslocamento dos picos. O processo aceleração-desaceleração se dá em menor tempo e com maior liberação de calor para temperaturas ambientes maiores, Figura 3.24. 


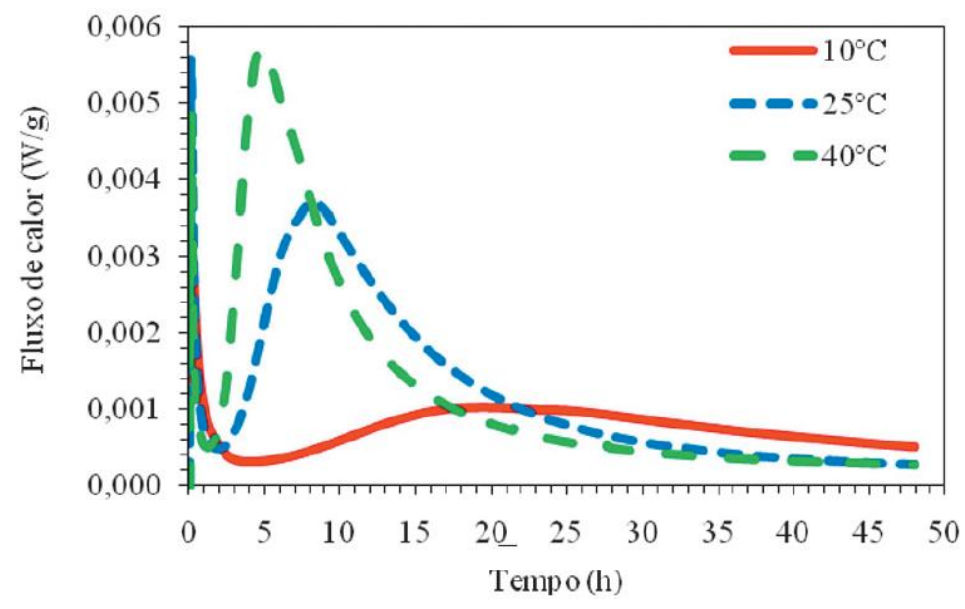

Figura 3.24 - Influência da temperatura ambiente no processo de hidratação do cimento (Cincotto, 2011).

Neville (2016) afirma que para fins práticos, não é o calor de hidratação que interessa, mas sua velocidade de desenvolvimento, pois a mesma quantidade de calor total pode ser dissipada em um tempo muito maior, resultando em menor elevação térmica.

Lawrence et al (2012) fizeram a análise da distribuição de temperatura e fissuração para quatro misturas de concreto massa utilizados na Florida, sendo que foram variadas as quantidades de cimento em substituição por outros materiais. Cada mistura foi usada para fazer dois blocos grandes de concreto de 1,07 $\mathrm{m} \times 1,07 \mathrm{~m} \times 1,07 \mathrm{~m}$. A Figura 3.25, apresenta os resultados das temperaturas adiabáticas para cada traço de concreto:

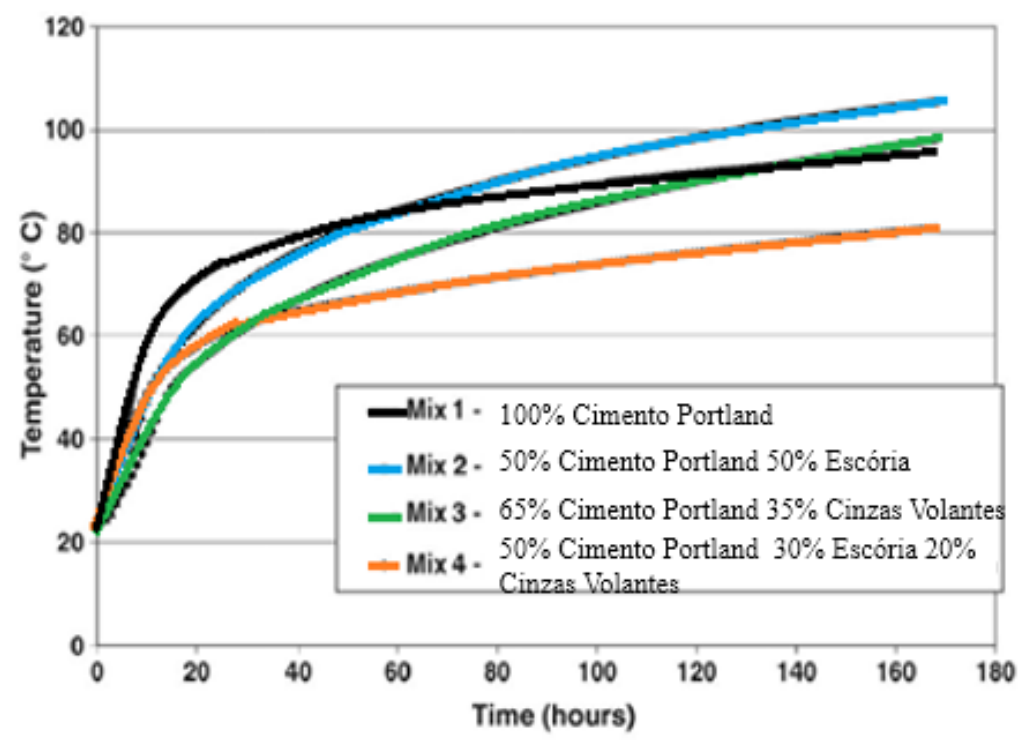

Figura 3.25 - Temperatura adiabática para as diferentes misturas de concreto. 
Os autores chegaram à conclusão que o concreto massa contendo $100 \%$ de cimento sem adições apresentou fissuras em todas as suas superfícies, mesmo aquelas isoladas. Para a mistura com $50 \%$ de escória de alto forno a taxa de reação de hidratação e a taxa do aumento da temperatura foi significativamente mais lenta, no entanto, houve fissuração em idade precoce, pois houve também redução da resistência a tração do concreto oriunda da integridade do material. Para a mistura com 35\% de cinzas volantes também ocorreu fissuração, embora as cinzas volantes reduziu a temperatura de pico, não teve qualquer efeito sobre a taxa de aumento de temperatura inicial levando à fissuração precoce. O concreto com $30 \%$ de escória e $20 \%$ de cinzas volantes teve o melhor desempenho em termos de reduzir as tensões térmicas induzidas em relação à resistência à tração e, por conseguinte, um menor potencial de fissuração.

Muitos são os problemas desencadeados pela elevação de temperatura no interior do concreto, assim, para tentar reduzir a geração de calor interno do concreto algumas medidas ou artifícios podem ser adotados (Coelho, 2012):

- Escolher um cimento Portland com uma composição química que resulte um desprendimento lento de calor. Os cimentos recomendados para esse tipo de estrutura são os cimentos CP III - Cimento Portland de alto-forno, que possui de 35\% a 70\% de escória (NBR 5735, 1991), e o cimento CP IV - Cimento Portland pozolânico, no qual o teor de materiais pozolânicos secos deve estar compreendido entre $15 \%$ e 50\% da massa total de aglomerante (NBR 5736, 1991). Esses cimentos possuem um menor teor dos compostos que se hidratam mais rapidamente, $\mathrm{C}_{3} \mathrm{~S}$ e $\mathrm{C}_{3} \mathrm{~A}$, tendo uma evolução mais lenta da resistência, mas que não altera a resistência final. Cincotto (2011) mostra as diferentes gerações de calor, Figura 3.26a, e calor acumulado, Figura 3.26 b, no decorrer do tempo para os cimentos CPIII, curva verde, CPIV, curva roxa, $\mathrm{CPV}$, vermelha, e CPV $+10 \%$ de fíler calcário, curva azul. Nota-se um menor calor acumulado para o CPIII, seguido pelo CPIV, normalmente utilizados no concreto massa. 

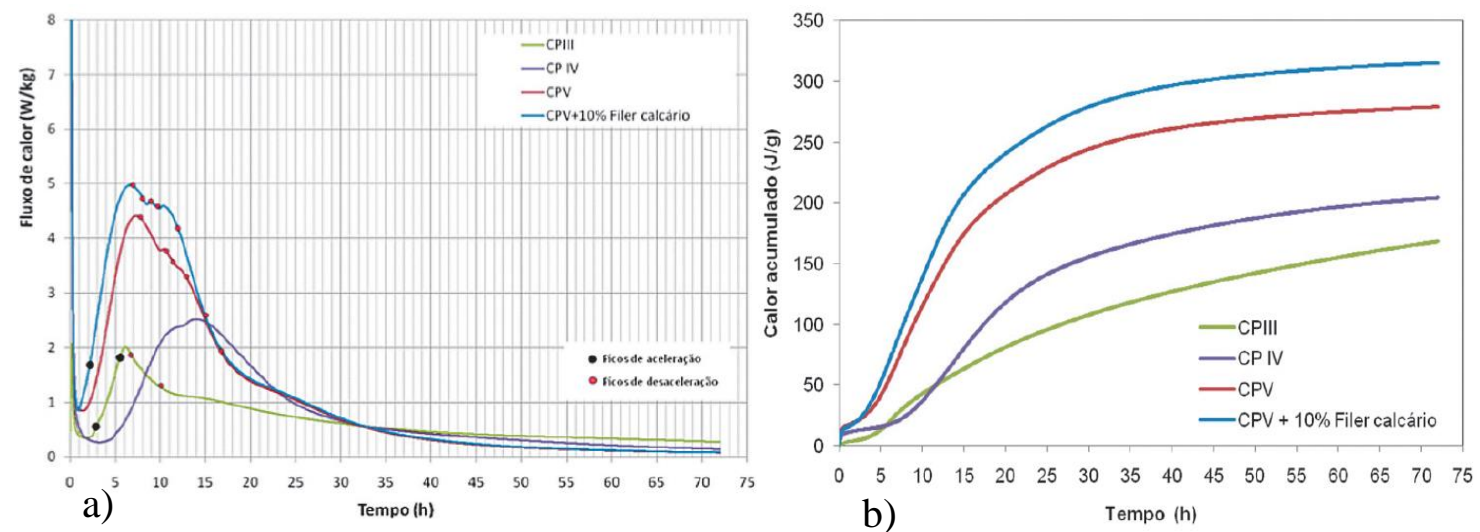

Figura 3.26 - a) Geração de calor e b) Calor acumulado para diferentes tipos de cimento (Cincotto, 2011).

- O uso de agregado com um tamanho máximo grande, $75 \mathrm{~mm}$ ou mesmo $150 \mathrm{~mm}$, permite uma redução do teor de água na mistura. A relação água/cimento pode ser alta em barragens de gravidade, até 0,75 , pois a resistência do concreto tem pouca importância estrutural (Neville, 2016).

Mehta e Monteiro (2016) relatam que sempre que possível deve-se escolher um agregado com baixa expansão térmica no concreto massa, que determinam as tensões de resfriamento do concreto.

- O isolamento da superfície também é uma técnica que propicia a redução da taxa de resfriamento, pois a fissuração acontece pela diferença de temperatura entre o interior e a superfície. A isolação deve controlar a perda de calor por evaporação, por condução e por radiação.

Choktaweekarn e Tangtermsirikul (2010) mostraram em um gráfico a variação da temperatura com o tempo, conforme a Figura 3.27. Na superfície, por volta de 4,6 dias, observa-se uma queda de temperatura. Esta queda é devido a retirada do isolamento da superfície. Logo, percebe-se que a partir desse momento pode haver um aumento no gradiente térmico. 


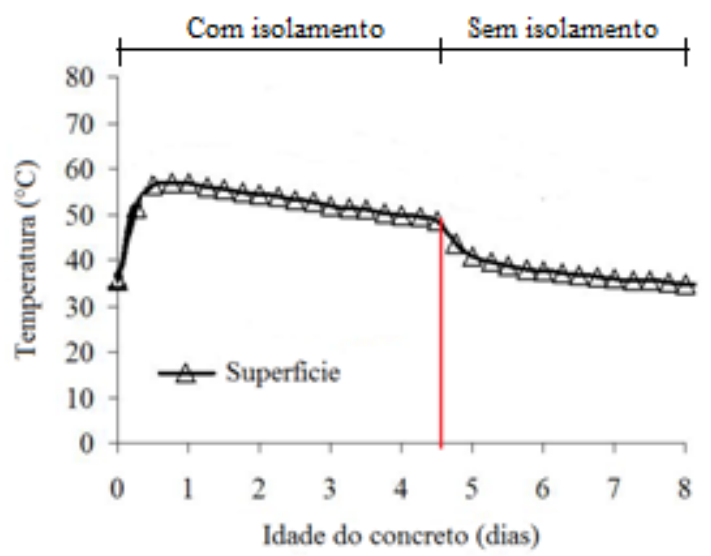

Figura 3.27 - Temperatura na superfície de um bloco de concreto (modificado -

Choktaweekarn e Tangtermsirikul, 2010).

- Outra forma de redução do calor de hidratação é o processo de pré-resfriamento do concreto. As formas de resfriamento do concreto incluem o sombreamento e a aspersão de água nas pilhas de agregados, uso de água gelada, substituição da água da mistura por gelo e a o uso do nitrogênio líquido. $\mathrm{O}$ resfriamento dos agregados tem um grande efeito visto que representam de 70 a $85 \%$ do peso do concreto. $\mathrm{O}$ uso do nitrogênio líquido tem permitido sucesso, mas uma de suas desvantagens é o alto custo (Gadja e Vangeem, 2002).

A adição do gelo em substituição a água de amassamento, na própria obra, previamente ao lançamento do concreto, apresenta resultados satisfatórios para temperaturas de lançamento inferiores a $16^{\circ} \mathrm{C}$. Para este tipo de concretagem é importante que todos os sacos de gelo sejam pesados antes de serem adicionados à betoneira. Recomenda-se que o gelo seja adicionado em escamas porque minimiza o tempo de mistura no caminhão betoneira (Funahashi et al 2010).

- Existe também o processo de pós-resfriamento do concreto. Este consiste em tubos de refrigeração que são inseridos no concreto massa para reduzir de forma rápida a temperatura interior, reduzindo a temperatura máxima atingida por esse concreto.

Kim et al (2001) estudaram a presença de tubos de resfriamento em concreto massa através do MEF. Observaram que a temperatura do concreto com tubos de resfriamento diminui mais rapidamente do que nos que não possuem. Esta tendência é muito mais evidente nos pontos mais próximos desses tubos de refrigeração. Nos pontos próximos às extremidades, a redução de temperatura é relativamente menor, sendo atribuída à convecção atmosférica.

Liu et al (2015) também estudaram os tubos de resfriamento em uma estrutura de concreto massa. Mostraram que as temperaturas próximas aos tubos de resfriamento 
têm uma queda, podendo também haver oscilações nesses valores. Além disso, a tensão térmica perto dos tubos de refrigeração, é, obviamente, maior e fissurações são mais propensas a serem iniciadas, portanto, deve ser mais pesquisado. A Figura 3.28 , mostra a variação térmica no concreto massa em tempos distintos.
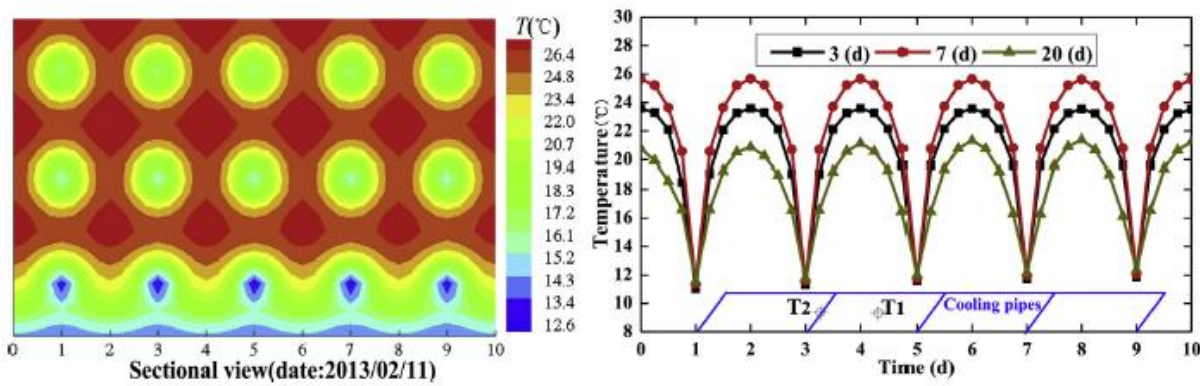

Figura 3.28 - Tubos de resfriamento no concreto (Liu et al 2015).

\subsubsection{Valores numéricos para o calor de hidratação}

Quanto aos valores numéricos do calor de hidratação, alguns autores trazem conceitos distintos para encontrá-lo, como mostra a Tabela 3.5. No entanto, sempre há referências ao concreto e suas propriedades térmicas que influenciam diretamente na temperatura de elevação adiabática e consequentemente no calor gerado.

Tabela 3.5 - Formulações para o calor de hidratação do concreto massa.

\begin{tabular}{|c|c|c|}
\hline Autor & Calor de hidratação & Definições \\
\hline Liu et al (2010) & $\dot{q}=q_{i}\left(1-e^{-\propto t^{\beta}}\right)$ & $\begin{array}{l}q_{i}, \propto, \beta=\text { constantes obtidas do } \\
\text { concreto; sendo que } q_{i} \text { é o calor inicial }\end{array}$ \\
\hline $\begin{array}{l}\text { Mehta e Monteiro } \\
\text { (2016) }\end{array}$ & $\dot{q}=\rho c \frac{\partial T_{a}}{\partial t}=C_{c} \frac{\partial Q}{\partial t}$ & $\begin{array}{l}C_{c}=\text { consumo de cimento } \\
\rho c=\text { massa e calor especifico }\end{array}$ \\
\hline Silveira (1961) & $\begin{array}{c}\dot{q}=m c \frac{\partial T_{a}}{\partial t} \\
m=1+x+a_{r}+b\end{array}$ & $\begin{array}{l}\text { traço= } 1: x: a_{r}: b= \\
\text { cimento:água:areia:brita }\end{array}$ \\
\hline $\begin{array}{l}\text { De Schutter e } \\
\text { Taerwe (1995) } \\
\text { De Schutter (1999) } \\
\text { De Schutter (2002) }\end{array}$ & $\begin{aligned} q(r, T)=q_{\max }, 20 \\
\cdot \\
\cdot f(r) \\
\cdot g(T)\end{aligned}$ & $\begin{array}{l}r=\frac{Q}{Q_{\max }}=[0,1]=\text { grau de hidratação; } \\
\mathrm{T}=\text { temperatura; } \\
q_{\max , 20}=\text { máxima geração de calor à } \\
20^{\circ} \mathrm{C} ; \\
\quad \frac{q}{q_{\max }}=f(r)=c \cdot[\sin (r \pi)]^{a} \cdot e^{-b r} \\
\quad a=0,667 ; \quad b=3,0 ; \quad c=2,5968\end{array}$ \\
\hline $\begin{array}{l}\text { Japan Society of } \\
\text { Civil Engineers } \\
\text { (1999) apud } \\
\text { Aurich (2008) }\end{array}$ & $\dot{q}=\rho c \frac{\partial T_{a}}{\partial t}$ & $T_{a}=T_{\max }\left(1-e^{1,25 t}\right)$ \\
\hline
\end{tabular}

Gomes (2011) diz que a taxa de geração interna de calor $\dot{q}$ não é constante ao longo do processo de hidratação do concreto. Pode ser determinada experimentalmente por meio de 
ensaios calorimétricos adiabáticos, semi-adiabáticos ou isotérmicos. É influenciada pela temperatura em dado instante e pelo grau de hidratação, cujo efeito pode ser desprezado dentro de certas limitações.

\subsubsection{Energia de Ativação}

O fenômeno da hidratação é dependente da evolução da camada de hidratados que, com o seu crescimento progressivo (Figura 3.29), impede cada vez mais que a água penetre através dos nanoporos para se combinar com o cimento anidro e formar novos hidratos (Faria, 2004).

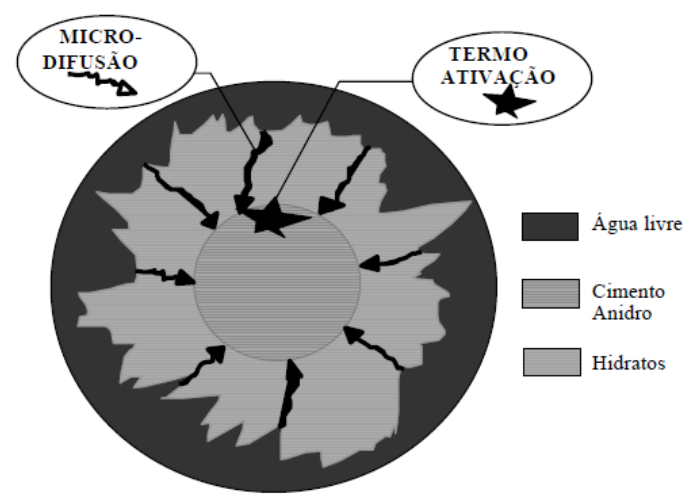

Figura 3.29 - Evolução da reação de hidratação (Faria, 2004).

A energia de ativação provém da ideia de que as moléculas devem possuir uma quantidade mínima de energia cinética para reagir. Esta energia é aquela necessária para transformar os reagentes em produtos. Nas reações do tipo exotérmicas, caso da hidratação do cimento, os reagentes estão em um estado de energia maior do que o estado dos produtos (Figura 3.30). Assim sendo, a energia de ativação é a diferença entre a energia necessária para ativar a reação e o nível de energia dos reagentes, sendo que o calor total gerado na reação é a diferença entre o nível de energia dos reagentes e o nível de energia dos produtos (Atkins, 1998, apud Carvalho, 2002). 


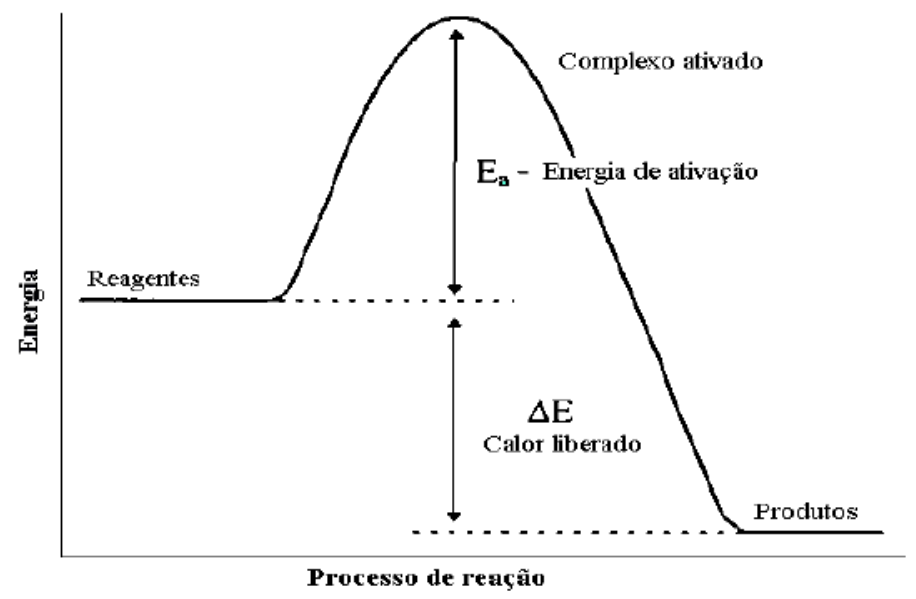

Figura 3.30 - Perfil de energia durante as reações (Brown et al 1991, apud Carvalho, 2002).

Ainda segundo o autor, em função do elevado grau de complexidade das reações de hidratação do cimento, a energia de ativação é determinada a partir de uma função que relaciona a modificação de uma propriedade particular ao longo do tempo, a uma determinada temperatura. Uma dessas propriedades pode ser a liberação de calor de hidratação ou o grau de hidratação. Afirmou que a energia de ativação é uma medida da sensibilidade de uma reação à temperatura.

\subsubsection{Grau de hidratação}

Numa perspectiva macroscópica está generalizada a utilização de dois conceitos distintos para quantificação do desenvolvimento das propriedades do concreto: o conceito de grau de hidratação e o conceito de maturidade. O grau de hidratação é um parâmetro compreendido entre 0 e 1, que descreve o avanço do processo de hidratação. A partir do grau de hidratação é possível estabelecer correlações com as propriedades do concreto (Azenha, 2004).

A noção de grau de hidratação ( $\xi$ ), concerne uma medida de avanço da reação entre a água e o cimento, constituindo um parâmetro objetivo, permitindo se caracterizar a maturidade do concreto. Quando $\xi$ possui valor zero implica que ainda não aconteceu o início da hidratação, e ao atingir o valor unitário indica que o processo de hidratação está finalizado (Carvalho, 2002). 
De acordo com o conceito de grau de hidratação, é possível ter em conta simultaneamente os efeitos do tempo e do histórico de temperaturas a que o concreto está sujeito para estimativa do grau de desenvolvimento das suas propriedades (Silva, 2013).

Todas as propriedades do concreto podem ser dadas em função do seu grau de hidratação. Existem algumas relações para se mensurar o grau de hidratação do concreto a partir de um parâmetro, a mais usual, citada por Carvalho (2002), Azenha (2004) e Gomes (2011) é dada pela Equação 3.24.

$$
\xi=\frac{\text { Quantidade de calor gerado no tempo } t}{\text { Quantidade de calor gerado no tempo } t=\infty}=\frac{Q(t)}{Q(t=\infty)}
$$

Gomes (2011) mostra uma relação entre as funções conforme a Figura 3.31. As Figura 3.31a e b são a taxa de geração interna de calor e o calor acumulado em função do tempo, respectivamente, para os resultados de um ensaio com calorímetro isotérmico. Considerando que $\xi=Q(t) / Q_{\text {total }}$, colocou-se $\dot{Q}$ em função de $\xi$, Figura 3.31c. Dividindo-se $\dot{Q} / Q_{\text {pico }}$, tem-se a função $f(\xi)$, que é a função do grau de hidratação e tem pico unitário, e independente da temperatura, como mostrado na Figura 3.31d.

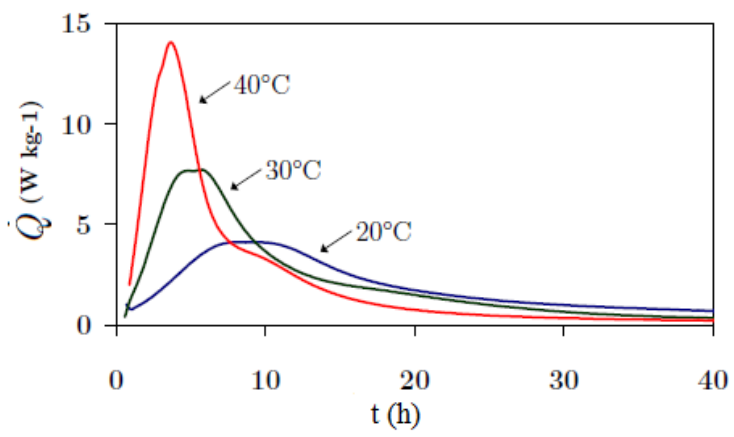

a) $\dot{Q}$

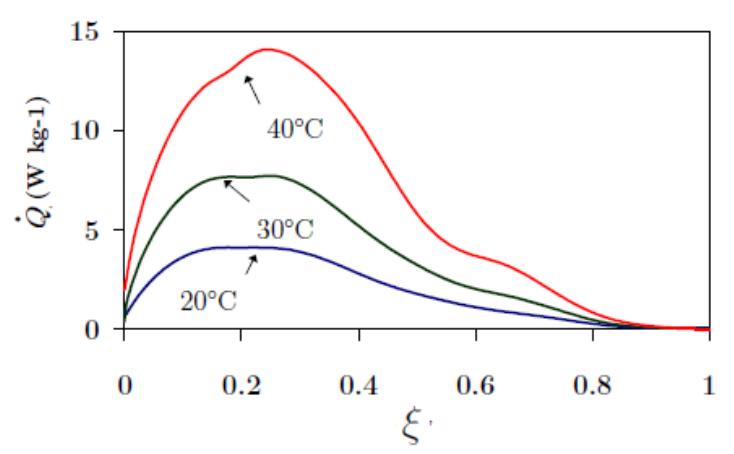

c)

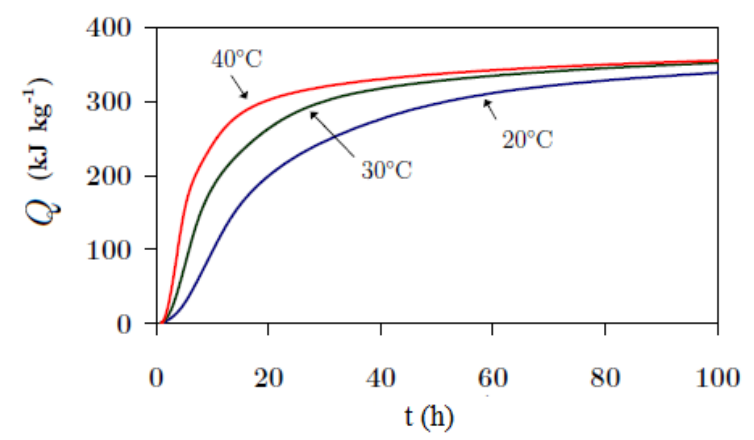

b) $Q$

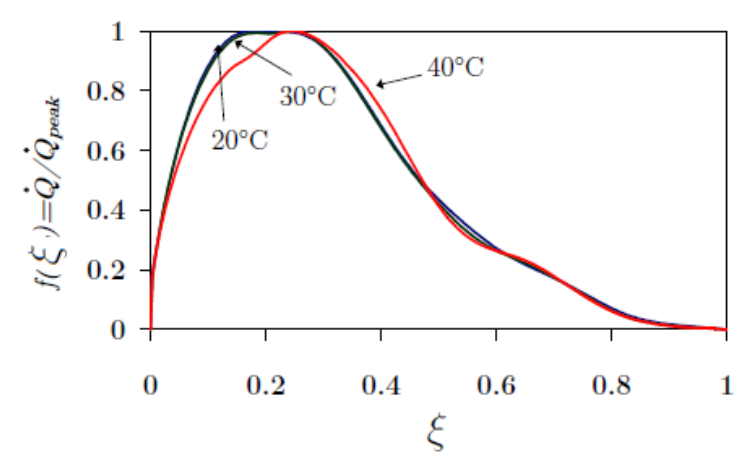

d)

Figura 3.31 - Funções do grau de hidratação (Gomes, 2011).

É importante frisar que para os cálculos presentes neste trabalho as propriedades não foram consideradas em termos do grau de hidratação. 


\section{FUNDAMENTOS TEÓRICOS}

\subsection{EQUAÇÃO DO CALOR}

A dedução apresentada a seguir é baseada em Azenha (2009), Rao (1999), Incropera (2008) e Çengel \& Ghajar (2012).

A equação de taxa de condução em sólidos é conhecida como a Lei de Fourier, representada pela Figura 4.1, e é expresso em uma dimensão como a Equação 4.1.

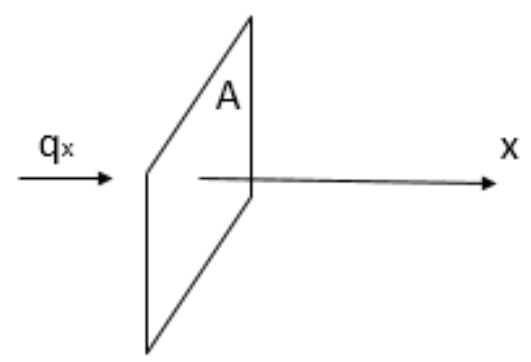

Figura 4.1 - Condução unidimensional.

$$
q_{x}=-k A \frac{\partial T}{\partial x}
$$

Onde:

- $q_{x}$ é o fluxo de calor $(\mathrm{W})$ através de uma área $A\left(\mathrm{~m}^{2}\right)$, cuja normal é x;

- $\quad k$ é a condutividade térmica $\left(\frac{W}{m K}\right)$;

- $T$ é a temperatura $(K)$;

- $x$ é a coordenada espacial $(m)$.

Em meios porosos, tais como no concreto, o calor pode também ser transmitida devido ao transporte de umidade. Com isso a Equação 4.1 ganha uma nova parcela pertencente a este fluxo adicional, o efeito Dufour, que pode ser definido como o fluxo de calor produzido por um gradiente de concentração. Assim a Equação 4.1 passa a ser:

$$
q_{x}=-k A \frac{\partial T}{\partial x}-k_{d u f} A \frac{\partial w}{\partial x}
$$

Onde:

- $\quad k_{d u f}$ é a condutividade térmica de proporcionalidade devido ao transporte de umidade $\left(\frac{W}{m K}\right)$; 
- $\quad w$ é a massa (kg) de água livre (não ligada quimicamente) por unidade de volume de concreto.

No entanto, o efeito Dufour, tem sido reconhecido como insignificante na transferência de calor de concreto em comparação com a temperatura ambiente, portanto, não é levada em consideração na presente pesquisa.

A equação de equilíbrio de energias em coordenadas cartesianas pode ser mostrada com relação a um volume infinitesimal elementar de matéria como representado na Figura 4.2, em que $\mathrm{q}_{\mathrm{x}}, \mathrm{q}_{\mathrm{y}}, \mathrm{q}_{\mathrm{z}}$ representam o calor que entra e $\mathrm{q}_{\mathrm{x}+\mathrm{dx}}, \mathrm{q}_{\mathrm{y}+\mathrm{dy}}, \mathrm{q}_{\mathrm{z}+\mathrm{dz}}$ o calor que sai nas direções $\mathrm{x}, \mathrm{y}$ e $\mathrm{z} ; \mathrm{dx}, \mathrm{dy}, \mathrm{dz}$, as variações dimensionais em $\mathrm{x}, \mathrm{y}$ e $\mathrm{z} ; \dot{E_{g}}$ e $\dot{E_{s t}}$ a energia gerada e que sai do corpo.

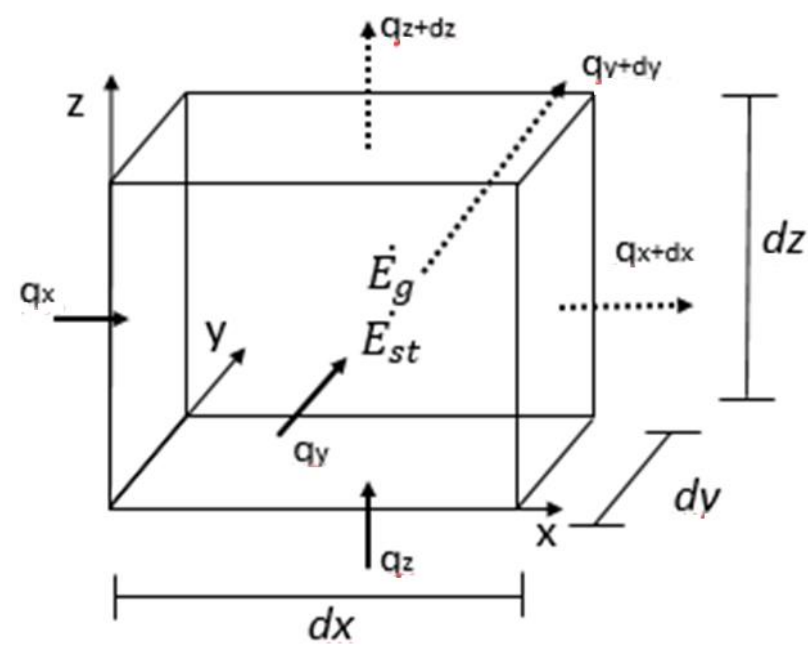

Figura 4.2 - Volume infinitesimal elementar de matéria.

$\mathrm{Na}$ presença de gradientes de temperatura haverá condução de calor através das faces da partícula infinitesimal, em direções perpendiculares às correspondentes superfícies. Nas três das faces da partícula os fluxos de calor podem ser identificados por $q_{x}, q_{y}$ e $q_{z}$. Nas faces opostas, os fluxos de calor podem ser representados em expansão de série de Taylor, ignorando termos de ordem superior, como mostra a Equação 4.3:

$q_{x+\partial x}=q_{x}+\frac{\partial q_{x}}{\partial x} d x \quad q_{y+\partial y}=q_{y}+\frac{\partial q_{y}}{\partial y} d y \quad q_{z+\partial z}=q_{z}+\frac{\partial q_{z}}{\partial z} d z$

A Equação do balanço energético com base na Figura 4.1 pode ser dado conforme o esquema da Figura 4.3. 


\begin{tabular}{|c|} 
Calor que \\
entra durante \\
o tempo $d t$
\end{tabular}$+\left[\begin{array}{c}\text { Calor gerado } \\
\text { durante } \mathrm{o} \\
\text { tempo } d t\end{array}\right]+\begin{gathered}\text { Calor que sai } \\
\text { durante o } \\
\text { tempo } d t\end{gathered}+\left[\begin{array}{c}\text { Armazenamento de } \\
\text { energia interna } \\
\text { durante o tempo } d t\end{array}\right.$

Figura 4.3 - Volume infinitesimal elementar de matéria.

Ou ainda, pela Equação 4.4.

$$
\dot{E_{\text {ln }}}+\dot{E_{g}}=\dot{E_{\text {out }}}+\dot{E_{s t}}
$$

Denotando por $\dot{q}\left(\frac{W}{m^{3}}\right)$, a taxa de geração de calor interno (devido à hidratação do cimento) por unidade de volume, a taxa de geração de energia no interior do volume é expressa pela Equação 4.5:

$$
\dot{E_{g}}=\dot{q} d_{x} d_{y} d_{z}
$$

A taxa de acumulação de energia no interior do volume, $\dot{E_{s t}}(W)$, pode ser expressa como uma função da derivada da temperatura em relação ao tempo $\frac{\partial T}{\partial t}$, do calor específico do material $c\left(\frac{\mathrm{J}}{\mathrm{kg}} K\right)$ e da massa específica $\rho\left(\frac{\mathrm{kg}}{\mathrm{m}^{3}}\right)$ :

$$
\dot{E_{g}}=\rho c \frac{\partial T}{\partial t} d_{x} d_{y} d_{z}
$$

Introduzindo os fluxos de energia ilustrados na Figura 4.1, e substituindo as Equação 4.5 e 4.6 em 4.4, tem-se a expressão 4.7 :

$$
q_{x}+q_{y}+q_{z}+\dot{q} d_{x} d_{y} d_{z}=q_{x+d x}+q_{y+d y}+q_{z+d z}+\rho c \frac{\partial T}{\partial t} d_{x} d_{y} d_{z}
$$

Ou ainda:

$$
q_{x}+q_{y}+q_{z}+\dot{q} d_{x} d_{y} d_{z}-q_{x+d x}-q_{y+d y}-q_{z+\partial z}=\rho c \frac{\partial T}{\partial t} d_{x} d_{y} d_{z}
$$

Introduzindo a Equação 4.3 na Equação 4.8, tem-se:

$$
-\frac{\partial q_{x}}{\partial x} d x q_{x}-\frac{\partial q_{y}}{\partial y} d y-\frac{\partial q_{z}}{\partial z} d z+\dot{q} d_{x} d_{y} d_{z}=\rho c \frac{\partial T}{\partial t} d_{x} d_{y} d_{z}
$$

De acordo com a Equação 4.1, tem-se:

$$
q_{x}=-k d_{y} d_{z} \frac{\partial T}{\partial x} \quad q_{y}=-k d_{x} d_{z} \frac{\partial T}{\partial y} \quad q_{x}=-k d_{x} d_{y} \frac{\partial T}{\partial z}
$$

Assim, a equação geral da condução de calor transiente (4.9) torna-se:

$$
\frac{\partial}{\partial x}\left(k \frac{\partial T}{\partial x}\right)+\frac{\partial}{\partial y}\left(k \frac{\partial T}{\partial y}\right)+\frac{\partial}{\partial z}\left(k \frac{\partial T}{\partial z}\right)+\dot{q}=\rho c \frac{\partial T}{\partial t}
$$


Por fim, para os casos em que a condutividade térmica é constante durante o período de análise, é usual para representar a Equação 4.11 como:

$$
k\left(\frac{\partial^{2} T}{\partial x^{2}}+\frac{\partial^{2} T}{\partial y^{2}}+\frac{\partial^{2} T}{\partial z^{2}}\right)+\dot{q}=\rho c \frac{\partial T}{\partial t}
$$

Ou:

$$
k \nabla T^{2}+\dot{q}=\rho c \frac{\partial T}{\partial t}
$$

A Equação 4.13 é a equação diferencial que rege a condução de calor de um corpo sólido ortotrópicos. As condutividades térmicas nas direções $x, y, z$ são assumidas como $k_{x}=k_{y}=$ $k_{z}=k=$ constante. Esta também pode ser escrita como:

$$
\nabla T^{2}+\frac{\dot{q}}{k}=\frac{1}{\delta} \frac{\partial T}{\partial t}
$$

Em que $\delta=\frac{k}{\rho c}$, é a difusividade térmica. A Equação 4.14 representa a transferência de calor num corpo isotrópico, ou seja, com propriedades materiais uniformes. Se não houver geração de calor interna a Equação 4.14 se reduz à Equação 4.15, chamada Equação de Fourier.

$$
\nabla T^{2}=\frac{1}{\delta} \frac{\partial T}{\partial t}
$$

Se o corpo está em estado estacionário com geração de calor interna, a Equação 4.14 tornase a Equação 4.16, ou Equação de Poisson.

$$
\nabla T^{2}+\frac{\dot{q}}{k}=0
$$

Se o corpo está em estado estacionário sem geração de calor interna, a Equação 4.14 tornase a Equação 4.17, ou Equação de Laplace.

$$
\nabla T^{2}=0
$$

\subsection{CALOR DE HIDRATAÇÃO}

Sendo a equação do calor mostrada na Equação 4.18, no ensaio adiabático, o termo $\mathrm{k} \nabla^{2} \mathrm{~T}$ é igual a zero, ou seja, não existe variação de temperatura nas direções x, y, z do espaço, caso em que todo o calor gerado internamente é armazenado pelo próprio material. Uma vez que a taxa de geração interna de calor cessa após certo tempo, a temperatura aumenta continuamente enquanto existe geração de calor, até se estabilizar em um patamar constante. Dessa forma, tem-se que:

$$
\dot{q}=\rho c\left(\Delta \dot{T}^{a d}\right)
$$


Em que:

- $\quad \rho, c$ - são a massa especifica e o calor especifico, respectivamente, são em geral consideradas constantes do material e independentes da temperatura.

- $\quad T$ e $\dot{T}$ - temperatura no ponto e taxa de variação da temperatura, respectivamente.

- $\quad \dot{q}$ - taxa de variação interna de calor no ponto.

Faria (2004) identificou uma função capaz de ajustar dados experimentais capaz de descaracterizar as curvas de elevação adiabática da temperatura através de três parâmetros, a qual pode ser vista na Equação 4.19, chamada de função Hill.

$$
T^{a d}(t)=T_{\max } \frac{t^{n}}{a^{n}+t^{n}}
$$

Em que:

$T_{\text {máx- }}$ máxima temperatura atingida durante o ensaio, em ${ }^{\circ} \mathrm{C}$;

$a$ - representa o atraso devido ao calor latente, grandeza adimensional;

$n$ - é o coeficiente de aceleração para o período assintótico, grandeza adimensional.

Observação: $a$ e $n$ são obtidos por meio do ajuste da curva experimental.

Ressalta-se que o tempo, $t$, utilizado na função de Hill é dado levando em consideração à maturidade do concreto, ou seja, utiliza-se o conceito de idade equivalente, descrito em 3.2.5, e com a formulação novamente representada pela Equação 4.20.

$$
t_{e}=\sum e^{-\beta\left(\frac{1}{T}-\frac{1}{T_{S}}\right) \Delta t}
$$

A partir de dados experimentais da temperatura adiabática para um calorímetro adiabático é possível fazer a curva de temperatura em função do tempo e, consequentemente, o ajuste desses valores. Neste trabalho, o ajuste é realizado com o Método dos Mínimos Quadrados com o erro minimizado através da função "solver" do Excel.

Fazendo a derivação da Equação 4.19 e substituindo na Equação 4.18, encontra-se o valor do calor de hidratação, Equação 4.21:

$$
\dot{q}=\rho \cdot c \cdot T_{\max } \cdot a^{n} \cdot n \cdot \frac{t^{n-1}}{\left(a^{n}+t^{n}\right)^{2}}
$$

Integrando a Equação 4.21 em função do tempo, tem-se o calor total gerado, Equação 4.22: 


$$
q=\rho \cdot c \cdot T_{\max } \cdot \frac{t^{n}}{a^{n}+t^{n}}
$$

Analisando as equações mostradas, observa-se que os autores Mehta e Monteiro (2014), Silveira (1961) e Gomes (2011), chegam à mesma equação, ou seja, o calor de hidratação será dado em função da massa especifica, do calor específico e da derivada da temperatura adiabática em função do tempo, Equação 4.18.

\subsubsection{Método dos Mínimos Quadrados}

O método busca ajustar uma função proporcionando um melhor ajuste aos dados fornecidos minimizando a diferença entre os valores dados da variável dependente e aqueles obtidos a partir da curva de aproximação. Uma curva que representa adequadamente a tendência geral dos dados, sem necessariamente passar através de cada ponto, é útil para caracterizar os dados e derivar equações correlacionadas para descrever quantitativamente o processo físico ou químico sob consideração. Estas correlações são extremamente importantes em aplicações de engenharia e são muitas vezes o resultado desejado a partir de um estudo experimental (Jaluria, 2011).

No problema em estudo, a equação que descreve o processo químico da variação térmica com o tempo é a função de Hill, mostrada na Equação 4.19. Apresenta-se a seguir o processo de aplicação do método segundo Jaluria (2011)

Seja uma função de aproximação descrita por $f(x)$ e os pontos dados indicados por $\left(x_{i}, y_{i}\right)$, onde $y$ é a variável dependente, $x$ é a variável independente, e $i=1,2, \ldots ., n$, o erro $e_{i}$ em $x=x_{i}$ é dada pela Equação 4.23.

$$
e_{i}=y_{i}-f\left(x_{i}\right)
$$

A abordagem mais frequentemente utilizada para um melhor ajuste é o Método dos Mínimos Quadrados. Neste método, a soma, SMQ, dos quadrados dos erros é minimizada. A expressão para SMQ é dada pela Equação 4.24.

$$
S M Q=\sum_{i=1}^{n} e_{i}^{2}=\sum_{i=1}^{n}\left[y_{i}-f\left(x_{i}\right)\right]^{2}
$$


Esta abordagem geralmente origina uma curva única que fornece uma boa representação dos dados fornecidos, se a função de aproximação é adequadamente escolhida.

\subsection{CONDIÇÕES INICIAIS E DE CONTORNO}

A equação geral do calor exprime uma relação entre a função da temperatura $\mathrm{T}$ e as variáveis $\mathrm{x}, \mathrm{y}, \mathrm{z}, \mathrm{t}$. A solução matemática por equações diferenciais de segunda ordem exige uma condição inicial e condições de contorno em determinados pontos. As definições das condições iniciais e de contorno aqui determinadas foram adaptadas de Santos (2004), Mehta e Monteiro (2016) e Gery (1998).

\subsubsection{Condições Iniciais (CI):}

A princípio deve-se definir a condição inicial pela prescrição da distribuição de temperatura através de um corpo no tempo zero para todo o domínio, como uma função de x, y e z, como mostrado na Equação 4.25.

$$
T(x, y, z, t=0)=f(x, y, z)
$$

\subsubsection{Condições de Contorno (CC):}

As condições gerais de contorno às quais se encontram sujeitas a Equação de Fourier são as condições de Dirichlet e de Neumann.

\section{Temperatura prescrita no contorno:}

A condição de Dirichlet, também dita condição essencial de contorno, mostra que a temperatura existente em uma porção do contorno do corpo $\Gamma_{t}$, ou seja, é a temperatura imposta na superfície, dada pela Equação 4.26:

$$
T(x, y, z, t)=f(x, y, z, t) \quad x, y, z \text { em } \Gamma_{t}
$$

Indica que a temperatura na superfície do concreto é igual a temperatura do corpo/fluido em contato.

\section{Fluxo prescrito no contorno:}

O fluxo de calor prescrito no contorno é dado pela condição de Neumann. Esta supõe que o fluxo de calor através de uma parte do contorno exterior do domínio $\Gamma_{q}$ é conhecido para todo ponto de tal contorno e para qualquer instante de tempo t. Matematicamente tal condição se traduz em determinar a derivada do campo de temperaturas em relação à normal 
ao sólido na fronteira $\Gamma_{q}$, sendo tal derivada uma função conhecida, como mostra a Equação 4.27:

$$
k \frac{\partial T}{\partial n}(x, y, z, t)=q_{n}(x, y, z, t) \quad x, y, z \quad \text { em } \Gamma_{q}
$$

Sendo $q_{n}$ a quantidade de fluxo de calor dada no ponto $(\mathrm{x}, \mathrm{y}, \mathrm{z})$, e $n$ é a normal externa à superfície.

O fluxo de calor nas superfícies externas analisadas pode ser dado segundo o somatório dos fluxos de calor devido à radiação solar, convecção e radiação, segundo Equação 4.28.

$$
q_{n}(x, y, z, t)=q_{s}(x, y, z, t)+h_{c}\left[T(x, y, z, t)-T_{a}(t)\right]
$$

Sendo:

- $T(x, y, z, t)$ a temperatura existente em cada ponto do contorno;

- $T_{a}$ a temperatura ambiente existente no exterior do domínio;

- $h$ o coeficiente de transferência de calor global;

- $q_{s}(x, y, z, t)$ o calor ganho devido à radiação solar (radiação de onda curta) e é dado pela Equação 4.29:

$$
q_{s}(x, y, z, t)=a_{r} . I(x, y, z, t)
$$

Em que $a_{r}$ é o fator de absorção e $I(x, y, z, t)$ é a radiação total incidente sobre qualquer ponto da superfície no instante $t$.

\subsection{CÁLCULO DAS TENSÕES NO CONCRETO MASSA}

As tensões são calculadas segundo Gomes (2011), Gambale et al (2011a), Gambale et al (2011b), Gambale et al (2011c), Gambale et al (2011d), Gambale e Carmo (2002).

Temos que a matriz deformação, $[\Delta \varepsilon]$, é dada pela multiplicação da matriz de fluência, $[J]$, pela matriz de variação de tensões térmicas, $[\Delta \sigma]$, devido a cada variação térmica, $\Delta T(\Delta T=$ $T_{i}(t)-T_{0}=$ temperatura pontual no instante de tempo menos a temperatura inicial), Equação 4.30:

$$
[\Delta \varepsilon]=[J][\Delta \sigma]
$$

A matriz de deformação é dada pela multiplicação do coeficiente de restrição, $K_{r}$, pelo coeficiente de dilatação térmica, $\alpha$, pela variação térmica, como a Equação 4.31. 


$$
[\Delta \varepsilon]=\left[-K_{r} \alpha\left(T(t)-T_{0}\right)\right]
$$

Conhecendo $\Delta T, \alpha$, e $K_{r}$, encontra-se $[\Delta \varepsilon]$. Com a função de fluência escolhida e aplicada encontra-se a matriz de fluência, $[J]$. Com esses dados encontra-se a matriz $[\Delta \sigma]$ e a partir dela é possível encontrar a matriz de tensão $[\sigma]$, sabendo-se que:

$$
\sigma_{i}=\sigma_{i-1}+\Delta \sigma_{i}
$$

Assim uma tensão em um determinado tempo $t_{n}$ é dado pelo somatório de todos os incrementos de tensão como a Equação 4.33:

$$
\sigma\left(t_{n}\right)=\sum \Delta \sigma_{i}
$$

Bofang (2014) chama o método de soma das tensões individuais, Equação 4.33, de método explicito, o qual pode ser representado graficamente como a Figura 4.4, em que com o passar do tempo há incrementos de tensões, os quais são somados e, desse modo, encontra-se a curva da tensão em função do tempo.

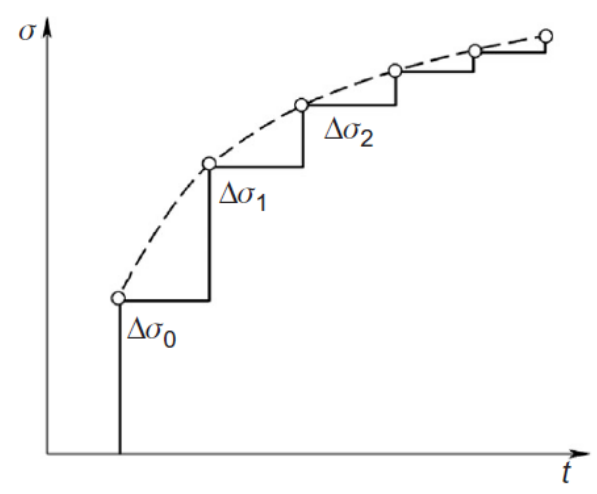

Figura 4.4 - Representação da curva de tensão pela soma das tensões individuais (Bofang, 2014).

Ressalta-se que com esses cálculos obtêm-se as tensões longitudinais, direção z, no sentido do comprimento do corpo, como mostrado na Figura 4.5, representados por $\sigma_{z}$, para um elemento no interior do volume mostrado. Dessa forma, os efeitos da gravidade, peso próprio, estariam na direção $\mathrm{y}$, representadas por $\sigma_{\mathrm{y}}$, e apenas uma pequena parcela desse valor seria absorvido pela direção z, através do coeficiente de Poisson, portanto, as tensões 
relativas ao peso próprio são desconsideradas nesta tese. No apêndice E, é possível visualizar a influência do peso próprio para uma das estruturas apresentadas neste trabalho.

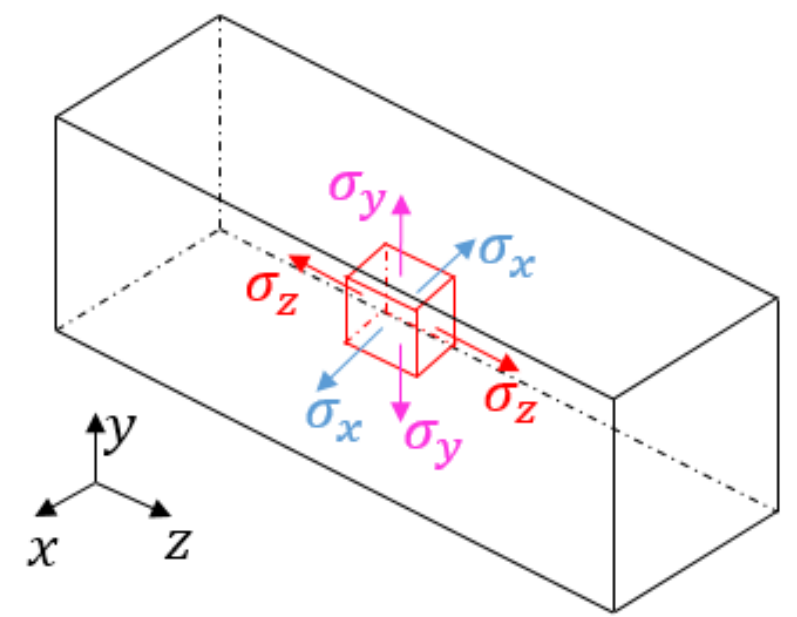

Figura 4.5 - Representação das tensões em um corpo.

A matriz fluência é dada de acordo com o modelo de fluência escolhido, alguns deles são mostrados no item que segue.

\subsection{MODELOS DE PREDIÇÃO DE FLUÊNCIA}

Os modelos para a previsão de fluência em função do tempo têm o mesmo princípio: uma curva hiperbólica que tende para um valor assintótico. A forma da curva e valor final dependerá de vários fatores, tais como condições de cura, idade em aplicação da carga, proporção da mistura, temperatura ambiente e umidade (ACI 209-2R, 2008).

São vários os modelos para predição da fluência, aqui serão apresentados quatro deles: USBR, Dupla Potência - DP ou Bazant-Panula - DP, ACI e CEB MC90. Para todos os casos a simbologia utilizada corresponde a:

- $\quad \mathrm{J}$ = função de fluência, dada em função do módulo de elasticidade $\mathrm{E}$ (Mpa), e do coeficiente de fluência $\phi\left(1 / 10^{-6} \mathrm{Mpa}\right)$, em $1 / 10^{-6} \mathrm{Mpa}$.

- $\mathrm{t}=$ tempo, dias.

- $\tau=$ idade, dias. 


\subsubsection{Bureau Reclamation - USBR (1992):}

É utilizada uma expressão logarítmica que aproxima o comportamento normal de fluência com precisão para o período de um ano. A função $J$ é dada pela Equação 4.34:

$$
J(t, \tau)=\frac{1}{E(\tau)}+\emptyset(z) \log (t-\tau+1)
$$

Sendo:

$$
\emptyset(z)=a+\frac{b}{\tau}
$$

Sendo a e b coeficientes de ajuste.

Este modelo é utilizado pelos pesquisadores de Furnas (1997).

\subsubsection{Dupla Potência - DP (Azenha, 2004):}

É aplicável a concretos com idades de carregamento entre um dia e vários anos, e para durações de carga compreendidas entre um segundo e vários anos, talvez por isso, tem ampla implementação (Azenha, 2004). É dada como a expressão 4.36:

$$
J(t, \tau)=\frac{1}{E(\tau)}+\frac{\emptyset_{1}}{E(\tau)}\left(\tau^{-m}+\gamma\right)(t-\tau)^{n}
$$

Em que $\mathrm{m}=1 / 3, \mathrm{n}=1 / 8$ e $\gamma=0,05$ (Azenha, 2004).

\subsubsection{ACI 209-2R (2008):}

O modelo do ACI é de simples aplicação, com dependência de apenas três parâmetros que já são fornecidos.

$$
\begin{aligned}
& J(t, \tau)=\frac{1+\emptyset(t, \tau)}{E(\tau)} \\
& \varnothing(t, \tau)=\frac{(t-\tau)^{\psi}}{d+(t-\tau)^{\psi}} \emptyset_{u}
\end{aligned}
$$

Sendo recomendado $\mathrm{d}=10$ dias, $\psi=0,6$ e $\emptyset_{u}=2,35$. 


\subsubsection{CEB MC90-99 (ACI 209-2R, 2008):}

O modelo do CEB é similar ao do ACI, e pode ser utilizado para concretos com resistências entre 12 e 80 Mpa (ACI 209-2R, 2008). No entanto, são necessários mais parâmetros e cálculos para obtenção da curva, Equações de 4.39 a 4.54 .

$$
\begin{aligned}
& J(t, \tau)=\frac{1+\emptyset(t, \tau)}{E(\tau)} \\
& \emptyset(t, \tau)=\emptyset_{0} \beta_{c}(t-\tau) \\
& \emptyset_{0}=\emptyset_{R H}(h) \beta\left(f_{c m 28}\right) \beta(\tau) \\
& \emptyset_{R H}(h)=\left(1+\frac{1-h / h_{0}}{\sqrt[3]{0,1\left[(V / S) /(V / S)_{0}\right]}} \gamma_{1}\right) \gamma_{2} \\
& \beta\left(f_{c m 28}\right)=\frac{5,3}{\sqrt{f_{c m 28} / f_{c m 0}}} \\
& \beta(z)=\frac{1}{0,1+\left(\tau / t_{1}\right)^{0,2}} \\
& \gamma_{1}=\left(\frac{3,5 f_{c m 0}}{f_{c m 28}}\right)^{0,7} \\
& \gamma_{2}=\left(\frac{3,5 f_{c m 0}}{f_{c m 28}}\right)^{0,2} \\
& f_{c m 28}=f_{c}+8,0 \\
& f_{c m 0}=10 M P a \\
& h_{0}=1 \\
& \left(\frac{V}{s}\right)_{0}=50 \mathrm{~mm} \\
& t_{1}=1 \mathrm{dia}
\end{aligned}
$$




$$
\begin{gathered}
\beta_{c}(t-\tau)=\left(\frac{(t-\tau) / t_{1}}{\beta_{H}+(t-\tau) / t_{1}}\right)^{0,3} \\
\beta_{H}=\frac{150\left[1+\left(1,2 \cdot \frac{h}{h_{0}}\right)^{18}\right]\left(\frac{V}{s}\right)}{\left(\frac{V}{S}\right)_{0}}+250 \gamma_{3} \leq 1500 \gamma_{3} \\
\gamma_{3}=\left(\frac{3,5 f_{c m 0}}{f_{c m 28}}\right)^{0,5}
\end{gathered}
$$

\subsubsection{Comparação entre os métodos}

Normalmente, as curvas de fluência, independente do modelo aplicado, devem ser ajustadas a valores de ensaios experimentais, a partir dos quais se obtêm os parâmetros das equações. A partir dessas informações, com os resultados de ensaios publicados por Gomes (2011), foi feito um ajuste com os diferentes modelos citados, para verificar a possibilidade de se ter uma curva para qualquer um destes modelos.

A Figura 4.6, expõe as curvas elaboradas neste trabalho para o concreto nas idades de 4, 7, 28 e 96 dias em comparação com os dados experimentais de Gomes (2011), exibidos pelos pontos pretos, que serviram como base para os ajustes. Após o ajuste feito com o Método dos Mínimos Quadrados e minimizados os erros com o EXCEL, observa-se que todas as curvas para os diferentes modelos nas suas respectivas idades, se aproximam. Assim, afirmase que qualquer uma delas pode ser utilizada para o cálculo de tensões no concreto.

Observe que o eixo das abscissas representa a diferença entre o tempo e a idade do concreto, por isso todas as curvas se iniciam no ponto zero. Caso representasse a idade, as curvas de fluência estariam deslocadas para cada idade. 


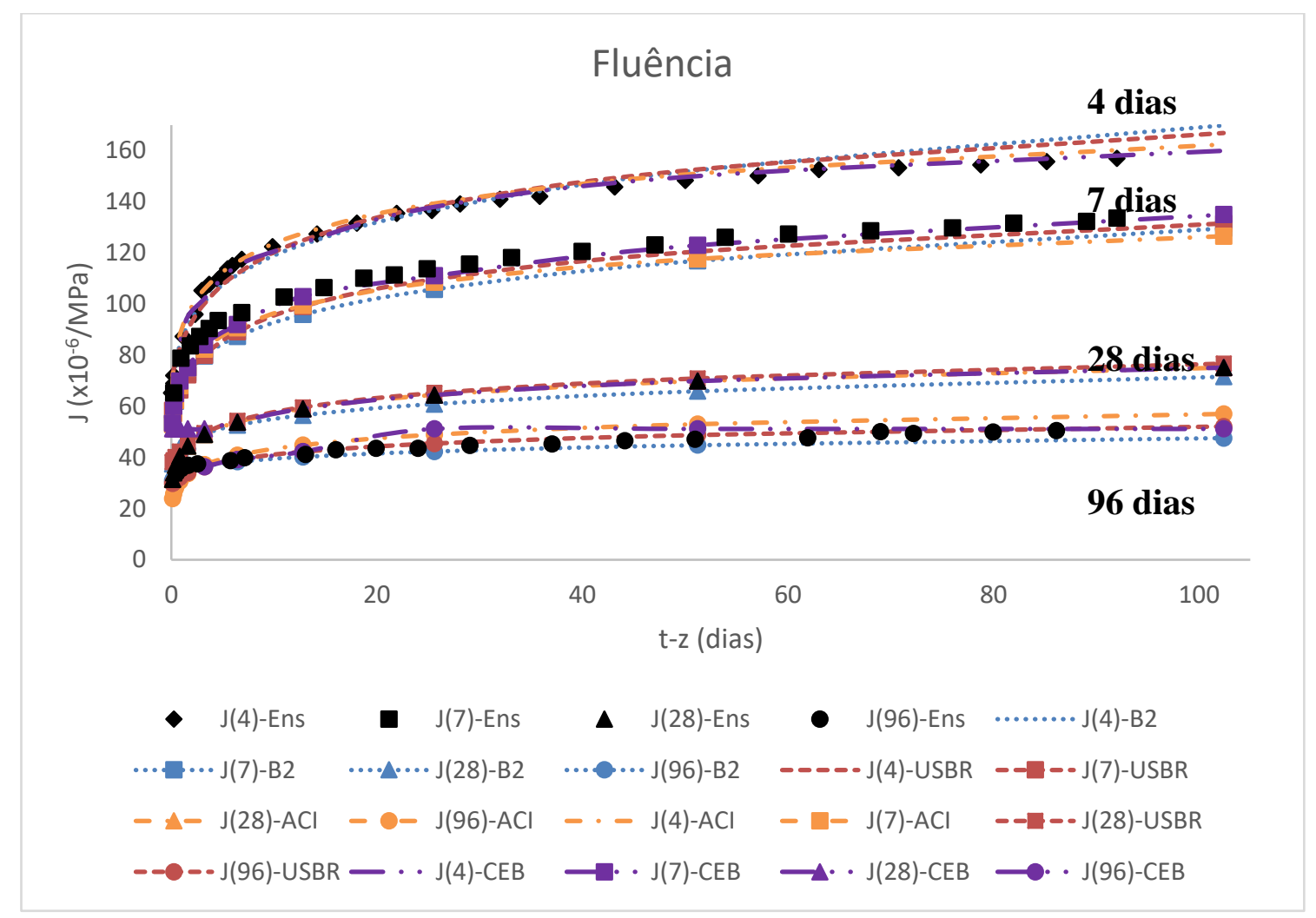

Figura 4.6 - Comparação dos modelos de fluência.

\subsubsection{Comparação entre temperatura, geração de calor e tensão}

A Figura 4.7 mostra os gráficos da temperatura, da taxa de geração de calor e da tensão em função do tempo, em dias. Primeiramente, observa-se o gráfico da temperatura, tracejado em preto, com uma máxima de aproximadamente $78^{\circ} \mathrm{C}$ em torno de 2,4 dias e resfriando lentamente no decorrer do tempo. A curva de geração de calor, linha preta contínua superior, tem uma taxa máxima de $2100 \mathrm{~W} / \mathrm{m}^{3}$ ocorrendo antes de 1 dia de concretagem. Neste período, nota-se um aquecimento acelerado do concreto, embora essa taxa seja reduzida rapidamente, o resfriamento não acompanha o ritmo, pois internamente tem-se condições adiabáticas, e a dificuldade de dissipação do calor devido as propriedades do material. Abaixo, também com uma linha contínua preta, há a curva de tensão térmica, em que há uma compressão, parte negativa do gráfico, seguida de uma tração. Essas curvas são obtidas para um ponto central de um bloco de concreto massa, obtidas nas análises mostradas nos resultados deste trabalho.

Fazendo uma correlação entre as curvas, nota-se que com a taxa de geração de calor alta, há um aumento acelerado da temperatura no ponto analisado. Para a idade em que há o pico de geração de calor, linha laranja, as tensões de compressão estão crescendo, sendo a máxima 
tensão de compressão é atingida a um valor um pouco abaixo da temperatura máxima do concreto, linha rosa. A partir desse ponto, começa a haver um alívio das tensões de compressão, até atingir o valor zero, linha vermelha, quando a temperatura do concreto já está resfriando, confirmando as informações da literatura, que enfatizam que a tensão máxima de compressão é dada num intervalo de tempo superior ao da máxima temperatura encontrada. No valor da temperatura máxima, linha azul, já está ocorrendo alivio de tensões. Após o valor zero, as tensões passam para valores positivos de tração, que vão aumentando à medida que o concreto é resfriado, devido às restrições impostas, até atingir uma temperatura de equilíbrio, e parar de elevar as tensões de tração do concreto, o que ainda não ocorreu para o caso em estudo no intervalo de 20 dias.

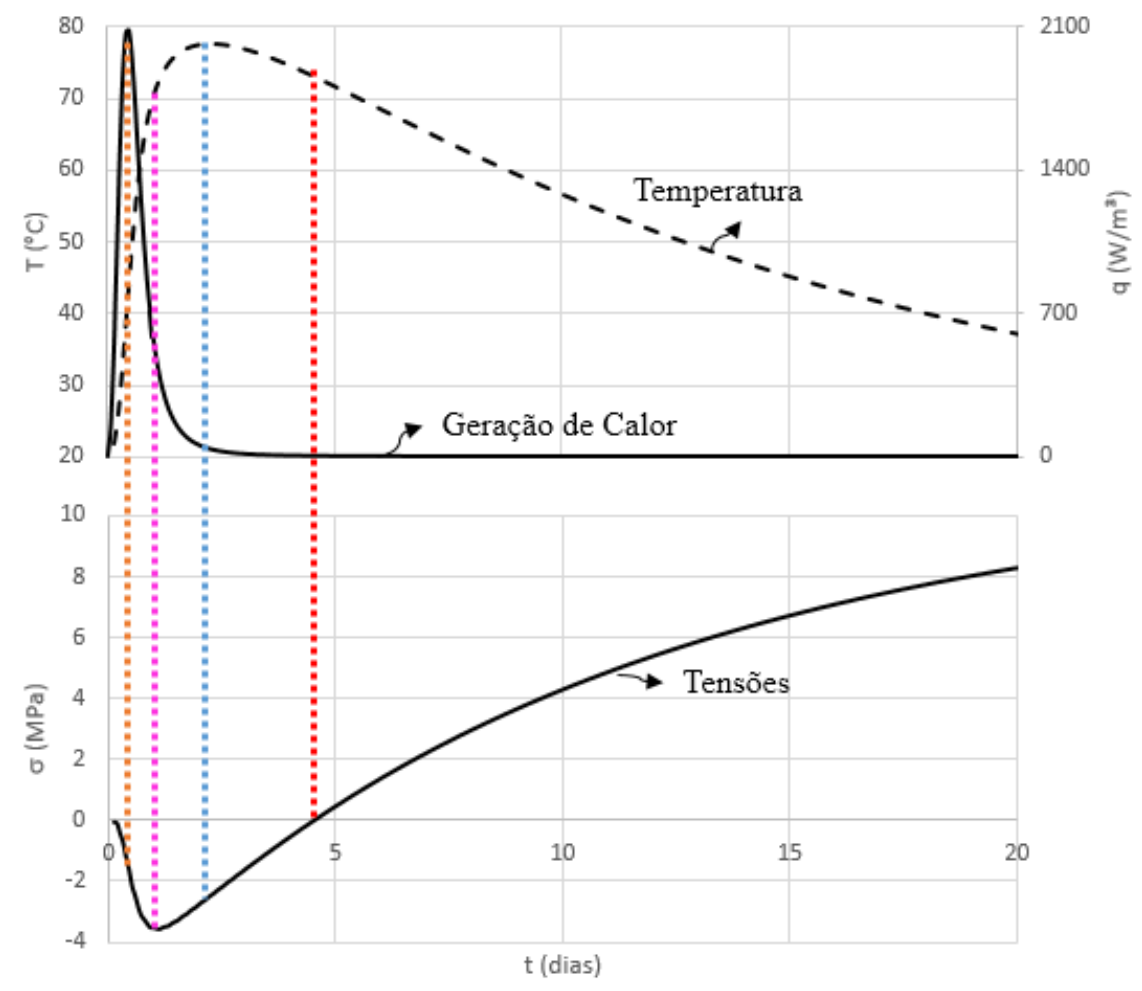

Figura 4.7 - Relação entre temperatura, calor gerado e tensões. 


\section{MÉTODOS DE SOLUÇÃO, ASPECTOS COMPUTACIONAIS E VALIDAÇÕES}

Os problemas de concreto massa são comuns e de difícil solução. Para situações mais simples é possível resolvê-los analiticamente, mas à medida que as estruturas vão aderindo a formas e dimensões maiores e diferenciadas as soluções tornam-se mais complexas. Por isso, é usual fazer uso de ferramentas numéricas para conseguir representar os problemas de forma relativamente simples e rápida. Este trabalho consistiu na mesclagem dos modelos analíticos e numéricos para a solução dos problemas termomecânicos em concreto massa.

Considerando a equação geral do calor para condutividade térmica constante, foram estudados cada termo desta isoladamente e comparados os resultados obtidos pelos três métodos. Primeiro estudou-se a Equação de Laplace, representando a distribuição de calor por diferenças de temperaturas sem variação no tempo. Em seguida, a Equação de Poisson, que é a Equação de Laplace acrescida de uma fonte de calor permanente e constante. Posteriormente, a Equação de Fourier, onde há um fluxo de calor que influi diretamente na distribuição de temperatura. Por fim, a Equação completa do calor, com fluxo e geração de calor, o qual pode ser constante ou transiente. A Figura 5.1, mostra o fluxograma da sequência das equações estudadas.

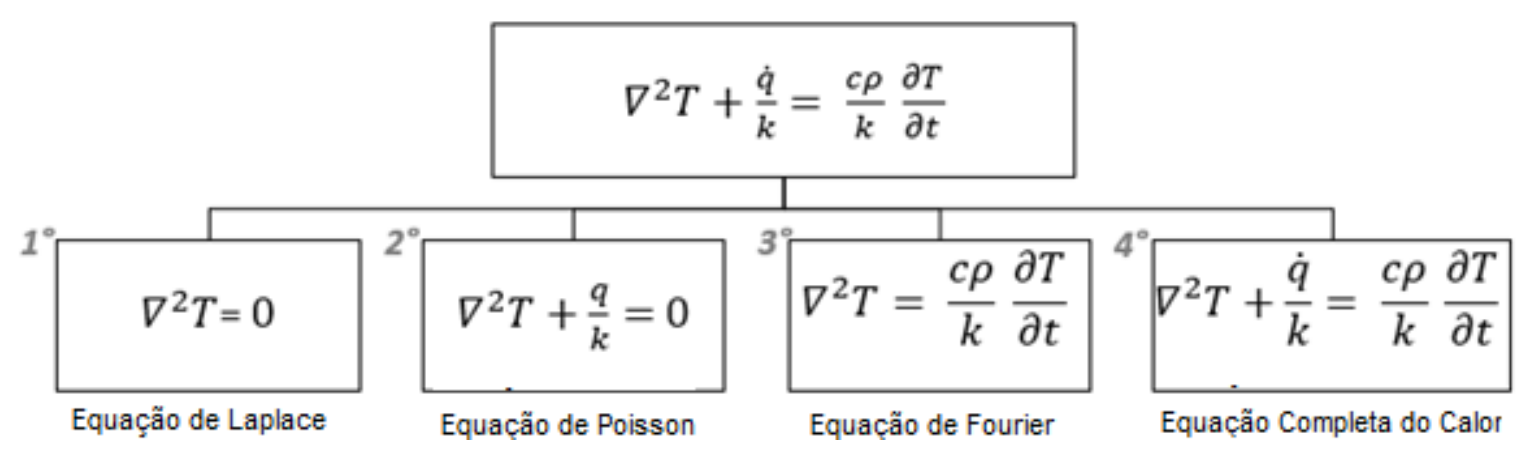

Figura 5.1 - Metodologia de resolução da equação do calor.

\subsection{SOLUÇÕES ANALÍTICAS}

Métodos analíticos são limitados a problemas altamente simplificados em geometrias simples. Mesmo em geometrias simples, os problemas de transferência de calor não poderão ser resolvidos analiticamente se as condições de contorno não forem suficientemente simples. A consideração da variação da condutividade térmica com temperatura, a variação 
do coeficiente de transferência do calor sobre a superfície ou a transferência de calor por radiação nas superfícies pode tornar impossível a obtenção de uma solução analítica (Çengel e Ghajar, 2012).

O primeiro passo para o desenvolvimento da pesquisa foi a verificação das soluções térmicas dadas pelos métodos analíticos, MDF e MEF.

Para as soluções analíticas da equação do calor utilizou-se o Método de Separação de Variáveis (MSV), também chamado de Método do Produto. Kreyszig (2006) descreve o método em três passos:

1. Dada uma equação qualquer, ela pode ser admitida como o produto de duas variáveis independentes, por exemplo, $u(x, t)=F(x) G(t)$, dessa forma, obtem-se duas Equações Diferenciais Ordinárias (EDO), $F(x)$ e $G(t)$, mais fáceis de serem resolvidas.

2. Determinam-se as soluções das EDO's que satisfaçam as CC dadas no problema.

3. Usando a Séries de Fourier é composta a solução geral com auxílio das CI e atendendo as soluções individuais de cada EDO.

Observação: Embora a equação esteja mostrando x e t, o MSV também é aplicável para dimensões apenas espaciais e para mais dimensões.

As soluções matemáticas encontradas para algumas geometrias, CI e CC foram elaboradas baseadas em estudos de Haberman (1987), Hildebrand (1965), Incropera et al (2008), Kreyszig (2006) e Hetnarski e Eslami (2009) e uma Tabela resumo pode ser vista no apêndice A. As deduções completas poderão ser encontradas nos relatórios internos de pesquisa de Coelho e Pedroso: RTP-NAC-01/2013, RTP-NAC-02/2013, RTP-NAC07/2013, RTP-NAC-10/2014, RTP-NAC-11/2014. RTP-NAC-16/2015. Para expansão das séries analíticas foi utilizada o programa MAPLE 17.0.

\subsection{MÉTODO DAS DIFERENÇAS FINITAS}

As respostas via MDF foram obtidas com ajuda do MATLAB 12.0. Foram elaborados os códigos computacionais para resolução dos sistemas criados com o método. Seja o domínio mostrado na Figura 5.2, a malha de diferenças finitas, é possível identificar a temperatura de cada ponto $\mathrm{T}_{\mathrm{i}, \mathrm{j}, \mathrm{k}}$ a partir das temperaturas do seu contorno. 


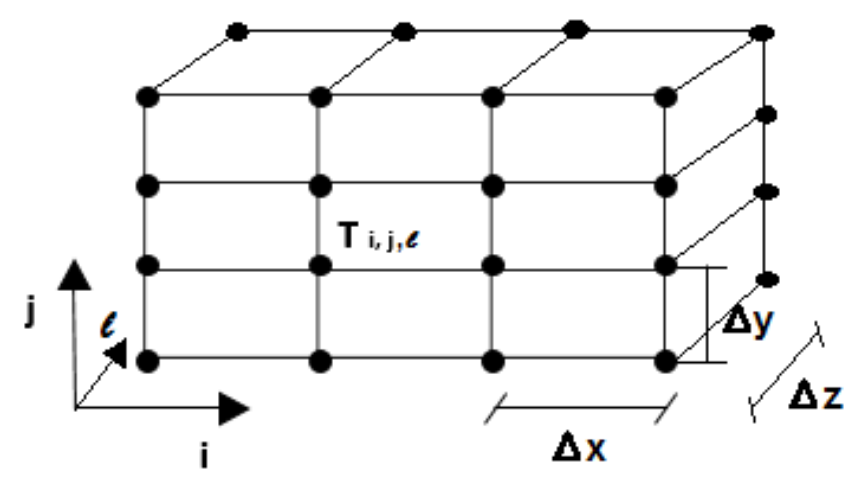

Figura 5.2 - Malha das diferenças finitas.

No caso unidimensional, seja i a posição de um ponto na direção x, j sua representação no eixo y e 1 sua direção em z, as expressões para a temperatura em cada direção levam em consideração o ponto e seus vizinhos, ou seja, a temperatura do ponto i é dada pela diferença entre as temperaturas dos pontos i-1 e i+1 divido pela distância desses. Assim, para a Equação Diferencial de Primeira Ordem (ODE) as equações são dadas pelas expressões mostradas em 5.1, 5.2, 5.3:

$$
\begin{aligned}
& \frac{\partial T}{\partial x}=\frac{T_{i+1}-T_{i-1}}{x_{i+1}-x_{i-1}}=\frac{T_{i+1}-T_{i-1}}{2 \Delta x} \\
& \frac{\partial T}{\partial y}=\frac{T_{j+1}-T_{j-1}}{y_{j+1}-y_{j-1}}=\frac{T_{j+1}-T_{j-1}}{2 \Delta y} \\
& \frac{\partial T}{\partial z}=\frac{T_{l+1}-T_{l-1}}{z_{l+1}-z_{l-1}}=\frac{T_{l+1}-T_{l-1}}{2 \Delta z}
\end{aligned}
$$

Para a análise bidimensional são levadas em consideração os quatro pontos vizinhos, como mostra a Figura 5.3, em que são feitas as diferenças entre os pontos vizinhos em razão da distância entre eles ao quadrado, da mesma forma que para o caso unidimensional. Se fosse um estudo tridimensional, a temperatura do ponto seria baseada nas temperaturas dos seis pontos vizinhos. Assim, fazendo o tratamento matemático, as Equações Diferenciais de Segunda Ordem (ODE) são dadas pelas expressões 5.4, 5.5 e 5.6. 


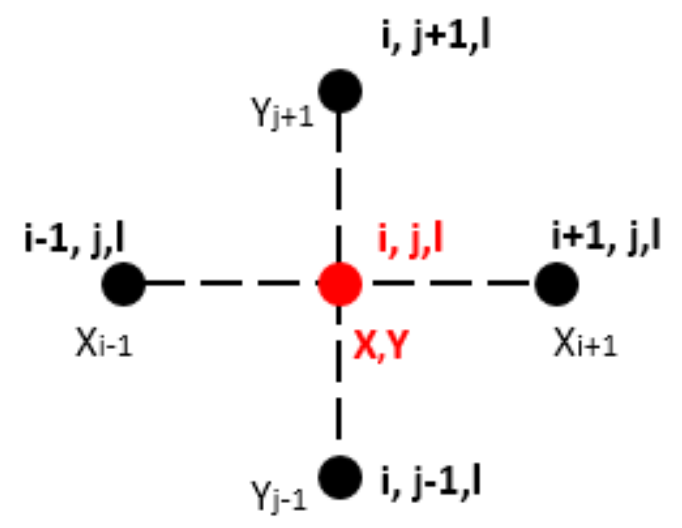

Figura 5.3 - Coordenadas para análise bidimensional de um ponto em MDF.

$$
\begin{aligned}
& \frac{\partial^{2} T}{\partial x^{2}}=\frac{T_{i+1, \mathrm{j}, \mathrm{l}}-2 T_{i, j, \mathrm{l}}+T_{i-1, \mathrm{j}, \mathrm{l}}}{\left(x_{i+1}-x_{i-1}\right)^{2}}=\frac{T_{i+1, \mathrm{j}, 1}-2 T_{i, j, \mathrm{l}}+T_{i-1, \mathrm{j}, \mathrm{l}}}{\Delta x^{2}} \\
& \frac{\partial^{2} T}{\partial y^{2}}=\frac{T_{i, j+1,1}-2 T_{i, j, 1}+T_{i, j-1,1}}{\left(y_{j+1}-y_{j-1}\right)^{2}}=\frac{T_{i, j+1,1}-2 T_{i, j, 1}+T_{i, j-1,1}}{\Delta y^{2}} \\
& \frac{\partial^{2} T}{\partial z^{2}}=\frac{T_{i, j, 1+1}-2 T_{i, j, 1}+T_{i, j, \mathrm{l}-1}}{\left(z_{l+1}-z_{l-1}\right)^{2}}=\frac{T_{i, j, 1+1}-2 T_{i, j, 1}+T_{i, j, \mathrm{l}-1}}{\Delta z^{2}}
\end{aligned}
$$

No caso dos problemas transientes, ou seja, variáveis com tempo, existe ao menos uma derivada no tempo, como por exemplo, o termo $\frac{\partial T}{\partial t}$ implementado com incrementos de tempo, denominados aqui por $\kappa$, como está mostrado na Equação 5.7.

$$
\frac{\partial T}{\partial t}=\frac{T_{i}^{\kappa+1}-T_{i}^{K}}{\Delta t}
$$

A Tabela B.1 do apêndice B mostra algumas soluções em MDF para a equação do calor desenvolvidas pela autora. O desenvolvimento completo pode ser visualizado no relatório interno de pesquisa RTP-NAC-17/2015, e outros resultados encontrados em Vasconcelos et al (2015) e Almeida et al (2016).

\subsection{MÉTODO DOS ELEMENTOS FINITOS}

A equação do calor já comentada anteriormente é apresentada abaixo. Observa-se que para cada direção, há um correspondente valor de k, Equação 5.8. No entanto, neste trabalho considera-se $k_{x}=k_{y}=k_{z}=k$, por saber entender que no caso do concreto íntegro a condutividade térmica não muda com a direção.

$$
k_{x} \frac{\partial^{2} T}{\partial x^{2}}+k_{y} \frac{\partial^{2} T}{\partial y^{2}}+k_{z} \frac{\partial^{2} T}{\partial z^{2}}+\dot{q}=\rho c \frac{\partial T}{\partial t}
$$


Para fins de representação das figuras, para cada $\mathrm{CC}$ foi adotada uma convenção em forma de desenho a fim de entender visualmente quais as condições impostas, Figura 5.4.
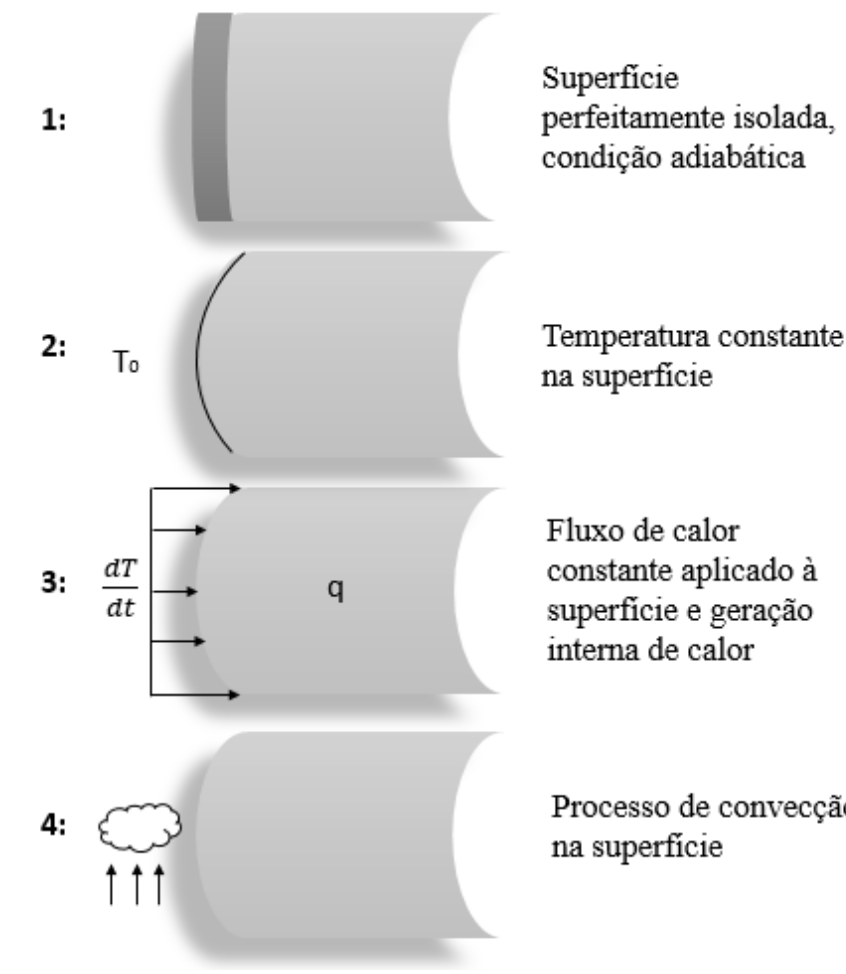

\section{CONVENÇÃO ADOTADA}
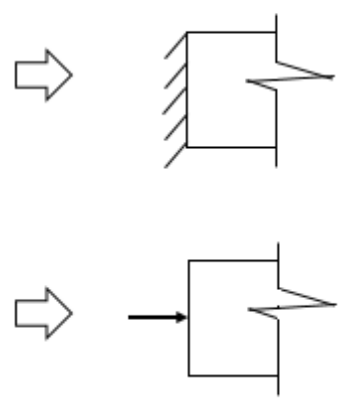

Fluxo de calor constante aplicado à superficie e geração interna de calor

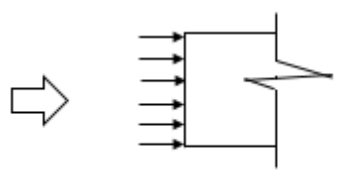

Processo de convecção na superficie

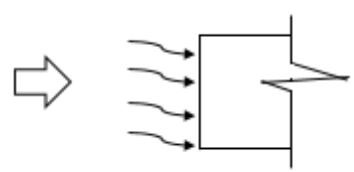

Figura 5.4 - Representação das Condições de Contorno.

As condições de contorno mostradas na Figura 5.4 são:

1. Perfeito isolamento - sem qualquer troca ou perca de calor, caso adiabático;

2. Temperatura imposta na superfície;

3. Fluxo de calor na superfície e geração interna de calor - a geração de calor pode representar o caso estático ou transiente;

4. Convecção - processo de troca de calor entre o meio externo e interno, ou seja, entre o ar e o corpo.

Neste desenvolvimento, serão aplicadas as CC 2 em S1, 3 em S2 e 4 em S3. Dessa forma, pode-se escrever:

$$
\begin{gathered}
T(x, y, z, t)=T_{0} \quad \text { para } t>0 \text { em } S_{1} \\
k_{x} \frac{\partial T}{\partial x} l_{x}+k_{y} \frac{\partial T}{\partial y} l_{y}+k_{z} \frac{\partial T}{\partial z} l_{z}+q=0 \quad \text { para } t>0 \text { em } S_{2} \\
k_{x} \frac{\partial T}{\partial x} l_{x}+k_{y} \frac{\partial T}{\partial y} l_{y}+k_{z} \frac{\partial T}{\partial z} l_{z}+h\left(T-T_{\infty}\right)=0 \quad \text { para } t>0 \text { em } S_{3}
\end{gathered}
$$

Lembrando que aqui será considerado sempre $k_{x}=k_{y}=k_{z}=k$. 
Pelo MEF o problema tridimensional da condução, dada a distribuição de temperatura $T(x, y, z, t)$ no interior de um corpo sólido, pode ser representado pela integral da Equação 5.12:

$$
I=\frac{1}{2} \iiint_{V}\left[k\left(\left(\frac{\partial T}{\partial x}\right)^{2}+\left(\frac{\partial T}{\partial y}\right)^{2}+\left(\frac{\partial T}{\partial z}\right)^{2}\right)-2\left(\dot{q}-\rho c \frac{\partial T}{\partial t}\right) T\right] d V
$$

Utilizando o método de Galerkin, a solução pode ser descrita nos seguintes passos (Rao, 2004):

1. Divide-se o domínio V em E elementos finitos com p nós.

2. Assume-se a forma variacional adequada de $\mathrm{T}$ em elementos finitos com $e$ elementos expressos por

$$
T^{(e)}(x, y, z, t)=[N(x, y, z)] \vec{T}^{(e)}
$$

onde:

$$
\begin{gathered}
{[N(x, y, z)]=\left[\begin{array}{llll}
N_{1}(x, y, z) & N_{2}(x, y, z) & \cdots & N_{p}(x, y, z)
\end{array}\right]} \\
\vec{T}^{(e)}=\left\{\begin{array}{c}
T_{1}(t) \\
T_{2}(t) \\
\vdots \\
T_{p}(t)
\end{array}\right\}
\end{gathered}
$$

onde $\mathrm{p}=1$...número de elementos.

3. No método de Galerkin, a integral do resíduo ponderado sobre o domínio do elemento é definida igual a zero, tendo os mesmos pesos que as funções de interpolação Ni. Desde que a solução da equação anterior não seja exata, faz-se a substituição dela pela equação diferencial, que terá um valor diferente de zero em vez de zero. Este valor diferente de zero será o resíduo. Assim, o critério a ser satisfeito em cada instante de tempo é

$$
\iiint_{V^{e}} N_{i}\left[k\left(\frac{\partial}{\partial x}\left(\frac{\partial T^{(e)}}{\partial x}\right)+\frac{\partial}{\partial y}\left(\frac{\partial T^{(e)}}{\partial y}\right)+\frac{\partial}{\partial z}\left(\frac{\partial T^{(e)}}{\partial z}\right)\right)+\dot{q}-\rho c \frac{\partial T^{(e)}}{\partial t}\right] d V
$$

O primeiro termo integral pode ser escrito como:

$$
\iiint_{V^{e}} N_{i} k \frac{\partial}{\partial x}\left(\frac{\partial T^{(e)}}{\partial x}\right) d V=-\iiint_{V^{e}} k \frac{\partial N_{i}}{\partial x} \frac{\partial T^{(e)}}{\partial x} d V+\iiint_{V^{e}} N_{i} k \frac{\partial T^{(e)}}{\partial x} l_{x} d S
$$

Sendo $l_{x}$ o cosseno da direção x. Para a equação completa, tem-se:

$$
\begin{gathered}
-\iiint_{V^{e}} k\left[\frac{\partial N_{i}}{\partial x} \frac{\partial T^{(e)}}{\partial x}+\frac{\partial N_{i}}{\partial y} \frac{\partial T^{(e)}}{\partial y}+\frac{\partial N_{i}}{\partial z} \frac{\partial T^{(e)}}{\partial z}\right] d V+\iiint_{V^{e}} N_{i} k\left[\frac{\partial T^{(e)}}{\partial x} l_{x}+\right. \\
\left.\frac{\partial T^{(e)}}{\partial y} l_{y}+\frac{\partial T^{(e)}}{\partial z} l_{z}\right] d S+\iiint_{V^{e}} N_{i} k\left[\dot{q}-\rho c \frac{\partial T^{(e)}}{\partial t}\right] d V
\end{gathered}
$$


Sendo o contorno do elemento $S^{(e)}$ composto de $S_{1}^{(e)}, S_{2}^{(e)}$ e $S_{3}^{(e)}$, a integral de superfície seria zero (desde que $T^{(e)}$ fosse prescrito como uma constante $T_{0}$ em $S_{1}^{(e)}$, as derivadas de $T^{(e)}$ com relação a x, y e z também seriam zero). Nas superfícies $S_{2}^{(e)}$ e $S_{3}^{(e)}$, as condições de contorno devem satisfizer os dados do problema. Para isso, a integral de superfície em $S_{2}^{(e)}$ e $S_{3}^{(e)}$ tornam-se:

$$
\begin{aligned}
& \iint_{S_{2}^{(e)}+S_{3}^{(e)}} N_{i} k\left[\frac{\partial T^{(e)}}{\partial x} l_{x}+\frac{\partial T^{(e)}}{\partial y} l_{y}+\frac{\partial T^{(e)}}{\partial z} l_{z}\right] d S=\iint_{S_{2}^{(e)}} N_{i} q d S_{2}- \\
& \iint_{S_{2}^{(e)}} h\left(T^{(e)}-T_{\infty}\right) d S_{3}
\end{aligned}
$$

Pode-se ainda escrever as equações em forma matricial:

$$
\left[K_{1}^{(e)}\right] \vec{T}^{(e)}+\left[K_{2}^{(e)}\right] \vec{T}^{(e)}+\left[K_{3}^{(e)}\right] \vec{T}^{(e)}-\vec{P}^{(e)}=\overrightarrow{0}
$$

Sendo:

$$
\begin{gathered}
K_{1 i j}^{(e)}=\iiint_{V^{e}} k\left[\frac{\partial N_{i}}{\partial x} \frac{\partial T N_{j}}{\partial x}+\frac{\partial N_{i}}{\partial y} \frac{\partial N_{j}}{\partial y}+\frac{\partial N_{i}}{\partial z} \frac{\partial N_{j}}{\partial z}\right] d V \\
K_{2 i j}^{(e)}=\iint_{S_{3}^{(e)}} h N_{i} N_{j} d S_{3} \\
K_{3 i j}^{(e)}=\iint_{V^{(e)}} \rho c N_{i} N_{j} d V \\
P_{i}^{(e)}=\iint_{V^{(e)}} \dot{q} N_{i} d V-\iint_{S_{2}^{(e)}} q N_{i} d S_{2}-\iint_{S_{2}^{(e)}} h T_{\infty} d S_{3}
\end{gathered}
$$

4. Os elementos da matriz podem ser escritos de forma usual:

$$
\left[\underline{K}_{3}\right] \underline{\vec{T}}^{(e)}+[\underline{K}] \underline{T}^{(e)}=\underline{\vec{P}}
$$

Sendo:

$$
\begin{aligned}
& {\left[\underline{K}_{3}\right]=\sum_{e=1}^{E}\left[K_{3}^{(e)}\right]} \\
& {[\underline{K}]=\sum_{e=1}^{E}\left[\left[K_{1}^{(e)}\right]+\left[K_{2}^{(e)}\right]\right]} \\
& \underline{\vec{P}}=\sum_{e=1}^{E}\left[\vec{P}^{(e)}\right]
\end{aligned}
$$

5. As equações devem ser resolvidas incorporando-se as condições de contorno e as condições iniciais.

As expressões $\left[K_{1}^{(e)}\right],\left[K_{2}^{(e)}\right],\left[K_{3}^{(e)}\right]$ e $\vec{P}^{(e)}$ podem ser escritas como matriz de notação:

$$
\begin{aligned}
& {\left[K_{1}^{(e)}\right]=\iiint_{V^{e}}[\mathrm{~B}]^{T}[D][\mathrm{B}] d V} \\
& {\left[K_{2}^{(e)}\right]=\iint_{S_{3}^{(e)}} h[N]^{T}[N] d S_{3}}
\end{aligned}
$$




$$
\begin{aligned}
& {\left[K_{3}^{(e)}\right]=\iiint_{V^{e}} \rho c[\mathrm{~N}]^{T}[N] d V} \\
& \vec{P}^{(e)}=\vec{P}_{1}^{(e)}-\vec{P}_{2}^{(e)}+\vec{P}_{3}^{(e)}
\end{aligned}
$$

Onde:

$$
\begin{gathered}
\vec{P}_{1}^{(e)}=\iiint_{V^{e}} \dot{q}[\mathrm{~N}]^{T} d V \\
\vec{P}_{2}^{(e)}=\iint_{S_{3}(e)} q[\mathrm{~N}]^{T} d S_{2} \\
\vec{P}_{3}^{(e)}=\iint_{S_{3}(e)} h T_{\infty}[\mathrm{N}]^{T} d S_{3} \\
{[D]=\left[\begin{array}{ccc}
k_{x} & 0 & 0 \\
0 & k_{y} & 0 \\
0 & 0 & k_{z}
\end{array}\right]} \\
{[\mathrm{B}]=\left[\begin{array}{cccc}
\frac{\partial N_{1}}{\partial x} & \frac{\partial N_{2}}{\partial x} & \ldots & \frac{\partial N_{p}}{\partial x} \\
\frac{\partial N_{1}}{\partial y} & \frac{\partial N_{2}}{\partial y} & \ldots & \frac{\partial N_{p}}{\partial y} \\
\frac{\partial N_{1}}{\partial z} & \frac{\partial N_{2}}{\partial z} & \ldots & \frac{\partial N_{p}}{\partial z}
\end{array}\right]}
\end{gathered}
$$

A formulação apresentada serve de base para mostrar como funciona o MEF para problemas térmicos, não tendo o compromisso de reproduzir a formulação presente no ANSYS, que foi o software adotado no presente trabalho.

\subsection{ASPECTOS COMPUTACIONAIS}

Na solução dos problemas abordados ao longo do trabalho, foram utilizados três programas prioritariamente: o MAPLE como método de expansão das series de Fourier, encontradas nas soluções analíticas pelo MSV, e plotagem das curvas geradas por essas soluções; O MATLAB, como base para solução das soluções via MDF e também para encontrar as tensões analiticamente; e o ANSYS como ferramenta de utilização do MEF.

Em um primeiro momento a equação do calor foi degenerada, e cada parte desta estudada isoladamente. O fluxograma da Figura 5.5 mostra os casos que foram estudados por cada método. Todas os casos apresentados foram estudados pelo MEF, a análise pelos três 
métodos foi dada para a Equação de Laplace em 1D, 2D e 3D, a Equação de Poisson 1D e 2D, a Equação de Fourier e a equação completa em 1D. Para a equação geral o caso 2D foi confrontado com o MDF e o MEF. A presença dos símbolos $\left(',{ }^{*},{ }^{+}\right)$ao lado dos casos significam que foram estudados pelos respectivos métodos, MEF, MSV, MDF.

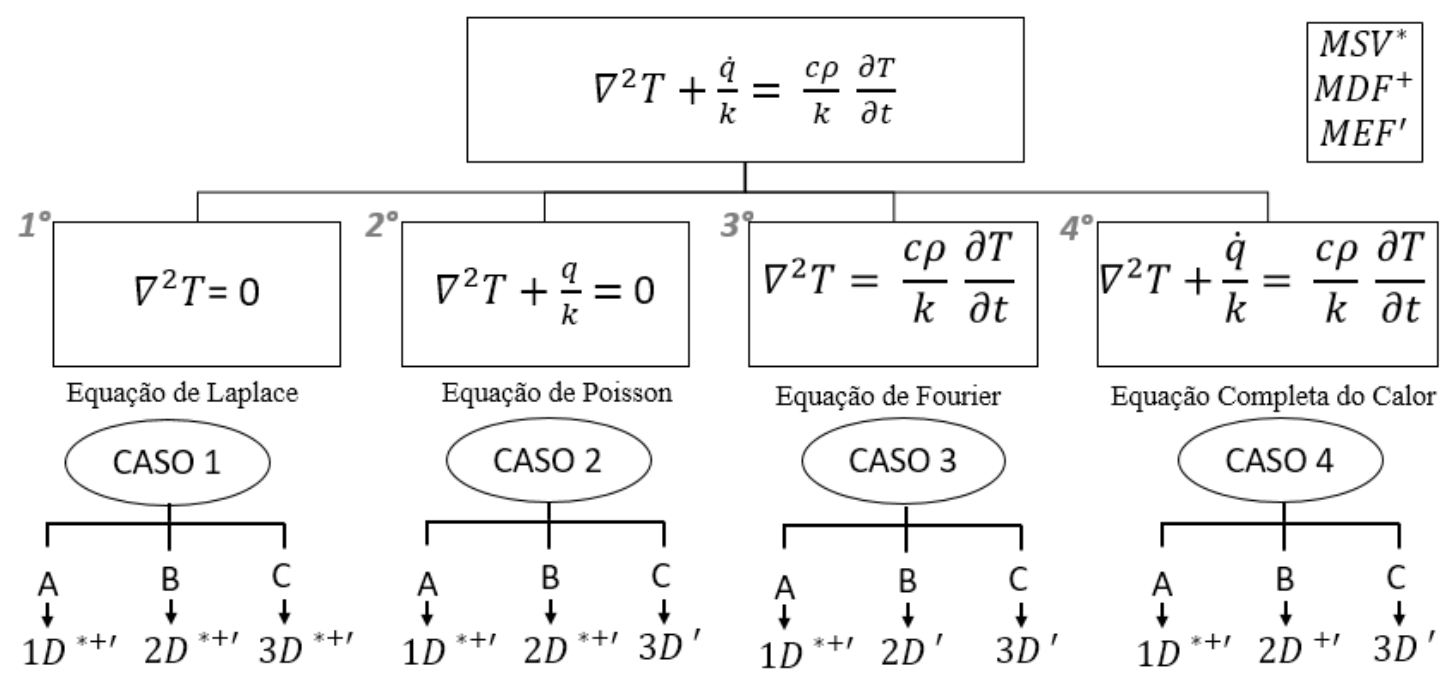

Figura 5.5 - Fluxograma de solução das equações.

\subsubsection{MAPLE}

Este é um programa matemático que permite encontrar soluções analíticas, porém é necessário conhecer o método de solução para cada equação e ir informando as etapas seguintes no processo de solução. Desta forma, optou-se por resolver as equações analíticas manualmente e utilizar o programa para expandir e gerar gráficos dos resultados e poder comparar com os demais, já que as soluções obtidas são em forma de séries e em função de senos e cossenos.

A Figura 5.6, mostra o gráfico da solução analítica para a equação completa em 1D, sendo a base formada pelo tempo e o comprimento de uma barra e a altura determinando as temperaturas obtidas. Nota-se que o gráfico segue a tendência da curva de geração de calor ou do resfriamento térmico. 


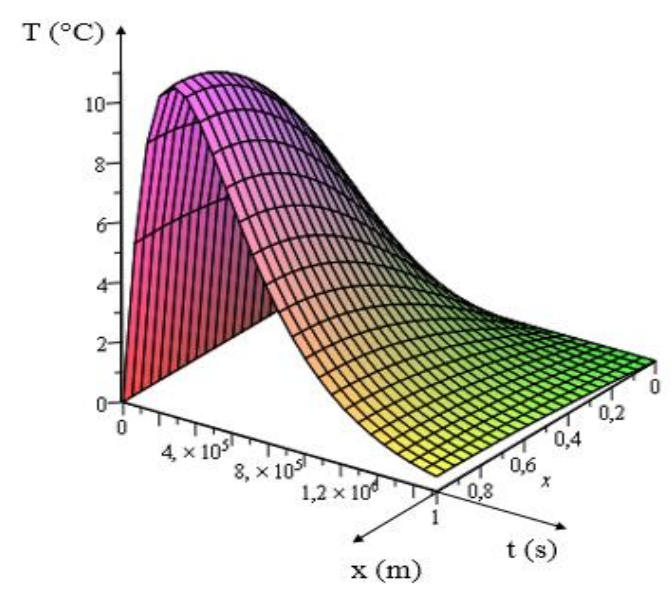

Figura 5.6 - Gráfico no MAPLE para a solução da equação completa do calor em 1D.

\subsubsection{MATLAB}

Este é um programa que permite a utilização de sub-rotinas internas, como para a solução de matrizes, por exemplo, assim como permite a criação de códigos computacionais, rotinas e funções que podem ser utilizadas em outras programações. Diante da sua performance, foi utilizado para as soluções em MDF e também para encontrar as tensões viscoelásticas do concreto.

Para as primeiras análises, em MDF, foram programadas rotinas para solução da equação do calor conforme mostrado no fluxograma da Figura 5.7, que mostra a equação e os dados de entrada necessários, e todos eles fornecem a temperatura como resposta. No entanto, para cada alteração dos dados de entrada, as soluções também serão alteradas. Ressalta-se também que para cada dimensão utilizada, 1D, 2D ou 3D, uma nova rotina deve ser elaborada, levando-se consideração a nova dimensão, e consequentemente, há um aumento do número de nós analisados e um maior tempo de processamento.

Para os casos transientes, em que o tempo é considerado como outra dimensão na elaboração do problema, e o tempo é abordado em segundos, há também um maior requerimento de performance do computador, pois para cada intervalo de tempo, uma nova matriz de soluções é gerada. 


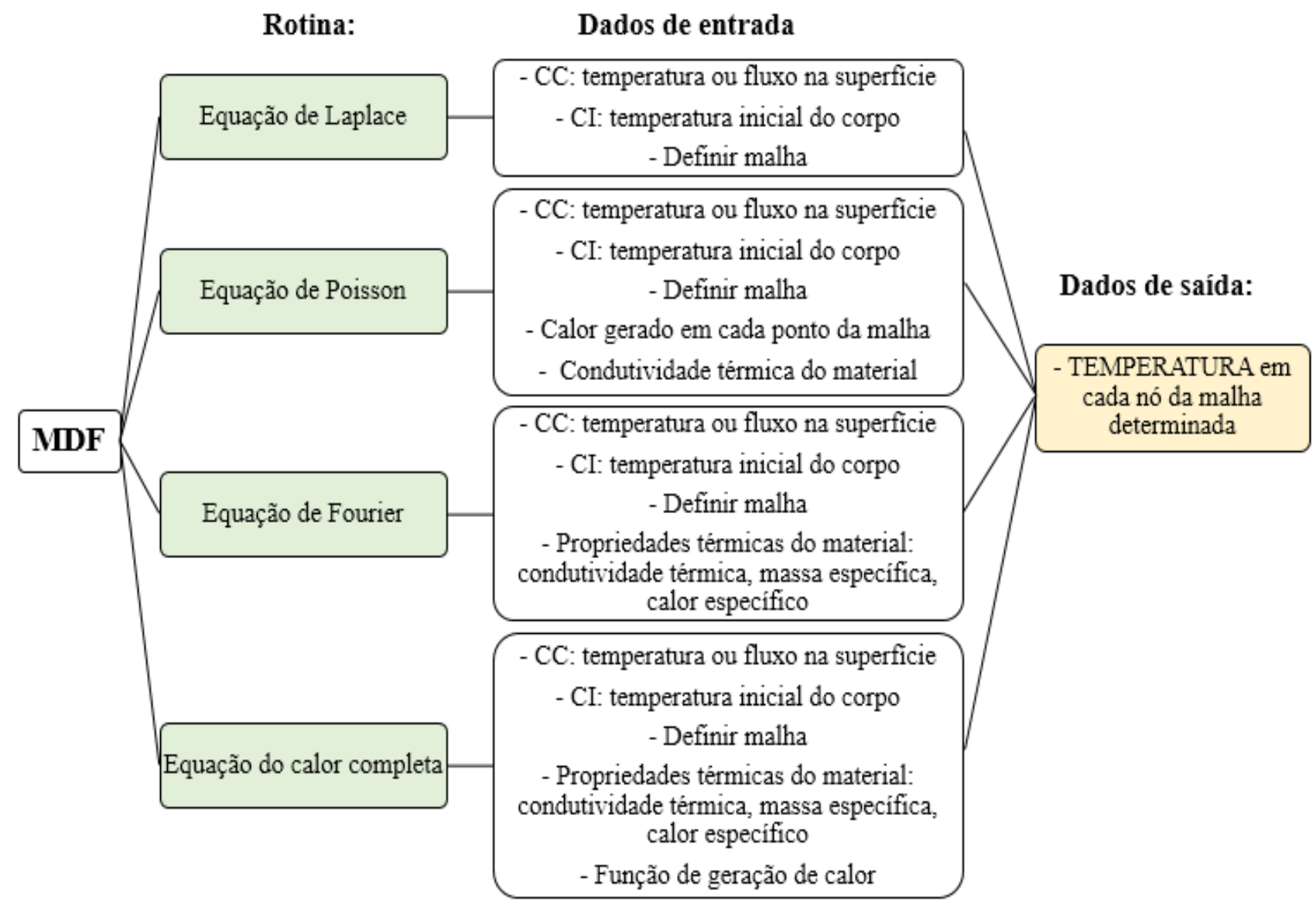

Figura 5.7 - Rotinas implementadas no MATLAB para solução do MDF.

Para os cálculos das tensões viscoelásticas, primeiro foram criadas as funções de fluência, matriz fluência do ACI, DP e USBR, designadas respectivamente de creepACI, creepDP e creepUSBR. Para a criação dessas funções é necessário entrar com suas respectivas funções de fluência e módulo e elasticidade, além das matrizes do tempo e da idade do concreto. A função do módulo de elasticidade depende da idade do concreto, e a função de fluência, por sua vez, depende tanto da matriz idade do concreto quanto dos seus respectivos coeficientes de fluência, que serão alterados para cada concreto diferente utilizado. As rotinas de solução são criadas a partir dos dados de entrada das matrizes de tempo, idade e temperatura, obtidas com o programa do MEF, com as funções 'creep' criadas e com a inserção do coeficiente de dilatação térmica. Os resultados serão as variações de tensões e, com o somatório destas, as tensões termomecânicas esperadas. O fluxograma da Figura 5.8 representa o método de solução explanado de forma simplificada. 


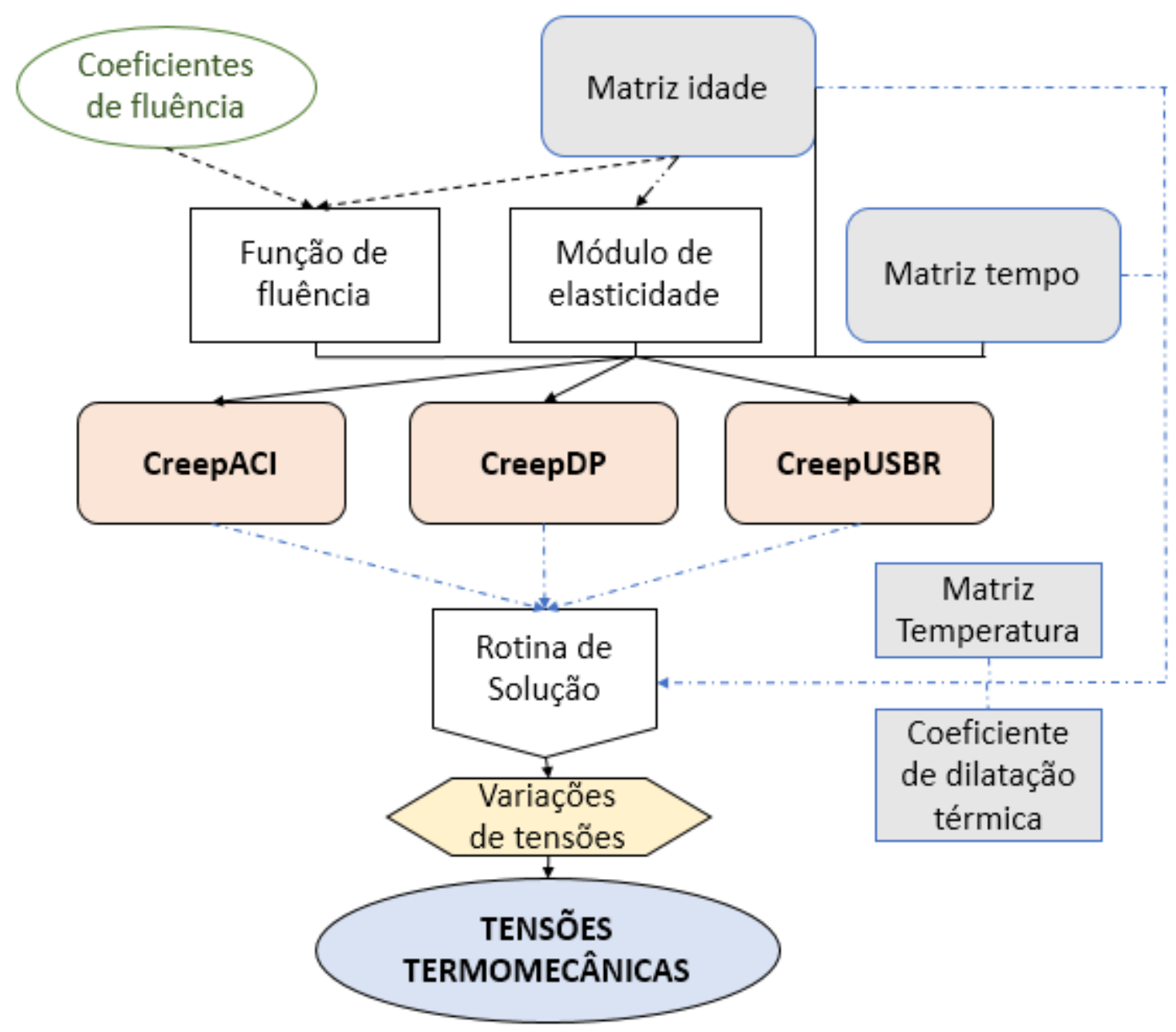

Figura 5.8 - Forma de implementação de rotinas para solução das tensões térmicas.

\subsubsection{ANSYS}

Em geral uma solução em MEF pode ser dividida em três fases, pré-processamento, solução e pós-processamento, como mostra a Figura 5.9. Essa é uma diretriz geral que pode ser usada para a criação de qualquer análise. 


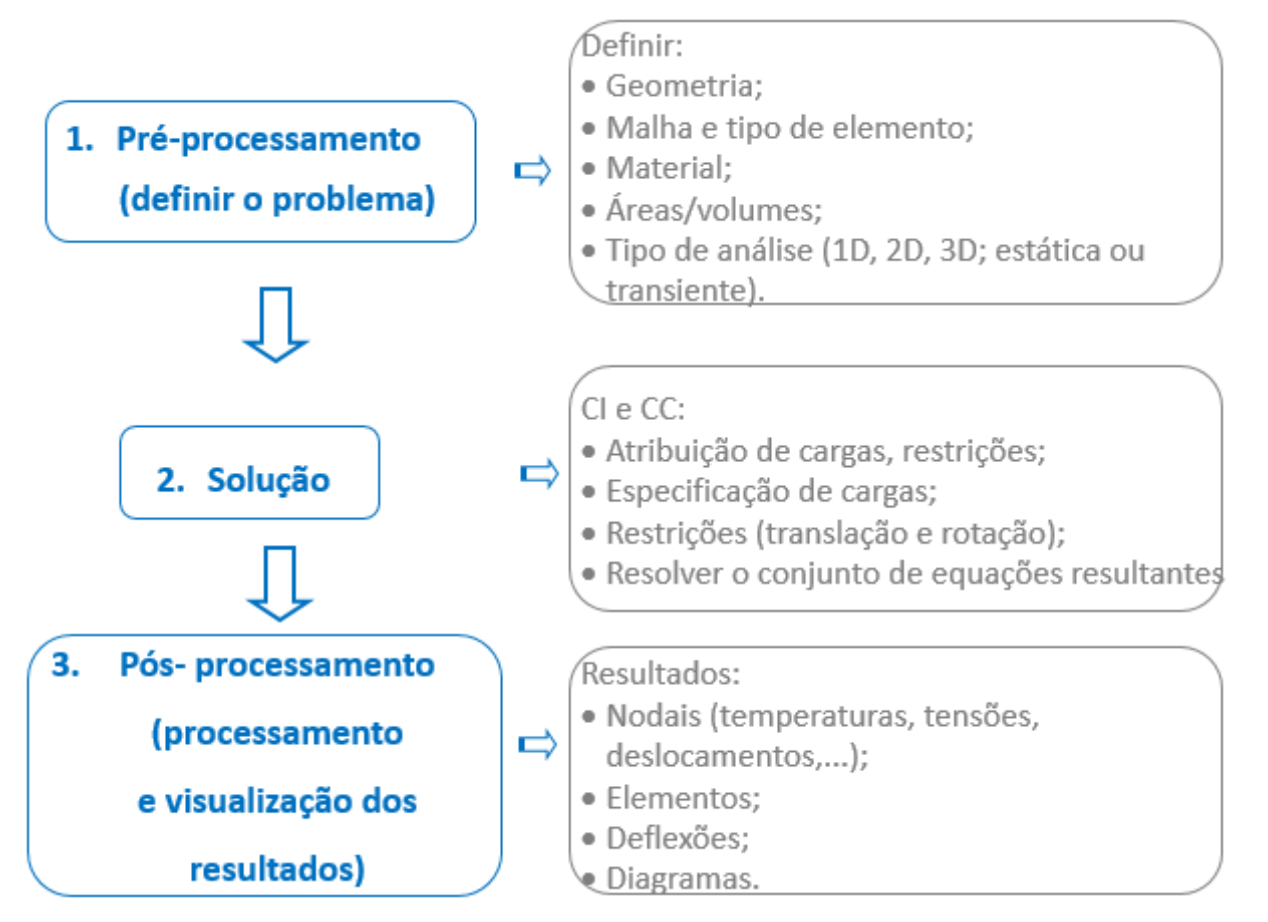

Figura 5.9 - Solução em MEF.

Para as análises mostradas neste trabalho podem ser utilizados os elementos do ANSYS identificados abaixo, todas essas informações e figuras a seguir são retiradas da biblioteca do ANSYS.

- PLANE55 - tem capacidade de condução térmica em duas dimensões, 2D. O elemento tem quatro nós e um único grau de liberdade em cada nó, a temperatura. O elemento é mostrado na Figura 5.10. Para análise estrutural, o elemento deve ser substituído por um elemento estrutural equivalente (tal como PLANE182).

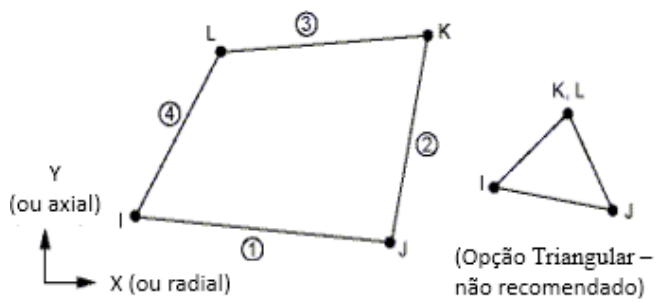

Figura 5.10- Geometria do elemento PLANE55 (adaptado da biblioteca do ANSYS, 2013).

- PLANE 77 - análises térmicas em duas dimensões. Apresenta um grau de liberdade, a temperatura e oito nós, adequado para desenhar fronteiras curvas. Para análise estrutural, o elemento deve ser substituído por um elemento estrutural equivalente (tal como PLANE183). 


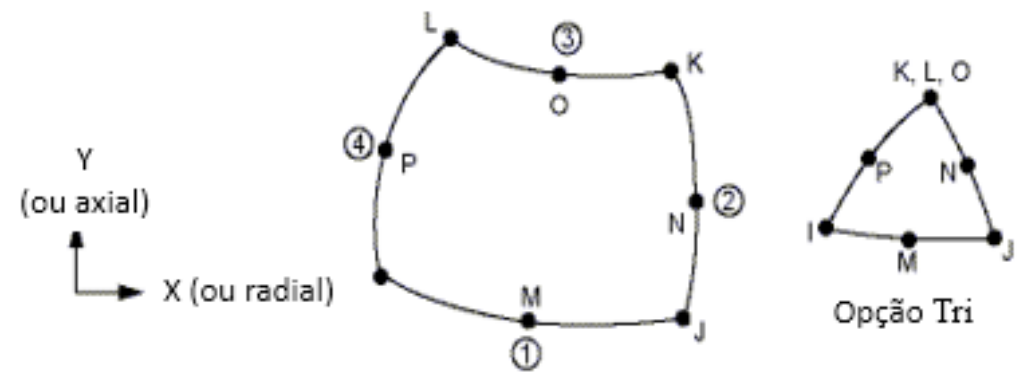

Figura 5.11- Geometria do elemento PLANE77 (biblioteca do ANSYS, 2013).

- PLANE182 - utilizado para modelar estruturas sólidas em 2-D. O elemento pode ser usado tanto como um elemento ou um elemento assimétrico. É definido por quatro nós com dois graus de liberdade em cada nó: a translação nos nós de x e y.

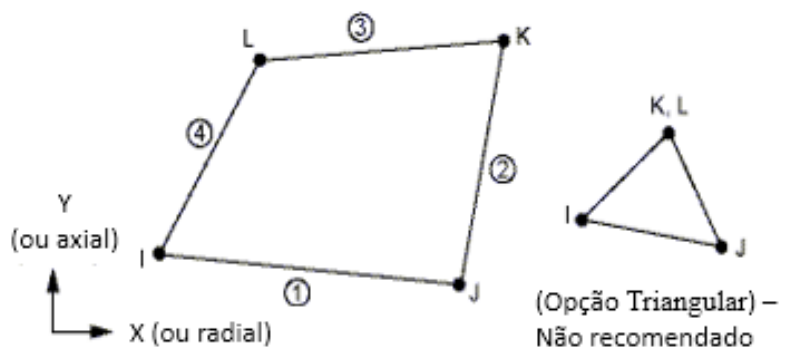

Figura 5.12- Geometria do elemento PLANE182 (adaptado da biblioteca do ANSYS, 2013).

- PLANE183 - elemento em 2-D, com 8 ou 6 nós, dois graus de liberdade em cada nó: a translação nos eixos nodais x e y. $\mathrm{O}$ elemento pode ser utilizado como um elemento plano ou como um elemento de simetria axial.

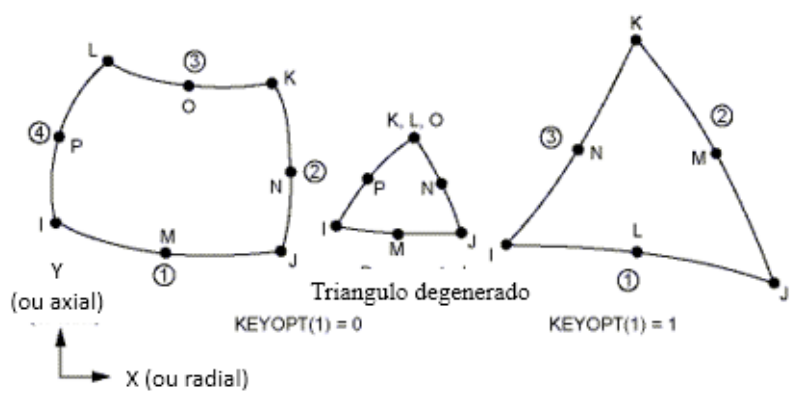

Figura 5.13- Geometria do elemento PLANE183 (adaptado da biblioteca do ANSYS, 2013).

- PLANE42 - utilizado para modelar estruturas sólidas em 2-D. O elemento pode ser usado tanto como um elemento plano ou como um elemento de simetria axial. O elemento é definido por quatro nós com dois graus de liberdade em cada nó: a translação nos eixos nodais x e y. 

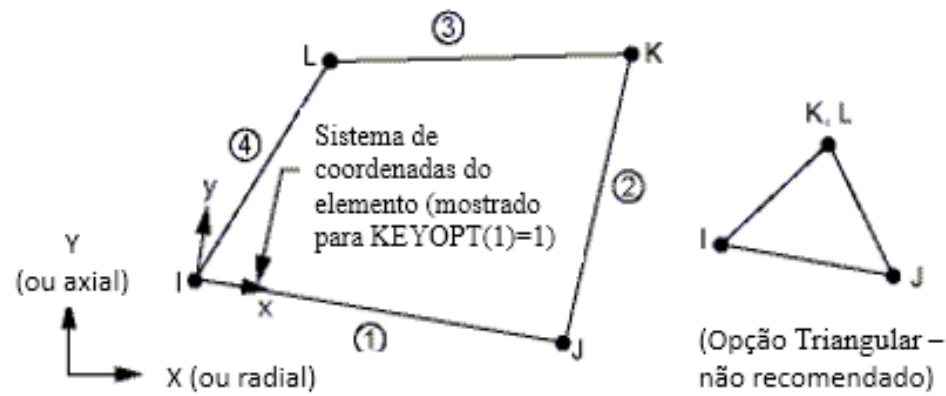

Figura 5.14- Geometria do elemento PLANE42 (adaptado da biblioteca do ANSYS, 2013).

- SOLID278 - capacidade de condução térmica 3-D. O elemento tem oito nós com um único grau de liberdade, a temperatura, em cada nó. O elemento é aplicável a uma análise térmica no estado estacionário ou transiente. Se o modelo contendo o elemento sólido necessitar ser analisados estruturalmente, deve ser substituído por um elemento estrutural equivalente (tal como SOLID185).

- SOLID90 - é um elemento térmico 3-D de 20 nós com um único grau de liberdade, a temperatura, em cada nó, Figura 5.15. Os elementos de 20 nós têm formas de temperatura compatíveis e são bem adequados para modelar limites curvos. É aplicável a uma ao estado estacionário ou transitório. Se o modelo que contém este elemento também for analisado estruturalmente, o elemento deve ser substituído pelo elemento estrutural equivalente (tal como SOLID186).
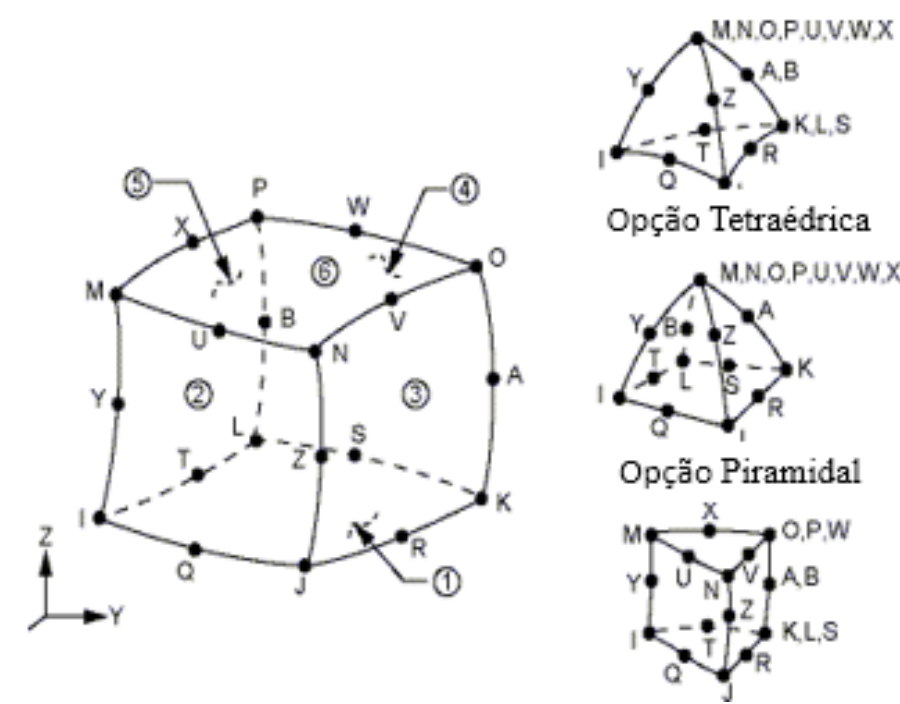

Figura 5.15 - Geometria do elemento SOLID90 (adaptado da biblioteca do ANSYS, 2013).

- CONTA174 - é utilizado para representar o contato e deslizamento entre superfícies "target" 3-D (TARGE170) e uma superfície deformável, definida por este elemento. O elemento é aplicável a análises tridimensionais e de campo acoplado. 


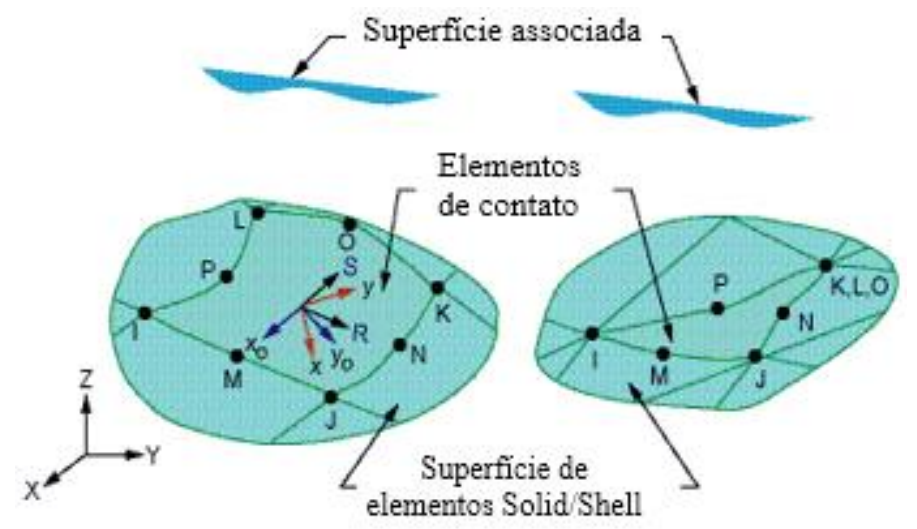

Figura 5.16- Geometria do elemento CONTA174 (adaptado da biblioteca do ANSYS, 2013).

$\mathrm{R}=$ Elemento, eixo $\mathrm{x}$, para fricção isotrópica;

$\mathrm{x}_{\mathrm{o}}=$ Eixo do elemento para fricção ortotrópica se a orientação não for definida;

$\mathrm{x}=$ Eixo do elemento para fricção ortotrópica se a orientação for definida.

- O TARGE170 é utilizado para representar várias superfícies "target" 3-D para os elementos de contato associados. Os próprios elementos de contato sobrepõem os elementos sólidos, de casca ou de linha que descrevem o limite de um corpo deformável e estão potencialmente em contato com a superfície de destino, definida por TARGE170.

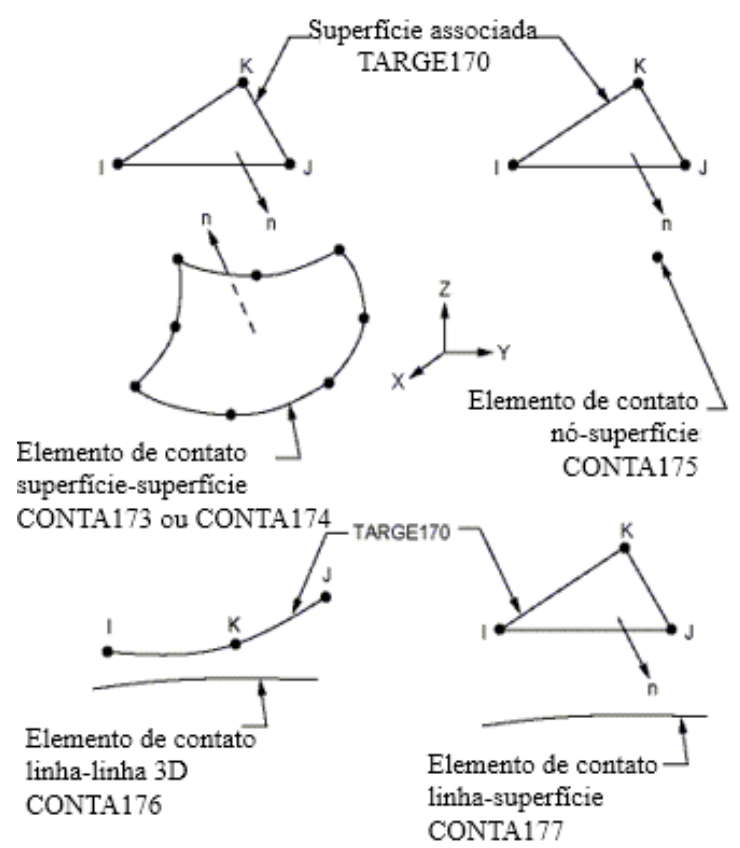

Figura 5.17 - Geometria do elemento TARGE170 (adaptado da biblioteca do ANSYS, 2013).

- O SURF152 pode ser usado para várias aplicações de carga e efeito de superfície. Pode ser sobreposta numa superfície de qualquer elemento térmico 3-D. O elemento 
é aplicável às análises térmicas 3-D. Várias cargas e efeitos de superfície podem existir simultaneamente.

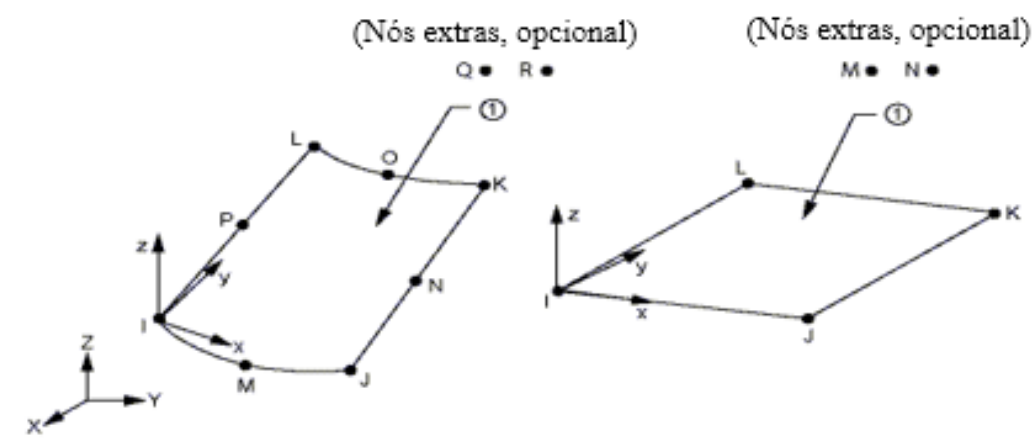

Figura 5.18 - Geometria do elemento SURF152 (adaptado da biblioteca do ANSYS, 2013).

- SOLID186 é um elemento sólido 3-D de 20 nós de ordem superior que exibe um campo de deslocamentos quadrático. O elemento possui três graus de liberdade por nó: translações nas direções nodais x, y, e z. O elemento suporta plasticidade, hiperelasticidade, fluência, tensão de endurecimento, grande deflexão e grandes capacidades de deformação. Tem também capacidade de formulação mista para simular deformações de materiais elastoplásticos quase incompressíveis e materiais hiperelásticos totalmente incompressíveis.

\subsection{TESTES PRELIMINARES DE VERIFICAÇÃO DE CONVERGÊNCIA}

Para os casos em que não há o fenômeno transiente é necessário verificar apenas a malha, ou seja, àquela que melhor se adequa a fim de se obter o resultado mais próximo possível dos resultados analíticos, que são tidos como os valores de referência. Assim, pode-se afirmar que há convergência quando os valores numéricos se aproximam dos analíticos, assumindo uma única tendência.

As equações de Laplace e Poisson não tem variação temporal, portanto, verifica-se apenas a malha. Já para a Equação de Fourier e a equação completa necessitam de um parâmetro em que uma razão entre o espaço e o tempo seja atendida.

Desta forma, houve a verificação da malha utilizada na Equação de Laplace e esta foi utilizada para as demais situações, sendo igual ou menor, consequentemente, com o mesmo número ou mais elementos, pois, quanto mais refinada a malha, maior o número de elementos e mais preciso os resultados. 


\section{Teste 1 - Análise Estática}

Considerando-se um corpo com $\mathrm{L}_{1}=1 \mathrm{~m} \mathrm{e} \mathrm{L}_{2}=1 \mathrm{~m}$, Figura 5.19, para haver sempre um ponto central, foi verificada a malha de forma que houvesse simetria, a mesma quantidade de elementos em ambos os lados. No modelo, as $\mathrm{CC}$ foram consideradas $0^{\circ} \mathrm{C}$, exceto no lado $\mathrm{B}$ que teve temperatura de $100^{\circ} \mathrm{C}$. Na análise, primeiro foi verificado o ponto central do corpo, e em seguida, a linha central em L, eixo x, representados na Figura 5.19, pelo ponto indicado e a linha tracejada.

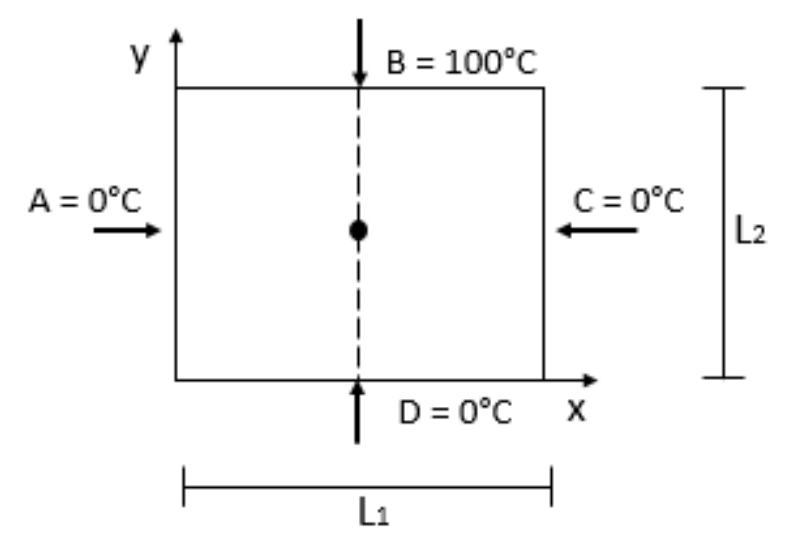

Figura 5.19 - Corpo analisado na convergência estática.

A Figura 5.20 mostra a malha de 0.5, 0.1 e 0.05 com, respectivamente, 4, 100 e 400 elementos, evidenciando que quanto menor a malha maior o número de elementos e, consequentemente, maior a precisão dos resultados por haver matrizes maiores aproximando-se cada vez mais de um elemento infinitesimal. Ressalta-se que, dizer que a malha é de 0,5 significa que suas dimensões em forma quadrada serão de $0,5 \mathrm{~m}$, com isso, sendo o comprimento do corpo de $1,0 \mathrm{~m}$, para cada ordenada haverá dois elementos de 0,5 m. Isto é válido para ambos os métodos numéricos, MDF e MEF. Ressalta-se que as malhas apresentadas apenas mostram que existe uma diferença entre elas, mas outras malhas também foram estudadas, como é possível perceber nos gráficos. 


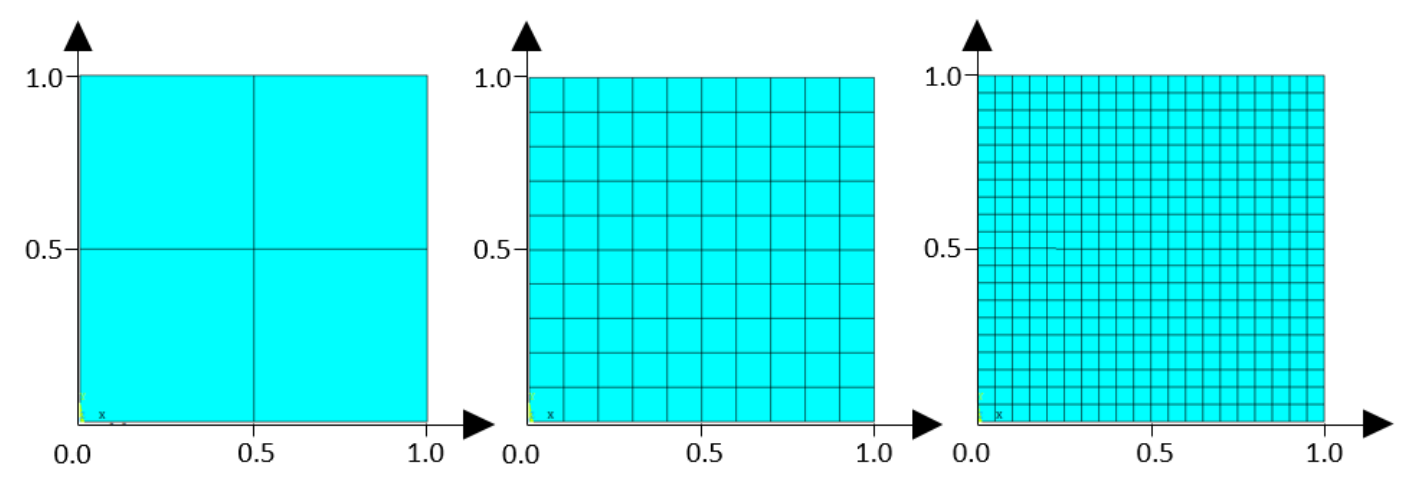

Figura 5.20 - Exemplo de malha com 4, 100, 400 elementos.

A primeira análise de convergência é feita para o ponto central, em x e y, Figura 5.21, em que no eixo das abscissas tem-se o número de elementos e o eixo das ordenadas a temperatura. Sabendo-se que o valor analítico da temperatura neste ponto será sempre $25^{\circ} \mathrm{C}$, obtido pela Equação 6.1, é possível visualizar a aproximação entre o método numérico, MEF, e o analítico a partir do refinamento da malha.

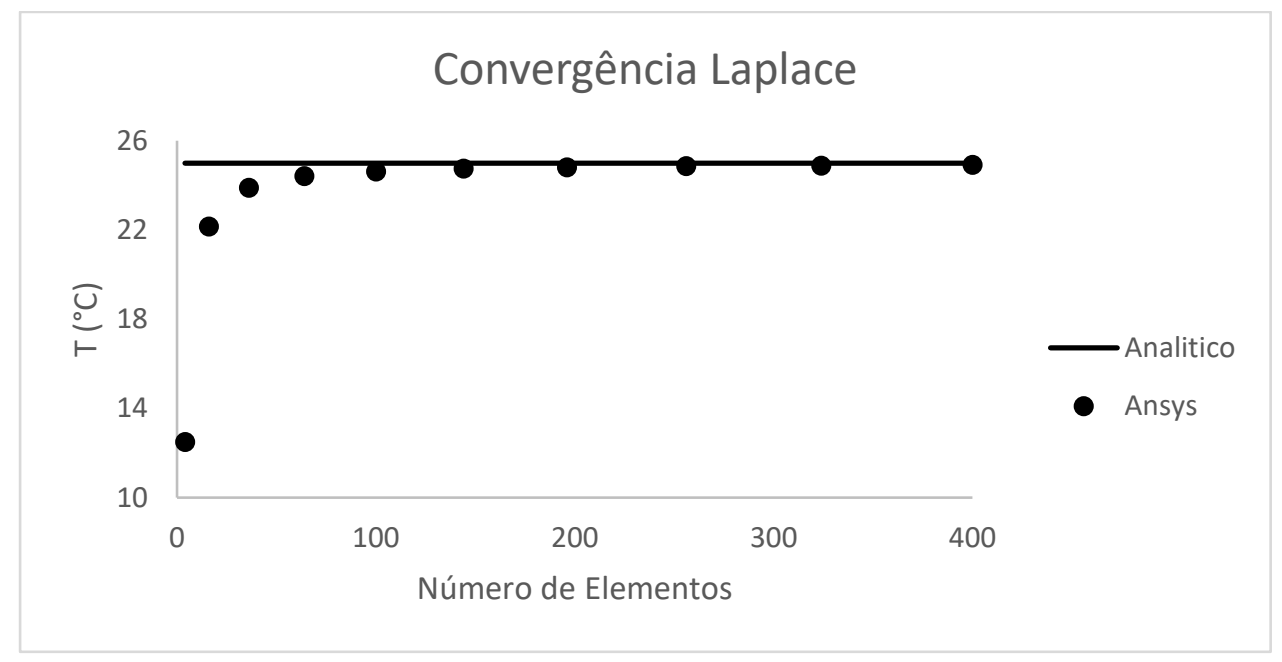

Figura 5.21 - Convergência para o ponto central em Laplace.

Para os pontos ao longo da direção y, com x constante, linha apresentada na Figura 5.22, é traçado o gráfico com os valores obtidos de forma analítica, e os valores para diferentes malhas, obtidos com o MDF e o MEF (ANSYS). Observa-se no MDF, que o caso mais simples, malha $0,5(\mathrm{x} / 2=0,5 \Rightarrow 4$ elementos), já converge, obtendo o mesmo valor numérico. O MEF apresenta bons resultados com uma malha de 0,25. 


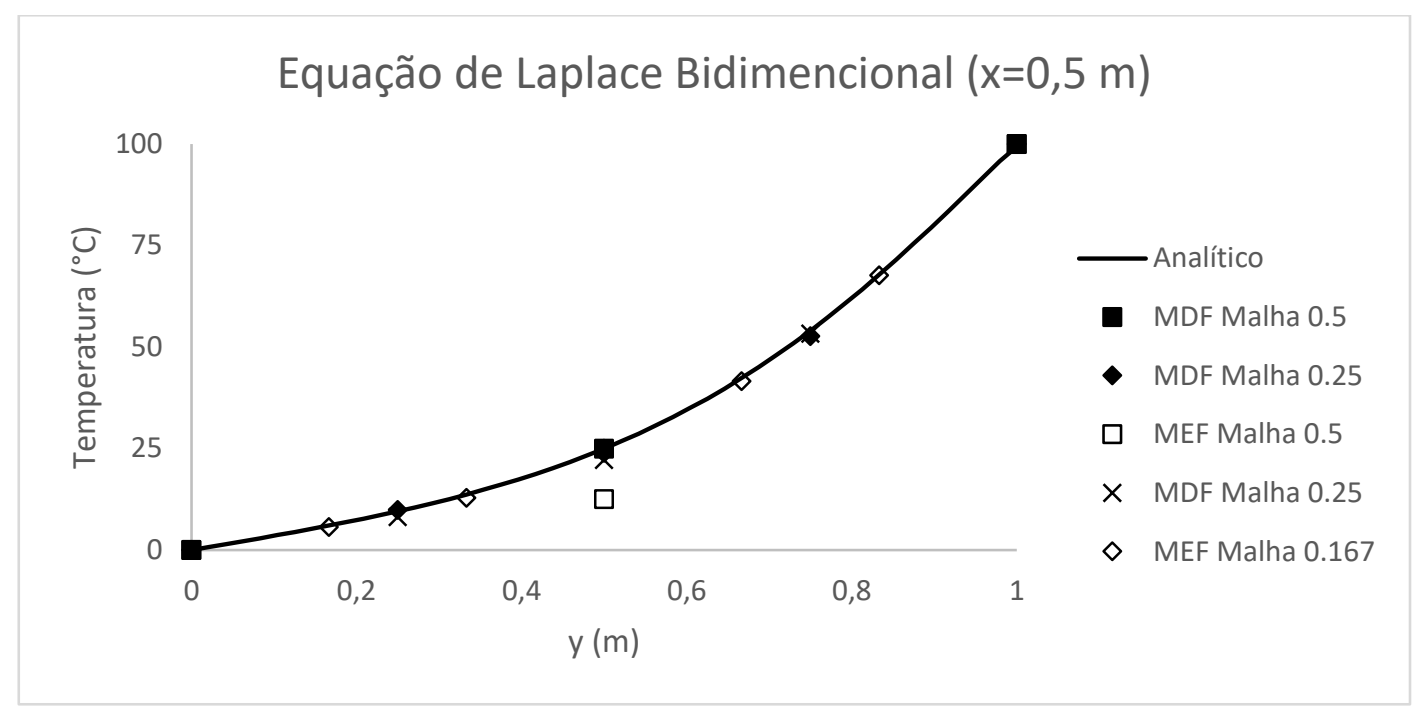

Figura 5.22 - Convergência da Equação de Laplace no eixo y.

\section{Teste 2 - Análise Transiente}

Ao se tratar de um problema transiente, este será estável se eventuais distúrbios não são amplificados ao longo do tempo. Para evitar oscilações divergentes nas temperaturas nodais o passo de tempo deve ser mantido abaixo de certo limite estabelecido pelo critério da estabilidade no método explicito, utilizado neste trabalho. Isso pode ser representado pela Equação 5.38 ou 5.39 (Dabbene e Paillere, 2003; Çengel e Ghajar, 2012):

$$
\frac{\Delta t \cdot D}{\Delta x^{2}} \leq \frac{1}{2}
$$

Ou ainda:

$$
\Delta t \leq \frac{\Delta x^{2}}{2 D}
$$

Em que:

- $\Delta t=$ Incremento de tempo;

- $\Delta x=$ Incremento de espaço;

- $\quad D=$ Difusividade térmica.

As Equações 5.38 e 5.39 são válidas para problemas unidimensionais. No caso de análise bidimensional, leva-se em consideração outra dimensão e o passo de tempo deve obedecer à Equação 5.39, a qual é denominada Número de Fourier (Çengel e Ghajar, 2012):

$$
\Delta t \leq \frac{\Delta x^{2}}{4 D}
$$


Para esta verificação foi analisado uma viga unidimensional com variação térmica no tempo, com as $\mathrm{CC}$ de temperatura $0^{\circ} \mathrm{C}$ em $\mathrm{A}$ e $100^{\circ} \mathrm{C}$ em B e temperatura inicial $0^{\circ} \mathrm{C}$, como mostra a Figura 5.23. Dadas as propriedades térmicas da Tabela 5.1.

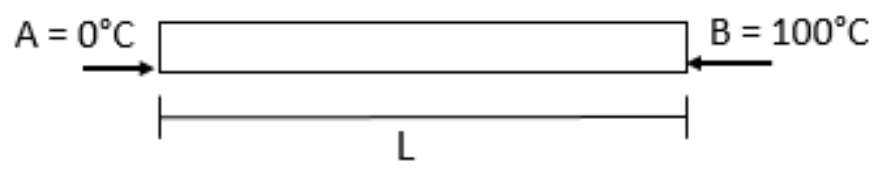

Figura 5.23 - Corpo unidimensional para verificação de convergência transiente.

Tabela 5.1 - Parâmetros térmicos utilizados na análise de convergência.

\begin{tabular}{|l|c|}
\hline Condutividade Térmica $\left(\mathrm{W} / \mathrm{m} .{ }^{\circ} \mathrm{C}\right)$ & 1,79 \\
\hline Calor Específico $\left(\mathrm{J} / \mathrm{g} .{ }^{\circ} \mathrm{C}\right)$ & 1000 \\
\hline Massa Específica $\left(\mathrm{kg} / \mathrm{m}^{3}\right)$ & 2388 \\
\hline
\end{tabular}

A Figura 5.24 representa a Equação de Fourier unidimensional, analítica comparada com diferentes malhas pelo MEF - ANSYS, sendo o tempo representado no eixo das abcissas e a temperatura no eixo das ordenadas.

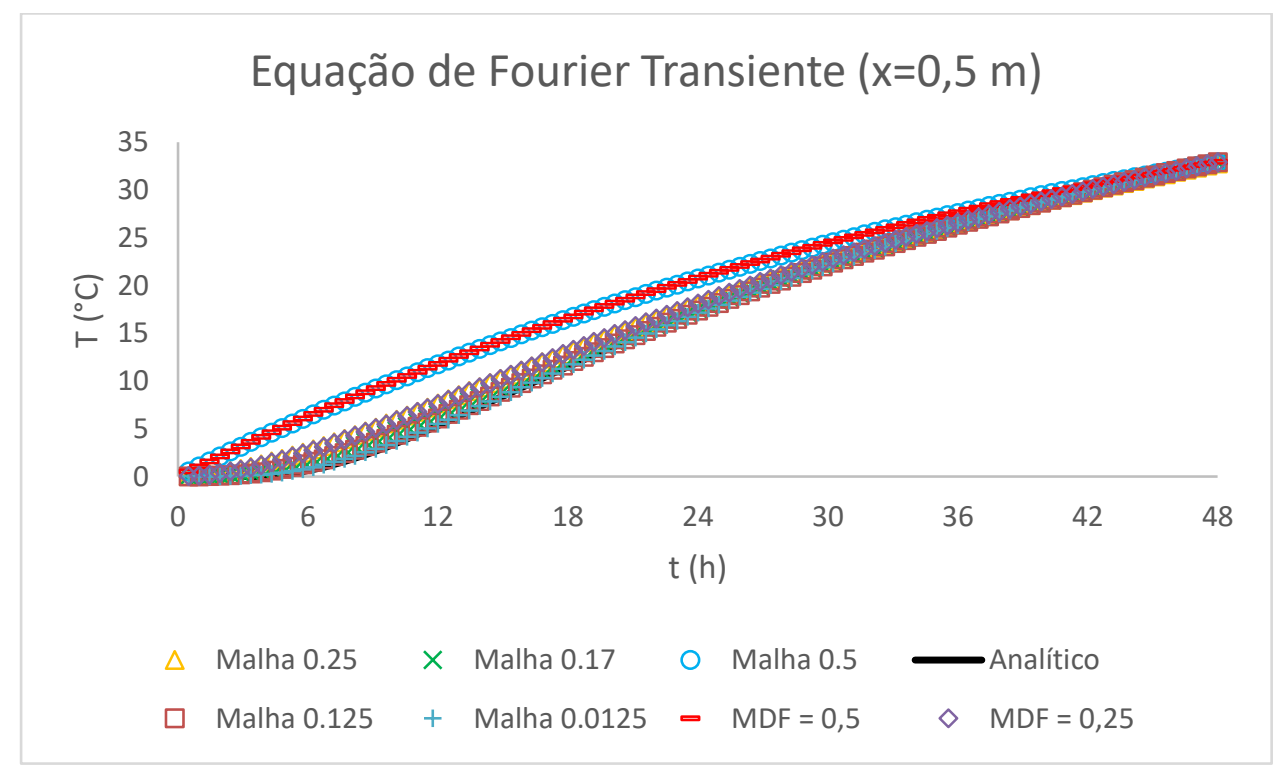

Figura 5.24 - Analise de convergência para fenômeno transiente.

Na Figura 5.24 é notável que apenas a malha de 0,5, dois elementos, se distancia um pouco da curva analítica, as demais seguem a mesma tendência. Isso acontece porque o passo de tempo utilizado com o programa é de $1 \mathrm{~s}$, e levando em consideração que D representa a difusividade térmica e tem um valor muito baixo $(\approx 0,00000078)$ no denominador, seria necessário um passo de tempo muito maior para que esses valores ficassem fora da curva, sabendo-se que o passo espacial também é pequeno. O mesmo acontece para o MDF que foi 
resolvido com $\Delta x=0,025$ e $\Delta t=1$, neste caso $\Delta t \leq 401$, ou seja, apenas para a malha 0,5 ficou um pouco fora da curva, para a malha 0,25 já ficou dentro do esperado, por esta razão, não foram feitas mais aproximações.

Desta forma, é possivel observar que a malha a partir de 0,25 já converge, e neste trabalho foram utilizadas malhas muito menores, 0,02 , portanto, o problema da convergência foi superado.

\subsection{VALIDAÇÃO DOS RESULTADOS NUMÉRICOS}

\subsubsection{Temperatura}

Para a validação dos resultados de comparação dos métodos, foram efetuadas análises em estruturas de dimensões unitárias, pois facilitam e agilizam o processamento dos dados devido a um menor número de elementos, nós e malhas. Havendo a comprovação em corpos pequenos a mesma metodologia pode ser aplicada às estruturas de dimensões maiores apenas utilizando o MEF, tendo a garantia que funcionarão da mesma forma, apenas tendo o cuidado de manter as devidas proporções.

Embora tenham sido validados todos os casos citados, será apresentado neste trabalho apenas o caso geral com geração de calor transiente. Foi analisado um corpo quadrado de lado $1 \mathrm{~m}$, com diferentes $\mathrm{CC}$ em todas as superfícies: $0^{\circ} \mathrm{C}$ na superfície superior, $10^{\circ} \mathrm{C}$ no lado direito, $50^{\circ} \mathrm{C}$ na base e $100^{\circ} \mathrm{C}$ no lado esquerdo. Admitindo-se uma geração de calor de valor $\dot{q}=q_{0} m \exp (-m t)$, foram analisados nove pontos ao longo do corpo de modo a visualizar a temperatura influenciada pelas CC. A Figura 5.25 mostra as CC impostas, a posição e os pontos analisados, P1, P2, P3, P4, P5, P6, P7, P8 e P9.

Para o exemplo não é conhecida a solução analítica, portanto serão comparados apenas os resultados numéricos. 


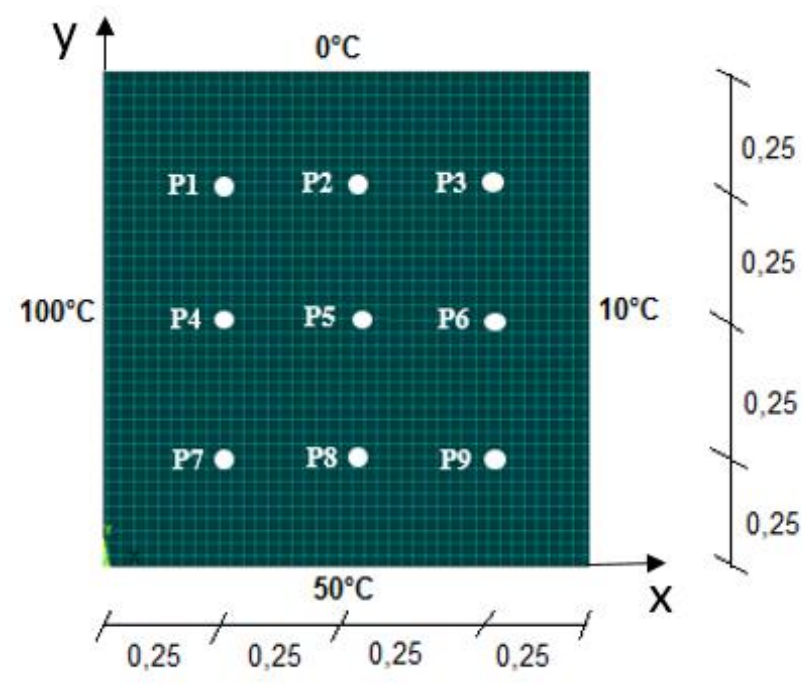

Figura 5.25 - Corpo e pontos analisados na equação completa 2D.

\section{Solução Numérica - MEF}

Pelo MEF com o ANSYS é possível visualizar as isotermas de temperatura ao final do tempo de 17280 s, como mostra a Figura 5.26, utilizando o elemento PLANE55 do ANSYS APDL, com malha de 0,025 e dimensões unitárias em x e y. Observa-se que há uma longa faixa em azul, que representa temperaturas entre $0^{\circ} \mathrm{C}$ e $11,111^{\circ} \mathrm{C}$, ou seja, não significa que tem as mesmas temperaturas em todos os pontos.

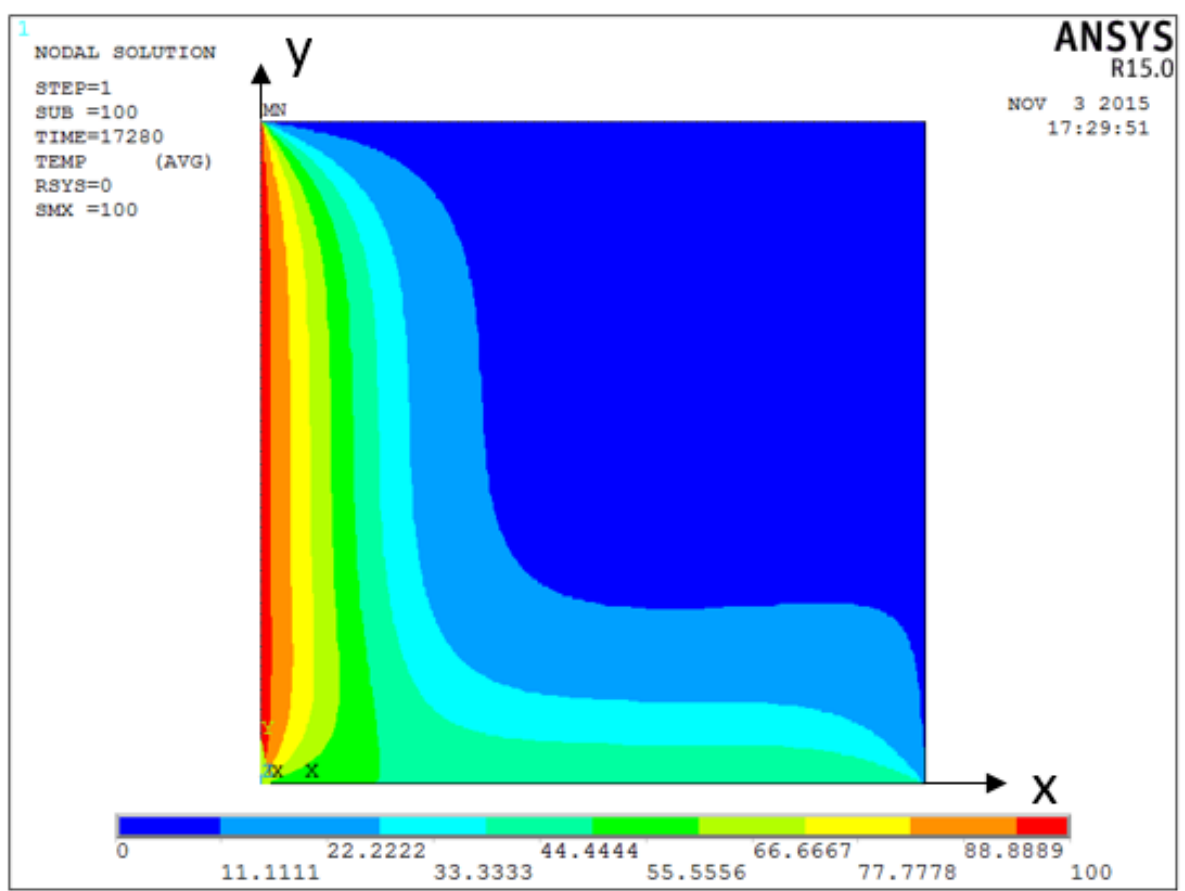

Figura 5.26 - Isotermas de temperatura ao final da análise 2D. 


\section{Solução Numérica - MDF}

A solução numérica é encontrada com a Equação 5.41. Esta leva em consideração as duas dimensões, as propriedades térmicas e a geração de calor em cada instante de tempo.

$$
T_{i, j}^{\kappa+1}=\left(T_{i+1, j}^{\kappa}+T_{i-1, j}^{\kappa}+T_{i, j+1}^{\kappa}+T_{i, j-1}^{\kappa}\right) F+(1-4 F) T_{i, j}^{\kappa}+G
$$

Em que:

- $F=\frac{D \Delta t}{\Delta x^{2}}$

- $G=\frac{\mathrm{q}^{\kappa} \Delta x^{2} \Delta t}{\rho c}$

\section{Comparação dos Resultados}

Primeiramente, ao final da análise transiente, no tempo estipulado, $17280 \mathrm{~s}$, foram verificadas as temperaturas pelo MEF e MDF nas direções x e y sempre considerando o ponto central.

A Figura 5.27 apresenta a posição de $\mathrm{x}$ nas abscissas e a temperatura nas ordenadas para $\mathrm{o}$ tempo final de $17280 \mathrm{~s}$. Observa-se que para a posição $\mathrm{x}=0$ a temperatura será $100^{\circ} \mathrm{C}$ e para a posição $\mathrm{x}=1$ a temperatura será $10^{\circ} \mathrm{C}$, que são as $\mathrm{CC}$, no restante do corpo, os resultados se sobrepõe, mostrando a confiabilidade das análises. Os pontos foram verificados para y $=$ $0,5 \mathrm{~m}$.

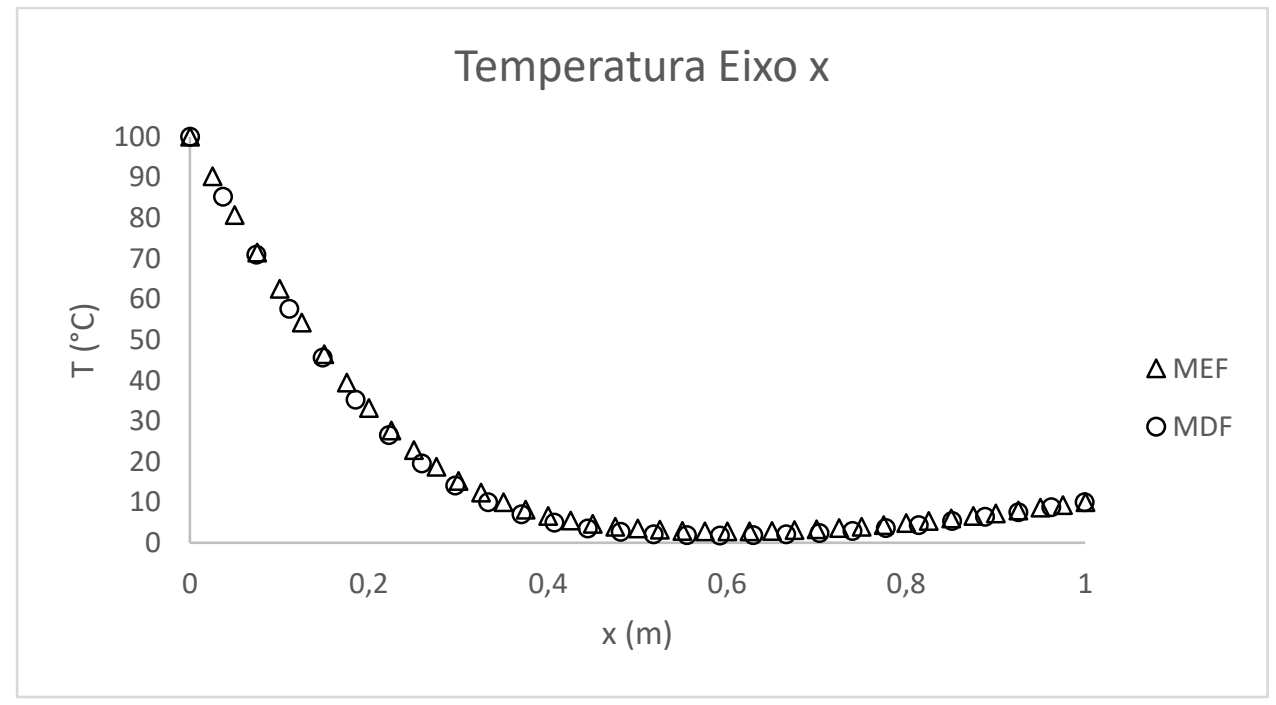

Figura 5.27 - Temperatura ao longo do eixo x para equação completa 2D. 
Para a Figura 5.28, a verificação é feita em torno de y, com esses dados nas abscissas e a temperatura nas ordenadas. Nas extremidades de y as temperaturas do contorno prevalecem, $50^{\circ} \mathrm{C}$ e $0^{\circ} \mathrm{C}$. Nas outras partes do domínio as temperaturas são coincidentes, evidenciando um bom tratamento nos dados para um tempo final de $17280 \mathrm{~s}$. Os pontos foram verificados para $\mathrm{x}=0,5 \mathrm{~m}$.

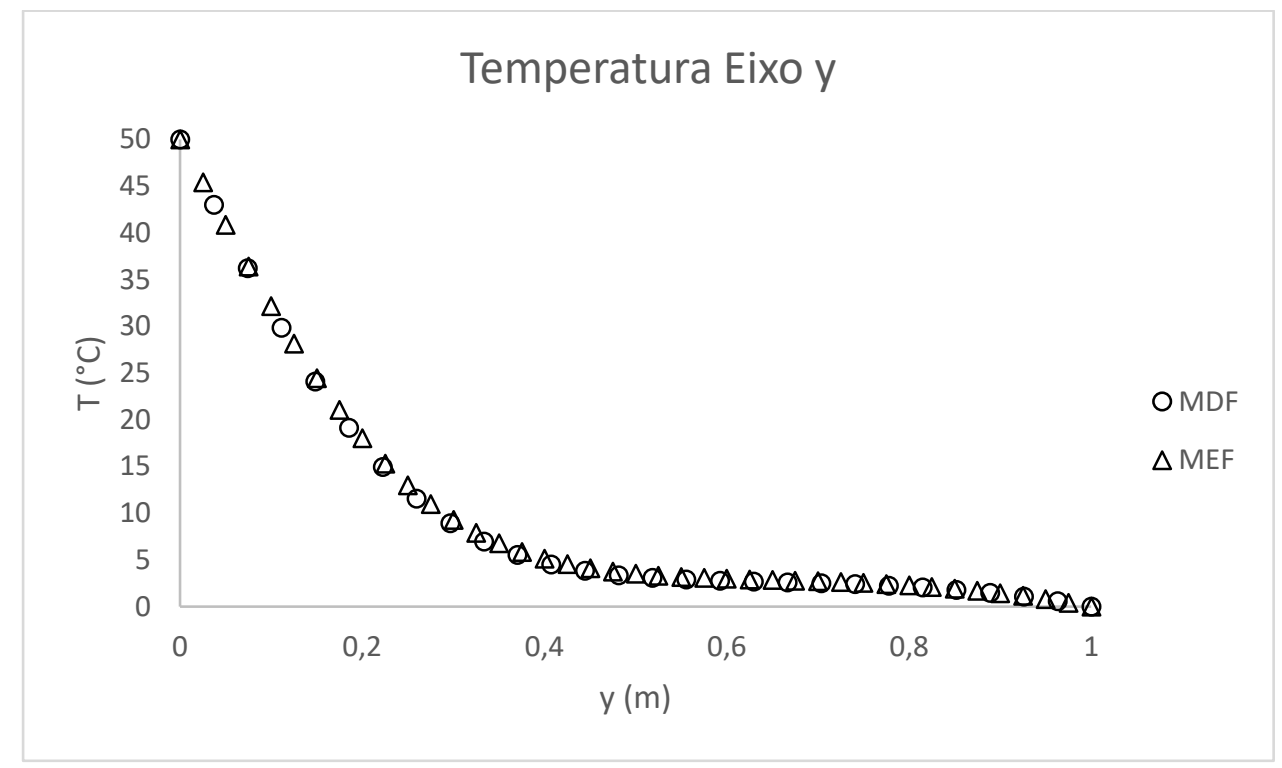

Figura 5.28 - Temperatura ao longo do eixo y para equação completa 2D.

Após a análise para um determinado tempo, foram verificados os pontos de P1 a P9 no decorrer do tempo, fazendo gráficos temporais para estes pontos, os quais são exibidos na Figura 5.29. Em todos os casos a abscissa representa o tempo em segundos e a ordenada a temperatura em ${ }^{\circ} \mathrm{C}$ e os pontos foram definidos na Figura 5.25. Observa-se que para todos eles, os pontos de ambas as análises numéricas ficaram sobrepostos, ou seja, ambos deram os mesmos valores ou muito próximos.

Nota-se também que os pontos mais próximos às $\mathrm{CC}$ com maiores temperaturas também atingiram maiores valores, é o caso de P1, P4 e P7, sendo que P7 atingiu a máxima, justamente por estar entre as duas maiores temperaturas dos contornos. Seguido desses pontos, vieram P8 e P9 que estão perto da temperatura de $50^{\circ} \mathrm{C}$. Enquanto P2, P3, P5 e P6 atingiram menores temperaturas por situarem-se em zonas com temperaturas mais amenas. P5, o ponto central, também não atingiu altas temperaturas, por receber grande influência de toda a vizinhança. 

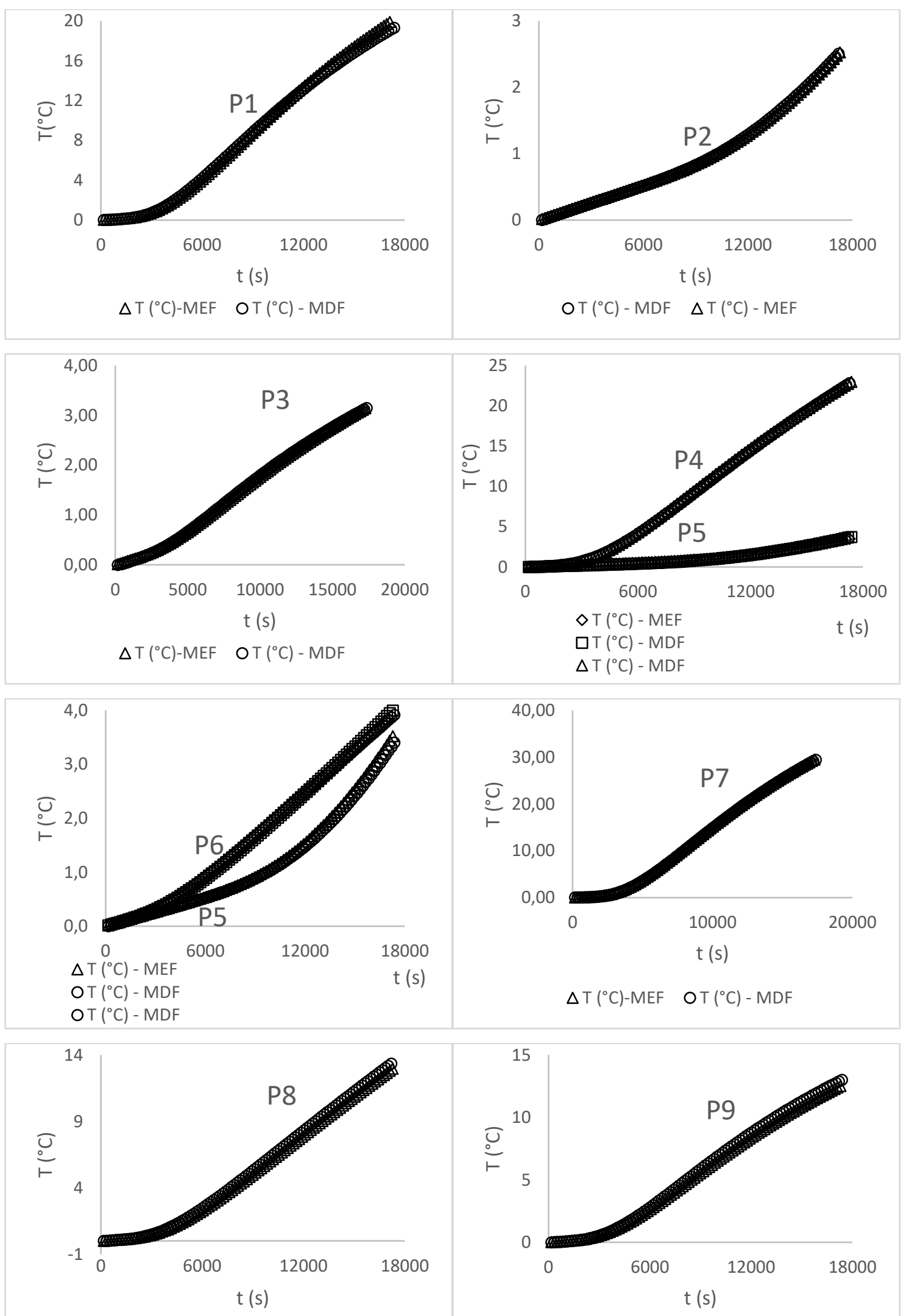

$\Delta \mathrm{T}\left({ }^{\circ} \mathrm{C}\right)-\mathrm{MEF} \quad \mathrm{OT}\left({ }^{\circ} \mathrm{C}\right)-\mathrm{MDF}$

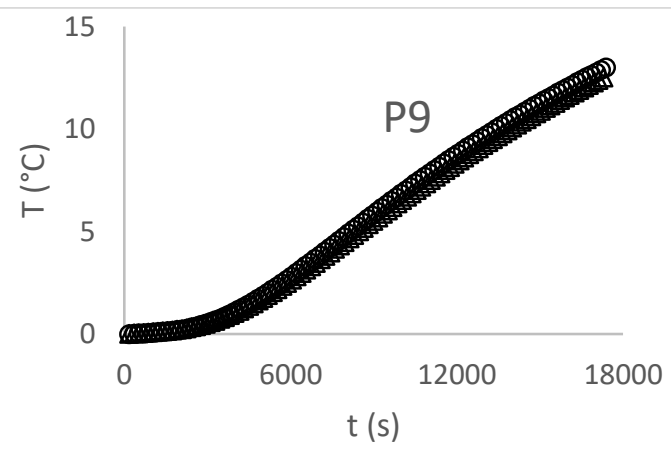

$\triangle \mathrm{T}\left({ }^{\circ} \mathrm{C}\right)-\mathrm{MEF} \quad \mathrm{OT}\left({ }^{\circ} \mathrm{C}\right)-\mathrm{MDF}$

Figura 5.29 - Análise de temperatura transiente do ponto P9 - Caso 4B. 
Com isso cabem duas conclusões, a primeira é que os métodos utilizados são confiáveis, devido a precisão dos resultados utilizando dois métodos numéricos distintos e dois programas de computador que auxiliam na busca por esses resultados. A segunda é que é claramente perceptível a influência das CC, mas isto é notável para os pontos mais próximos dos contornos, portanto, quanto mais perto do contorno maior a ação deste no ponto.

\subsubsection{Tensões Elásticas}

Para a verificação das tensões termomecânicas, será apresentado o resultado de uma laje fixa, engastada nas suas laterais e na sua base, proposta por Bofang (2014), para a qual foram adotadas temperaturas de $20^{\circ} \mathrm{C}$ na superfície superior e $100^{\circ} \mathrm{C}$ na sua base, cuja solução mecânica analítica é dada pela Equação 5.42. Outros resultados de lajes abordadas por Szilard (2004) podem ser encontradas em Coelho et al (2016a) e nos apêndices C. As propriedades utilizadas no modelo são mostradas na Tabela 5.2.

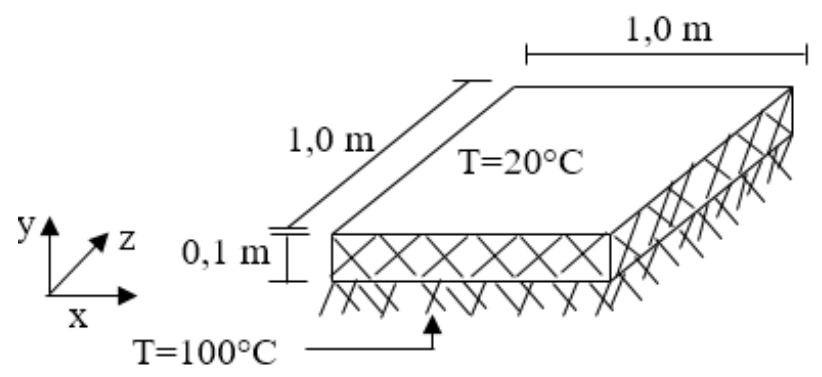

Figura 5.30 - Laje estudada.

$$
\sigma_{x}=\sigma_{z}=\sigma=-\frac{E \alpha T}{1-v}
$$

Tabela 5.2 - Propriedades da placa.

\begin{tabular}{|l|c|}
\hline Propriedade & Valor \\
\hline Massa especifica $(\rho)$ & $2500,00 \mathrm{~kg} / \mathrm{m}^{3}$ \\
\hline Coeficiente de dilatação térmica $(\alpha)$ & $1,40 \times 10^{-5} /{ }^{\circ} \mathrm{C}$ \\
\hline Modulo de elasticidade $(\mathrm{E})$ & $21000,00 \mathrm{MPa}$ \\
\hline Coeficiente de Poisson $(v)$ & 0,18 \\
\hline Condutividade térmica $(\mathrm{k})$ & $2,00 \mathrm{~W} / \mathrm{m}^{\circ} \mathrm{C}$ \\
\hline Calor específico $(\mathrm{c})$ & $1000,00 \mathrm{~J} / \mathrm{kg}^{\circ} \mathrm{C}$ \\
\hline
\end{tabular}


Como CC da temperatura foram adotadas as temperaturas de $100^{\circ} \mathrm{C}$ na base e $20^{\circ} \mathrm{C}$ na superfície superior, formando um gradiente térmico conforme mostra a Figura 5.31a. A Figura 5.31b, representa as tensões térmicas em $\mathrm{x}, \sigma(\mathrm{x}, \mathrm{T})$. Sendo as $\mathrm{CC}$ iguais nos eixos $\mathrm{x}$ e $\mathrm{y}$, as tensões serão equivalentes.
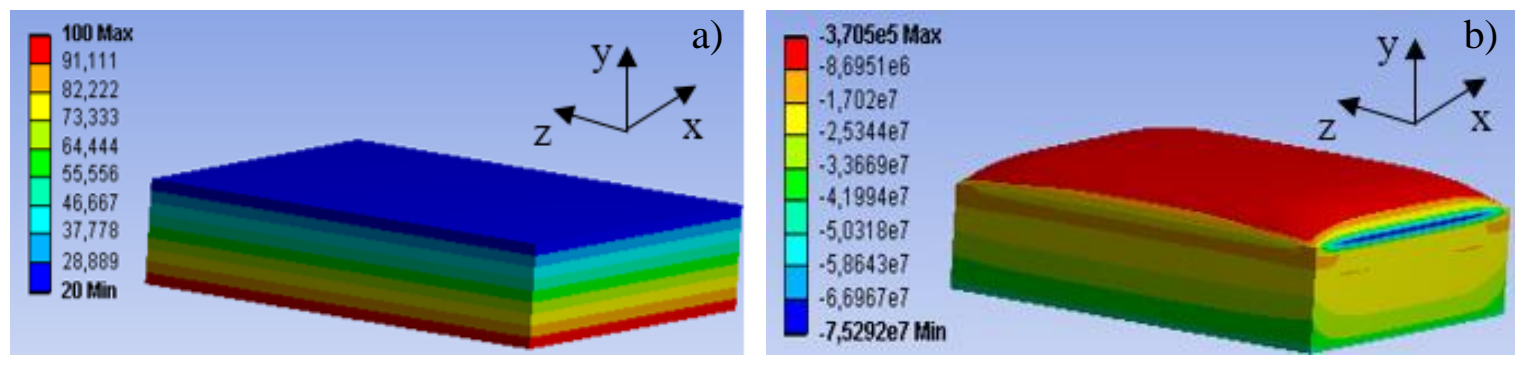

Figura 5.31 - a) Gradiente térmico e b) Tensões térmicas em x.

Fazendo as comparações entre os resultados analíticos e numéricos para o ponto central, Figura 5.32, nota-se que não houve distinção entre as análises, mostrando que a validação foi satisfatória. Ressalta-se que as tensões em x e z são iguais devido as CC impostas serem equivalentes. No eixo y a laje está livre para se movimentar na superfície, por isso as tensões são nulas.

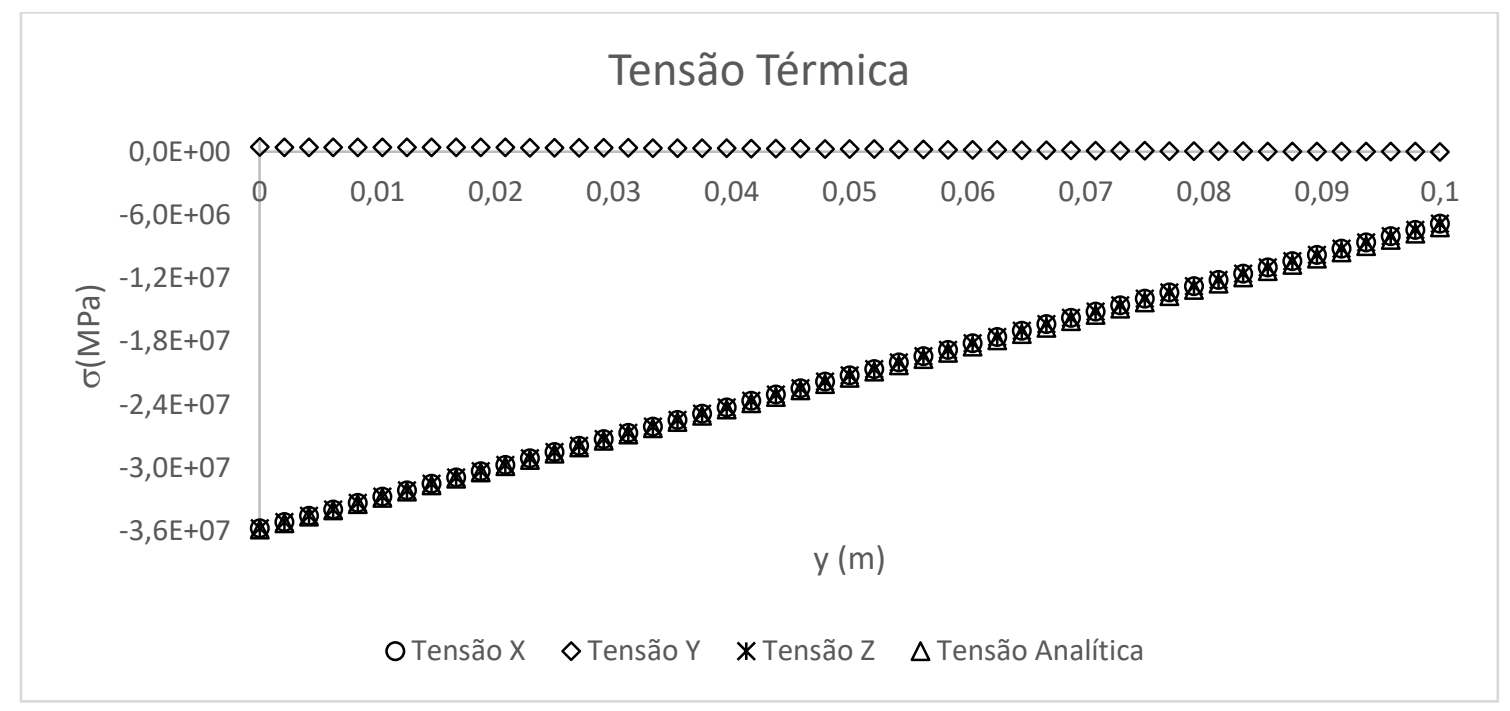

Figura 5.32 - Comparação analítica-numérica para os pontos centrais em y.

Para um ponto qualquer do corpo, Figura 5.33, de onde foram extraídas as temperaturas e tensões em função do tempo, em segundos, observa-se que os resultados de ambos foram 
condizentes com os resultados analíticos, com boa precisão. Dessa forma, afirma-se que as tensões elásticas transientes ou estáticas podem ser tratadas com o programa de MEF.

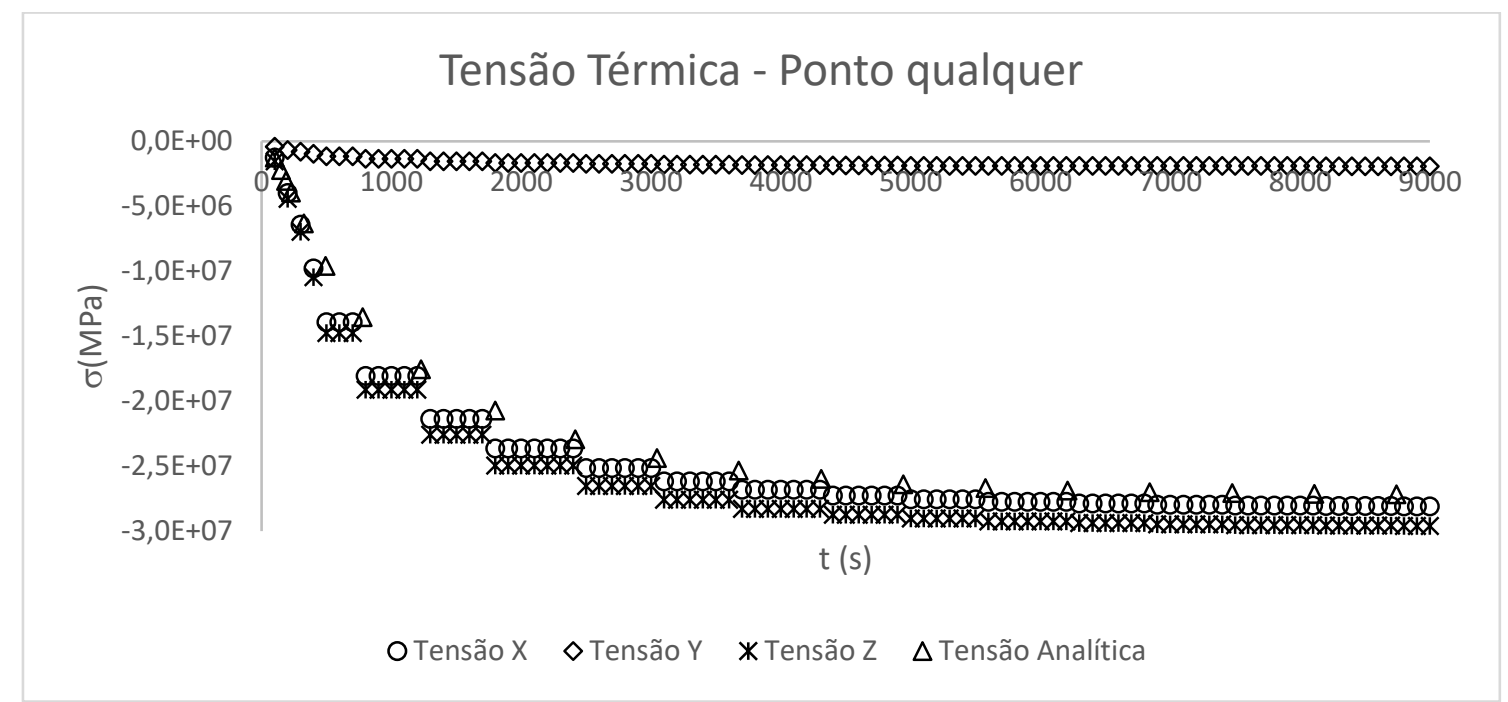

Figura 5.33 - Comparação analítico-numérica para um ponto em função do tempo.

Para este exemplo, encontra-se no apêndice $\mathrm{C}$ uma análise efetuada com o módulo de elasticidade variando com a temperatura.

\subsubsection{Tensões Viscoelásticas - problemas reais}

Para validação das tensões viscoelásticas foram simulados alguns problemas reais estudados por outros autores. Os casos investigados levam em consideração a presença de tubos de refrigeração e também a construção em camadas, conforme itens explorados a seguir.

\subsubsection{Viga da Serra da Mesa}

Gambale et al (2003); Santos et al (2005); e Santos (2004), apresentam análises térmicas e mecânicas para a seção transversal de uma viga suporte de rolamento da ponte rolante da UHE Serra da Mesa, conforme Figura 5.34, descrita por Furnas (1997). A viga possui tubos de pós-refrigeração e $130 \mathrm{~m}$ de comprimento longitudinal, portanto foi analisada apenas uma seção transversal, hipótese bidimensional. 


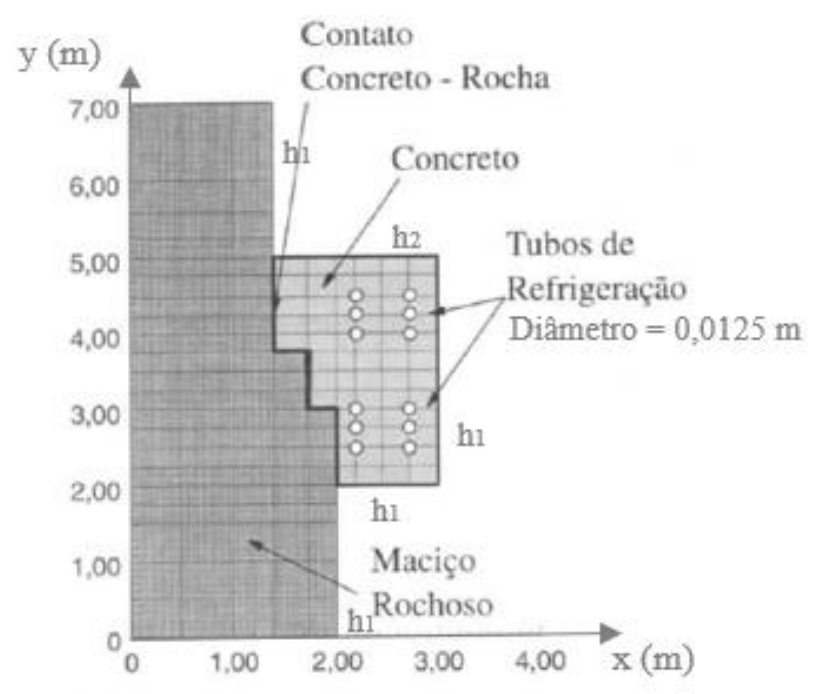

Figura 5.34 - Viga analisada (Furnas, 1997).

Para a análise térmica, as propriedades da viga, Tabela 5.3, foram consideradas iguais as da fundação, pelo fato do agregado ser do mesmo tipo litológico (Gambale et al 2003).

Tabela 5.3 - Propriedades da viga.

\begin{tabular}{|l|l|}
\hline Propriedades Térmicas & Valor \\
\hline Massa específica $\left(\mathrm{kg} / \mathrm{m}^{3}\right)$ & 2395 \\
\hline Condutividade térmica $\left(\mathrm{W} / \mathrm{m}{ }^{\circ} \mathrm{C}\right)$ & 2,27 \\
\hline Calor específico $\left(\mathrm{J} / \mathrm{kg}{ }^{\circ} \mathrm{C}\right)$ & 1063 \\
\hline Coeficiente de convecção concreto/ar $\left(\mathrm{W} / \mathrm{m}^{2}{ }^{\circ} \mathrm{C}\right)-\mathrm{h}_{1}$ & 12 \\
\hline Coeficiente de convecção concreto/agua de cura $/ \mathrm{ar}\left(\mathrm{W} / \mathrm{m}^{2}{ }^{\circ} \mathrm{C}\right)-\mathrm{h}_{2}$ & 300 \\
\hline Temperatura de lançamento do concreto $\left({ }^{\circ} \mathrm{C}\right)$ & 30 \\
\hline Temperatura do pós-resfriamento $\left({ }^{\circ} \mathrm{C}\right)$ & 30 \\
\hline Temperatura da fundação $\left({ }^{\circ} \mathrm{C}\right)$ & 30 \\
\hline
\end{tabular}

A temperatura adiabática $\left(T_{a d}\right)$ do concreto em função do tempo $(t)$ é dada conforme o gráfico da Figura 5.35. A partir do gráfico foi feito o ajuste da curva chegando a Equação 5.43:

$$
T_{a d}=\frac{t^{1,55}}{1,07^{1,55}+t^{1,55}}
$$




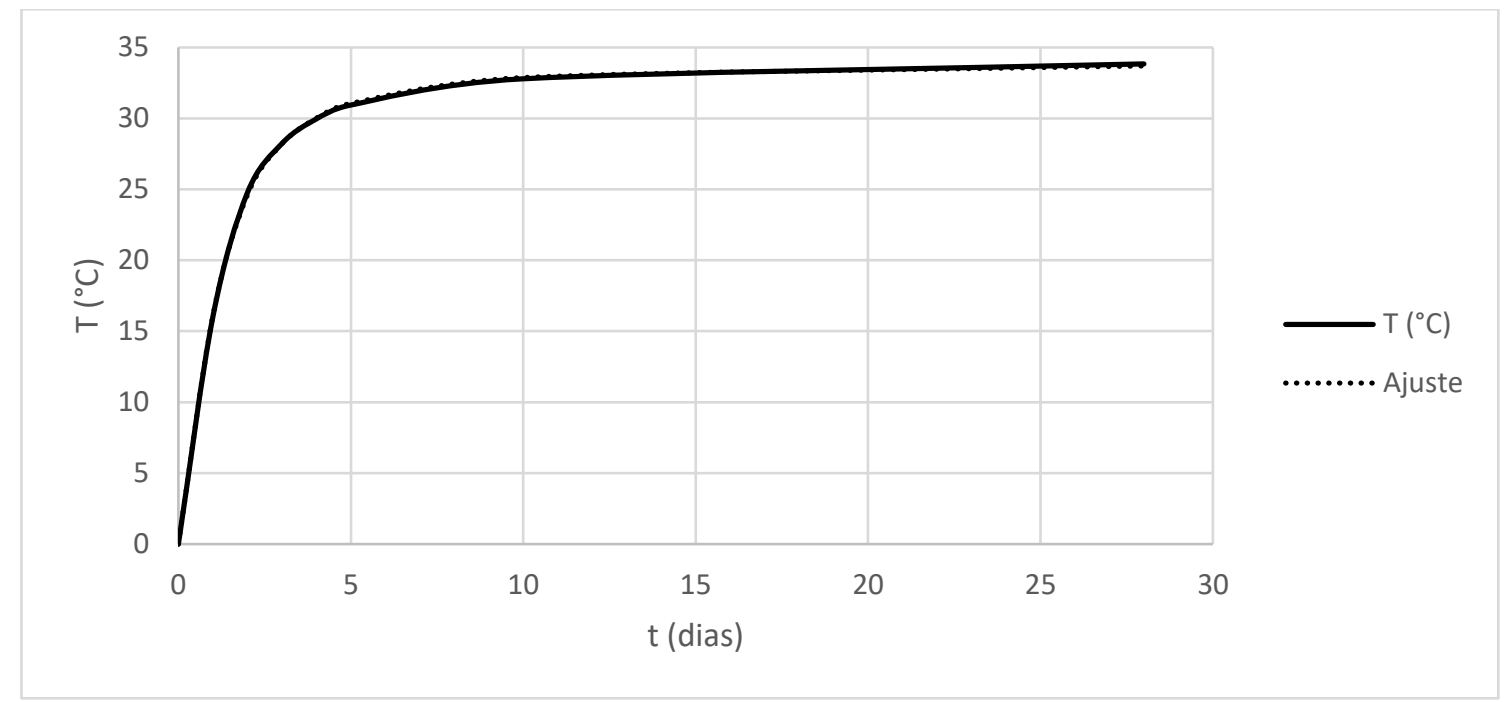

Figura 5.35 - Temperatura adiabática para a viga.

$\mathrm{Na}$ análise térmica para este exemplo foram utilizados 41867 nós e 9920 elementos.

A Figura 5.36 mostra o ponto de análise das temperaturas em função do tempo, T, para a comparação dos resultados.

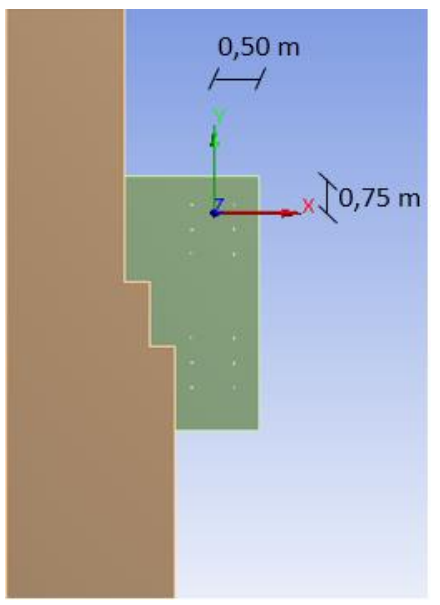

Figura 5.36 - Ponto T analisado.

A Figura 5.37 mostra os perfis de temperatura para os pontos analisados por Gambale et al (2003) - TG, por Santos et al (2005) - TS e pelo trabalho atual - T. Nota-se, nas primeiras idades, uma queda de temperatura e no momento em que é deligado a circulação de água, aproximadamente quatro dias, a temperatura volta a subir. As diferenças entre as temperaturas observadas para as três isotermas (TG, TS e T) ocorrem em virtude de não haver exatidão dos pontos de análise, bem como nos valores dos parâmetros utilizados pelos autores. 


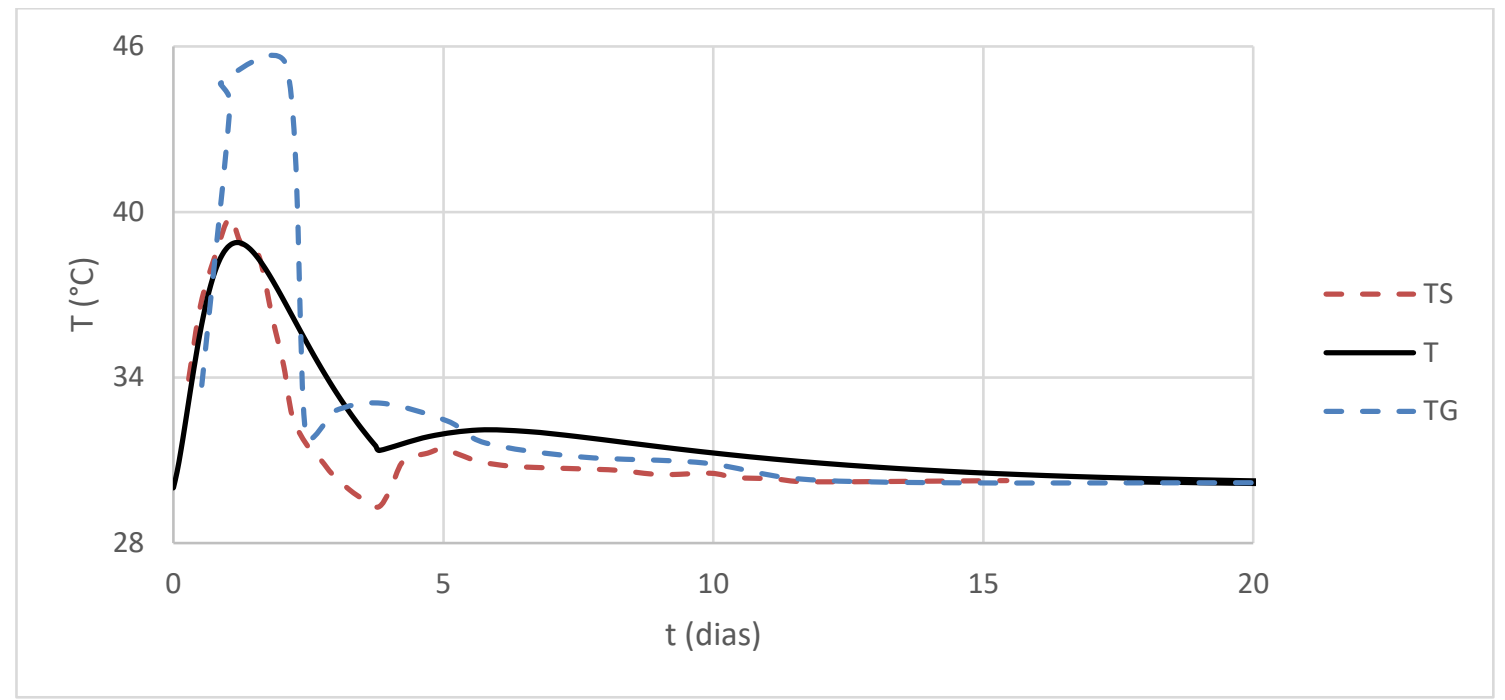

Figura 5.37 - Temperaturas para um ponto da viga.

Para a análise mecânica, o módulo de elasticidade - E (GPa), o coeficiente de fluência - $\phi$ $\left(10^{-6} \mathrm{MPa}\right)$ e a resistência à tração $-\mathrm{f}_{\mathrm{t}}(\mathrm{MPa})$ foram definidas por Gambale et al (2003) e Santos et al (2005) pelas Equações 5.44, 5.45 e 5.45 .

$$
\begin{array}{r}
E(z)=\frac{z}{0,08609+0,04225 z} \\
\varnothing(z)=\frac{z}{5,976+14,700 z} \\
f_{t}(z)=\frac{z}{1,053+0,2816 z}
\end{array}
$$

A Figura 5.38 mostra as tensões, a partir das curvas de temperatura da Figura 5.35, obtidas por Gambale et al (2003) - SG, por Santos et al (2005) - SS, pelo trabalho atual - S e obtidas por leituras de extensômetros inseridos na viga - SL. Todas as curvas (SG, SS, S e SL) apresentam comportamentos similares, ou seja, uma compressão seguida de tração térmica. No entanto, a comparação não é perfeita em virtude da discrepância dos parâmetros utilizados, como relatado anteriormente. Quanto maiores as temperaturas, maiores as tensões, sejam de tração ou compressão. O pico que representa a queda de temperatura também é evidenciado nas curvas de tensões, em que se percebe o momento de desligamento dos tubos de resfriamento. Pela curva de resistência à tração - $\mathrm{f}_{\mathrm{t}}$, dada pela Equação 5.46, em nenhuma das hipóteses, esta seria ultrapassada. 


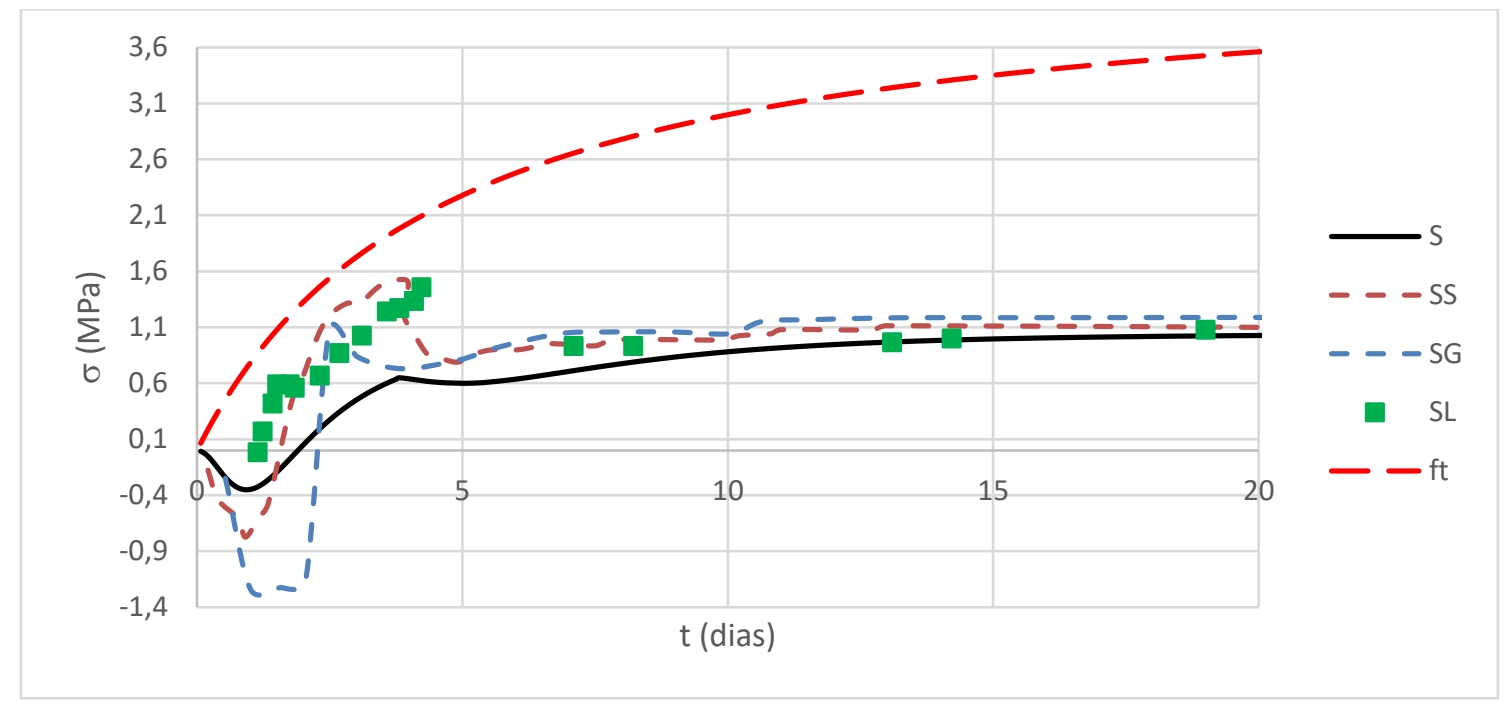

Figura 5.38 - Comparação das tensões para a viga.

A fim de representar e observar as isotermas de temperatura para um determinado instante do tempo da viga com e sem a consideração dos tubos de pós-refrigeração, as Figuras 5.39a e $5.39 \mathrm{~b}$ mostram, no tempo de $104970 \mathrm{~s}$, as isotermas para a máxima temperatura atingida nas duas situações. Para as disposições dos tubos de resfriamento, verifica-se uma diferença significativa nas distribuições das temperaturas, estando as máximas concentradas em uma região bem menor (Figura 5.39a) quando comparadas com a viga sem os tubos de refrigeração (Figura 5.39b). No entanto, a diferença entre a máxima temperatura alcançada foi de apenas $1,707^{\circ} \mathrm{C}$, ou 3,6\% . Assim, deve-se avaliar a viabiliadade de inserção de tubos de pós-resfriamento e suas respectivas disposições. Ressalta-se que para a modelagem os tubos foram modelados como sendo cilindros vazios com temperaturas uniforme de $30^{\circ} \mathrm{C}$ no seu contorno, e não como pontos dentro da massa. 

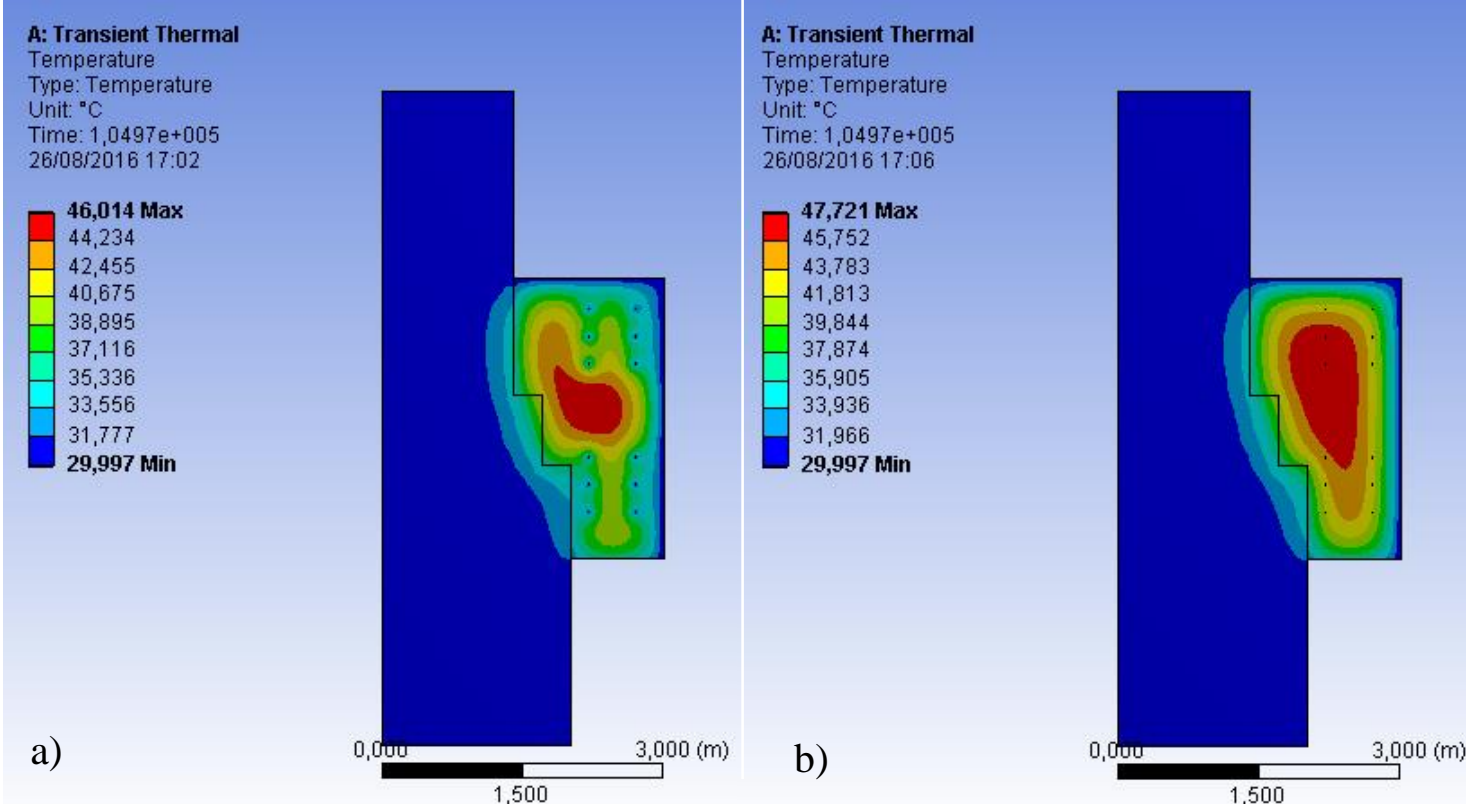

Figura 5.39 - a) Isotermas com presença de tubos de resfriamento; b) Isotermas com tubos desativados

\subsubsection{Laje}

Gomes (2011) estudou uma laje de reservatório com as dimensões mostradas na Figura 5.40. Devido às condições de simetria a figura representa apenas metade da estrutura. A malha utilizada contém 11079 nós e 3421 elementos.

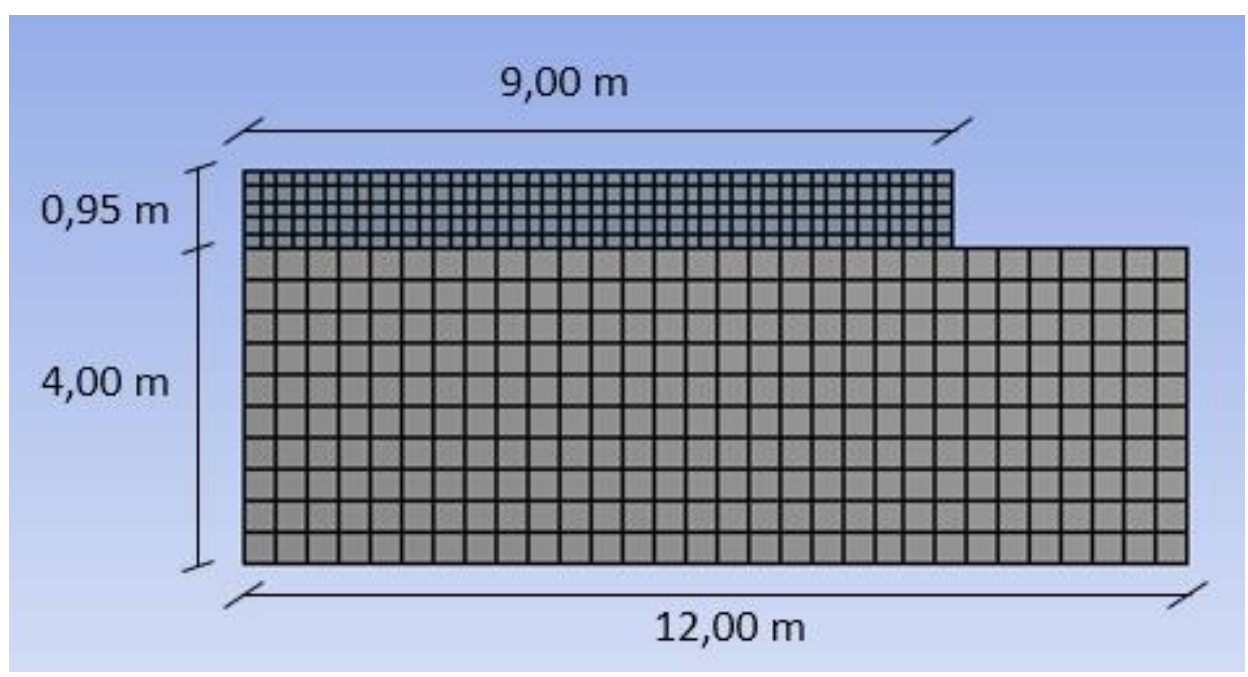

Figura 5.40 - Geometria e malha utilizadas na laje.

As propriedades do concreto foram consideradas iguais as da fundação, conforme a Tabela 5.4 . 
Tabela 5.4 - Propriedades utilizadas para laje.

\begin{tabular}{|l|l|}
\hline Propriedades do concreto & Valor \\
\hline Condutividade térmica $\left(\mathrm{kJ} / \mathrm{mh}^{\circ} \mathrm{C}\right)$ & 9,36 \\
\hline Calor específico $\left(\mathrm{kJ} / \mathrm{kg}^{\circ} \mathrm{C}\right)$ & 0,89845 \\
\hline Massa específica $\left(\mathrm{kg} / \mathrm{m}^{3}\right)$ & 2370 \\
\hline Coeficiente de dilatação térmica $\left({ }^{\circ} \mathrm{C}^{-1}\right)$ & $10^{-5}$ \\
\hline Temperatura ambiente $\left({ }^{\circ} \mathrm{C}\right)$ & 27 \\
\hline Temperatura inicial da fundação $\left({ }^{\circ} \mathrm{C}\right)$ & 27 \\
\hline Temperatura de lançamento do concreto $\left({ }^{\circ} \mathrm{C}\right)$ & 33 \\
\hline $\begin{array}{l}\text { Coeficiente de convecção da fundação } \\
\left(\mathrm{kJ} / \mathrm{m}^{2} \mathrm{~h}{ }^{\circ} \mathrm{C}\right)\end{array}$ & $\begin{array}{l}\text { Base horizontal e simetria }=0 \\
\text { Demais }=18\end{array}$ \\
\hline Coeficiente de convecção da laje $\left(\mathrm{kJ} / \mathrm{m}^{2} \mathrm{~h}^{\circ} \mathrm{C}\right)$ & $\begin{array}{l}\text { Até } 48 \mathrm{~h}=1080 \\
\text { Após } 48 \mathrm{~h}=18\end{array}$ \\
\hline
\end{tabular}

A elevação adiabática, o módulo de elasticidade e a resistência à compressão do concreto foram definidas de acordo com como as Equações 5.47, 5.48 e 5.59.

$$
\begin{gathered}
T_{a d}=51,75(1-\exp (-1,25 t)) \\
E=0,043 \cdot 2370^{1,5} f_{c}^{0,5}+0,01 \\
f_{c}=35 \frac{t}{4+0,85 t}
\end{gathered}
$$

A partir dos dados de entrada, o perfil de temperatura para o ponto de temperatura máxima -T foi esboçado e comparado com os resultados obtidos por Gomes (2011) - TG, conforme a Figura 5.41. Observa-se que nas primeiras horas a evolução das temperaturas coincidem, afastando-se um pouco, mas seguindo a mesma tendência, a partir do segundo passo de tempo. Isso pode ter ocorrido em virtude do pouco refinamento da discretização temporal do modelo. O segundo passo de tempo é definido no momento em que se muda o coeficiente de convecção, simulando o fim da cura úmida. Foram utilizados dois passos de tempo, o primeiro até $172800 \mathrm{~s}$ dividido em 25 subpassos, $\Delta \mathrm{t}=6912 \mathrm{~s}$; e o segundo passo de tempo de $172800 \mathrm{~s}$ até $2160000 \mathrm{~s}$ divido em 200 subpassos, $\Delta \mathrm{t}=9936 \mathrm{~s}$. 


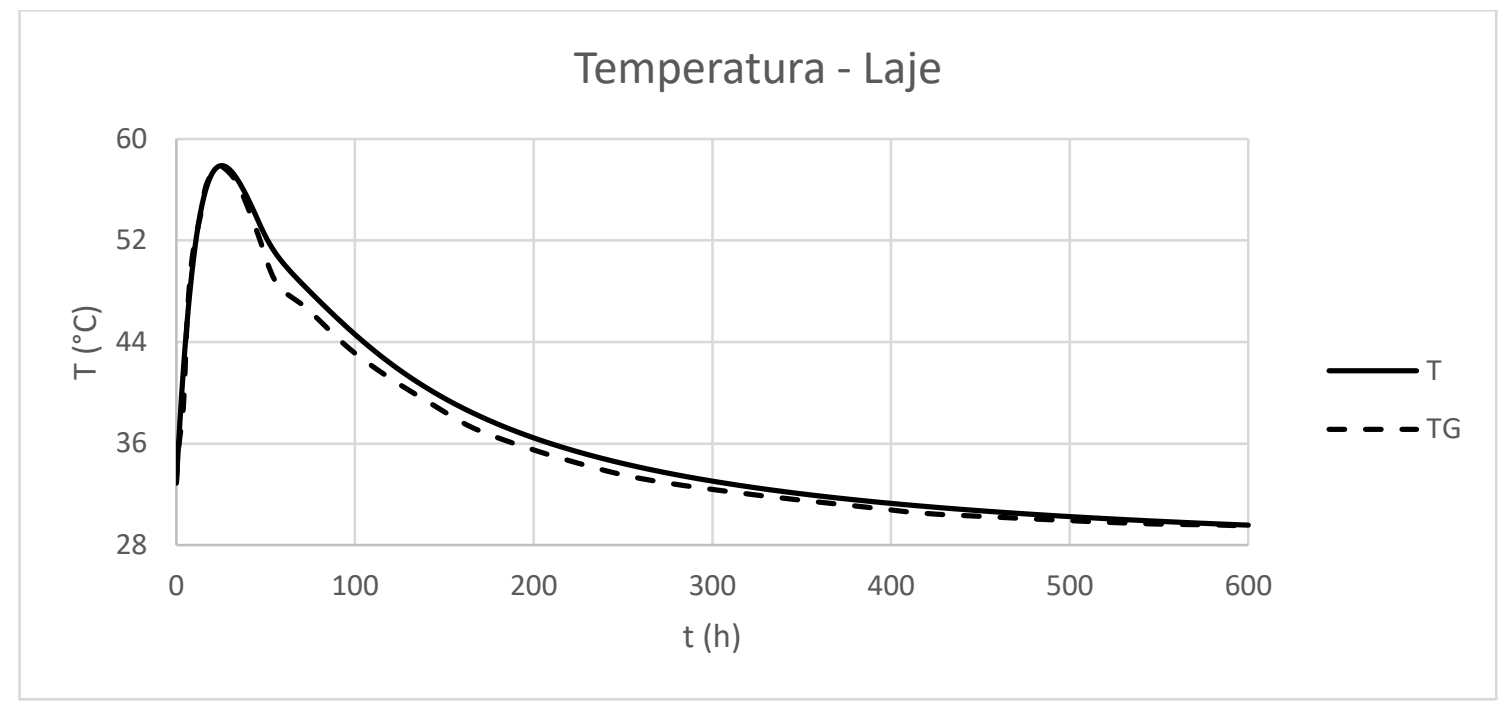

Figura 5.41 - Comparação das máximas temperaturas da laje.

A Figura 5.42, mostra as isotermas de temperatura para a laje no momento que atinge a temperatura máxima, $58,4^{\circ} \mathrm{C}$, no tempo de $96768 \mathrm{~s}$ ou $26,88 \mathrm{~h}$. A princípio, a fundação praticamente não sofreu influencia termica da laje. A laje, por sua vez, apresenta-se quase totalmente com sua temperatura máxima, verificando-se também a influência da temperatura do contorno sobre ela, quando ainda está no processo de cura.

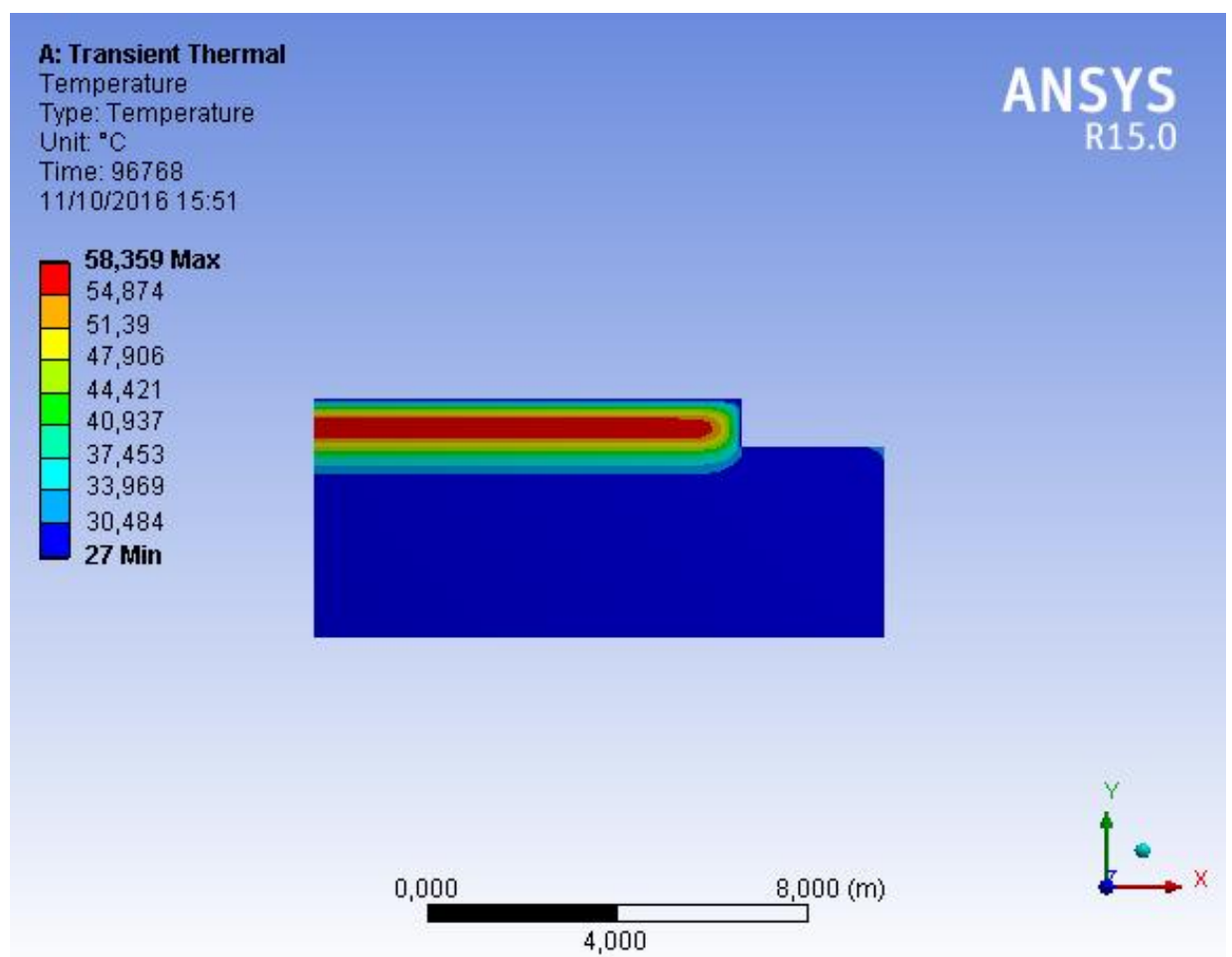

Figura 5.42 - Isotermas de temperatura para a laje. 
Com as temperaturas foram calculadas as tensões pelo método de fluência do ACI, mesma função utilizada por Gomes (2011). Pela Figura 5.43, nota-se que as tensões calculadas neste trabalho $-\mathrm{S}$ apresentaram valores equivalentes nas mesmas idades para as tensões calculadas pelo autor - SG. Constata-se também que as tensões de tração calculadas estão abaixo da linha de resistência de tração do concreto, portanto, não há possibilidade de fissuração da laje com as caracteristicas utilizadas.

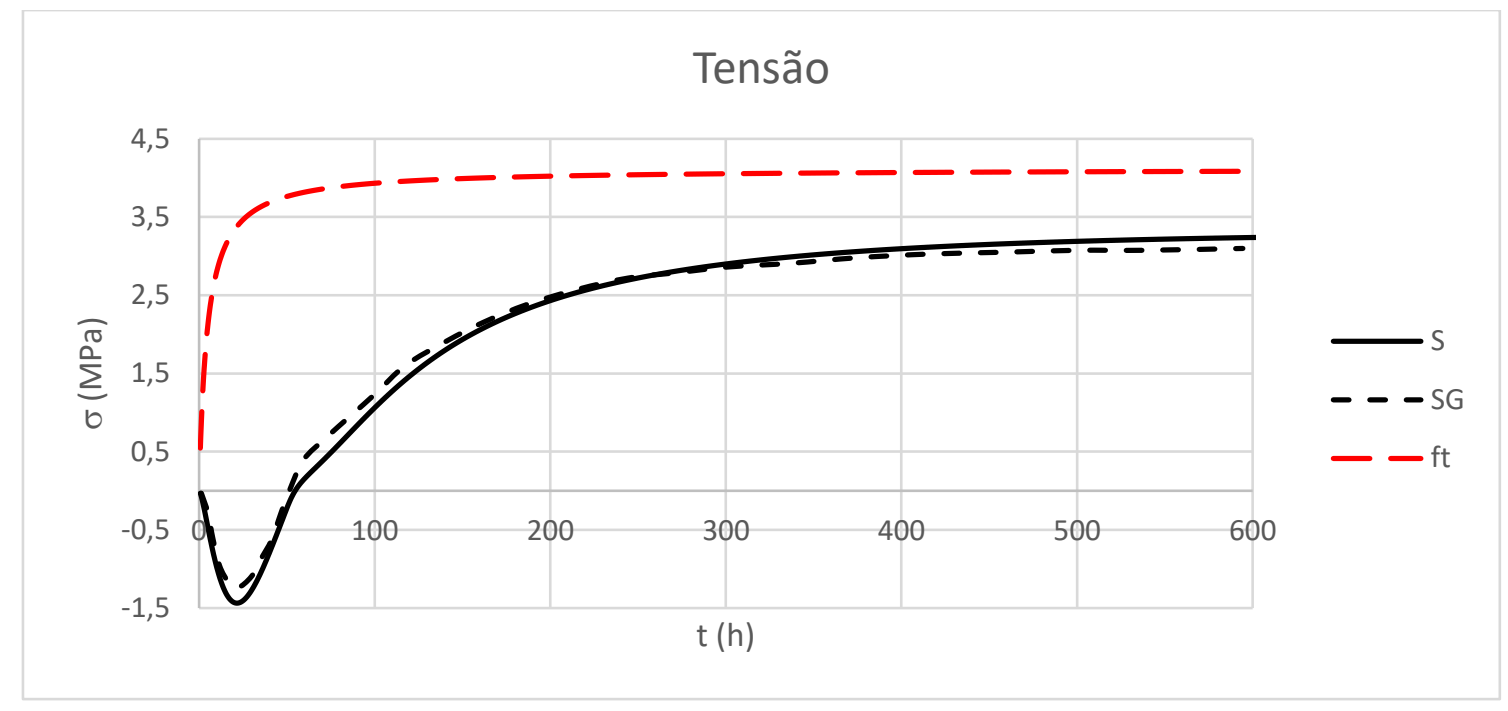

Figura 5.43 - Tensões térmicas para a laje.

\subsubsection{Muro}

Para verificação e validação das tensões de fluência, foram feitas análises no muro estudado por Gomes (2011) e Azenha (2004). O muro possui 0,4 m de espessura. Para viabilizar o tempo nas análises, faz-se uso da simetria, simulando apenas metade deste, visto que, sendo as condições de contorno - CC iguais, as temperaturas e tensões podem ser espelhadas para a outra metade do corpo.

Desta forma, a estrutura apresenta as dimensões da Figura 5.44, com espessura de 0,2 m e altura de 3,0 m; fundação com 1,5 m de espessura e 1,0 m de altura. Para o comprimento foi adotado $0,5 \mathrm{~m}$, para agilizar o tempo de processamento, tendo em vista que, devido a simetria, o aumento desse valor, não provoca alterações nas temperaturas.

Os pontos de verificação foram o ponto central - PC situado na metade do muro, 1,5 m, um ponto a $0,1 \mathrm{~m}$ do topo - PT e um ponto a 0,1 $\mathrm{m}$ da base - PB. Esses distanciamentos de 0,1 $\mathrm{m}$ são colocados para reduzir a influência das CC nesses locais. 


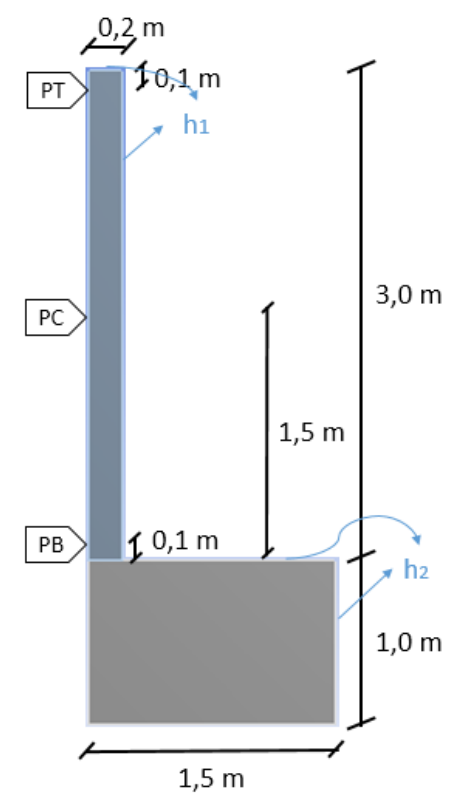

Figura 5.44 - Dimensões do muro.

A modelagem foi feita com o ANSYS Workbench, que utilizou o elemento SOLID90, por default. Para a região do muro, a malha foi refinada com elementos de 0,05 m, gerando um total de 3157 nós e 480 elementos. Na fundação foram utilizados 714 nós e 88 elementos. Totalizando 3871 nós e 727 elementos. Como incremento temporal, um tempo de 1728000 s foi dividido em 300 subpassos. Ressalta-se que o número de elementos e passos de tempo adotados teve como valores que levaram à convergência dos resultados, ou seja, um maior refinamento, seja do tempo ou da malha, não alterariam os resultados obtidos.

Como propriedades dos materiais foram adotados os valores exibidos na Tabela 5.5.

Tabela 5.5 - Propriedades térmicas utilizadas para o muro.

\begin{tabular}{|l|c|c|}
\hline Propriedade & Valor & Unidade \\
\hline Massa específica $(\rho)$ & 2393,0 & $\mathrm{Kg} / \mathrm{m}^{3}$ \\
\hline Calor específico $(\mathrm{c})$ & 898,5 & $\mathrm{~J} / \mathrm{kg}^{\circ} \mathrm{C}$ \\
\hline Condutividade térmica $(\mathrm{k})$ & 2,6 & $\mathrm{~W} / \mathrm{m}^{\circ} \mathrm{C}$ \\
\hline Coeficiente de convecção da fundação $-\mathrm{h}_{2}$ & 5,0 & $\mathrm{~W} / \mathrm{m}^{2 \circ} \mathrm{C}$ \\
\hline Coeficiente de convecção do muro $-\mathrm{h}_{1}$ & 3,1 & $\mathrm{~W} / \mathrm{m}^{2}{ }^{\circ} \mathrm{C}$ \\
\hline $\begin{array}{l}\text { Temperatura ambiente e temperatura } \\
\text { inicial do concreto }\end{array}$ & 20 & ${ }^{\circ} \mathrm{C}$ \\
\hline Temperatura adiabática do concreto $\left(\mathrm{T}_{\mathrm{ad}}\right)$ & $T_{a d}=59,44 \cdot \frac{t^{2,831}}{13,62^{2,831}+t^{2,831}}$ & ${ }^{\circ} \mathrm{C}$ \\
\hline
\end{tabular}


A Figura 5.45 apresenta os resultados de temperatura (ordenada) ao longo do tempo (abscissa), em PT, PC e PB, para Azenha (2004) - simbolizado por A (representado por linhas traço e ponto), para Gomes (2011) - simbolizado por G (linhas tracejadas) e, para o trabalho atual, em linhas contínuas. Observa-se que as tendências de todas as curvas são semelhantes e as temperaturas máximas atingidas ficam próximas. Contudo, os resultados do trabalho atual apresentam maior similaridade com os resultados de Gomes (2011), por este ter fornecido mais informações sobre o problema.

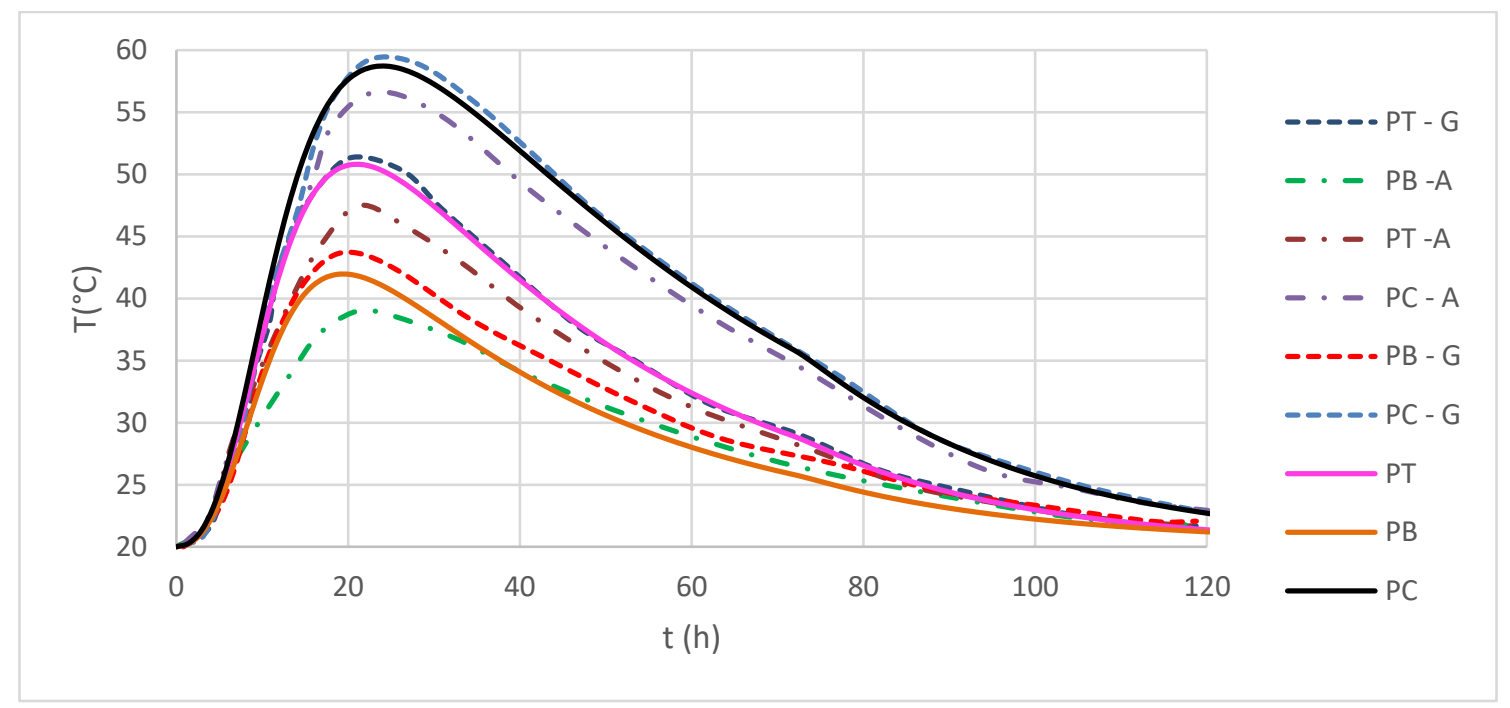

Figura 5.45 - Perfis de temperatura para o muro.

O concreto apresenta fluência no seu processo de carregamento e envelhecimento. Neste sentido, suas tensões não podem ser analisadas diretamente por intermédio de programação baseada no método dos elementos finitos como uma deformação plana. Faz-se necessário aplicar funções de fluência para que estes possam representar a realidade do concreto.

Embora o programa utilizado possua um modelo de fluência, este se difere dos conhecidos e apresentados anteriormente neste trabalho, não sendo possível utilizá-lo como ferramenta de cálculo de tensões.

Desta forma, as tensões aqui apresentadas foram calculadas analiticamente, com suporte de programações no MATLAB 12.0 para solução de matrizes, a partir de um histórico de temperaturas em determinados pontos no tempo. 
Para a análise de tensões, Gomes (2011) utilizou o método USBR e Azenha (2004), o método de dupla potência - DP, também conhecido como Bazant-Panula. Neste trabalho foram utilizados os dois métodos e comparados com os resultados dos autores citados. A Tabela 5.6 traz os dados necessários para aplicação dos métodos.

Tabela 5.6 - Propriedades mecânicas para o muro.

\begin{tabular}{|l|c|c|}
\hline Propriedade & USBR & DP \\
\hline Módulo de elasticidade - E (MPa) & $E=29420 \frac{t^{2,0007}}{0,375^{2,007}+t^{2,0007}}$ \\
\hline Parâmetros da curva de fluência & $\mathrm{a}=14,36$ & $\phi_{0}=1,28$ \\
& $\mathrm{~b}=30,32$ & $\mathrm{~m}=0,35$ \\
& & $\mathrm{n}=0,30$ \\
\hline
\end{tabular}

Ressalta-se que os resultados das análises de tensão obtidos por Azenha (2004) e Gomes (2011) são diferenciados através da identificação A e G, respectivamente.

A Figura 5.46 apresenta os resultados da análise de tensões em PC, ponto central do muro (sem multiplicar pelo coeficiente de restrição), somente para Azenha (2004) e o trabalho atual, tendo em vista que Gomes (2011) não apresentou esta análise. Observa-se que ambos os resultados apresentaram a mesma tendência, com diferença de aproximadamente 12,3\% na máxima tensão de tração e 4,6\% na máxima compressão, observadas nas idades de 20 e $120 \mathrm{~h}$ do concreto, respectivamente; as idades posteriores para a tração não foram analisadas. Neste caso, ainda não está sendo levado em consideração o comprimento do muro.

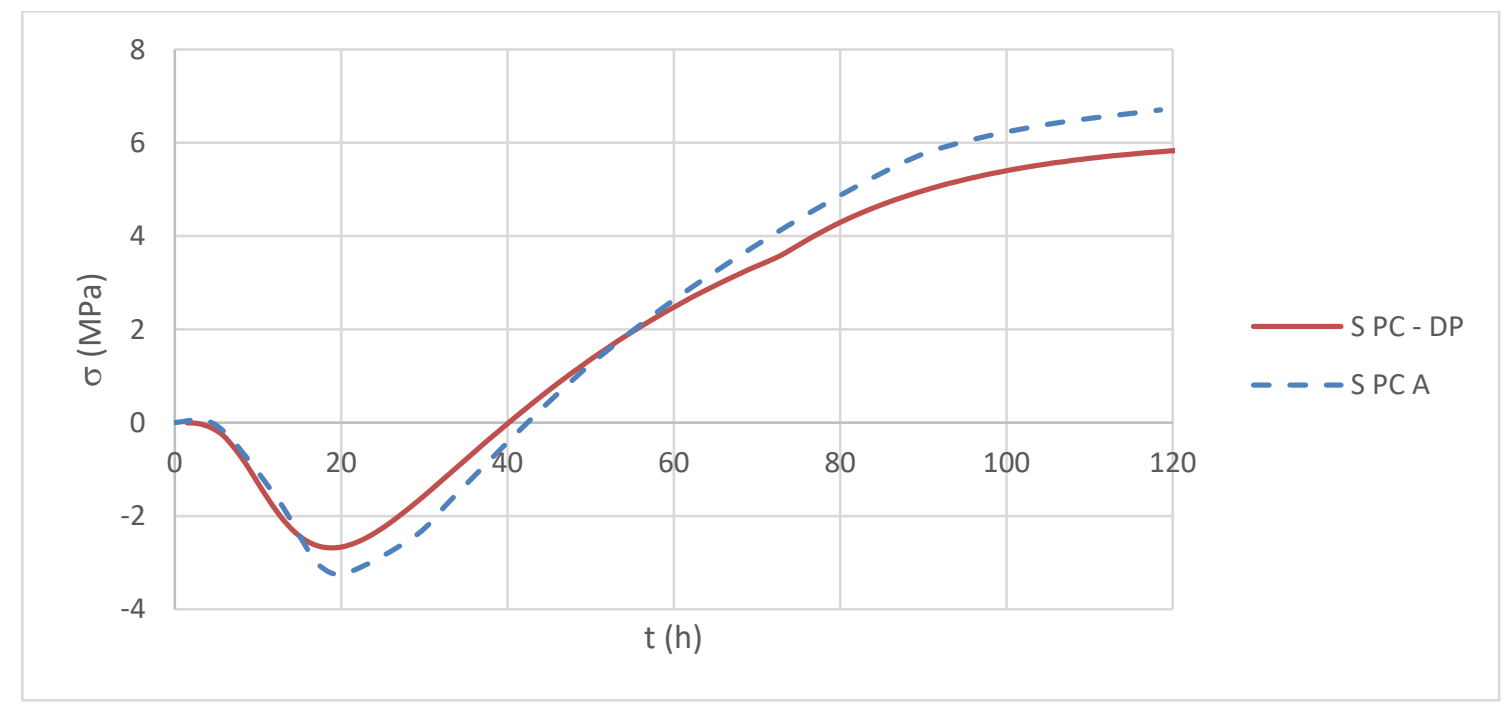

Figura 5.46 - Tensões para o muro. 
Considerando o muro com comprimento de $8,0 \mathrm{~m}$, há a necessidade de multiplicar as tensões obtidas na Figura 5.47, pelo coeficiente de restrição (Kr). Gomes (2011) utilizou $\mathrm{Kr}=0,225$ e Azenha (2004), $\mathrm{Kr}=0,420$, ambos os valores são obtidos por meio de ábacos, Azenha (2004) utiliza o ábaco do ACI 207-2R (2007) para o coeficiente de restrição, enquanto Gomes (2011) utiliza um ábaco mostrado no seu próprio trabalho. Os resultados das curvas de tensões obtidas a partir da reprodução dos métodos estudados pelos autores são equivalentes. No entanto, entre os métodos, há uma diferença de aproximadamente 39,33\% nas tensões de tração no tempo final da análise, mesmo seguindo uma tendência. Neste caso, o método DP apresenta maior probabilidade de fissuração.

Azenha (2004) ainda apresentou para o tempo de $120 \mathrm{~h}$ as tensões para um modelo tridimensional com o programa DIANA. O resultado para este modelo, representado por um ponto, denominado no gráfico como $3 D 8 A$, também é comparado na Figura 5.47, cujo resultado ficou próximo do valor encontrado pela DP.

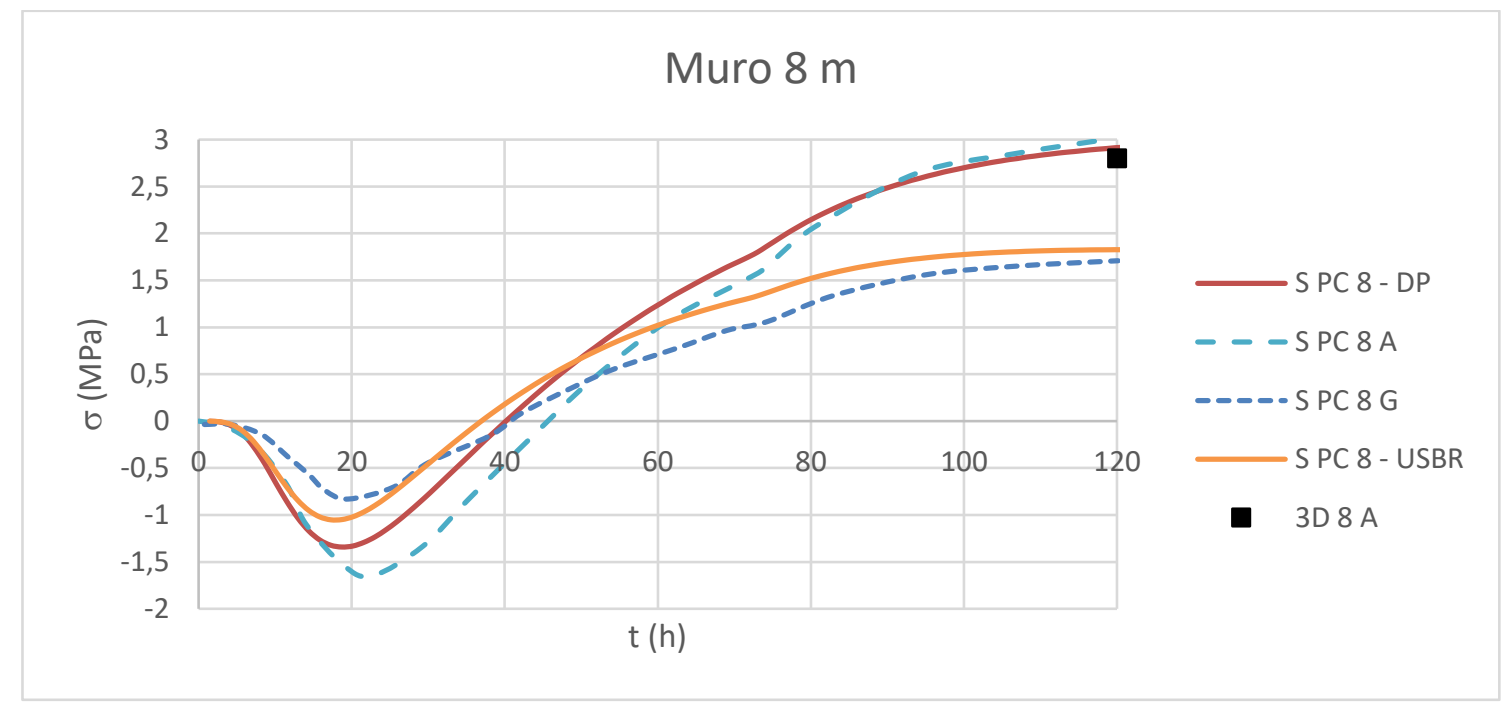

Figura 5.47 - Tensões para o muro de 8,0 m.

Para o muro com 16,0 m de comprimento, Figura 5.48, os coeficientes de restrição foram $\mathrm{Kr}$ $=0,492(\mathrm{USBR})$ e $\mathrm{Kr}=0,72(\mathrm{DP})$. Neste caso, para os diferentes métodos, as curvas de tensões ficaram mais próximas se compradas com os resultados obtidos para o muro de $8 \mathrm{~m}$, Figura 5.46, e as máximas tensões de tração se distanciaram em média 1,0\%. 


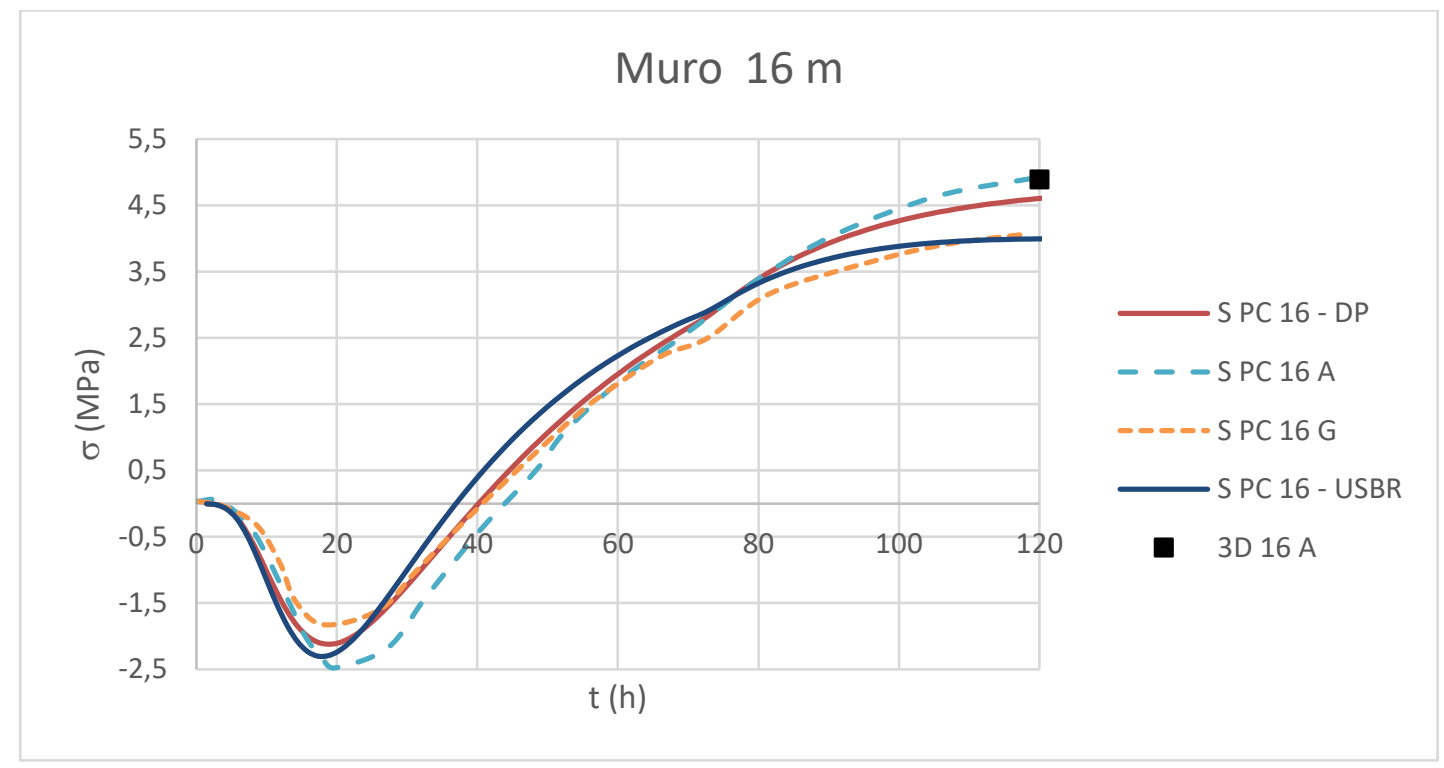

Figura 5.48 - Tensões para o muro de $16,0 \mathrm{~m}$.

Para o muro de 32,0 m, Figura 5.49, as tensões de tração e compressão foram semelhantes havendo uma diferença insignificante entre elas. As idades em que foram encontradas as máximas de tração e compressão também foram os mesmos. Os coeficientes de restrição neste caso foram $\mathrm{Kr}=0,808$ (USBR) e $\mathrm{Kr}=0,86$ (DP).

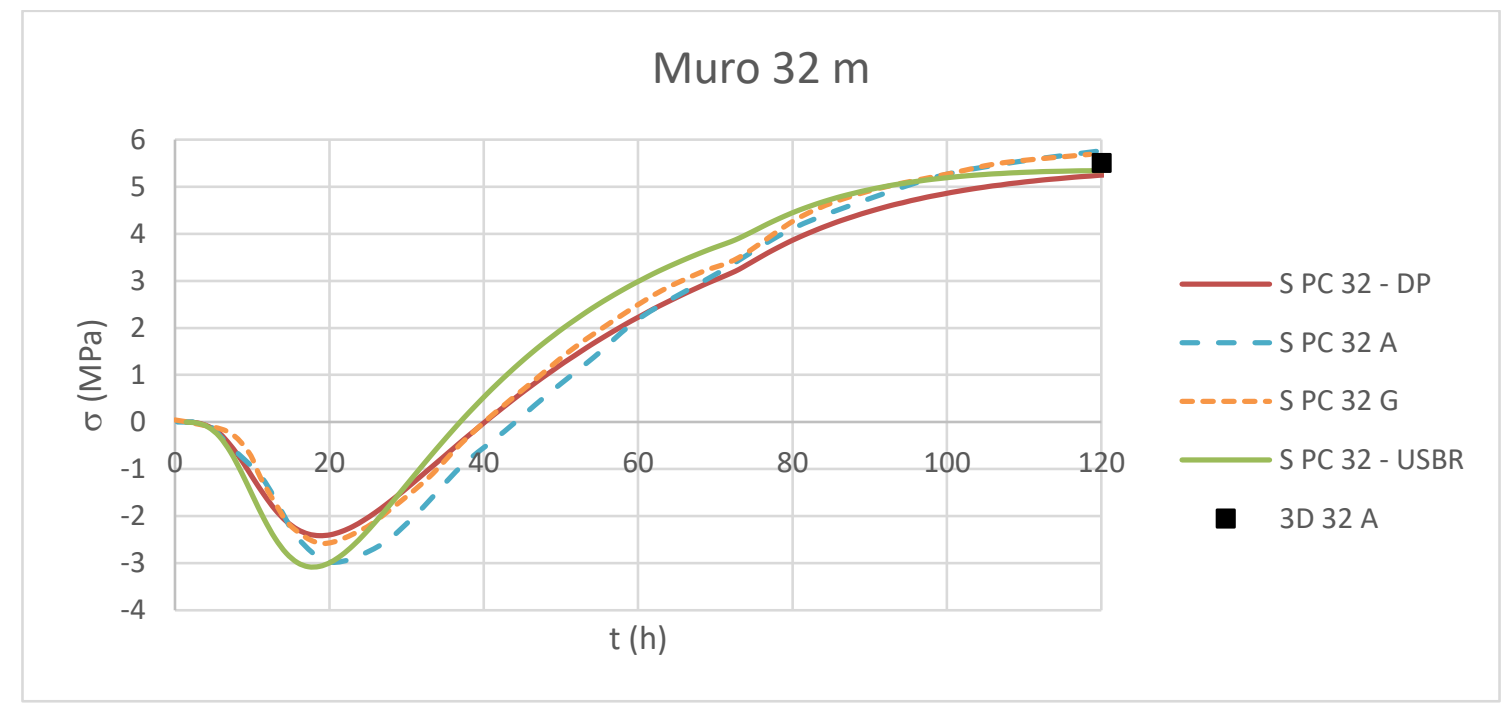

Figura 5.49 - Tensões para o muro de $8,0 \mathrm{~m}$.

\subsubsection{Sala de Radioterapia}

Funahashi Júnior et al (2010) publicaram os estudos realizados para a construção de uma sala de radioterapia, com paredes espessas e que não podia haver fissuração por causa da 
radiação. A sala apresenta as dimensões, em planta, da Figura 5.50, e o corte AA foi seção analisada. Foram instalados termopares na estrutura, pontos T1 e T4 a 1,10 m da fundação e T5 a 2,90 m da fundação.

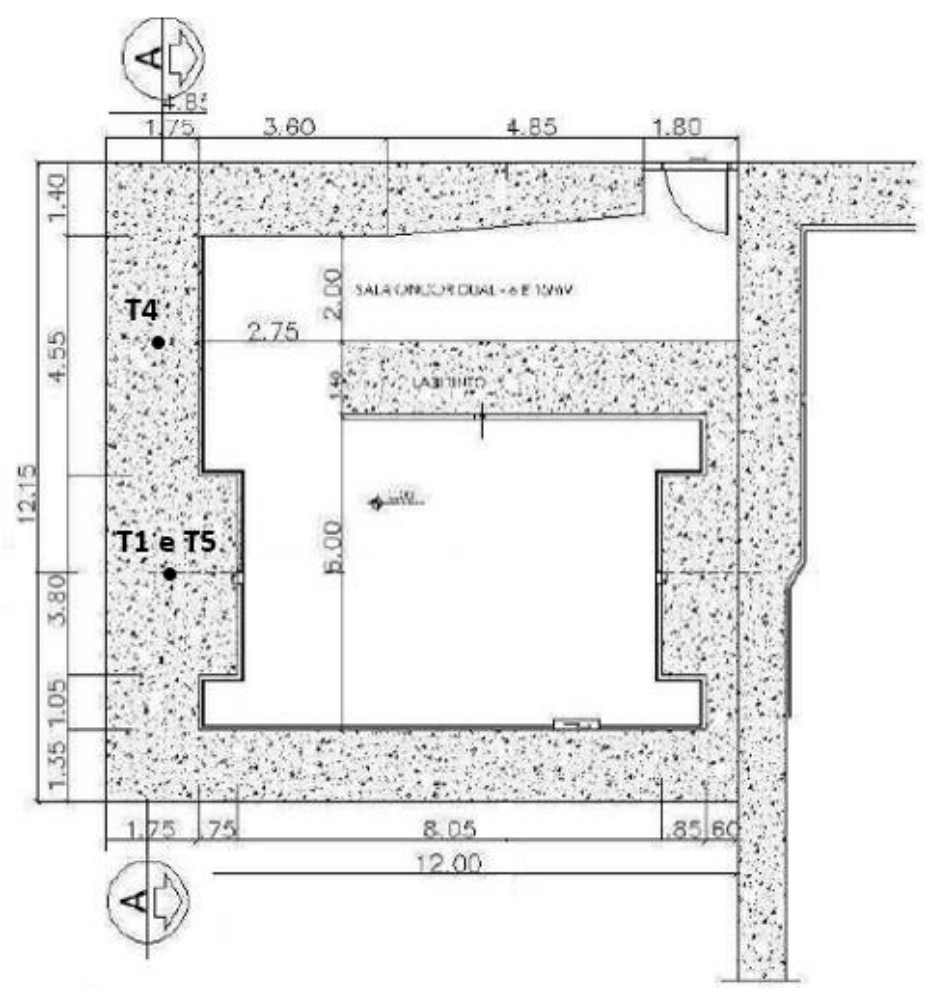

Figura 5.50 - Planta da sala.

A sala foi concretada em cinco fases, ou cinco camadas, como mostra a Figura 5.51. Foram verificados os perfis de temperatura dos pontos $\mathrm{A}, \mathrm{B}, \mathrm{C}$ e D.

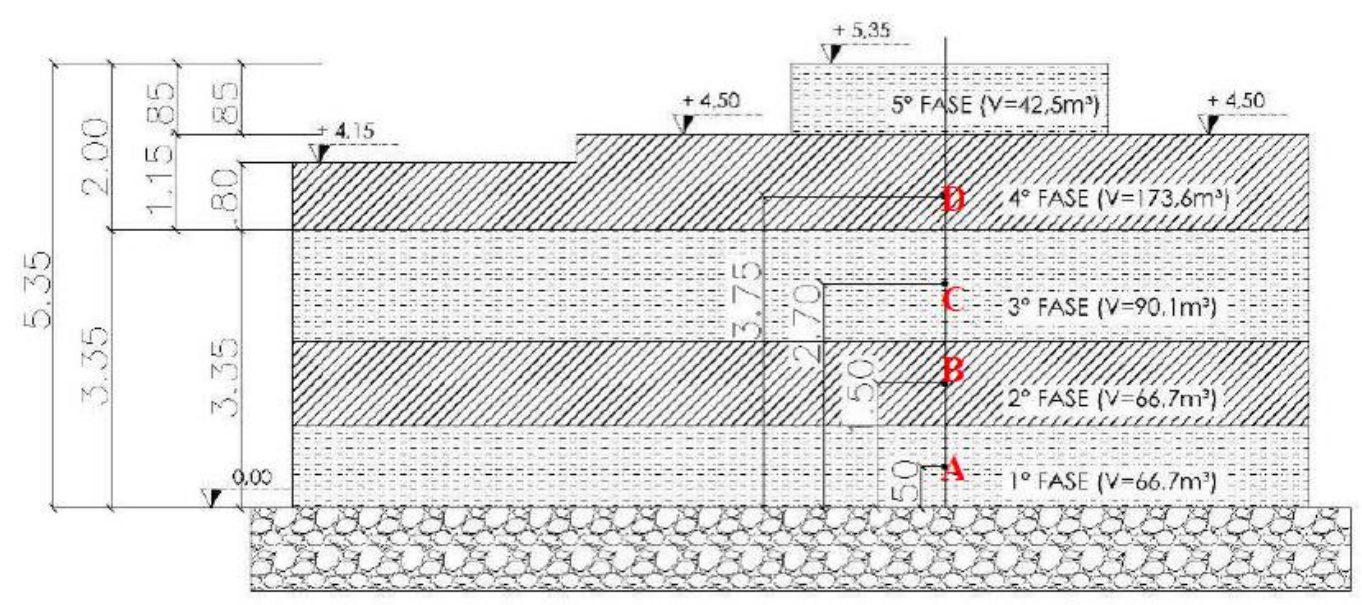

Figura 5.51 - Pontos analisados no muro.

As fases foram concretadas conforme o cronograma e características da Tabela 5.7, que mostra a parte da estrutura a qual a camada pertence, suas respectivas alturas e volumes, o 
intervalo de lançamento entre as camadas e as temperaturas de lançamento de cada uma delas.

Tabela 5.7 - Cronograma de concretagem.

\begin{tabular}{|c|c|c|c|c|c|}
\hline $\begin{array}{l}\text { Fase / } \\
\text { Camada }\end{array}$ & Estrutura & $\begin{array}{l}\text { Altura da } \\
\text { camada }(m)\end{array}$ & $\begin{array}{l}\text { Volume de } \\
\text { concreto }\left(\mathrm{m}^{3}\right)\end{array}$ & $\begin{array}{l}\text { Intervalo de } \\
\text { lançamento } \\
\text { (dias) }\end{array}$ & $\begin{array}{l}\text { Temperatura } \\
\text { de } \\
\text { lançamento }\end{array}$ \\
\hline $1^{\mathrm{a}}$ & \multirow[t]{3}{*}{ Paredes } & 1,00 & 66,7 & 3 & 14,5 \\
\hline $2^{a}$ & & 1,00 & 66,7 & 18 & 12,4 \\
\hline $3^{a}$ & & 1,35 & 90,1 & 42 & 18,8 \\
\hline $4^{a}$ & \multirow[t]{2}{*}{ Lajes } & 1,15 & 173,6 & 3 & 16,5 \\
\hline $5^{a}$ & & 0,85 & 42,5 & - & 16,5 \\
\hline
\end{tabular}

As propriedades térmicas da rocha e do concreto utilizados são mostrados na Tabela 5.8.

Tabela 5.8 - Propriedades da sala.

\begin{tabular}{|l|l|l|}
\hline Propriedade & Rocha & Concreto \\
\hline Massa específica $\left(\mathrm{kg} / \mathrm{m}^{3}\right)$ & 2840,00 & 2503,90 \\
\hline Calor específico $\left(\mathrm{kJ} / \mathrm{kg}^{\circ} \mathrm{C}\right)$ & 0,70 & 0,95 \\
\hline Condutividade térmica $\left(\mathrm{kJ} / \mathrm{mh}^{\circ} \mathrm{C}\right)$ & 6,80 & 6,25 \\
\hline
\end{tabular}

Os coeficientes de convecção foram utilizados conforme a Tabela 5.9. As fôrmas foram simuladas como colocadas no início da concretagem e retiradas quando a camada seguinte é lançada. Neste trabalho adotou-se como temperatura ambiente $20^{\circ} \mathrm{C}$.

Tabela 5.9 - Cronograma de concretagem.

\begin{tabular}{|l|l|}
\hline Tipo de troca & Coeficiente de convecção $\left(\mathbf{k J} / \mathbf{m}^{2} \mathbf{h}^{\circ} \mathbf{C}\right)$ \\
\hline Concreto-ar & 48,57 \\
\hline Concreto-água de cura & 1256,04 \\
\hline Concreto-fôrma-vento & 138,6 \\
\hline
\end{tabular}


A curva de elevação adiabática e o respectivo ajuste feito são mostrados na Figura 5.52. Nota-se que as curvas se sobrepõe, e tem-se uma curva assintótica, tendendo a $35^{\circ} \mathrm{C}$.

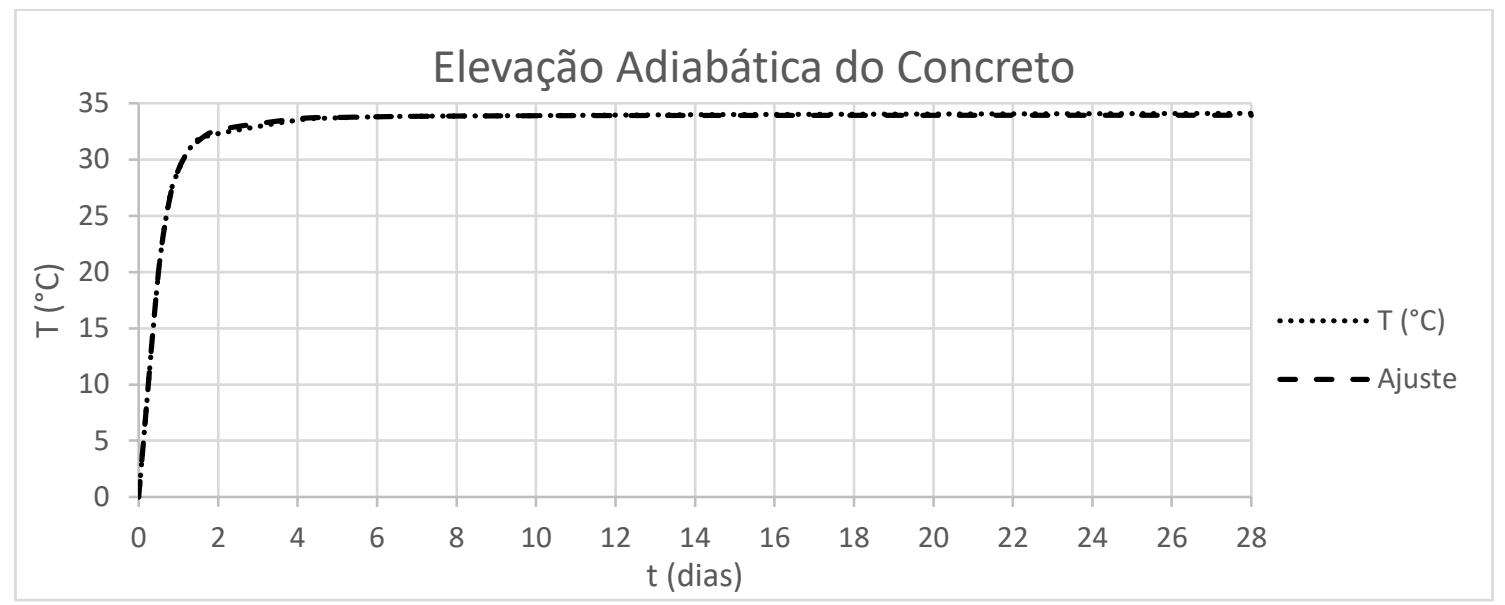

Figura 5.52 - Temperatura adiabática da sala.

Para a simulação térmica foram utilizados 44991 nós e 18524 elementos na malha, Figura 5.53, sendo que os elementos do concreto foram refinados para $0,1 \mathrm{~m}$. Havendo intervalos de tempo diferentes para as camadas, a primeira foi dividida em 20 subpassos, a segunda em 65, a terceira em 1500, a quarta em 15 e a quinta em 45 subpassos. Essa modelagem foi feita no ANSYS WORKBENCH e Funahashi et al 2010 utilizaram o programa B4CAST.

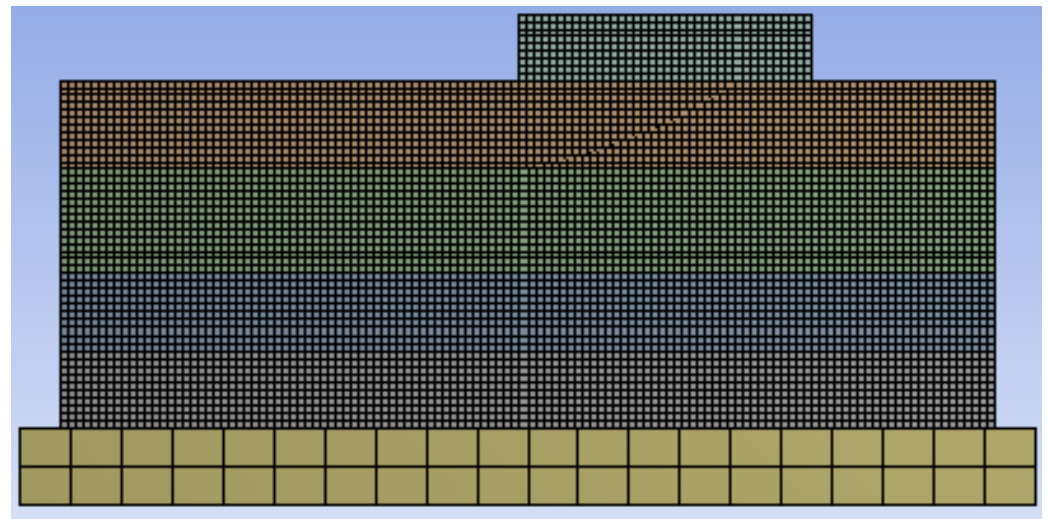

Figura 5.53 - Malha utilizada para análise da sala.

A Figura 5.54 mostra as isotermas de temperatura para a máxima temperatura atingida em $1911400 \mathrm{~s}$, ou 22,12 dias. Neste período a quarta e a quinta camada ainda não foram concretadas, portanto são desconsideradas pois estão desativadas, mesmo aparecendo na imagem. Nota-se que a máxima está na terceira e última camada concretada até o intervalo analisado. 


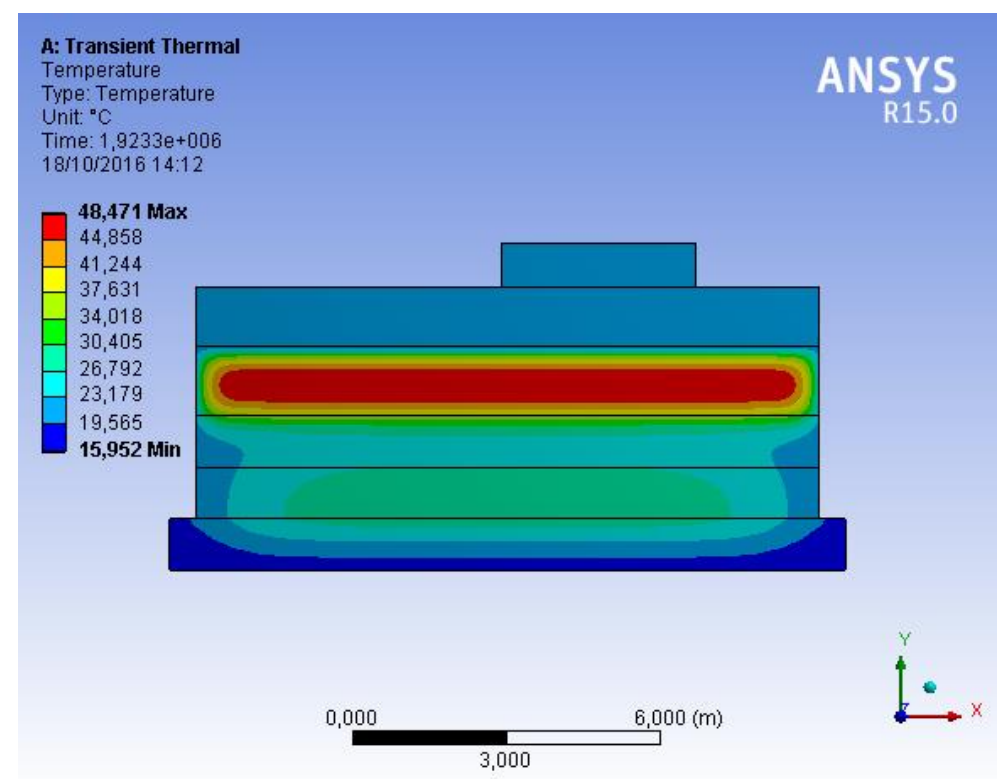

Figura 5.54 - Isotermas para a sala em 22,12 dias.

A fim de mostrar um perfil para a concretagem completa, a Figura 5.55, mostra as isotermas de temperatura no tempo de $6255400 \mathrm{~s}$, ou 72,40 dias. As análises foram efetuadas para 90 dias do lançamento da primeira camada.

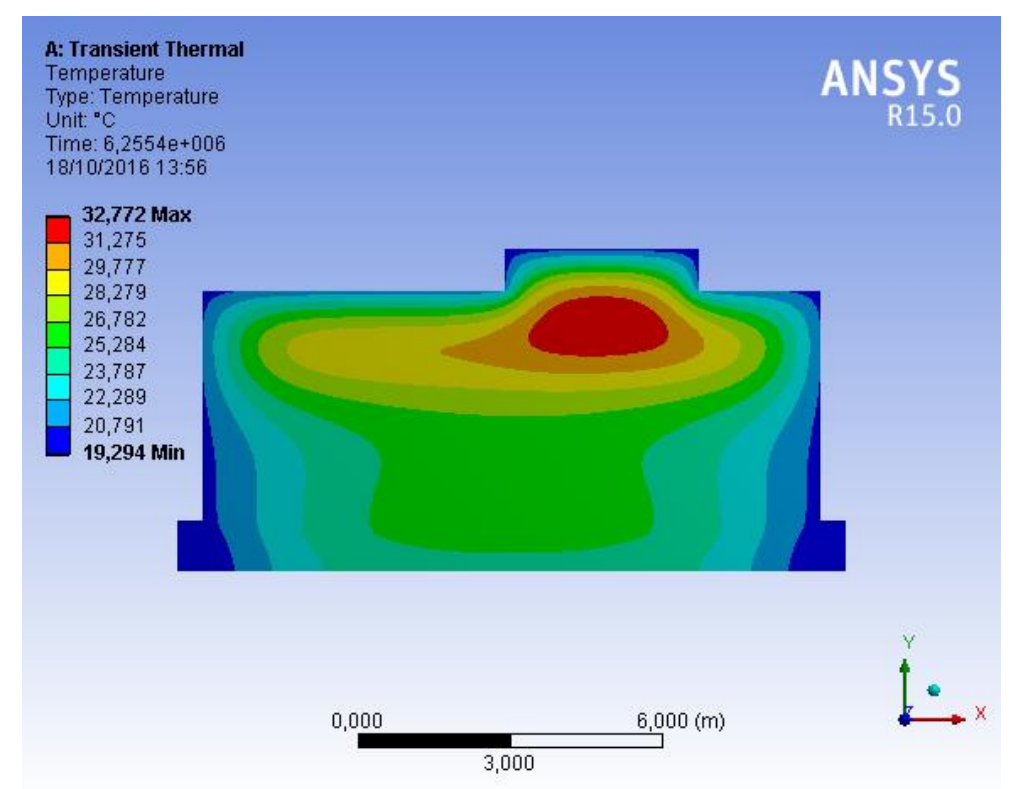

Figura 5.55 - Isotermas para a sala em 72,40 dias.

Os resultados dos pontos de instalação dos termopares são mostrados nas Figuras 5.56a e 5.56b. Na simulação com os ANSYS WORKBENCH as temperaturas dos pontos T1 e T4 foram iguais, Figura 5.56a, por estarem na mesma camada e posição vertical, diferindo 
apenas na posição horizontal. Funahashi Júnior et al (2010) obtiveram valores diferentes para esses pontos, T1F e T4F, durante o resfriamento. As leituras de campo, T1L e T4L, tiveram a mesma tendência das curvas apresentadas. No entanto, tiveram a máxima menor que os valores simulados com um resfriamento mais rápido, principalmente no ponto T1.

Na Figura 5.56 b o ponto T5 na análise deste trabalho ficou com a temperatura máxima abaixo do simulado pelos autores, T5F, em torno de 7,7\% assim como dos valores medidos, T5L, que não foi possível verificar o resfriamento no tempo da leitura. A tendência do resfriamento dos autores é a mesma dos modelados neste trabalho. Portanto, considera-se que os resultados apresentaram boa concordância.

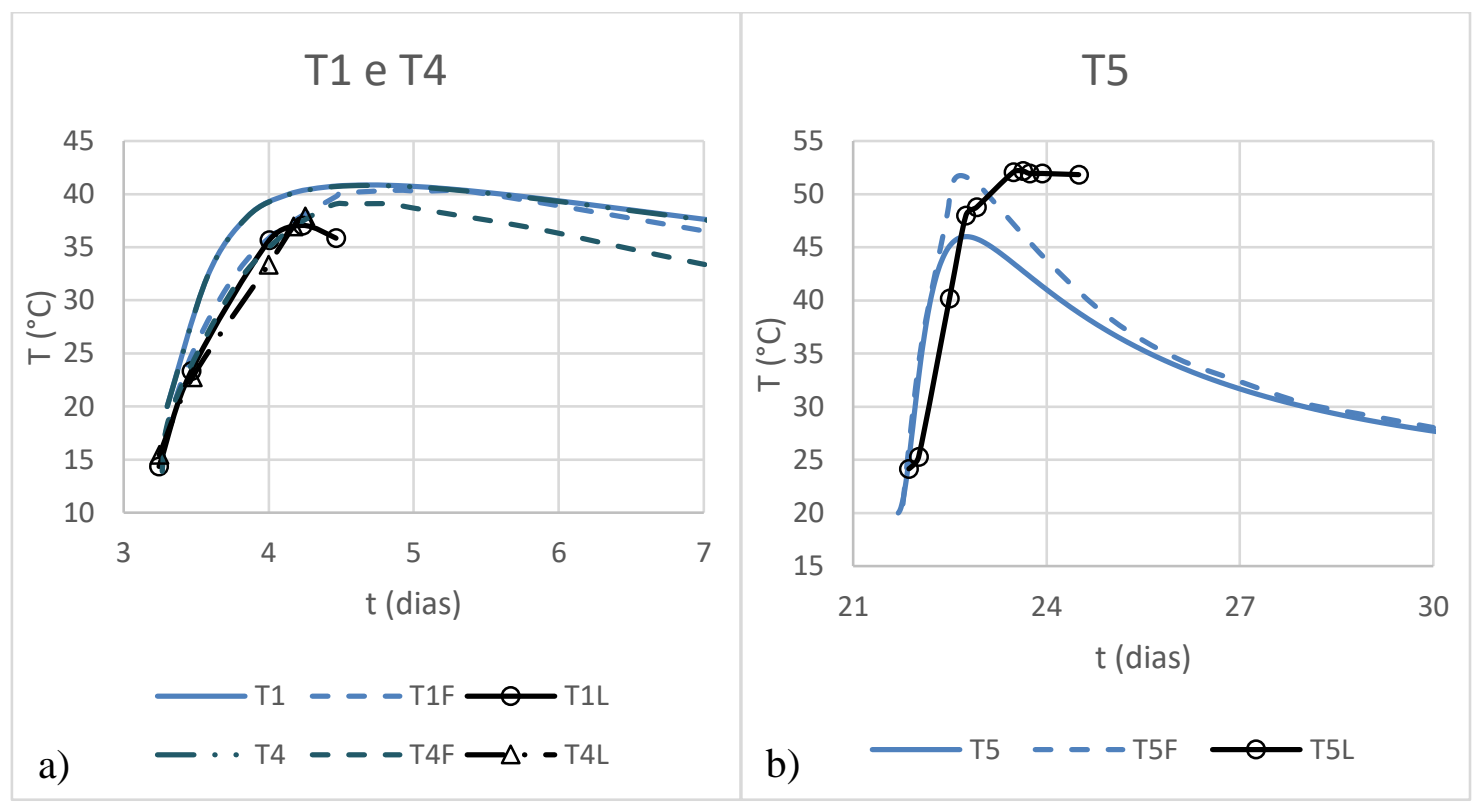

Figura 5.56 - Comparação de resultados numéricos e experimentais para três pontos da sala.

Analisando os pontos A, B, C e D, os perfis térmicos de ambas as análises numéricas ficaram semelhantes, como mostra o gráfico da Figura 5.57. A linhas continuas são os resultados pelo MEF para este trabalho e as linhas tracejadas os resultados da publicação. Em ambos os casos a máxima temperatura foi obtida na terceira camada, em aproximadamente 22 dias, havendo uma diferença aceitável entre esses valores. Assim, afirma-se que houve uma boa concordância entre os resultados térmicos para análise em camadas. 


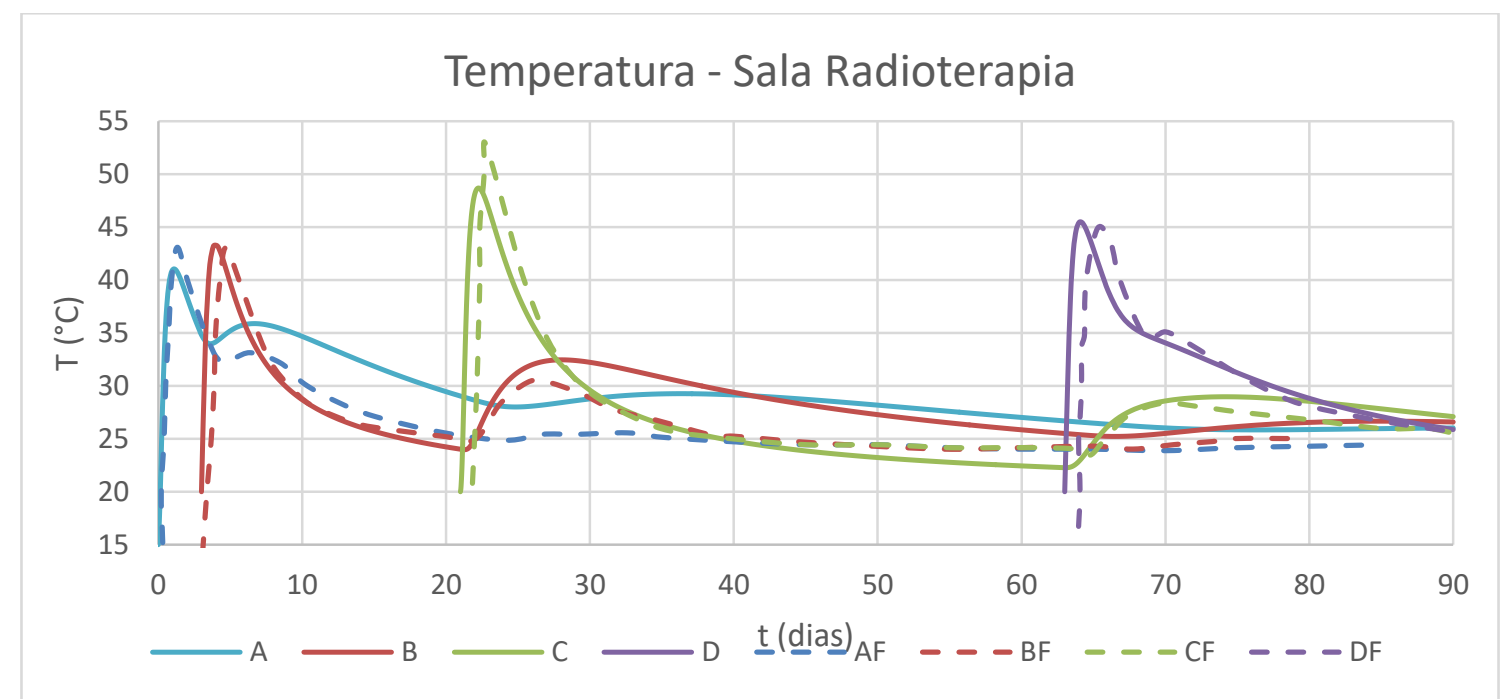

Figura 5.57 - Perfis de temperatura para pontos nas diferentes camadas.

Os autores apresentam também as tensões térmicas para os pontos A, B, C e D. No entanto, não é fornecido nenhum dado de fluência, apenas as curvas de tensão no tempo. A fim de verificar as tensões obtidas com a temperatura, empregou-se a curva de fluência do ACI, que já fornece os parâmetros necessários para sua elaboração para encontrar as curvas de tensão. O módulo de elasticidade em função do tempo é dado pela curva da Figura 5.58.

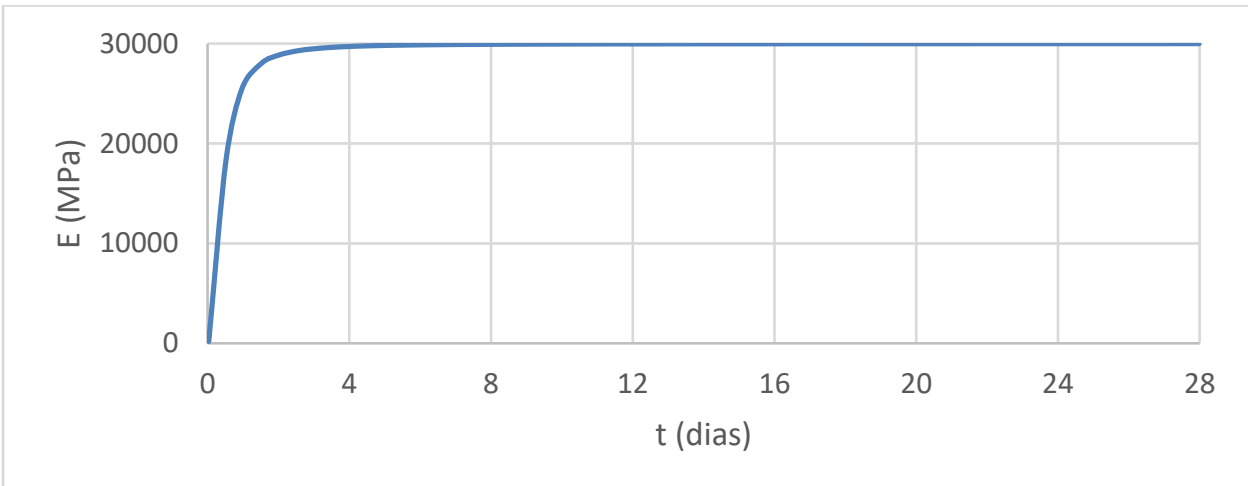

Figura 5.58 - Módulo de elasticidade em função do tempo para a sala.

Para o caso do perfil da sala, como cada camada tem uma altura diferente, cada uma delas terá um coeficiente de restrição diferente. A primeira estando sobre uma fundação rígida, não será multiplicada pelo coeficiente de restrição da fundação, as demais terão $K_{\mathrm{f}}=0,5$, pois estão sobre uma base flexível e o ponto está na metade de sua altura. Assim os valores de $\mathrm{Kr}$ adotados com base no gráfico do ACI foram 0,88 para a primeira e segunda camada, 0,81 para a terceira camada e 0,86 para a quarta camada, pontos A, B, C e D, respectivamente. 
A Figura 5.59 a, b, c, d mostra as tensões de tração para os respectivos pontos no decorrer do tempo, com as respectivas restrições aplicadas. Em todos eles observa-se que houve uma tendência entre as análises deste trabalho e as encontradas por Funahashi et al (2010), representados pela curva tracejada e com a letra $\mathrm{F}$ à frente do ponto de estudo. $\mathrm{O}$ termo $\mathrm{f}_{\mathrm{t}}$ representa a resistência a tração do concreto, dessa forma, em nenhuma das hipóteses haveria fissuração do concreto, pois todas as tensões de tração estariam abaixo das suportadas pelo concreto. Neste trabalho as análises foram realizadas para até 90 dias após a concretagem da primeira camada, por isso as análises dos pontos $\mathrm{B}, \mathrm{C}$ e $\mathrm{D}$, linhas continuas, não chegam ao final do tempo de 90 dias. A diferença encontrada entre as tensões pode ser explicada pelo não conhecimento da função de fluência e seus respectivos parâmetros utilizados pelos autores.

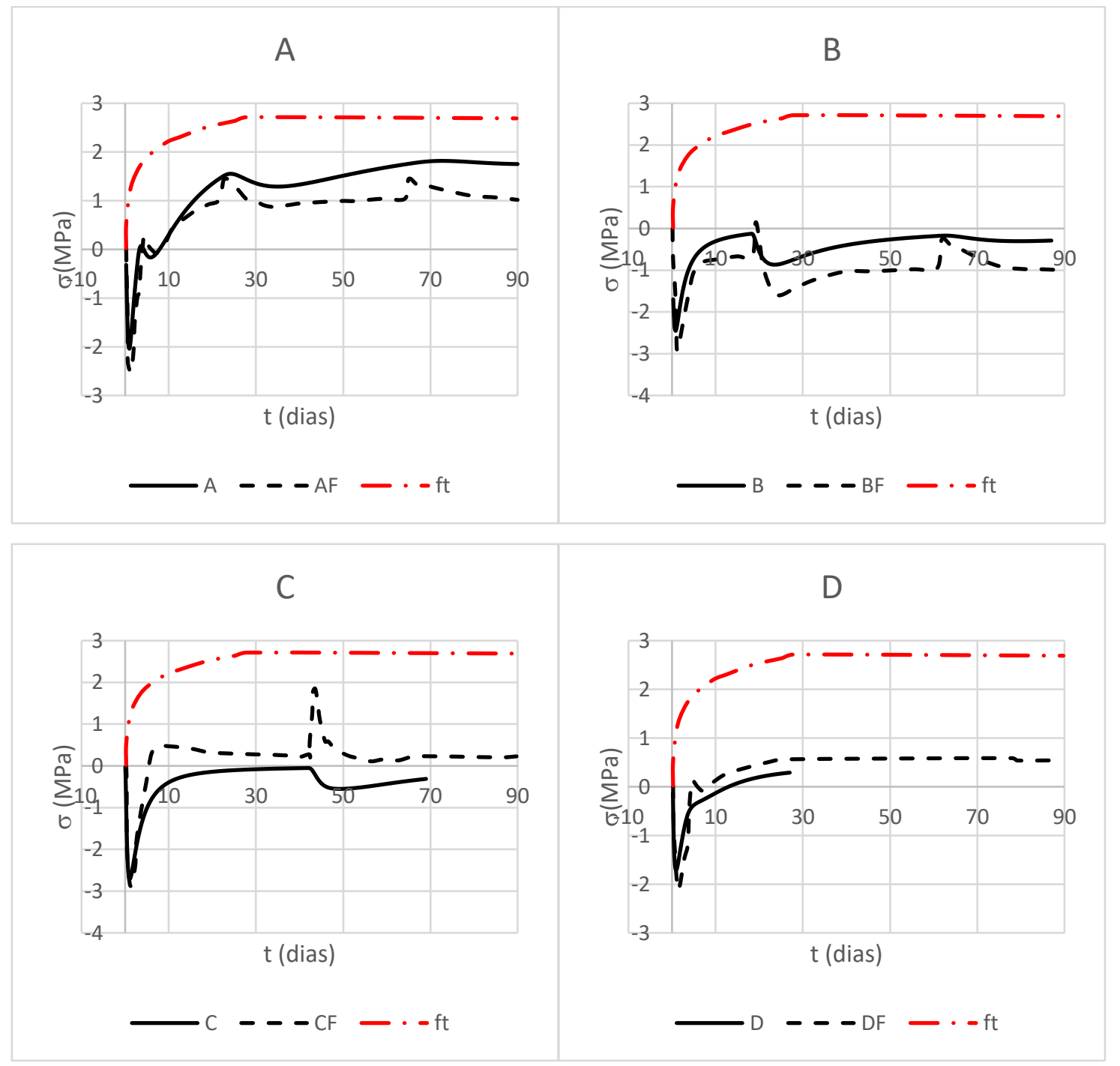

Figura 5.59 - Tensões nos pontos de cada camada. 


\section{RESULTADOS - ESTUDOS DE CASOS E SIMULAÇÕES}

Após os estudos de casos mostrados no capítulo cinco para validação dos modelos termomecânicos, alguns deles foram analisados com outras considerações geométricas, a fim de entender o comportamento das tensões para outras situações práticas existentes em estruturas de concreto massa.

\subsection{MURO COM VARIAÇÕES GEOMÉTRICAS}

Após a validação das tensões do muro apresentado no item 5.6.3.3, foram analisadas as tensões com variações nas dimensões do muro. Cabe ressaltar que, devido a simetria, apenas metade do muro foi analisado e as CC, CI, curva de geração de calor, assim como demais propriedades utilizadas não tiveram distinção do caso de validação. Esse estudo consistiu em três casos. Para o caso 1 foram alteradas as dimensões do muro em relação ao eixo X, mantendo-se as demais fixas. Para o caso 2, as alterações foram consideradas em Z, mantendo as demais fixas e, no caso 3 , foram consideradas variações em $\mathrm{Y}$, simulando a construção do muro em camadas.

\subsubsection{CASO 1: Variações em X}

Para todas as situações foram verificadas as temperaturas e suas respectivas tensões. Para os casos em que a dimensão $\mathrm{X}$ era igual ou maior que $1,5 \mathrm{~m}$, foram adotados para a fundação o valor de $\mathrm{x}=5,0 \mathrm{~m}$, mantendo y e $\mathrm{z}$ constantes, com valores de $3,0 \mathrm{~m}$ e $0,5 \mathrm{~m}$, respectivamente. A Figura 6.1 mostra dois modelos de muro discretizados com dimensões em $\mathrm{X}$ de $0,2 \mathrm{~m}$ e 3,0 m, e fundações $1,5 \mathrm{~m}$ e 5,0 m, respectivamente. 

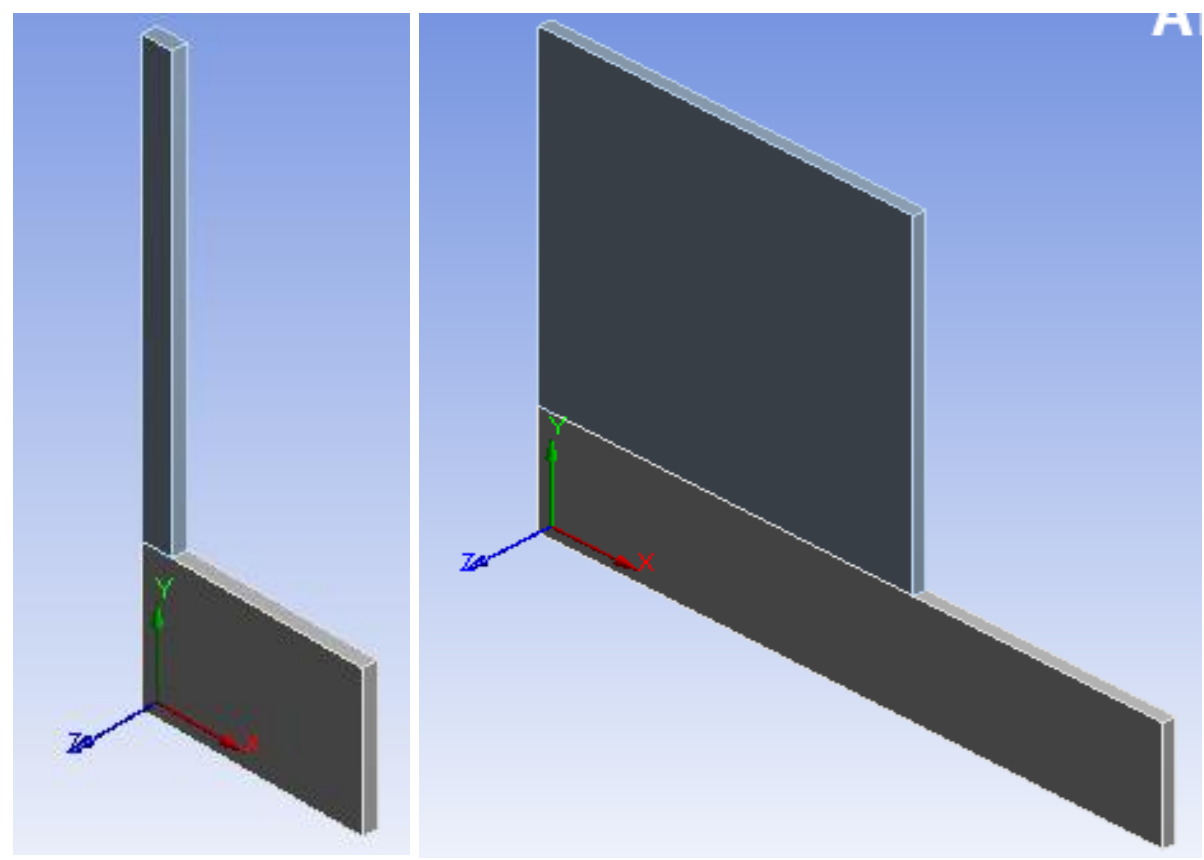

Figura 6.1 - Muro com espessura a) 0,2 m e b) 3,0 m.

A Tabela 6.1 apresenta oito diferentes tipos de modelos de composição do muro e fundação para as análises referentes ao Caso 1, cujas variações somente são consideradas na dimensão $\mathrm{X}$.

Tabela 6.1 - Variações em X analisadas.

\begin{tabular}{|l|l|l|l|}
\hline \multirow{2}{*}{ CASO 1 } & \multicolumn{2}{|l|}{ DIMENS ̃̃O X } & \multirow{2}{*}{$\stackrel{\text { XM }}{=}$} \\
\cline { 2 - 3 } & MURO - XM (m) & FUNDAÇÃO - XF (m) \\
\hline A & 1,0 & 1,5 \\
\hline B & 0,8 & 1,5 \\
\hline C & 0,6 & 1,5 \\
\hline D & 0,5 & 1,5 \\
\hline E & 0,4 & 1,5 \\
\hline F & 0,2 & 1,5 \\
\hline G & 1,5 & 5,0 & \\
\hline H & 3,0 & 5,0 & \\
\hline
\end{tabular}


Em todos os casos foram analisados três pontos, PC, PB, PT, denominados centro, base e topo, respectivamente, Figura 5.44. A Figura 6.2, apresenta as variações de temperatura para os pontos centrais de cada caso, representado pelo tempo em horas na abscissa e a temperatura em Celsius na ordenada. Nota-se que conforme se aumenta a espessura do muro, maiores as temperaturas atingidas e mais lentamente o concreto resfria. Para a espessura de 0,2 $\mathrm{m}$ obteve-se as menores temperaturas e um resfriamento mais rápido. Para as espessuras de 1,5 m e 3,0 m as máximas foram aproximadamente as mesmas. Nota-se que após $72 \mathrm{~h}$ o concreto não começou o resfriamento nestes casos. Infere-se disso que para comprimentos maiores que $1,5 \mathrm{~m}$ o comportamento térmico será equivalente. Nestes casos, a máxima chegou a quase $78^{\circ} \mathrm{C}$.

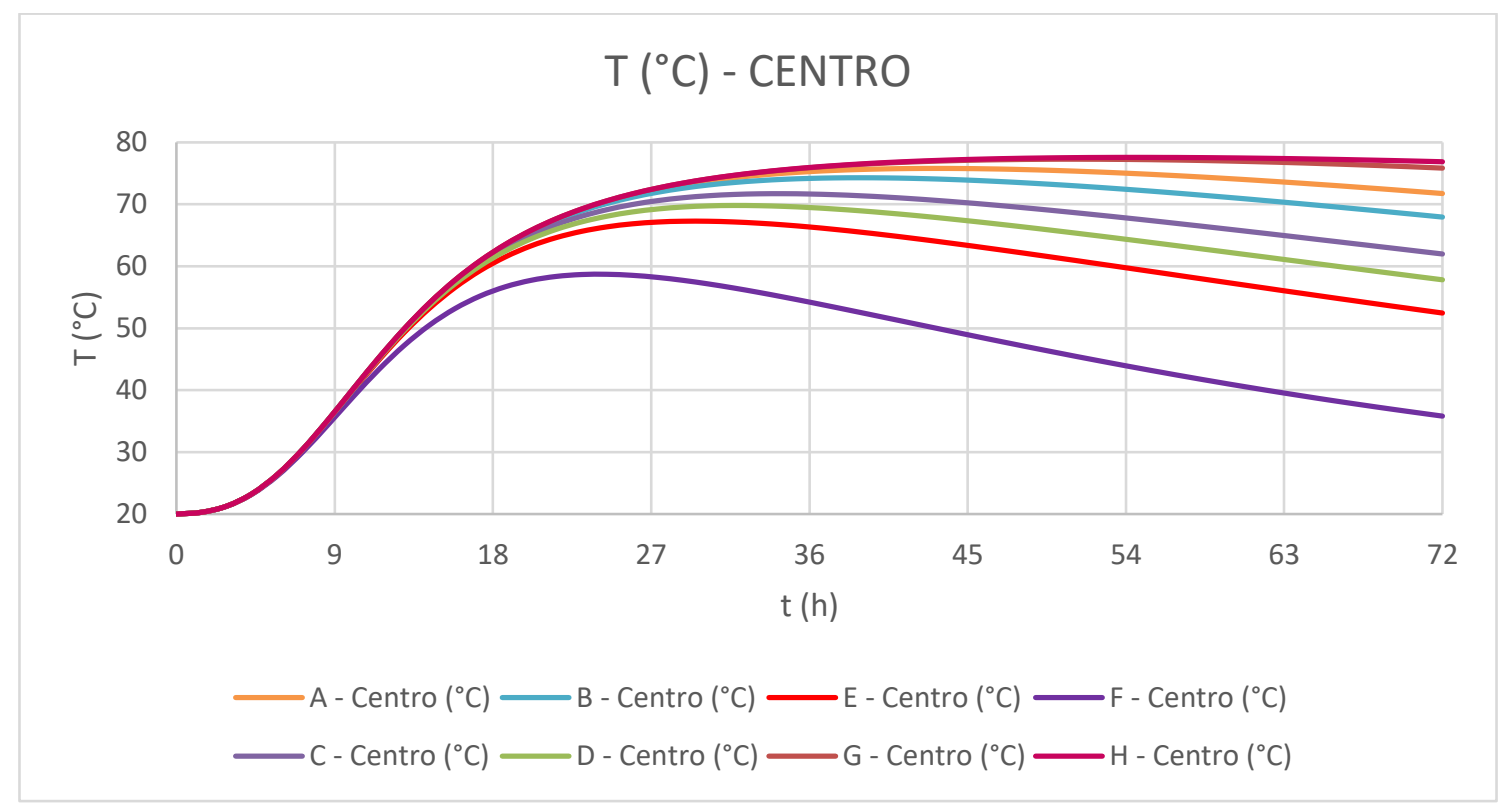

Figura 6.2 - Temperaturas em PC para variações em X.

No topo, o gráfico da Figura 6.3 mostra as mesmas evidências no comportamento térmico dos pontos centrais, ou seja, quanto mais espesso o muro, maiores as máximas de temperaturas atingidas. Os resultados observados para os muros de 1,5 $\mathrm{m} \mathrm{e} \mathrm{3,0} \mathrm{m} \mathrm{foram}$ semelhantes. No entanto, observa-se um maior resfriamento dos pontos no topo quando comparado aos pontos centrais, isso se dá pela influência da superfície próxima a esses pontos. 


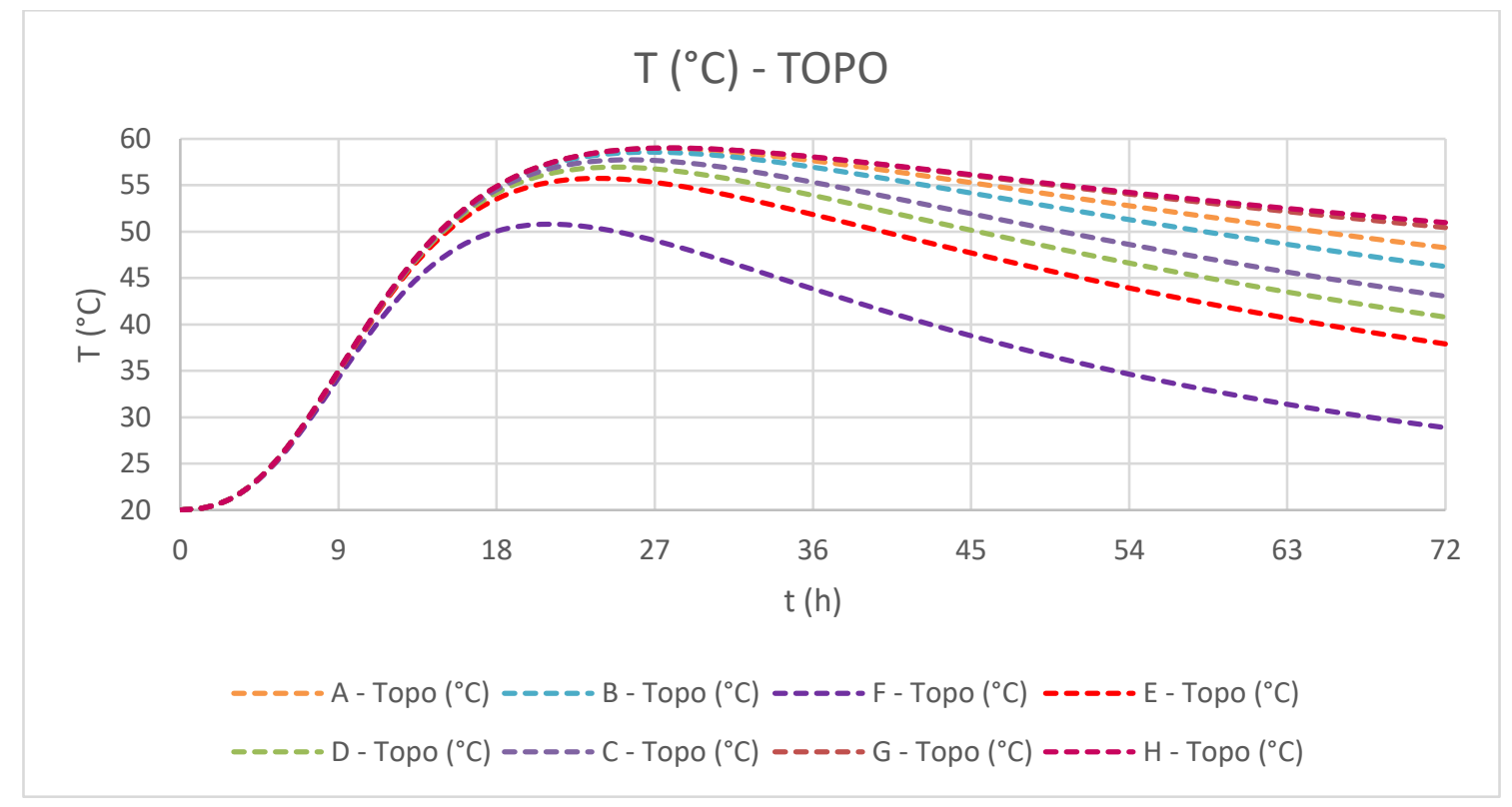

Figura 6.3 - - Temperaturas em PT para variações em X.

Quanto aos pontos da base, Figura 6.4, há um maior resfriamento que os pontos centrais, mas não tanto quanto os pontos do topo. Isso porque há influência das condições de contorno da fundação, porém com uma maior resistência que o contato com o meio externo.

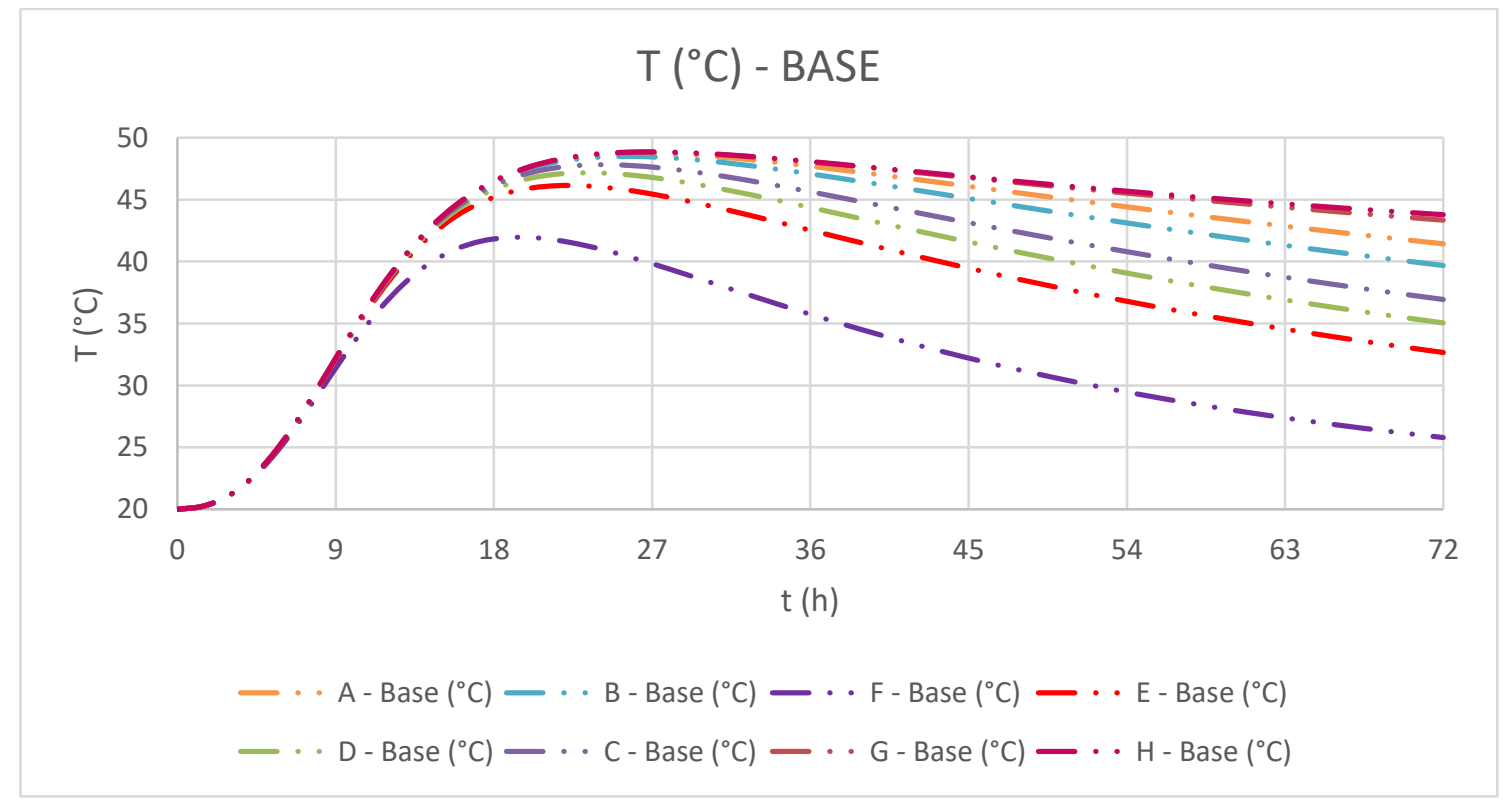

Figura 6.4 - - Temperaturas em PB para variações em X.

Para as variações em $\mathrm{X}$, observou-se as máximas temperaturas atingidas em PC, PT e PB, conforme a Tabela 6.2. 
Tabela 6.2 - Máximas temperaturas para as variações em X.

\begin{tabular}{|l|l|l|l|l|}
\hline CASO 1 & Dimensão X (m) & $\mathrm{PC}-\mathrm{T}_{\max }\left({ }^{\circ} \mathrm{C}\right)$ & $\mathrm{PT}-\mathrm{T}_{\max }\left({ }^{\circ} \mathrm{C}\right)$ & $\mathrm{PB}-\mathrm{T}_{\max }\left({ }^{\circ} \mathrm{C}\right)$ \\
\hline A & 1,0 & 75,80 & 59,01 & 48,85 \\
\hline B & 0,8 & 74,29 & 59,01 & 48,83 \\
\hline C & 0,6 & 71,10 & 58,88 & 48,73 \\
\hline D & 0,5 & 69,82 & 58,56 & 48,49 \\
\hline E & 0,4 & 67,28 & 57,74 & 47,82 \\
\hline F & 0,2 & 58,71 & 56,90 & 47,16 \\
\hline G & 1,5 & 77,29 & 55,72 & 46,13 \\
\hline H & 3,0 & 77,58 & 50,79 & 41,94 \\
\hline
\end{tabular}

Para os dados da Tabela 6.2, foram elaborados os gráficos para os pontos PC, PT e PB, conforme as Figuras 6.5, 6.6 e 6.7. Os gráficos mostram a relação entre o comprimento do corpo e a máxima temperatura alcançada. Em ambos os gráficos, nota-se uma mesma tendência de curva assintótica. Assim pode-se afirmar que a partir de um comprimento X, maior ou igual a 1,5 m, os valores de temperatura máxima, são os mesmos, ou muito próximos.

Essas curvas podem ser representadas por uma equação exponencial, Equação 6.1, que tem uma tendência assintótica, dada pela exponencial, e para dimensões acima de 1,5 m tende a uma temperatura máxima, definida aqui como $T_{\infty}$. Essas equações foram obtidas com o ajuste da curva pelo programa ORIGIN 8.0.

$$
T_{\max }=T_{\infty}-\beta \cdot \exp \left(-\frac{x}{\delta}\right)
$$

Em que $T_{\infty}, \beta, \delta$ são constantes de ajuste da curva, dadas, para os exemplos mostrados, conforme a Tabela 6.3.

Tabela 6.3 - Constantes de ajuste.

\begin{tabular}{|c|l|l|l|}
\hline Constantes & PC & PT & PB \\
\hline$T_{\infty}$ & 77,61 & 59,05 & 48,87 \\
\hline$\beta$ & $-33,93$ & $-20,58$ & $-17,71$ \\
\hline$\delta$ & 0,34 & 0,22 & 0,21 \\
\hline
\end{tabular}


Em todos os gráficos, a linha contínua representa a equação e os marcadores, os respectivos pontos das análises. Observa-se também que as máximas estão nos pontos centrais, seguidos do topo e, por fim, da base. Afirma-se, então, que a base, em contato com a fundação, apresentou uma maior dissipação de calor e, consequentemente, um maior resfriamento. Esse comportamento decorre tanto em virtude das propriedades dos corpos, bem como pelo fato de não haver geração de calor na fundação.

No centro há uma maior dificuldade de perda de calor devido a um maior confinamento e consequente resistência a trocas térmicas. O topo recebe a influência do contorno, portanto, consegue baixar um pouco a temperatura com relação ao centro.

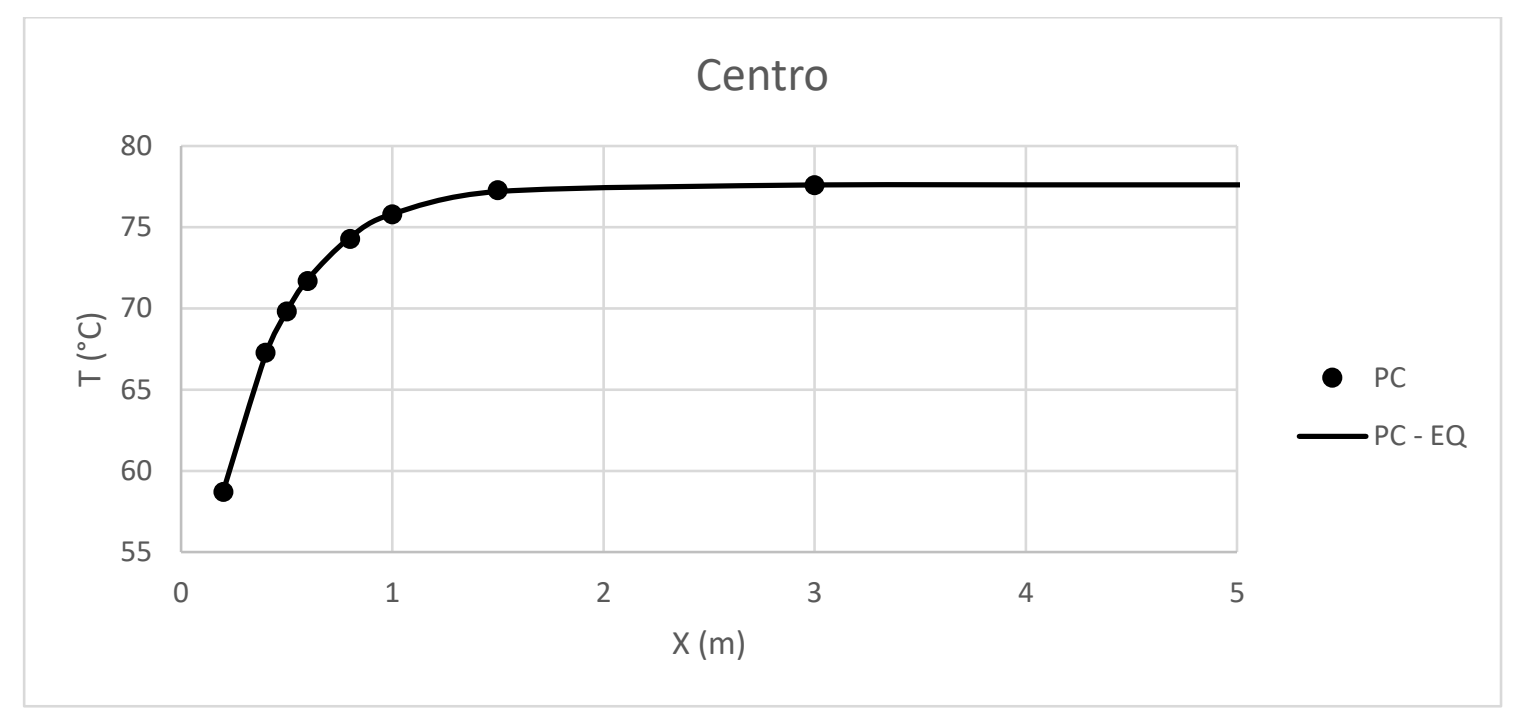

Figura 6.5 - Temperaturas máximas para PC.

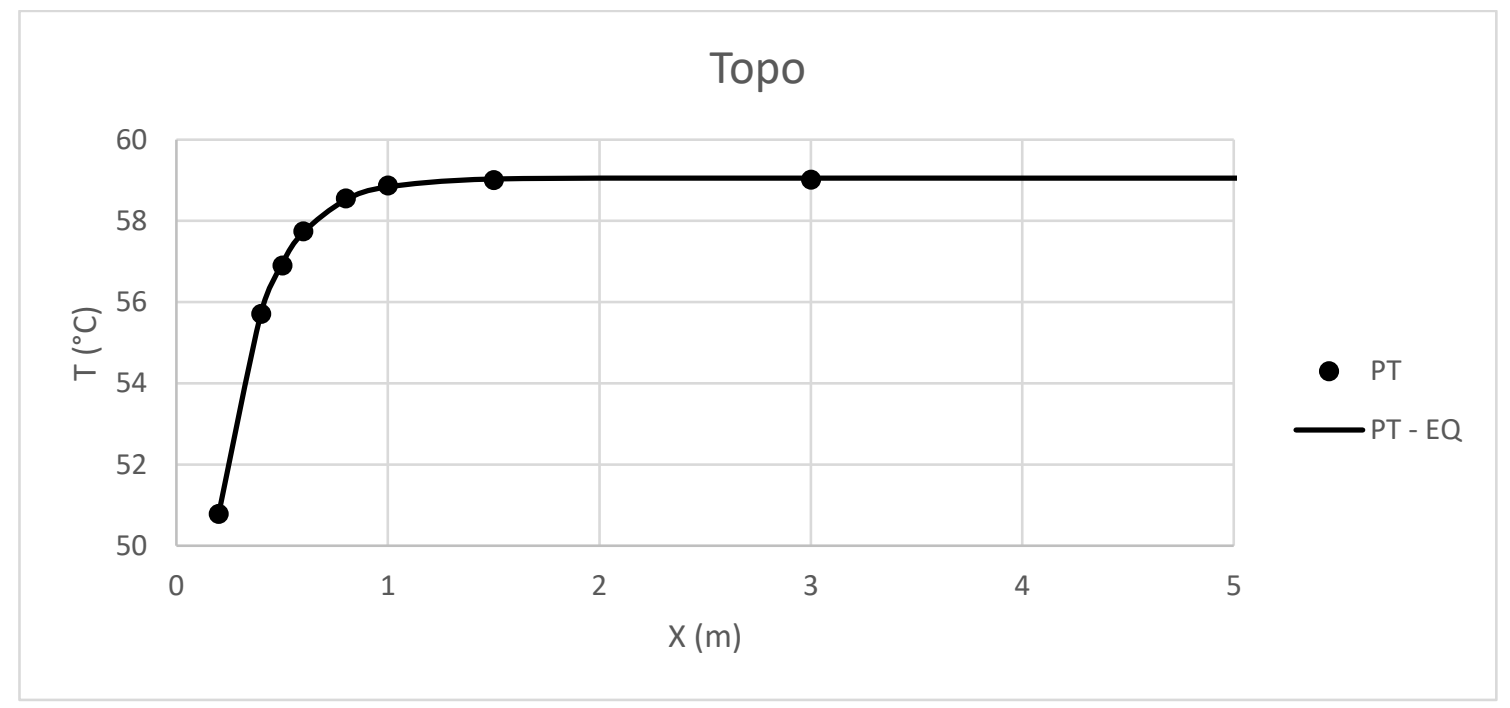

Figura 6.6 - Temperaturas máximas para PT. 


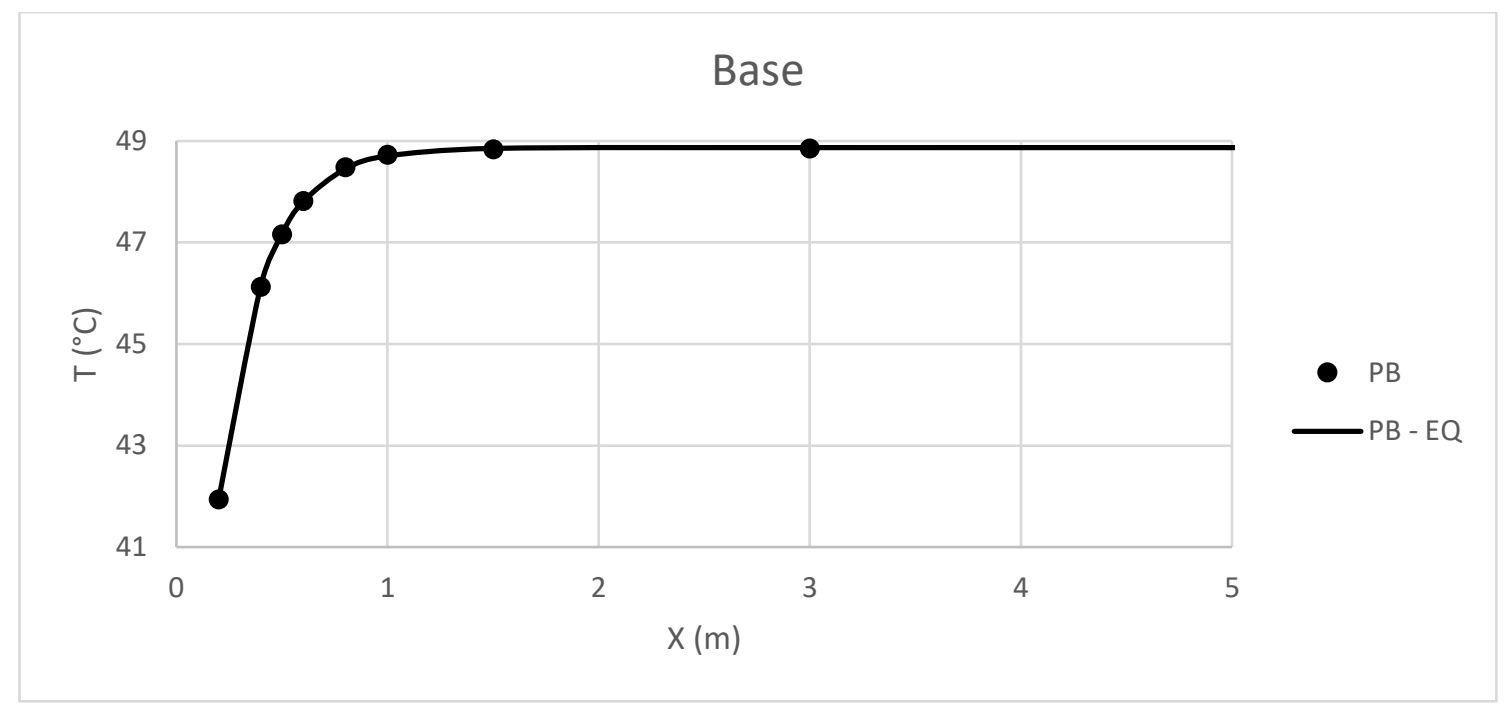

Figura 6.7 - Temperaturas máximas para PB.

A fim de observar o comportamento térmico na estrutura, as Figuras 6.8 e 6.9 mostram as isotermas de temperatura para os corpos de dimensões extremas em X: 0,2 m e 3,0 m. Os perfis exibem os momentos em que a temperatura atinge seu valor máximo. Nota-se que a região central é a mais aquecida, em ambos os casos, seguindo para o topo.

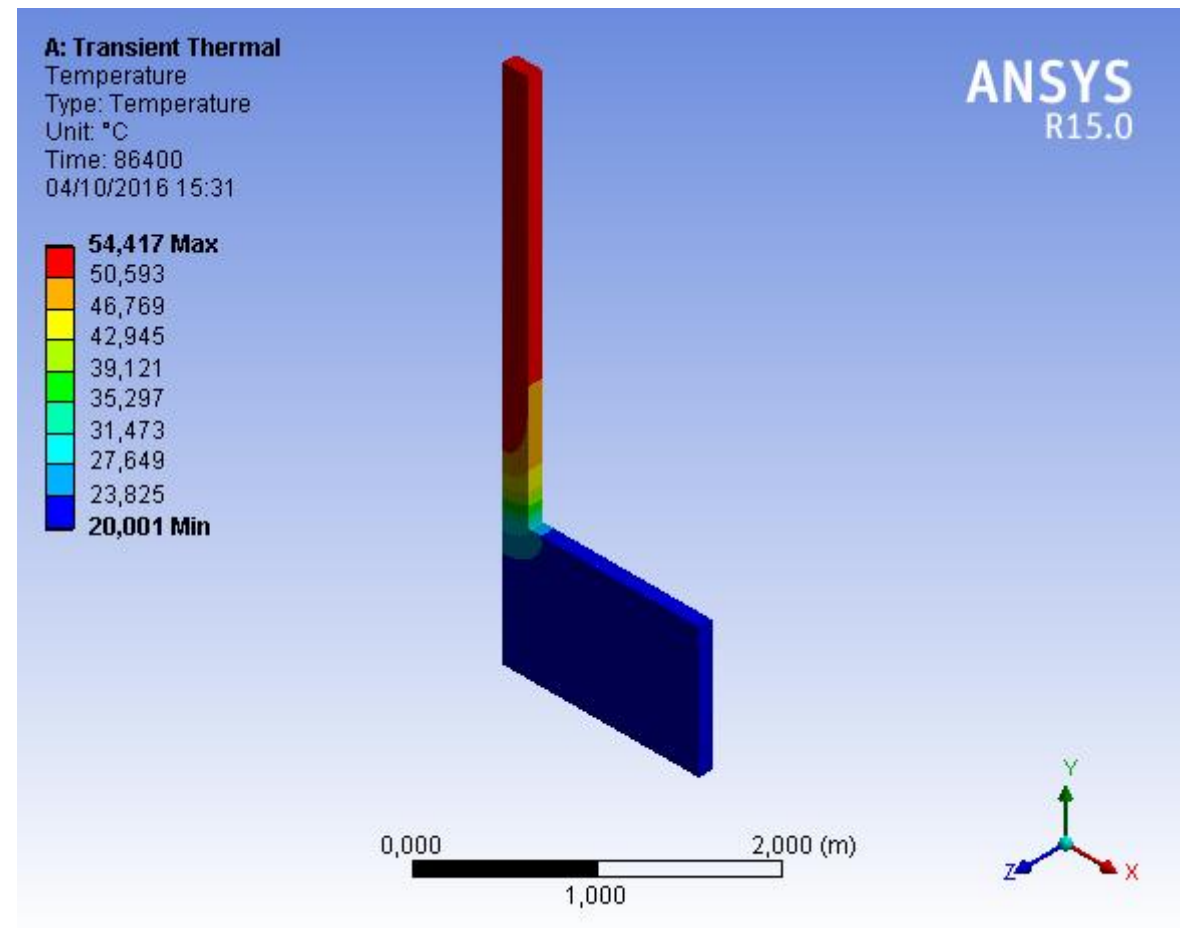

Figura 6.8 - Isotermas para $\mathrm{X}=0,2 \mathrm{~m}$. 


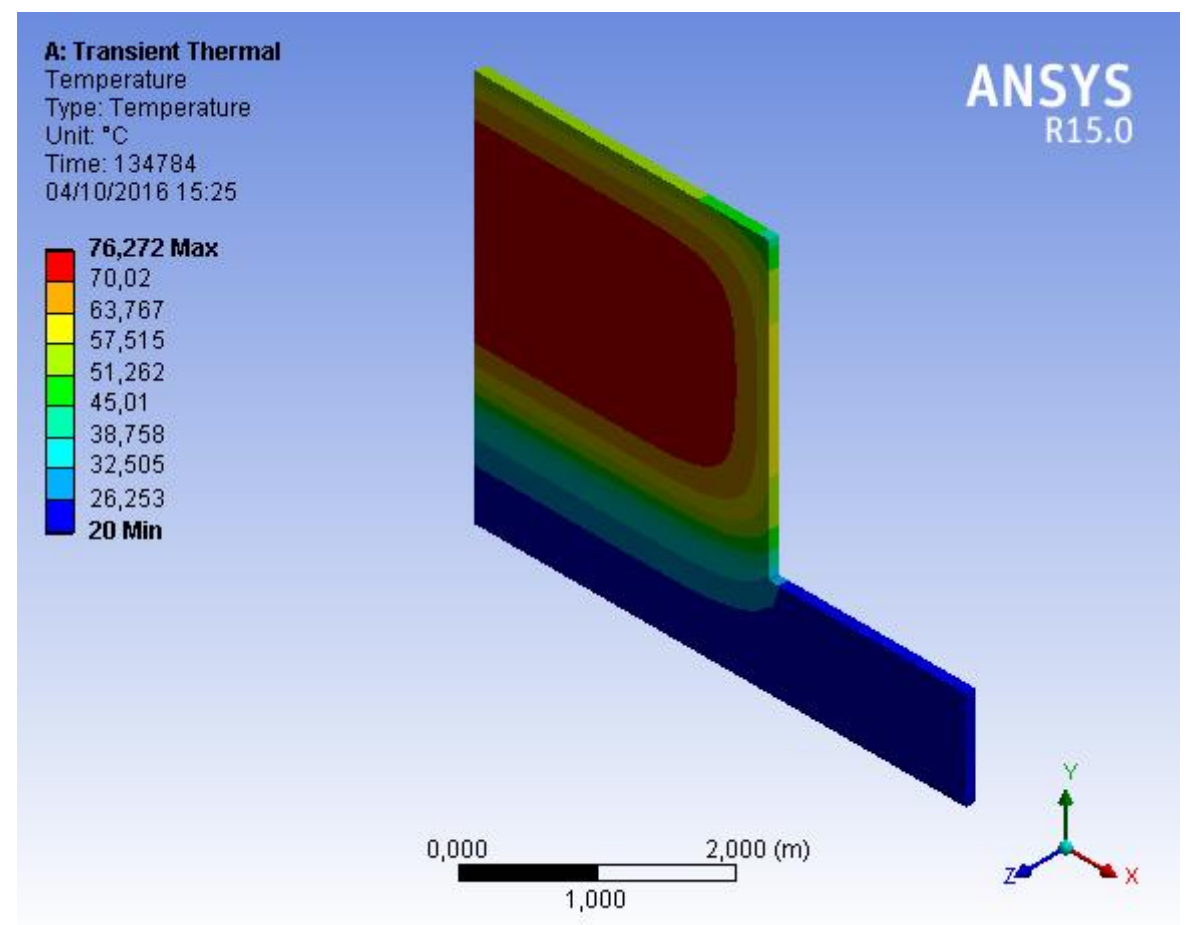

Figura 6.9 - Isotermas para $X=3,0 \mathrm{~m}$.

Após os cálculos térmicos obtidos pelo MEF, as máximas temperaturas são utilizadas para encontrar as variações de tensões em cada incremento temporal, e consequentemente, o perfil de tensões com a idade, fazendo-se uso do coeficiente de restrição para definir a influência da altura.

Considerando que o muro tem altura de $3,0 \mathrm{~m}$, o ponto central estará sempre na altura 1,5 m, ou $0,5 \mathrm{H}$, conforme o ábaco da Figura 2.17. Admitindo-se que o comprimento do muro é muito maior que sua altura, adotou-se para as análises das variações de largura $\mathrm{L} / \mathrm{H}=20$, logo, para o coeficiente de restrição, tem-se $\mathrm{Kr}=0,905$. Esse coeficiente foi o mesmo para todas as larguras dos casos analisados, por ser uma situação bastante crítica, ou seja, comprimento 20 vezes maior que a altura da estrutura.

Lembrando que, como mostrado no capitulo quatro, as tensões aqui calculadas não levam em consideração o peso próprio. Um exemplo da influência gravitacional é mostrada no apêndice E.

A curva de resistência à tração permite identificar o início do surgimento das fissuras no concreto. Essa curva representa $10 \%$ da resistência à compressão na idade $t\left(f_{c t}\right)$, conforme o ACI 209.2R, Equação 6.2, mostrada no item 3.2.1, e considerando a resistência a 
compressão do concreto aos 28 dias $35 \mathrm{MPa}\left(f_{c m 28}=35 \mathrm{MPa}\right)$. No momento em que a curva de tensão cruza a curva de resistência à tração $\left(f_{t}\right)$ atinge o seu limite, a partir de então haveria a fissuração térmica do concreto neste ponto em análise. É interessante ressaltar que, como este ponto está localizado internamente, à medida que o mesmo é tracionado, irá tracionar os demais pontos, até chegar à superfície. Utilizou-se cura úmida para cimento tipo I.

$$
f_{c t}=\left(\frac{t}{a+b t}\right) f_{c m 28}
$$

A Figura 6.10 mostra as tensões calculadas pelo método Bazant-Panula, enquanto a Figura 6.11 mostra as tensões para o método Bureau Reclamation. Em ambos os casos, observa-se que, quanto maior a largura do muro, maiores as tensões de compressão e tração, bem como, quanto menor a largura mais rapidamente as tensões máximas são atingidas. A medida que a temperatura vai se estabilizando, as tensões também vão se estabilizando, tendendo para uma curva assintótica.

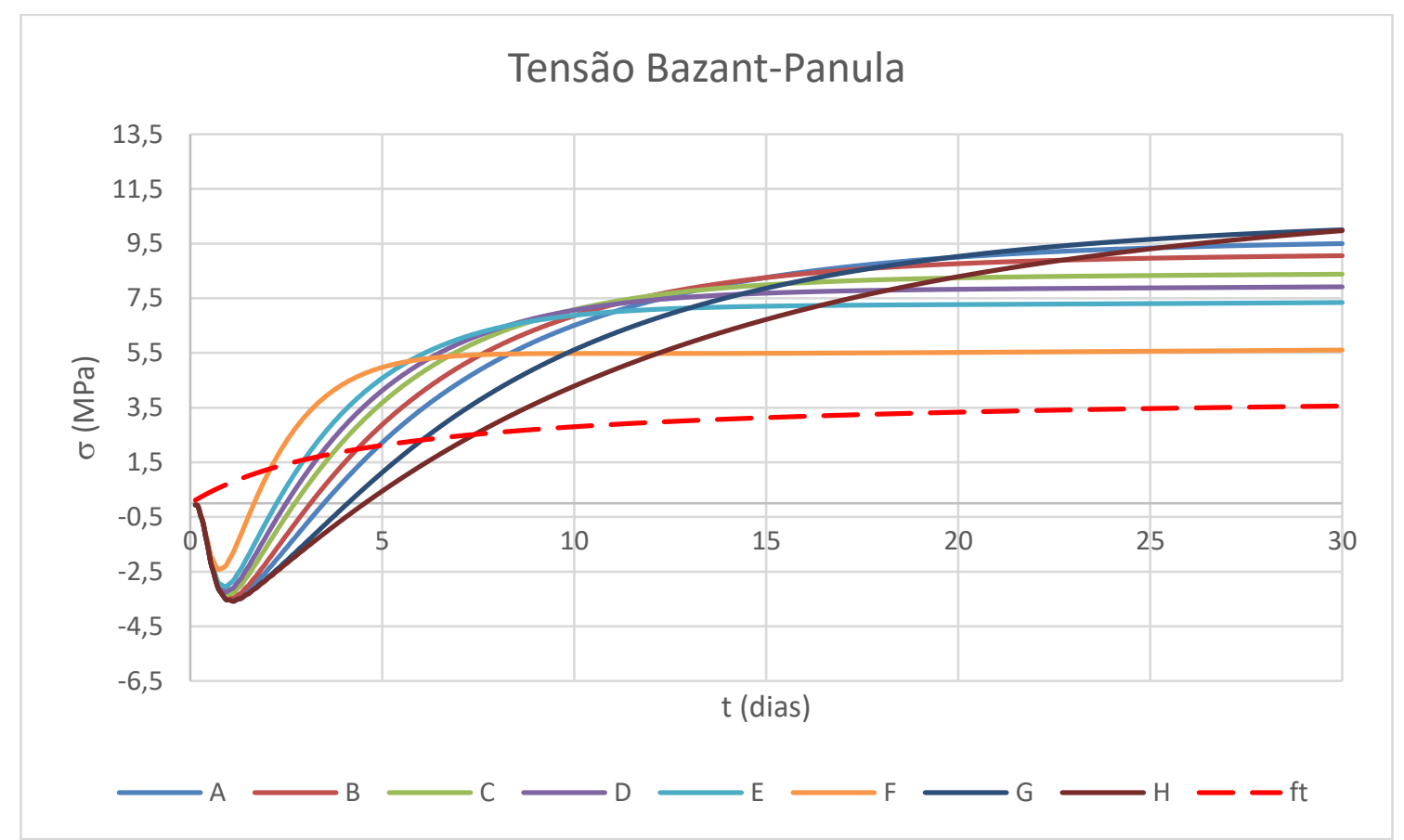

Figura 6.10 - Tensões pelo método DP para variações em X no muro. 


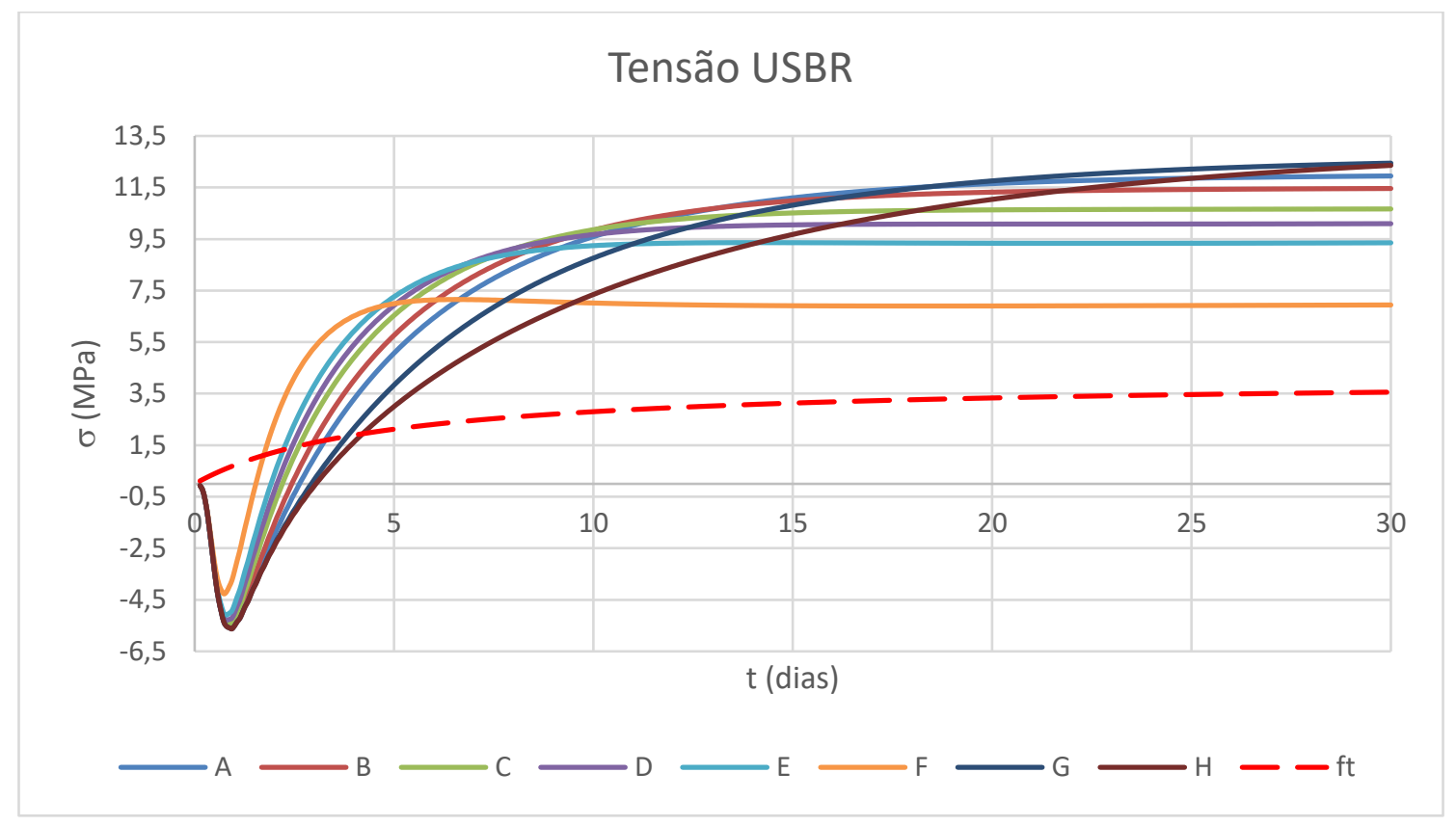

Figura 6.11 - Tensões pelo método USBR para variações em X no muro.

Pelos gráficos das Figuras 6.10 e 6.11, em que as abscissas representam o tempo em dias e as ordenadas as tensões em MPa, nota-se que pelo método Bazant-Panula as tensões máximas de tração e compressão são menores que as obtidas pelo método USBR. Observase também que a fissuração ocorre mais rápida no segundo método. Para os casos mais extremos, larguras de 0,2 m e 3,0 m, a fissuração ocorre no caso Bazant-Panula em 2,07 dias e 7,47 dias. Já no caso USBR essas fissuras ocorrem em 1,70 e 4,40 dias. De forma geral, para as situações investigadas, independentemente do método, haverá fissuração térmica.

\subsubsection{CASO 2: Variações em Z}

Para verificar a influência do comprimento nas tensões internas foram analisadas as tensões para dois comprimentos do muro para o Caso H - situação mais crítica, com maiores temperaturas, tensões e risco de fissuração. Foram verificadas as razões $\mathrm{L} / \mathrm{H}=20, \mathrm{Kr}=0,905$, e $\mathrm{L} / \mathrm{H}=2, \mathrm{Kr}=0,340$. Nas Figuras 6.12 e 6.13 as abscissas representam o tempo em dias e as ordenadas as tensões em MPa. São apresentadas as tensões sem o coeficiente de restrição, linha azul, e com a aplicação das devidas restrições, linhas laranja e cinza, e a resistência à tração em vermelho.

Vale ressaltar que, quanto menor o comprimento para a mesma altura há uma redução significativa das tensões, ou seja, a redução do comprimento contribui para evitar a 
fissuração térmica. Isso se torna evidente ao analisar o concreto massa com referência ao seu volume, ou seja, quanto maior a dimensão do concreto massa, maiores serão as tensões no mesmo.

Verifica-se também que, pelo método DP na razão $\mathrm{L} / \mathrm{H}=20$, o concreto iria fissurar em aproximadamente 7 dias, e pela razão $\mathrm{L} / \mathrm{H}=2$ não haveria fissuração térmica até os 30 dias. No entanto, pelo método USBR ambos fissurariam em aproximadamente 4 e 7 dias, respectivamente.

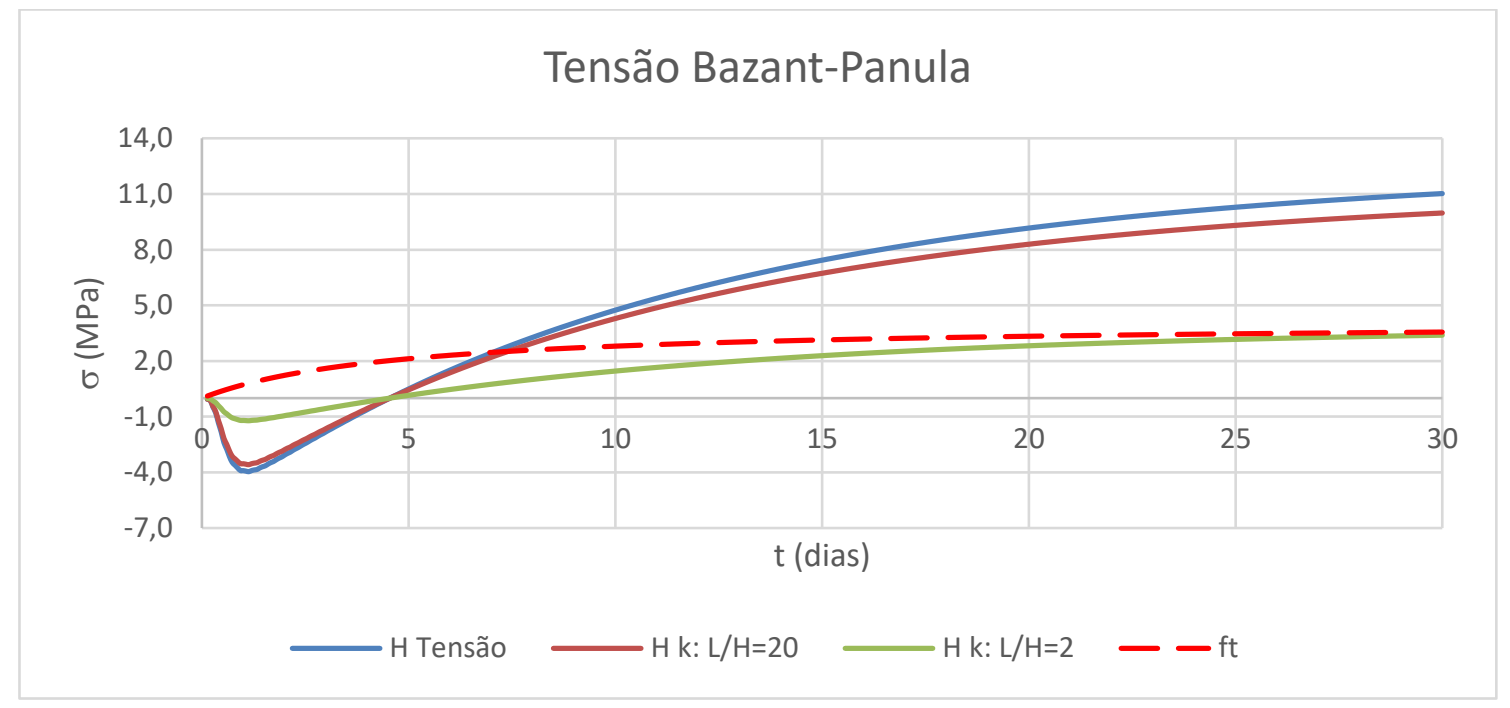

Figura 6.12 - Tensões pelo método DP para variações em Z no muro.

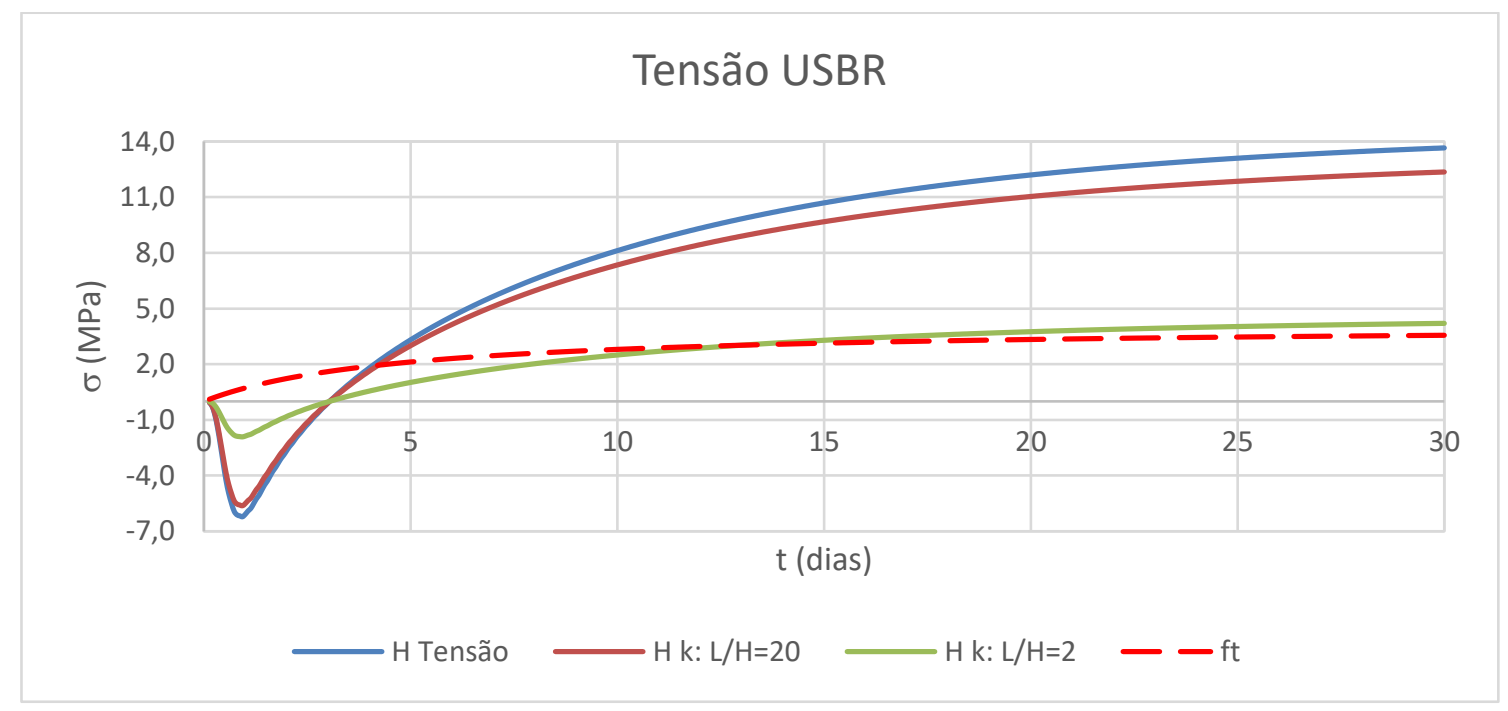

Figura 6.13 - Tensões pelo método USBR para variações em Z no muro. 


\subsubsection{CASO 3: Variações em Y - Camadas}

Para a altura foi simulado a construção em camadas, a fim de verificar a influência nas temperaturas e tensões. No caso das tensões, há uma observação importante: a primeira camada está sobre a fundação, aqui considerada rígida, ou seja, o coeficiente de restrição é obtido pelo ábaco da Figura 2.17; as demais camadas estão situadas sobre outra camada de concreto, considerada flexível, portanto, além do coeficiente de restrição $\mathrm{Kr}$, as tensões devem ser multiplicadas pelo coeficiente de fundação Kf, dado pela Equação 6.3:

$$
K_{f}=\frac{1}{1+\frac{A_{g} E_{c}}{A_{f} E_{f}}}
$$

Em que:

- $A_{g}=$ área bruta de seção transversal de concreto;

- $A_{f}=$ área da fundação, geralmente tomado como uma superfície plana em contato;

- $E_{c}=$ módulo de elasticidade do concreto;

- $\quad E_{f}=$ módulo de elasticidade da fundação.

Para esta análise, foram lançadas camadas com intervalos de $12 \mathrm{~h}$ e $24 \mathrm{~h}$, e foram analisadas as tensões da primeira e segunda camada e também daquela que obteve a temperatura máxima em cada camada.

No muro de $3 \mathrm{~m}$, as simulações foram efetuadas conforme a Tabela 6.4:

Tabela 6.4 - Casos de camadas analisados.

\begin{tabular}{|c|c|c|}
\hline CASO 3 & $\mathrm{N}^{\circ}$ DE CAMADAS & ALTURA DAS CAMADAS (m) \\
\hline $\mathrm{A}$ & 1 & 3,00 \\
\hline $\mathrm{B}$ & 2 & 1,50 \\
\hline $\mathrm{C}$ & 3 & 1,00 \\
\hline $\mathrm{D}$ & 4 & 0,75 \\
\hline $\mathrm{E}$ & 5 & 0,60 \\
\hline $\mathrm{F}$ & 6 & 0,50 \\
\hline $\mathrm{G}$ & 8 & $7 \times 0,4+1 \times 0,2$ \\
\hline $\mathrm{H}$ & 10 & 0,30 \\
\hline $\mathrm{I}$ & 15 & 0,20 \\
\hline
\end{tabular}


As Figuras de 6.15 a 6.38 mostram os gráficos das temperaturas no eixo das ordenadas no decorrer do tempo, eixo das abscissas, ao longo de 30 dias, para todas as análises efetuadas. As curvas são representadas pela simbologia mostrada na Figura 6.14.

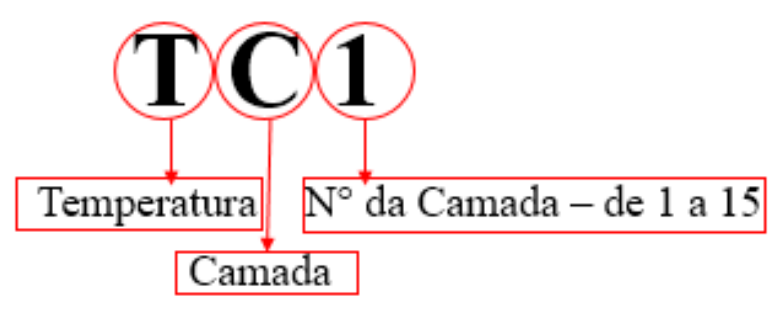

Figura 6.14 -Nomenclatura das análises.

As Figuras 6.15, 6.16 e 6.17 representam um intervalo de lançamento entre as camadas de 12 h, 24 h e 48 h, respectivamente, com duas camadas de 1,5 m. Nos três casos, a máxima temperatura se deu na segunda camada, mas a primeira camada teve um resfriamento mais rápido para maiores intervalos de lançamento. Após 15 dias as temperaturas praticamente se igualaram e, em 30 dias estavam quase totalmente resfriados. Observa-se também que devido à grande espessura das camadas, $1,5 \mathrm{~m}$, a segunda camada praticamente não tem efeito sobre a primeira, pois cada uma delas já se comporta como um corpo adiabático, ou seja, com dificuldade de dissipação do calor no interior e já atingindo as temperaturas máximas possíveis.

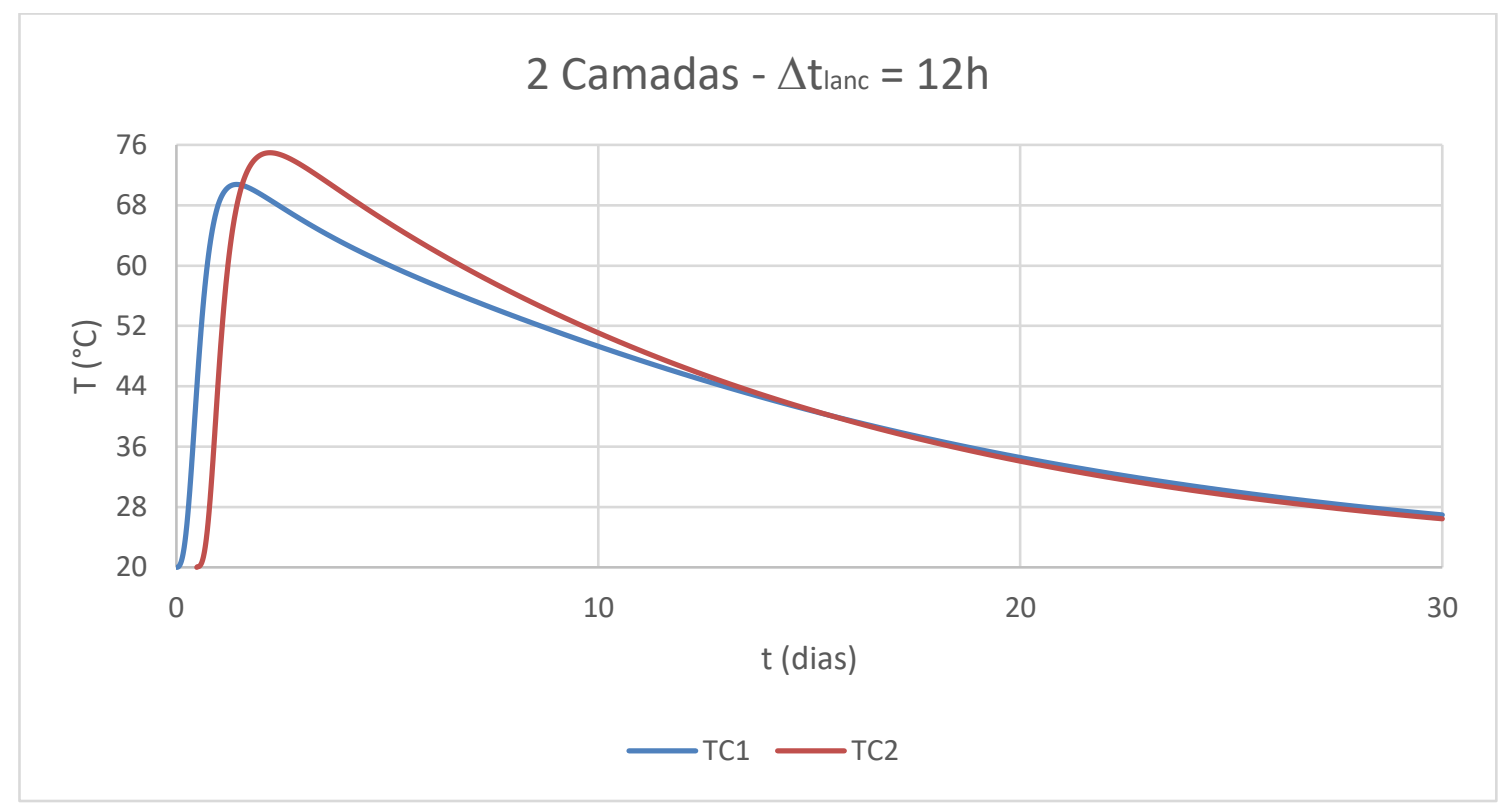

Figura 6.15 - Temperaturas para o Caso B com intervalo de lançamento de $12 \mathrm{~h}$. 


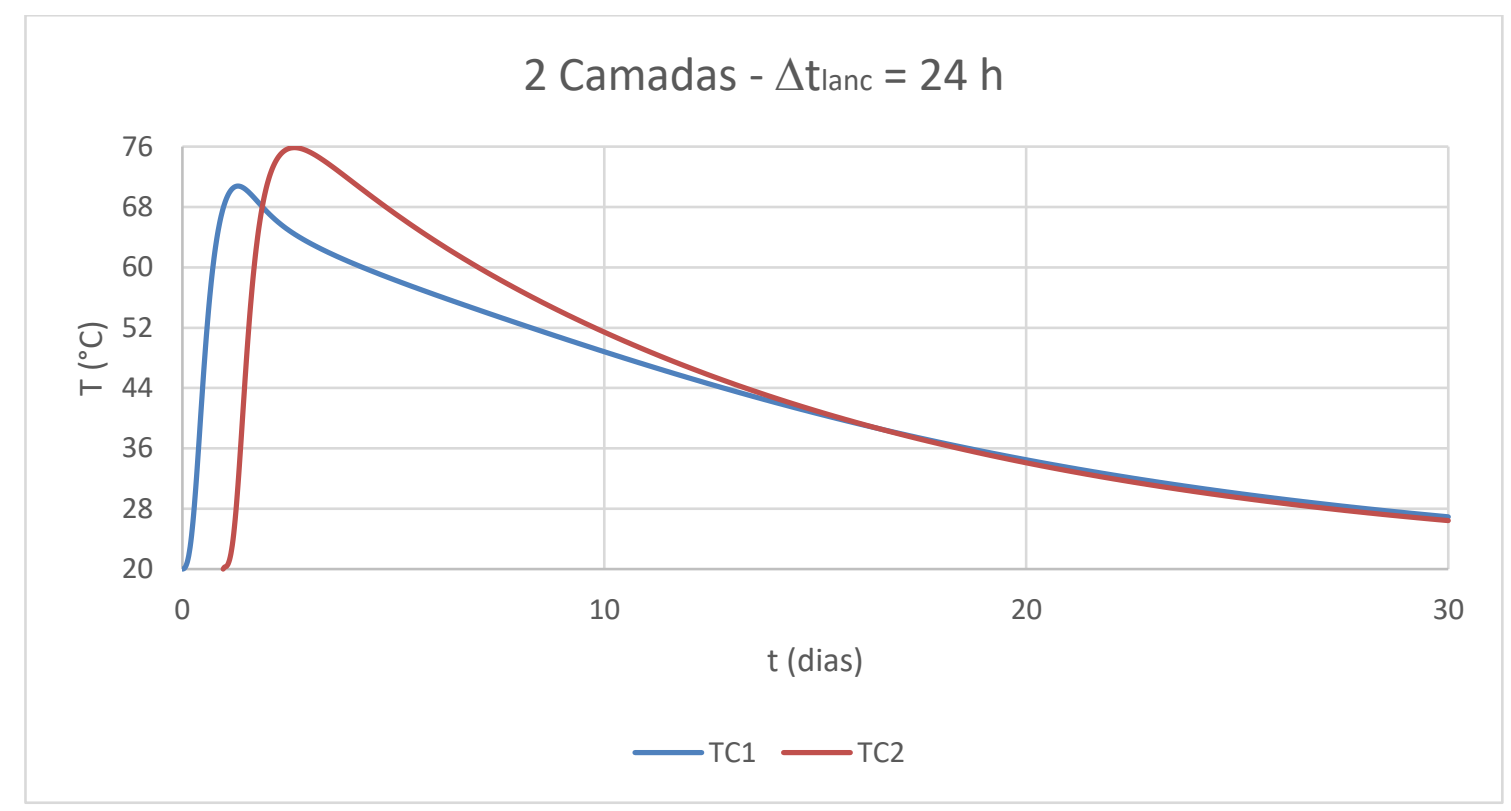

Figura 6.16 - Temperaturas para o Caso B com intervalo de lançamento de $24 \mathrm{~h}$.

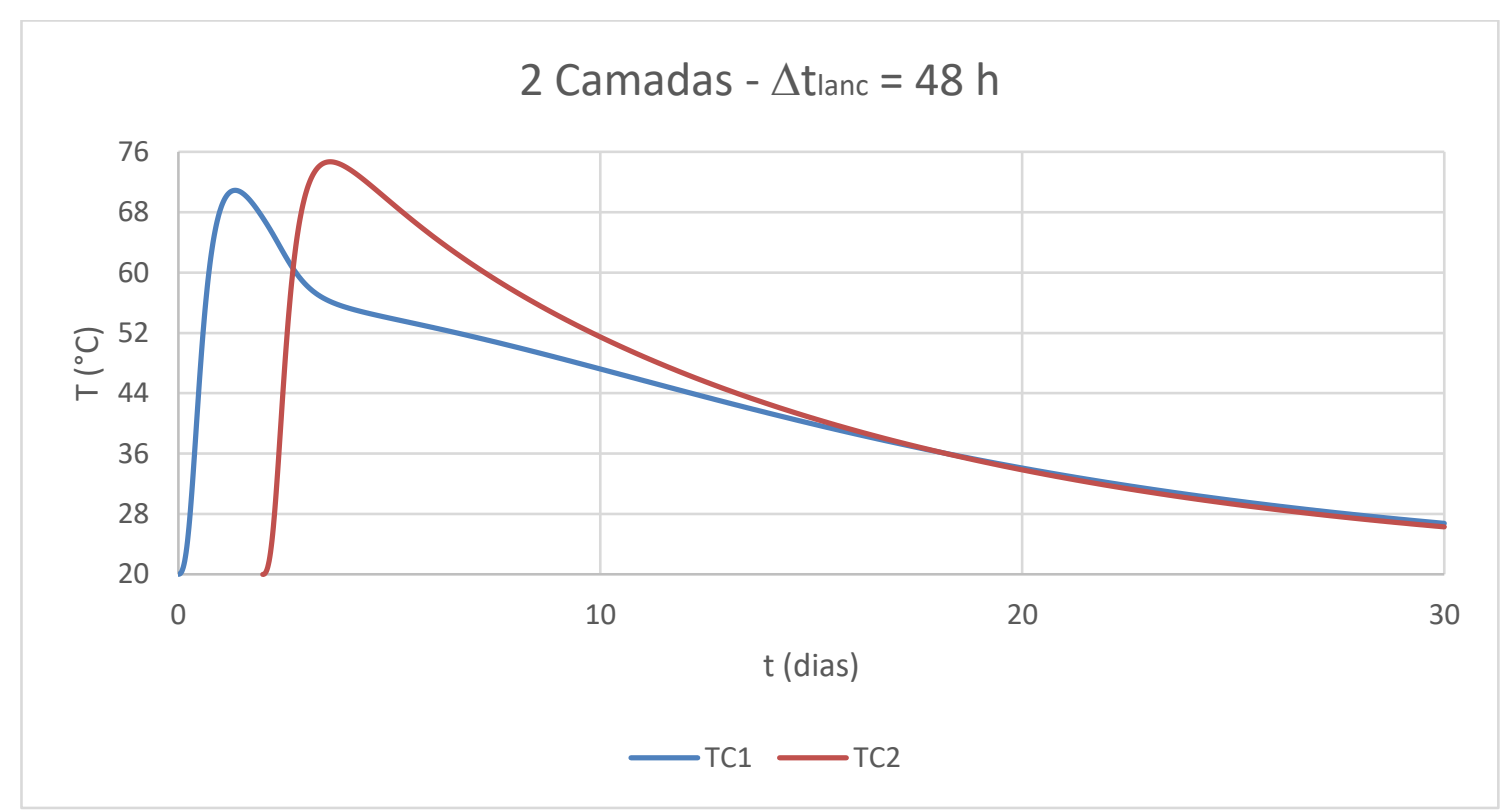

Figura 6.17 - Temperaturas para o Caso B com intervalo de lançamento de 48h.

As Figuras 6.18, 6.19 e 6.20, representam a construção com intervalos de lançamento das camadas de 12 h, 24 h e 48 h para três camadas de 1,0 m de espessura.

$\mathrm{Na}$ simulação para intervalos de 12 h de lançamento, a máxima temperatura ocorreu na segunda camada, atingindo aproximadamente $75^{\circ} \mathrm{C}$, enquanto para o intervalo de $24 \mathrm{~h}$, a máxima ocorreu na terceira camada, com valor aproximado de $73^{\circ} \mathrm{C} \mathrm{e}$, com intervalos de 48 
h de lançamento, a máxima também ocorreu na terceira camada com um valor menor, aproximadamente $70^{\circ} \mathrm{C}$.

Nota-se, nos dois últimos casos, que as camadas inferiores iniciam o processo de resfriamento e, quando a camada seguinte é lançada, essa temperatura volta a aumentar, o que não acontece para um intervalo de lançamento menor, pois não há tempo suficiente para o início do resfriamento, também devido a espessura da camada.

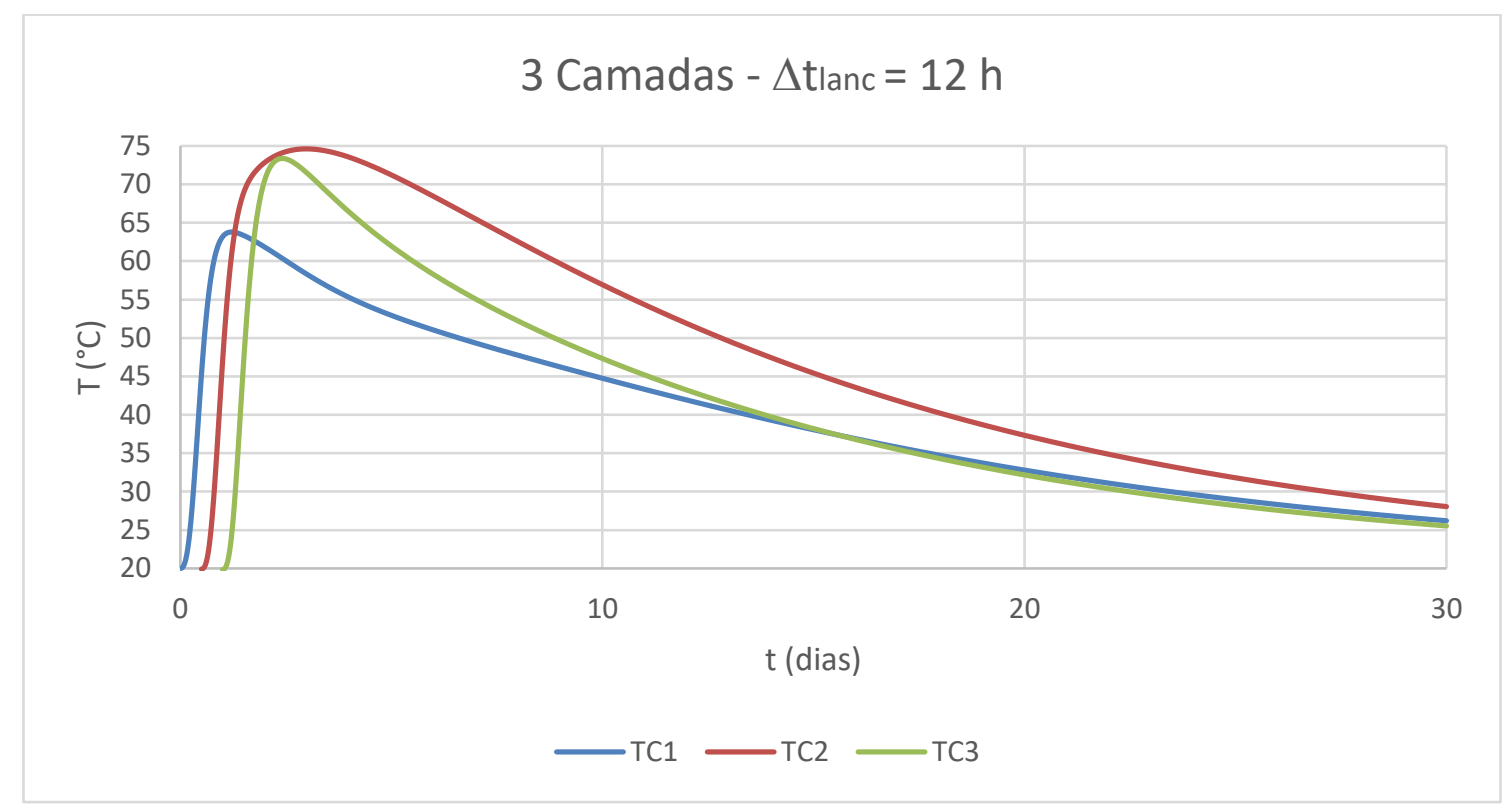

Figura 6.18 - Temperaturas para o Caso C com intervalo de lançamento de $12 \mathrm{~h}$.

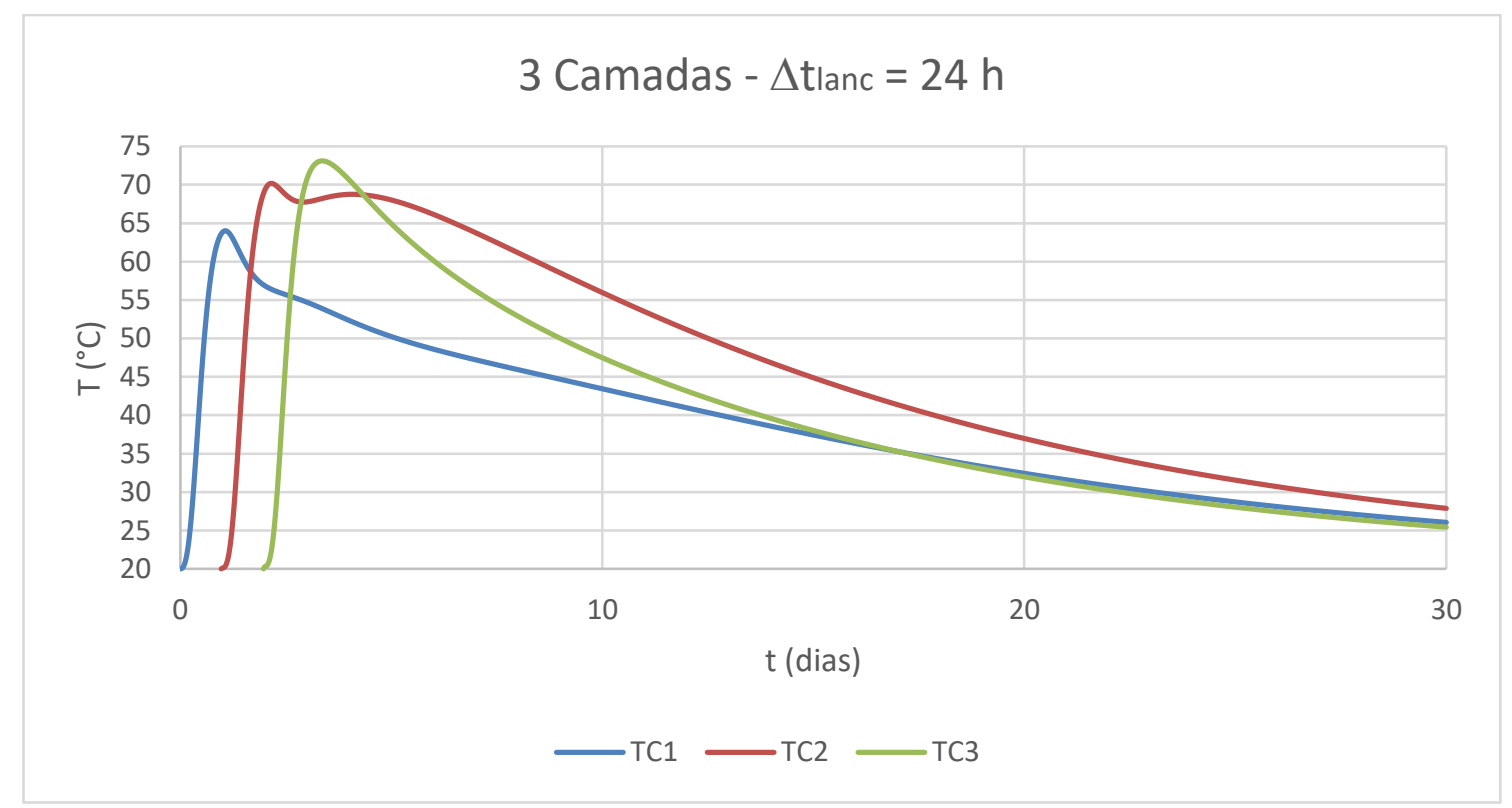

Figura 6.19 - Temperaturas para o Caso C com intervalo de lançamento de $24 \mathrm{~h}$. 


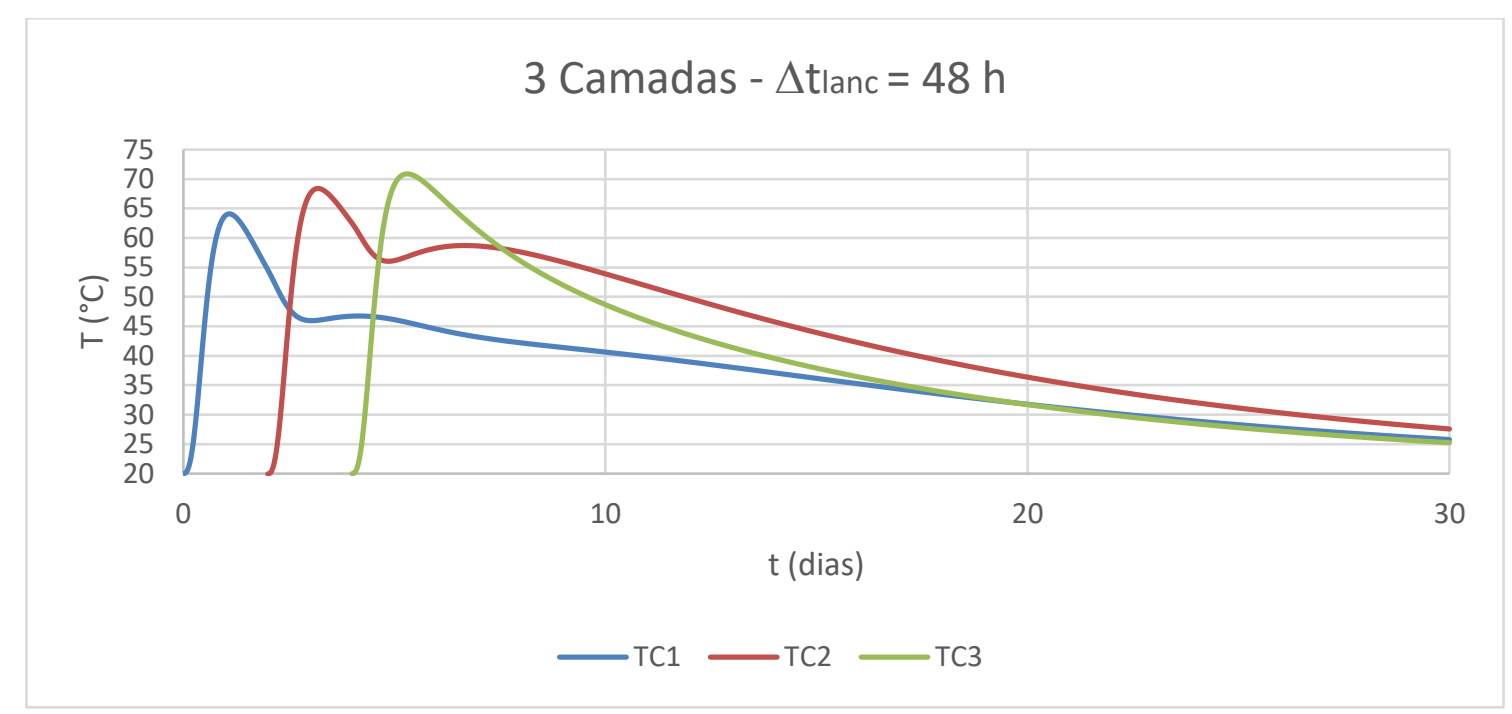

Figura 6.20 - Temperaturas para o Caso C com intervalo de lançamento de 48h.

As Figuras 6.21, 6.22 e 6.23 mostram as simulações de intervalo de lançamento entre as camadas de 12 h, $24 \mathrm{~h}$ e $48 \mathrm{~h}$, respectivamente, para quatro camadas de 0,75 m. observa-se que as máximas temperaturas foram $75^{\circ} \mathrm{C}$ na terceira camada $-12 \mathrm{~h}, 70^{\circ} \mathrm{C}$ na quarta camada $-24 \mathrm{~h}$ e $67^{\circ} \mathrm{C}$ na quarta camada - $48 \mathrm{~h}$. Esta situação já mostra uma diferença significante nos perfis de temperatura. Observa-se também um resfriamento mais rápido em todas as camadas para um maior intervalo de lançamento, pois há uma maior dissipação do calor entre os lançamentos do concreto.

É importante verificar que, nas três simulações, o resfriamento das camadas próximas aos contornos é mais rápido. Já as camadas centrais demandam mais tempo para resfriar, consequentemente, mantém temperaturas maiores por mais tempo.

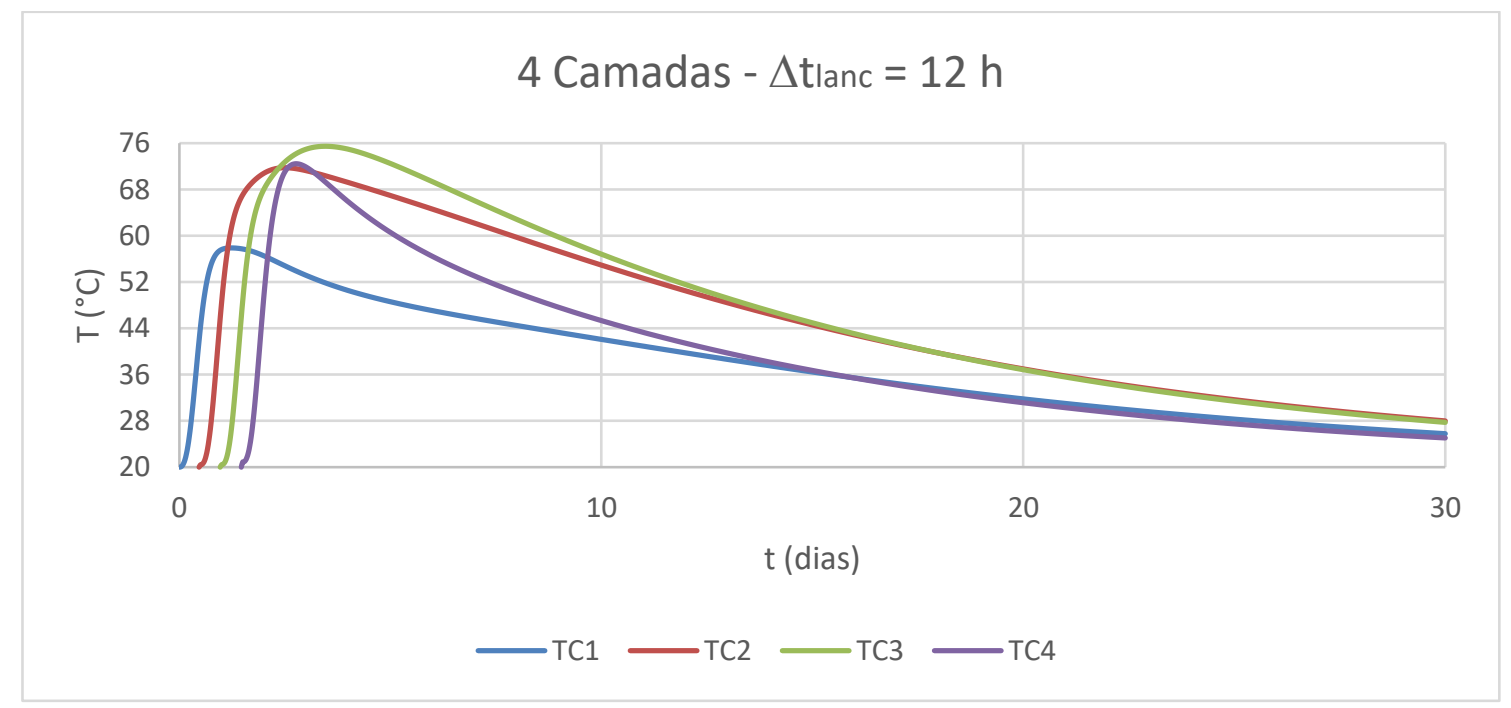

Figura 6.21 - Temperaturas para o Caso D com intervalo de lançamento de $12 \mathrm{~h}$. 
4 Camadas $-\Delta$ tlanc $=24 \mathrm{~h}$

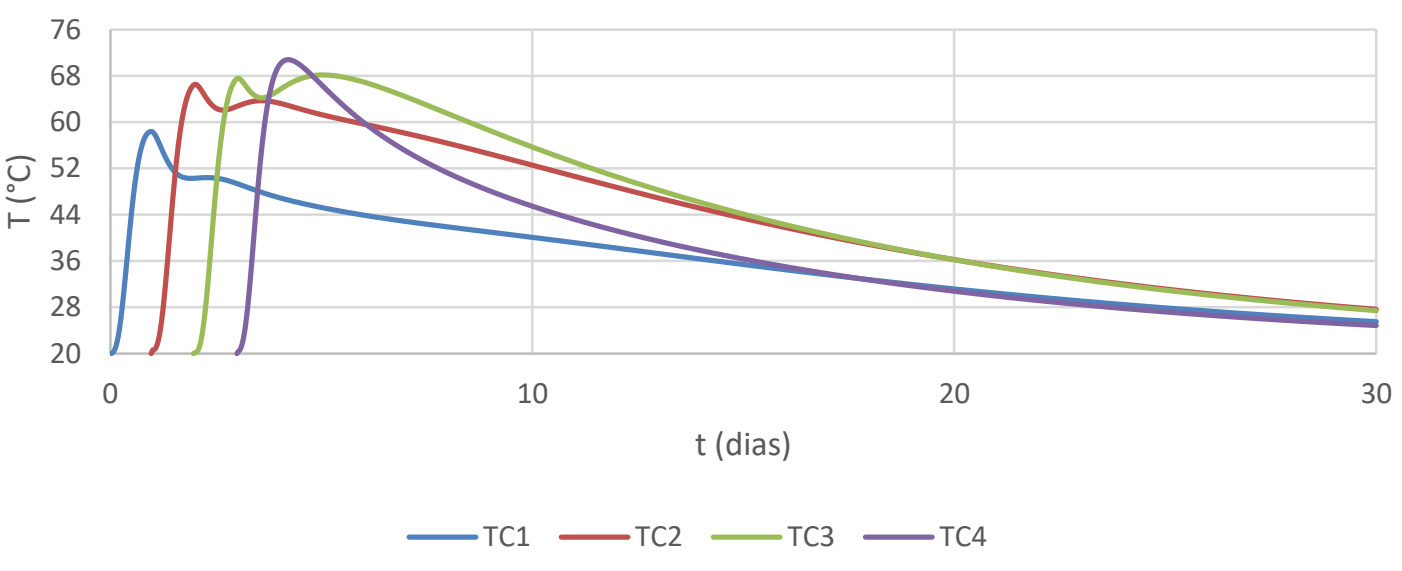

Figura 6.22 - Temperaturas para o Caso D com intervalo de lançamento de $24 \mathrm{~h}$.

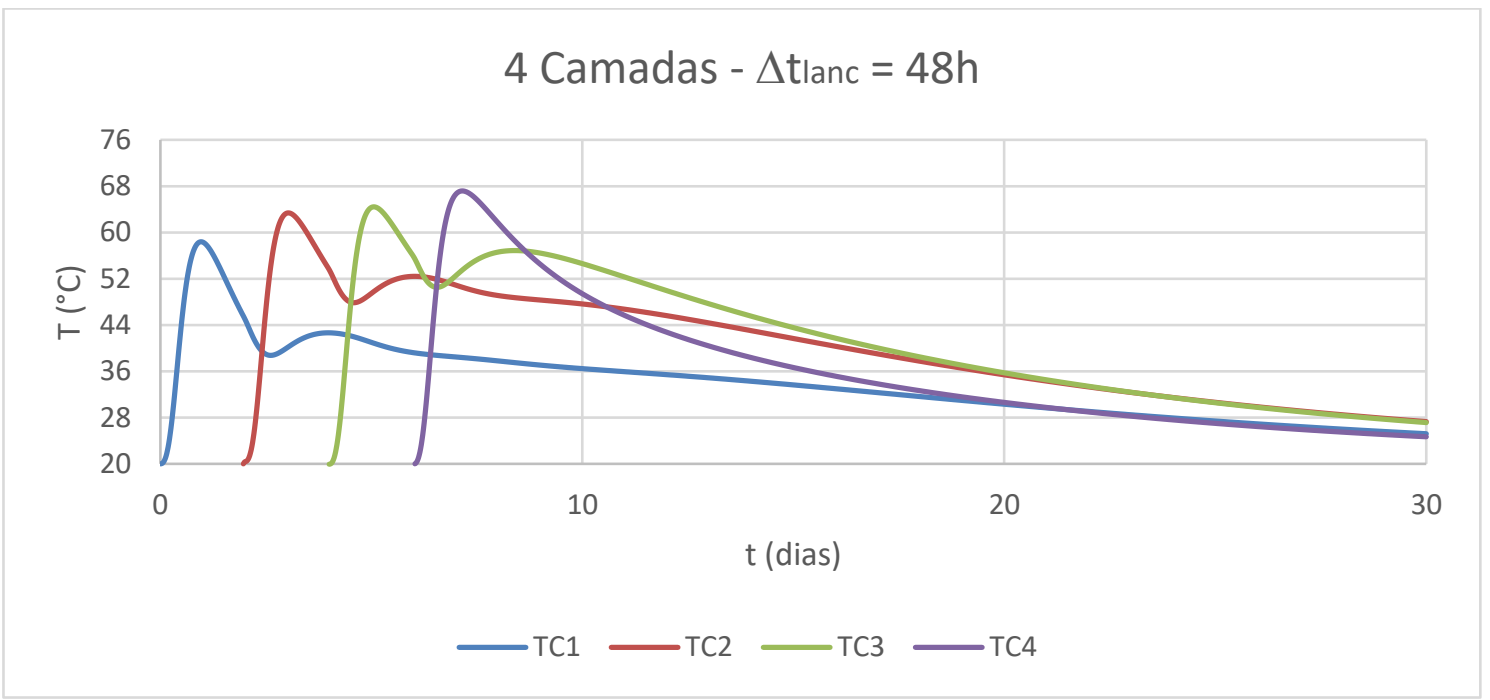

Figura 6.23 - Temperaturas para o Caso D com intervalo de lançamento de 48h.

Com cinco camadas, Figuras 6.24, 6.25 e 6.26, de 0,6 $\mathrm{m}$ a diferença entre as máximas temperaturas para diferentes intervalos de lançamento é bem mais significativa. No intervalo de lançamento de $12 \mathrm{~h}$, a máxima ocorreu na quarta camada com $75^{\circ} \mathrm{C}$. Para intervalo de 24 h, a máxima foi de $68^{\circ} \mathrm{C}$ na última camada, enquanto para o intervalo de $48 \mathrm{~h}$, esse valor foi de $62^{\circ} \mathrm{C}$. Nota-se uma diferença de $13^{\circ} \mathrm{C}$ entre o primeiro e o último, e de $6^{\circ} \mathrm{C}$ entre os dois últimos. 


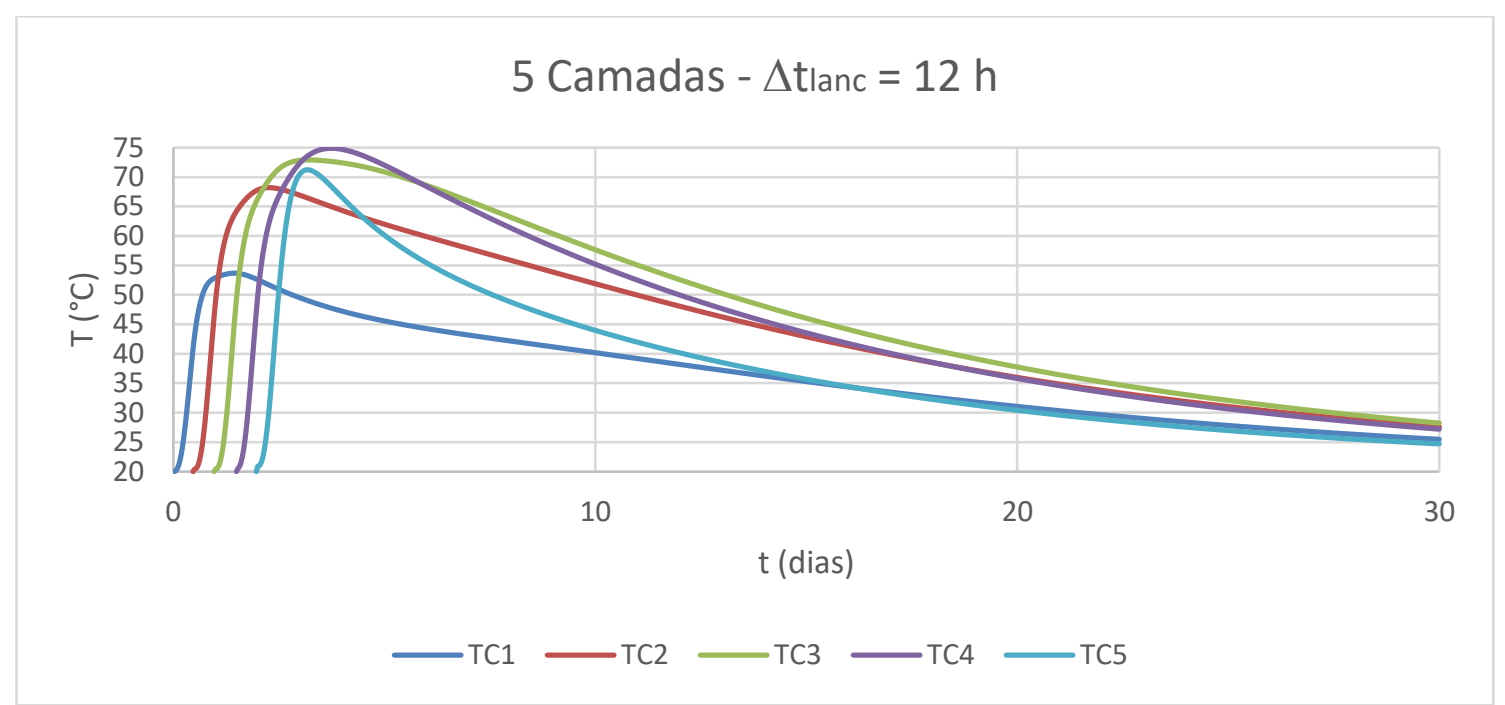

Figura 6.24 - Temperaturas para o Caso E com intervalo de lançamento de 12h.

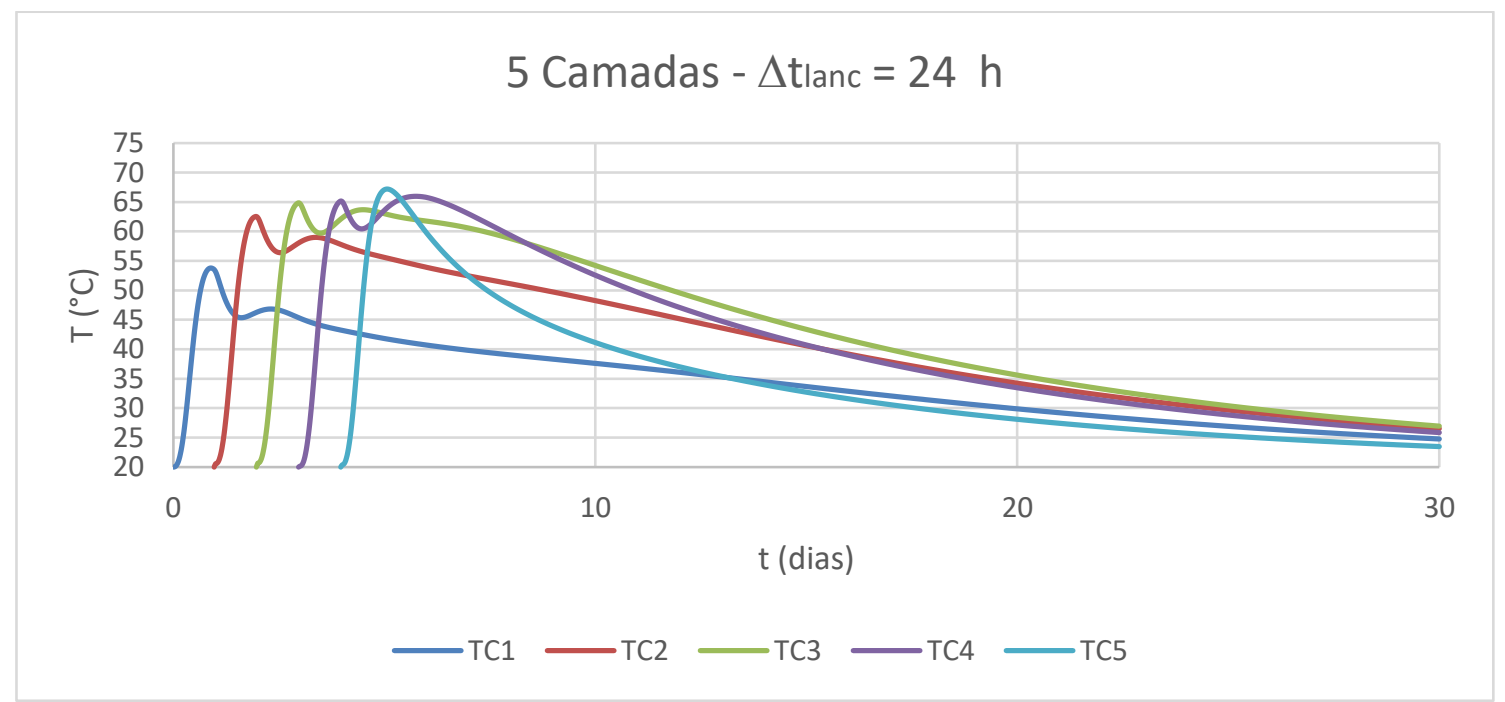

Figura 6.25 - Temperaturas para o Caso E com intervalo de lançamento de $24 \mathrm{~h}$.

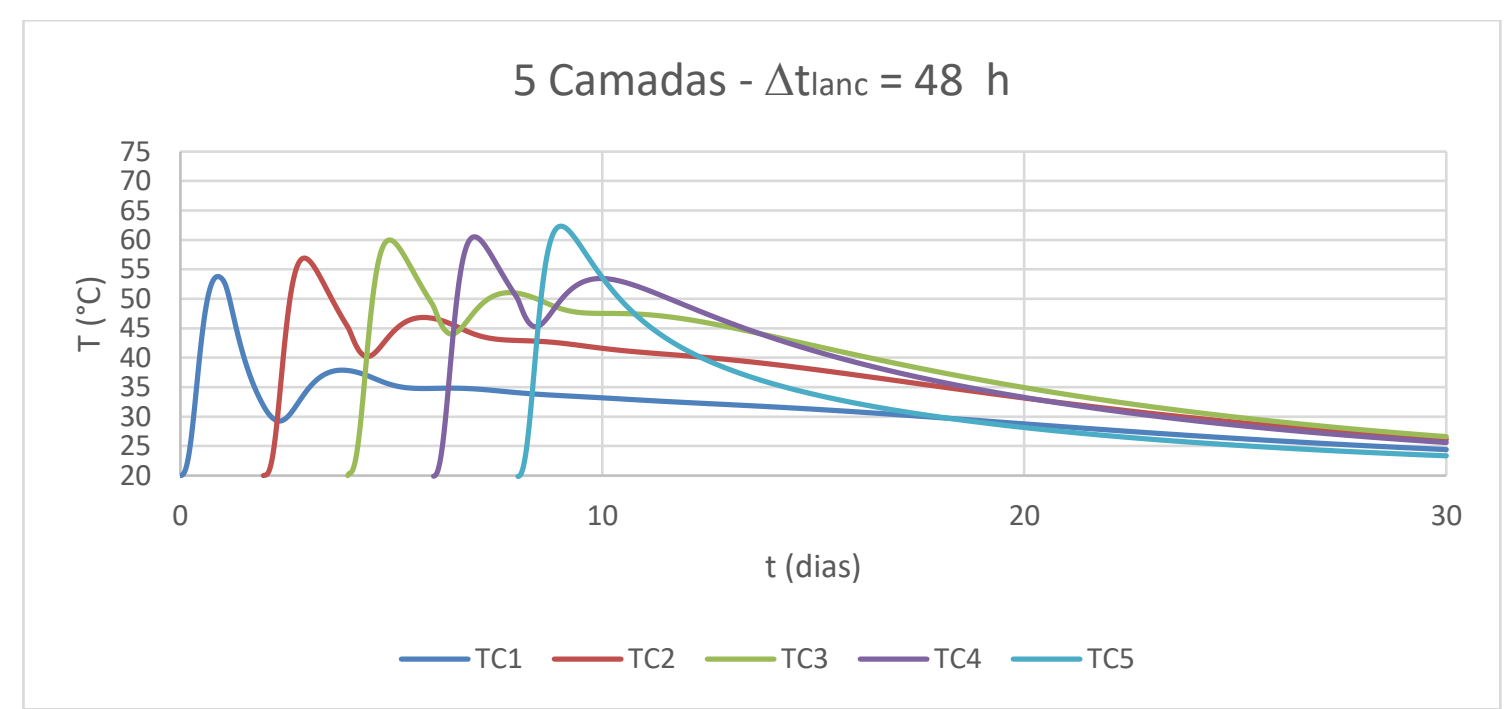

Figura 6.26 - Temperaturas para o Caso E com intervalo de lançamento de 48h. 
Para seis camadas de 0,5 m, Figuras 6.27, 6.28 e 6.29, obteve-se quase $10^{\circ} \mathrm{C}$ de diferença entre as temperaturas máximas atingidas para intervalos de lançamento de 12 h e 24 h, sendo as máximas atingidas na quinta e na sexta camada, respectivamente; e gradiente de temperatura de $15^{\circ} \mathrm{C}$ entre intervalos de $12 \mathrm{~h}$ e $48 \mathrm{~h}$.

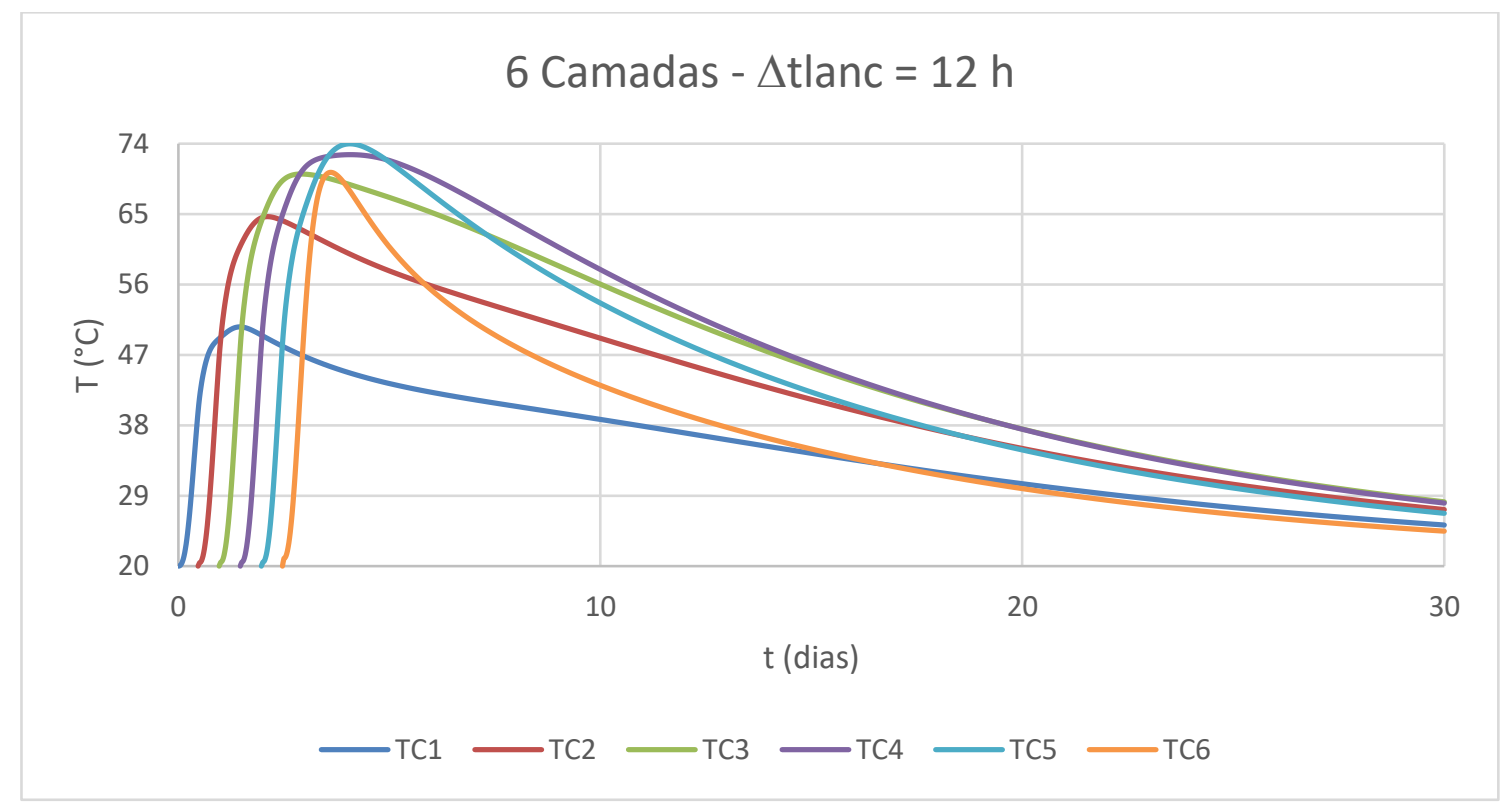

Figura 6.27 - Temperaturas para o Caso F com intervalo de lançamento de $12 \mathrm{~h}$.

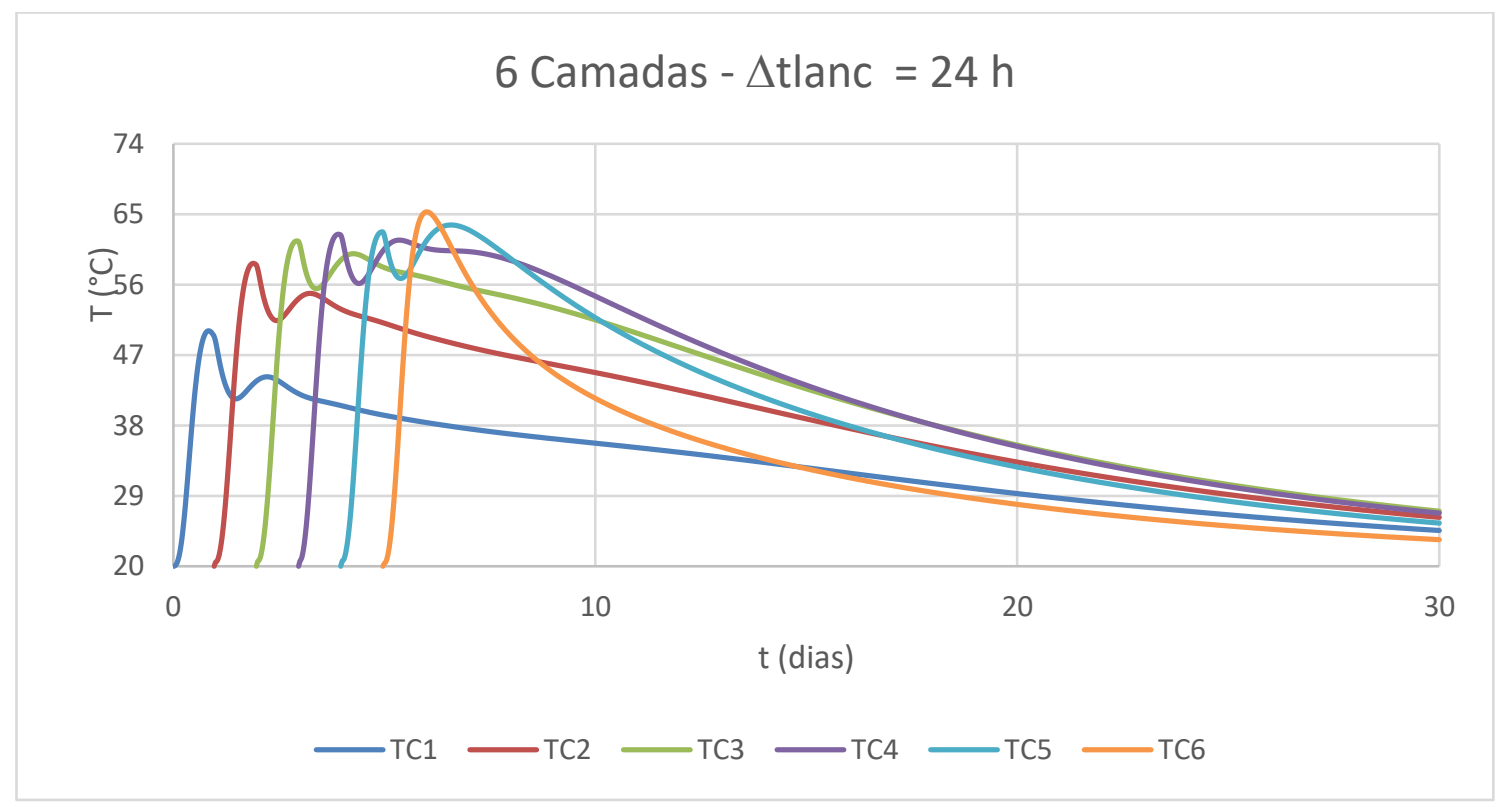

Figura 6.28 - Temperaturas para o Caso F com intervalo de lançamento de $24 \mathrm{~h}$. 


\section{Camadas $-\Delta$ tlanc $=48 \mathrm{~h}$}

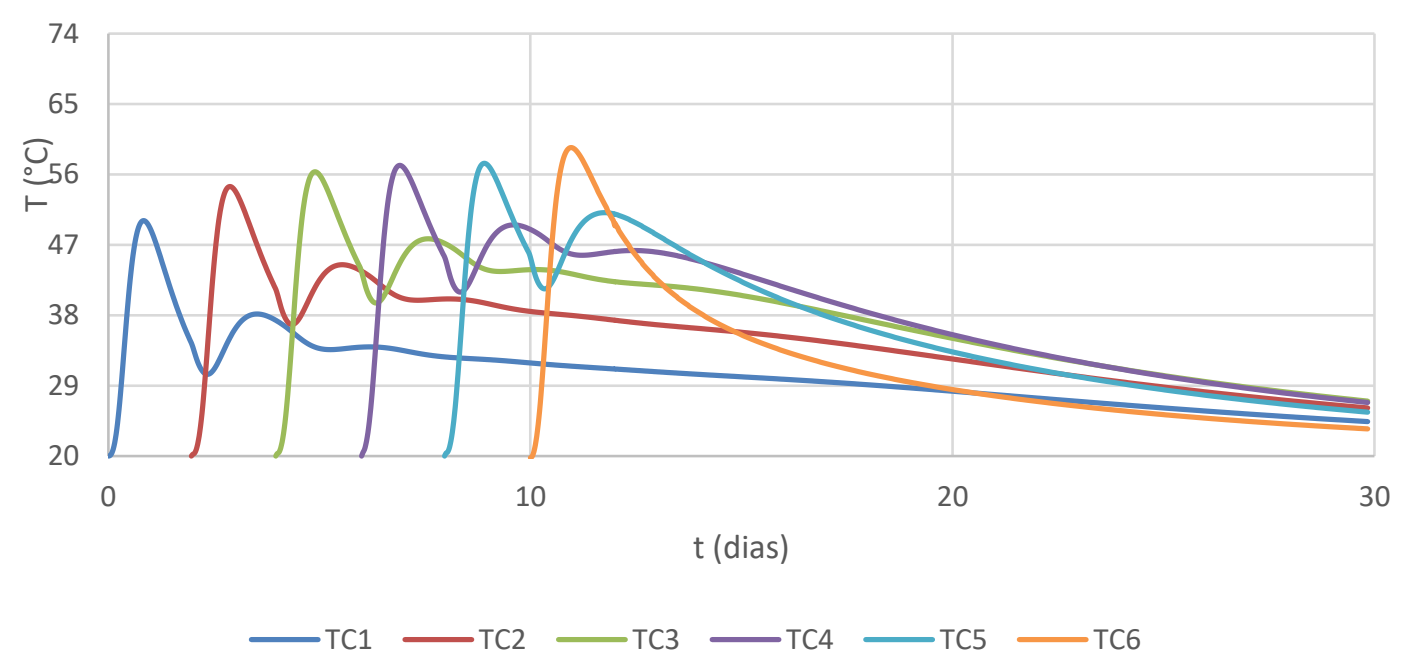

Figura 6.29 - Temperaturas para o Caso F com intervalo de lançamento de 48h.

Para oito camadas, Figuras 6.30, 6.31 e 6.32 sendo sete de 0,4 m e uma (a última) de 0,2 m, as máximas foram de aproximadamente $70^{\circ} \mathrm{C}, 59^{\circ} \mathrm{C}$ e $52^{\circ} \mathrm{C}$ na sexta camada para $12 \mathrm{~h}$ de intervalo de lançamento e na sétima camada para os demais intervalos. Para intervalos de lançamento de 24 h e 48 h é notável uma maior uniformidade entre as máximas atingidas pelas camadas. Estas iniciam um processo de resfriamento que aumenta com o lançamento da próxima camada. Com intervalos de 48 h, as máximas das camadas são muito próximas.

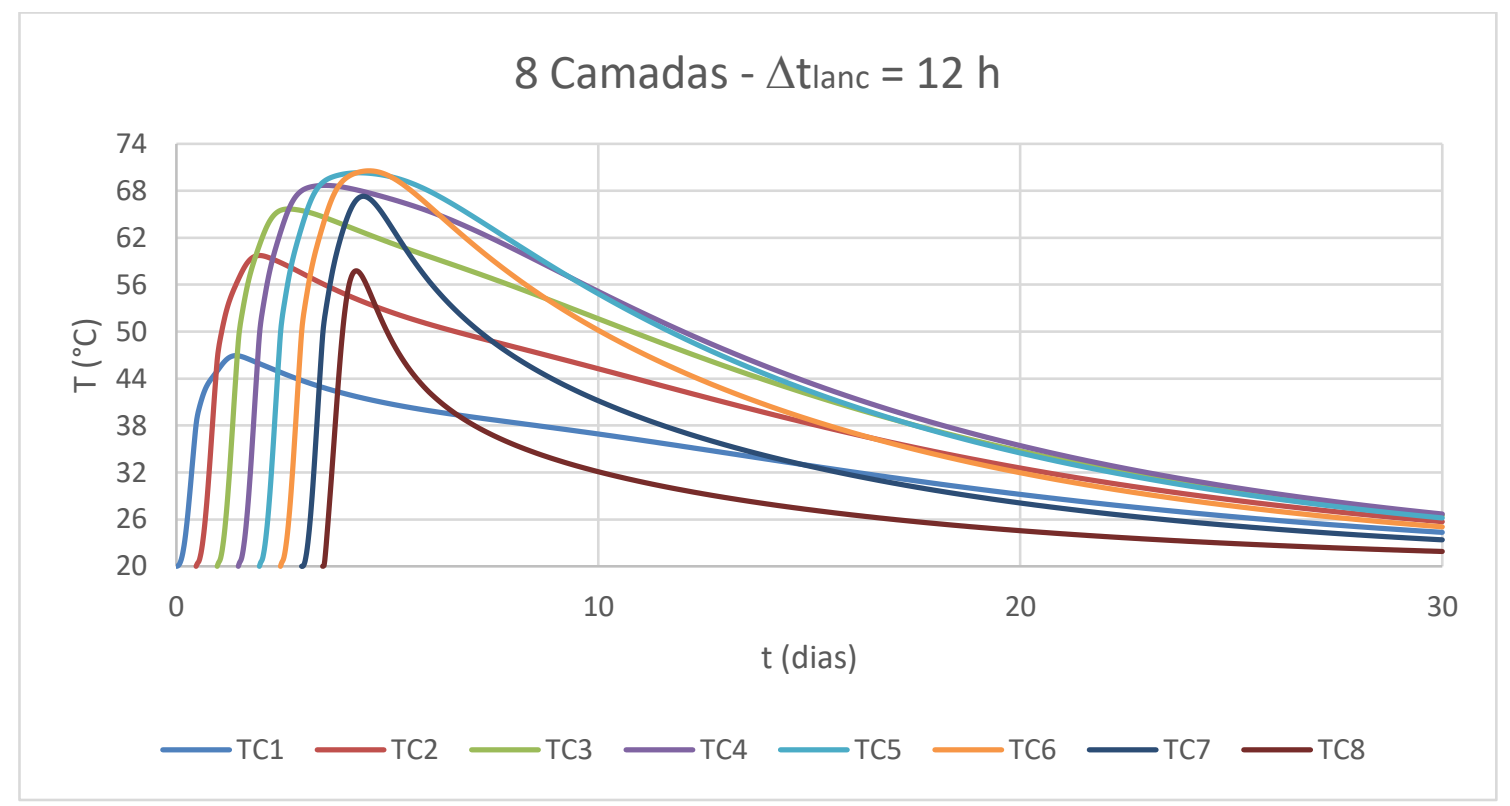

Figura 6.30 - Temperaturas para o Caso G com intervalo de lançamento de $12 \mathrm{~h}$. 


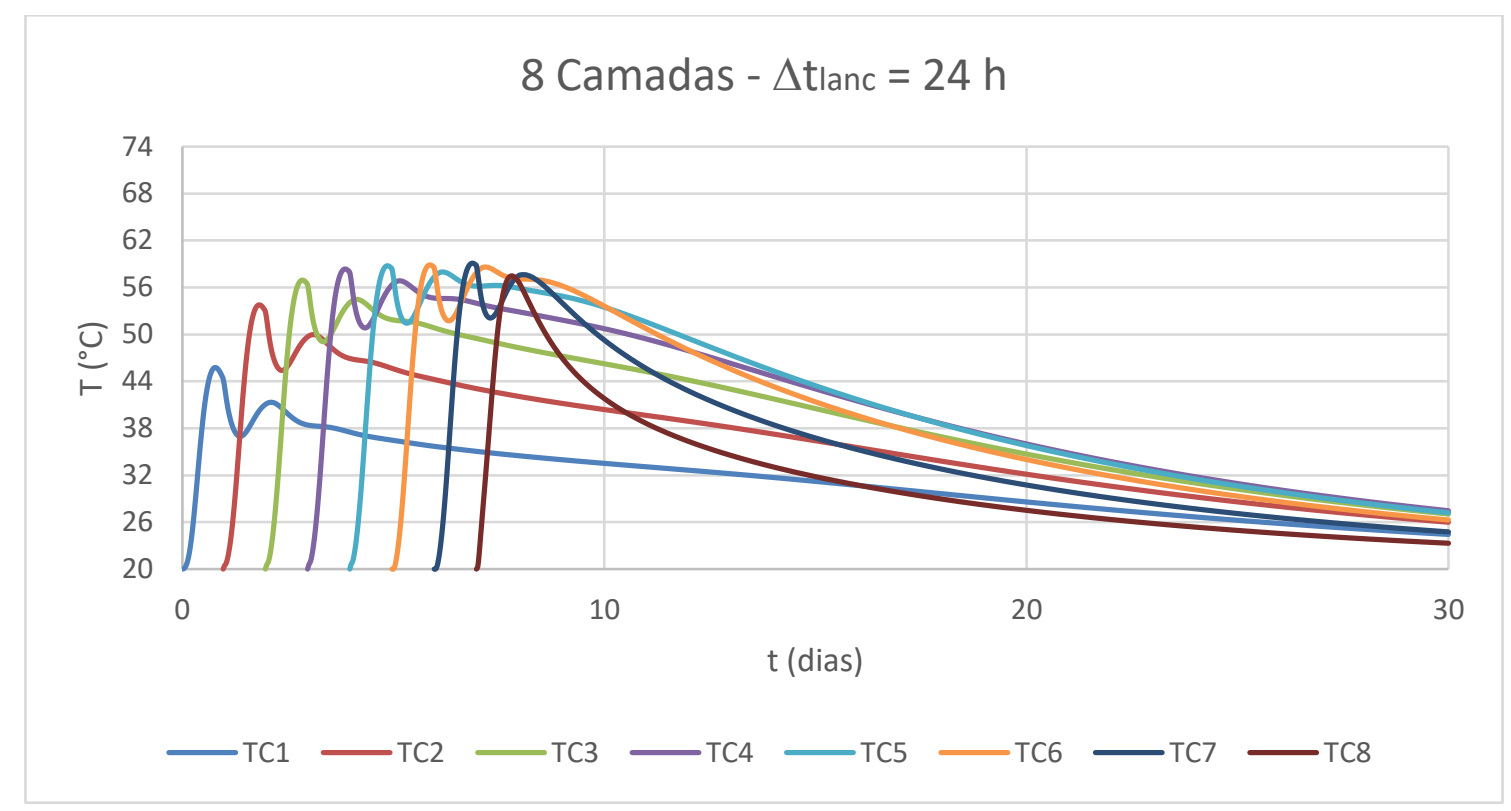

Figura 6.31 - Temperaturas para o Caso G com intervalo de lançamento de 24h.

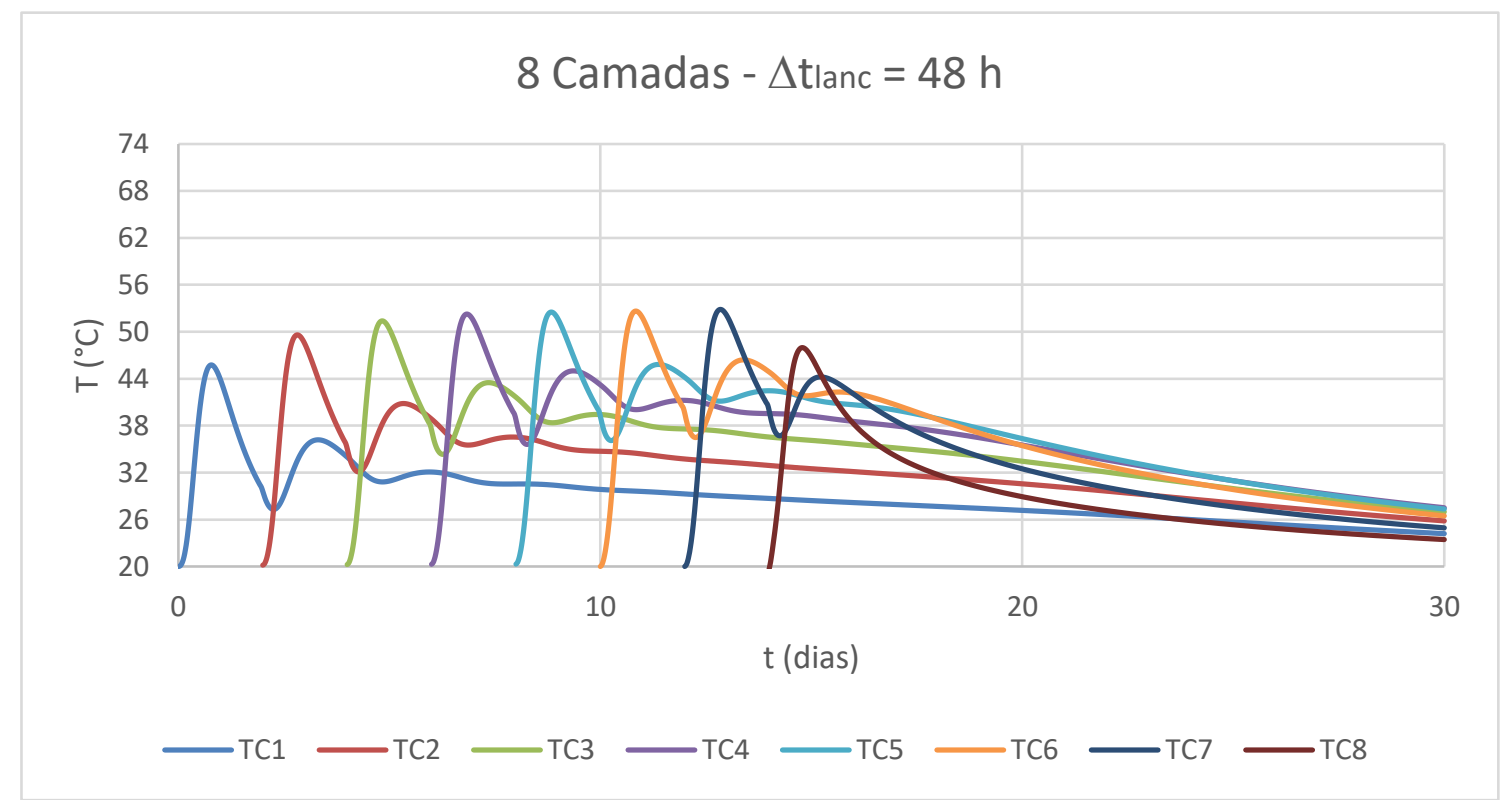

Figura 6.32 - Temperaturas para o Caso G com intervalo de lançamento de 48h.

Com 10 camadas de 0,3 m, Figuras $6.33,6.34,6.35$, as diferenças evidenciam-se ainda mais. Entres as temperaturas máximas para intervalos de lançamento de camadas de $12 \mathrm{~h}$ e $48 \mathrm{~h}$ há, aproximadamente, $47 \%$ de diferença térmica. Com intervalos de 12 h e $24 \mathrm{~h}$ essa mudança cai para $15 \%$, mas com valores bastante expressivos. Para $24 \mathrm{~h}$ de intervalo de lançamento as últimas camadas e todas para $48 \mathrm{~h}$ apresentam praticamente o mesmo valor de temperatura máxima. 
10 Camadas $-\Delta$ tlanc $=12 \mathrm{~h}$

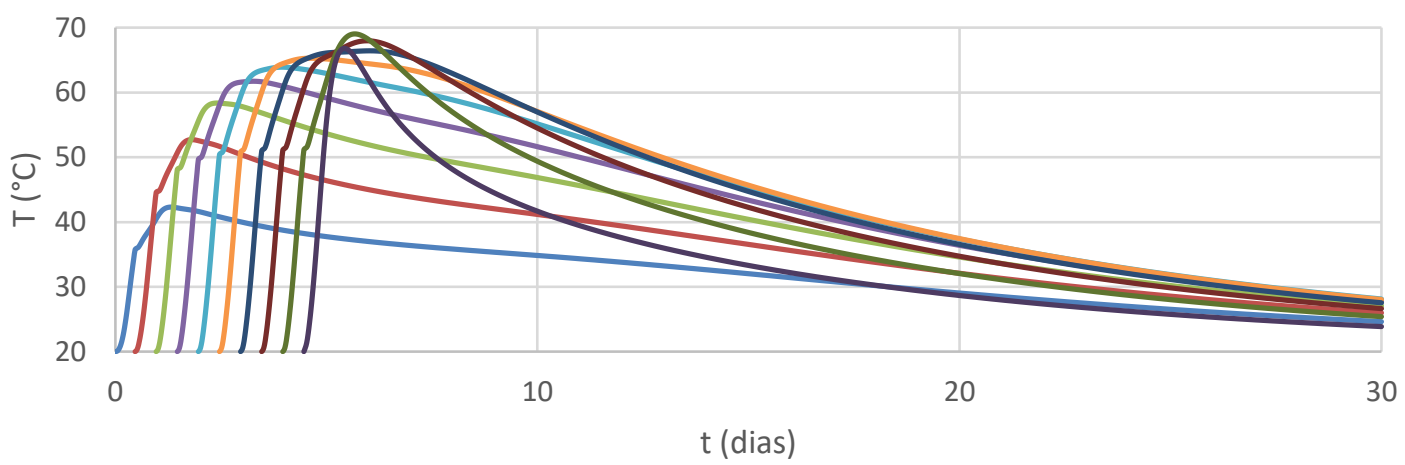

$-\mathrm{TC} 1-\mathrm{TC} 2-\mathrm{TC} 3-\mathrm{TC} 4-\mathrm{TC} 5-\mathrm{TC} 6-\mathrm{TC} 7-\mathrm{TC} 8-\mathrm{TC} 9-\mathrm{TC} 10$

Figura 6.33 - Temperaturas para o Caso H com intervalo de lançamento de $12 \mathrm{~h}$.

10 Camadas $-\Delta$ tlanc $=24 \mathrm{~h}$

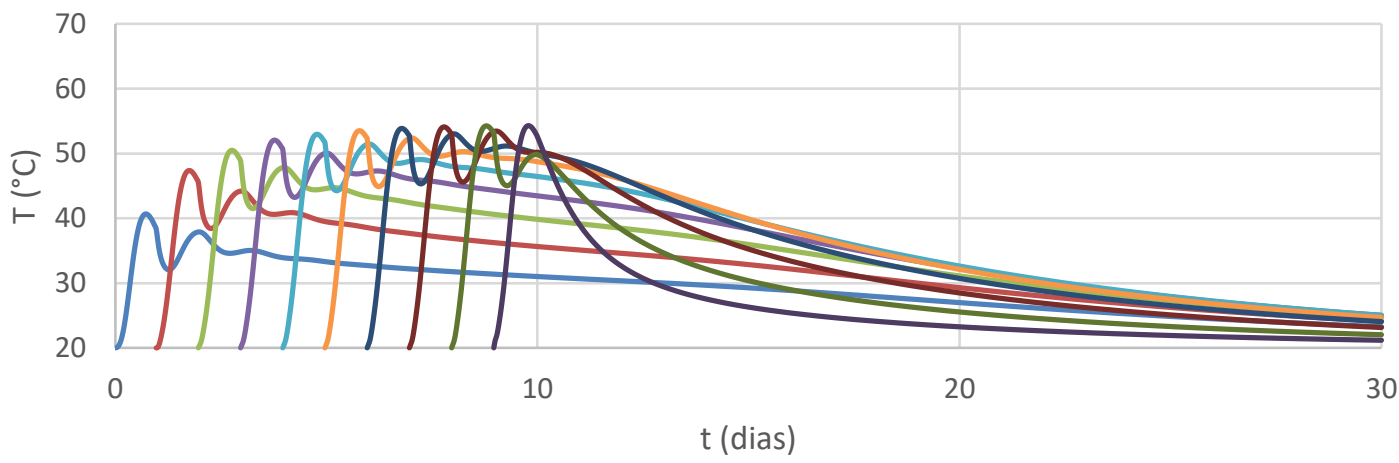

$\longrightarrow \mathrm{TC} 1-\mathrm{TC2} \longrightarrow \mathrm{TC} 3-\mathrm{TC} 4-\mathrm{TC5}-\mathrm{TC} 6-\mathrm{TC} 7-\mathrm{TC} 8-\mathrm{TC} 9-\mathrm{TC} 10$

Figura 6.34 - Temperaturas para o Caso H com intervalo de lançamento de $24 \mathrm{~h}$.

10 Camadas $-\Delta$ tlanc $=48 \mathrm{~h}$

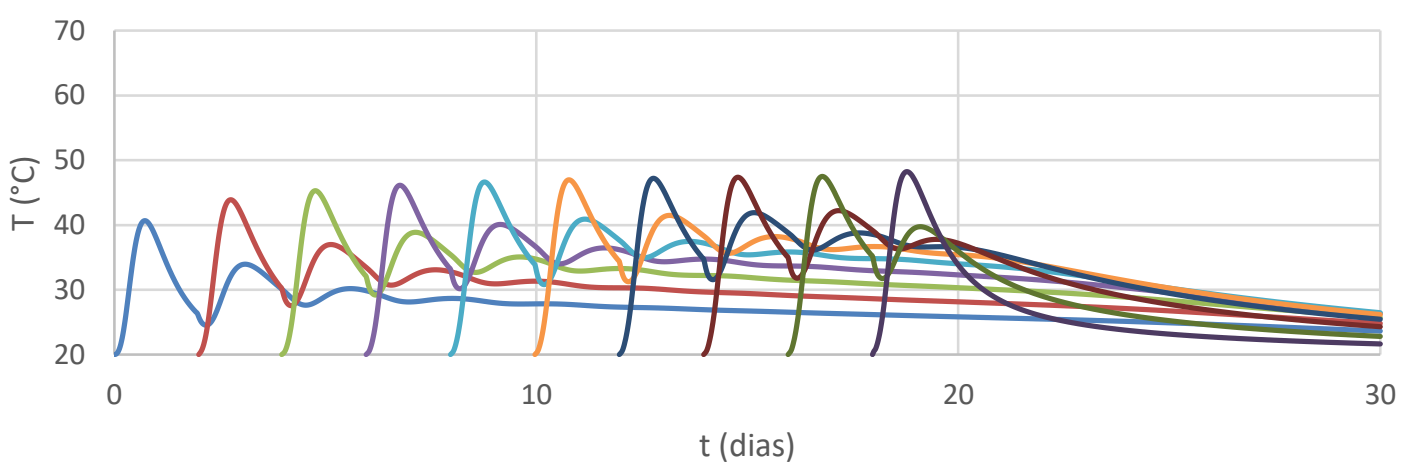

$-\mathrm{TC} 1-\mathrm{TC} 2-\mathrm{TC} 3-\mathrm{TC} 4-\mathrm{TC} 5-\mathrm{TC} 6-\mathrm{TC} 7-\mathrm{TC} 8-\mathrm{TC} 9-\mathrm{TC} 10$

Figura 6.35 - Temperaturas para o Caso H com intervalo de lançamento de 48h. 
Por fim, para camadas de 0,2 m, Figuras 6.36, 6.37 e 6.38, totalizando 15 camadas, as máximas temperaturas atingidas para intervalos de lançamento da camada de $12 \mathrm{~h}$ são claramente muito mais elevadas que nas outras situações.

Para um maior intervalo de tempo houve também uma maior uniformidade entre as temperaturas do concreto, assim como no processo de resfriamento. Em virtude da espessura da camada e do tempo necessário para o resfriamento, ocorre uma redução significativa das temperaturas para maiores intervalos. Observa-se também que, entre os dois últimos lançamentos, a diferença entre as máximas foi de aproximadamente $4^{\circ} \mathrm{C}$.

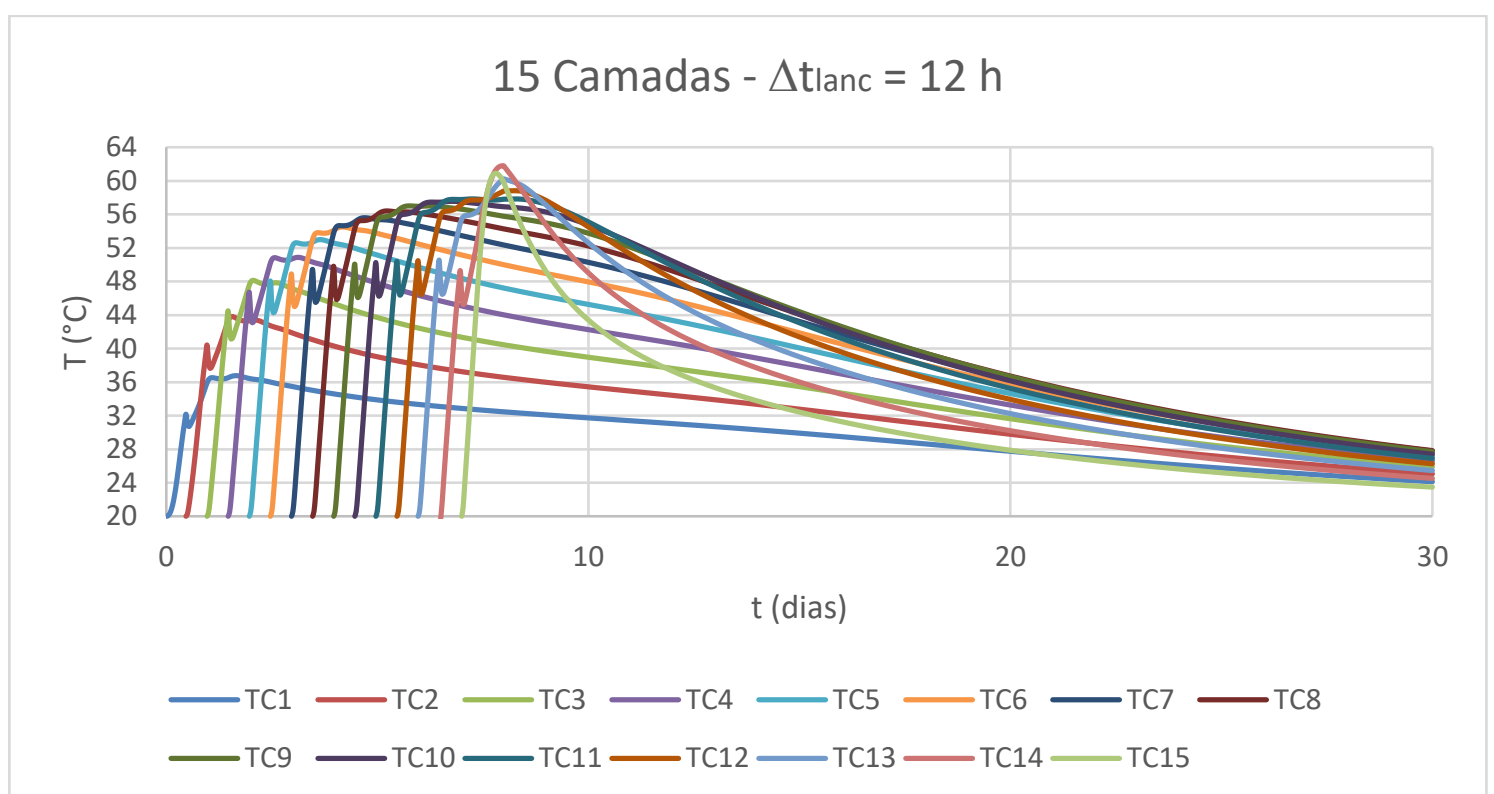

Figura 6.36 - Temperaturas para o Caso I com intervalo de lançamento de $12 \mathrm{~h}$.

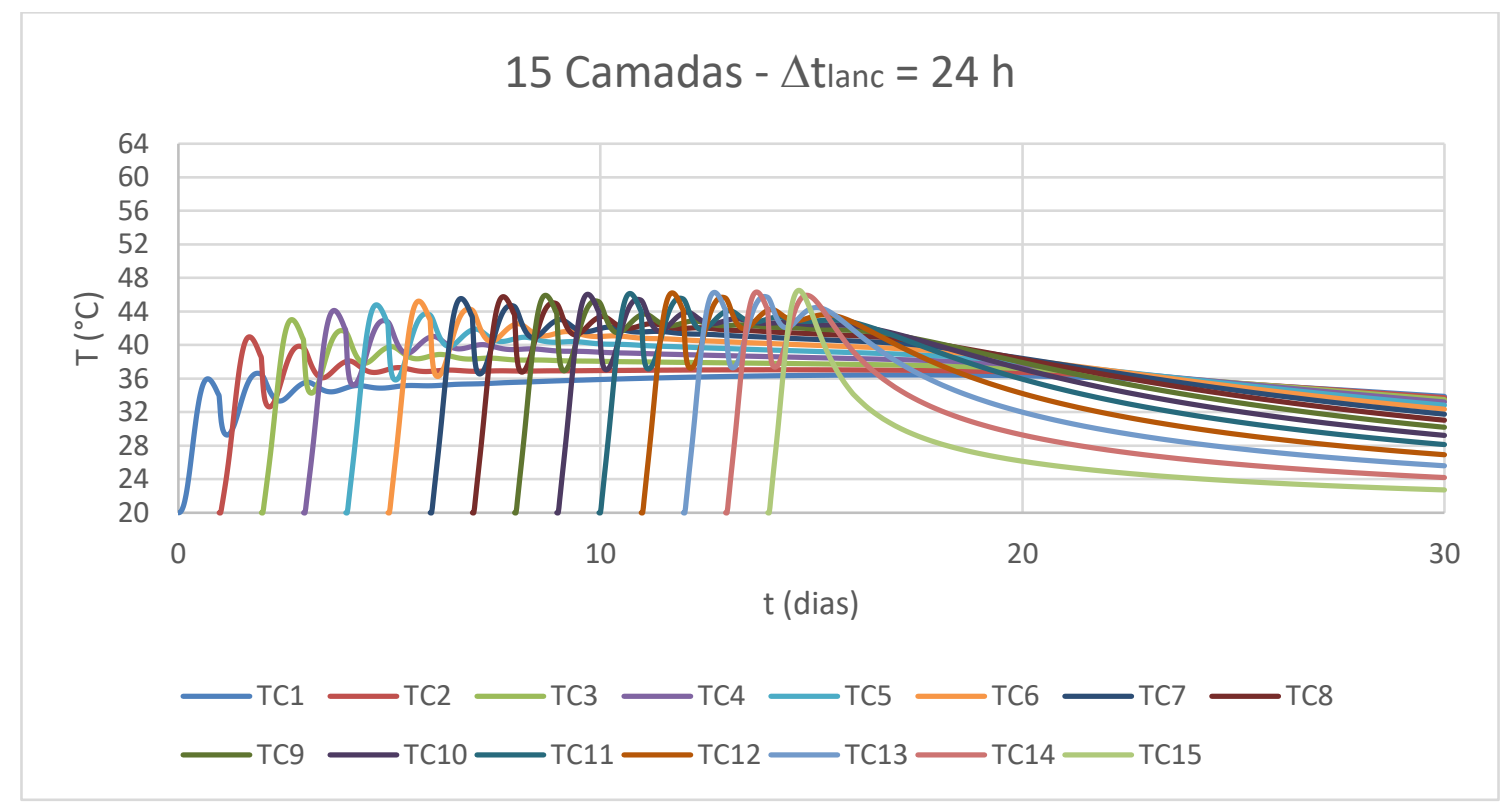

Figura 6.37 - Temperaturas para o Caso I com intervalo de lançamento de $24 \mathrm{~h}$. 


\section{Camadas $-\Delta$ tlanc $=48 \mathrm{~h}$}

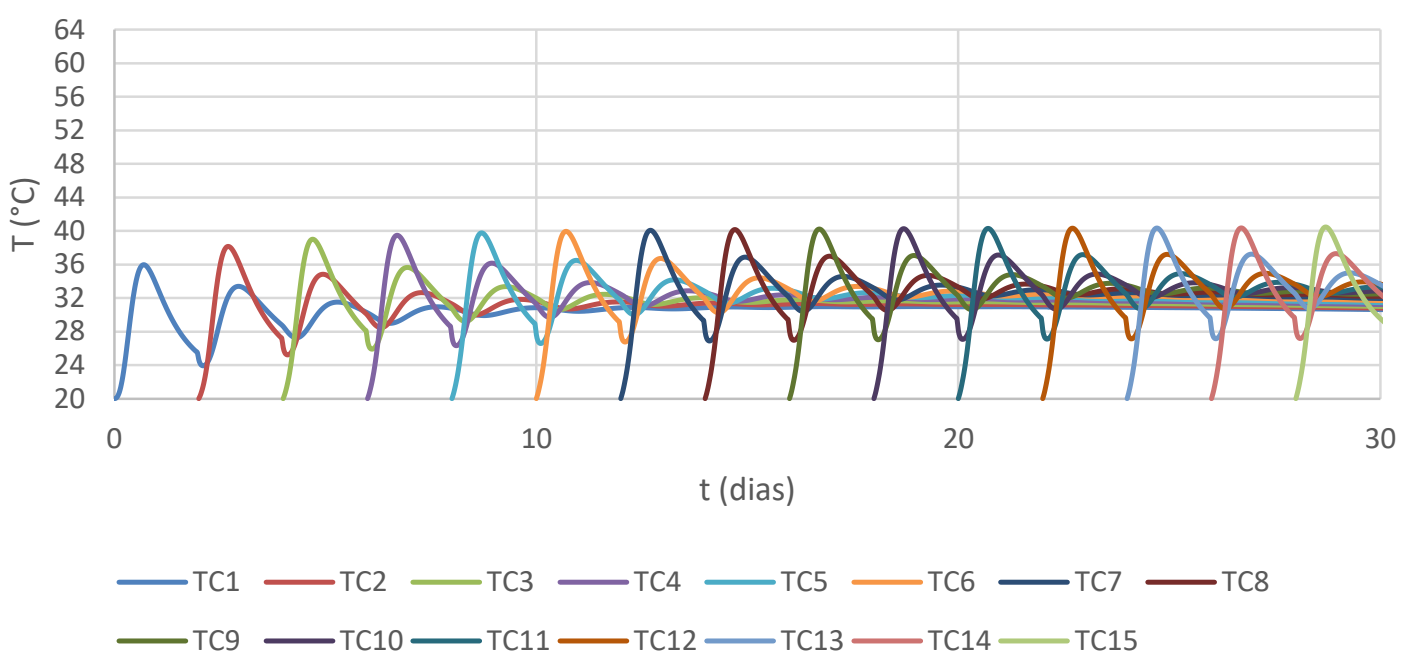

Figura 6.38 - Temperaturas para o Caso I com intervalo de lançamento de 48h.

Observa-se pelas simulações efetuadas que os casos maiores de oito camadas apresentam anomalia nos resultados referentes a última camada, que pode ser parcialmente explicada por:

- Como o número de pontos de convergência no tempo e no espaço é muito grande poderá haver limitação computacional. A máquina utilizada foi um notebook com processador Intel Core i 7 com velocidade de $2 \mathrm{GHz}$, memória RAM de $8 \mathrm{~GB}$, sistema operacional 64 bits, placa de vídeo dedicada de 2GB e 1 TB de HD.

- Pode ser um efeito físico associado ao próprio fenômeno, em função da pequena espessura da última camada.

- Tamanho da malha. Para os casos com maior número de camadas, o fenômeno não foi suficientemente investigado para se obter justificativas fundamentadas e conclusivas.

- O tempo de convergência para o fenômeno em relação ao tempo de análise pode não ter sido suficiente.

Para os casos anteriormente relatados, foram analisadas as tensões da primeira e segunda camada, bem como da camada que apresentou temperatura máxima. A primeira camada apresenta coeficiente de restrição diferente das demais, por estar sobre a fundação. Da segunda camada em diante, como ficam apoiadas sobre outra camada de concreto, além do coeficiente de restrição, deverá ser multiplicado pelo coeficiente de fundação dado pela Equação 6.3. 


\subsubsection{CASO 3.1 - Primeira Camada - C1}

A Figura 6.39 mostra as temperaturas ao longo do tempo, com lançamento das camadas a cada $12 \mathrm{~h}$ para o ponto central da primeira camada em todos os Casos 3.1, conforme foi mostrado na Tabela 6.4. O Caso 3.1 - A tem uma única camada de 3,0 m e desenvolve a maior temperatura. À medida que a espessura da camada diminui, a máxima temperatura também é reduzida, sendo as menores desenvolvidas para o Caso 3 - I, que tem a menor espessura, $0,2 \mathrm{~m}$.

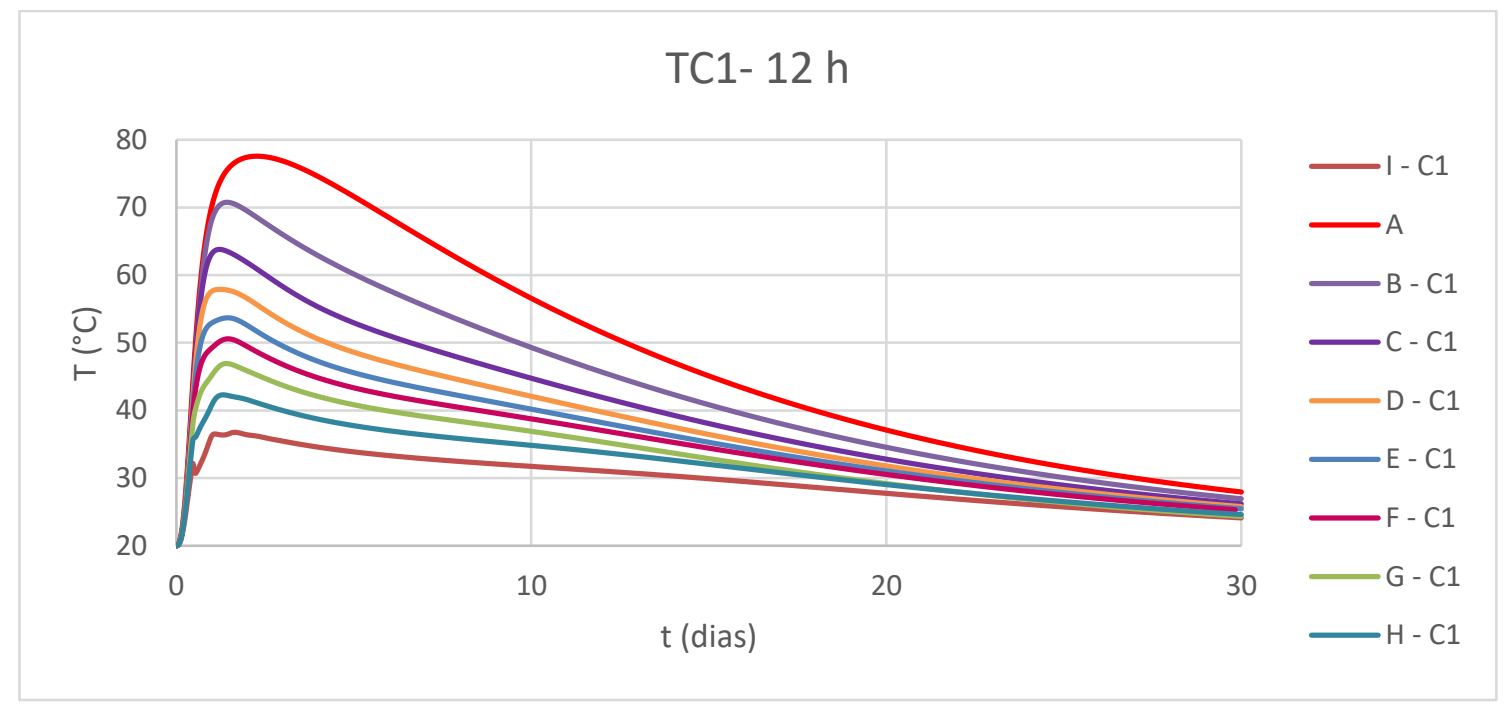

Figura 6.39 - Temperaturas para TC1 com intervalo de lançamento de $12 \mathrm{~h}$.

As Figuras 6.40 e 6.41 mostram as tensões na primeira camada calculadas pelos métodos DP e USBR, respectivamente. Nos dois gráficos verifica-se que as tensões acompanham as curvas de temperatura; inicialmente ocorre uma compressão, em virtude da restrição na parte inferior do corpo, provocando aumento da temperatura do concreto; com o resfriamento, surgem as tensões de tração. Sendo a linha tracejada a resistência à tração do concreto, o cruzamento desta indica uma possível fissuração do concreto.

Observa-se que, pelo método USBR, todos os casos teriam fissuração e estas ocorreriam mais rapidamente. Pela DP, o Caso 3.1-I não fissuraria. Para o USBR, tanto as tensões de tração quanto as de compressão apresentam valores mais elevados que pelo método DP. 


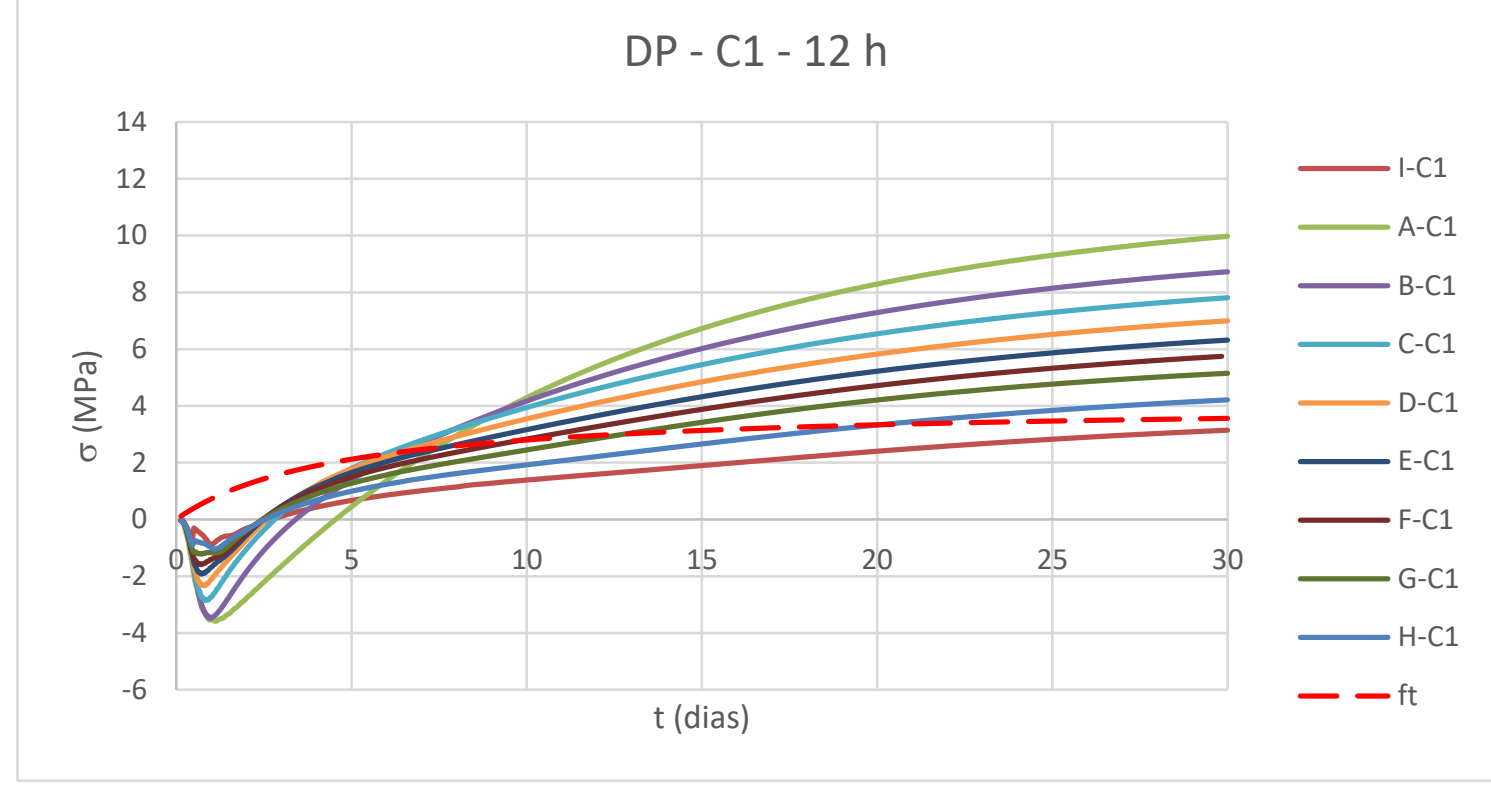

Figura 6.40 - Tensões para C1 pelo método DP com intervalo de lançamento de $12 \mathrm{~h}$.

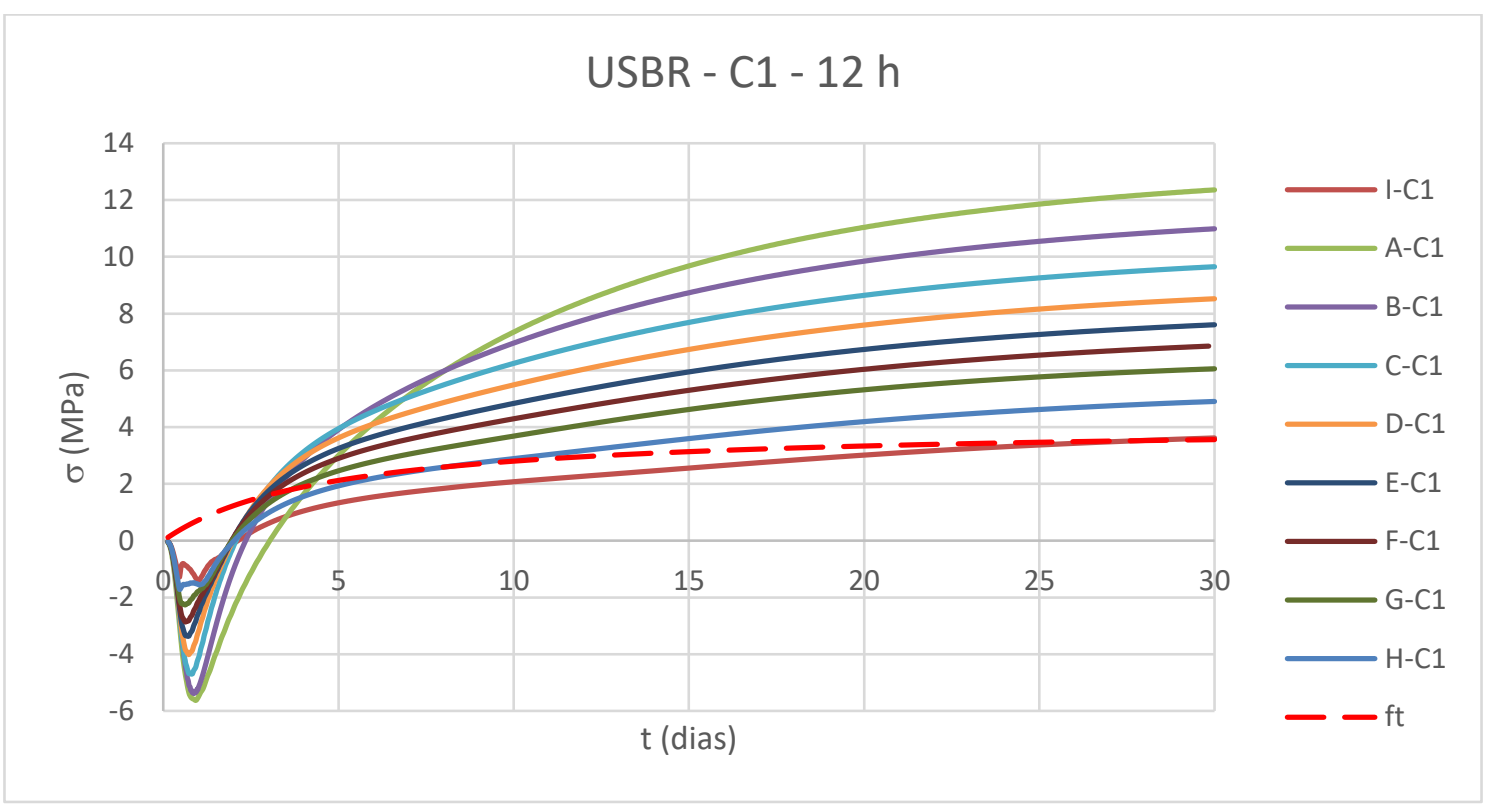

Figura 6.41 - Tensões para C1 pelo método USBR com intervalo de lançamento de $12 \mathrm{~h}$.

A Figura 6.42 mostra a primeira camada, com a segunda lançada após 24 h. As sequencias das máximas temperaturas acompanha a espessura da camada. Quanto maior, mais alta a máxima temperatura atingida.

Percebe-se também que quanto mais fina a camada, mais evidente é o seu resfriamento inicial e também maior a influência da camada seguinte sobre ela - há um resfriamento inicial e, quando a camada seguinte é lançada, há novamente aumento desta temperatura. 
Observa-se também que, para o Caso 3.1-I no tempo final ocorre um aumento da temperatura. Isto se deve ao aumento no incremento de tempo provocando perda de precisão nos resultados para ganhar tempo de processamento.

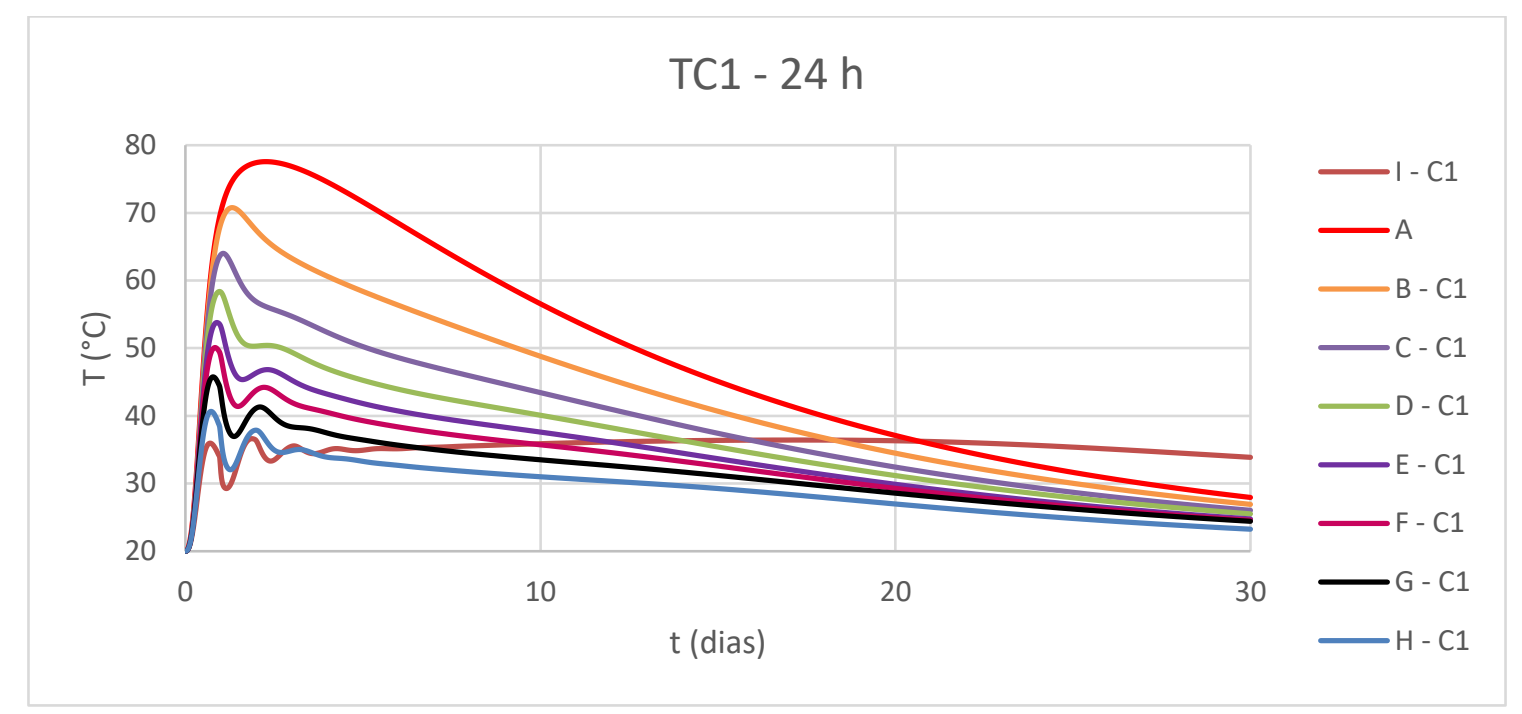

Figura 6.42 - Temperaturas para TC1 com intervalo de lançamento de $24 \mathrm{~h}$.

Com os perfis de temperatura da Figura 6.42 foram elaborados os perfis de tensões pelos métodos DP e USBR, conforme as Figuras 6.43 e 6.44. As considerações feitas para a concretagem a cada $12 \mathrm{~h}$ se estende para a concretagem a cada 24 h e apenas o Caso 3-I não iria fissurar.

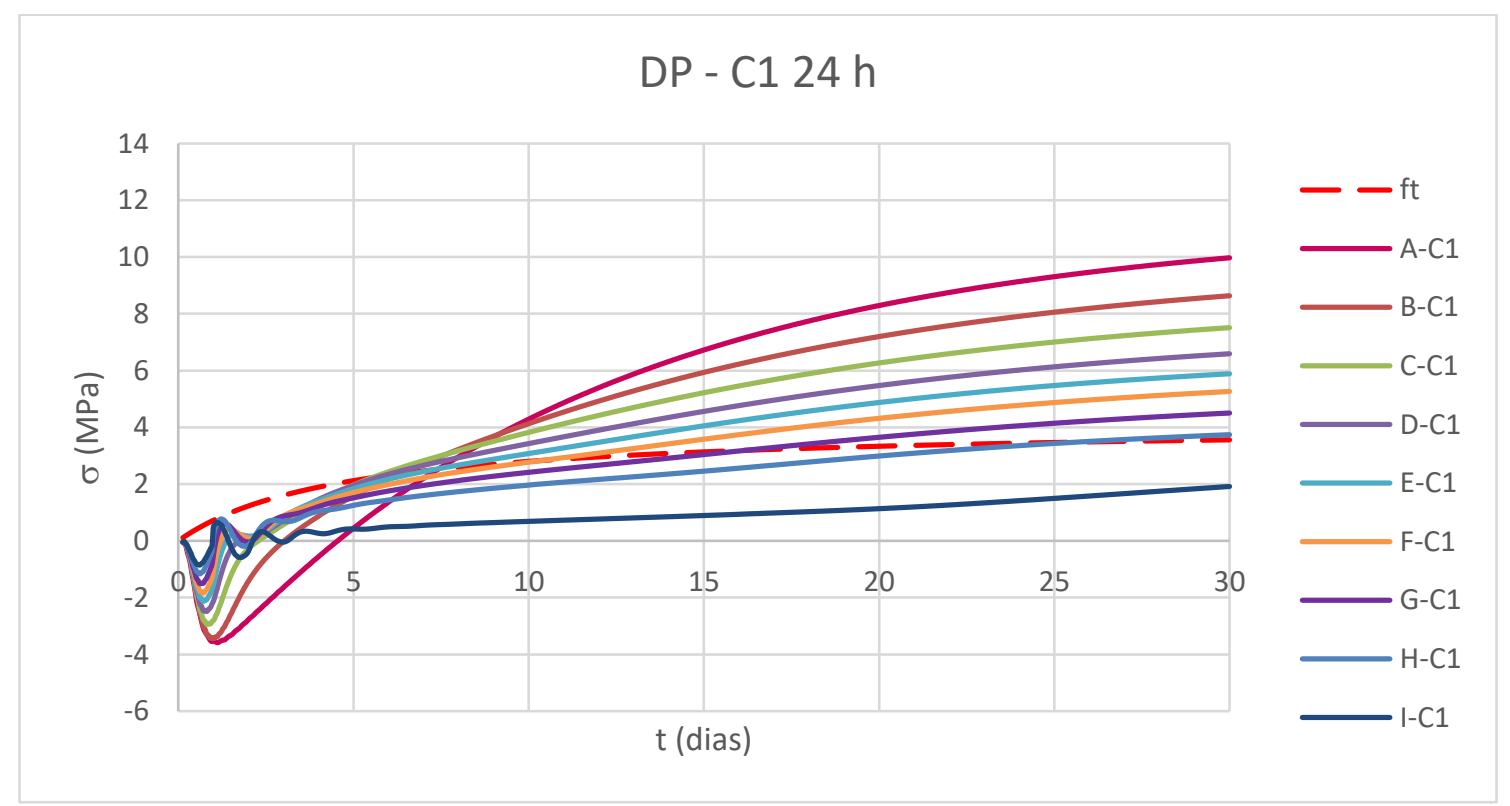

Figura 6.43 - Tensões para C1 pelo método DP com intervalo de lançamento de $24 \mathrm{~h}$. 


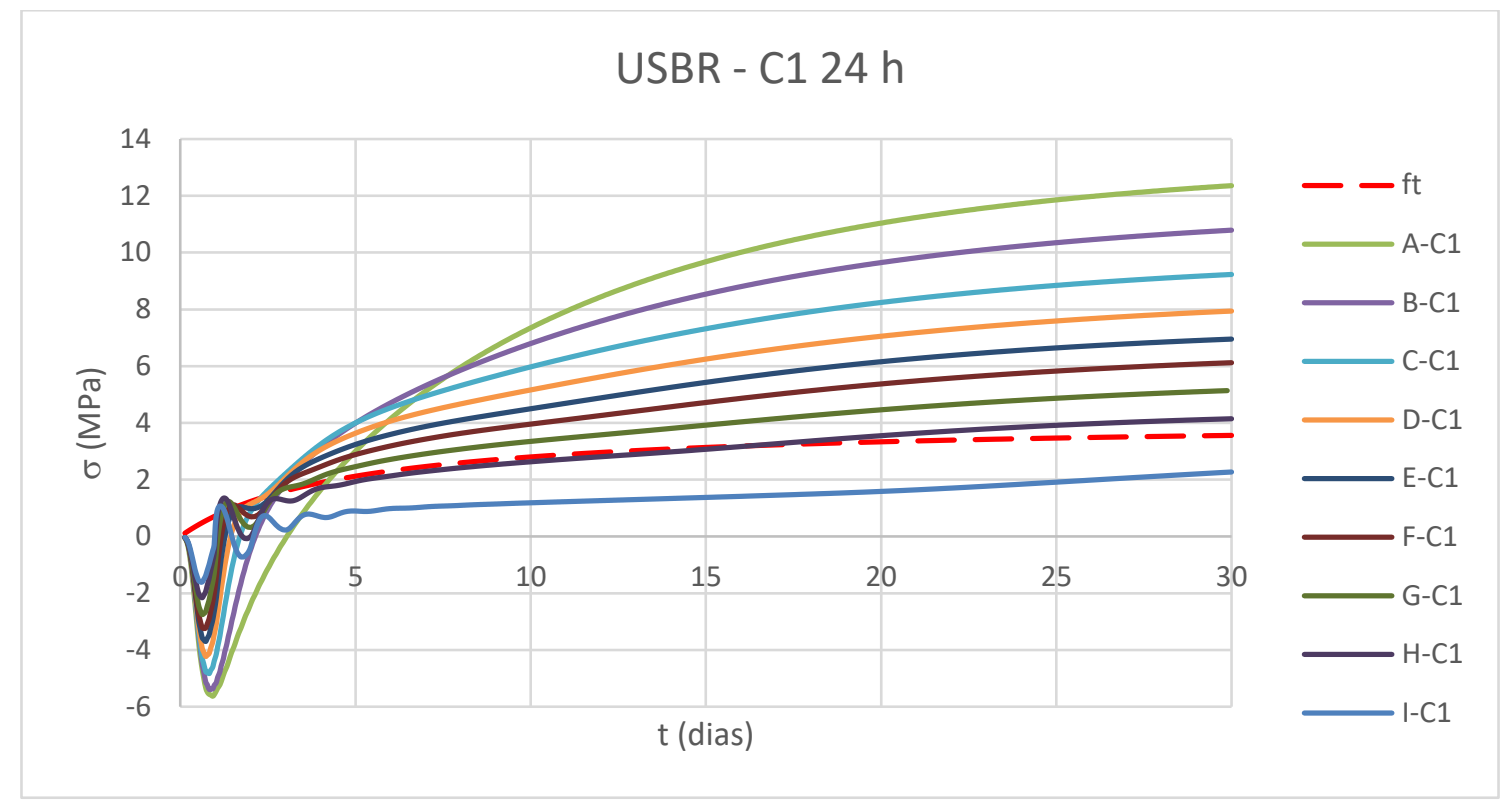

Figura 6.44 - Tensões para C1 pelo método USBR com intervalo de lançamento de $24 \mathrm{~h}$.

Havendo intervalos de lançamento entre as camadas de 48 h, observa-se que há um pico de temperatura, mas o resfriamento se dá mais rapidamente que os exemplos anteriores, Figura 6.45. À medida que a espessura da camada diminui isso fica ainda mais evidente.

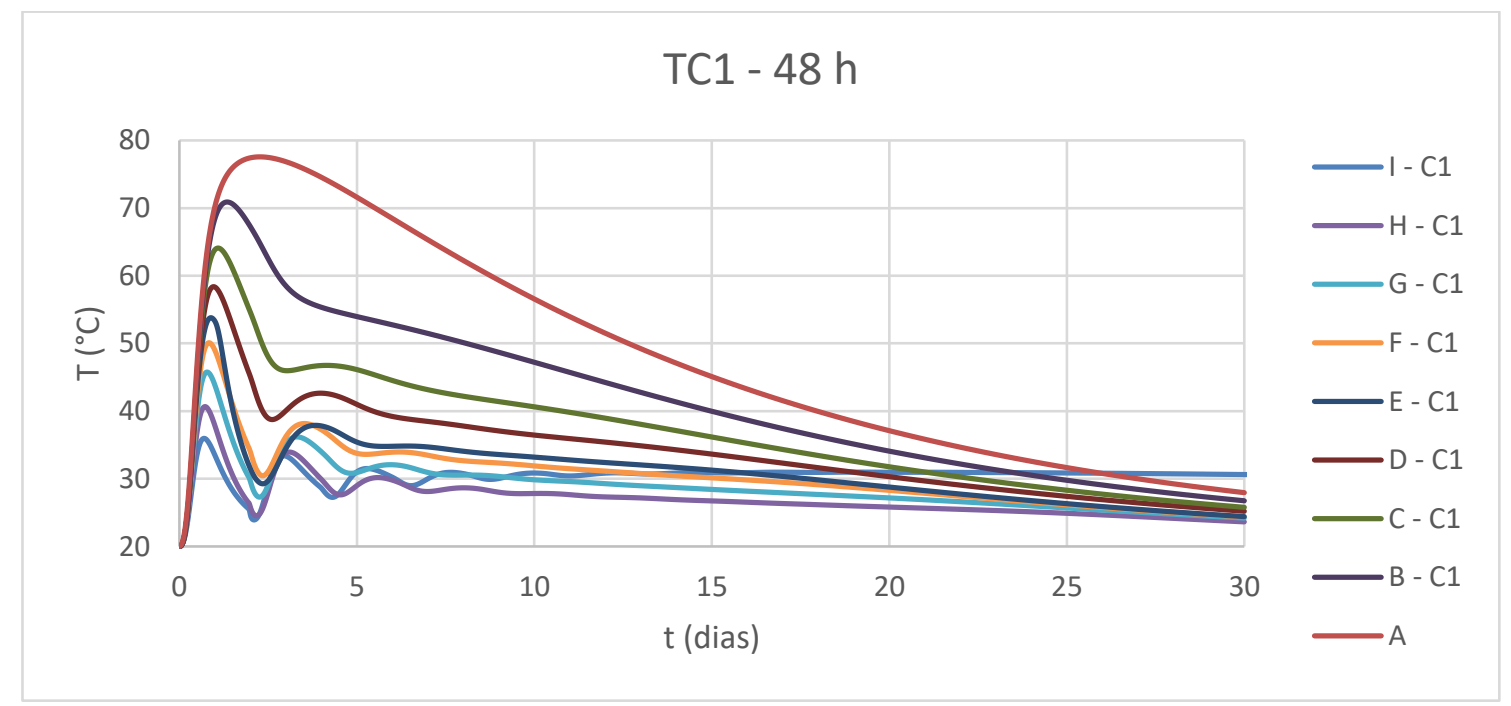

Figura 6.45 - Temperaturas para TC1 com intervalo de lançamento de $48 \mathrm{~h}$.

O reflexo do resfriamento mais rápido é nítido nas tensões. Analisando pelo método DP, aos 30 dias, apenas os Casos 3.1-A, 3.1-B e 3.1-C, ultrapassariam as tensões resistidas pelo concreto, Figura 6.46. Pelo USBR, Figura 6.47, além dessas, também o 3-D estaria com problemas nesse período. As tensões para $12 \mathrm{~h}$ e $24 \mathrm{~h}$ de intervalo de lançamento mostram 
fissurações em todas as camadas, exceto para o Caso 3.1-I. Vale lembrar que todos os casos apresentam as mesmas propriedades, características, $\mathrm{CC}$ e $\mathrm{CI}$.

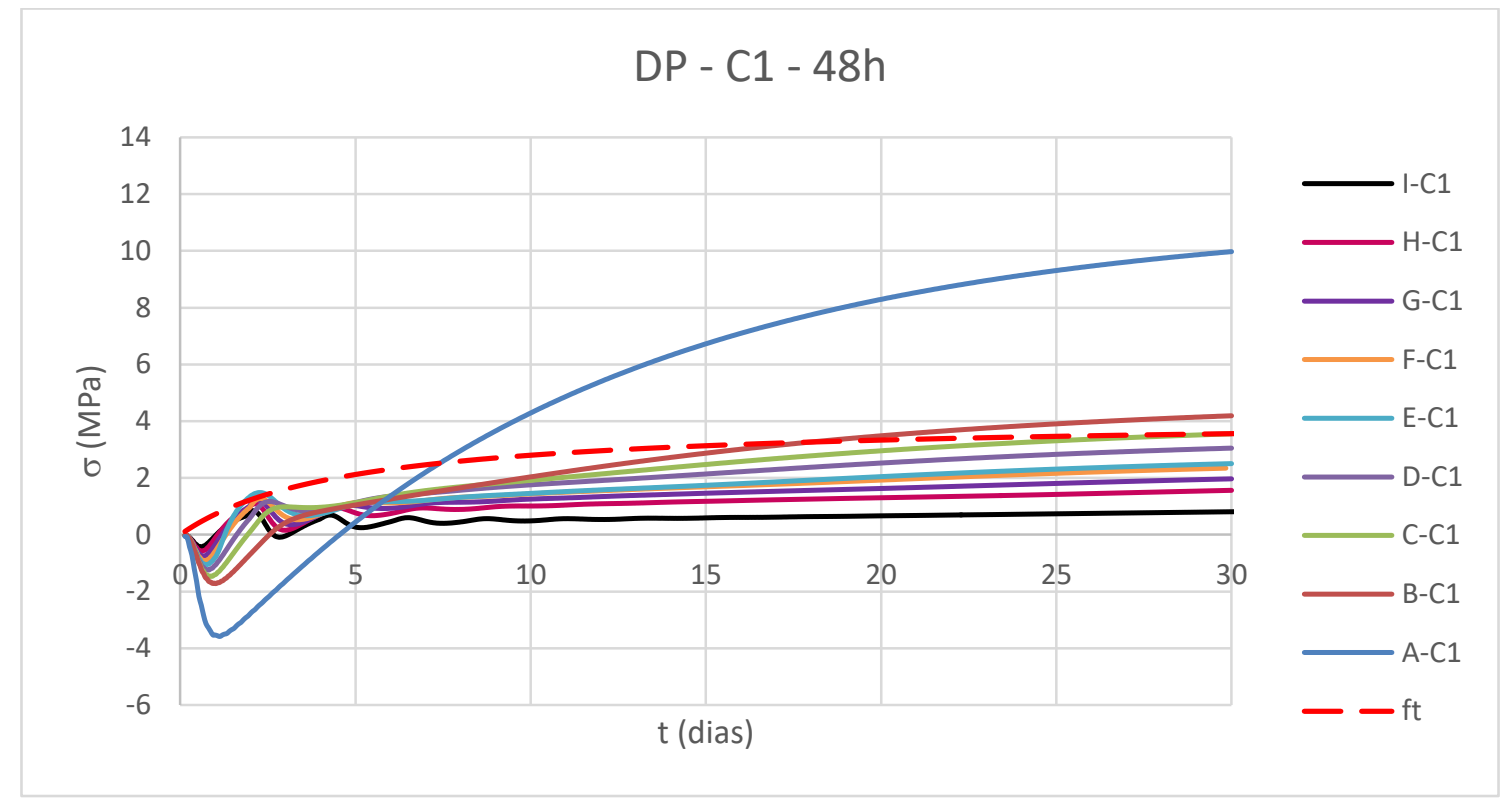

Figura 6.46 - Tensões para C1 pelo método DP com intervalo de lançamento de 48h.

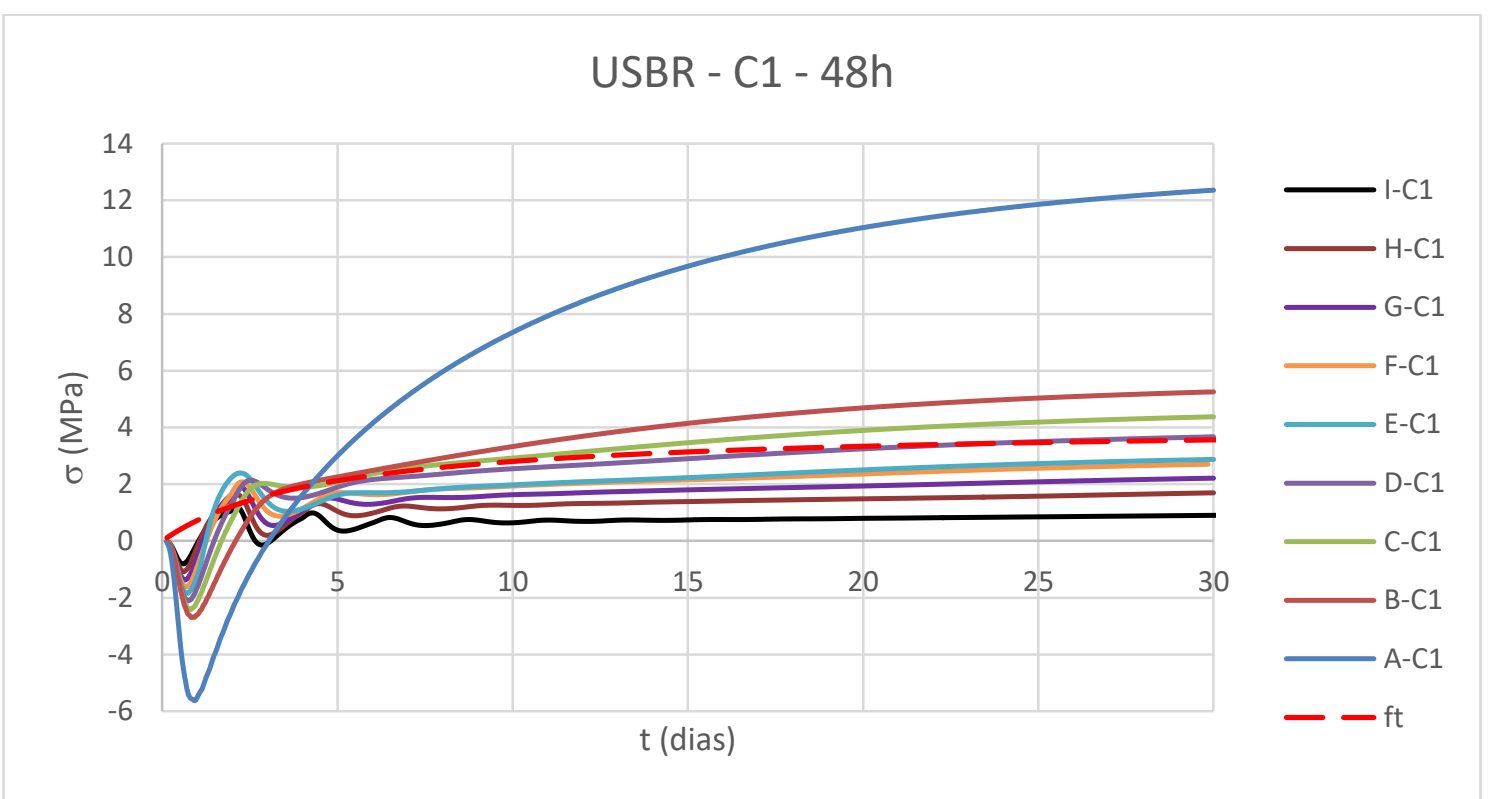

Figura 6.47 - Tensões para C1 pelo método USBR com intervalo de lançamento de $48 \mathrm{~h}$. 


\subsubsection{CASO 3.2 - Segunda Camada - C2}

A segunda camada e as posteriores são todas dispostas sobre outra camada de concreto, ou seja, não são mais assentadas em uma fundação rígida e sim flexível, devendo ser considerada a variação do módulo de elasticidade e as tensões devem ser multiplicadas pelo coeficiente da fundação $k_{f}$, dado pela Equação 6.3 (pag. 164).

Sendo as camadas de mesma dimensão, tem-se que $A_{g}$ (área do concreto) será igual a $A_{f}$ (área da fundação), pois a fundação será um concreto um pouco mais envelhecido. No entanto, haverá diferença entre os módulos de elasticidade da fundação $\left(E_{f}\right)$ e do concreto $\left(E_{c}\right)$ com relação a idade.

A fim de identificar a diferença entre esses módulos, a Figura 6.48 mostra o gráfico de $E_{f}$ e $E_{c}$ para a equação do problema em análise, dada na Tabela 5.6. Observa-se que para concretos lançados a cada $12 \mathrm{~h}$ os módulos se igualam em aproximadamente dois dias. Dessa forma, afirma-se que as diferenças entre os módulos ocorrerão apenas nas idades iniciais.

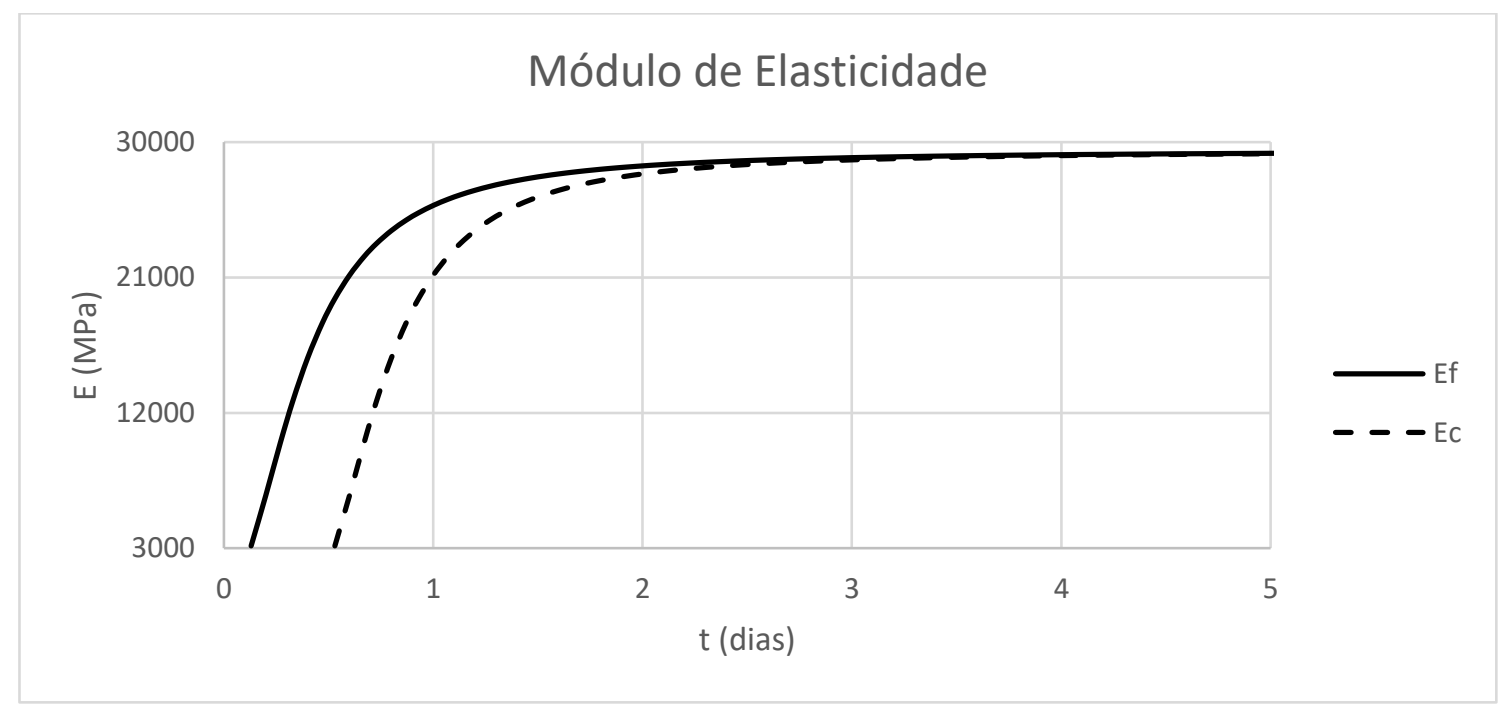

Figura 6.48 - Módulo de elasticidade para diferentes camadas.

Para verificar a influência das diferenças entre os módulos nas tensões, estas foram analisadas para o Caso 3.2-B - $12 \mathrm{~h}$. Inicialmente, considerou-se $E_{c}=2 E_{c f}$ até o primeiro dia, que resultou em $k_{f}=0,667$. Após o primeiro dia, esse valor foi reduzido até $k_{f}=0,5$ no segundo dia, que configura $E_{c}=E_{c f}$. 
Foi considerado também o perfil de tensões apenas para $E_{c}=E_{c f}$ e os resultados comparados com o perfil descrito anteriormente. Os resultados das tensões são mostrados na Figura 6.49. Observa-se que, como a variação do módulo só ocorre nas idades iniciais, só haverá alteração nas tensões iniciais, que são de compressão. Portanto, para as tensões de tração, as de interesse, pois são as que podem levar à fissuração, a diferença entre os módulos do concreto na fundação e na atual camada não terá influência.

Diante disso, foi adotado em todas as modelagens que seguem, o valor constante de $k_{f}=$ 0,5 , tanto para a segunda camada quanto para as camadas que apresentaram a temperatura máxima.

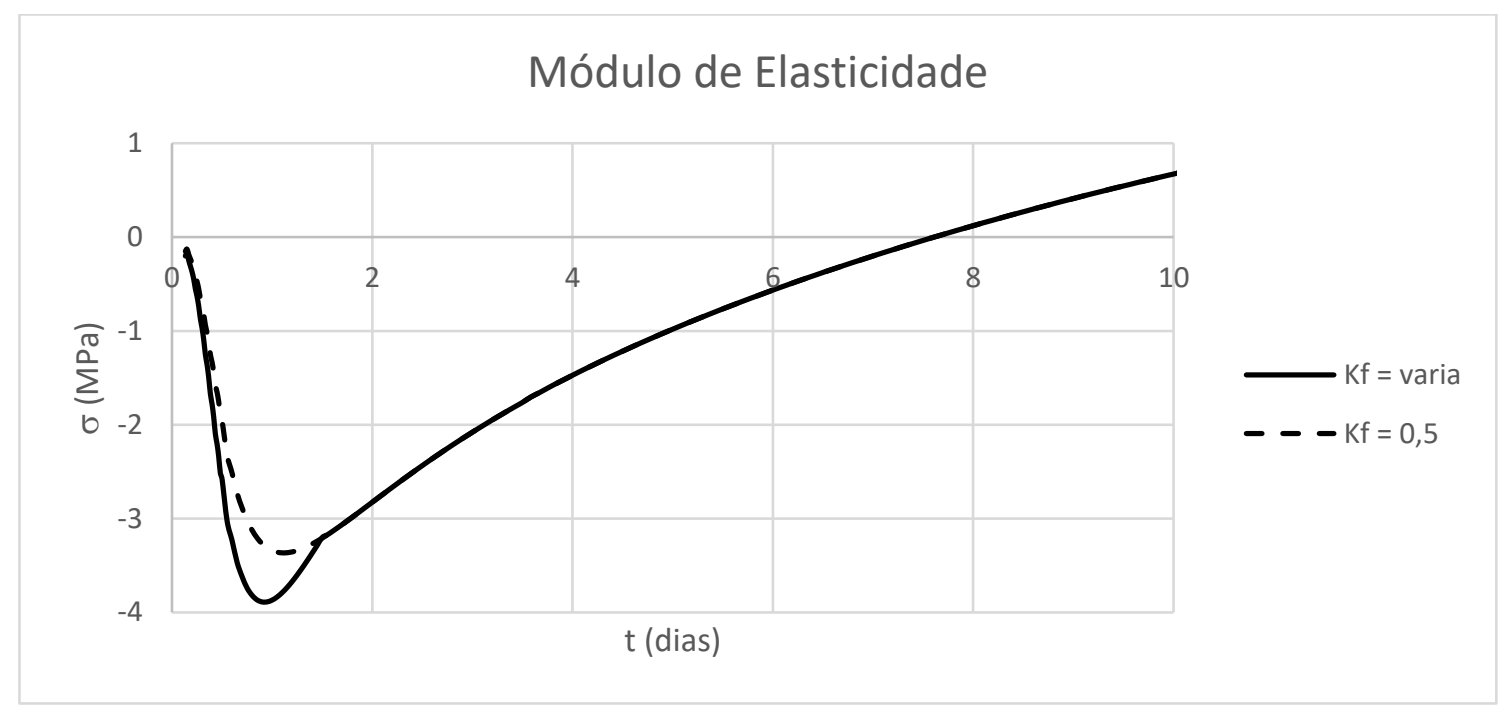

Figura 6.49 - Tensões sob variação do módulo de elasticidade.

A Figura 6.50 mostra a evolução térmica para o ponto central da segunda camada em todos os casos. Ressalta-se que o Caso 3.2-A tem camada única, logo, inicia-se no tempo zero. As demais, iniciam-se em 0,5 dias, representando a concretagem a cada 12 h. As máximas temperaturas também vão diminuindo junto com a redução da altura da camada. 
TC2- $12 \mathrm{~h}$

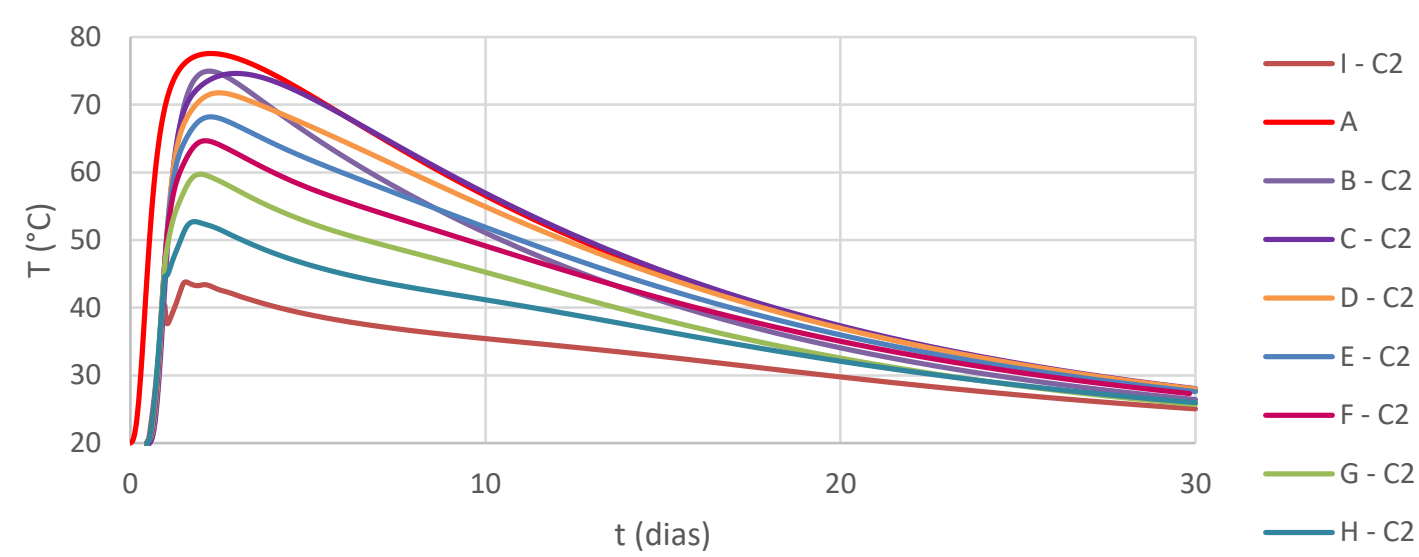

Figura 6.50 - Temperaturas para TC2 com intervalo de lançamento de $12 \mathrm{~h}$.

Os gráficos das Figuras 6.51 e 6.52 mostram as tensões obtidas pela DP e pelo USBR. Verifica-se que pelo método DP, até os 30 dias nenhuma das camadas seria fissurada e para as camadas mais espessas talvez pudessem surgir para um tempo longo. Pelo USBR até os 30 dias permaneceriam sem riscos de fissuração os Casos 3.2-I, 3.2-H, 3.2-G.

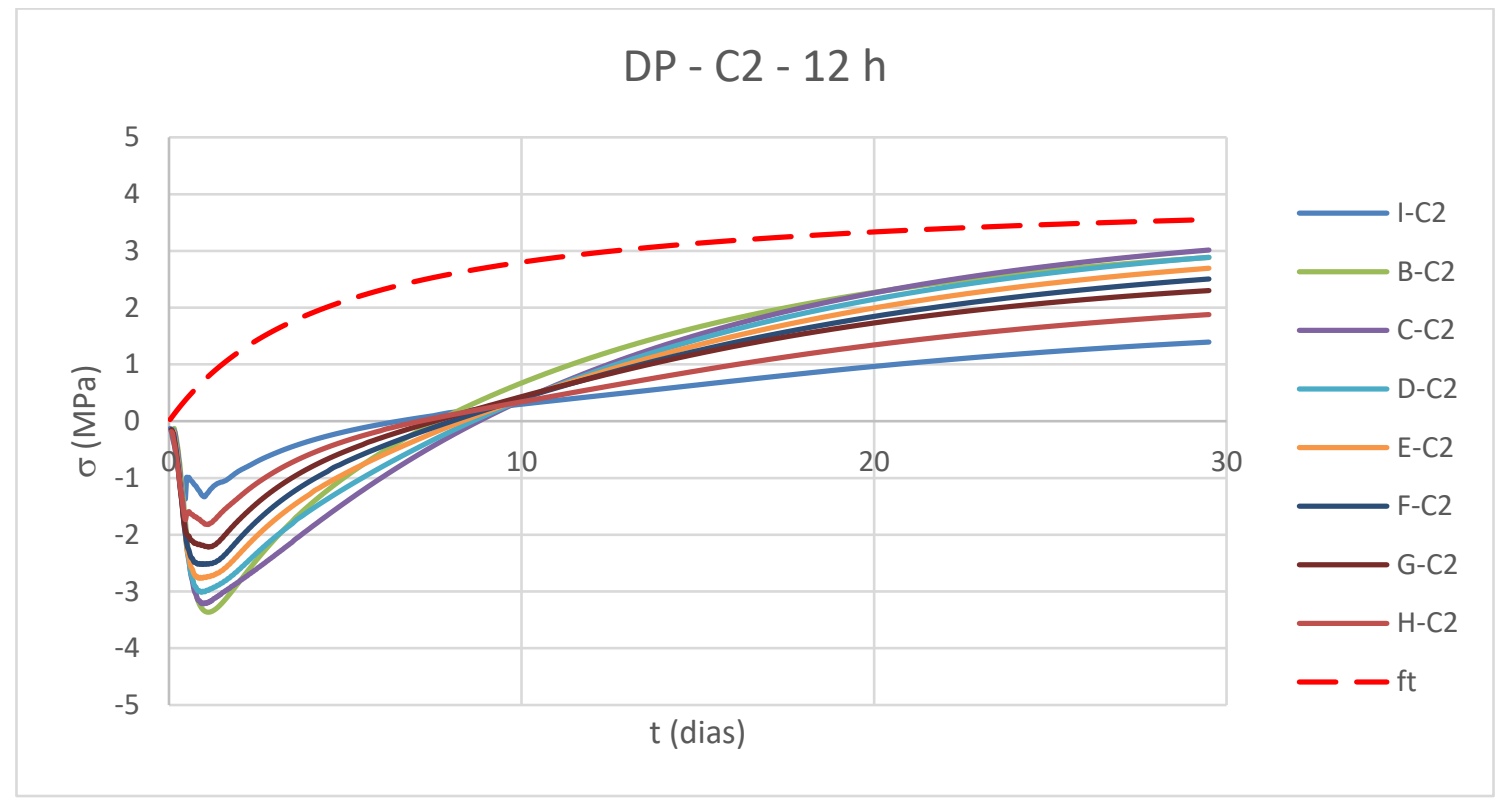

Figura 6.51 - Tensões para C2 pelo método DP com intervalo de lançamento de $12 \mathrm{~h}$. 


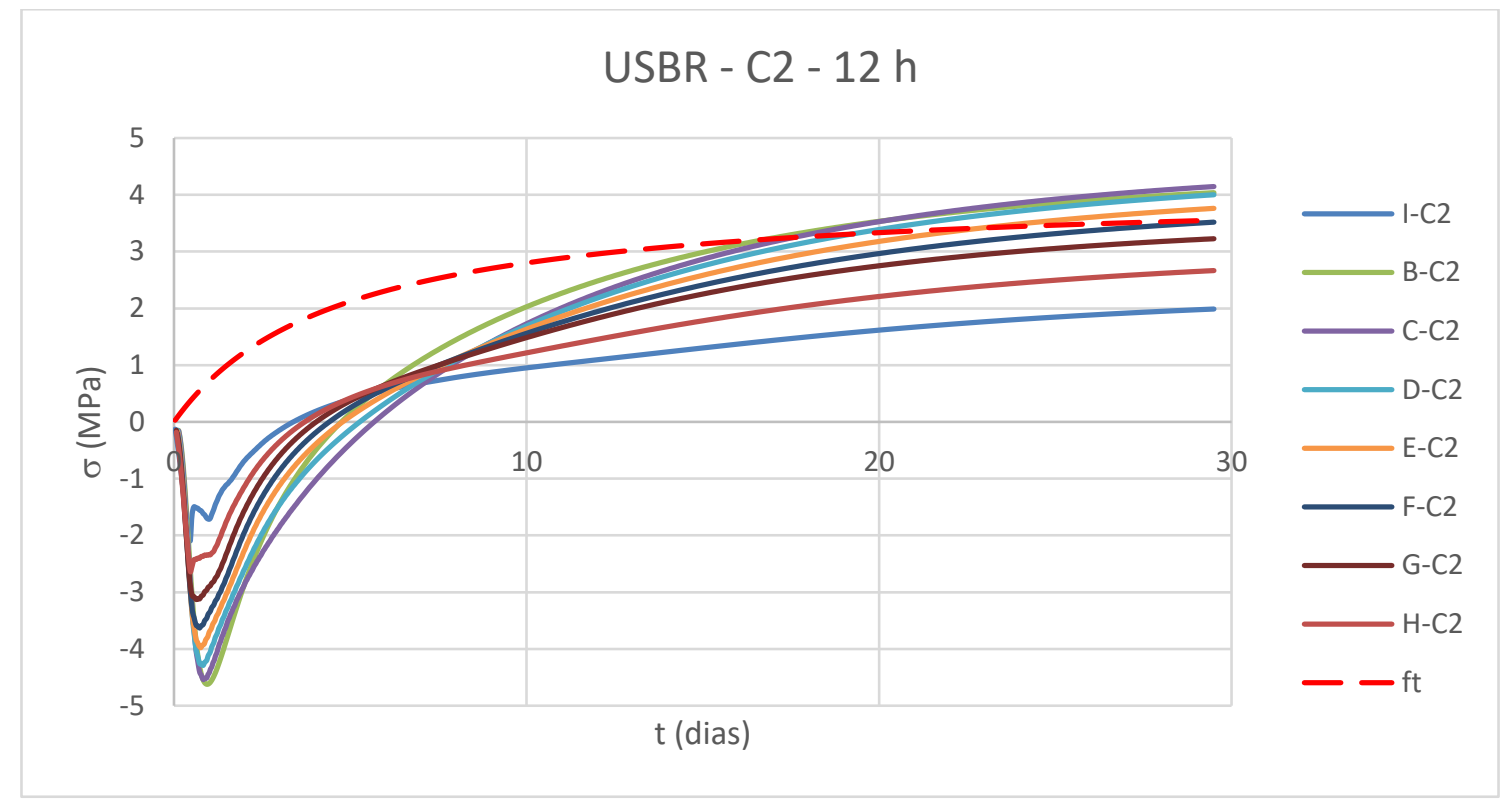

Figura 6.52 - Tensões para C2 pelo método USBR com intervalo de lançamento de $12 \mathrm{~h}$.

Aumentando o intervalo de lançamento das camadas para 24 h, nota-se que há uma redução da máxima temperatura para os mesmos pontos analisados anteriormente, Figura 6.53. O valor da redução varia com a espessura das camadas. Evidencia-se também que as curvas passam a ter ondulações, mostrando um resfriamento inicial, seguido de um aumento de temperatura, devido a influência térmica da camada de cima.

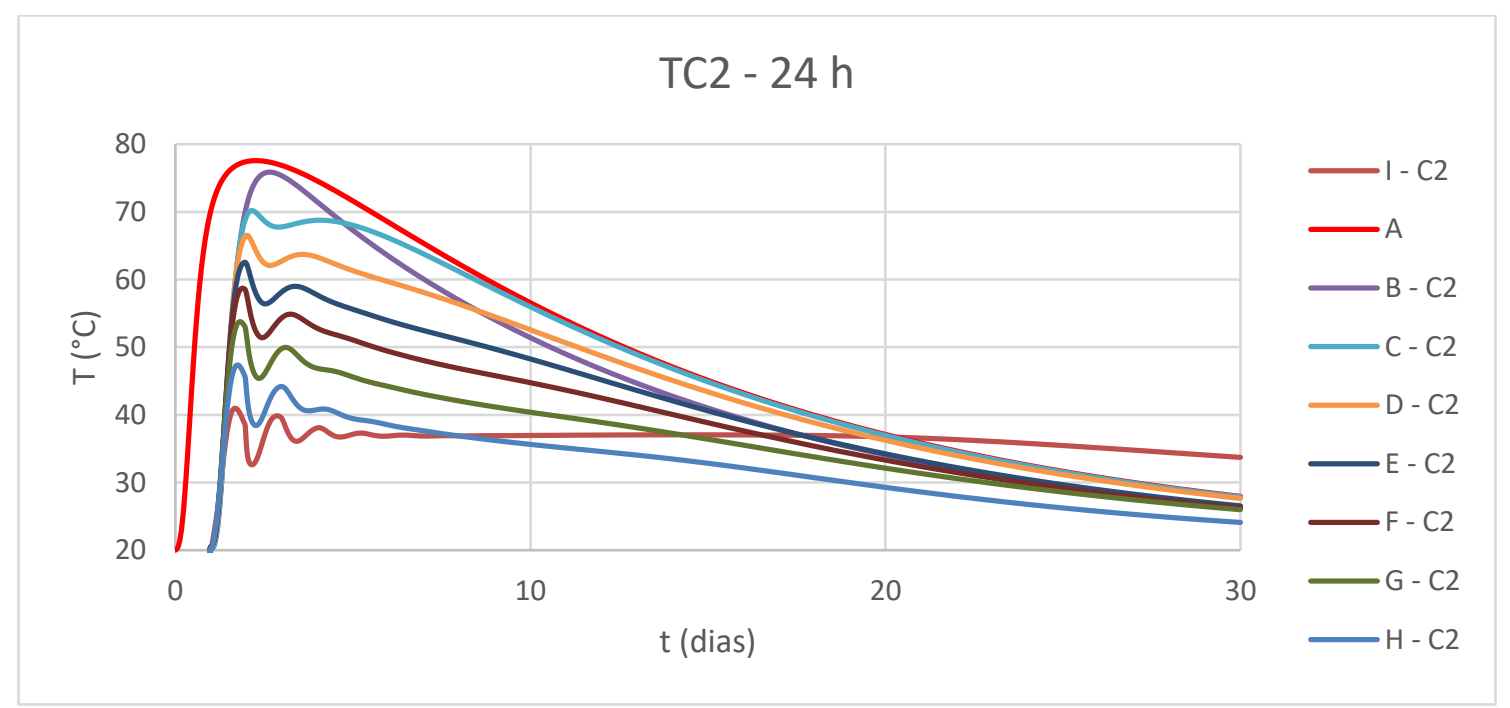

Figura 6.53 - Temperaturas para TC2 com intervalo de lançamento de $24 \mathrm{~h}$.

As tensões calculadas através dos perfis térmicos da Figura 6.53 são apresentadas nas Figuras 6.54 e 6.55. Pelo método DP observa-se que não há possibilidade de fissuração de nenhuma das camadas. Pelo USBR, até os 29 dias não haverá fissuração, visualmente. Nessa 
idade, todas as tensões tendem a uma curva assintótica, ou seja, não provocariam fissuras no concreto.

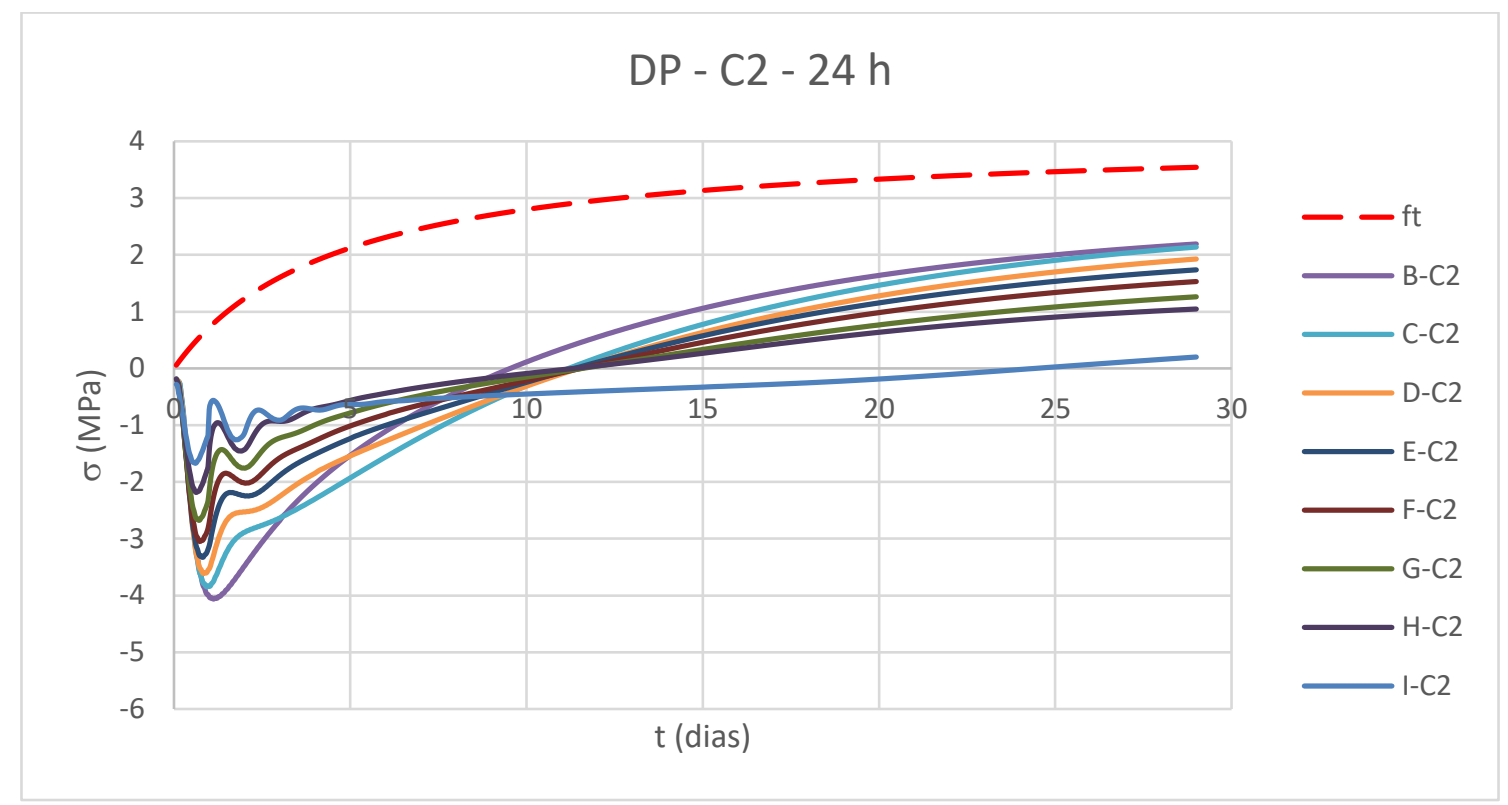

Figura 6.54 - Tensões para C2 pelo método DP com intervalo de lançamento de $24 \mathrm{~h}$.

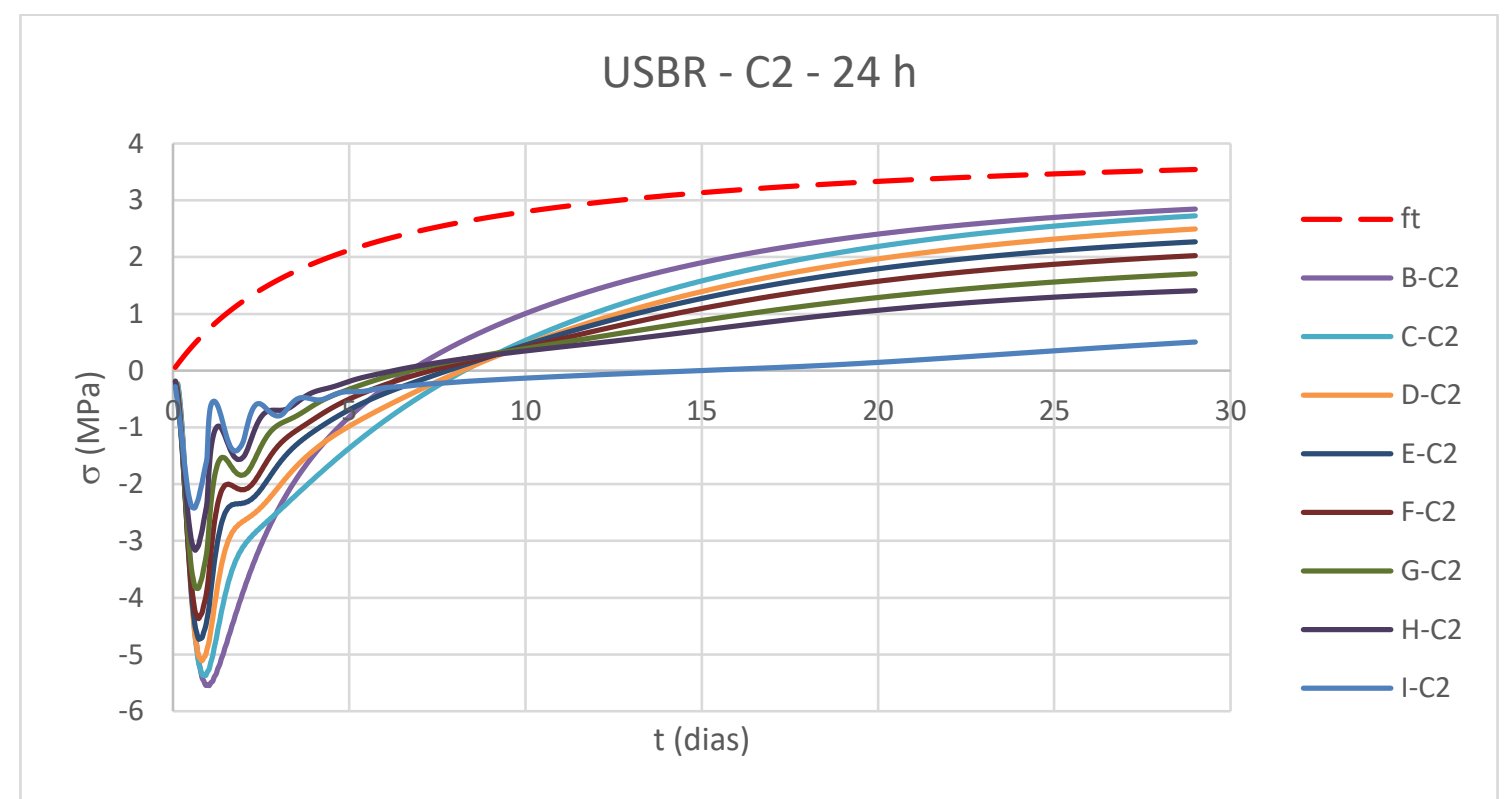

Figura 6.55 - Tensões para C2 pelo método USBR com intervalo de lançamento de $24 \mathrm{~h}$.

A Figura 6.56 mostra as temperaturas para intervalo de lançamento das camadas a cada $48 \mathrm{~h}$ para a segunda camada. As considerações são as mesmas para a primeira camada. 
TC2 - $48 \mathrm{~h}$

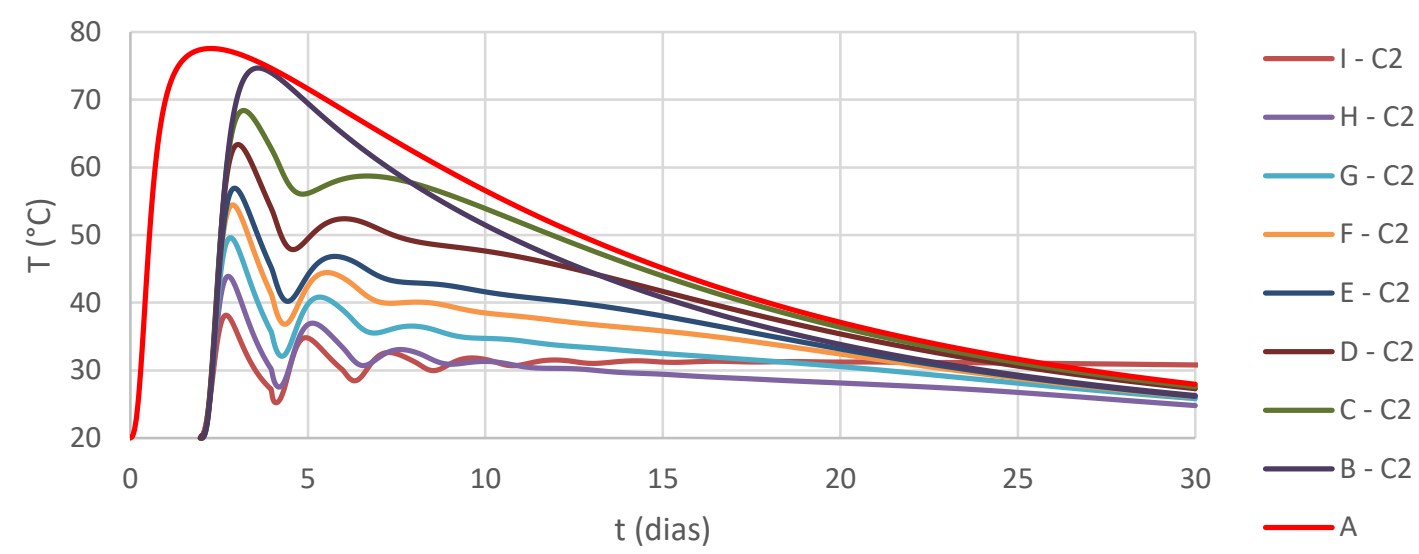

Figura 6.56 - Temperaturas para TC2 com intervalo de lançamento de $48 \mathrm{~h}$.

Analisando as tensões pelo método DP, Figura 6.57, e USBR, Figura 6.58, utilizando o mesmo coeficiente de restrição das simulações anteriores, constata-se que não há o menor risco de fissuração em nenhum dos casos.

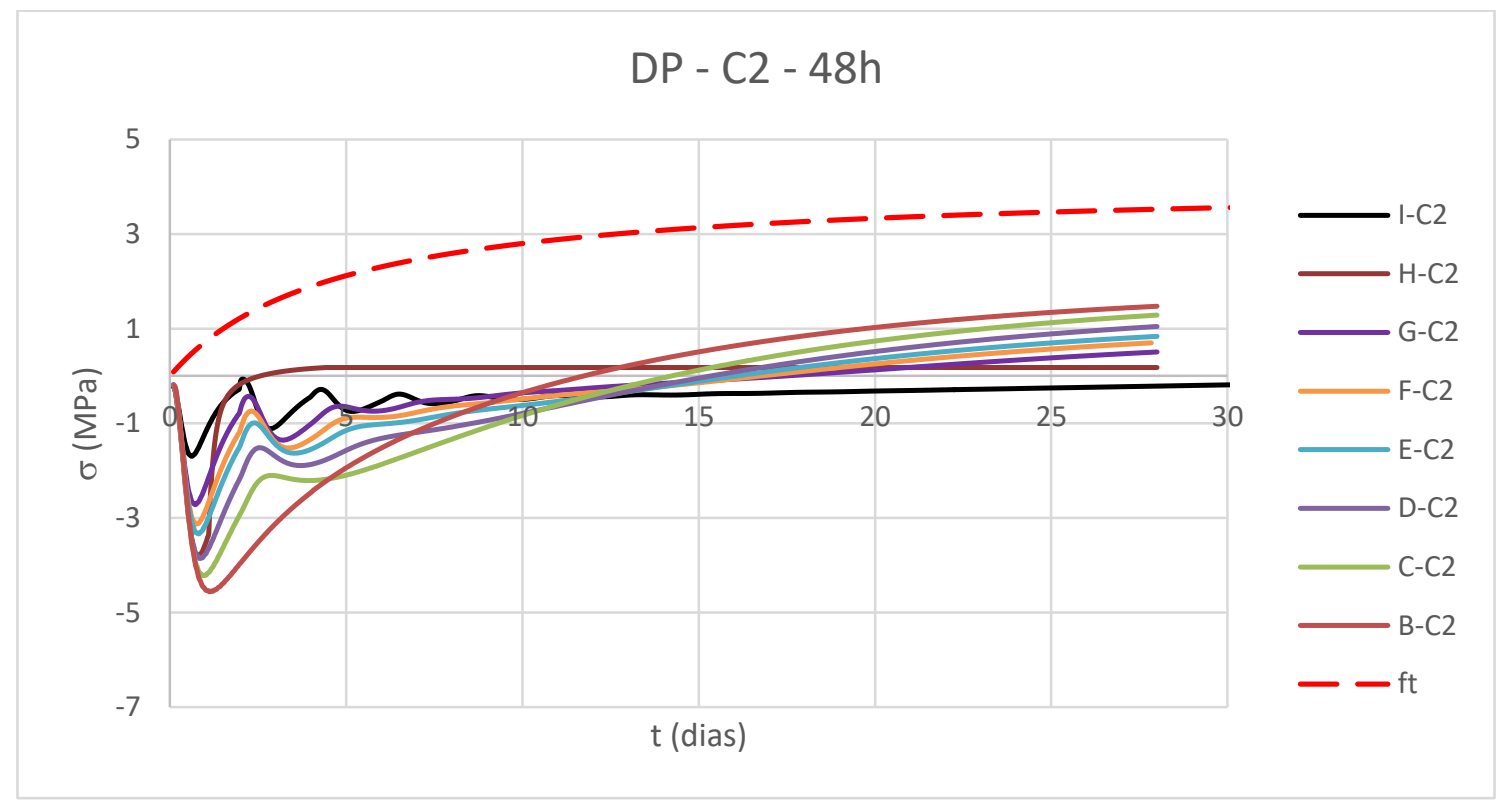

Figura 6.57 - Tensões para C2 pelo método DP com intervalo de lançamento de 48h. 


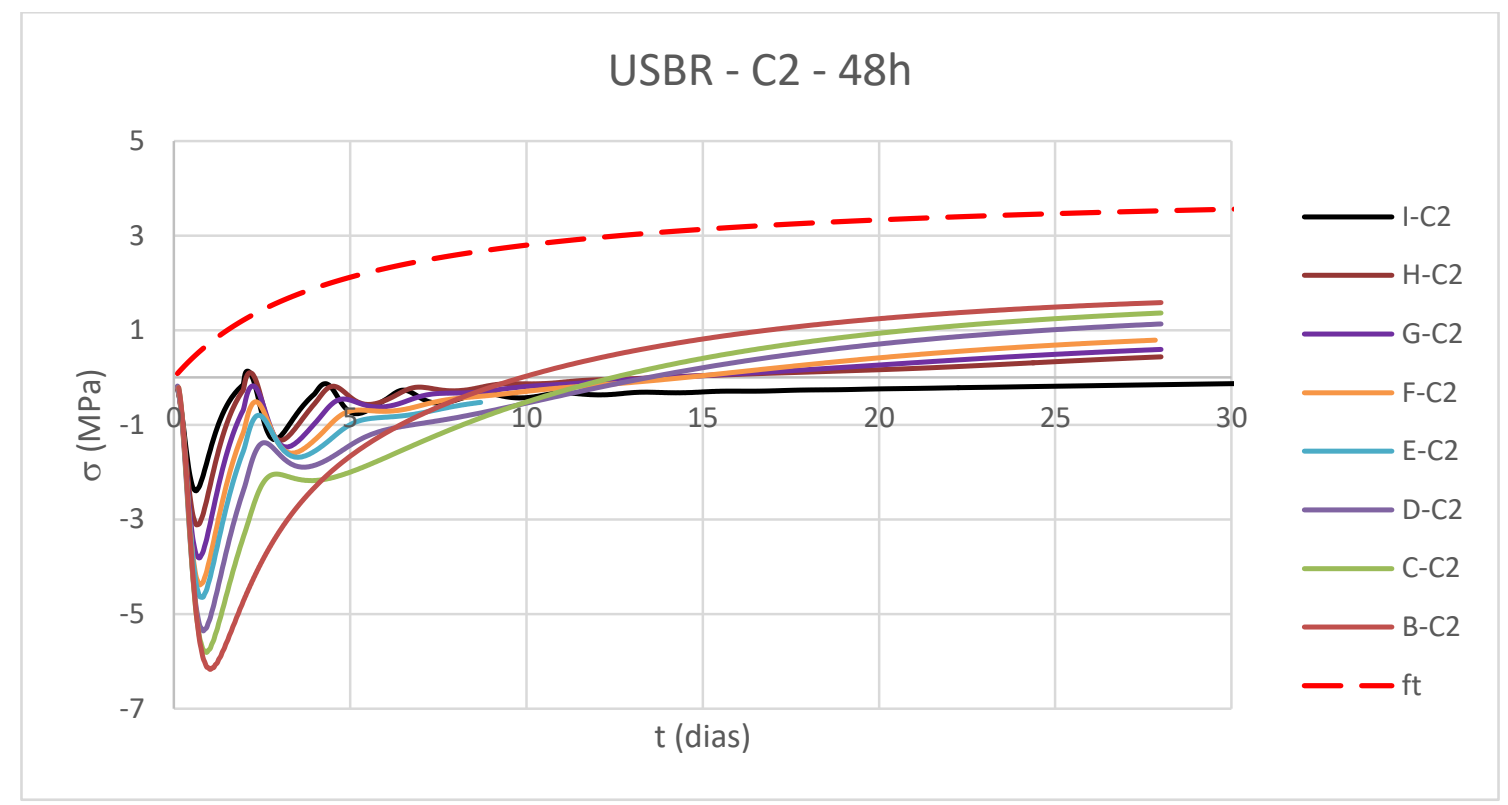

Figura 6.58 - Tensões para C2 pelo método DP com intervalo de lançamento de $48 \mathrm{~h}$.

\subsubsection{CASO 3.3 - Camada com temperatura máxima - $\mathrm{C}_{\max }$}

A última análise foi efetuada para as camadas que apresentaram a temperatura máxima. Ressalta-se que não necessariamente os pontos verificados apresentam as temperaturas máximas para a construção, pois foram analisados os pontos centrais de cada camada e, para estes pontos foram calculadas as tensões para o PC que mostrou a máxima temperatura.

Desta forma, a Figura 6.59 apresenta o perfil de temperatura para o PC de temperatura máxima para cada caso. É importante relatar que, em algumas situações, mais de uma camada pode ter o mesmo valor de temperatura máxima, sendo assim, apenas uma delas é examinada.

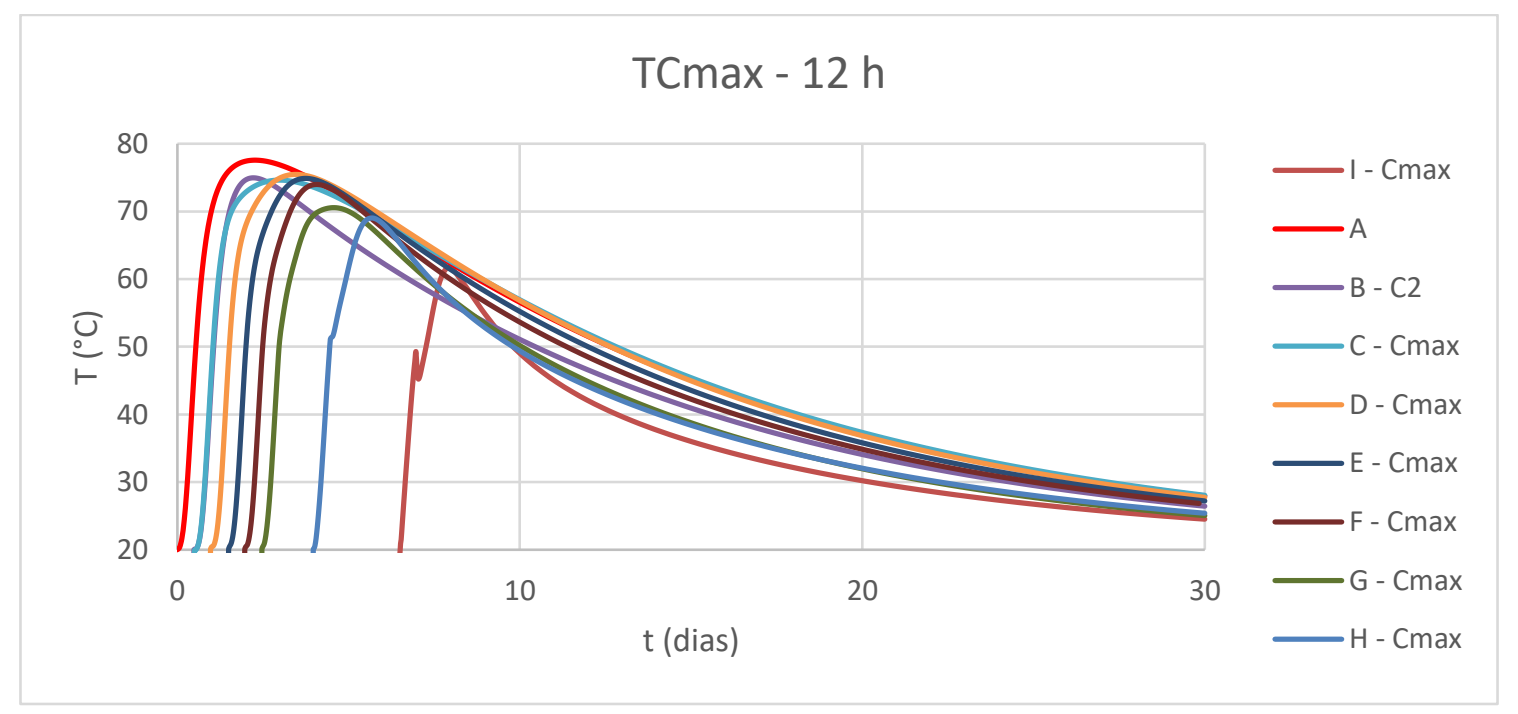

Figura 6.59 - Temperaturas para $\mathrm{TC}_{\max }$ com intervalo de lançamento de $12 \mathrm{~h}$. 
Com intervalo de lançamento das camadas de $12 \mathrm{~h}$, até os 30 dias pela DP, apenas o Caso A terá tensões de tração maiores que as tensões resistidas pelo concreto; já pelo USBR além da A, terão tensões maiores os Casos B e C, Figuras 6.60 e 6.61.

Percebe-se que nem todos os casos chegam aos 30 dias, pois, dependendo da camada estudada, como a mesma foi concretada mais tarde, a sua idade é inferior à 30 dias.

O ponto zero no eixo das abcissas representa a idade inicial da camada. Já no ponto 10, por exemplo, significa que a camada (DP $-\mathrm{C}_{\max }-12 \mathrm{~h}$ ) foi analisada durante 10 dias, mas as camadas inferiores certamente terão idade maior.

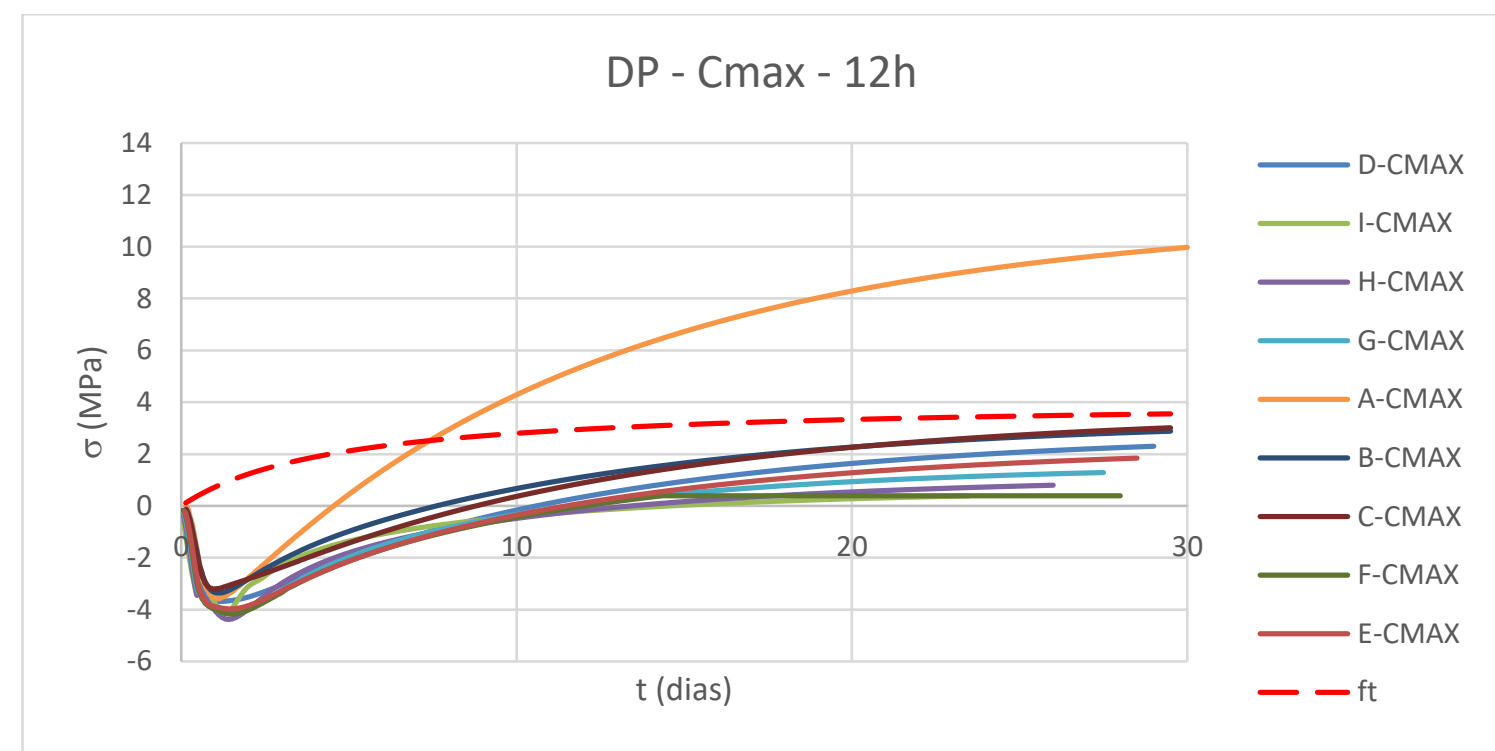

Figura 6.60 - Tensões para $C_{\max }$ pelo método DP com intervalo de lançamento de $12 \mathrm{~h}$.

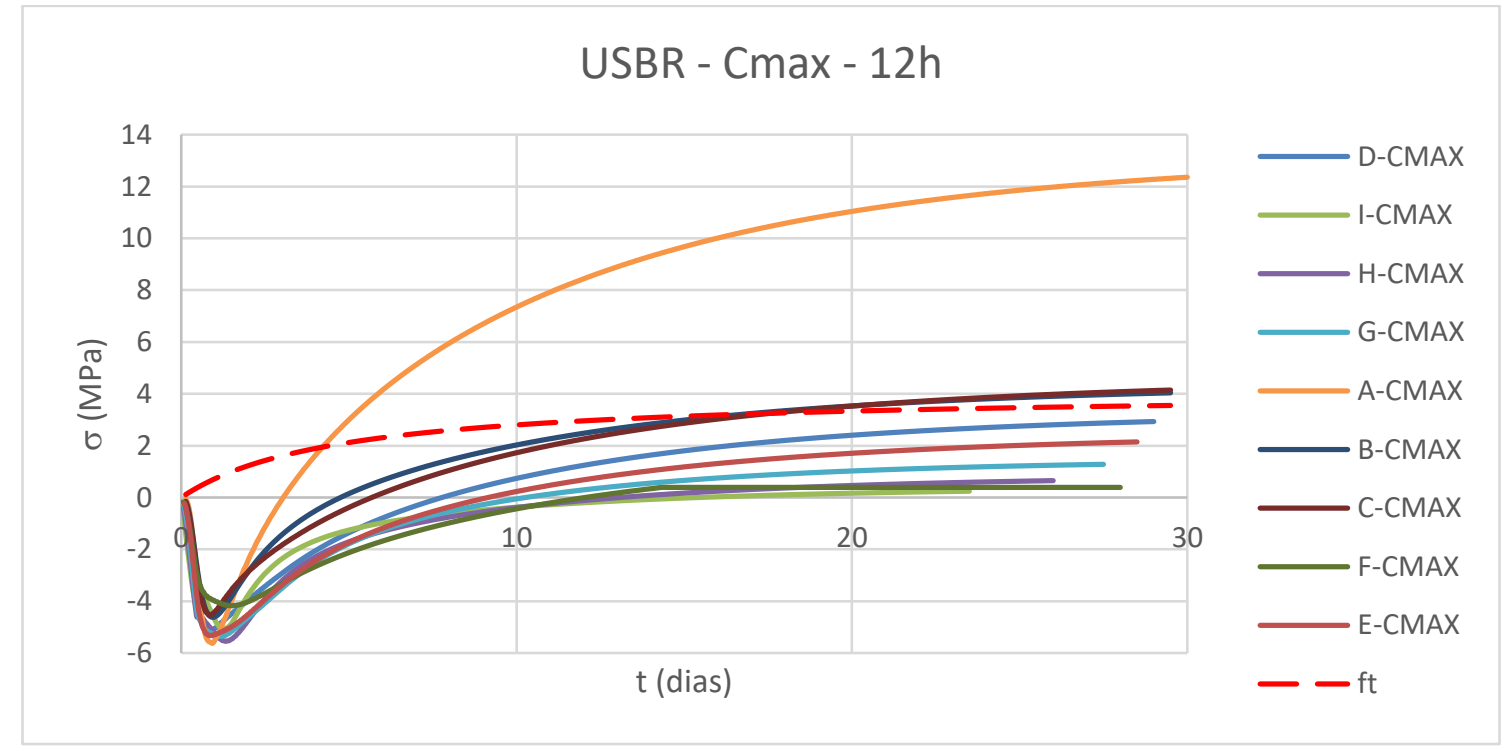

Figura 6.61 - Tensões para $\mathrm{C}_{\max }$ pelo método USBR com intervalo de lançamento de $12 \mathrm{~h}$. 
A Figura 6.62 representa os PC de temperaturas máximas para o Caso $3.3 \mathrm{com}$ intervalo de lançamento entre as camadas de $24 \mathrm{~h}$. Nota-se uma redução das temperaturas e um resfriamento mais rápido quando comparados com as análises anteriores.

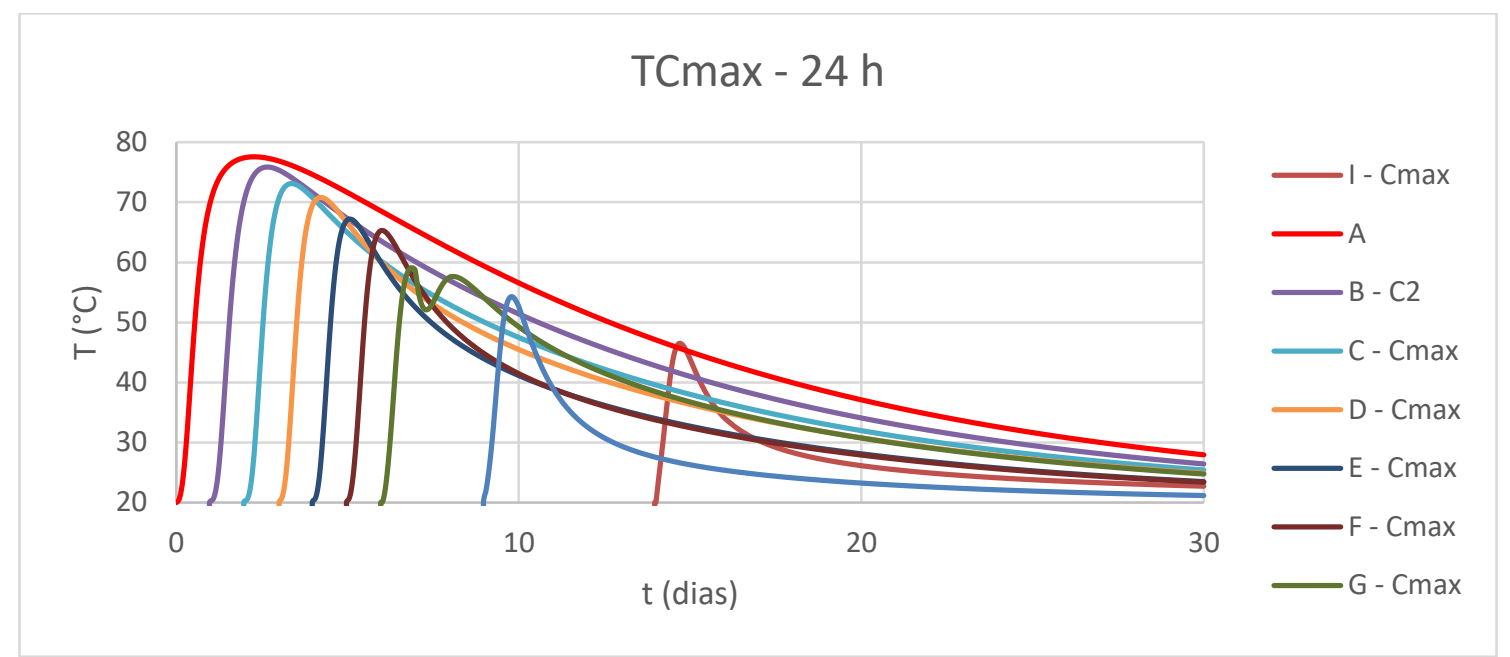

Figura 6.62 - Temperaturas para $\mathrm{TC}_{\max }$ com intervalo de lançamento de $24 \mathrm{~h}$.

As tensões para os perfis de temperatura mostrados na Figura 6.62, são ilustradas nas Figuras 6.63 e 6.64 para os métodos DP e USBR, respectivamente. Verifica-se que até os 30 dias apenas o Caso 3.3-A apresenta tensões de tração não resistidas pelo concreto em ambos os gráficos.

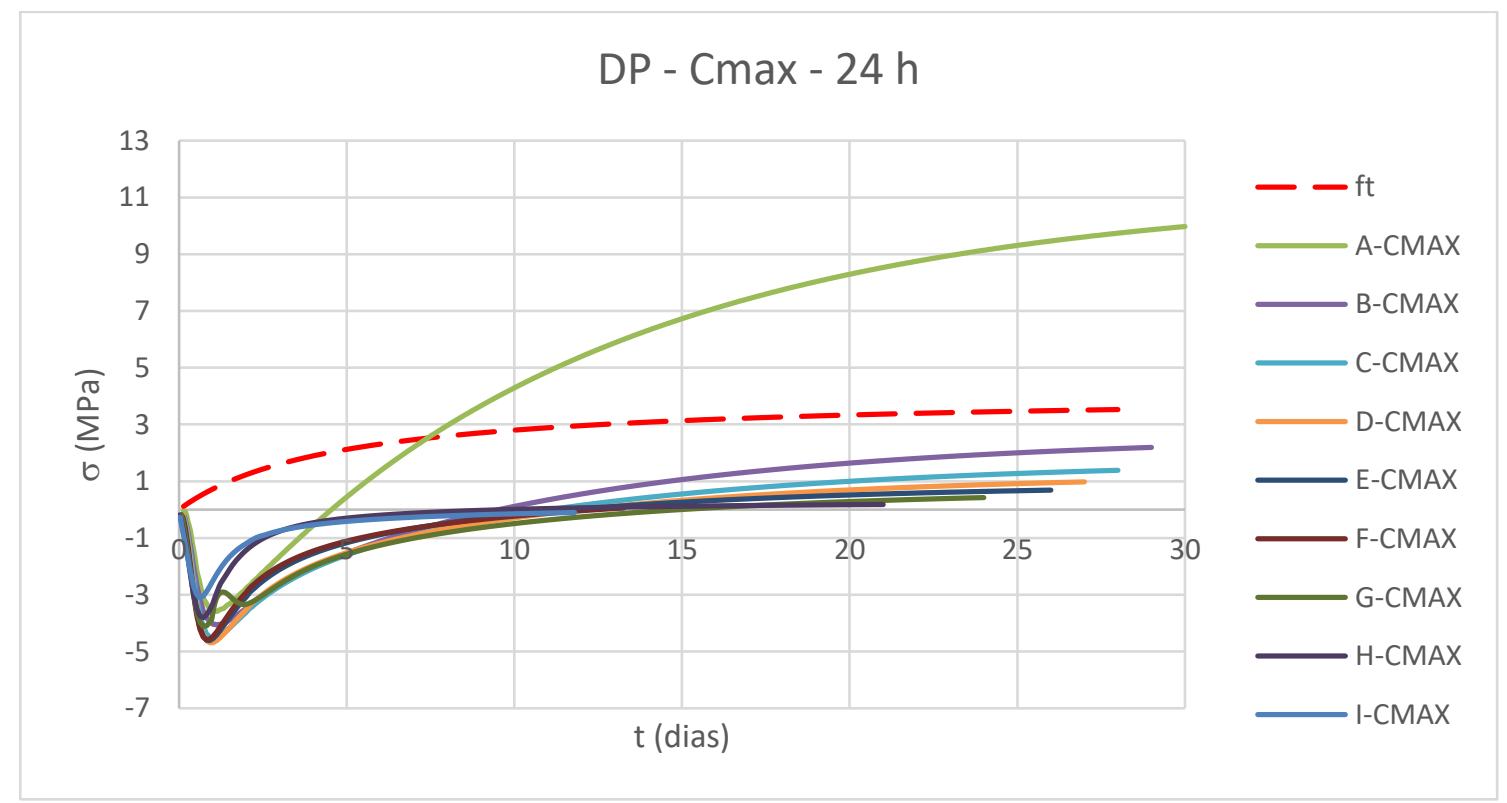

Figura 6.63 - Tensões para $C_{\max }$ pelo método DP com intervalo de lançamento de $24 \mathrm{~h}$. 


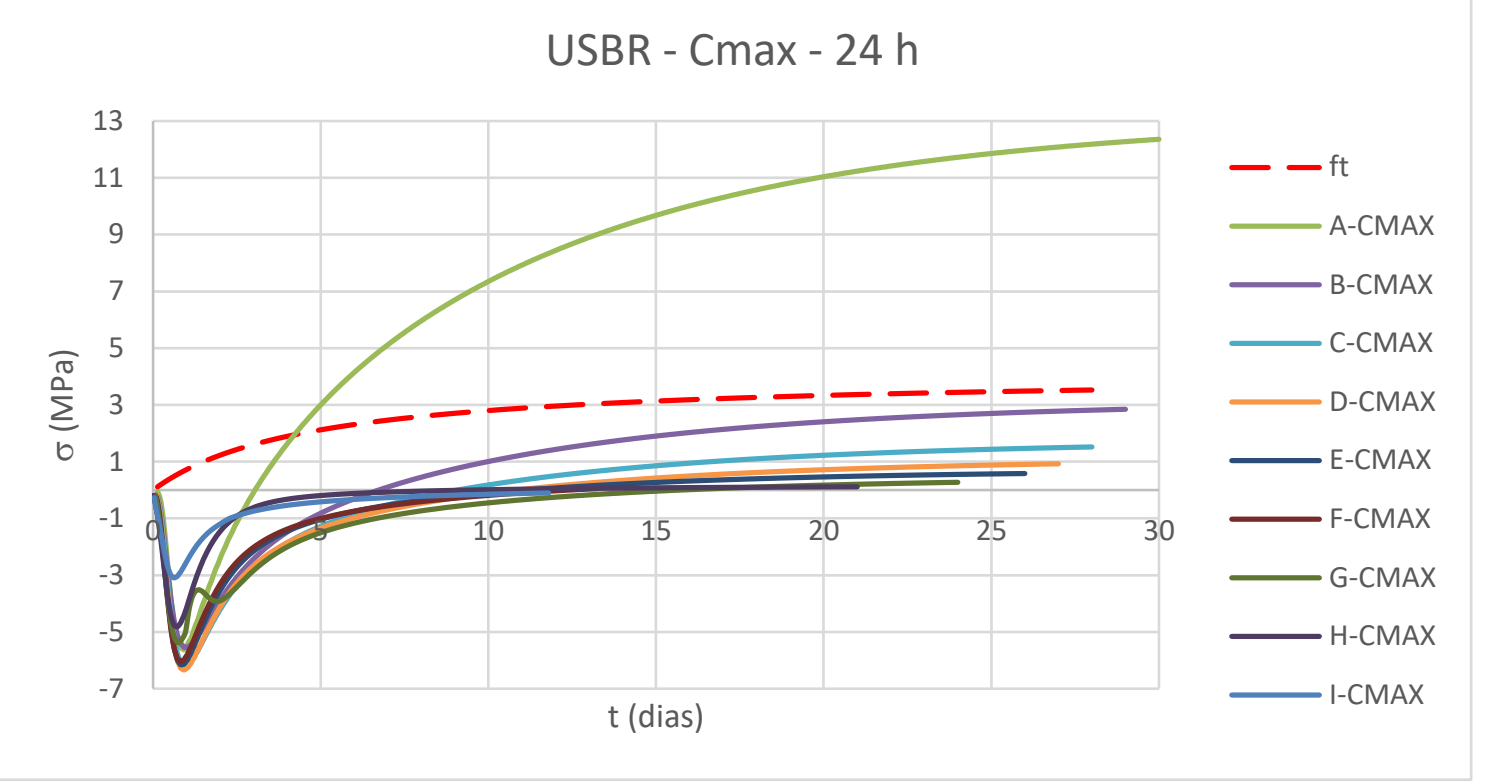

Figura 6.64 - Tensões para $C_{\max }$ pelo método USBR com intervalo de lançamento de $24 \mathrm{~h}$.

Com intervalo de lançamento das camadas a cada $48 \mathrm{~h}$, os perfis de temperatura para os PC de cada caso são exibidos na Figura 6.65. Nota-se que as máximas reduzem gradativamente com a redução da espessura da camada.

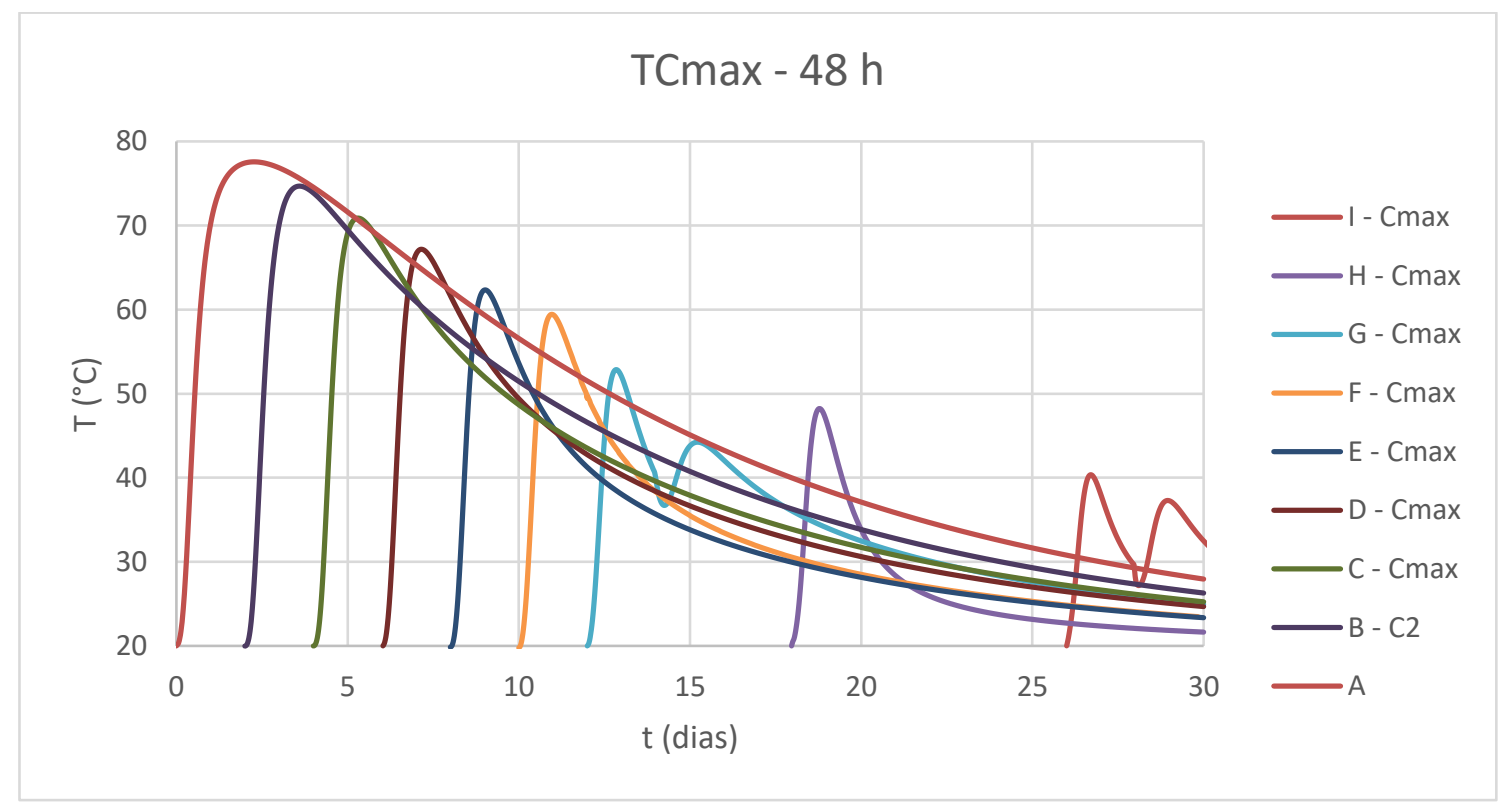

Figura 6.65 - Temperaturas para $\mathrm{C}_{\max }$ com intervalo de lançamento de $48 \mathrm{~h}$.

As Figuras 6.66 e 6.67 mostram as tensões por DP e USBR para os perfis de temperatura da Figura 6.65. Nos dois exemplos, apenas o Caso 3-A fissuraria, por ser concretado em camada única e estar sobre uma fundação rígida. 


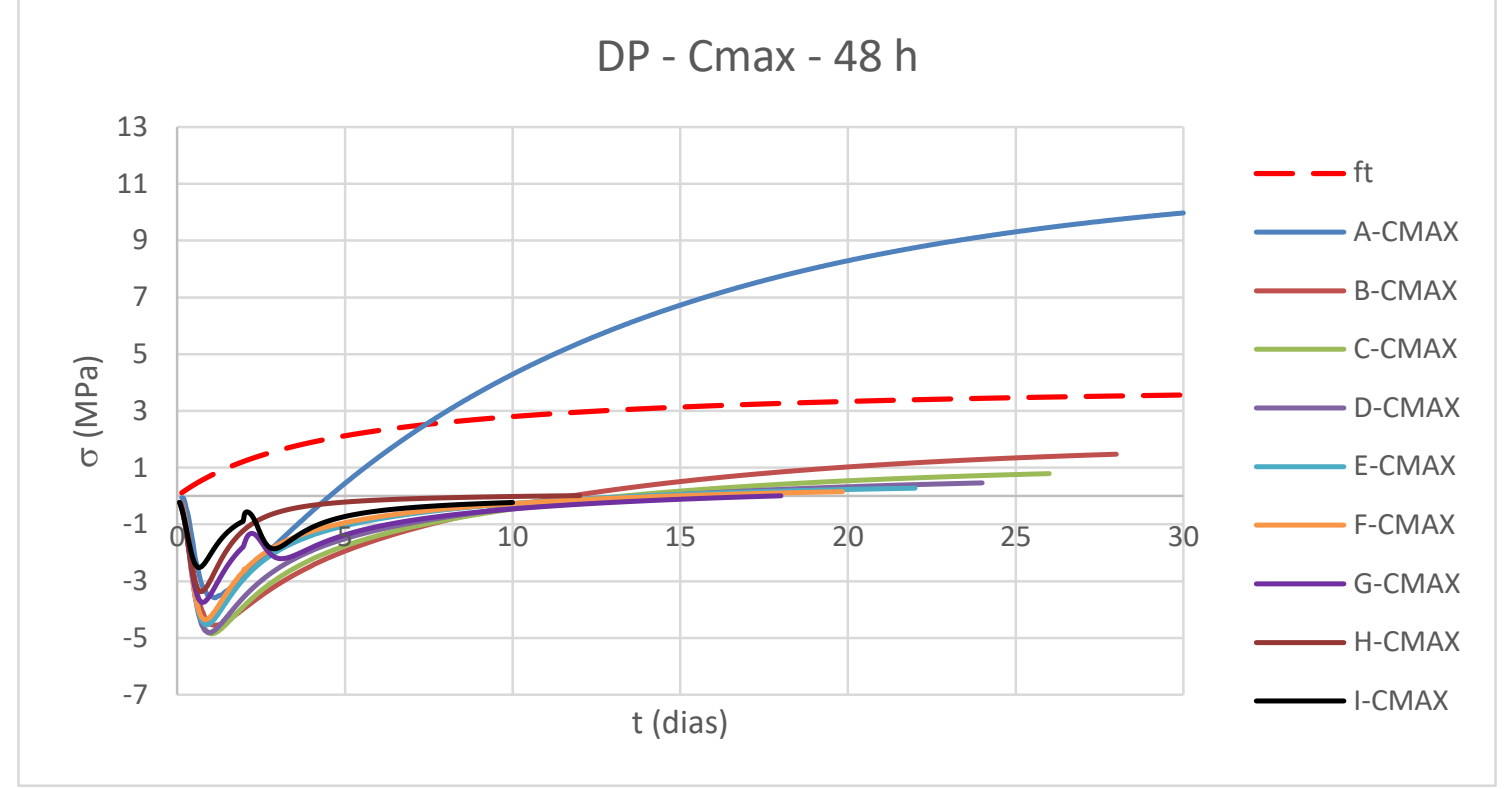

Figura 6.66 - Tensões para $C_{\max }$ pelo método DP com intervalo de lançamento de $48 \mathrm{~h}$.

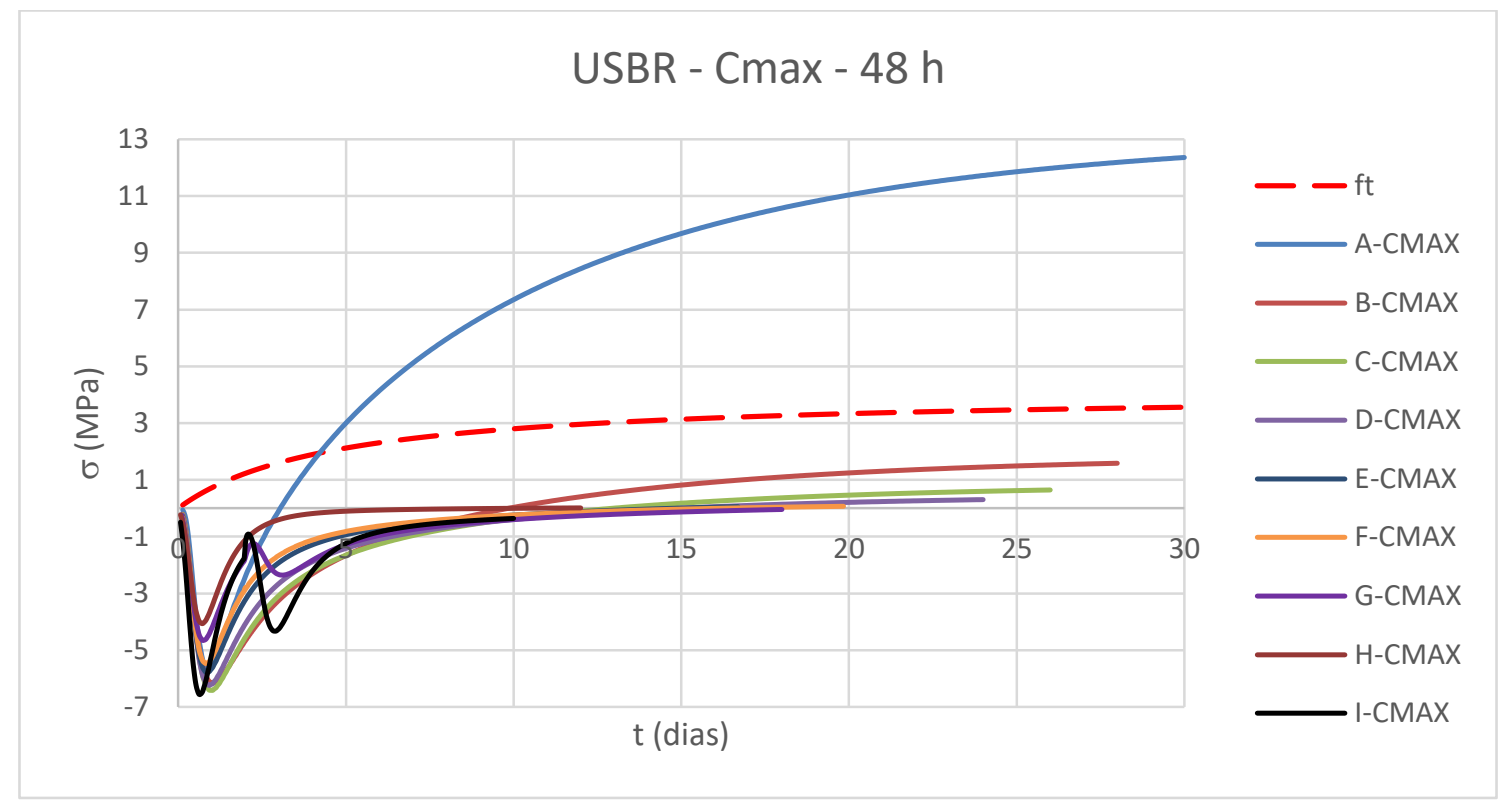

Figura 6.67 - Tensões para $C_{\max }$ pelo método USBR com intervalo de lançamento de $48 \mathrm{~h}$.

Com o intuito de facilitar o entendimento e visualização dos resultados mostrados até o momento, a Tabela 6.5 apresenta de forma resumida os resultados para os casos estudados, sempre pegando as situações extremas. Para as variações em $\mathrm{X}$ foram expostos os casos do muro com espessura de $0,2 \mathrm{~m}$ e 3,0 m. Para as variações em Y, em camadas, foram mostrados os casos para 3 e 10 camadas, assim como os dois casos de variação em Z.

De forma geral, para as simulações de construção em camadas efetuadas verificou-se que: 
- As CC e CI são extremamente decisivas nos resultados finais, qualquer pequena alteração modifica completamente as respostas.

- A malha e o incremento do tempo têm influência direta nos resultados. O dimensionamento errado falseia os resultados.

- As análises em camadas devem ser feitas cautelosamente e deve-se atentar para que a camada posterior não aumente sua temperatura inicial ou resfrie a camada inferior.

- Quanto mais espessa a camada, maior a temperatura atingida e, consequentemente, maiores as tensões de tração e compressão.

- Para um intervalo de lançamento das camadas de $12 \mathrm{~h}$ a camada não tem tempo para resfriar antes do lançamento da camada posterior, diferente do que acontece quando o intervalo de lançamento é de $24 \mathrm{~h}$, em que as camadas começam a resfriar e, quando a seguinte é lançada, a temperatura aumenta novamente. No entanto, isso não se verifica para camadas com espessura maior ou igual a $1,5 \mathrm{~m}$.

- Alguns perfis de temperatura apresentam ondulações que indicam aquecimento/resfriamento e as tensões acompanham essas ondulações, havendo compressão/tração, respectivamente.

- As camadas postas sobre uma fundação rígida terão tensões bem maiores que aquelas sobre uma fundação flexível de aproximadamente mesmo modulo de elasticidade.

- O método USBR sempre apresenta tensões mais elevadas que o método DP e atinge a tensão de resistência à tração do concreto mais rapidamente.

- As tensões de compressão do concreto são muito baixas se comparadas a sua capacidade resistente, não havendo, portanto, preocupação com a compressão. 
Tabela 6.5 - Resumo dos resultados para variações em X, Y e Z.

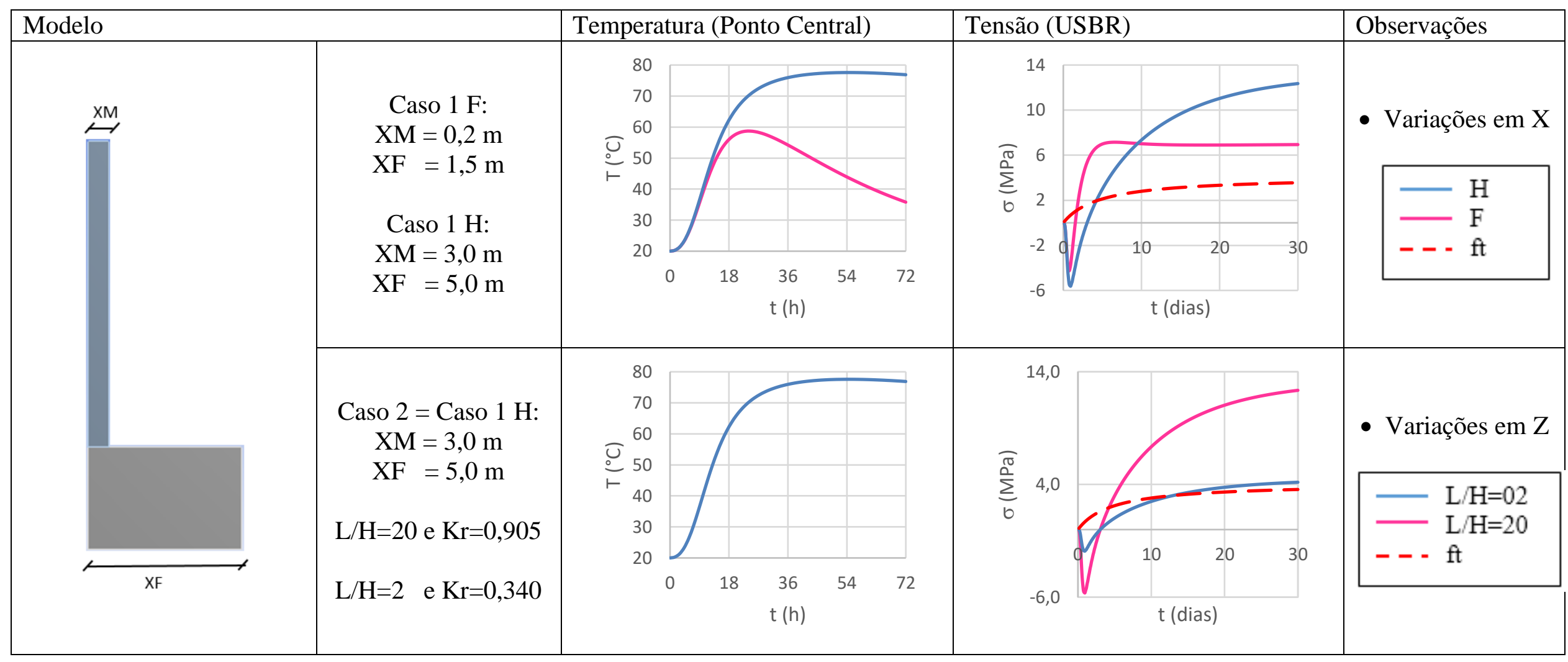




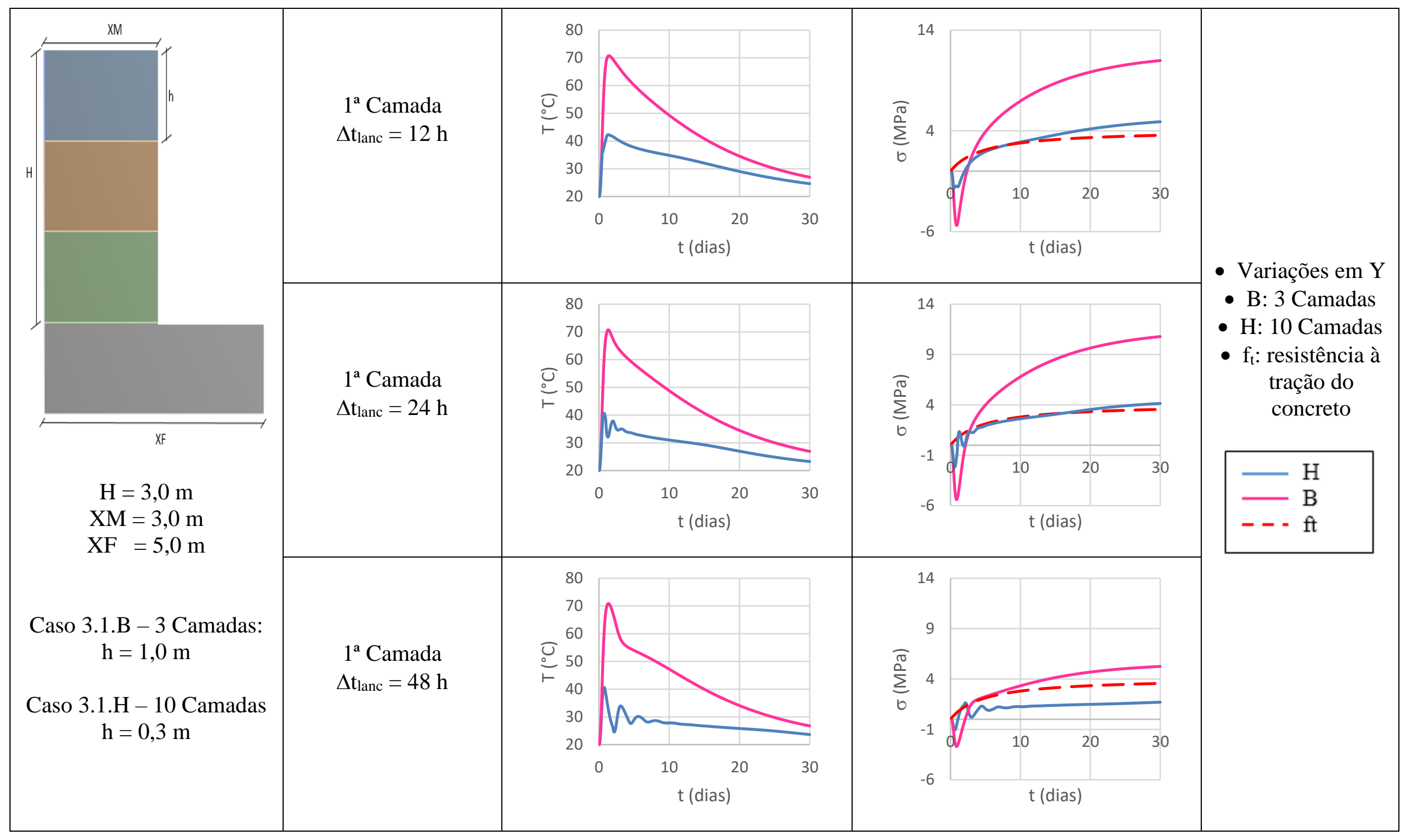




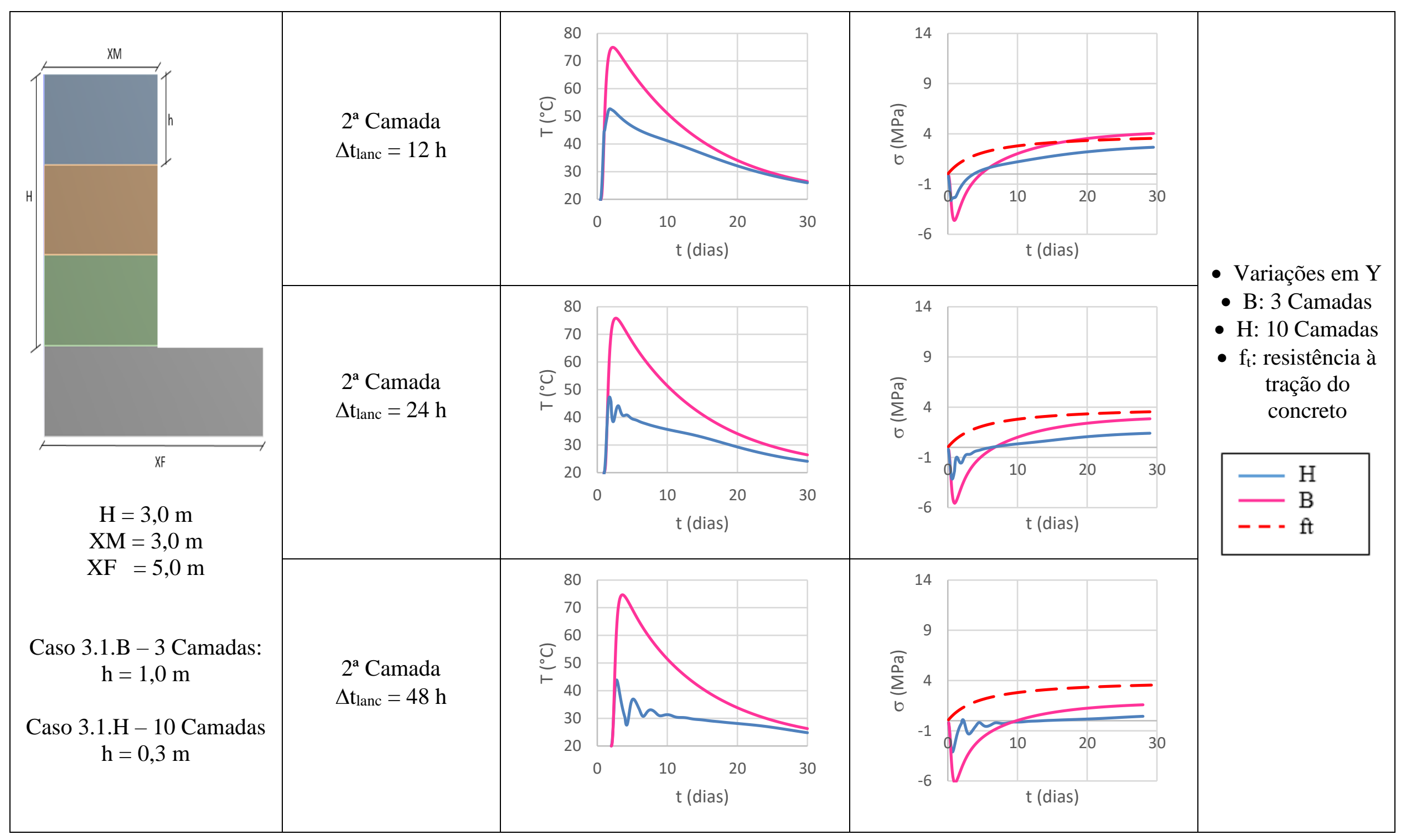




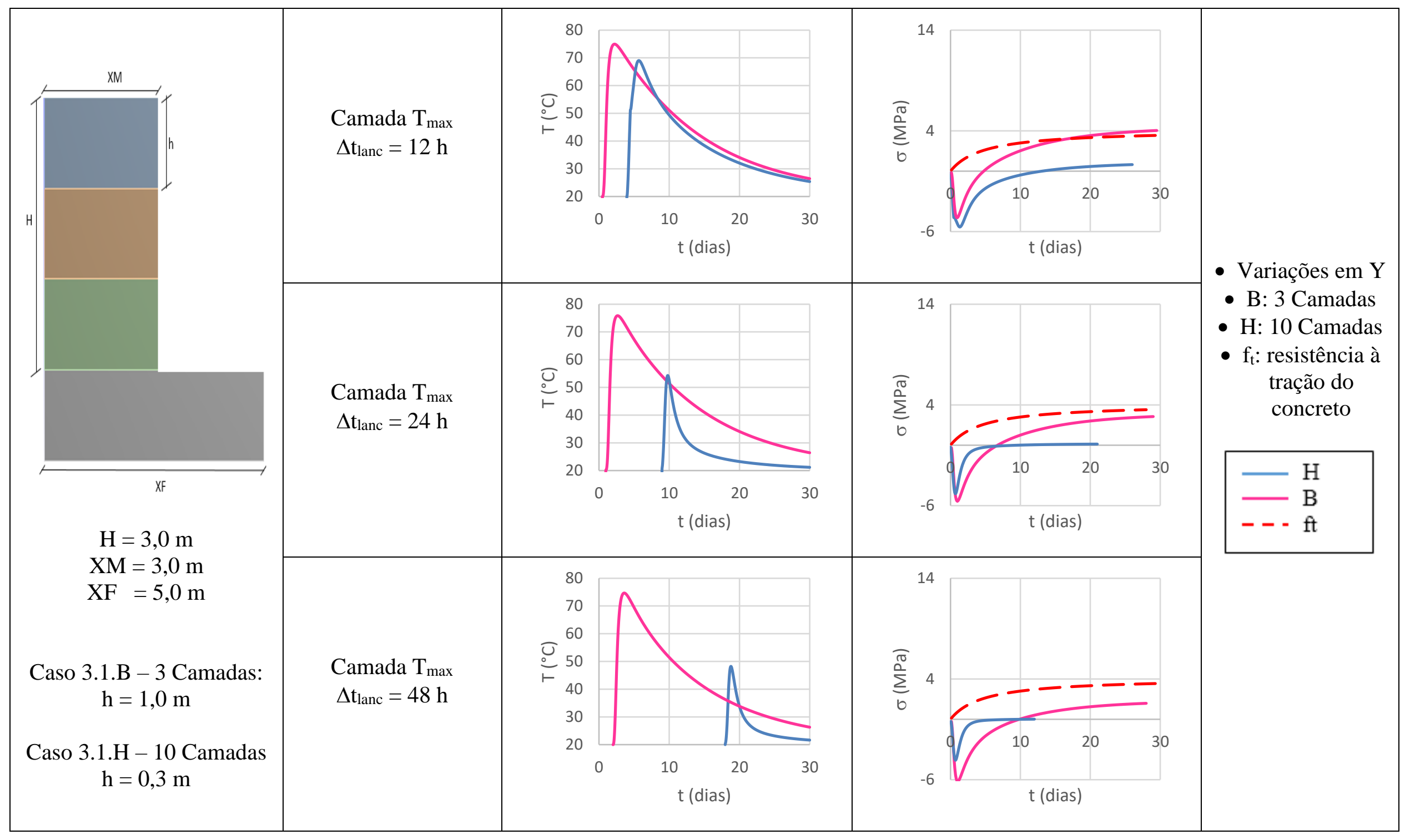




\subsection{CASO 4: MESMO NÚMERO DE CAMADAS COM ESPESSURAS DIFERENTES}

Para o Caso 4, foram simuladas a construção de quatro camadas com intervalo de lançamento de 24 h, com alteração das espessuras conforme descrito na Tabela 6.6. Sendo o número de camadas e a espessuras fixas, a altura total da estrutura será modificada em cada situação.

Tabela 6.6 - Denominação dos Casos 4 analisados.

\begin{tabular}{|l|l|l|}
\hline CASO 4 & Altura da camada $(\mathrm{m})$ & Altura total $(\mathrm{m})$ \\
\hline A & 0,20 & 0,80 \\
\hline B & 0,30 & 1,20 \\
\hline C & 0,40 & 1,60 \\
\hline D & 0,50 & 2,00 \\
\hline E & 0,60 & 2,40 \\
\hline F & 0,75 & 3,00 \\
\hline G & 1,00 & 4,00 \\
\hline
\end{tabular}

A Figura 6.68 mostra as isotermas de temperatura para os casos da Tabela 6.5 no tempo de 432000 s, que equivale a 5 dias. Esse tempo não necessariamente representa a idade de temperatura máxima em todos os casos, isso pode ser verificado nos gráficos das Figuras de 6.69 a 6.82. No entanto, é possível verificar o ponto de temperatura máxima, identificado pela seta vermelha, alterado para cada caso, assim como o valor da máxima e as isotermas de temperatura. Porém é perceptível, que a área mais aquecida é sempre mais próxima à superfície, nessa situação.

Ressalta-se que as análises deste caso não são elaboradas para os pontos de temperatura máxima, e sim para o PC de cada camada. 


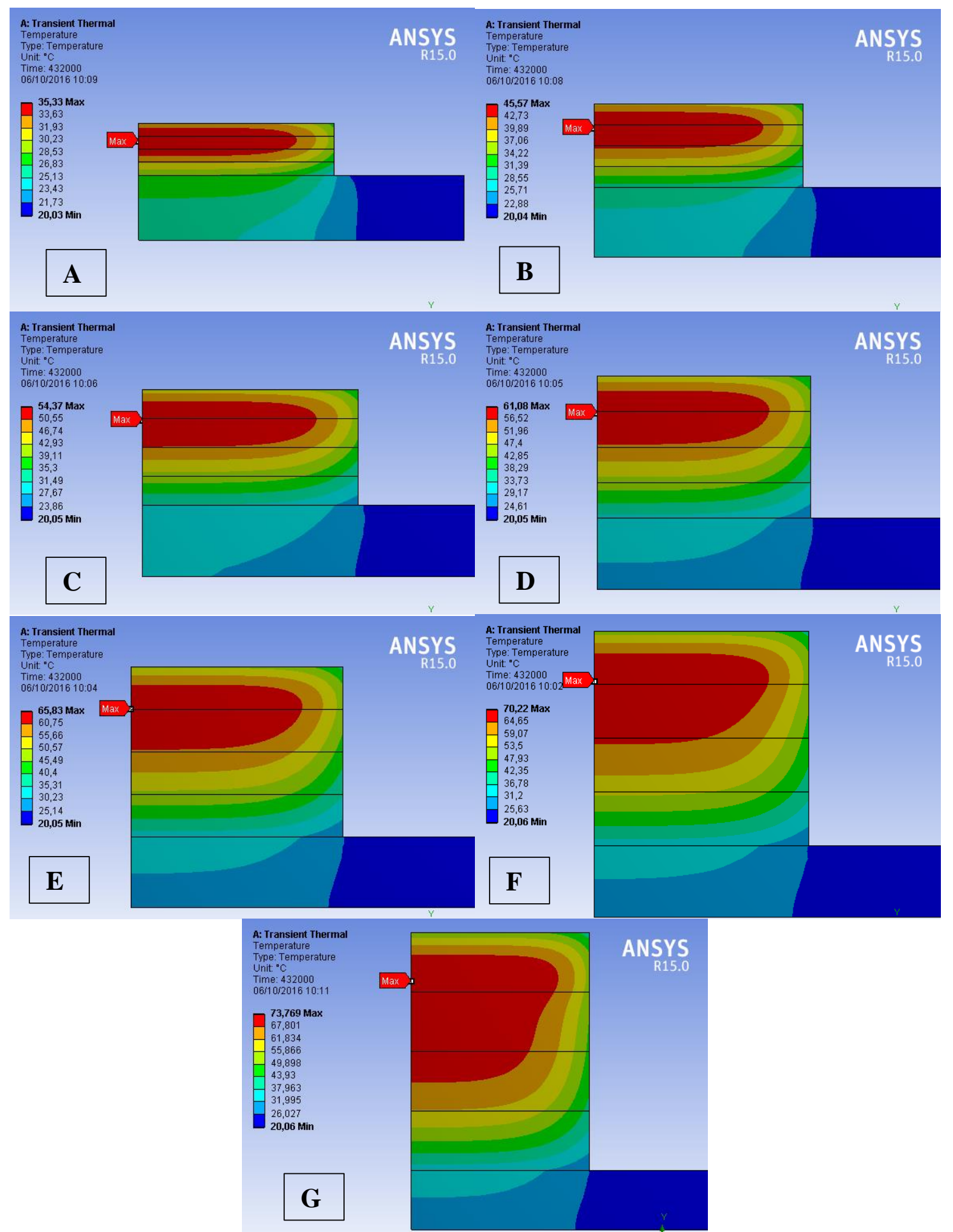

Figura 6.68 - Isotermas para diferentes alturas para construção com quatro camadas.

A Figura 6.69 apresenta as temperaturas do Caso 4-A. A última camada alcança a maior temperatura, $47^{\circ} \mathrm{C}$; as outras aumentam sua temperatura com o lançamento das camadas posteriores. 


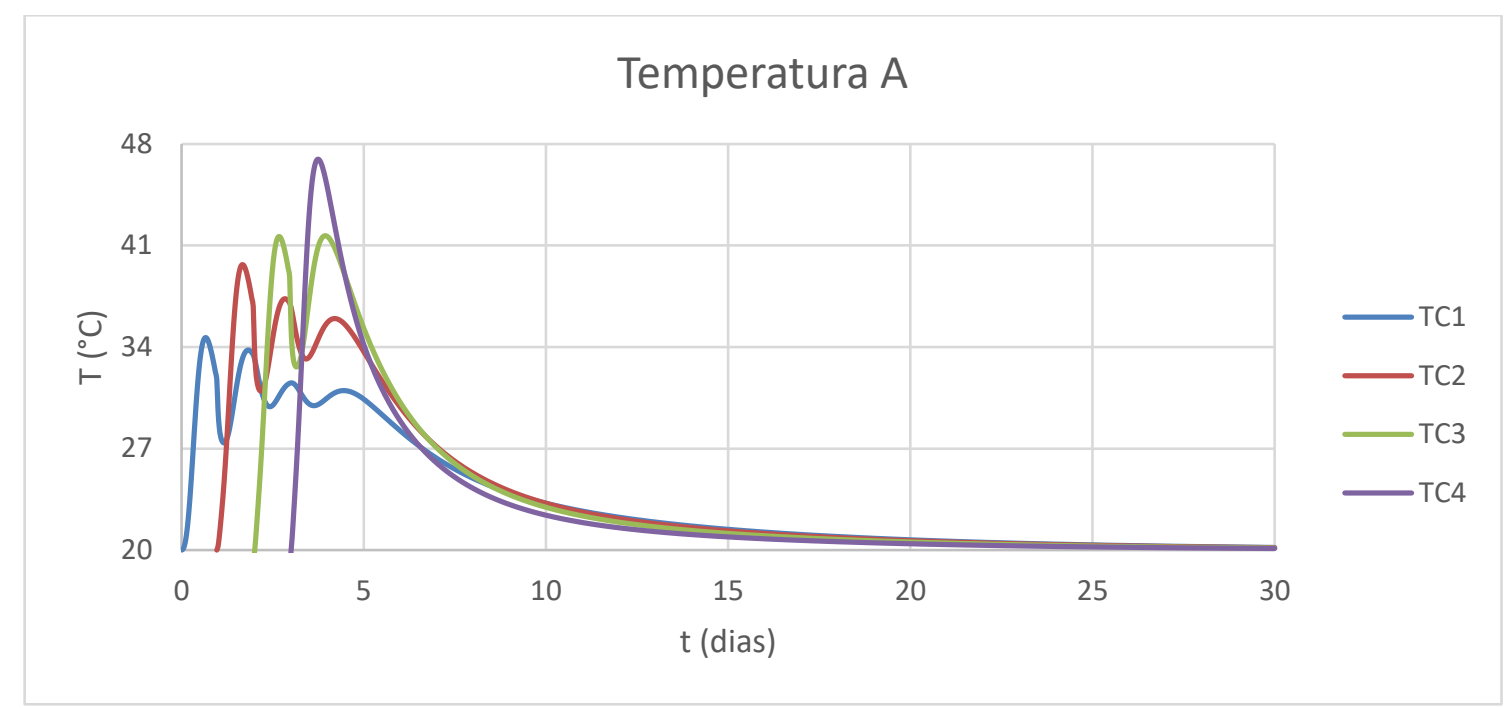

Figura 6.69 - Temperaturas para o Caso 4-A.

A Figura 6.70 mostra os perfis de tensão para o Caso 4-A. Para este caso foram calculadas as tensões apenas pelo método USBR, por se mostrarem maiores que pelo DP observadas no Caso 3 em todos os exemplos. As condições de restrição são as mesmas utilizadas para o Caso 3, em que a primeira camada se encontra sobre uma fundação rígida e as demais sobre outra camada de concreto, considerada flexível.

Ressalta-se que os perfis de tensões para todas as camadas iniciam-se no tempo zero, ou seja, as tensões são mostradas a partir da idade inicial da camada. No entanto, entre as camadas há um intervalo de idade de $24 \mathrm{~h}$. Assim, quando a quarta camada é lançada, a terceira está com um dia, a segunda com dois dias e a terceira com três dias.

Nas idades iniciais, Figura 6.70, provavelmente devido ao primeiro resfriamento brusco da primeira camada, as tensões de tração atingem patamares superiores ao limite resistente do concreto. As demais não fissurariam ao longo do tempo.

É interessante observar que para TC2, TC3, TC4, que apresentam mesma espessura e condições de restrição, as tensões máximas não foram obtidas para os pontos que apresentaram a temperatura máxima, mas sim para aquela que demorou mais tempo para resfriar, TC2. 


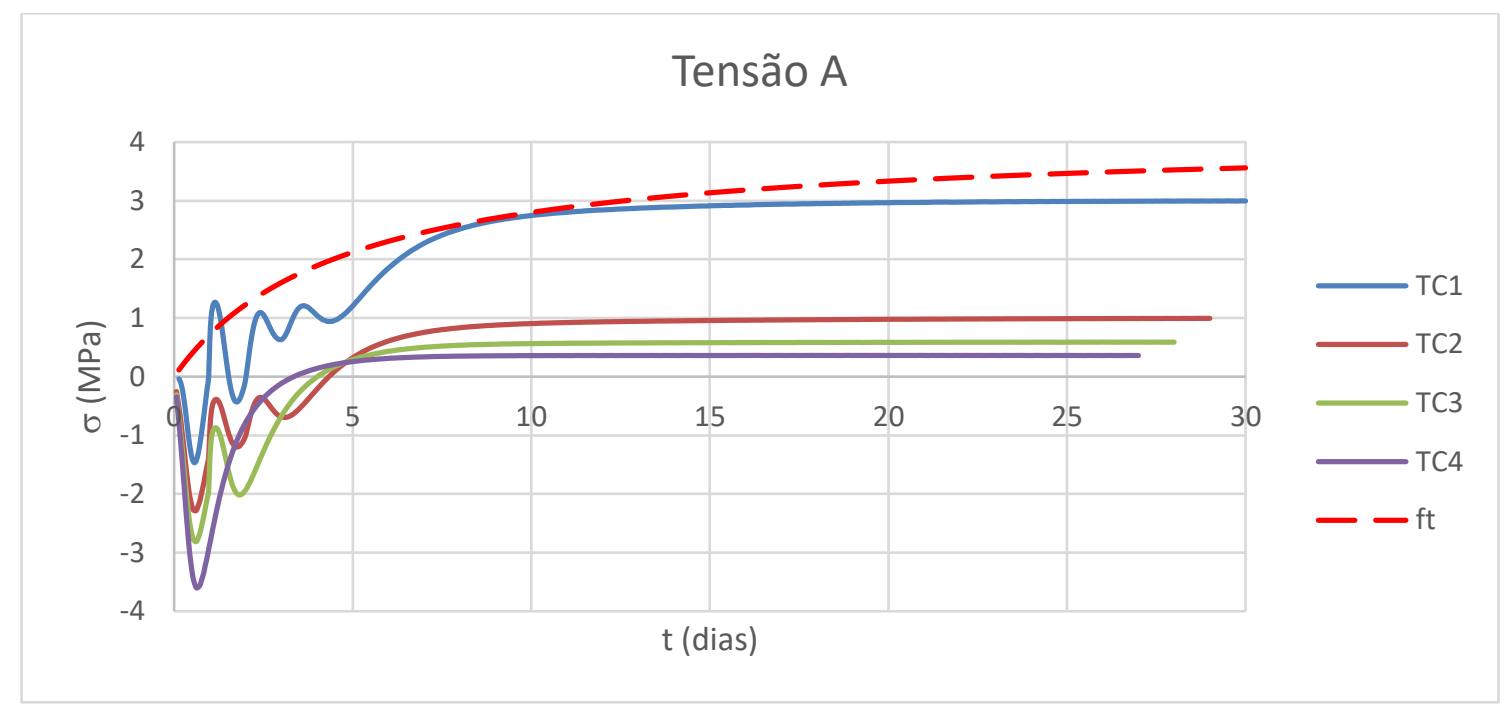

Figura 6.70- Tensões para o Caso 4-A.

A Figura 6.71, traz o gráfico das temperaturas para o Caso 4-B. Em todas as camadas houve aumento de temperatura e aos 30 dias, todas as camadas estão resfriadas.

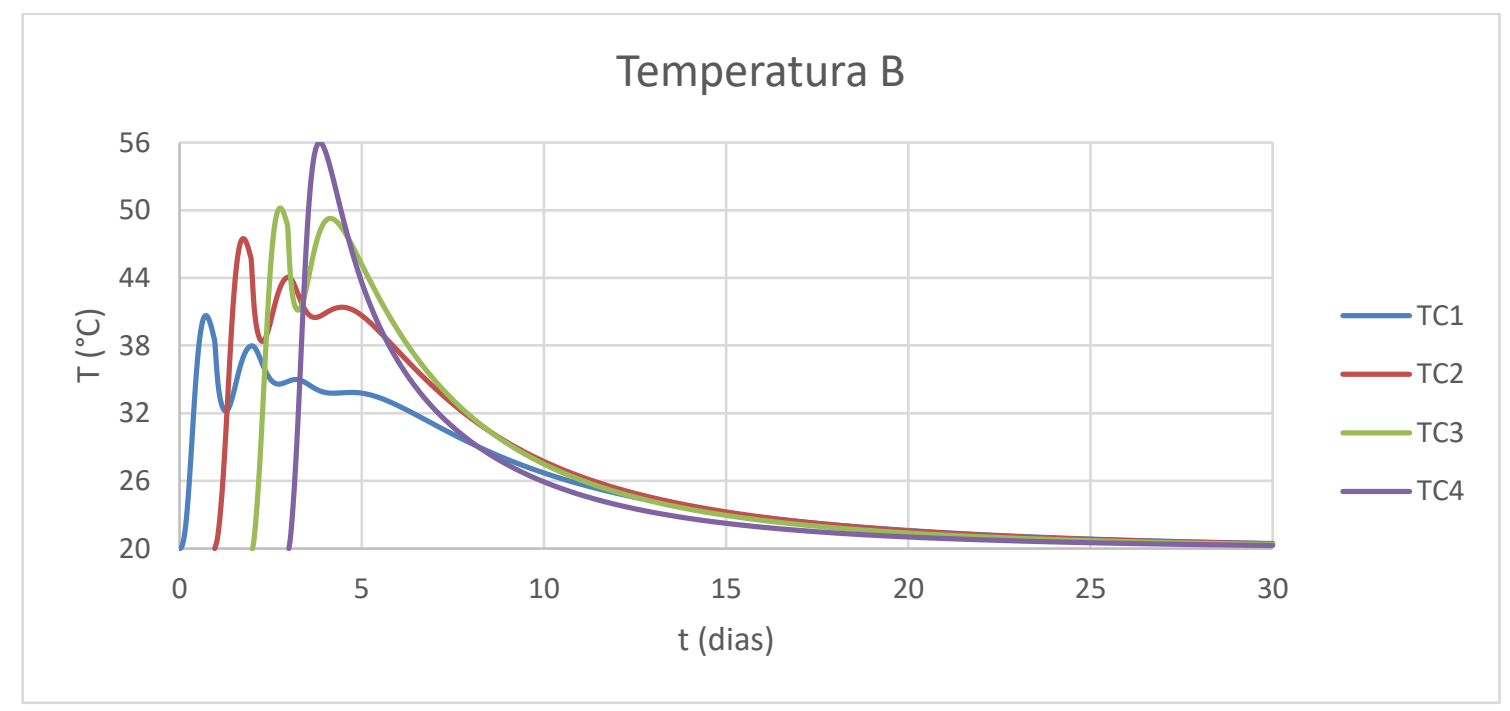

Figura 6.71 - Temperaturas para o Caso 4-B.

As tensões para o Caso 4-B, Figura 6.72, acompanham as temperaturas das camadas, assim são maiores que para o Caso 4-A. A primeira camada ultrapassa a tensão em 1 dia e após 2,4 dias. As demais não ultrapassam a resistência do concreto à tração. 


\section{Tensão B}

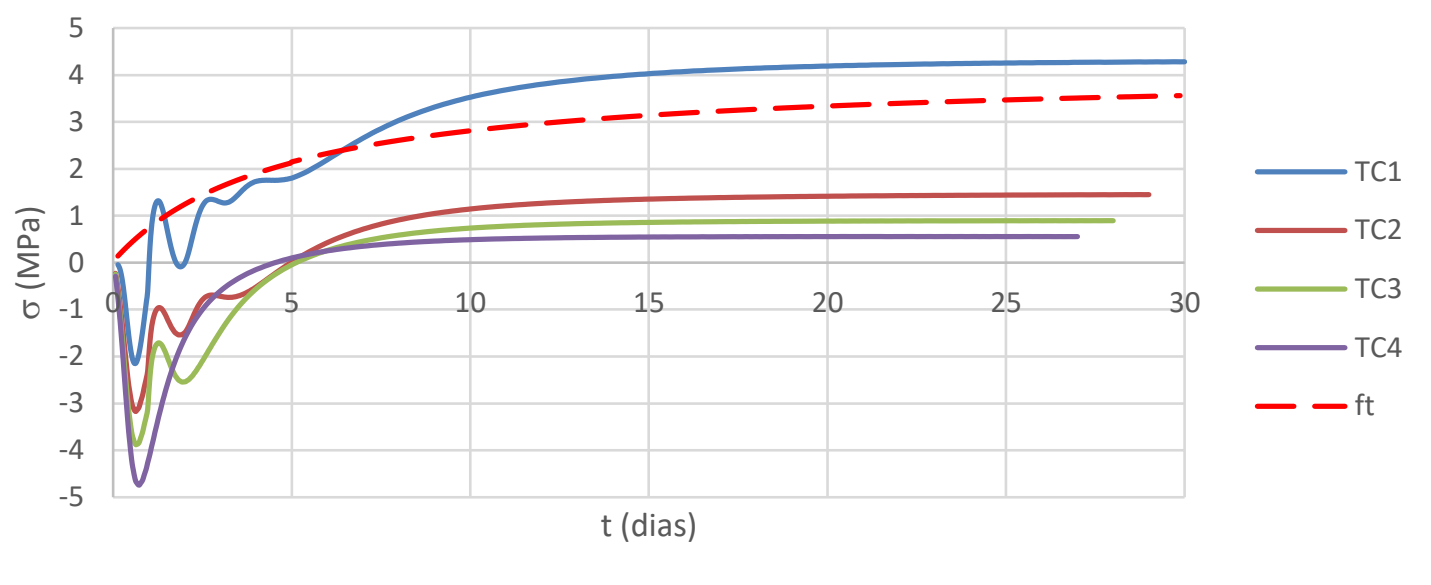

Figura 6.72 - Tensões para o Caso 4-B.

Para o Caso 4-C, Figura 6.73 , a quarta camada atingiu $62^{\circ} \mathrm{C}, 6^{\circ} \mathrm{C}$ a mais que a anterior, com resfriamento mais lento.

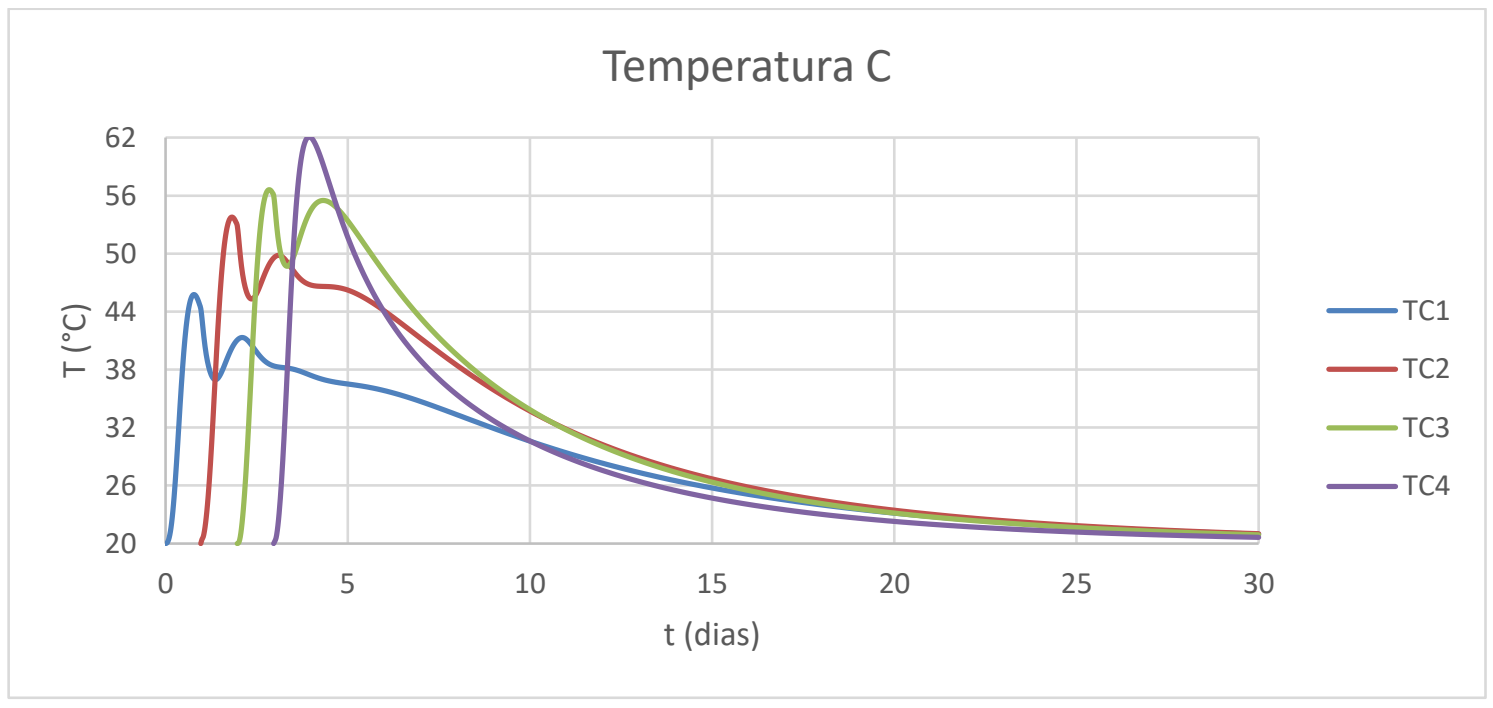

Figura 6.73 - Temperaturas para o Caso 4-C.

Mesmo atingindo menores tensões de tração nas idades iniciais, Figura 6.74, estas ainda superam a resistência do concreto e, a partir de 1,5 dias, todas conduzem a uma possível fissuração do concreto. 


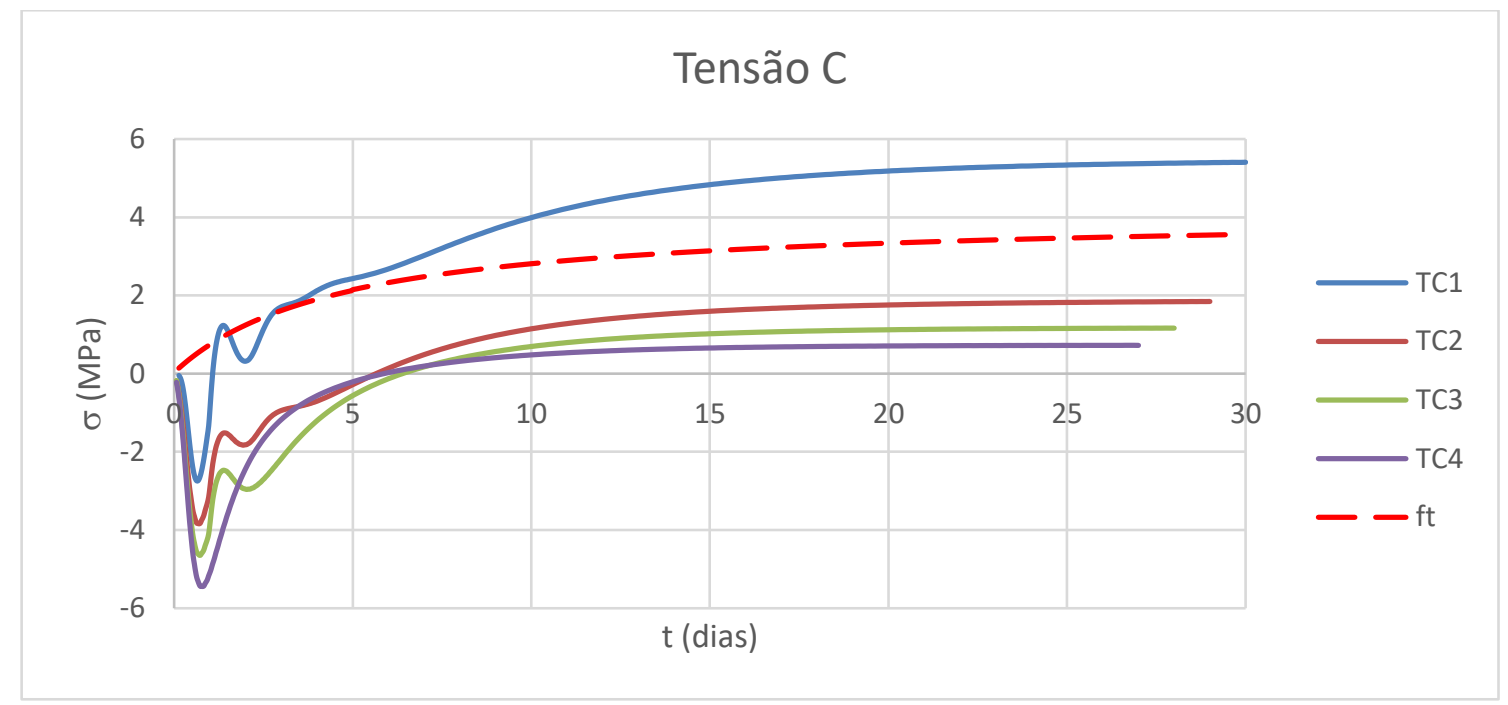

Figura 6.74 - Tensões para o Caso 4-C.

A Figura 6.75 mostra a evolução térmica para o Caso 4-D. A máxima foi atingida pela quarta camada em aproximadamente quatro dias e com temperatura de $63^{\circ} \mathrm{C}$. Nota-se que a primeira camada acelerou o seu resfriamento em relação aos casos anteriores.

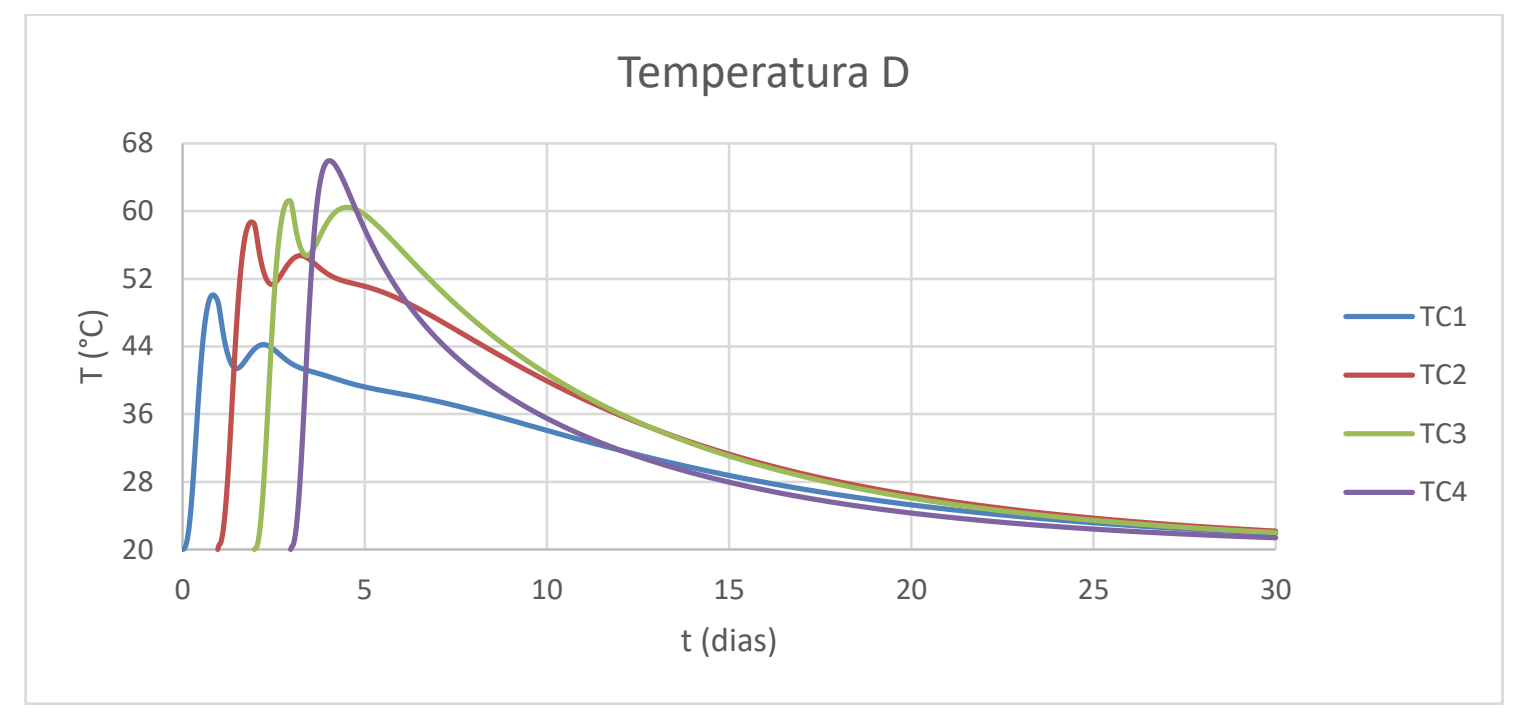

Figura 6.75 - Temperaturas para o Caso 4-D.

As tensões para o Caso 4-D exibidas na Figura 6.76 enfatizam o risco de fissuração da primeira camada. As demais não ultrapassam a resistência a tração do concreto. 


\section{Tensão D}

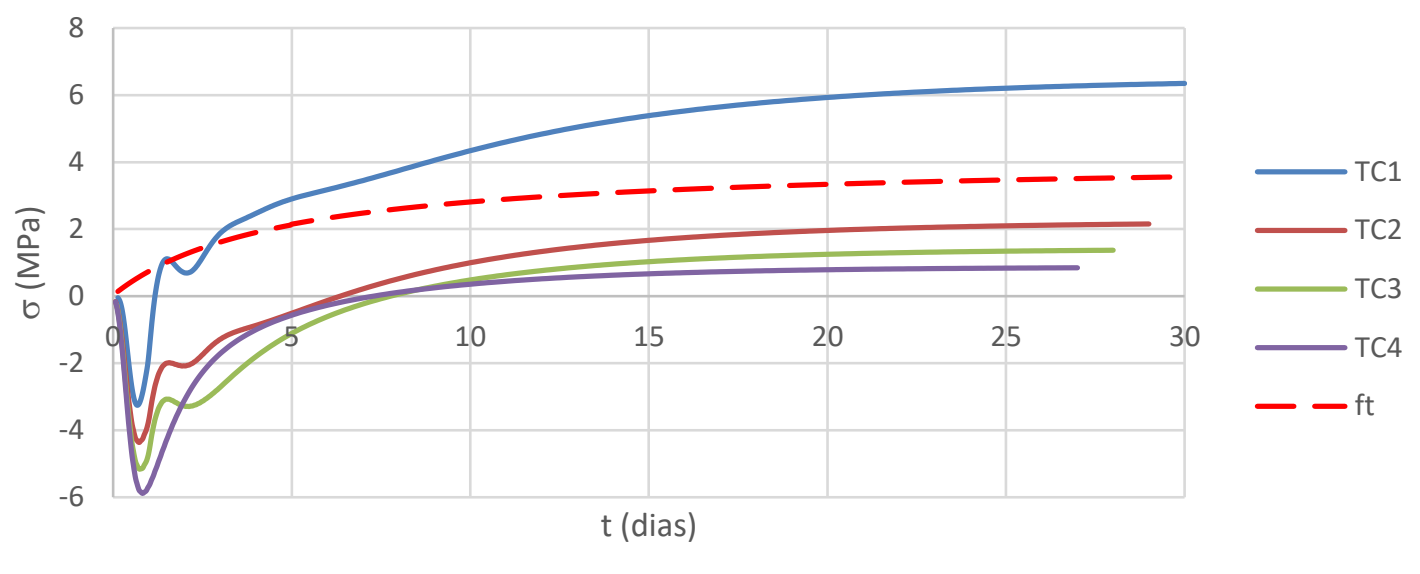

Figura 6.76 - Tensões para o Caso 4-D.

Com espessura de 0,60 m, Caso E, a temperatura máxima também ocorre na quarta camada com $68^{\circ} \mathrm{C}$ no quarto dia, Figura 6.77 . Verifica-se também um retardamento no resfriamento.

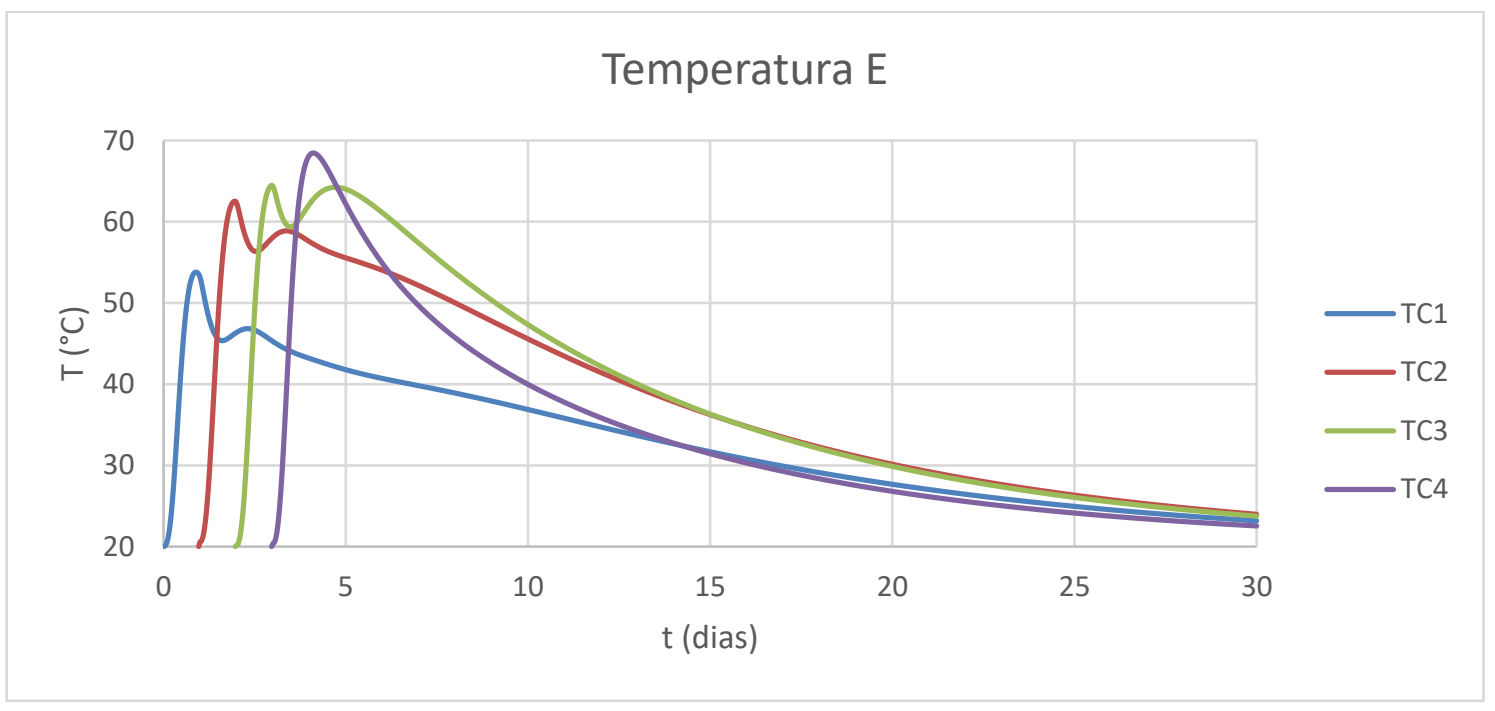

Figura 6.77 - Temperaturas para o Caso 4-E.

Os resultados apresentados no Caso 4-E mostram um aumento das tensões da primeira camada levando a risco de fissuração, Figura 6.78. Embora as outras também aumentem, não atingem a resistência à tração do concreto. 


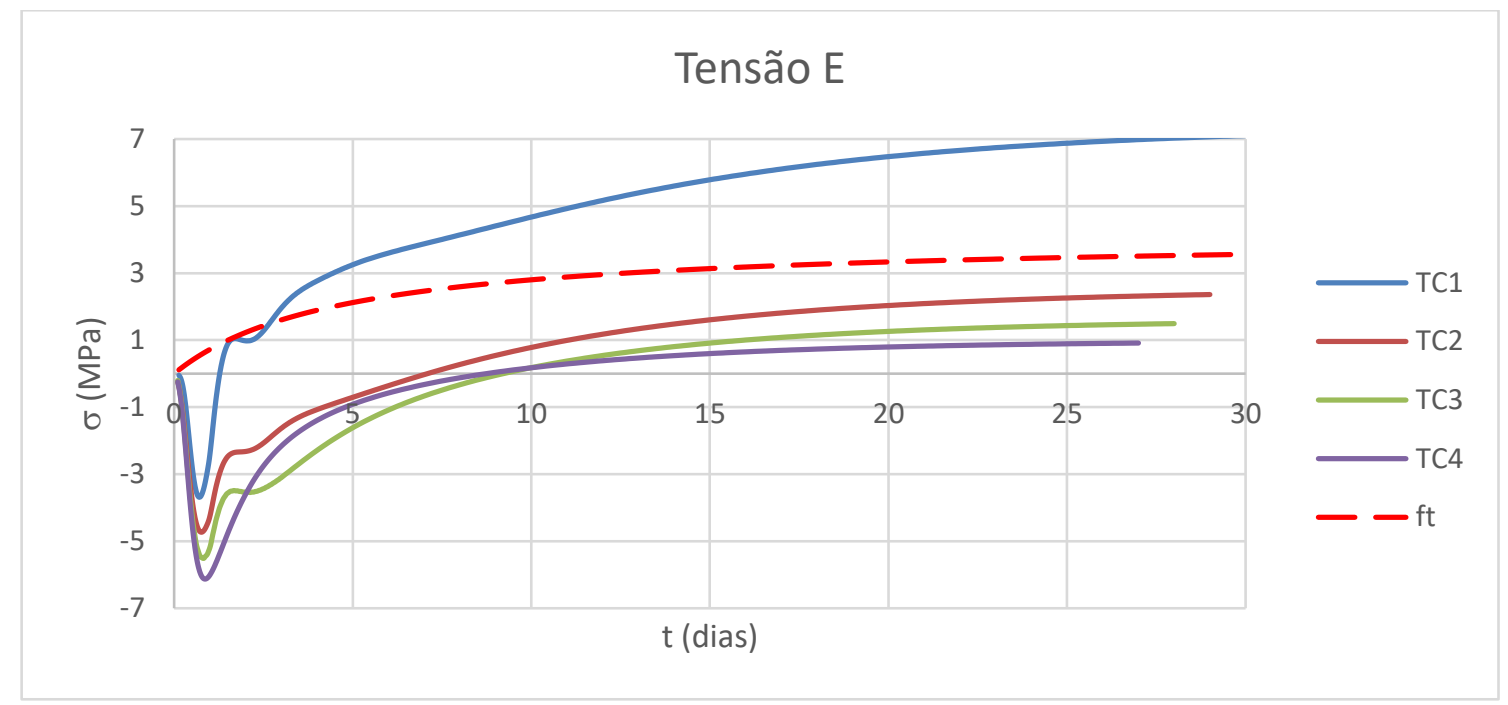

Figura 6.78 - Tensões para o Caso 4-E.

No Caso 4-F, Figura 6.79 , a máxima atinge $70^{\circ} \mathrm{C}$ e a segunda e terceira camada demoram mais a resfriar.

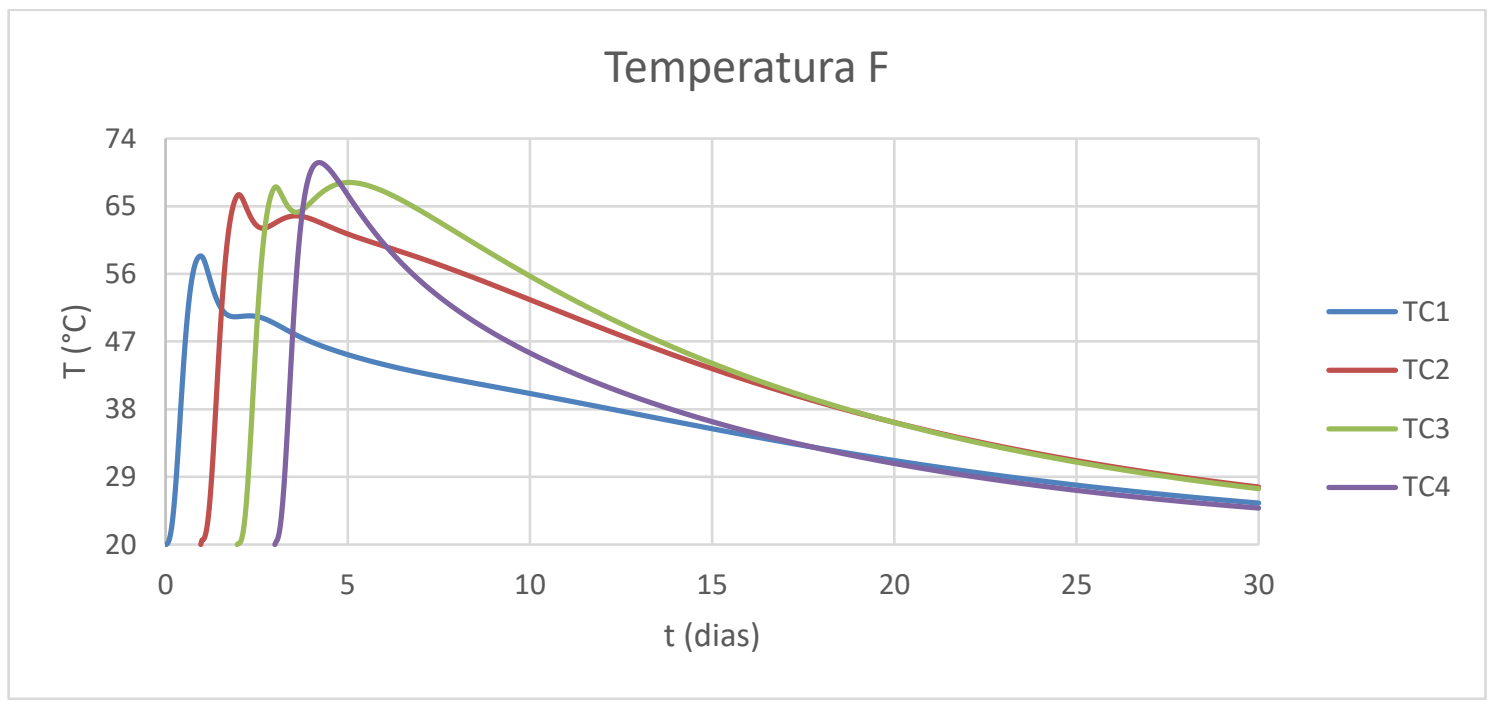

Figura 6.79 - Temperaturas para o Caso 4-F.

Acompanhando as temperaturas, as tensões também aumentam de valor, Figura 6.80, em que a primeira camada atinge o limite do concreto antes dos dois dias. A segunda e terceira camada aos 30 dias também não atingiram esse valor e aparentemente já tende a uma assíntota. 


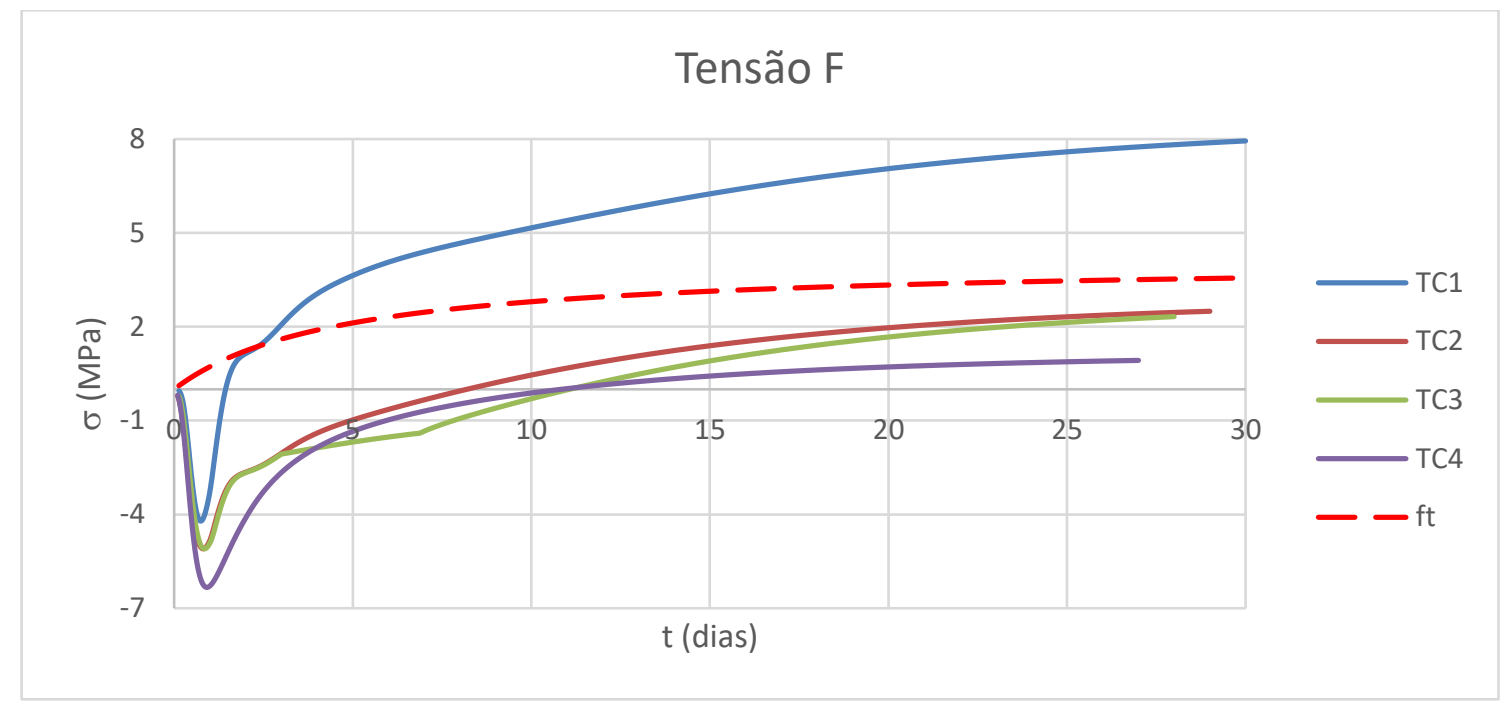

Figura 6.80 - Tensões para o Caso 4-F.

Com camadas de $1,00 \mathrm{~m}$, chega-se a quase $74^{\circ} \mathrm{C}$ e a terceira camada em um determinado momento atinge quase esse valor máximo, Figura 6.81.

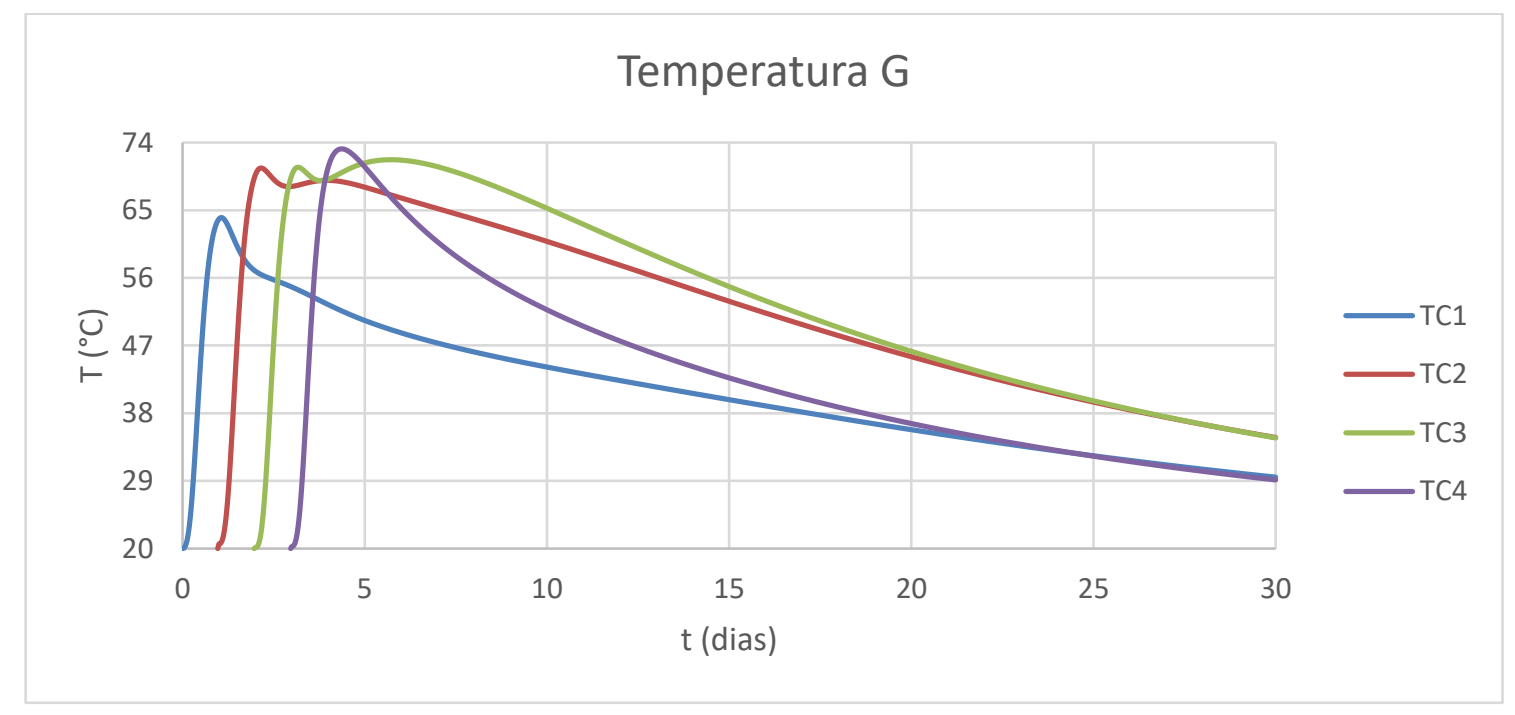

Figura 6.81 - Temperaturas para o Caso 4-G.

No Caso 4-G, a primeira camada fissuraria nas idades iniciais e aos 30 dias nenhuma das outras atingiu a resistência a tração do concreto, Figura 6.82. No entanto, observa-se que TC2 ainda continua aumentado. 


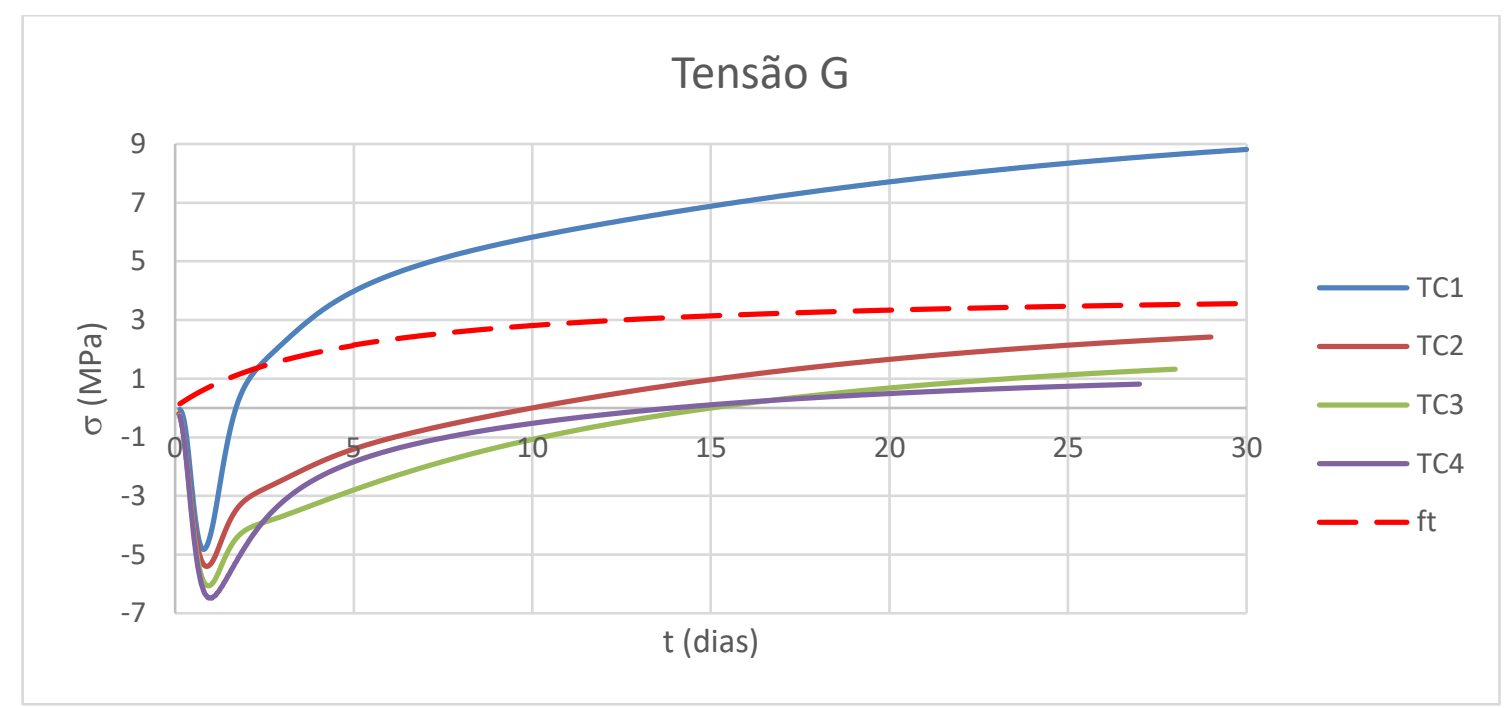

Figura 6.82 - Temperaturas para o Caso 4-G.

Diante dessas analises verificou-se que:

- A espessura da camada influência nas temperaturas máximas atingidas. Quanto mais espessa, maior sua temperatura máxima.

- A camada que atinge a temperatura máxima não necessariamente resfriará mais lentamente. Normalmente as camadas centrais demoram mais a resfriar.

- As tensões de tração máximas não são atingidas pelas camadas que apresentam a temperatura máxima, mas por aquelas que resfriam mais lentamente, ou melhor, por aquelas que permanecem mais tempo com temperaturas elevadas.

- Para quatro camadas e intervalo de lançamento de 48 h, as temperaturas máximas foram atingidas pela quarta camada, independente da espessura.

- A primeira camada, considerada sobre fundação rígida, ultrapassaria a resistência à tração do concreto em todos os casos.

- Entre as camadas sobre outras camadas de concreto as maiores tensões de tração foram obtidas para a segunda camada. 


\subsection{CASO 5 - INFLUÊNCIA DE FUROS EM UMA ESTRUTURA}

Esta análise tem o intuito de verificar a presença de aberturas no interior do concreto massa. Para isso foram verificadas as estruturas com um e quatro furos, mostrados nos Casos $5.1 \mathrm{e}$ 5.2 .

\subsubsection{CASO 5.1 - Bloco com um furo}

Após a verificação das tensões para a laje, exemplo 5.6.3.2, a mesma foi modelada com altura de 4,0 m e com um furo situado à 4,5 $\mathrm{m}$ da superfície direita centro, a temperatura no contorno do furo foi considerada de $20^{\circ} \mathrm{C}$. Três pontos, P1, P2 e P3, foram analisados, buscando verificar a influência da temperatura no furo, agindo como uma $\mathrm{CC}$, provoca no restante da estrutura. As condições de CC e CI empregadas são as mesmas para a laje estudada anteriormente e a configuração analisada pode ser observada na Figura 6.83 .

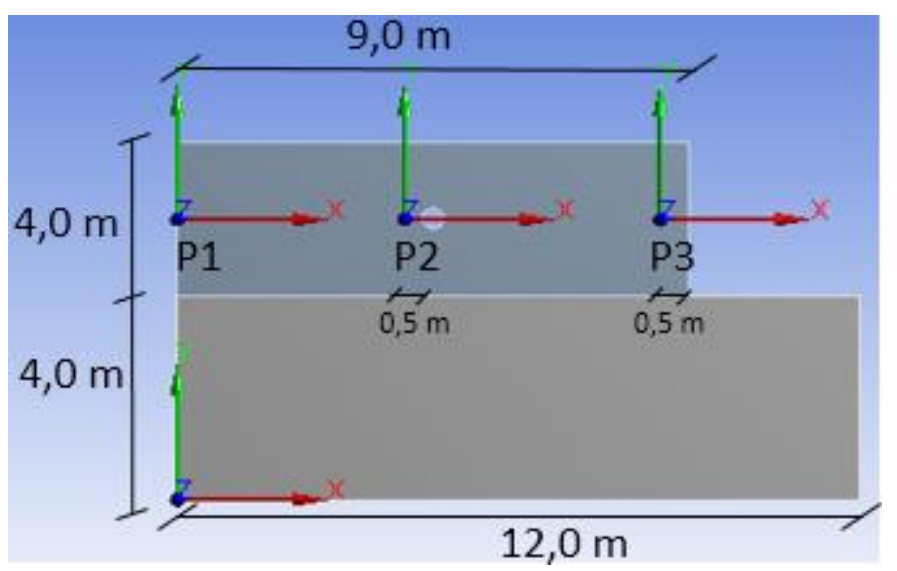

Figura 6.83 - Pontos analisados com um furo.

Para o corpo superior, houve um refinamento da malha, tamanho adotado de $0,1 \mathrm{~m}$, devido à influência ao redor do furo, e para a fundação malha de $0,4 \mathrm{~m}$, totalizando 179121 nós e 44560 elementos, conforme a Figura 6.84. Essa figura é dada para o menor raio do furo. 


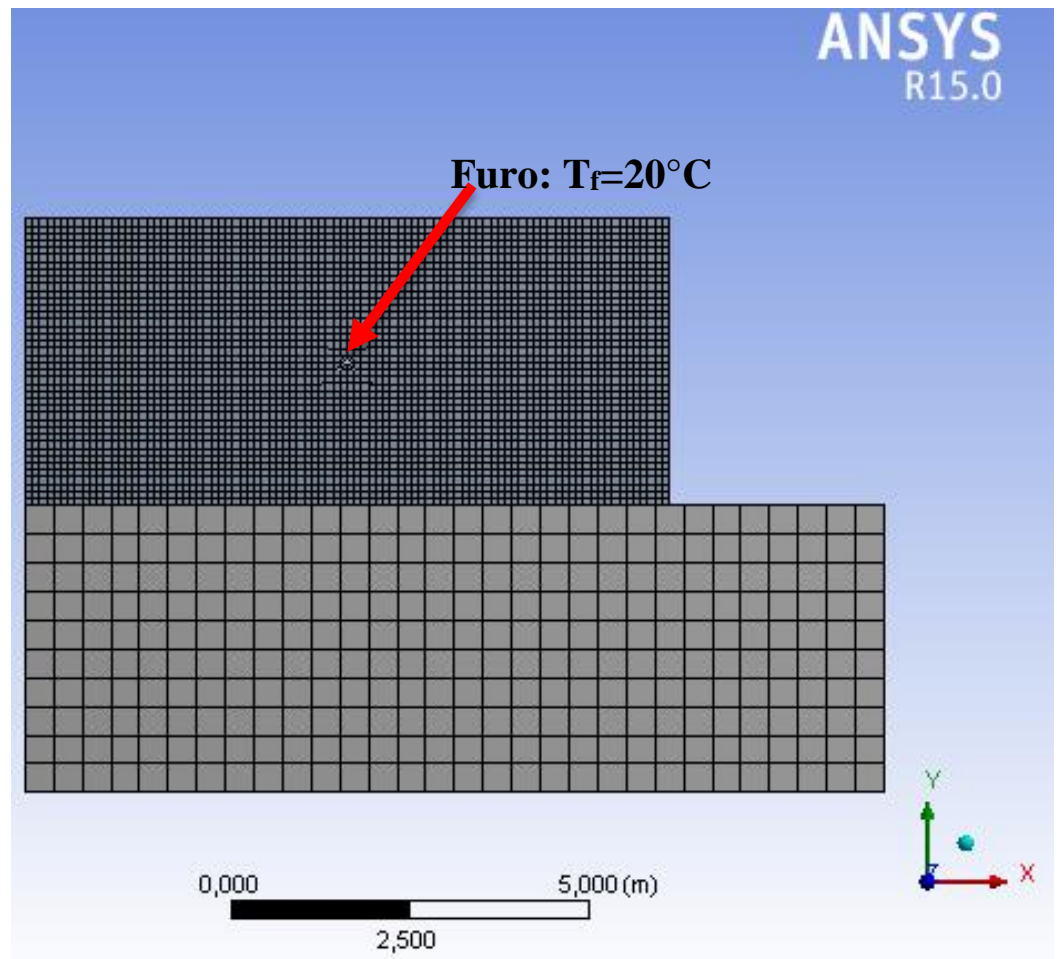

Figura 6.84 - Malha utilizada para análise com furo.

O furo teve sua seção variada conforme a Tabela 6.7, em que o raio, $r$, foi aumentado em $0,05 \mathrm{~m}$.

Tabela 6.7 - Denominação do Caso 5.

\begin{tabular}{|l|l|}
\hline Caso & $\mathbf{r}(\mathbf{m})$ \\
\hline A & 0,05 \\
\hline B & 0,10 \\
\hline C & 0,15 \\
\hline$D$ & 0,20 \\
\hline E & 0,25 \\
\hline F & 0,30 \\
\hline G & 0,35 \\
\hline H & 0,40 \\
\hline
\end{tabular}

A Figura 6.85 mostra as isotermas de temperatura para todos os casos no tempo em que se obteve a temperatura máxima, 297220 s ou 3,44 dias; os valores das temperaturas máximas permaneceram iguais em todas as modelagens, $80,647^{\circ} \mathrm{C}$. Isso evidencia uma área de influência do furo muito pequena em relação ao tamanho do corpo. Para fins de comparação a Figura 6.85 I mostra o caso sem a presença do furo. 


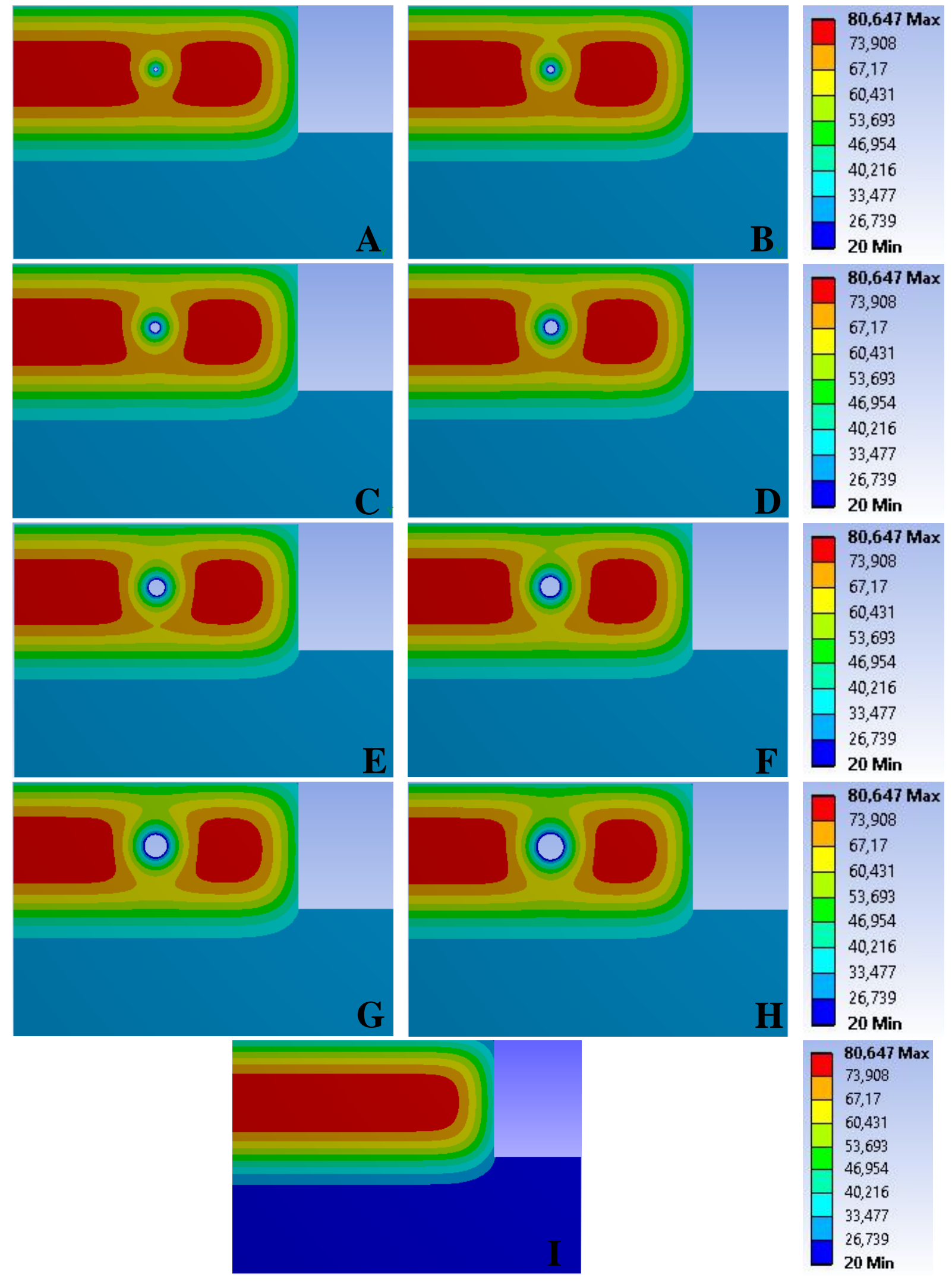

Figura 6.85 - Isotermas para estrutura com um furo. 
Após as análises anteriores, foram verificados os diâmetros e as áreas de influência $\left(A_{\text {inf }}\right)$ de cada raio. No desenvolvimento das isotermas constatou-se que sendo a abertura circular, a sua área de influência é dada pela área de um círculo maior subtraída a área do furo. A medição da área de influência foi realizada pelas figuras impressas com auxílio de escalímetro, levando em consideração a escala presente nos resultados do programa. A Tabela 6.8 exibe o diâmetro e a área do furo $\left(\mathrm{d}_{\mathrm{f}} \mathrm{e} \mathrm{A}_{\mathrm{f}}\right)$ com seus respectivos diâmetros e áreas de influência $\left(\mathrm{d}_{\mathrm{inf}}, \mathrm{A}_{\mathrm{inf}}\right)$.

Tabela 6.8 - Relação entre diâmetros e áreas de influência.

\begin{tabular}{|l|l|l|l|l|}
\hline Caso & $\mathbf{d}_{\mathbf{f}}(\mathbf{m})$ & $\mathbf{A}_{\mathbf{f}}\left(\mathbf{m}^{2}\right)$ & $\mathbf{d}_{\text {inf }}(\mathbf{m})$ & $\mathbf{A}_{\text {inf }}\left(\mathbf{m}^{2}\right)$ \\
\hline A & 0,10 & 0,008 & 1,59 & 1,982 \\
\hline B & 0,20 & 0,031 & 1,86 & 2,681 \\
\hline C & 0,30 & 0,071 & 2,09 & 3,353 \\
\hline D & 0,40 & 0,126 & 2,23 & 3,784 \\
\hline E & 0,50 & 0,196 & 2,35 & 4,131 \\
\hline F & 0,60 & 0,283 & 2,51 & 4,666 \\
\hline G & 0,70 & 0,385 & 2,69 & 5,298 \\
\hline H & 0,80 & 0,502 & 2,80 & 5,655 \\
\hline
\end{tabular}

A Figura 6.86 traz a relação em forma de gráfico entre o diâmetro do furo e seus respectivos diâmetros do círculo de influência. Quanto maior $\mathrm{d}_{\mathrm{f}}$, maior $\mathrm{d}_{\mathrm{inf}}$, no entanto, o crescimento não é na mesma proporção. Para menores dimensões a região de influência é maior, no caso, um diâmetro de $0,10 \mathrm{~m}$ tem influência em uma abertura de aproximadamente 16 vezes a sua extensão, enquanto para um diâmetro de 0,80 m essa influência é de apenas 3,5 vezes sua grandeza para as CC e CI aplicadas ao problema. 


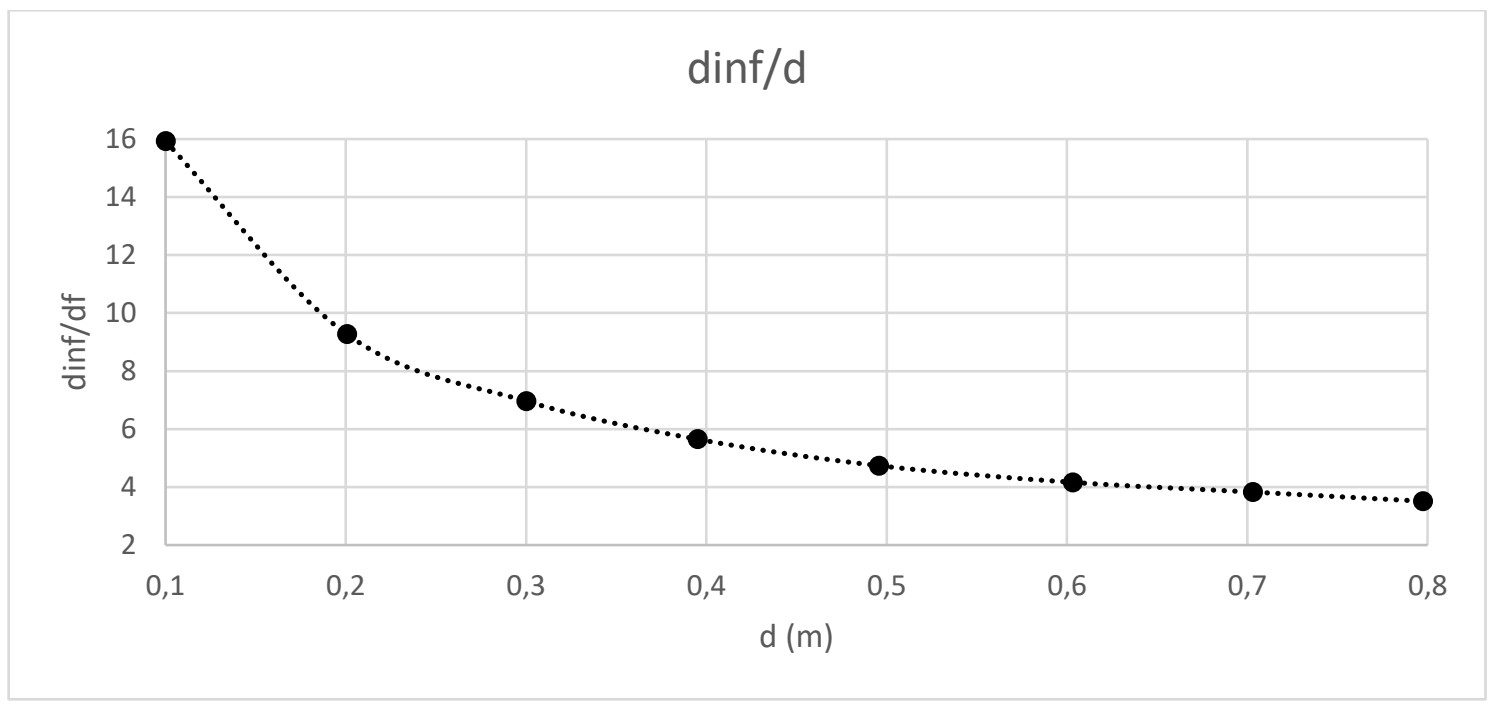

Figura 6.86 - Relação $d_{\text {inf }} \mathrm{x} \mathrm{d}_{\mathrm{f}}$.

Essa situação pode acontece, por exemplo, no processo de pós-resfriamento com tubos de refrigeração, porém, nestas situações, são utilizados apenas tubulações com diâmetros pequenos. Os raios grandes são apenas hipóteses para simulação.

Fazendo a análise térmica nos pontos P1 e P3, todos os casos apresentam o mesmo perfil de temperatura ao longo do tempo, isso é devido aos pontos estarem fora de suas respectivas áreas de influência. Entretanto, nota-se em P3 uma queda de temperatura próximo ao tempo de 2 dias, reflexo da $\mathrm{CC}$ do furo. $\mathrm{P} 1$, localizado no centro da estrutura não tem redução térmica com a presença da abertura, atingindo aproximadamente $80^{\circ} \mathrm{C}$, enquanto em $\mathrm{P} 3$ a máxima é de $62^{\circ} \mathrm{C}$, Figura 6.87 .

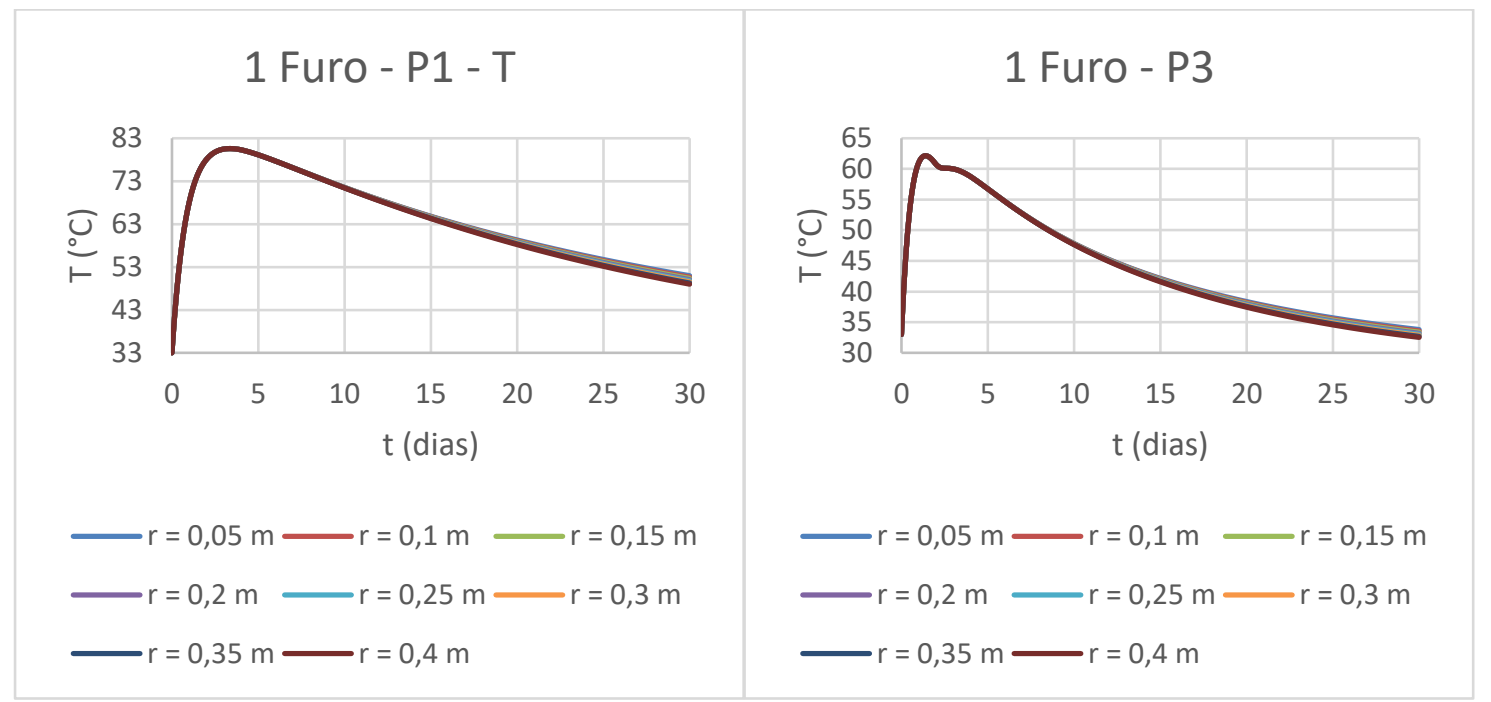

Figura 6.87 - Histórico de temperatura dos pontos P1 e P3. 
A Figura 6.88 mostra as tensões dos pontos P1 e P3 no intervalo de 30 dias, calculadas pelo método do ACI, com os mesmos parâmetros utilizados para a laje sem furos. P1 apresenta uma compressão maior, pois possui temperaturas mais elevadas e, aos 30 dias, aparentemente, P3 já está tendendo a uma assíntota e P1 ainda subirá um pouco suas tensões de tração, mas não muito.

Ressalta-se que para as condições da laje, mostrada no item 5.6.3.2, não haveria fissuração, diferente da estrutura analisada com o furo. O bloco com a presença do furo tem altura quatro vezes maior que a laje, por isso, há maior elevação térmica e fissuração. Neste caso, seriam necessárias medidas alternativas para que não houvesse tensões de tração superior à capacidade de resistência do concreto.

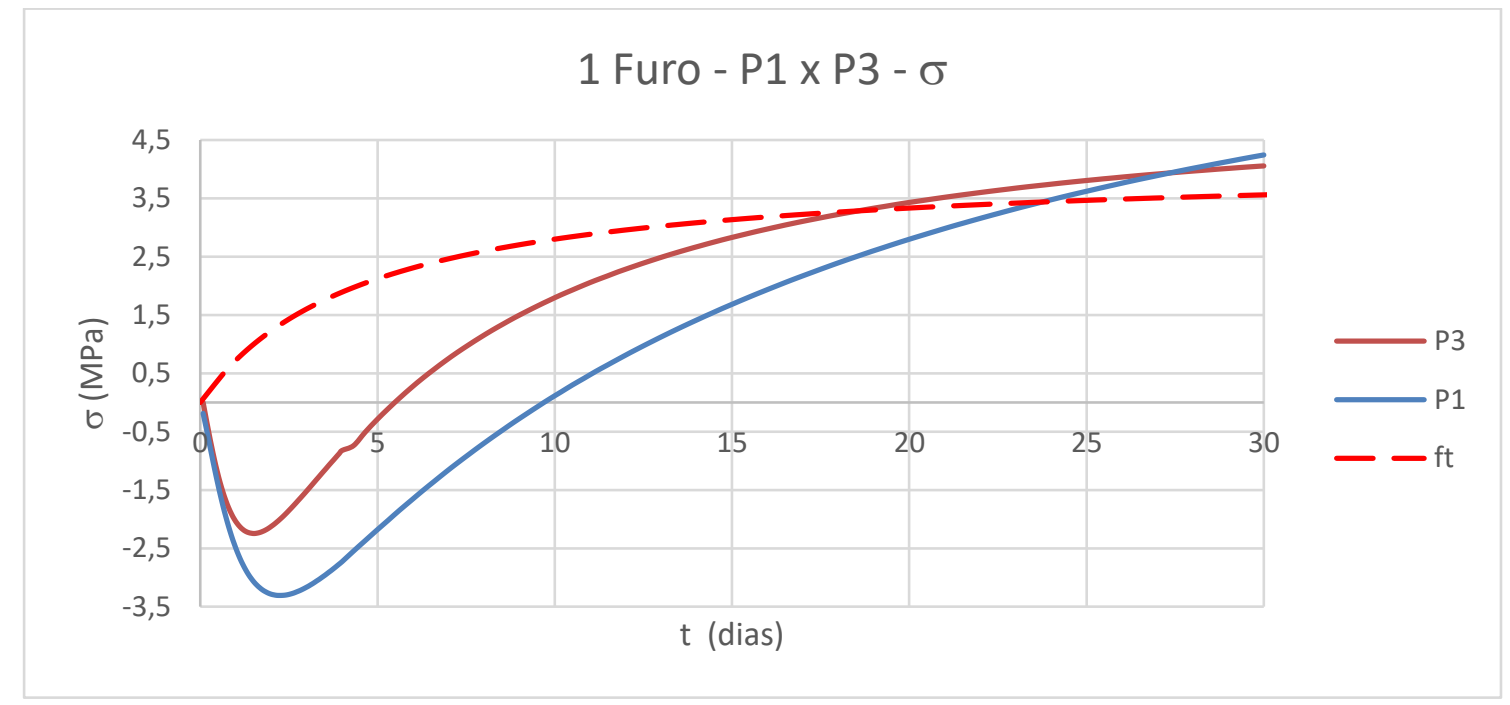

Figura 6.88 - Histórico de tensões dos pontos P1 e P3.

O ponto $\mathrm{P} 2$ está mais próximo ao furo, dentro de sua área de influência, portanto há diferença entre as temperaturas. Estando o ponto fixo, ressalta-se que seu distanciamento para a borda do furo (d) é reduzido com o aumento do raio do furo, Tabela 6.9.

Tabela 6.9 - Distância do ponto P2.

\begin{tabular}{|c|c|c|}
\hline Caso & $\mathrm{d}(\mathrm{m})$ & Representação \\
\hline A & 0,70 & \multirow{8}{*}{ P2 } \\
\hline B & 0,65 & \\
\hline $\mathrm{C}$ & 0,60 & \\
\hline $\mathrm{D}$ & 0,55 & \\
\hline $\mathrm{E}$ & 0,50 & \\
\hline $\mathrm{F}$ & 0,45 & \\
\hline $\mathrm{G}$ & 0,40 & \\
\hline $\mathrm{H}$ & 0,35 & \\
\hline
\end{tabular}


O gráfico da Figura 6.89 mostra os perfis de temperatura para os casos em estudo em P2, quanto maior o raio, menores são suas temperaturas e quanto menor o raio, maiores as temperaturas atingidas. Isso mostra que dentro da área de influência a redução de temperatura é significativa.

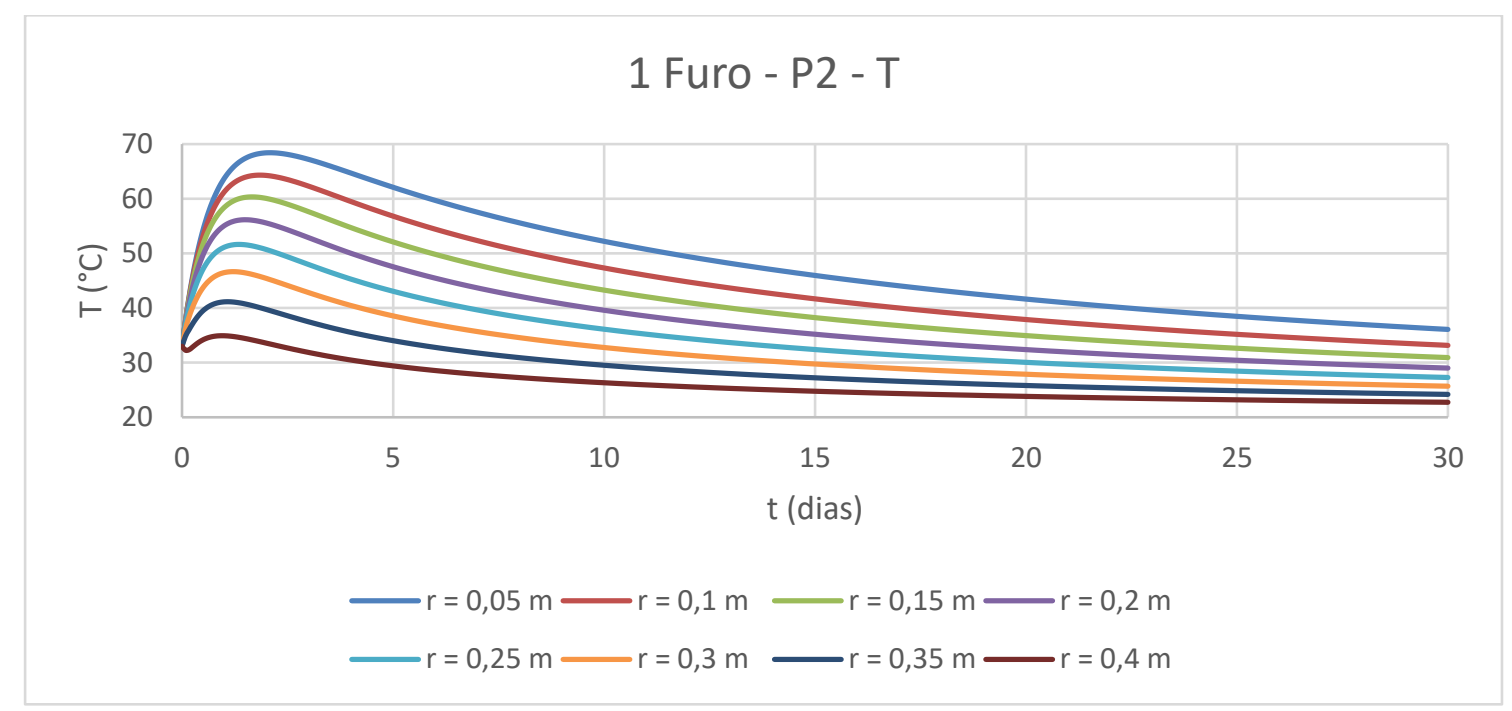

Figura 6.89 - Histórico de temperaturas do ponto P2.

As tensões em P2 podem ser vistas na Figura 6.90. Estas seguem os perfis de temperatura, apresentando maiores tensões para maiores temperaturas. O Caso $\mathrm{H}, \mathrm{r}=0,4 \mathrm{~m}$, tem tensões de tração abaixo de 1,5 MPa, valor praticamente insignificante. A máxima tensão de tração foi obtida para o ponto A, $r=0,05 \mathrm{~m}$, com valor de 4,5 MPa. Nota-se que houve fissuração em $\mathrm{P} 2$ para os Casos $\mathrm{A}, \mathrm{B}, \mathrm{C}$ e $\mathrm{D}$, que possuem raios menores.

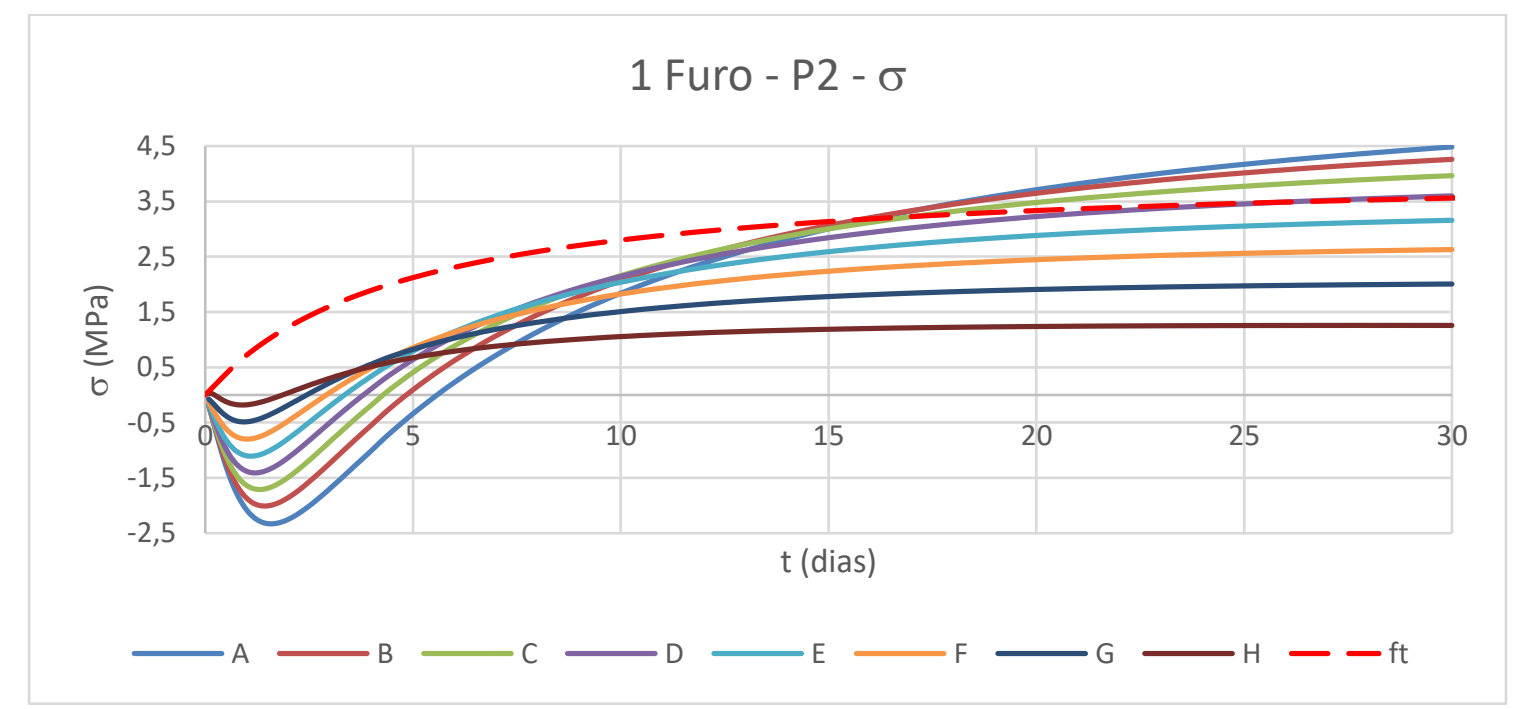

Figura 6.90 - Histórico de tensões do ponto P2. 


\subsubsection{CASO 5.2 - Bloco com quatro furos}

Após a análise com um furo, a fim de visualizar o efeito das áreas de influência, foi modelada a mesma laje com quatro furos com distancias entre os centros de $2,25 \mathrm{~m}$, a partir do ponto central. Um furo fica na extremidade, portanto as temperaturas e tensões foram verificadas em um ponto no meio de dois furos, $\mathrm{P} 1$, e um ponto a $0,5 \mathrm{~m}$ da extremidade direita, $\mathrm{P} 2$, como pode ser observado na Figura 6.91. Para a situação imposta, $a=2,25$ m.

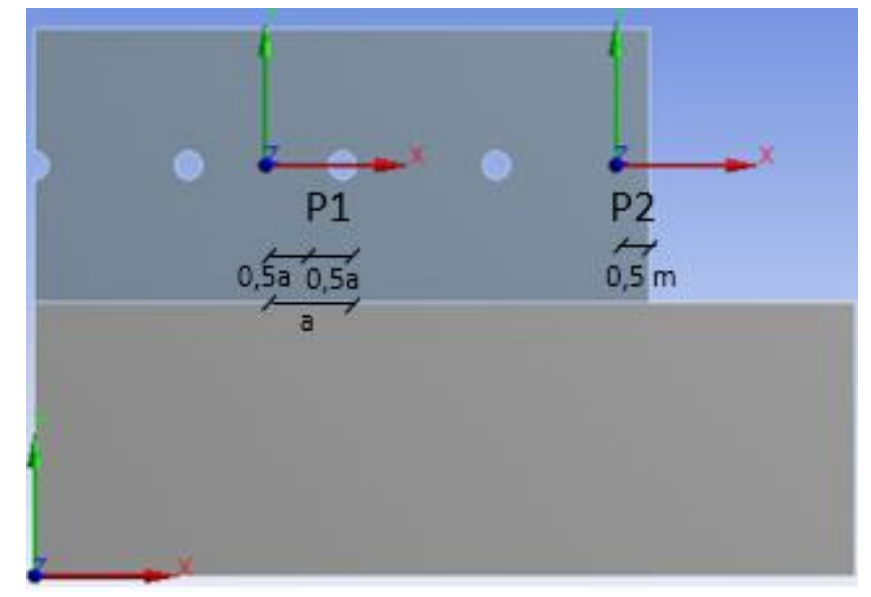

Figura 6.91 - Geometria com quatro furos.

A Tabela 6.10 mostra a denominação de cada caso e as temperaturas máximas atingidas em cada situação, evidenciando a redução da temperatura máxima com o aumento do diâmetro do furo. Ressalta-se que as situações são hipotéticas, por isso se utilizou raios grandes com relação à altura do corpo.

Tabela 6.10 - Definição dos casos analisados.

\begin{tabular}{|l|l|l|}
\hline Caso & $\mathbf{r}(\mathbf{m})$ & $\mathbf{T}_{\max }\left({ }^{\circ} \mathbf{C}\right)$ \\
\hline A & 0,05 & 77,178 \\
\hline B & 0,10 & 76,391 \\
\hline C & 0,15 & 75,652 \\
\hline D & 0,20 & 74,905 \\
\hline E & 0,25 & 74,126 \\
\hline F & 0,30 & 73,314 \\
\hline G & 0,35 & 72,449 \\
\hline H & 0,40 & 71,537 \\
\hline
\end{tabular}


A Figura 6.92 traz as isotermas de temperatura para os casos citados. Observa-se que a máxima temperatura normalmente acontece na região entre o furo da extremidade direita e o contorno, diferindo das máximas entre dois furos. Isso ocorre porque os pontos internos recebem influência de dois furos com temperaturas de $20^{\circ} \mathrm{C}$. Enquanto próximo à extremidade, há a influência de apenas um furo e do contorno, que tem temperatura ambiente de $27^{\circ} \mathrm{C}$. As isotermas são mostradas para o tempo de $210816 \mathrm{~s}$ ou 2,44 dias, com um total de 181646 nós e 45088 elementos para o Caso A, reduzindo proporcionalmente à abertura para os demais casos.
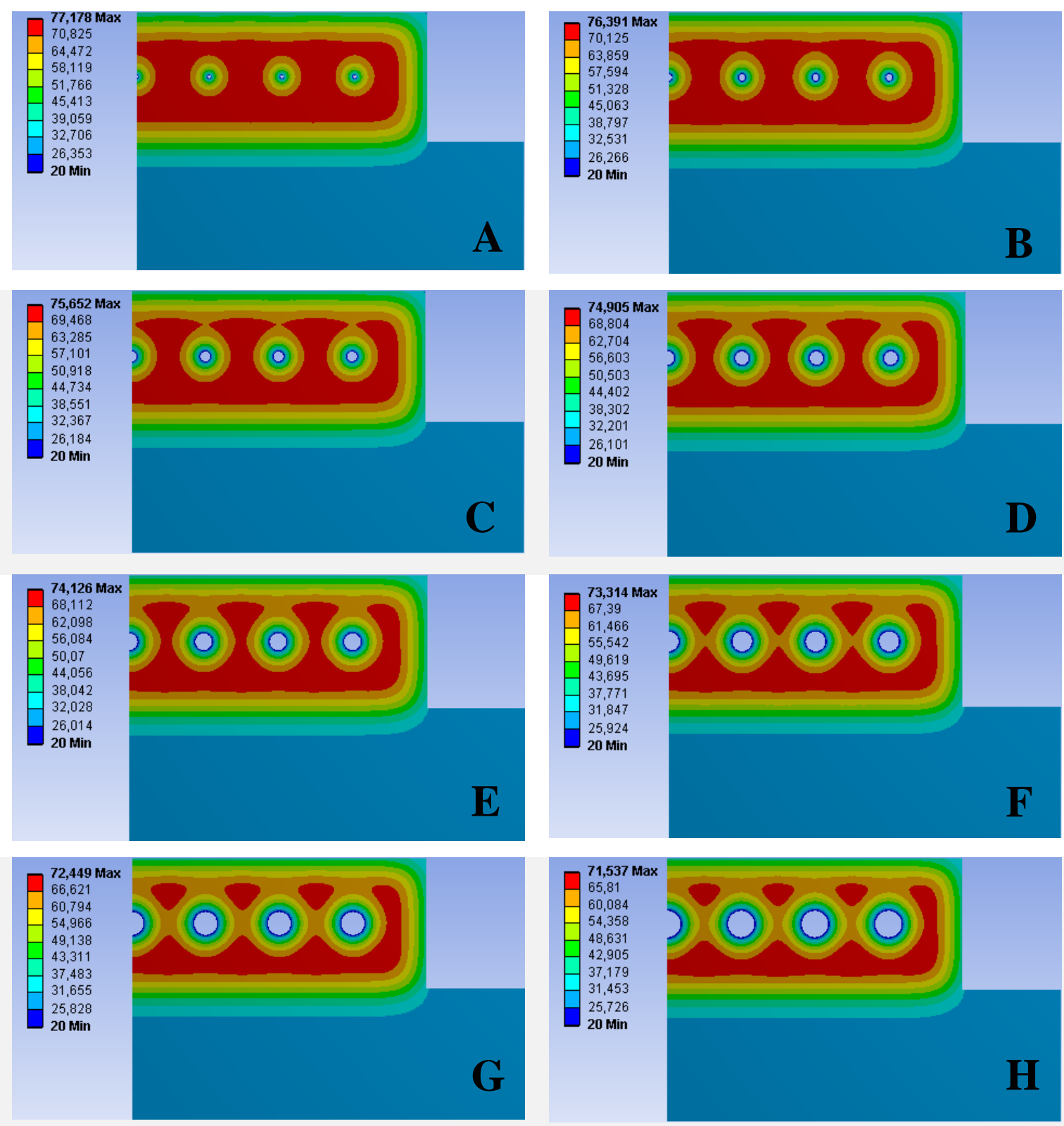

Figura 6.92 - Isotermas para estrutura com quatro furos. 
Na Figura 6.93, percebe-se há diferença entre as temperaturas máximas para os diferentes casos no ponto $\mathrm{P} 1$, a qual aumenta gradativamente com o tempo. Para as máximas atingidas há diferença de aproximadamente $10^{\circ} \mathrm{C}$ entre o menor e o maior raio. No tempo de 7,5 dias esse valor aumenta para $21^{\circ} \mathrm{C}$ de diferença, reduzindo para aproximadamente $7^{\circ} \mathrm{C}$ ao final de 30 dias.

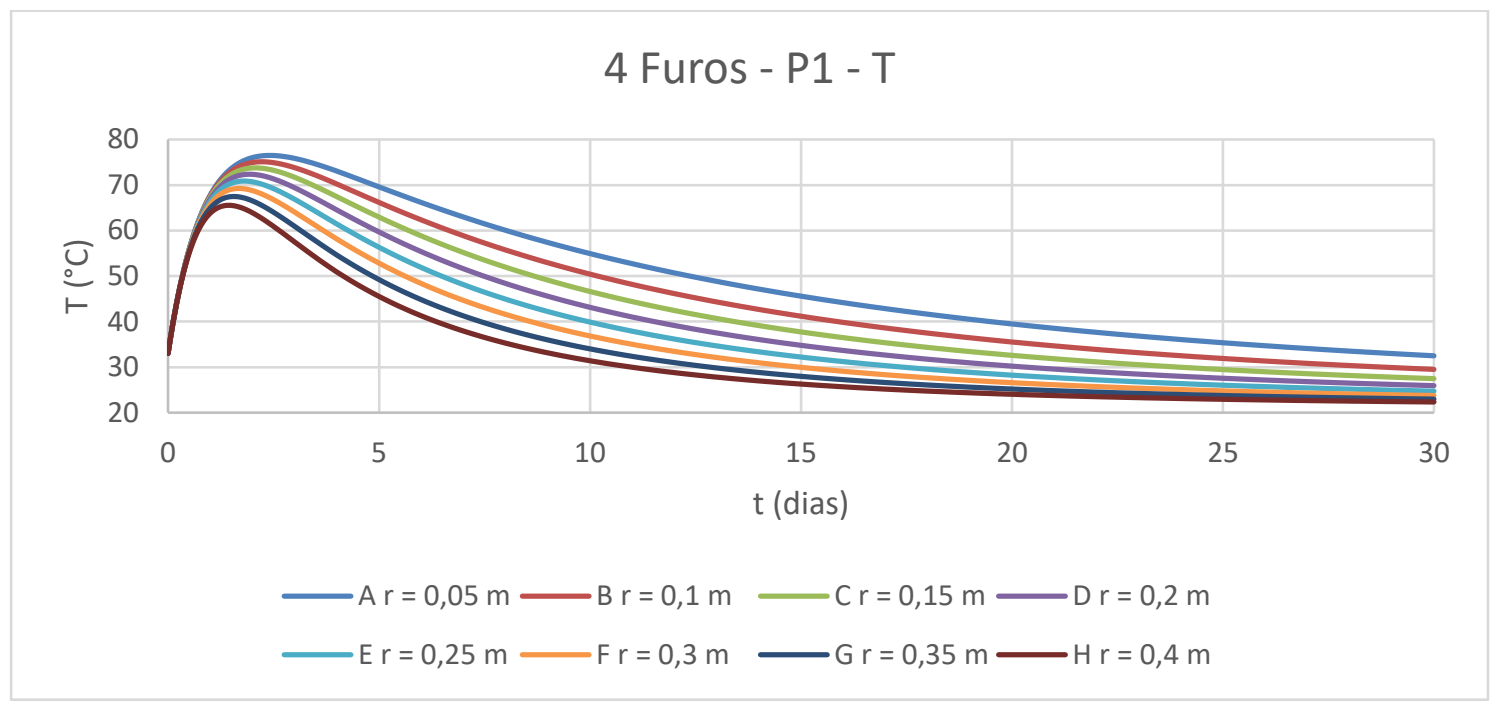

Figura 6.93 - Histórico de temperaturas para estrutura com quatros furos em P1.

As tensões obtidas com os perfis de temperatura da Figura 6.94 evidenciam a baixa diferença entre as tensões máximas nesse ponto. No entanto, para a geometria e quantidade de furos modelados, haveria fissuração em todos os casos. É interessante ressaltar que as tensões obtidas neste caso são maiores que as tensões encontradas quando há a existência de um único furo.

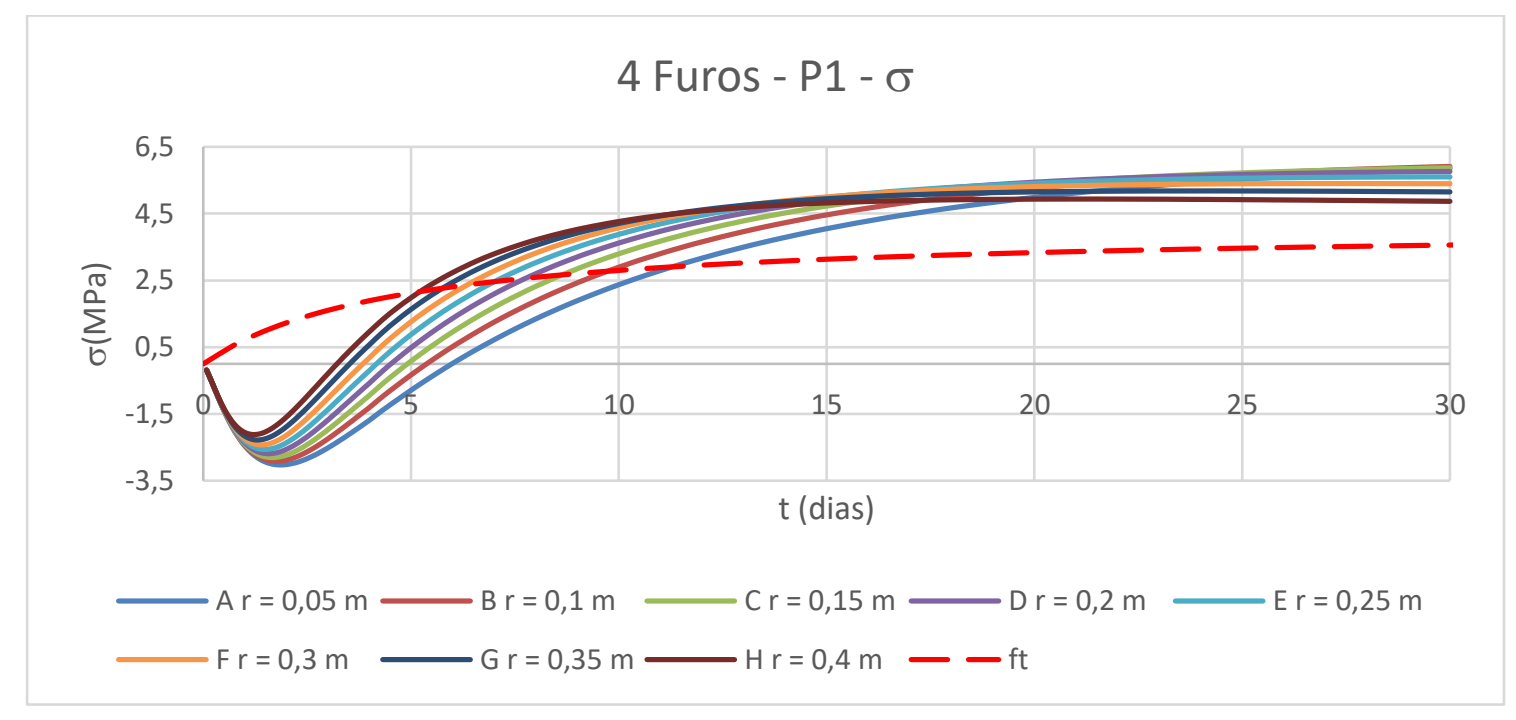

Figura 6.94 - Histórico de tensões para estrutura com quatros furos em P1. 
Para P2, quase não há diferença entre as temperaturas, Figura 6.95, mostrando que são mais influenciadas pelo contorno da superfície que pelo furo.

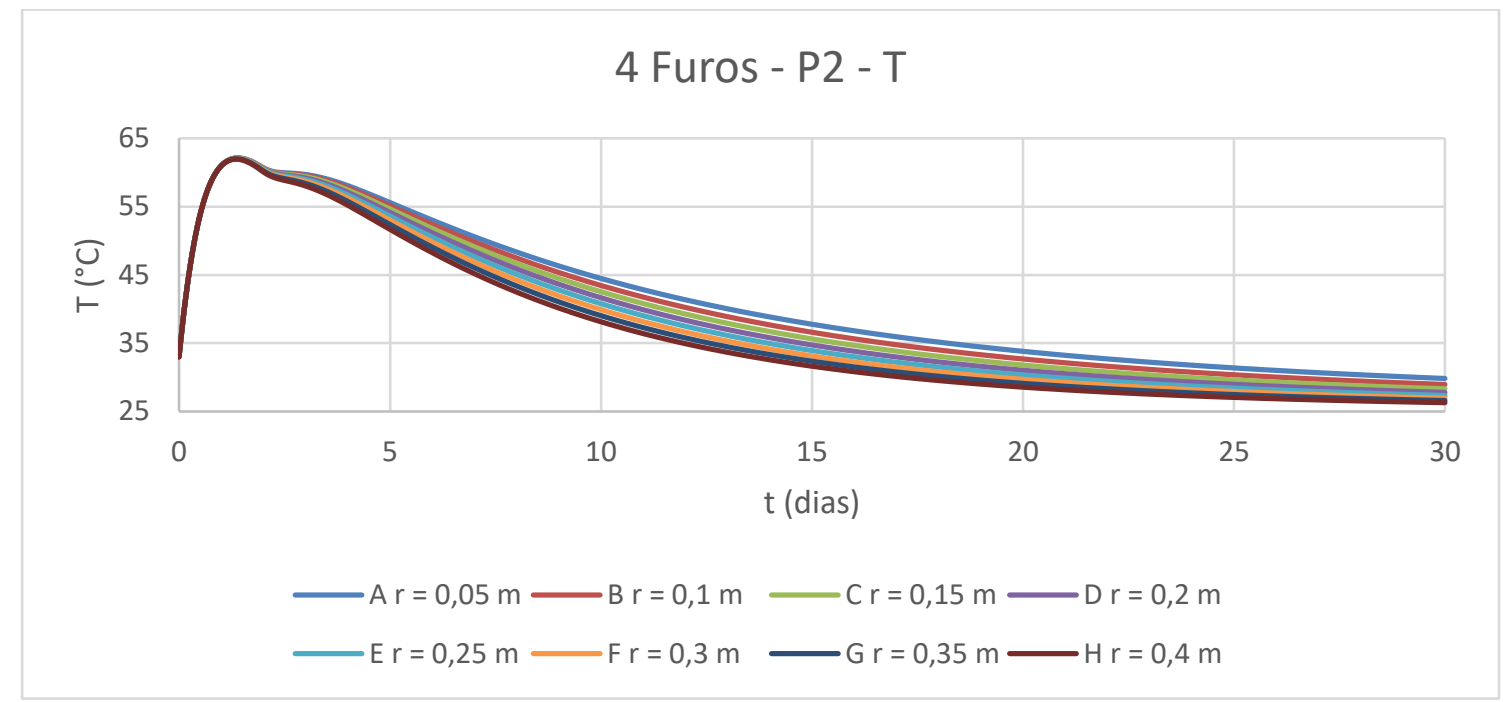

Figura 6.95 - Histórico de temperaturas para estrutura com quatros furos em P2.

As tensões também se modificam no ponto P2, Figura 6.96. As máximas tensões de compressão e tração são equivalentes. Novamente, há fissuração em todos os casos.

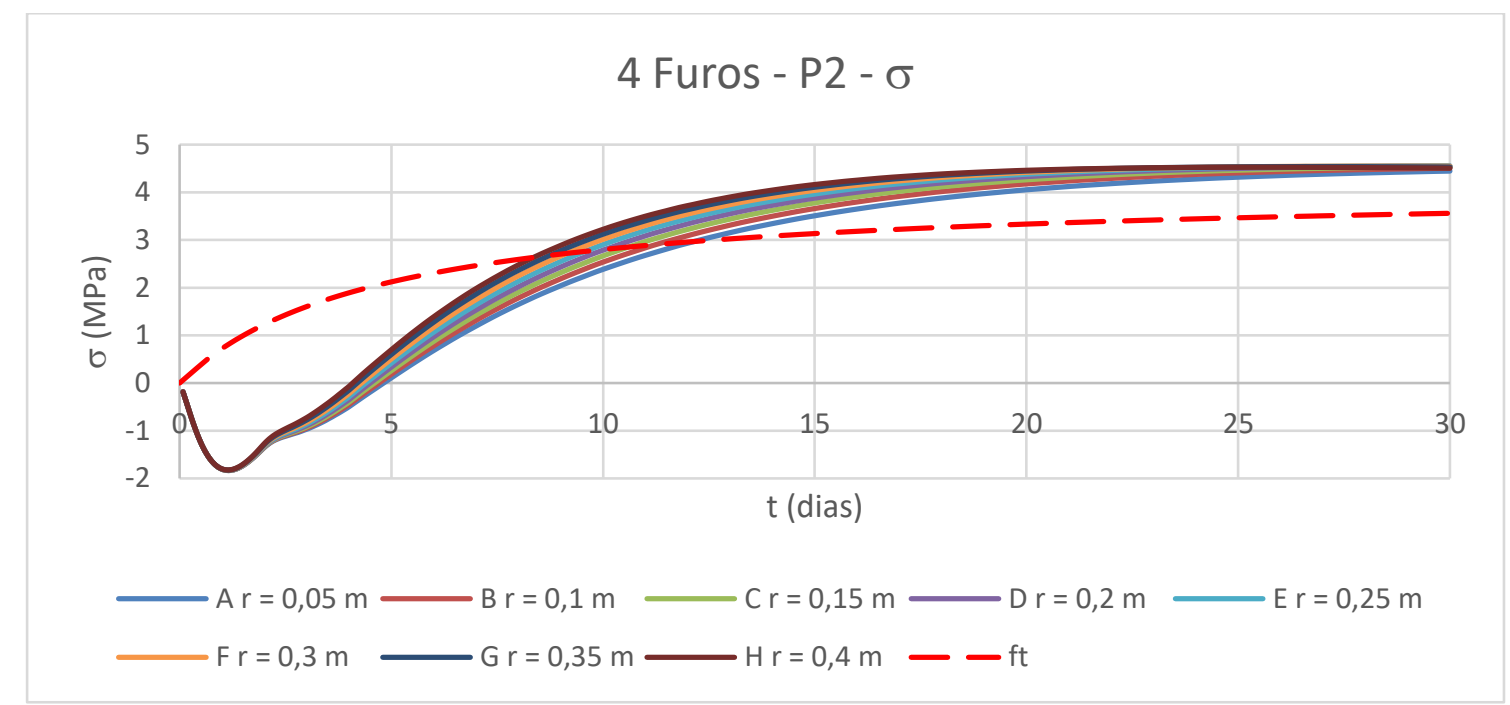

Figura 6.96 - Histórico de temperaturas para estrutura com quatros furos em P1.

Este estudo foi realizado com o intutito de verificar a influencia das temperaturas e tensões impostas com a presença de aberturas em uma estrutura de concreto. no entanto, cabe advertir que se deve preocupar prioritariamente com as tensões de tração, buscando alternativas que eliminem essa degradação, como não foi o caso do bloco apresentado. 


\subsection{CASO 6 - BARRAGEM DE GRAVIDADE}

O último caso analisado neste trabalho refere-se a análise da simulação de uma barragem construída com concreto massa. Variou-se a geometria, portanto, na Figura 6.97, são mostradas as dimensões algebricamente, as quais serão definidas para cada caso. São destacadas as nomenclaturas das camadas, sendo a primeira definida como $\mathrm{C} 1$, seguida da segunda, C2, e assim sucessivamente até a última. Foi utilizada a massa específica de 2393,0 $\mathrm{kg} / \mathrm{m}^{3}$, condutividade térmica de $2,6 \mathrm{~W} / \mathrm{m}^{\circ} \mathrm{C}$ e calor específico de $898,5 \mathrm{~J} / \mathrm{kg}^{\circ} \mathrm{C}$ para a modelagem.

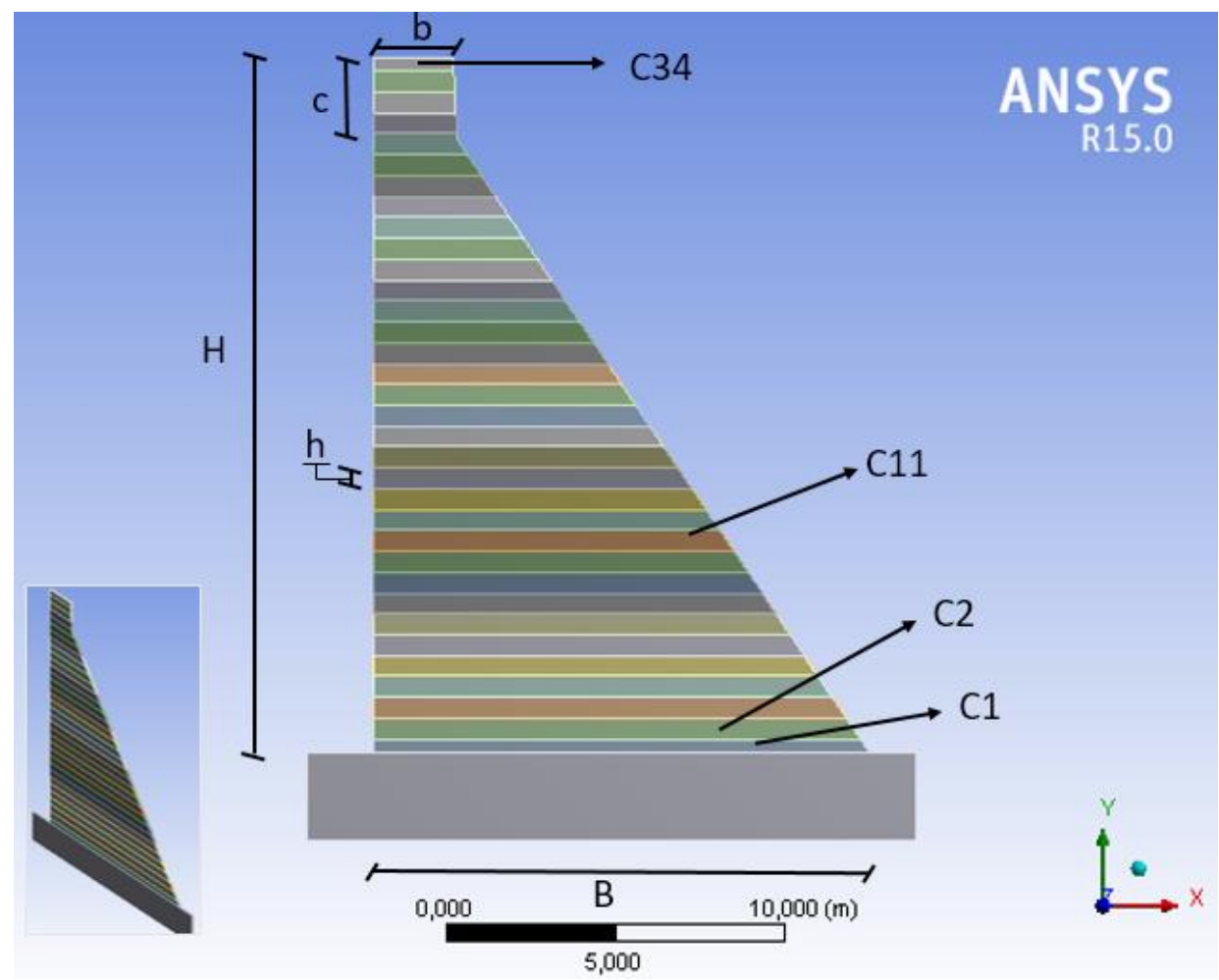

Figura 6.97 - Geometria da barragem.

A Figura 6.98 mostra o exemplo da variação das malhas utilizadas nos exemplos. Para a fundação, a malha utilizada é maior por não necessitar de grande precisão nos resultados destes elementos. Neste modelo, $\mathrm{C} 1$ é menor que $\mathrm{C} 2$, portanto, tem uma malha mais refinada. 


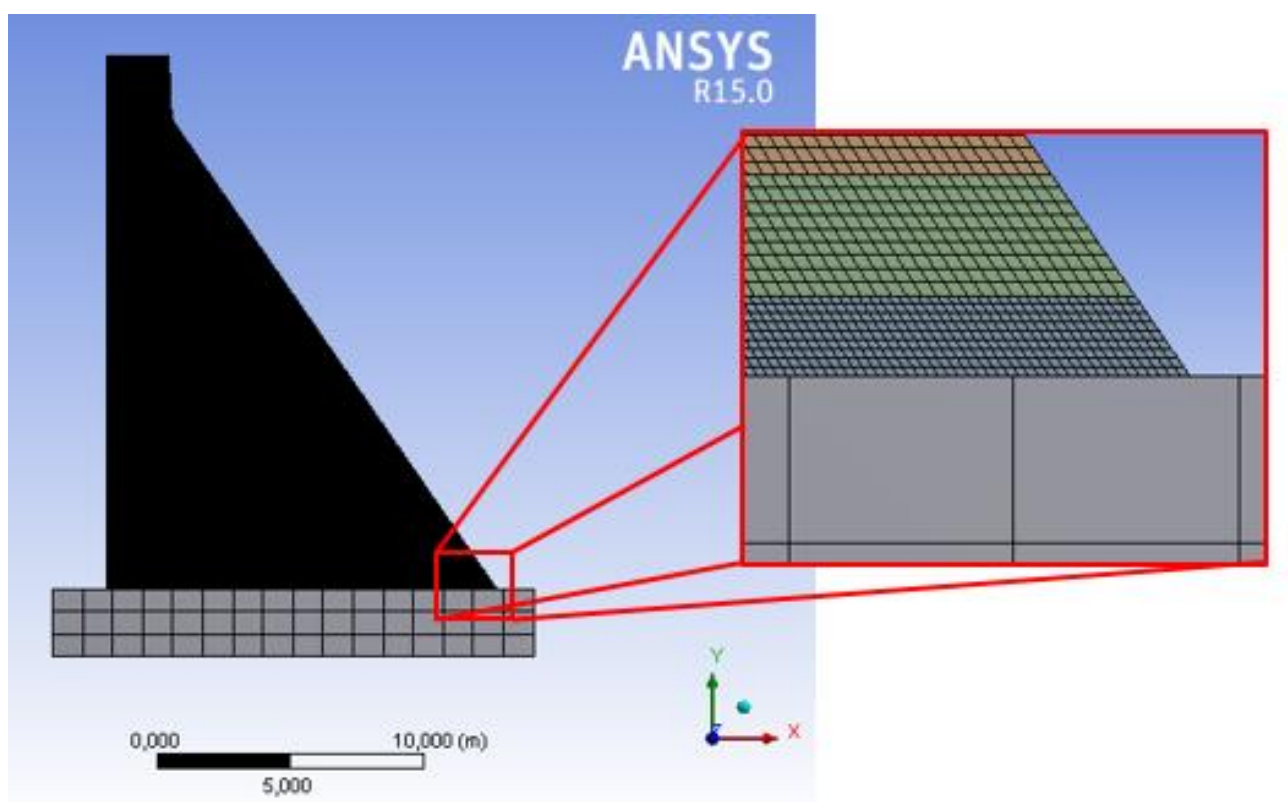

Figura 6.98 - Modelo de malha utilizada.

Foram analisados vários casos, mostrados de forma resumida na Tabela 6.11. Para melhor entendimento e visualização desta, a Figura 6.99 mostra o que variou de uma simulação para outra de forma progressiva.

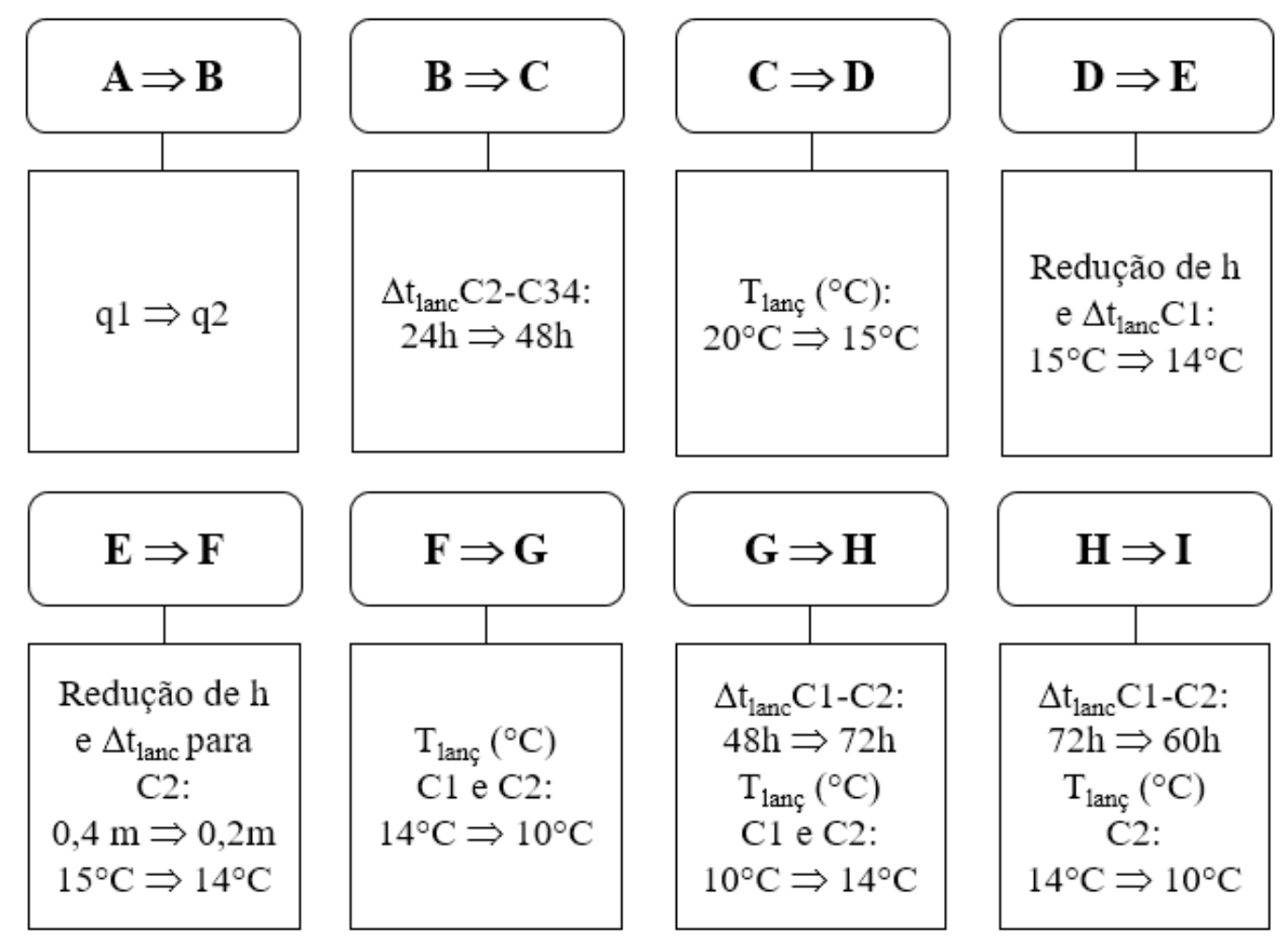

Figura 6.99 - Variações nas análises. 
Tabela 6.11 - Casos de barragens analisados.

\begin{tabular}{|c|c|c|c|c|c|c|c|c|c|c|c|c|c|c|c|c|c|c|}
\hline CASO & \multicolumn{2}{|c|}{$\mathbf{A}$} & \multicolumn{2}{|c|}{ B } & \multicolumn{2}{|c|}{$\mathrm{C}$} & \multicolumn{2}{|c|}{ D } & \multicolumn{2}{|c|}{$\mathbf{E}$} & \multicolumn{2}{|l|}{$\mathbf{F}$} & \multicolumn{2}{|c|}{ G } & \multicolumn{2}{|c|}{$\mathbf{H}$} & \multicolumn{2}{|l|}{ I } \\
\hline $\mathbf{N}$ & \multicolumn{2}{|c|}{34} & \multicolumn{2}{|c|}{34} & \multicolumn{2}{|c|}{34} & \multicolumn{2}{|c|}{34} & \multicolumn{2}{|c|}{$66^{*}$} & \multicolumn{2}{|c|}{$66^{*}$} & \multicolumn{2}{|c|}{$66^{*}$} & \multicolumn{2}{|c|}{$66^{*}$} & \multicolumn{2}{|c|}{$66^{*}$} \\
\hline \multirow[b]{2}{*}{$\mathbf{h}(\mathbf{m})$} & $\mathrm{C} 1$ & 0,4 & $\mathrm{C} 1$ & 0,4 & $\mathrm{C} 1$ & 0,4 & $\mathrm{C} 1$ & 0,4 & $\mathrm{C} 1$ & 0,2 & $\mathrm{C} 1-\mathrm{C} 2$ & 0,2 & $\mathrm{C} 1-\mathrm{C} 2$ & 0,2 & $\mathrm{C} 1$ & 0,2 & $\mathrm{C} 1$ & 0,2 \\
\hline & $\begin{array}{l}\mathrm{C} 2- \\
\mathrm{C} 34\end{array}$ & 0,6 & $\begin{array}{l}\text { C2 - } \\
\text { C34 }\end{array}$ & 0,6 & $\begin{array}{l}\text { C2 - } \\
\text { C34 }\end{array}$ & 0,6 & $\begin{array}{l}\text { C2 - } \\
\text { C34 }\end{array}$ & 0,6 & $\begin{array}{l}\mathrm{C} 2- \\
\mathrm{C} 34\end{array}$ & 0,4 & $\begin{array}{l}\text { C3 - } \\
\text { C34 }\end{array}$ & 0,4 & $\begin{array}{l}\text { C3 - } \\
\text { C34 }\end{array}$ & 0,4 & $\begin{array}{l}\text { C2 - } \\
\text { C34 }\end{array}$ & 0,4 & $\begin{array}{l}\mathrm{C} 2- \\
\mathrm{C} 34\end{array}$ & 0,4 \\
\hline H (m) & \multicolumn{2}{|c|}{20} & \multicolumn{2}{|c|}{20} & \multicolumn{2}{|c|}{20} & \multicolumn{2}{|c|}{20} & \multicolumn{2}{|c|}{16} & \multicolumn{2}{|c|}{16} & \multicolumn{2}{|c|}{16} & \multicolumn{2}{|c|}{16} & \multicolumn{2}{|c|}{16} \\
\hline B (m) & \multicolumn{2}{|c|}{14,63} & \multicolumn{2}{|c|}{14,63} & 14 , & & 14 & & 1 & & 12 & & 12 & & 12 & & 12 & \\
\hline b (m) & 2,3 & & 2, & & 2,3 & & 2, & & 1 , & & 1,86 & & 1,8 & & 1,8 & & 1,8 & \\
\hline $\mathbf{c}(\mathbf{m})$ & 2,3 & & 2, & & 2,3 & & 2, & & 1, & & 1,9 & & 1,9 & & 1,9 & & 1,9 & \\
\hline & $\mathrm{C} 1$ & 0,05 & $\mathrm{C} 1$ & 0,05 & $\mathrm{C} 1$ & 0,05 & $\mathrm{C} 1$ & 0,025 & $\mathrm{C} 1$ & 0,025 & $\mathrm{C} 1-\mathrm{C} 2$ & 0,025 & $\mathrm{C} 1$ & 0,025 & $\mathrm{C} 1$ & 0,025 & $\mathrm{C} 1$ & 0,025 \\
\hline Malha & $\begin{array}{l}\mathrm{C} 2- \\
\mathrm{C} 34\end{array}$ & 0,08 & $\begin{array}{l}\text { C2 - } \\
\text { C34 }\end{array}$ & 0,08 & $\begin{array}{l}\text { C2 - } \\
\text { C34 }\end{array}$ & 0,08 & $\begin{array}{l}\mathrm{C} 2- \\
\mathrm{C} 34\end{array}$ & 0,05 & $\begin{array}{l}\text { C2 - } \\
\text { C34 }\end{array}$ & 0,075 & $\begin{array}{l}\text { C3 - } \\
\text { C34 }\end{array}$ & 0,075 & $\begin{array}{l}\mathrm{C} 2- \\
\mathrm{C} 34\end{array}$ & 0,075 & $\begin{array}{l}\text { C2 - } \\
\text { C34 }\end{array}$ & 0,075 & $\begin{array}{l}\mathrm{C} 2- \\
\mathrm{C} 34\end{array}$ & 0,075 \\
\hline $\mathbf{N}^{\circ}$ nós & 548 & & 548 & & 548 & & 548 & & 5338 & & 58266 & & 54888 & & 54888 & & 5488 & $87 *$ \\
\hline $\mathbf{N}^{\circ}$ Elementos & 230 & & 230 & & 230 & & 230 & & 2227 & $94 *$ & 23632 & & 2300 & & 23003 & & 2300 & $35^{*}$ \\
\hline$\Delta \mathrm{t}(\mathrm{h})$ & 10 & & 12 & & 18 & & 15 , & & 30 , & & 21,5 & & 8,25 & & 18,5 & & 11,5 & \\
\hline & $\mathrm{C} 1$ & 48 & $\mathrm{C} 1$ & 48 & $\mathrm{C} 1$ & 48 & $\mathrm{C} 1$ & 48 & $\mathrm{C} 1$ & 48 & $\mathrm{C} 1$ & 48 & $\mathrm{C} 1-\mathrm{C} 2$ & 48 & $\mathrm{C} 1-\mathrm{C} 2$ & 72 & $\begin{array}{c}\mathrm{C} 1- \\
\mathrm{C} 2\end{array}$ & 60 \\
\hline$\Delta$ tlanc & $\begin{array}{l}\mathrm{C} 2- \\
\mathrm{C} 34\end{array}$ & 24 & $\begin{array}{l}\mathrm{C} 2- \\
\mathrm{C} 34 \\
\end{array}$ & 24 & $\begin{array}{l}\mathrm{C} 2- \\
\mathrm{C} 34\end{array}$ & 48 & $\begin{array}{l}\mathrm{C} 2- \\
\mathrm{C} 34 \\
\end{array}$ & 48 & $\begin{array}{l}\mathrm{C} 2- \\
\mathrm{C} 34\end{array}$ & 48 & $\begin{array}{l}\mathrm{C} 2- \\
\mathrm{C} 34 \\
\end{array}$ & 48 & $\begin{array}{l}\text { C3 - } \\
\text { C34 }\end{array}$ & 48 & $\begin{array}{l}\text { C3 - } \\
\text { C34 }\end{array}$ & 48 & $\begin{array}{l}\text { C3 - } \\
\text { C34 }\end{array}$ & 48 \\
\hline & $\mathrm{C} 1$ & 20 & $\mathrm{C} 1$ & 20 & $\mathrm{C} 1$ & 20 & $\mathrm{C} 1$ & 15 & $\mathrm{C} 1$ & 14 & $\mathrm{C} 1-\mathrm{C} 2$ & 14 & $\mathrm{C} 1$ - C2 & 10 & $\mathrm{C} 1-\mathrm{C} 2$ & 14 & $\mathrm{C} 1 / \mathrm{C} 2$ & $14 / 10$ \\
\hline $\mathbf{T}_{\text {lanç }}\left({ }^{\circ} \mathbf{C}\right)$ & $\begin{array}{l}\text { C2 - } \\
\text { C34 }\end{array}$ & 20 & $\begin{array}{l}\text { C2 - } \\
\text { C34 }\end{array}$ & 20 & $\begin{array}{l}\mathrm{C} 2- \\
\mathrm{C} 34\end{array}$ & 20 & $\begin{array}{l}\mathrm{C} 2- \\
\mathrm{C} 34\end{array}$ & 15 & $\begin{array}{l}\mathrm{C} 2- \\
\mathrm{C} 34\end{array}$ & 15 & $\begin{array}{l}\text { C3 - } \\
\text { C34 }\end{array}$ & 15 & $\begin{array}{l}\text { C3 - } \\
\text { C34 }\end{array}$ & 15 & $\begin{array}{l}\text { C3 - } \\
\text { C34 }\end{array}$ & 15 & $\begin{array}{l}\mathrm{C} 3- \\
\mathrm{C} 34\end{array}$ & 15 \\
\hline $\mathbf{q}$ & $\mathrm{q}$ & & $\mathrm{q}$ & & $\mathrm{q}^{\prime}$ & & $q$ & & $\mathrm{q}^{\prime}$ & & $\mathrm{q} 1$ & & $\mathrm{q} 2$ & & $\mathrm{q} 2$ & & $\mathrm{q} 2$ & \\
\hline $\mathbf{T}_{\max }\left({ }^{\circ} \mathbf{C}\right)$ & 6 & & 47 & & 6 & & 40 & & 37 , & & 38,6 & & 28,3 & & 35,2 & & 35,9 & \\
\hline $\begin{array}{l}\mathrm{q} 1=2150000 \mathrm{x} \\
\mathrm{q} 2=2377945 \mathrm{x}\end{array}$ & $\begin{array}{l}4 \times 49 \\
4 \times 36\end{array}$ & $\begin{array}{l}32^{2,831} \\
88^{2,05}\end{array}$ & $\begin{array}{l}, 831 \times \\
05 \times \mathrm{t}\end{array}$ & $\begin{array}{l}831 /(4 \\
(362\end{array}$ & $\begin{array}{l}332^{2,831} \\
2,05+t^{2}\end{array}$ & $2,831)^{2}$ & & & & & & & & & & & & \\
\hline
\end{tabular}


As Figuras 6.100 a, b, c apresentam as isotermas de temperatura para uma barragem com $34,37 \mathrm{~h}, 36,86 \mathrm{~h}$ e $39,34 \mathrm{~h}$, respectivamente. O intuito é mostrar que o resfriamento é mais lento internamente, na região próxima ao centro de gravidade do modelo, no núcleo da barragem. Em Coelho et al (2016b) pode ser visto a variação térmica para outros modelos de barragens.

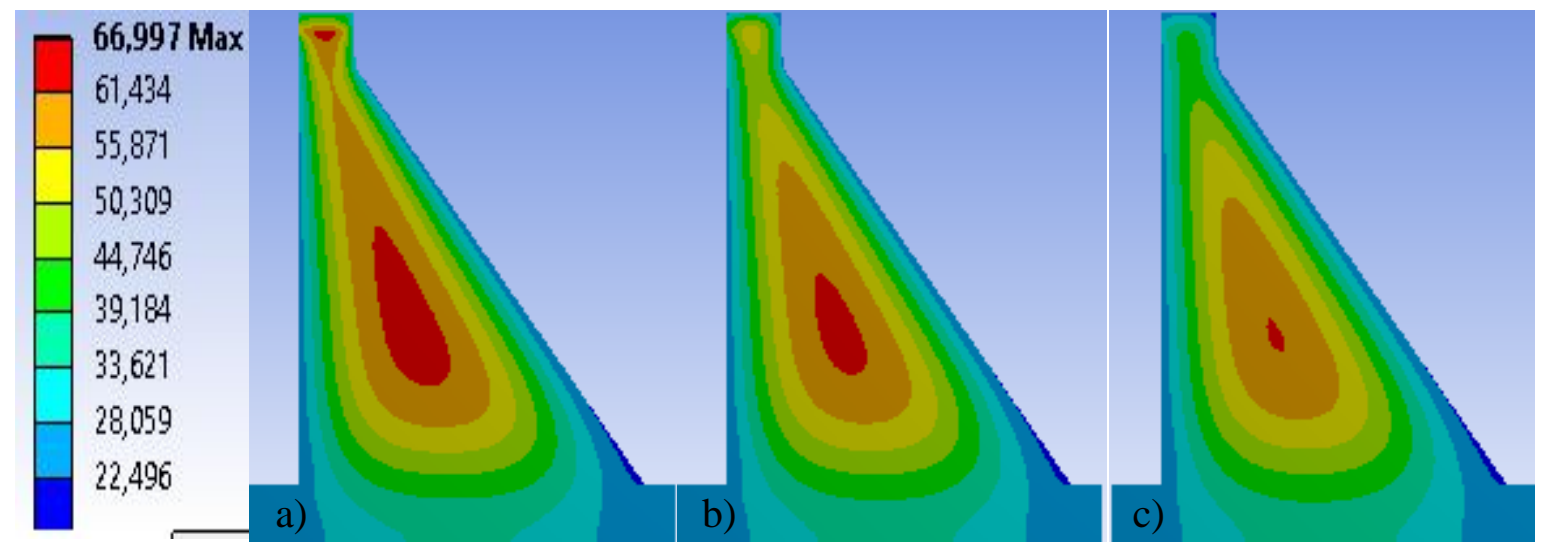

Figura 6.100 - Isotermas de temperatura para diferentes idades da barragem: a) 34,37 h; b) $36,86 \mathrm{~h}$; c) $39,34 \mathrm{~h}$.

Como mostrado na Figura 6.100 e visto nas análises anteriores, mesmo que atinjam a máxima temperatura, o resfriamento das camadas é mais rápido próximo a superfície. Para a barragem, que tem geometria diferenciada, o fenômeno se repete, como pode ser observado na Figura 6.101, que apresenta o perfil de temperaturas para todas as camadas do Caso 6-A, verificadas sempre para a região central da camada. Há um destaque, uma figura interna menor, para a camada onze, TC11, mostrando que devido ao seu posicionamento o seu resfriamento é lento e, portanto, foi uma das camadas estudadas. 
Caso A
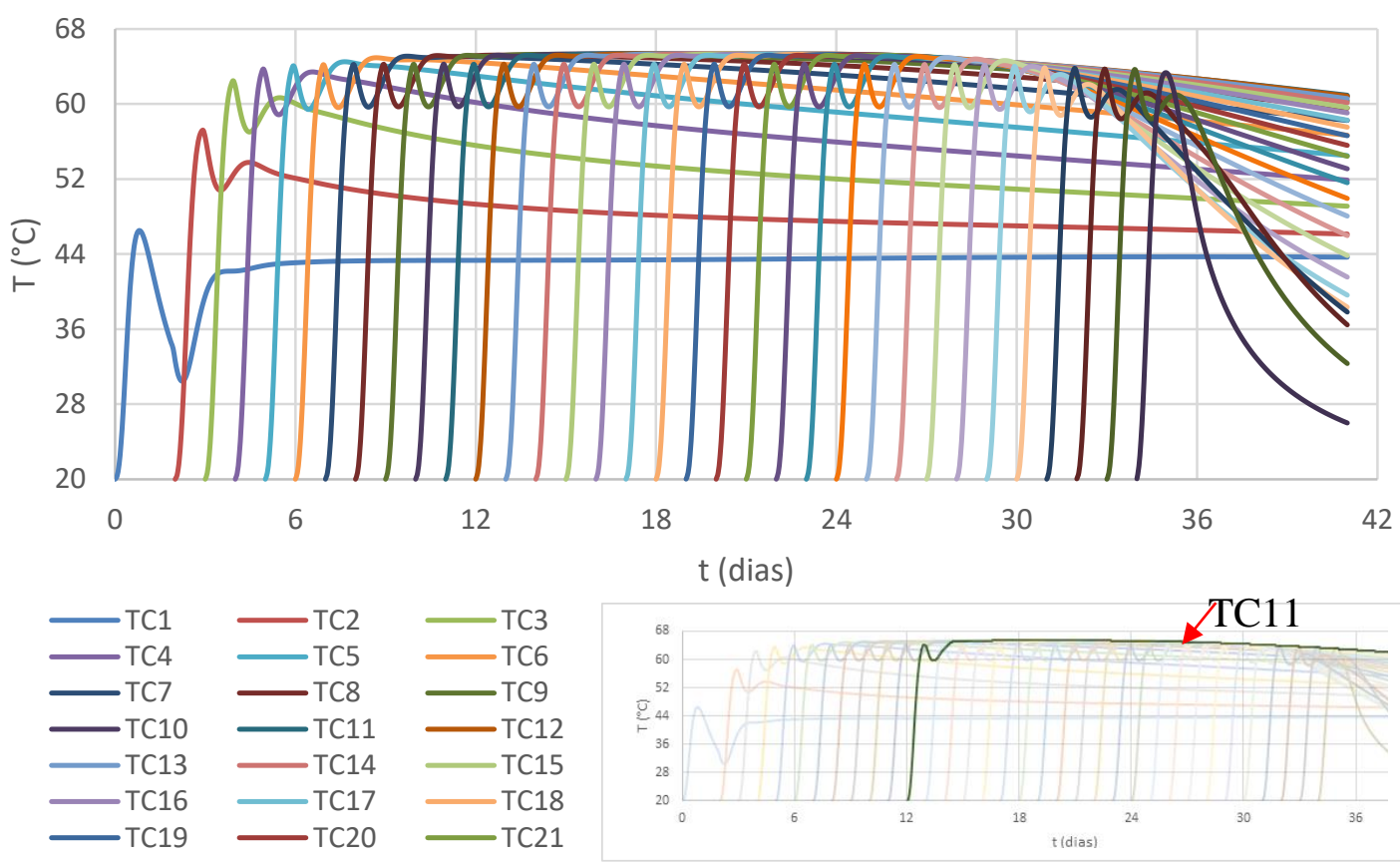

Figura 6.101 - Temperaturas para o Caso 6-A.

Em todas os casos foram analisadas a primeira camada, Figura 6.102. As simulações são processadas desconsiderando o comprimento da estrutura, o qual é considerado nas tensões térmicas através do coeficiente de restrição. Foram adotadas as hipóteses mostradas na Tabela 6.12. O método de fluência adotado foi o USBR, com os parâmetros utilizados no caso do muro.

Tabela 6.12 - Coeficientes de restrição utilizados na barragem.

\begin{tabular}{|c|c|c|}
\hline Nomenclatura & $\mathrm{L} / \mathrm{H}$ & $\mathrm{k}_{\mathrm{r}}$ (ACI 207.2R, 2007) \\
\hline $\mathrm{k}_{\mathrm{r}} 1$ & 20 & 0,905 \\
\hline $\mathrm{k}_{\mathrm{r}} 2$ & 10 & 0,870 \\
\hline $\mathrm{k}_{\mathrm{r}} 3$ & 5 & 0,685 \\
\hline $\mathrm{k}_{\mathrm{r}} 4$ & 2 & 0,330 \\
\hline
\end{tabular}



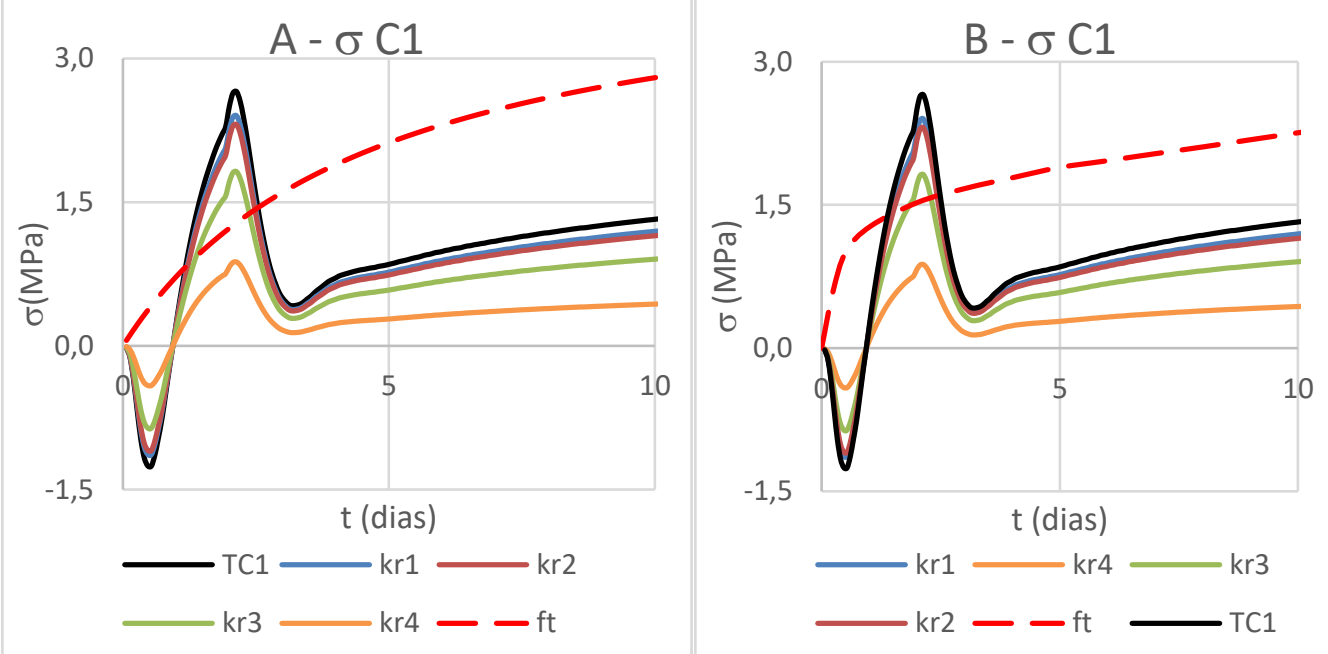

$-1,5$
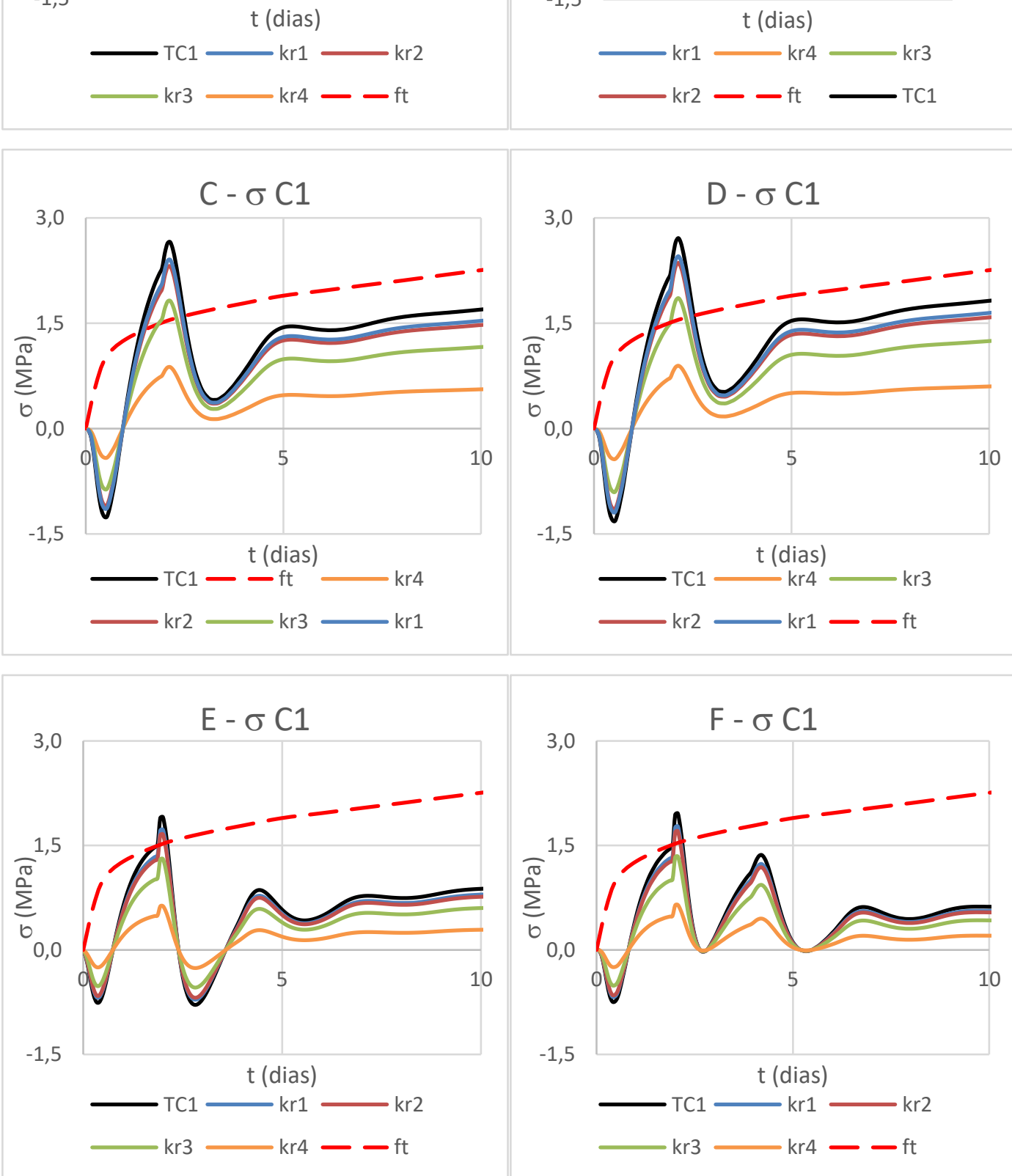


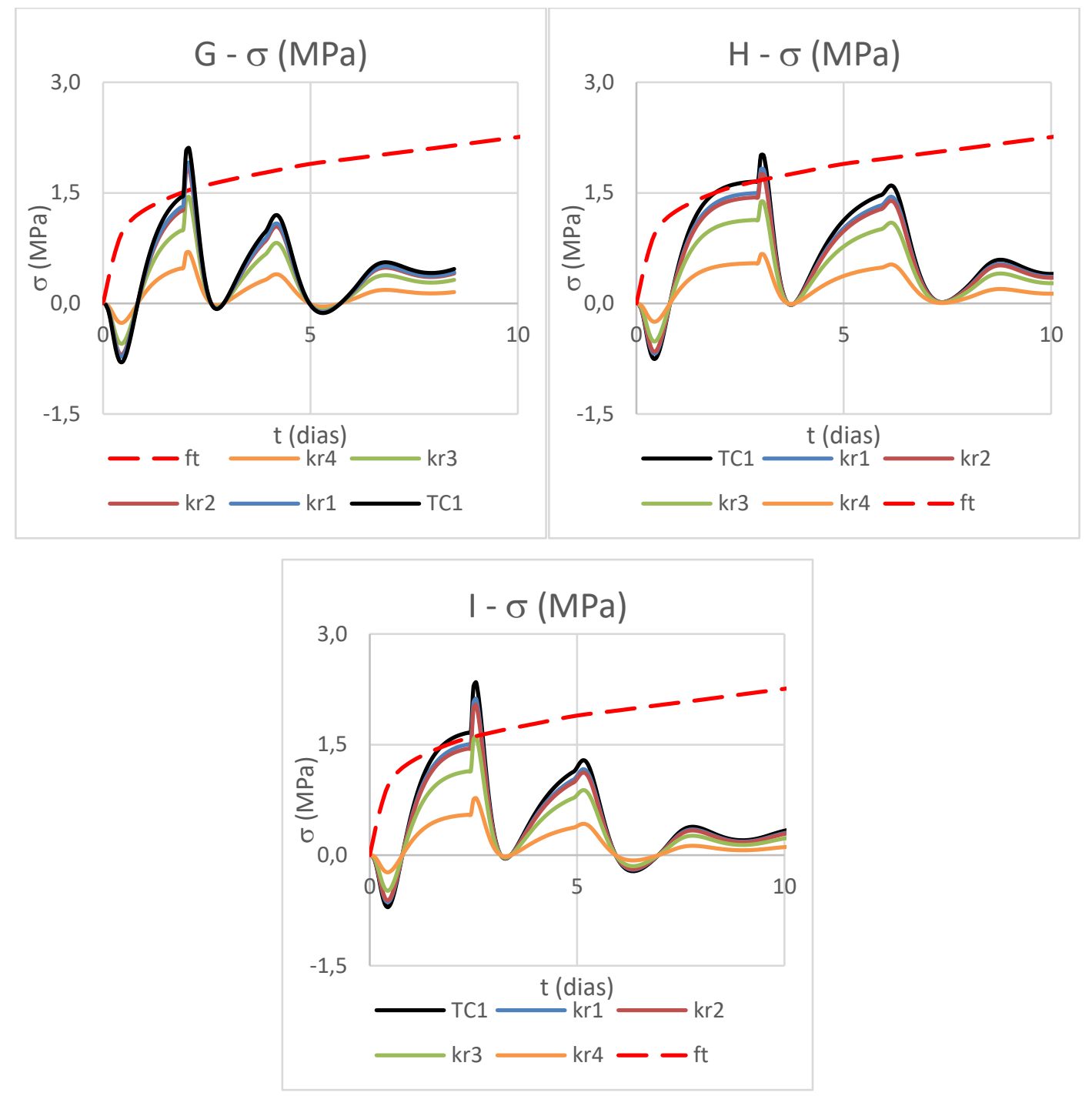

Figura 6.102 - Tensões para $\mathrm{C} 1$ das estruturas analisadas.

Para os casos e condições analisados, a primeira camada é bastante crítica pois, normalmente, é construída sobre fundação rígida, portanto, requer uma maior cautela na sua execução.

Na prática é costume a utilização de concretos com maior capacidade de deformação face à restrição e menores espessuras, com agregados menores e mais pasta nas primeiras camadas. Ressalta-se também que a temperatura da água de cura, quando é utilizada, aumenta muito em virtude da temperatura do concreto. ${ }^{1}$

1 Informação fornecida pelo professor DSc. Vladimir A. Paulon (examinador externo) na defesa desta tese, em dezembro de 2016. 
Nas situações verificadas, houve fissuração para todos os casos com o coeficiente de restrição $\mathrm{k}_{\mathrm{r}} 1$. Apenas no Caso $\mathrm{H}$, poderia haver uma relação $\mathrm{L} / \mathrm{H}$ maior, igual a 10 , correspondente a $\mathrm{k}_{\mathrm{r}}$ 2. Nos Casos E, F, G, H, I, poderia se usar $\mathrm{k}_{\mathrm{r}} 3$. E para os Casos A, B, C e D, apenas a situação mais favorável poderia ser aderida, ou seja, com o comprimento máximo igual ao dobro da altura.

Com isso percebe-se a influência do coeficiente de restrição, ou melhor da relação entre o comprimento e a altura da estrutura. Nota-se que para uma fundação rígida, quando menor L/H, menor a probabilidade de fissuração.

Entre A e B, houve mudança da curva de geração de calor simulando um concreto com menor elevação da temperatura adiabática. Entre os dois casos percebe-se a importância da escolha de um concreto com menor geração de calor, com uma diferença de aproximadamente $20^{\circ} \mathrm{C}$ nas máximas temperaturas das camadas. Essa redução é percebida também nas tensões, porém continuam ultrapassando a capacidade resistiva do concreto, exceto para $\mathrm{L} / \mathrm{H}=2$.

Para as variações da espessura de $\mathrm{C} 1$, notou-se quanto mais espessa aumenta-se as tensões de tração, atingindo facilmente a capacidade resistiva do concreto. A redução da temperatura de lançamento do concreto também proporciona menores tensões, menor risco de fissuração, como pode ser notado do Caso D para o E. Nas situações em que não houve fissura, as temperaturas de lançamento das camadas iniciais foram reduzidas.

O intervalo de lançamento das camadas também altera as condições de tração, pois havendo mais tempo, a camada acelera o resfriamento diminuindo os riscos de atingir tensões de tração elevadas, como o Caso H, com intervalo de lançamento de $72 \mathrm{~h}$ para lançamento de $\mathrm{C} 2$ e C3.

Além de C1, foram também examinadas as camadas C2 e C11. Esta última foi escolhida por situar-se na região mais crítica da estrutura e por ter um resfriamento lento, como pode ser visualizado na Figura 6.101, e por já ter sido demonstrado que essas características colaboram para as maiores tensões de tração no corpo. 
A partir de C2, as tensões são multiplicadas também pelo coeficiente da fundação, agora considerada flexível, de valor 0,5 , por razões indicadas no início do capitulo. No primeiro estudo, Caso A, comprovou-se que as tensões para C2 são menores que para C11, deste modo, para os outros casos C2 não foi investigada. A Figura 6.103, expõe as tensões em C2 e constata-se que não haveria fissuração em nenhuma das relações L/H consideradas.

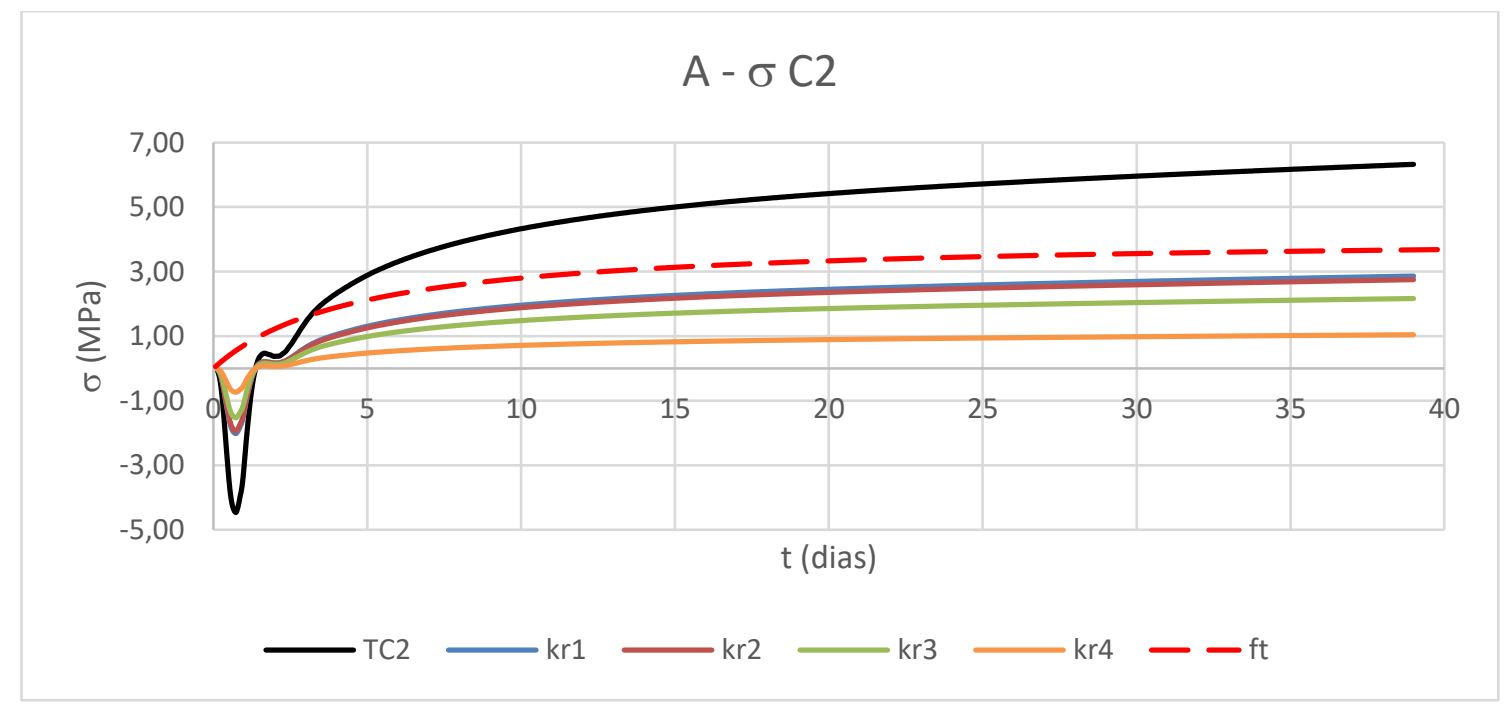

Figura 6.103 - Tensões termomecânicas para a barragem em C2, caso A.

Para a camada onze, Figura 6.104, mesmo considerando base flexível e reduzindo as tensões em $50 \%$, quando a camada foi considerada $0,6 \mathrm{~m}$ com temperatura de lançamento de $20^{\circ} \mathrm{C}$, houve fissuração em uma idade de aproximadamente 30 dias, Casos A e B, e para o Caso C, as tensões de tração continuam subindo, tendendo à fissuração. No Caso $\mathrm{D}$, em que a temperatura de lançamento foi reduzida para $15^{\circ} \mathrm{C}$, ao final da idade analisada não se pode afirmar se irá ou não fissurar, o tempo de análise deve ser estendido para chegar a uma conclusão mais precisa. Quando houve redução da espessura da camada para 0,4 m, Casos E e F, o risco de fissuração diminuiu consideravelmente, por isso, os Casos G, H, I não foram averiguados. 


\section{A - $\sigma$ C11}
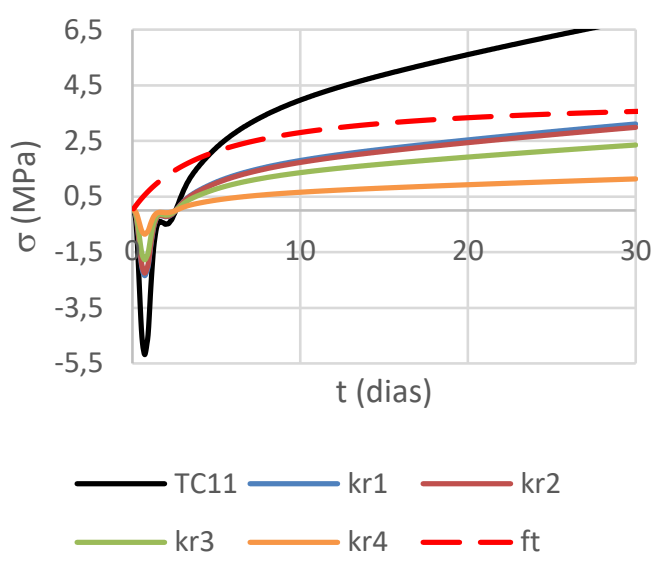

\section{C - $\sigma$ C11}
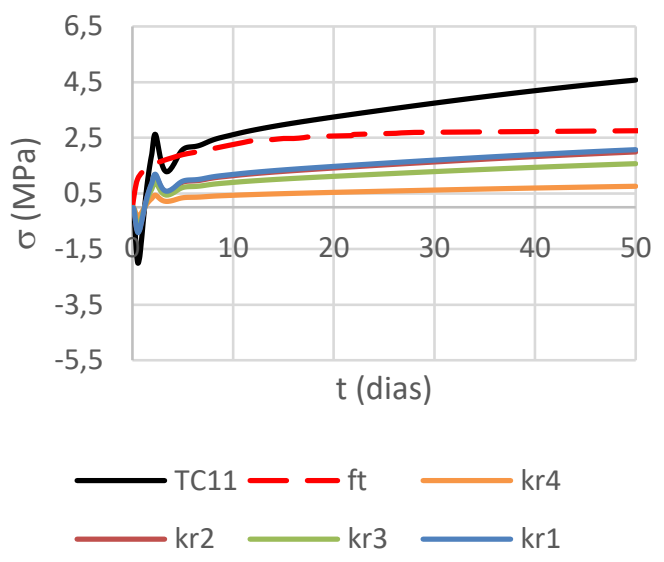

\section{$E-\sigma$ C11}

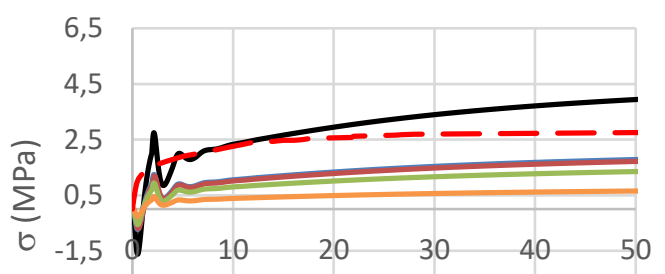

$-3,5$

$-5,5$
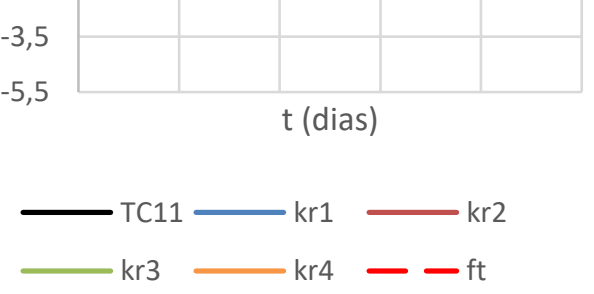

B - C11
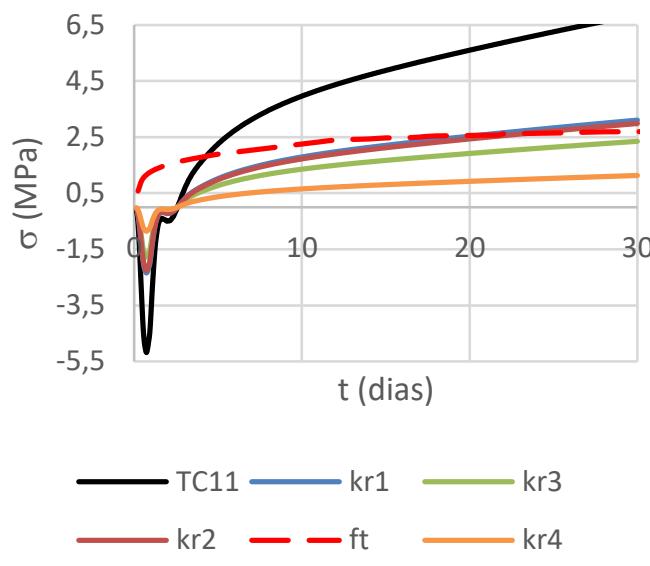

D - $\sigma$ C11

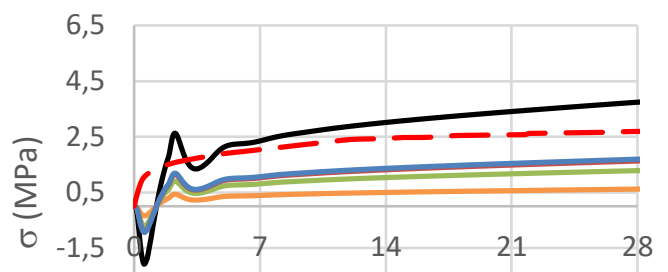

$-3,5$

$-5,5$

$$
\mathrm{t} \text { (dias) }
$$

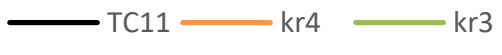

$\mathrm{kr} 1-\mathrm{ft}$
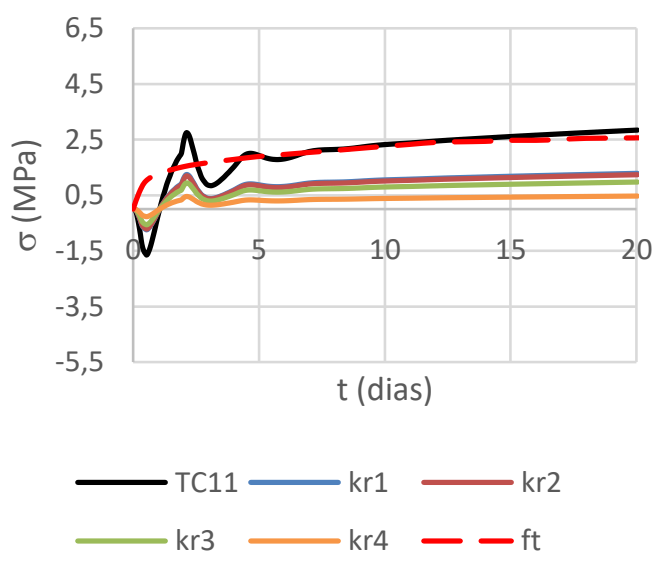

Figura 6.104 - Tensões termomecânicas para a barragem em C11. 


\section{CONCLUSÕES}

O concreto massa é um material de características peculiares. Devido ao seu grande volume, apresenta uma geração de calor interna proveniente da hidratação do cimento chamado de calor de hidratação. Essa geração provoca um aumento da temperatura no interior da estrutura, o que não ocorre no concreto convencional.

Com a imposição das restrições às estruturas juntamente com o gradiente térmico proveniente das diferenças de temperatura ocasionadas com a geração de calor, podem ocorrer fissuras no corpo danificando sua capacidade de resistir aos esforços. Logo, é interessante verificar as probabilidades desses fenômenos ocorrerem antes da construção por meio de simulação.

A fim de propor alternativas de análises, este trabalho foi elaborado com um estudo progressivo das interveniências ocorridas nas estruturas de grande porte. Num primeiro momento, buscou-se definir a curva de geração de calor. Esta foi ajustada, a partir de ensaios experimentais, pela função Hill, com o uso do Método dos Mínimos Quadrados, mostrandose adequada e eficiente nos ajustes para diferentes composições de concreto, sendo indicada para o tratamento dos dados.

Foram estudadas as equações do calor, completa e degenerada, nas suas diversas formas, Laplace, Poisson, Fourier e completa, de forma analítica e numérica e comparados os resultados. Procuraram-se métodos matemáticos que fossem capazes de resolver os problemas, de forma que foi utilizado o Método de Separação de Variáveis analiticamente. Nessas verificações observou-se a importância da aplicação das corretas CC e CI, pois uma simples alteração pode modificar os resultados.

A fim de verificar os resultados analíticos, foram estudados dois métodos numéricos, o MDF e MEF por meio do programa ANSYS. Para o MDF foi utilizado o MATLAB como ferramenta de programação e o MAPLE foi empregado para expandir as series das equações analíticas. Constatou-se, então, que ambos os programas fornecem respostas condizentes com o esperado, desde que corretamente utilizados.

As tensões termomecânicas, foram obtidas analiticamente após a solução térmica via MEF. Para esses cálculos foram estudados distintos modelos de fluência, ACI, USBR, CEB e 
Bazant-Panula. Ambos os modelos mostram a deformação do concreto ao logo do tempo e da idade do concreto, todos podem ser utilizados, porém, devem ser ajustados aos parâmetros do concreto utilizados inicialmente.

Verificou-se que, dependendo do modelo utilizado, as tensões de tração e compressão podem ser maiores ou menores, e a idade de fissuração pode ser alterada também. Ressalta-se ainda que os modelos são muito sensíveis aos valores dos parâmetros das curvas de fluência, uma pequena modificação, aproximação em seus valores numéricos podem alterar o perfil final das tensões. Por isso é importante averiguar e defini-los corretamente.

Variando as dimensões da largura para o estudo do caso do muro, observou-se a relação entre a largura e as temperaturas e tensões. Quanto mais largo, maiores as temperaturas e tensões obtidas, de tração e compressão, que estão diretamente relacionadas com a idade em que haverá fissuração. Ficou claro também o aumento das tensões de compressão enquanto aumenta a temperatura e o aumento das tensões de tração durante o resfriamento.

Notou-se que para larguras maiores que $1,5 \mathrm{~m}$, as temperaturas e tensões quase não sofrem alterações, assim como não é possível visualizar as tensões de tração nas primeiras idades, até dois ou três dias nos corpos mais largos. Para a largura de 0,2 m, a partir do sétimo dia, aproximadamente, as tensões de tração já entram em equilíbrio, mostrando sua relação com o resfriamento mais rápido para este caso.

Na variação do comprimento, não há alteração na parte térmica, pois internamente as temperaturas serão influenciadas apenas nas proximidades do contorno. O estudo mostra o perfil de uma região interna. No entanto, com um maior comprimento, mantida a altura, haverá modificação do coeficiente de restrição aplicado, segundo as normas do ACI 207-2R (2007) e USBR (1981). Desta forma, maiores relações L/H introduzirão maiores tensões na estrutura.

Nas simulações da construção em camadas evidenciou-se o efeito do intervalo de lançamento das camadas, bem como suas respectivas alturas, nos perfis de temperaturas encontrados. Observou-se anomalias que podem ter ocorrido por limitação computacional, tamanho da malha, tempo de convergência ou pode ser o próprio fenômeno físico associado. 
Examinou-se o resfriamento das camadas e posterior aquecimento devido a influência térmica da camada sobrepostas, formando ondulações que também são acompanhadas pelas curvas de tensões. No entanto, para pequenos intervalos de lançamento, 12 h, não há tempo para o resfriamento da camada inferior, portanto, há ausência das ondulações. O fenômeno também não é constatado para camadas superiores a 1,5 m, pois, devido ao grande volume, não há tempo para o resfriamento.

Para as camadas sobrepostas em outras camadas de concreto, funcionando como uma fundação flexível, constatou-se redução das tensões de tração em aproximadamente 50\%, associados ao coeficiente de fundação dado pelo ACI 207-2R (2007). Sendo a geometria a mesma, levaria em consideração o módulo de elasticidade que seriam distintos nas camadas apenas nas idades iniciais que representam a compressão, portanto, em aproximadamente dois dias os módulos das camadas mais antiga e recente se igualariam, provocando a redução das tensões de tração.

As tensões são modificadas com a posição das camadas e podem ser reduzidas com a redução da relação L/H. Estando sobre uma fundação flexível tem menor probabilidade de fissuração. Portanto, alteração do comprimento e construir a primeira camada com uma altura menor podem ser medidas eficientes para evitar deterioração das estruturas.

Ficou evidente que a camada que possui maior temperatura, não necessariamente resfriará mais lentamente. Em alguns casos, as temperaturas máximas foram atingidas em mais de uma camada. Entretanto, àquelas que mantem altas temperaturas por mais tempo, terão maiores tensões de tração e, geralmente, estão nas regiões centrais do corpo, próximos ao centro de gravidade. Constatou-se ainda que a camada que possui a temperatura máxima pode ser modificada com a geometria analisada.

De forma geral, nas análises por MEF simulando o efeito de camadas, sobretudo nas mais finas, deve-se ter cuidado para simular corretamente o fenômeno, visto que as CC podem falsear os resultados se a malha não estiver bem discretizada.

Quanto ao caso do furo, observa-se que para um mesmo concreto com geometria maior, a temperatura e, consequentemente, as tensões, são mais elevadas. A presença de um furo modifica as temperaturas e tensões apenas em uma região próxima, denominada área de 
influência, que é maior, proporcionalmente, para aberturas menores. Quando há mais furos na estrutura, as tensões também são maiores, o que pode ser explicado pela maior variação interna das temperaturas.

Mesmo utilizando propriedades, concreto, intervalo de lançamento, entre outras características, iguais para outras análises já efetuadas, na barragem, devido as suas maiores dimensões houve variação nas temperaturas e tensões, com uma maior probabilidade de fissuração. A primeira camada, sobre fundação rígida, requer atenção especial, pois a sua configuração proporciona aumento das tensões de tração facilmente. As demais camadas, embora devam ser investigadas, podem ter suas tensões reduzidas com mais facilidade, por estarem consideradas sobre fundação flexível, outra camada de concreto.

Assim, em situações de dimensões demasiadamente grandes, as verificações devem ser realizadas com mais atenção. Nestes casos, recomenda-se que as duas primeiras camadas sejam construídas com espessura menor que as demais, e que o intervalo tempo de lançamento para a camada seguinte seja maior, as outras podem ter esse tempo reduzido, além de uma baixa temperatura de lançamento do concreto nessas camadas, processo de préresfriamento.

Diante dos estudos elaborados, afirma-se que cada construção tem as suas particularidades, e uma avaliação nunca será igual a outra. A metodologia e sequência de etapas a serem investigadas seguem um mesmo roteiro, porém os resultados variam com a geometria, condições impostas e concreto utilizado.

De forma geral, observou-se que através de uma metodologia híbrida é possível obter as tensões térmicas para as estruturas de concreto massa. O programa do MEF respondeu satisfatoriamente às análises térmicas e com o método analítico obteve-se as tensões oriundas das variações de temperatura. Foram utilizados diferentes métodos, embora com resultados semelhantes, há algumas variações nas tensões, entre eles, sugere-se o uso do método do USBR, que é simples, apresenta bons resultados e é utilizado pela equipe de Furnas.

Com isso, este trabalho mostrou minuciosamente todos os passos e considerações para uma análise termomecânica em concreto massa a fim de colaborar para que avanços acadêmicos 
possam ser obtidos na área, já que muitos dos conhecimentos são obtidos por empresas, e nem sempre divulgados, e também não temos no Brasil uma norma que oriente o estudo ou construção desse tipo de estrutura.

\subsection{SUGESTÕES PARA TRABALHOS FUTUROS}

- Otimização da construção em camadas, estabelecendo a melhor relação da altura da camada com o máximo gradiente térmico gerado.

- Estudo da viabilidade do processo de construção pelo método rampado e comparálo com o método de camadas.

- Fazer análise termomecânica 3D via MEF.

- Implementar a relaxação do concreto, bem como verificar outros modelos para fluência do concreto.

- Abordar os efeitos da transferência de umidade associado aos fenômenos mostrados - acoplamento termohídrico.

- Acrescentar a retração autógena do concreto, bem como os efeitos do vento e radiação sobre as estruturas de concreto massa.

- Estudar mais detalhadamente a equação do calor, implementando as variações das propriedades com a temperatura do concreto.

- Utilizar o efeito da superposição dos efeitos para problemas mais complexos em concreto massa.

- Acrescentar o efeito da energia de ativação aos modelos estudados.

- Analisar os feitos termomecânicos em barragem de gravidade aliviada.

- Verificar a influência de um reservatório cheio sobre as temperaturas e tensões em barragens.

- Aplicar a metodologia exposta a uma barragem monitorada.

- Comparar os resultados de tensões deste trabalho com coeficientes de restrição e de fundação com os obtidos pelo MEF. 


\section{REFERÊNCIAS BIBLIOGRÁFICAS}

ABDEL-JAWAD, Y. A.. The maturity method: Modifications to improve estimation of concrete strength at later ages. Construction and Building Materials. Elsevier: 2006.

ALBUQUERQUE, A. C.; Estudo das propriedades de concreto massa com adição de partículas de borracha de pneu. $259 \mathrm{f}$. Tese de Doutorado. Universidade Federal do Rio Grande do Sul - UFRGS. Porto Alegre: 2009.

AlbuQuerQue, A. L.. Usina Hidrelétrica de Tucuruí. Disponível em: $<$ http://antonival2.blogspot.com.br/2016/07/usina-hidreletrica-de-tucurui.html>. Acesso: em 16 nov. 2016a.

Eclusas de Tucuruí. Disponível em: <http://antonival2.blogspot.com.br/ 2015/10/eclusas-de-tucurui.html>. Acesso: em 16 nov. 2016b.

AlHOZAIMY, A.; FARES, G.; ALAWAD, O.A.; AL-NEGHEIMISH, A.; Heat of hydration of concrete containing powdered scoria rock as a natural pozzolanic material. Construction and Building Materials. Elsevier: 2015.

ALMEIDA, G. V.; COELHO, N. A.; PEDROSO, L. J.. Distribuição de temperatura em placas em regime transiente: comparação entre solução analítica e numérica. In: XXXVII Iberian Latin American Congress on Computational Methods in Engineering. Brasília: 2016.

ALVES FILHO, A.; Elementos Finitos: A Base da Tecnologia CAE. $1^{\text {a }}$ ed. São Paulo: Érica, 2000. 320 p.

AMERICAN CONCRETE INSTITUTE. Cement and Concrete Terminology. ACI 116R. Farmington Hills, 2005.

Guide for Modeling and Calculating Shrinkage and Creep in Hardened Concrete. ACI 209.2R-08. Farmington Hills, 2008. 
Report on Thermal and Volume Change Effects on Cracking of Mass Concrete. ACI 207.2R-07. Farmington Hills, 2007.

Guide to Mass Concrete. ACI 207.1R-05. Farmington Hills, 2005.

AMERICAN SOCIETY FOR TESTING AND MATERIALS. Standard Practice for

Estimating Concrete Strength by the Maturity Method. ASTM C1074-11. West Conshohocken, 2000. DOI: 10.1520/C1074-11.

AMIN, M. N.; KIM, J.; LEE, Y.; KIM., J.. Simulation of the thermal stress in mass concrete using a thermal stress measuring device. Cement and Concrete Research. Elsevier: 2009. Doi:10.1016/j.cemconres.2008.12.008.

ANDRADE, J. J. O.; TUTIKIAN, $\quad$ B.. Resistência Mecânica do Concreto. Concreto: Ciência e Tecnologia. São Paulo: IBRACON, 2011.

ANSYS. Modeling and Meshing Guide. Canonsburg: ANSYS, INC, 2013.

ASSOCIAÇÃO BRASILEIRA DE NORMAS TÉCNICAS. NBR 12818: Concreto Determinação da difusividade térmica. Rio de Janeiro: 1993.

NBR 5735: Cimento Portland de alto forno. Rio de Janeiro: 1991.

NBR 5736: Cimento Portland pozolânico. Rio de Janeiro: 1991.

NBR 6118: Projeto e execução de obras de concreto armado. Rio de Janeiro: 2014.

AURICH, M., Simulação Computacional do Comportamento do Concreto nas Primeiras Idades. Tese de Doutorado, Escola Politécnica da Universidade de São Paulo, POLI, USP, 2008.

AZENHA, M. A. D.; Comportamento do betão nas primeiras idades. Fenomenologia e análise termomecânica. 248 f. Dissertação de Mestrado. Faculdade de Engenharia da Universidade do Porto - FEUP. Porto: 2004. 
Numerical Simulation of The Structural Behaviour of Concrete Since Its

Early Ages. 379 f. Tese de Doutorado. Faculdade de Engenharia da Universidade do Porto - FEUP. Porto: 2009.

AZENHA, M. A. D.; CRUZ, J. S.; CAMÕES, A.; FERREIRA, R. M.; Numerical Simulation of the Structural Behaviour of Concrete Tetrapods Subject to Imposed Deformations and Applied Loads. Congress on Numerical Methods in Engineering. Coimbra. Junho: 2011.

BACALTCHUK SOBRINHO, J.. Barragens em concreto compactado com rolo, com casa de força incorporada, em caverna, na base do maciço. In: III Seminário Nacional de Concreto Compactado. Foz do Iguaçu: 1998.

BACALTCHUK SOBRINHO, J.; PLATCHECK, I.; CASTELO, G.. Soluções de arranjos visando a economia e a redução de prazos no projeto e construção de barragens de concreto compactado com rolo. In: XXX Seminário Nacional de Grandes Barragens: Foz do Iguaçu, 2015.

BAGHERI-ZADEH, S.; KIM, H.; HOUNSELL, S.; WOOD, H. S.; KING, M.. Field Study of Concrete Maturity Methodology in Cold Weather. Journal of Construction Engineering and Management. Novembro, 2007. DOI: 10.1061/(ASCE)07339364(2007)133:11(827).

BALLIN, Y.; A numerical model and associated calorimeter for predicting temperature profiles in mass concrete. Cement and Concrete Research. Elsevier: 2004. Doi:10.1016/S0958-9465(03)00093-3.

BAtTagin, A. F.; Cimento Portland. Concreto: Ciência e Tecnologia. São Paulo: IBRACON, 2011.

BATISTA, E. L.; GRAÇA, N. G.; GAMBALE, E. A.; ANDRADE, W. P.; SANTOS, F. C. R.; MOREIRA, L. C.. Execução do concreto Bombeado nas Ogivas dos Vãos Rebaixados do Vertedouro de Lajeado. In: 44 ${ }^{\circ}$ Congresso do Ibracon, 2002, Belo Horizonte, 2002. 
BEER, F. P.; JOHNSTON JUNIOR, E. R; DEWOLF, J. T.; MAZUREK, D. F.; Mechanics of materials. 15 ed. New York: Mc Graw Hill, 2009.

BOFANG, Z.; Thermal Stresses and Temperature Control of Mass Concrete. 1 ed. Elsevier: 2014.

BORST, R.; BOOGAARD, A. H.; Numerical Simulation of Deformation and Cracking in Maturing Concrete. Journal of Engennering Mechanics: 1994.

BOTASSI, S. S.; CALMON, J. L.; SILVA FILHO, L. C. P.; LIDUÁRIO, A. S.; GAMBALE, E. A.. Fluência do Concreto Massa: Análise dos Modelos de Predição por meio de Ensaios. In: $52^{\circ}$ Congresso Brasileiro do Concreto. Fortaleza: Ibracon, 2010.

BRASIL. Presidência da República. Lei n. 12.334 de 20 de set. de 2010. Estabelece a Política Nacional de Segurança de Barragens destinadas à acumulação de água para quaisquer usos, à disposição final ou temporária de rejeitos e à acumulação de resíduos industriais, cria o Sistema Nacional de Informações sobre Segurança de Barragens. Brasília: Síntese, 2010.

CALMON, J. L.; MURCIA, J.; BOTASSI, S. S. ; GAMBALE, E. A.; SILVA, C. J.. Modelo numérico para determinação do campo de temperaturas e tensões em barragens usando o método dos elementos finitos. Estudo de caso na barragem de cana brava estado de Goiás - Brasil. In: $46^{\circ}$ Congresso Brasileiro do Concreto, 2004, Florianópolis SC. Anais do $46^{\circ}$ Congresso Brasileiro do Concreto, 2004.

CARINO, N. J.; LEW. H. S.. The maturity method: from theory to application. American Society of Civil Engineers. Washington: National Institute of Standards and Technology, 2001, 19 p.

CARVAlHO, A. G.; Energia de Ativação dos Concretos: Experimentação e Modelagem. 144 f. Dissertação de Mestrado. Universidade Federal do Rio de Janeiro COPPE-UFRJ. Rio de Janeiro: 2002. 
ÇENGEL, Y. A.; GHAJAR, A. J.; Transferência de Calor e Massa - Uma Abordagem Prática. $4^{\mathrm{a}}$ Ed. MCGRAW-HILL: 2012.

CHAPRA, S. C.; CANALE, R. P.. Numerical Methods for Engineers. $5^{\text {a }}$ ed. New York: McGraw-Hill, 2006.

CHOKTAWEEKARN, P.; TANGTERMSIRIKUL, S.; Effect of aggregate type, casting, thickness, and curing condition on restrained strain of mass concrete. Songklanakarin J. Sci. Technol. Thailand: 2010.

CInCOTTO, M. A. Reações de Hidratação e Pozolânicas. Concreto: Ciência e Tecnologia. São Paulo: IBRACON, 2011.

CIRIA C660. Early-age thermal crack control in concrete. London: 2007.

COELHO, N. A.. Um Estudo Numérico do Efeito Térmico em Concreto Massa. 152 f. Dissertação de Mestrado. Universidade de Brasília - UnB. Brasília: 2012.

COElho, N. A.; GOMES, F. M. P.; PEDROSO, L. J.; SILVA, D. A.. Um estudo comparativo analítico-numérico de tensões térmicas em casos clássicos de vigas e placas. In: XXXVII Iberian Latin American Congress on Computational Methods in Engineering. Brasília: 2016a.

COELHO, N. A.; SILVA, D. A.; PEDROSO, L. J.; Efeito térmico provocado pelo calor de hidratação em barragem de gravidade construída em camadas. In: XXXVII Iberian Latin American Congress on Computational Methods in Engineering. Brasília: 2016b.

COELHO, N. A.; NEPOMUCENO, A. A.; PEDROSO, L. J.; O concreto massa e seus efeitos térmicos. Novas Edições Acadêmicas. Saarbrücken: 2014a.

COELHO, N. A.; PEDROSO, L. J.. Aplicação do método das diferenças finitas à equação do calor. 9 f. Relatório Técnico - RTP-NAC-17/2015. Universidade de Brasília - UnB. Brasília: 2013. 
Soluções analíticas para a equação do calor. 36 f. Relatório Técnico - RTPNAC-16/2015. Universidade de Brasília - UnB. Brasília: 2015.

Utilização do ANSYS WORKBENCH na solução de problemas do calor em concreto. 22 f. Relatório Técnico - RTP-NAC-11/2014. Universidade de Brasília - UnB. Brasília: 2014.

Teoria de tensões e deformações e solução da Equação de Poisson. $16 \mathrm{f}$. Relatório Técnico - RTP-NAC-10/2014. Universidade de Brasília - UnB. Brasília: 2014.

Comparação de resultados analíticos com o programa ANSYS. $20 \mathrm{f}$. Relatório Técnico - RTP-NAC-07/2013. Universidade de Brasília - UnB. Brasília: 2013.

Equação do Calor: Problemas não Homogêneos e Estudo das Condições de Contorno. 23 f. Relatório Técnico - RTP-NAC-02/2013. Universidade de Brasília - UnB. Brasília: 2013.

Estudo da equação de calor em elemento uni, bi e tridimensional. $22 \mathrm{f}$. Relatório Técnico - RTP-NAC-01/2013. Universidade de Brasília - UnB. Brasília: 2013.

COElHO, N. A.; PEDroso, L. J.; REGO, J. H. S.; NEPOMUCENO, A. A.. Influência das propriedades térmicas do concreto massa na análise da temperatura em estruturas de grandes dimensões. In: $10^{\text {th }}$ World Congresso n Computational Mechanics. São Paulo: $2012 b$.

Use of ANSYS for Thermal Analysis in Mass Concrete. Journal of Civil Engineering and Architecture. V. 8. N. 7. David Publishing Company: 2014b.

COElho, N. A.; REGO, J. H. S.; PEDROSO, L. J.; NEPOMUCENO, A. A.. Análise numérica e térmica de blocos de concreto massa por meio de um código computacional. In: $54^{\circ}$ Congresso Brasileiro do Concreto. Maceió: Ibracon, 2012a.

COMITÊ BRASILEIRO DE GRANDES BARRAGENS. Hidrelétrica Santo Antônio: Quarta maior em geradora hídrica do país. Revista Brasileira de Engenharia de Barragens. N. 03. CBDB: Abril: 2016. 
COMITÊ BRASILEIRO DE GRANDES BARRAGENS; ELETROBRÁS; INSTITUTO BRASILEIRO DO CONCRETO. Concreto massa no Brasil: memória técnica. Rio de Janeiro: Memória da Eletricidade, 1989.

CONCRETE IN PRACTICE. CIP 39 - Maturity Methods to Estimate Concrete Strength, 2006.

CORDEIRO, G. C.; SILVOSO, M. M.; FAIRBAIRN, E.M.R.; ASCE, M.; TOLEDO FILHO, R. D.; RIBEIRO, F. L. B.; ASCE, M.; FERREIRA, I. A.; GAMBALE, E. A.; SANTOS, S. B.. User friendly concretes in Brazil: simulation of dam construction using cement blended with sugar cane bagasse and rice-husk ashes. Engineering Mechanics Division Conference: 2007.

CREAGER, W.; HINDS, J.; JUSTIN, J. W.. Engineering for Dams. New York: J Wiley 1964. 3 v. :

DABBENE, F.; PAILLERE, H.. Initiation à la simulation numérique en mécanique des fluides: Eléments d'analyse numérique. Cours ENSTA MF307:2003.

DE SCHUTTER, G.. Finite element simulation of thermal cracking in massive hardening concrete elements using degree of hydration based material laws. Computers and Structures, 2002.

Applicability of degree of hydration concept and maturity method for thermo-visco-elastic behaviour of early age concrete. Vol. 26. Cement and Concrete Research. Elsevier: 2004; Doi:10.1016/S0958-9465(03)00067-2.

Hydration and temperature development of concrete made with blastfurnace slag cement. Cement and Concrete Research: 1999.

DE SCHUTTER, G.; TAERWE, L.; General hydration model for portland cement and blast furnace slag cement. Vol. 25. Cement and Concrete Research. Elsevier: 1995. 
DING, J.; CHEN, S.; Simulation and feedback analysis of the temperature field in massive concrete structures containing cooling pipes. Applied Thermal Engineering. Elsevier: 2013.

DOLADO, J. S.; BREUGEUL, K.; Recent advances in modeling for cementitious materials. Cement and Concrete Research. Elsevier: 2011; Doi:10.1016/j.cemconres.2011.03.014.

ELETROBRÁS. Critérios de Projeto Civil de Usinas Hidrelétricas. CBDB: 2003.

EMBORG, M.. Development of Mechanical Behaviour at Early Ages. In: SPRINGENSCHMID R. (Ed.); Prevention of Thermal Cracking in Concrete at Early Ages. RILEM Report 15. Londres: 1998a. P. 76 - 148.

Models and Methods for Computation of Thermal Stresses. In: SPRINGENSCHMID R. (Ed.); Prevention of Thermal Cracking in Concrete at Early Ages. RILEM Report 15. Londres: 1998b. P. 178 - 230.

FAIRBAIRN, E. M. R.; SILVOSO, M. M.; FILHO, R. D. T.; ALVES, J. L. D.; EBECKEN, N. F. F.; Optimization of mass concrete construction using genetic algorithms. Rio de Janeiro. Elsevier: 2003.

FARIA, E. F.; Predição da exotermia da reação de hidratação do concreto através de modelo termo-químico e modelo de dados. 145 f. Dissertação de Mestrado. Universidade Federal do Rio De Janeiro - COOPE/UFRJ. Rio de Janeiro: 2004.

FERREIRA, I. A.; Solução em paralelo de um modelo termo-químico-mecânico para concreto jovem. Tese de Doutorado. Universidade Federal do Rio De Janeiro COOPE/UFRJ. Rio de Janeiro: 2008.

FUNAHASHI JÚNIOR, E. I.; KUPERMAN, S. C.; VICENTE, G. R.; FORNI, E. S.; LIMA, E. C.. Simulação de tensões térmicas da sala de radioterapia do hospital das clínicas de Ribeirão Preto-SP. In: 52 ${ }^{\circ}$ Congresso Brasileiro do Concreto. Fortaleza: Ibracon, 2010. 
FUNAHASHI JÚNIOR, E. I.; KUPERMAN, S. C.. Estudo de tensões térmicas em vertedouro de pequena central hidrelétrica. In: VII SIMPÓSIO SOBRE PEQUENAS E MÉDIAS CENTRAIS HIDRELÉTRICAS. São Paulo: CBGB, 2010.

FUNAHASHI JÚNIOR, E.; KUPERMAN, S. C.; ROSSINI, D.. Simulação de tensões térmicas do bloco de fundação do edifício paulista corporate. In: $53^{\circ}$ Congresso Brasileiro do Concreto. Florianópolis: Ibracon, 2011.

FURNAS; Concretos: Massa, estrutural, projetado e compactado com rolo. São Paulo: Pini, 1997. $1 \mathrm{v}$.

GADJA, J.; VAngEEM M.; Controlling Temperatures in Mass Concrete. Concrete International. January, 2002.

GAMBALE, E. A.; ANDRADE, M. A. S. ; ANDRADE, W. P. ; BITTENCOURT, R. M. ; NASCIMEnTO, J. F. F. ; AMARAL, W. S. . Análise de Temperatura do Concreto Utilizado nas Estruturas da $3^{\circ}$ Ponte do Lago Sul de Brasilia-DF. In: Jornadas SulAmericanas de Engenharia Estrutural, Brasília: 2002.

GAMBAlE, E. A.; CARMO, J. B. M.. Análise de Temperatura do Concreto Utilizado nas Estruturas da $3^{\circ}$ Ponte do Lago Sul de Brasilia-DF. In: Jornadas Sul-Americanas de Engenharia Estrutural, Brasília: 2002.

GAMBAlE, E. A.; SANTOS, S. B.; ANDRADE, M. A. S.; BITTENCOUT, R. M.. Validação dos resultados do cálculo das tensões instaladas de origem térmica no concreto massa, com resultados reais. In: V Simpósio EPUSP sobre estruturas de concreto. São Paulo, USP: 2003.

GAMBALE, E.A.; CESAR, M. C.; QUEIROZ, A.C. E.; MOTTA C.F.C.; ANDRADE, M.A.S. Simulação numérica e verificação "in loco" das temperaturas da viga Munhão da UHE Foz do Chapecó. In: $51^{\circ}$ Congresso Brasileiro do Concreto. Curitiba: Ibracon, 2009a. 
GAMBAlE, E. A.; LUZ, M. P.; SANTANA, W. G.; BARBIN, A. S.. Estudo do Plano de Lançamento do Concreto a Partir de Análises Bidirecionais Térmicas e Tensionais da Estrutura da Ogiva do Vertedouro Principal da Usina Hidroelétrica de Santo Antônio. In: 53 Congresso Brasileiro do Concreto. Brasília: Florianópolis: 2011a.

Estudos Bidirecionais Térmicos e Tensionais como Forma de Orientar Condições Executivas em Estruturas de Tubos de Sucção Aplicados à Usina Hidroelétrica de Santo Antônio. In: 53 Congresso Brasileiro do Concreto. Brasília: Florianópolis: $2011 \mathrm{~b}$.

Análise de plano de lançamento de concreto a partir de estudo térmico bidirecional da estrutura stay column da Usina Hidroelétrica de Santo Antônio. In: 53 Congresso Brasileiro do Concreto. Brasília: Florianópolis: 2011c.

Estudos Bidirecionais Térmicos e Tensionais em Viga Munhão Aplicados à Usina Hidroelétrica de Santo Antônio. In: $53^{\circ}$ Congresso Brasileiro do Concreto. Brasília: Florianópolis: 2011d.

GAMBALE, E. A.; TRABOULSI, M. A.. Avaliação da temperatura máxima em estrutras executadas com concreto massa. In: $57^{\circ}$ Congresso Brasileiro do Concreto. Bonito: Ibracon, 2015.

GERY, M.. Transferts de chaleur. Apostila do Departamento de Engenharia Civil e Urbanismo. Instituto Nacional de Ciências Aplicadas de Lyon: 1998.

GOMES, F. M. P.; COELHO, N. A.; PEDROSO, L. J.. Uma solução analítico-numérica para a difusividade do calor em um cilindro com e sem geração de calor. In: XXXVII Iberian Latin American Congress on Computational Methods in Engineering. Brasília: 2016.

Uma solução analítico-numérica para a difusividade do calor em um cilindro com e sem geração de calor. Revista Interdisciplinar de Pesquisa em Engenharia - RIPE. V. 2. N. 12. Disponível em: < http://periodicos.unb.br/index.php/ ripe/article/view/23471> Acesso em: 15 de jan. 2014b. 
GOMES, F. M. P.; Concreto nas primeiras idades: propriedades e modelagem termomecânica simplificada. Dissertação de Mestrado. Universidade Federal de Goiás. Goiânia: 2011.

GRONDIN, F.; DUMONTET, H.; HAMIDA, A. B.; BOUSSA, H.. Micromechanical contributions to the behaviour of cement-based materials: Two-scale modelling of cement paste and concrete in tension. Cement \& Concrete Composites. Elsevier: 2011.

HA, J.; JUNG, Y.; CHO, Y.; Thermal crack control in mass concrete structure using an automated curing system. Automation in Construction. Elsevier: 2014.

HABERMAN, R.; Elementary Applied Partial Differential Equations. 2a ed. New Jersey: Prentice-Hall: 1987.

HAN F.; LIU, R.; WANG, D.; YAN, P.; Characteristics of the hydration heat evolution of composite binder atdifferent hydrating temperature. Thermochimica Acta. Elsevier: 2014.

HETNARSKI, R. B.; ESLAMI, M. R.; Thermal Stresses - Advanced Theory and Aplications. New York: Springer, 2009.

HILDEBRAND, F. B. Advanced Calculus for Applications. New Jersey: Prentice-Hall: 1965 .

INCROPERA, F. P.; DEWITT, D. P.; BERGMAN, T. L.; LAVINE, A. S.. Fundamentos de Transferência de Calor e Massa. $6^{a}$ ed. Rio de Janeiro: LTC, 2008.

INOUE, G.; Medidas Preventivas de Controle de Temperatura que Induz Fissuração no Concreto Massa. Boletim Técnico No 7; Escola Politécnica da Universidade de São Paulo - EPUSP; São Paulo: 1986.

INTERNATIONAL COMISSION ON LARGE DAMS; 80 anos - barragens para o desenvolvimento humano. Paris, CIGB: 2008. 
JALURIA, Y.. Computer Methods for Engineering with MATLAB Applications. 2. ed. Taylor \& Francis Group: New York, 2011.

JAVANMARDI, F., LÉGER, P., TINAWI, R.. Seismic Water Pressure in Cracked Concrete Gravity Dams: Experimental Study and Theoretical Modeling. Journal of Structural Engineering-Asce, 131: 2005. p. 139-150.

KALINTZIS, C. A. A.; KUPERMAN, S. C.. Estudo da fluência do concreto de elevado desempenho. Boletim Técnico $\mathrm{N}^{\circ}$ 274; Escola Politécnica da Universidade de São Paulo EPUSP; São Paulo: 2001.

KAVAMURA, E. E.; Estudo do comportamento termo-estrutural bidimensional de barragens de concreto utilizando o Método dos Elementos Finitos. Dissertação de Mestrado. Universidade Federal do Paraná - UFPR, Curitiba: 2005.

KHAN, M. I.; Factors affecting the thermal properties of concrete and applicability of its prediction models. Building and Environment. February, 2001.

KHAN, N. A.; Thermo-Mechanical Analysis of Roller Compacted Concrete Dams. Dissertação de Mestrado. University of Engineering and Technology Lahore. Paquistão: 2011.

KIM, J. K.; KIM, K. H.; YANG, J. K.. Thermal analysis of hydration heat in concrete structures with pipe-cooling system. Computers and Structures. Pergamon: 2001.

KIM, K.; JEON, S.; KIM, J.; YANG, S.; An experimental study on thermal conductivity of concrete. Cement and Concrete Research: 2002.

KLEMCZAK, B.; WRÓBEL, A. K.. Analysis of Early-Age Thermal and Shrinkage Stresses in Reinforced Concrete Walls. ACI Structural Journal, N. 111-S27. Abril: 2014.

KLEMCZAK, B.; KNOPPIK, A. W.K.. Reinforced concrete tank walls and bridge abutments: Early-age behaviour, analytic approaches and numerical models. Engineering Structures, February: 2015. DOI: 10.1016/j.engstruct.2014.11.031. 
KREYSZIG, E.; Advanced Enginnering Mathemathics. $10^{\mathrm{a}}$ ed. United States of America: John Wiley \& Sons, Inc.: 2006.

KRÜGER, D. A. V.; Análise térmica transiente de estruturas de concreto executadas por camadas. Dissertação de Mestrado. Universidade Federal do Paraná - UFPR, Curitiba: 2001.

LAWRENCE, A. M. L.; TIA, M.; FERRARO, C. C.; BERGIN, M.; Effect of Early Age Strength on Cracking in Mass Concrete Containing Different Supplementary Cementitious Materials: Experimental and Finite-Element Investigation. Journal of Materials in Civil Engineering. Miami: 2012.

LEE, C. H.; HOVER, K. C.. Compatible Datum Temperature and Activation Energy for Concrete Maturity. ACI Structural Journal, N. 113-M19. Abril: 2016.

LÉGER, P., SEYDOU, S. Seasonal Thermal Displacements of Gravity Dams Located in Northern Regions. Journal of Performance of Constructed Facilities v. 23: 2009. p. 166174.

LIN, Y.; CHEN, H. L.. Thermal analysis and adiabatic calorimetry for early-age concrete members. Journal of Thermal Analysis and Calorimetry: 2016. DOI 10.1007/s10973-0155131-x.

LIU, J.; QIAO, L; LI, P.; DAI, C.; Laboratory Test and Numerical Simulation of TimeDependent Thermomechanical Behavior of the Three-Gorges Dam; Journal of Materials in Civil Engineering. February, 2010.

LIU, X.; ZHANG, C.; CHANG, X., ZHOU, W; CHENG, Y.; DUAN, Y.; Precise simulation analysis of the thermal field in mass concrete with a pipe water cooling system. Applied Thermal Engineering. Elsevier: 2015.

LIWU, M.; MIN, D.. Thermal behavior of cement matrix with high-volume mineral admixtures at early hydration age. Cement and Concrete Research. Elsevier: 2006. 
MALISKA, C. R.. Transferência de Calor e Mecânica dos Fluidos Computacional. $2^{\text {a }}$ ed. Rio de Janeiro: LTC, 2004.

MARQUES FILHO, J. M.; Maciços experimentais de laboratório de concreto compactado com rolo aplicado às barragens. $278 \mathrm{f}$. Tese de doutorado. Universidade Federal do Rio Grande do Sul - UFRGS. Porto Alegre: 2005.

MARTINS, E. F. R.; PEDROSO, L. J.. Um estudo analítico-numérico da equação de Laplace orientado à problemas térmicos em estruturas de concreto. Revista Interdisciplinar de Pesquisa em Engenharia - RIPE. V. 2. N. 12. Disponível em: < http://periodicos.unb.br/index.php/ripe/article/view/23490> Acesso em: 15 de jan. 2014b.

MEHTA, P. K.; MONTEIRO, P. J. M.. Concreto: Estrutura, Propriedades e Materiais. 2 ed. São Paulo: IBRACON, 2014.

MELLO, F. M.. Síntese do Desenvolvimento da Implantação das Barragens no Brasil. A História das Barragens no Brasil Séculos XIX, XX, XXI: cinquenta anos do Comitê Brasileiro de Barragens. Rio de Janeiro: CBDB, 2011 a.

Resumo da História Remota da Hidroeletricidade no Brasil. A História das Barragens no Brasil Séculos XIX, XX, XXI: cinquenta anos do Comitê Brasileiro de Barragens. Rio de Janeiro: CBDB, 2011b.

MENDES, N. B.; PEDROSO, L. J.. Um estudo do acoplamento barragem em arcoreservatório sob ação de um sismo. Revista Interdisciplinar de Pesquisa em Engenharia - RIPE. V. 2. N. 4. Disponível em: < http://periodicos.unb.br/index.php/ ripe/article/view/23444> Acesso em: 15 de jan. 2014b.

MILANI FILHO, L.. O uso do concreto compactado com rolo em barragens - tendências futuras. 100 f. Dissertação de Mestrado. Universidade Federal de Itajubá. Itajubá: 2003.

MOAVENI, S. Finite Element Analyses: Theory and Application with ANSYS. New Jersey: Editora Prentice-Hall, 1999. 
MORABITO, P. Methods to Determine the Heat of Hydration of Concrete. In: SPRINGENSCHMID R. (Ed.); Prevention of Thermal Cracking in Concrete at Early Ages. RILEM Report 15. Londres: 1998. P. $01-25$.

NASCIMENTO JÚNIOR, C. A. Um Estudo Comparativo Analítico-Numérico de Tensões Locais e Globais em Barragens Gravidade de Concreto. 134 f. Dissertação de Mestrado. Universidade de Brasília - UnB. Brasília: 2012.

NEVES JUNIOR, A.; TOLEDO FILHO, R.D.; FAIRBAIRN, E. M. R.; Early stages hydration of high initial strength Portland cement. Journal of Thermal Analysis and Calorimetry. 2012. DOI 0.1007/s10973-012-2256-z.

NEVILLE, A. M. Propriedades do concreto. 5. ed. São Paulo: Pini, 2016. 888 p.

NOVAK, P.; MOFFAT, A. I. B.; NALLURI, C.. Hidraulic Strutures. 4 ed. New York: Taylor \& Francis, 2007.

OLliVER, J.; VICHOT, A.. Durabilidade do Concreto: Bases científicas para formulação de concretos duráveis de acordo com o ambiente. 1 ed. São Paulo: IBRACON, 2014.

PEDROSO, J. L. Barragens de Concreto: Aspectos Gerais e Fundamentos do Cálculo de Tensões e da Estabilidade Baseado no Método de Gravidade. Apostila do Curso de Barragens de Concreto. Universidade de Brasília - UnB, Brasília, 2002.

PEDROSO, L.J.. Método das Diferenças Finitas. In: Notas de Curso e Apostila Didática, UnB-FT/ENC, Vs.3 - Brasília, DF, 2003.

PEDROSO, L. J.. Método das diferenças finitas em vigas esbeltas. Apostilha didática. In: Programa de Pós-Graduação em Estruturas e Construção Civil - PECC, Universidade de Brasília, Brasilia, 2005.

PEDROSO, L. J.. Uma Introdução ao Método das Diferenças Finitas Centrais. Apostilha didática. In: Programa de Pós-Graduação em Estruturas e Construção Civil PECC, Universidade de Brasília, Brasilia, 2011. 
PEDROSO, L. J.. Manuscritos, esquemas, discussões e notas de seções de orientações, 2013-2016. In: Programa de Pós-Graduação em Estruturas e Construção Civil - PECC, Universidade de Brasília, Brasilia, 2016.

PETTRES, R.. Reconhecimento de padrões de defeitos em concreto a partir de imagens térmicas estacionárias e redes neurais artificiais. Dissertação de Mestrado. Universidade Federal do Paraná - UFPR, Curitiba: 2011.

POPPE, A.; DE SCHUTTER, G.; Cement hydration in the presence of high filler contentes. Cement and Concrete Research. Elsevier: 2005.

QIAN, C.; GAO, G.; Reduction of interior temperature of mass concrete using suspension of phase hange materials as cooling fluid. Construction and Building Materials. Elsevier: 2012.

RANI, S. D.; SANTHANAM, M.; Influence of moderately elevated temperatures on engineering properties of concrete used for nuclear reactor vaults. Cement \& Concrete Composites. Elsevier:2012

RAO, S. S.; The Finite Element Method in Engineering. $3^{\mathrm{a}}$ ed. United States of America: Butterworth-Heinemann: 1999.

ROSTÁsy, F. S.; TANABE, T.; LAUBE, M. Assessment of External Restraint. In: SPRINGENSCHMID R. (Ed.); Prevention of Thermal Cracking in Concrete at Early Ages. RILEM Report 15. Londres: 1998b. P. 149 - 177.

ROTH, S.-N., LÉGER, P., SOULAÏMANI, A. Coupled Hydro-Mechanical Cracking of Concrete using XFEM in 3D. 9th International Conference on Fracture Mechanics of Concrete and Concrete Structures (FraMCoS-9): 2016. DOI 10.21012/FC9.263.

SANTO ANTÔNIO ENERGIA. Hidrelétricas no Brasil. 2012

SANTOS, S. B. Uma Contribuição ao Estudo do Comportamento Termomecânico de Estruturas Maciças de Concreto. Modelagem Viscoelástica Linear e Aplicações. 287 f. Dissertação de Mestrado. Universidade Federal do Espírito Santo. Vitória: 2004. 
Análise da fluência do concreto massa nas primeiras idades de carregamento: influência de aditivos plastificantes e adições minerais. Universidade Federal do Rio Grande do Sul. Porto Alegre: 2011.

SANTOS, S. B.; CALMON, J. L.; GAMBALE, E. A.; ANDRADE, M. A. S.. Comparação entre resultados obtidos por um medidor de tensão instalado em um bloco de concreto massa e os valores gerados pelo programa PFEM_2DAT. In: $46^{\circ}$ Congresso Brasileiro do Concreto, 2004, Florianópolis - SC. Anais do $46^{\circ}$ Congresso Brasileiro do Concreto, 2004a.

Determinação do campo de temperaturas e tensões em um bloco de concreto massa utilizando os modelos elástico linear e viscoelástico linear. Um estudo comparativo. In: $46^{\circ}$ Congresso Brasileiro do Concreto, 2004, Florianópolis - SC. Anais do $46^{\circ}$ Congresso Brasileiro do Concreto, 2004b.

SANTOS, S. B.; CALMON, J. L.; GAMBALE, E. A.. Programa de análise termomecânica em estruturas de concreto massa durante a fase de construção. In: XXVI Seminário Nacional de Grandes Barragens: 2005.

SANTOS, S. B.; GAMBALE, E. A.; ANDRADE, M. A. S.; MURCIA, J.; CALMON, J. L. Análise de fluência do concreto compactado com rolo através de medidas de deformações tridimensionais sob carga uniaxial. Um ensaio piloto. In: $46^{\circ}$ Congresso Brasileiro do Concreto: Vitória, 2003.

SILVA, L. M. F.; Criação e implementação de um laboratório pedagógico de estruturas na Universidade do Minho. Dissertação de Mestrado. Universidade do Minho. Braga: 2013.

SILVA, M. T. Q. S.; Análise térmica transiente e de tensões em estruturas executadas em camadas. Dissertação de Mestrado. Universidade Federal do Paraná - UFPR, Curitiba: 2003. 
SILVA JUNIOR, A. F. S.; Método dos volumes finitos para equação de convecção e difusão em uma dimensão espacial. Dissertação de Mestrado. Universidade Federal Fluminense. Volta Redonda: 2012.

SILVEIRA, A. F.; As variações de temperatura nas barragens. Lisboa: Lab Nac Eng Civ, 1961. $437 \mathrm{p}$.

SILVOSO, M. M.; Modelagem numérica do concreto a poucas idades. 83 f. Dissertação de Mestrado. Universidade Federal do Rio de Janeiro - COPPE-UFRJ. Rio de Janeiro: 2002.

SZILARD, R.. Theory and Analysis of Plates: Classical and Numerical Methods. John Wiley \& Sons. New Jersey: 2004.

TAYLOR, H. F. W.. Cement Chemistry. 2 ed. Academic Press: Londres, 1997.

TEIXEIRA, R. R.; MACHADO, R. D.; HECKE, M. B.. Modelagem por elementos finitos para análise de tensões e Deformações por fluência no concreto compactado com rolo. 2006

TOPÇU, I. B.; KARAKURT, C.; ALTUN F.. Using the Maturity Method in Concrete Produced with Setting Agents. Journal of Materials in Civil Engineering. Miami: 2007. DOI: 10.1061/(ASCE)0899-1561(2007)19:7(569).

TOPÇU, I. B.; TOPRAK, M. U.. Fine aggregate and curing temperature effect on concrete maturity. Cement and Concrete Research. Elsevier: 2004.

TORQUATO, S.. Random Heterogeneous Materials. New York: Springer, 2001.

TYDLITAT, V.; MATAS, T.; CERNÝ, R.; Effect of w/c and temperature on the earlystage hydration heat development in Portland-limestone cement. Construction and Building Materials. Elservier: 2014.

UNITED STATES DEPARTMENT OF THE INTERIOR BUREAU OF RECLAMATION. Design Criteria for Concrete Arch and. Gravity Dams. Engineering Monograph N. 19. U.S. Government Printing Office: Washington, 1977. 
Concrete Manual: Part 2. 9 ed. U.S. Departamento of the interior. 1992.

Control of Cracking in Mass Concrete Structures. Engineering Monograph N. 34. U.S. Government Printing Office: Denver, 1981.

VASCONCELOS, M. A.; COELHO, N. A.; PEDROSO, L. J.. Estudo de diferenças finitas para a equação do calor em barragens de concreto. In: XXXVI Iberian Latin American Congress on Computational Methods in Engineering. Rio de Janeiro: 2015. Doi://10.20906/CPS/CILAMCE2015-0832.

VICENTE, G. R.; KUPERMAN, S. C.; FUNAHASHI JÚNIOR, E. I.. Fissuração de Origem Térmica em Blocos de Fundação: Quando Refrigerar o Concreto? In: $56^{\circ}$ Congresso Brasileiro do Concreto. Natal: Ibracon: 2014.

WALLER, V.; D'ALOIA, L.; CUSSIGH, F.; LECRUX, S.. Using the maturity method in concrete craking control at early ages. Cement \& Concrete Composites. Elsevier: 2004. Doi:10.1016/S0958-9465(03)00080-5.

WU, S.; HUANG, D.; LIN, F.; ZHAO, H.; WANG, P.. Estimation of cracking risk of concrete at early age based on thermal stress analysis. Journal of Thermal Analysis and Calorimetry. Hungary: 2011. DOI 10.1007/s10973-011-1512-y

WU, Y.; LUNA, R.. Numerical implementation of temperature and creep in mass concrete. Finite Elements in Analysis and Design. Elsevier: 2001.

YANG, J.; HU, Y.; ZUO, Z.; JIN, F.; LI, Q.. Thermal analysis of mass concrete embedded with double-layer staggered heterogeneous cooling water pipes. Applied Thermal Engineering. Elsevier: 2012.

YUNCHUAN, Z.; LIANG, B.; SHENGYUAN, Y.; GUTING, C.. Simulation Analysis of Mass Concrete Temperature Field. Procedia Earth and Planetary Science. Elsevier: 2012.

ZHAI, X.; WANG, Y.; WANG H. Thermal stress analysis of concrete wall of LNG tank during construction period. Materials and Structures. Rilem: 2016. DOI 10.1617/s11527015-0656-9 
APÊNDICES 


\section{APÊNDICE A - SOLUÇÕES ANALÍTICAS PARA A EQUAÇÃo DO CALOR}

A Tabela A.1 apresenta os resultados para a equação do calor completa e degenerada com diferentes CC. Essas soluções foram obtidas com base em Haberman (1987), Hildebrand (1965), Incropera et al (2008), Kreyszig (2006) e Hetnarski e Eslami (2009).

Tabela A.1 - Resumo das soluções analíticas.

\begin{tabular}{|c|c|c|}
\hline$\nabla^{2} \mathrm{~T}=\frac{\partial^{2} T^{(*)}}{\partial x^{2}}=0$ & $\begin{array}{l}T(0)=T_{1} \\
T(L)=T_{2}\end{array}$ & $T(x)=\frac{T_{2}-T_{1}}{L} x+T_{1}$ \\
\hline $\begin{array}{l}\nabla^{2} \mathrm{~T} \\
=\frac{\partial^{2} T}{\partial x^{2}}+\frac{\partial^{2} T}{\partial y^{2}} \\
=0\end{array}$ & $\begin{array}{c}T(0, y)=0 \\
T\left(L_{1}, y\right)=0 \\
T(x, 0)=0 \\
T\left(x, L_{2}\right)=f(x)\end{array}$ & $T(x, y)=\sum_{n=1}^{\infty} \frac{2}{L_{1}} \frac{\int_{0}^{L_{1}}\left(f(x) \operatorname{sen}\left(\frac{n \pi}{L_{1}} x\right) d x\right) \operatorname{sen}\left(\frac{n \pi}{L_{1}} x\right) \cdot \operatorname{senh}\left(\frac{n \pi}{L_{1}} y\right)}{\operatorname{senh}\left(\frac{n \pi}{L_{1}} L_{2}\right)}$ \\
\hline $\begin{array}{l}\nabla^{2} T \\
=\frac{\partial^{2} T}{\partial x^{2}}+\frac{\partial^{2} T}{\partial y^{2}} \\
+\frac{\partial^{2} T}{\partial z^{2}}=0\end{array}$ & \begin{tabular}{|c|}
$T(0, y, z)=0$ \\
$T\left(L_{1}, y, z\right)=0$ \\
$T(x, 0, z)=0$ \\
$T(x, y, 0)=0$ \\
$T\left(x, y, L_{3}\right)=0$ \\
$T\left(x, L_{2}, z\right)=f(x, z)$
\end{tabular} & $\begin{array}{c}T(x, y, z)=\sum_{m=1}^{\infty} \sum_{n=1}^{\infty} a_{m n} \operatorname{sen}\left(\frac{m \pi}{L_{2}} y\right) \operatorname{sen}\left(\frac{n \pi}{L_{3}} z\right) \frac{\operatorname{senh}\left(\lambda_{m, n} x\right)}{\operatorname{senh}\left(\lambda_{m, n} L_{1}\right)} \\
a_{m n}=\frac{4}{L_{2} L_{3}} \int_{0}^{L_{2}} \int_{0}^{L_{3}} f(y, z) \operatorname{sen}\left(\frac{m \pi}{L_{2}} y\right) \operatorname{sen}\left(\frac{n \pi}{L_{3}} z\right) d y d z \\
\lambda_{m, n}=\pi \sqrt{\left(\frac{m}{L_{2}}\right)^{2}+\left(\frac{n}{L_{3}}\right)^{2}}\end{array}$ \\
\hline $\begin{array}{l}\nabla^{2} \mathrm{~T} \\
=\frac{\partial^{2} T}{\partial x^{2}}+\frac{\partial^{2} T}{\partial y^{2}} \\
+\frac{\partial^{2} T}{\partial z^{2}}=0\end{array}$ & \begin{tabular}{|c|}
$T(0, y, z)=0$ \\
$T\left(L_{1}, y, z\right)=0$ \\
$T(x, 0, z)=0$ \\
$T(x, y, 0)=0$ \\
$\frac{\partial T}{\partial z}\left(x, y, L_{3}\right)=0$ \\
$T\left(x, L_{2}, z\right)=f(x, y)$
\end{tabular} & $\begin{array}{c}T(x, y, z)=\sum_{m=1}^{\infty} \sum_{n=1}^{\infty} a_{m n} \operatorname{sen}\left(\frac{m \pi}{L_{1}} x\right) \operatorname{sen}\left(\frac{n \pi}{L_{2}} y\right) \frac{\cosh \left(\lambda_{m, n} z\right)}{\cosh \left(\lambda_{m, n} L_{3}\right)} \\
a_{m n}=\frac{4}{L_{1} L_{2}} \int_{0}^{L_{2}} \int_{0}^{L_{1}} f(x, y) \operatorname{sen}\left(\frac{m \pi}{L_{2}} y\right) \operatorname{sen}\left(\frac{n \pi}{L_{1}} x\right) d y d x \\
\lambda_{m, n}=\pi \sqrt{\left(\frac{m}{L_{2}}\right)^{2}+\left(\frac{n}{L_{3}}\right)^{2}}\end{array}$ \\
\hline $\begin{array}{l}\mathrm{k} \nabla^{2} \mathrm{~T}+\mathrm{q} \\
=\frac{\partial^{2} T}{\partial x^{2}}+\frac{q}{k}=0\end{array}$ & $\begin{array}{l}T(0)=T_{1} \\
T(L)=T_{2}\end{array}$ & $T(x)=-\frac{q}{2 k} x^{2}+\frac{T_{2}-T_{1}}{L} x+\frac{q L}{2 k} x+T_{1}$ \\
\hline $\begin{array}{l}\mathrm{k} \nabla^{2} \mathrm{~T}+\mathrm{q} \\
=\frac{\partial^{2} T}{\partial x^{2}}+\frac{\partial^{2} T}{\partial y^{2}} \\
+\frac{q}{k}=0\end{array}$ & $\begin{aligned} T(0, y) & =0 \\
T\left(L_{1}, y\right) & =0 \\
T(x, 0) & =0 \\
T\left(x, L_{2}\right) & =f(x)\end{aligned}$ & $\begin{array}{c}T(x, y)=\sum_{n=1}^{\infty} a_{n} \operatorname{sen}\left(\frac{n \pi}{L_{1}} x\right) \cdot \operatorname{senh}(\emptyset y) \\
a_{n}=\frac{2}{L_{1}} \frac{\int_{0}^{L_{1}} f(x) \operatorname{sen}\left(\frac{n \pi}{L_{1}} x\right) d x}{\begin{array}{c}\operatorname{senh}\left(\varnothing L_{2}\right) \\
\emptyset^{2}=\frac{q}{k}+\lambda^{2}\end{array}}\end{array}$ \\
\hline $\begin{array}{l}\mathrm{k} \nabla^{2} \mathrm{~T}+\mathrm{q} \\
=\frac{\partial^{2} T}{\partial x^{2}}+\frac{\partial^{2} T}{\partial y^{2}} \\
+\frac{q}{k}=0\end{array}$ & $\begin{array}{l}T\left(L_{1}, y\right)=T_{\infty} \\
T\left(x, L_{2}\right)=T_{\infty} \\
\frac{d T}{d y}(x, 0)=0 \\
\frac{d T}{d x}(0, y)=0\end{array}$ & $\begin{array}{c}T(x, y)=T_{\infty}+\frac{q L_{1}^{2}}{2 k}\left[1-\left(\frac{x}{L}\right)^{2}\right]-2 \sum_{n=0}^{\infty} \frac{(-1)^{n}}{\left(\lambda_{n} L_{1}\right)^{3}} \frac{\cosh \lambda_{n} y}{\cosh \lambda_{n} L_{2}} \cos \lambda_{n} x \\
\lambda_{n} L_{1}=\frac{(2 n+1) \pi}{2}\end{array}$ \\
\hline $\mathrm{k} \nabla^{2} \mathrm{~T}=\rho \mathrm{c} \frac{\partial T}{\partial t}$ & $\begin{array}{l}T(0, t)=0 \\
T(L, t)=0 \\
T(x, 0)=f(x)\end{array}$ & $\begin{array}{c}T(x, t)=\sum_{n=1}^{\infty} \frac{2}{L} \int_{0}^{L}\left(f(x) \operatorname{sen}\left(\frac{n \pi}{L} x\right) d x\right) \operatorname{sen}\left(\frac{n \pi}{L} x\right) \cdot e^{-\mu^{2} t} \\
\mu=\frac{\delta n \pi}{L} \\
\delta^{2}=\frac{k}{\rho c}\end{array}$ \\
\hline$\delta^{2} \frac{\partial^{2} T}{\partial x^{2}}=\frac{\partial T}{\partial t}$ & $\begin{aligned} T(0, t) & =T_{1} \\
T(L, t) & =T_{2} \\
T(x, 0) & =f(x)\end{aligned}$ & $T(x, t)=T_{E}(x)+\sum_{n=1}^{\infty} \frac{2}{L} \int_{0}^{L}\left[f(x)-T_{E}(x)\right] \operatorname{sen} \frac{n \pi x}{L} d x \operatorname{sen} \frac{n \pi x}{L} e^{-\delta^{2}\left(\frac{n \pi}{L}\right)^{2} t}$ \\
\hline
\end{tabular}




\begin{tabular}{|c|c|c|}
\hline $\begin{array}{l}k \nabla^{2} \mathrm{~T} \\
=\mathrm{k} \frac{\partial^{2} T}{\partial x^{2}}+k \frac{\partial^{2} T}{\partial y^{2}} \\
=\rho c \frac{\partial T}{\partial t}\end{array}$ & $\begin{array}{c}T(0, y, t)=0 \\
T\left(L_{1}, y, t\right)=0 \\
T(x, 0, t)=0 \\
T\left(x, L_{2}, t\right)=0 \\
T(x, y, 0)=f(x, z)\end{array}$ & $\begin{array}{c}T(x, y, t) \\
=\sum_{\substack{m=1 \\
\infty}}^{\infty} \sum_{n=1}^{\infty} \frac{4}{L_{1} L_{2}} \int_{0}^{L_{1}} \int_{0}^{L_{2}} f(x, z) \operatorname{sen}\left(\frac{m \pi}{L_{1}} x\right) \operatorname{sen}\left(\frac{n \pi}{L_{2}} y\right) d x d y \operatorname{sen}\left(\frac{m \pi}{L_{1}} x\right) \operatorname{sen}\left(\frac{n \pi}{L_{2}} y\right) e^{-\lambda^{2} \delta^{2} t} \\
\lambda=\pi \sqrt{\left(\frac{m}{L_{1}}\right)^{2}+\left(\frac{n}{L_{2}}\right)^{2}}\end{array}$ \\
\hline $\begin{array}{l}k \nabla^{2} \mathrm{~T} \\
=\mathrm{k} \frac{\partial^{2} T}{\partial x^{2}}+k \frac{\partial^{2} T}{\partial y^{2}} \\
=\rho c \frac{\partial T}{\partial t}\end{array}$ & $\begin{array}{c}\frac{\partial T}{\partial x}(0, y, t)=0 \\
\frac{\partial T}{\partial x}\left(L_{1}, y, t\right)=0 \\
T(x, 0, t)=0 \\
T\left(x, L_{2}, t\right)=0 \\
T(x, y, 0)=f(x, y)\end{array}$ & $\begin{array}{l}T(x, y, t) \\
=\sum_{m=1}^{\infty} \sum_{n=1}^{\infty} \frac{4}{L_{1} L_{2}} \int_{0}^{L_{1}} \int_{0}^{L_{2}} f(x, y) \cos \left(\frac{n \pi}{L_{1}} x\right) \operatorname{sen}\left(\frac{m \pi}{L_{2}} y\right) d x d y \cos \left(\frac{n \pi}{L_{1}} x\right) \operatorname{sen}\left(\frac{m \pi}{L_{2}} y\right) e^{-\lambda^{2} \delta^{2} t} \\
\text { Em que: } \\
\qquad \lambda=\pi \sqrt{\left(\frac{m}{L_{1}}\right)^{2}+\left(\frac{n}{L_{2}}\right)^{2}}\end{array}$ \\
\hline $\begin{array}{l}k \nabla^{2} \mathrm{~T} \\
=\mathrm{k} \frac{\partial^{2} T}{\partial x^{2}}+k \frac{\partial^{2} T}{\partial y^{2}} \\
+k \frac{\partial^{2} T}{\partial z^{2}} \\
=\rho c \frac{\partial T}{\partial t}\end{array}$ & $\begin{array}{l}\frac{\partial T}{\partial x}(0, y, z, t)=0 \\
\frac{\partial T}{\partial x}\left(L_{1}, y, z, t\right)=0 \\
\frac{\partial T}{\partial y}(x, 0, z, t)=0 \\
\frac{\partial T}{\partial y}\left(x, L_{2}, z, t\right)=0 \\
\frac{\partial T}{\partial z}(x, y, 0, t)=0 \\
\frac{\partial T}{\partial x}\left(x, y, L_{3}, t\right)=0 \\
T(x, y, z, 0) \\
\quad=f(x, y, z)\end{array}$ & $\begin{array}{l}\quad T(x, y, z, t)=\sum_{m=1}^{\infty} \sum_{n=1}^{\infty} \sum_{n=1}^{\infty} a_{n m l} \frac{4}{L_{1} L_{2}} \cos \left(\frac{n \pi}{L_{1}} x\right) \cos \left(\frac{m \pi}{L_{2}} y\right) \cos \left(\frac{l \pi}{L_{3}} z\right) e^{-\lambda^{2} \delta^{2} t} \\
\text { Em que: } \\
\qquad \lambda=\pi \sqrt{\left(\frac{m}{L_{1}}\right)^{2}+\left(\frac{n}{L_{2}}\right)^{2}+\left(\frac{l}{L_{1}}\right)^{2}} \\
a_{n m l}=\frac{\int_{0}^{L_{1}} \int_{0}^{L_{2}} \int_{0}^{L_{3}} f(x, y, z) \cos \left(\frac{n \pi}{L_{1}} x\right) \cos \left(\frac{m \pi}{L_{2}} y\right) \cos \left(\frac{l \pi}{L_{3}} z\right) d x d y d z}{\int_{0}^{L_{1}} \int_{0}^{L_{2}} \int_{0}^{L_{3}} f(x, y, z) \cos ^{2}\left(\frac{n \pi}{L_{1}} x\right) \cos ^{2}\left(\frac{m \pi}{L_{2}} y\right) \cos ^{2}\left(\frac{l \pi}{L_{3}} z\right) d x d y d z}\end{array}$ \\
\hline$\delta^{2} \nabla^{2} \mathrm{~T}+q=\frac{\partial T}{\partial t}$ & $\begin{array}{l}\frac{\partial T}{\partial x}(0, t)=0 \\
T(L, t)=T_{\infty}\end{array}$ & $T(x, t)=T_{\infty}+\frac{q L^{2}}{\delta^{2}}\left[\frac{1}{2}\left(1-\left(\frac{x}{L}\right)^{2}\right)-\sum_{n=0}^{\infty}-(-1)^{n} \frac{2}{\left(\lambda_{n} L\right)^{3}} \cos \left(\lambda_{n} x\right) e^{-\delta^{2} \lambda_{n}^{2} t}\right]$ \\
\hline $\begin{array}{l}\delta^{2} \nabla^{2} \mathrm{~T} \\
+\theta_{0} m e^{-m t} \\
=\frac{\partial T}{\partial t}\end{array}$ & $\begin{array}{l}T(0, t)=0 \\
\frac{\partial T}{\partial x}(L, t)=0\end{array}$ & $\begin{array}{c}T(x, t)=\sum_{n=1}^{\infty} c_{n}\left(e^{-\delta^{2} w_{n}^{2} t}-e^{-m t}\right) \operatorname{sen}\left(w_{n} x\right) \\
c_{n}=-\frac{\theta_{0} m d_{n}}{\delta^{2} w_{n}^{2}-m} \\
w_{n}=\frac{(2 n+1) \pi}{2 L}\end{array}$ \\
\hline
\end{tabular}




\section{APÊNDICE B - SOLUÇÕES PELO MDF PARA A EQUAÇÃO DO CALOR}

São mostradas na Tabela B.1 as soluções pelo MDF para a equação do calor completa e degenerada.

Tabela B.1 - Soluções para as equações do calor via MDF.

\begin{tabular}{|c|c|}
\hline$\frac{\partial^{2} T}{\partial x^{2}}=0$ & $T_{i}=\frac{T_{i+1}+T_{i-1}}{2}$ \\
\hline$\frac{\partial^{2} T}{\partial x^{2}}+\frac{\partial^{2} T}{\partial y^{2}}=0$ & $T_{i, j}=\frac{T_{i+1, \mathrm{j}}+T_{i-1, \mathrm{j}}+T_{i, j+1}+T_{i, j-1}}{4}$ \\
\hline$\frac{\partial^{2} T}{\partial x^{2}}+\frac{\partial^{2} T}{\partial y^{2}}+\frac{\partial^{2} T}{\partial z^{2}}=0$ & $T_{i, j, l}=\frac{T_{i+1, j, 1}+T_{i-1, j, 1}+T_{i, j+1, l}+T_{i, j-1, l}+T_{i, j, l+1}+T_{i, j, l-1}}{6}$ \\
\hline$k \frac{\partial^{2} T}{\partial x^{2}}+\mathrm{q}=0$ & $T_{i}=\frac{T_{i+1}-2 T_{i}+T_{i-1}+q l^{2} / k}{2}$ \\
\hline$\frac{\partial^{2} T}{\partial x^{2}}+\frac{\partial^{2} T}{\partial y^{2}}+\frac{q}{k}=0$ & $T_{i, j}=\frac{T_{i+1, \mathrm{j}}+T_{i-1, \mathrm{j}}+T_{i, j+1}+T_{i, j-1}+{ }^{2 l^{2}} / k}{4}$ \\
\hline $\begin{array}{r}\frac{\partial^{2} T}{\partial x^{2}}+\frac{\partial^{2} T}{\partial y^{2}}+\frac{\partial^{2} T}{\partial z^{2}}+\frac{q}{k} \\
=0\end{array}$ & $\begin{array}{l}T_{i, j, l} \\
=\frac{T_{i+1, j, l}+T_{i-1, j, l}+T_{i, j+1, l}+T_{i, j-1, l}+T_{i, j, l+1}+T_{i, j, l-1}+}{4} l^{2} / k\end{array}$ \\
\hline$k \frac{\partial^{2} T}{\partial x^{2}}=\rho c \frac{\partial T}{\partial t}$ & $\begin{array}{c}T_{i}^{\kappa+1}=\left(T_{i+1}^{\kappa}+T_{i-1}^{\kappa}\right) F+(1-2 F) T_{i}^{\kappa} \\
F=\frac{D \Delta t}{\Delta x^{2}}\end{array}$ \\
\hline$k \frac{\partial^{2} T}{\partial x^{2}}+k \frac{\partial^{2} T}{\partial y^{2}}=\rho c \frac{\partial T}{\partial t}$ & $\begin{array}{c}T_{i, j}^{\kappa+1}=\left(T_{i+1, j}^{\kappa}+T_{i-1, j}^{\kappa}+T_{i, j+1}^{\kappa}+T_{i, j-1}^{\kappa}\right) F+(1-4 F) T_{i, j}^{\kappa} \\
F=\frac{D \Delta t}{\Delta x^{2}}\end{array}$ \\
\hline $\begin{array}{l}k \frac{\partial^{2} T}{\partial x^{2}}+k \frac{\partial^{2} T}{\partial y^{2}}+\frac{\partial^{2} T}{\partial z^{2}} \\
=\rho c \frac{\partial T}{\partial t}\end{array}$ & 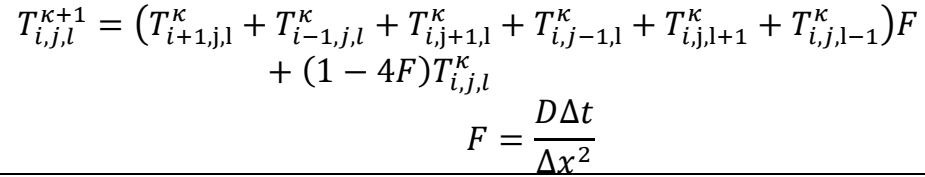 \\
\hline$k \frac{\partial^{2} T}{\partial x^{2}}+\frac{\partial \mathrm{q}}{\partial t}=\rho c \frac{\partial T}{\partial t}$ & $\begin{array}{c}T_{i}^{\kappa+1}=\left(T_{i+1}^{\kappa}+T_{i-1}^{\kappa}\right) F+(1-2 F) T_{i}^{\kappa}+G \\
F=\frac{D \Delta t}{\Delta x^{2}} \\
G=\frac{\mathrm{q}^{\kappa} \Delta x^{2} \Delta t}{\rho c}\end{array}$ \\
\hline $\begin{array}{l}k \frac{\partial^{2} T}{\partial x^{2}}+k \frac{\partial^{2} T}{\partial y^{2}}+\frac{\partial \mathrm{q}}{\partial t} \\
=\rho c \frac{\partial T}{\partial t}\end{array}$ & $\begin{array}{c}T_{i, j}^{\kappa+1}=\left(T_{i+1, j}^{\kappa}+T_{i-1, j}^{\kappa}+T_{i, j+1}^{\kappa}+T_{i, j-1}^{\kappa}\right) F+(1-4 F) T_{i, j}^{\kappa}+G \\
F=\frac{D \Delta t}{\Delta x^{2}} \\
G=\frac{\mathrm{q}^{\kappa} \Delta x^{2} \Delta t}{\rho c}\end{array}$ \\
\hline $\begin{array}{l}k \frac{\partial^{2} T}{\partial x^{2}}+k \frac{\partial^{2} T}{\partial y^{2}}+\frac{\partial^{2} T}{\partial z^{2}} \\
+\frac{\partial \mathrm{q}}{\partial t}=\rho c \frac{\partial T}{\partial t}\end{array}$ & $\begin{array}{c}T_{i}^{\kappa+1}=\left(T_{i+1, j, 1}^{K}+T_{i-1, j, l}^{K}+T_{i, j+1, l}^{K}+T_{i, j-1,1}^{K}+T_{i, j, 1+1}^{K}+T_{i, j, l-1}^{K}\right) F \\
+(1-6 F) T_{i}^{K}+G \\
F=\frac{D \Delta t}{\Delta x^{2}} \\
G=\frac{\mathrm{q}^{\kappa} \Delta x^{2} \Delta t}{\rho c}\end{array}$ \\
\hline
\end{tabular}




\section{APÊNDICE C - EFEITO TERMOMECÂNICO}

Neste item serão comparados resultados analíticos-numéricos para casos clássicos de vigas e placas, considerando apenas o efeito elástico com distintas CC e CI. Também será mostrado um estudo com o módulo de elasticidade variando com a temperatura.

\section{C.1 Viga biengastada}

Para análise termomecânica será analisada uma viga biengastada, Figura C.1, de comprimento $1,5 \mathrm{~m}$, espessura $0,1 \mathrm{~m}$, a qual está submetida a uma temperatura de $20^{\circ} \mathrm{C}$ na face inferior e $40^{\circ} \mathrm{C}$ na face superior. Pelo efeito físico de condução, há um gradiente de temperaturas no interior da viga, como mostra a Figura C.2 em análise térmica no ANSYS $A P D L$ através do elemento PLANE 55. Esse gradiente é analisado no ponto médio da viga, com relação ao eixo horizontal, em cinco pontos distintos, sendo as duas extremidades com temperaturas fixas, e três pontos no interior a partir da condução com diferentes temperaturas

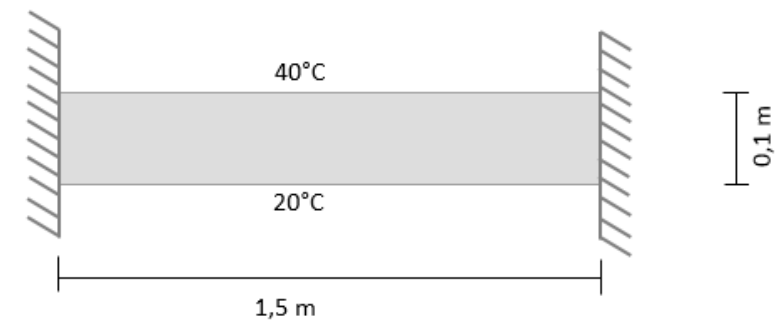

Figura C.1 - Viga biengastada analisada.

A temperatura de equilíbrio, $T(y)$, é dada pela Equação C.1:

$$
T(y)=A+\frac{B-A}{h} y
$$

Em que $h$ é a altura da viga, $A$ e $B$, são as temperaturas inferior e superior da viga, respectivamente.

Os resultados encontrados pelo ANSYS podem ser observados na Figura C.2, onde é mostrado o gradiente de temperatura e as temperaturas nos nós para a posição de $\mathrm{x}=0,75$ m. Para análise térmica foi utilizado o elemento PLANE 55 e para análise de tensões o elemento utilizado foi o PLANE 182, com uma malha de 0,025.

Os resultados são obtidos utilizando os seguintes valores para as propriedades:

- Coeficiente de dilatação térmica: $16,67 E-6 /{ }^{\circ} C$;

- Módulo de elasticidade de $210000 \mathrm{MPa}$; 
- $\quad$ Massa específica de $2388.00 \mathrm{Kg} \mathrm{m}^{3}$;

- Calor específico utilizado de 1105,00 $\mathrm{J} \mathrm{Kg}^{\circ} \mathrm{C}(1105,00 \mathrm{~J} \mathrm{Kg} \mathrm{K})$;

- Condutividade térmica de 6445,93 $\mathrm{J} \mathrm{mh}^{\circ} \mathrm{C}(1,79 \mathrm{~W} \mathrm{mK})$;

- Coeficiente de transferência de calor considerado concreto-ar de 50232,00 $\mathrm{J} \mathrm{m}^{2} \mathrm{~h}^{\circ} \mathrm{C}$ $\left(12 \mathrm{kcal} \mathrm{mh}{ }_{0} \mathrm{C}=13,95 \mathrm{~W} \mathrm{mK}\right)$;

- Coeficiente de Poisson 0,3.

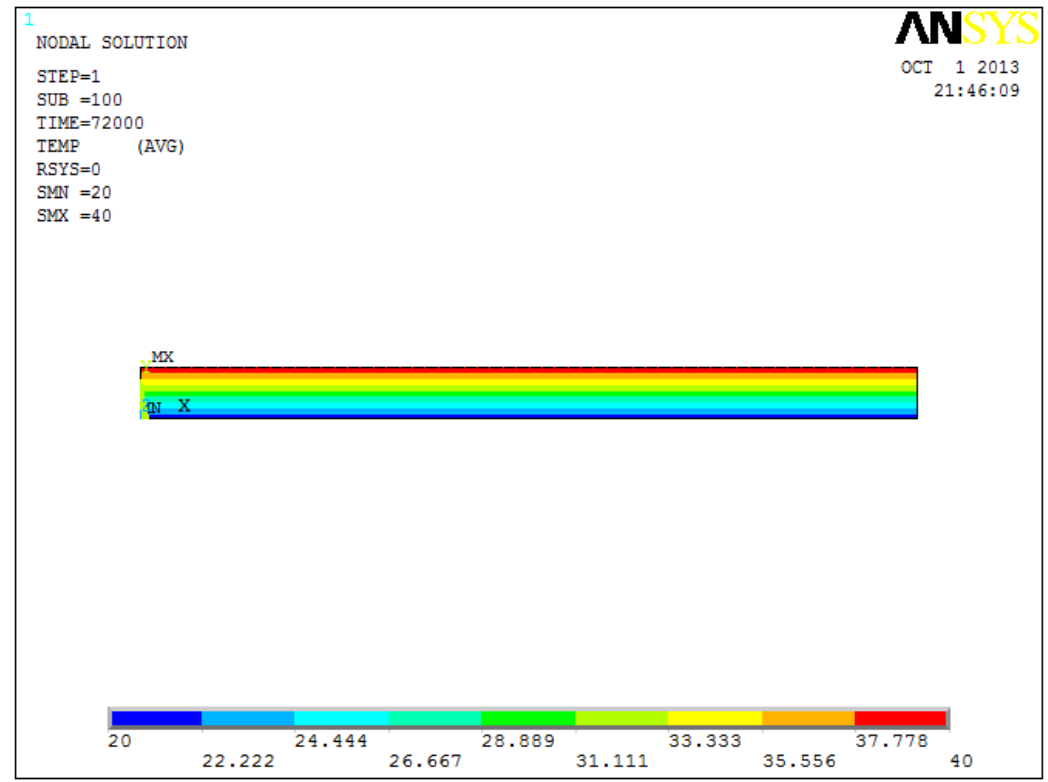

Figura C.2 - Resultado para análise térmica.

A Figura C.3 mostra a comparação entre os resultados analíticos e numéricos para a temperatura, nota-se que os resultados são idênticos, não há qualquer diferença entre os valores.

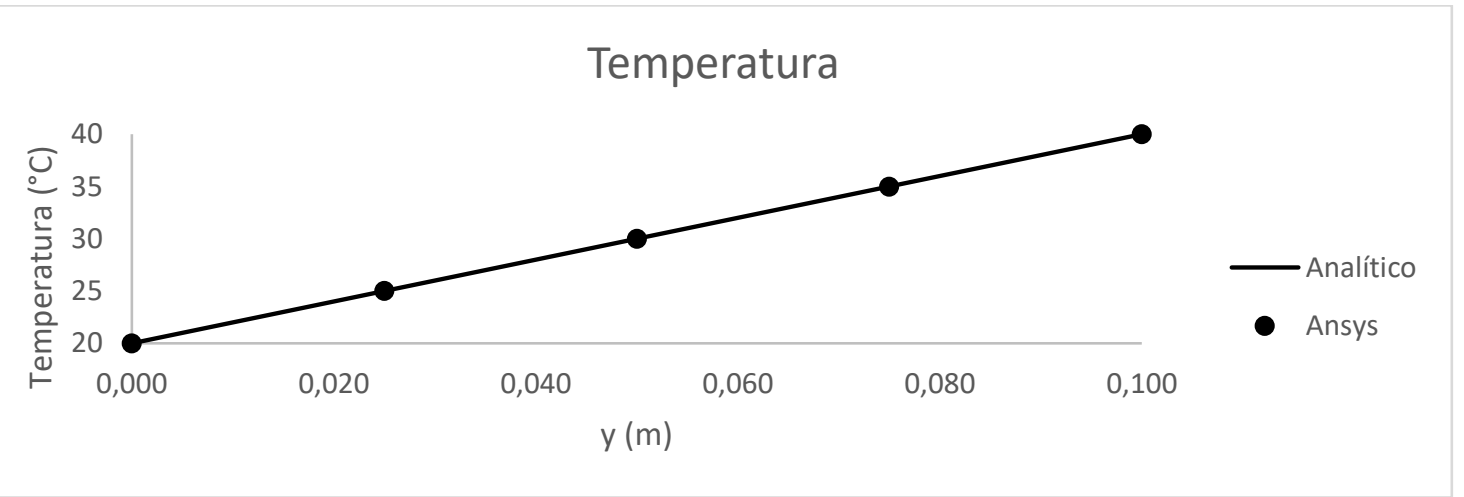

Figura C.3 - Comparação entre resultados analíticos e o ANSYS APDL para temperatura em viga biapoiada. 
Sabendo-se que a tensão, $\sigma$, é mostrada na Equação C.2:

$$
\sigma=-\alpha \times T(y) \times E
$$

Em que $\alpha$ é o coeficiente de dilatação térmica, $\Delta t$ a variação de temperatura e $E$ o módulo de elasticidade.

Os valores de tensão obtidos pelo ANSYS são mostrados na Figura C.4 para os mesmos nós da análise térmica mostrados na Figura C.2.

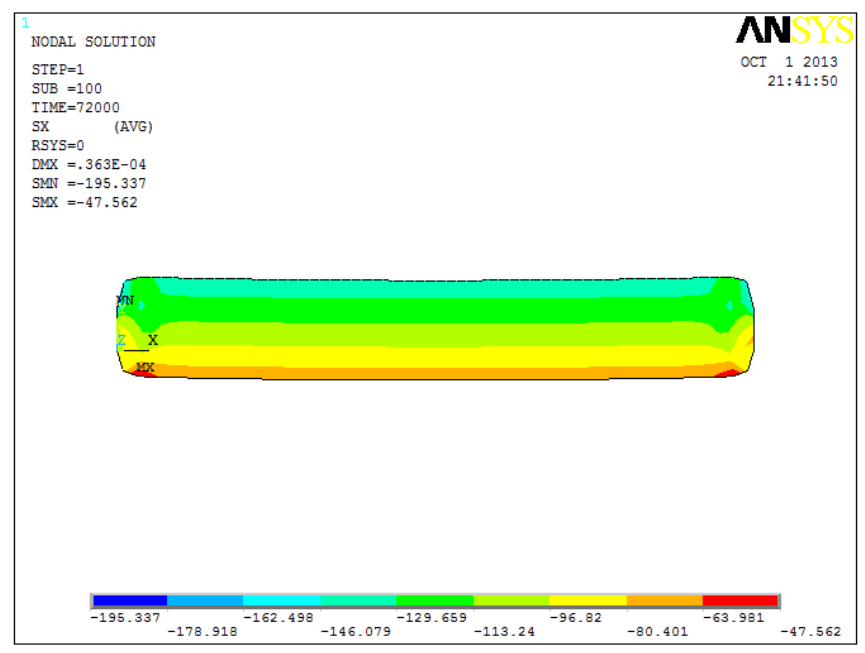

Figura C.4 - Análise termomecânica a partir do ANSYS.

Utilizando a equação C.2 e os resultados térmicos mostrados na Figura C.3, são indicados na Figura C.5 os resultados para análise termomecânica, ou seja, os resultados de tensão originadas a partir do gradiente térmico. Observa-se que a diferença entre os valores encontrados analiticamente e pelo MEF são insignificantes. Dessa forma, pode-se afirmar que o programa pode ser utilizado para esse tipo de análise de forma mais prática e rápida que os resultados analíticos.

\section{Análise Termomecânica}

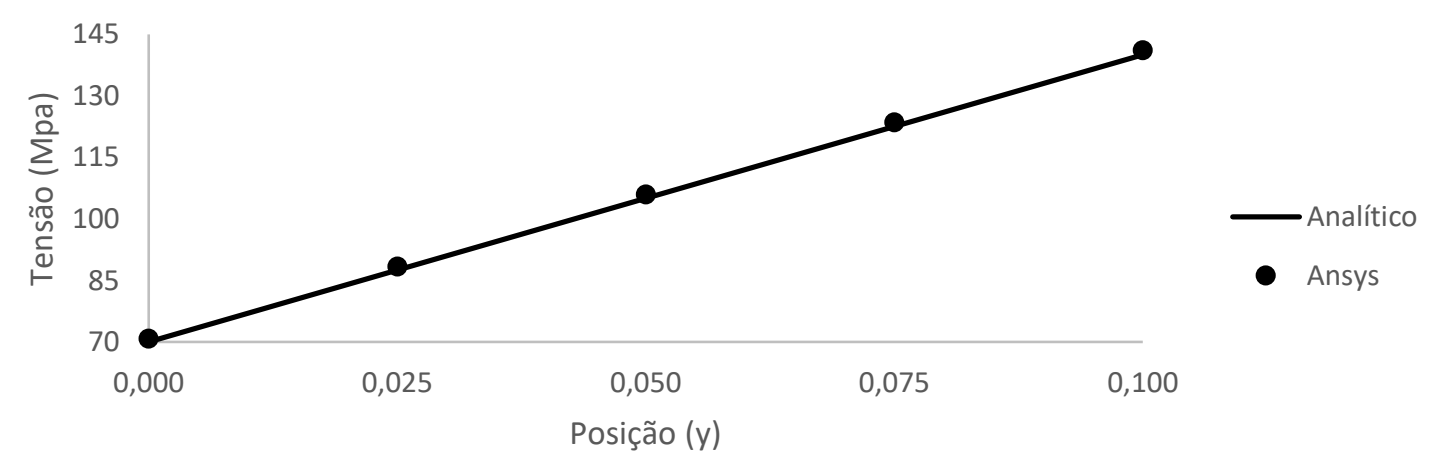

Figura C.5 - Comparação entre resultados analíticos e o ANSYS para tensão em viga biapoiada. 


\section{C.2 Viga com Geração de Calor Interno}

A fim de mostrar a correta utilização do programa do MEF, será representado neste tópico uma análise termomecânica para uma viga com distintas condições de contorno, para a qual as soluções analíticas são dadas por Hetnarski e Eslami (2009). A primeira verificação, será a térmica, em que a viga está com temperatura imposta $T_{1}$ e $T_{2}$, geração de calor interno $q$, e o eixo cartesiano se encontra no meio da extremidade esquerda. A Figura C.6 representa o problema bidimensional e a Equação C.3, mostra a solução dada.

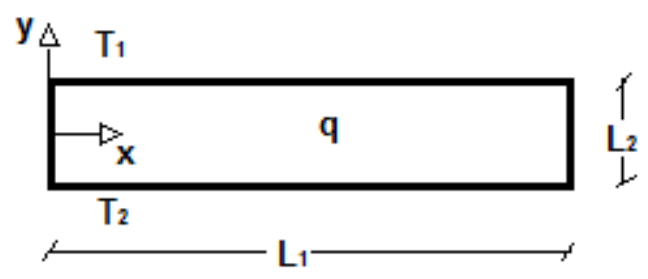

Figura C.6 - Viga retangular para análise térmica.

$$
T=\left(-\frac{q}{2 k}\right) y^{2}+\left(\frac{T_{1}-T_{2}}{L_{2}}\right) y+\left(\frac{T_{1}+T_{2}}{2}+\frac{q}{8 k} L_{2}^{2}\right)
$$

Utilizando-se os valores $T_{1}=100^{\circ} \mathrm{C}, T_{2}=0^{\circ} \mathrm{C}, L_{2}=0,5 \mathrm{~m}, L_{1}=1 \mathrm{~m}, q=200 \mathrm{~W} / \mathrm{m}^{3}$, obtem-se as isotermas de temperatura conforme a Figura C.7.

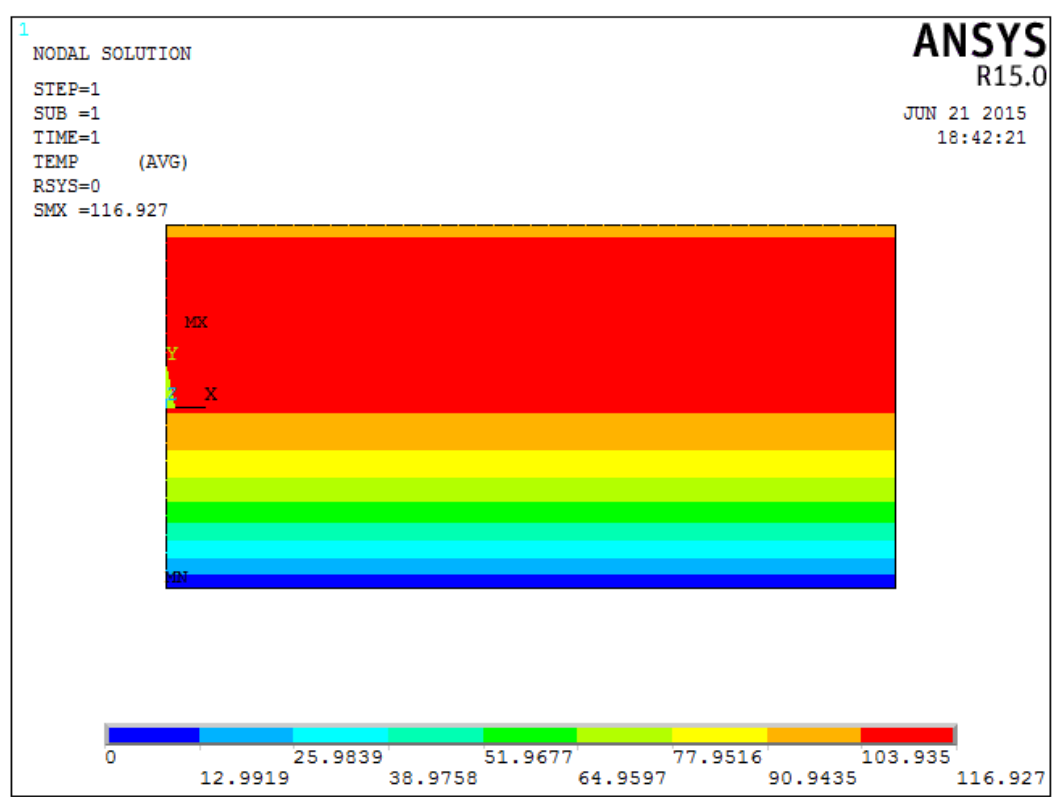

Figura C.7 - Isotermas de temperatura para viga retangular pelo MEF (ANSYS).

Comparando os resultados analíticos obtidos com os valores numéricos tem-se o gráfico da Figura C.8. Nota-se que não há distinção entre eles. 


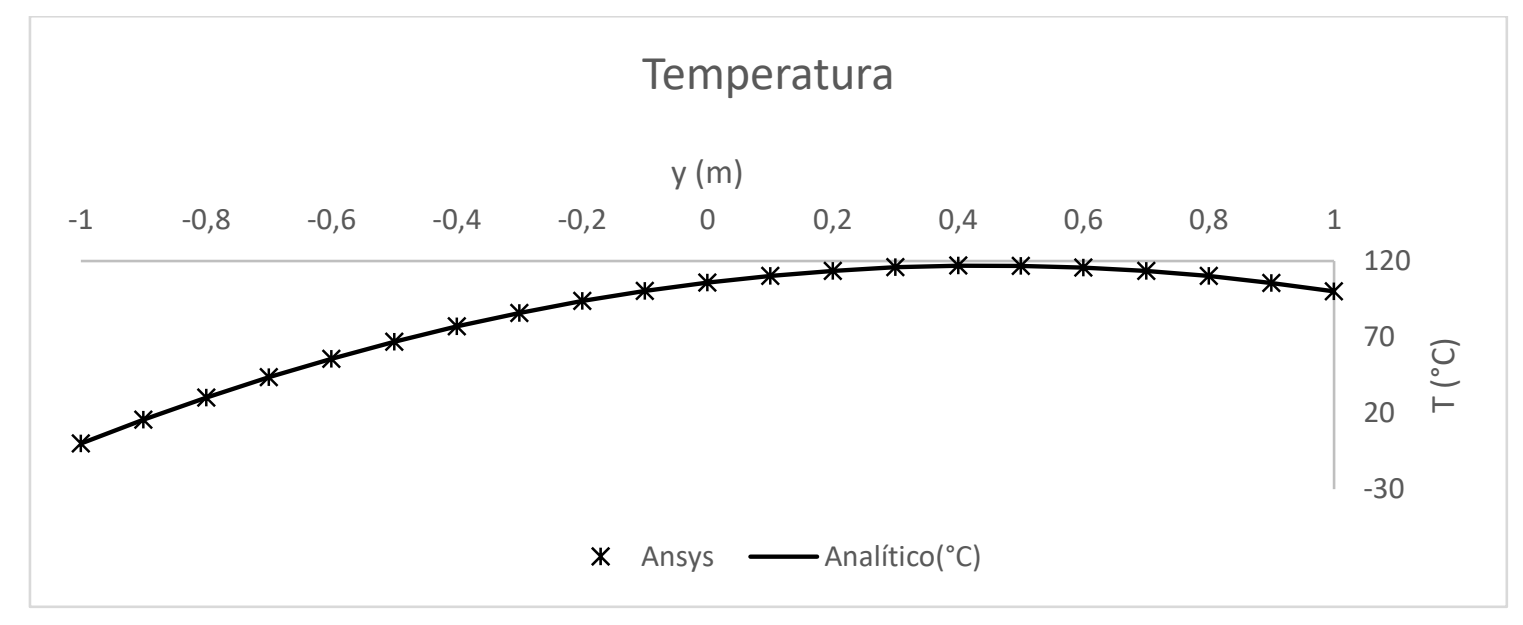

Figura C.8 - Comparação dos resultados térmicos entre o método analítico e o MEF (ANSYS).

Para a tensão, serão consideradas vigas engastadas em uma extremidade e três condições de contorno distintas na outra extremidade:

1. Extremidade apoiada - para $x=L_{1}$, a viga é simplesmente apoiada na direção de $y$, assim, a deformação e o momento nesta extremidade deve ser igual a zero:

$$
\begin{gathered}
\left.v\right|_{x=L_{1}}=0 \\
\left.M_{M_{y}}\right|_{x=L_{1}}=\left(-E I_{y} \frac{d^{2} v}{d x^{2}}-M_{T_{y}}\right)_{x=L_{1}}=0
\end{gathered}
$$

2. Extremidade engastada - para $x=L_{1}$, neste caso, a deformação e a deflexão nesta extremidade deve ser igual a zero:

$$
\begin{aligned}
& \left.v\right|_{x=L_{1}}=0 \\
& \left.\frac{d v}{d x}\right|_{x=L_{1}}=0
\end{aligned}
$$

3. Extremidade livre - para $x=L_{1}$, essa situação implica que a força e o cisalhamento neste ponto devam ser igual a zero:

$$
\begin{gathered}
\left.M_{M_{y}}\right|_{x=L_{1}}=\left(-E I_{y} \frac{d^{2} v}{d x^{2}}-M_{T_{y}}\right)_{x=L_{1}}=0 \\
Q_{x=L_{1}}=\left(\frac{d M_{M_{y}}}{d x}\right)_{x=L_{1}}=-\frac{d}{d x}\left(E I_{y} \frac{d^{2} v}{d x^{2}}\right)_{x=L_{1}}-\left(\frac{d M_{T y}}{d x}\right)_{x=L_{1}}=0
\end{gathered}
$$

Para a primeira C.C., representada pela Figura C.9, a tensão é dada pela Equação C.10. 


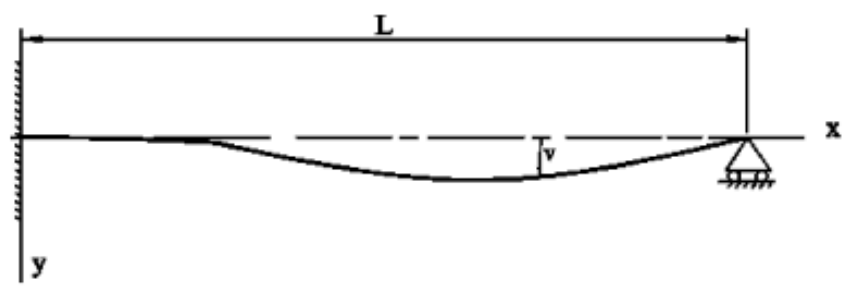

Figura C.9 - Viga com uma extremidade engastada e outra simplesmente apoiada (Hetnarski e Eslami, 2009).

$$
\sigma_{x x}=E \alpha\left[\frac{q}{2 k} y^{2}+\frac{3\left(T_{1}-T_{2}\right)}{2 L_{2} L_{1}} y x-\frac{3\left(T_{1}-T_{2}\right)}{2 L_{2}} y-\frac{q}{24 k} L_{2}{ }^{2}\right]
$$

Para aplicação, foram utilizadas as propriedades mecânicas mostradas a seguir, as demais são propriedades térmicas. Ressalta-se que esses valores foram utilizados em todos os exemplos.

- Módulo de elasticidade: $E=210000 \mathrm{MPa}$

- Coeficiente de dilatação térmica: $\alpha=7 \times 10^{-6} /{ }^{\circ} \mathrm{C}$

Assim, a solução pelo software é dada conforme a Figura C.10, e a comparação entre os resultados numéricos e analíticos para os pontos centrais em $x$, é mostrada no gráfico da Figura C.11.

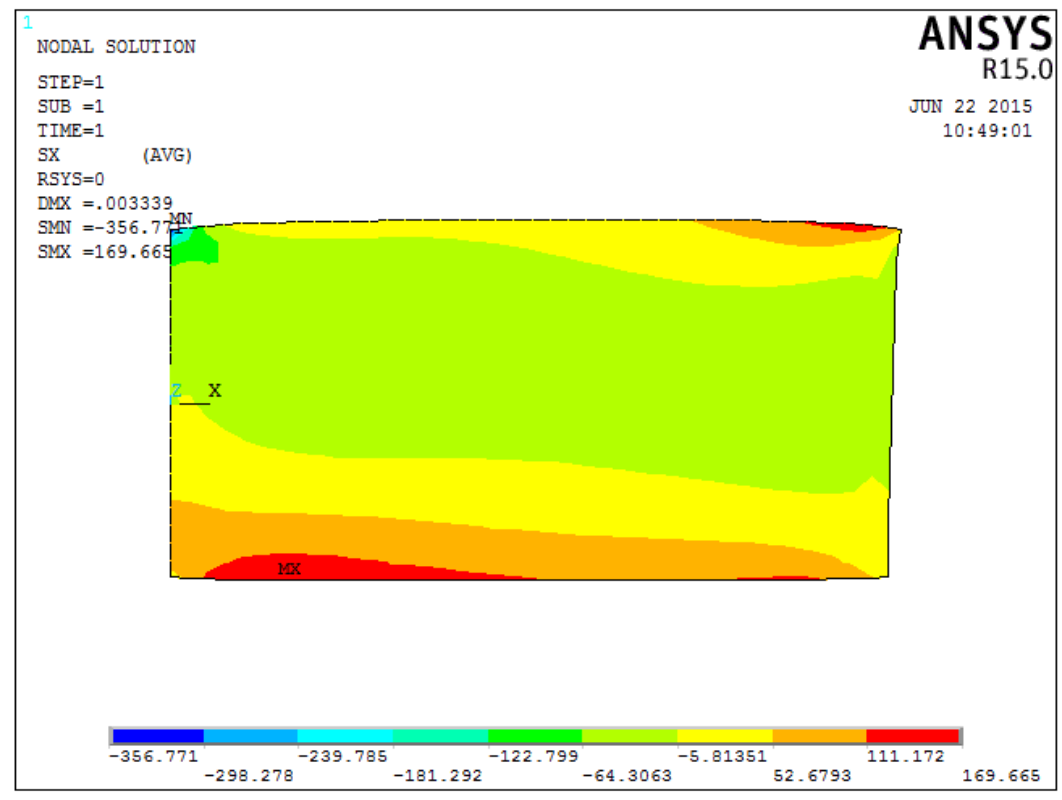

Figura C.10 - Análise pelo MEF (ANSYS) dos resultados termomecânicos para a viga engastada-apoiada. 


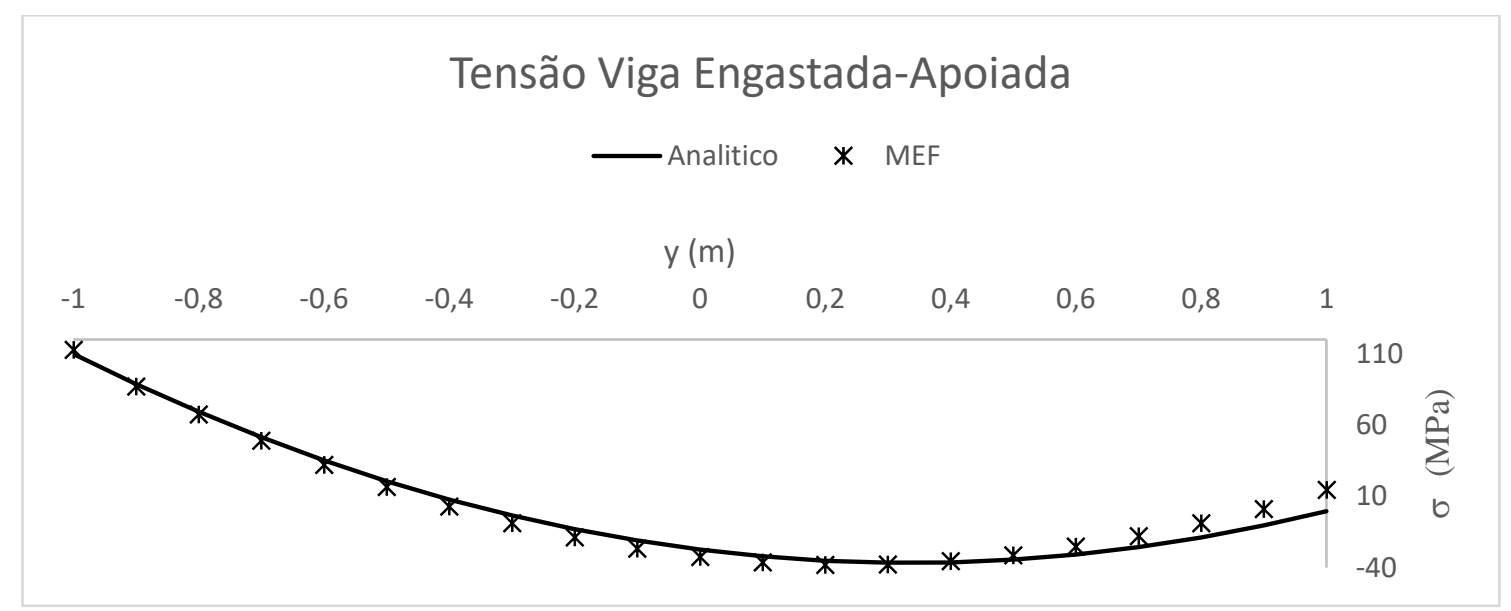

Figura C.11 - Comparação dos resultados mecânicos para a viga engastada-apoiada.

Na segunda hipótese, a viga é biengastada, Figura C.12, e a equação da tensão em $x$ é dada pela Equação C.11.

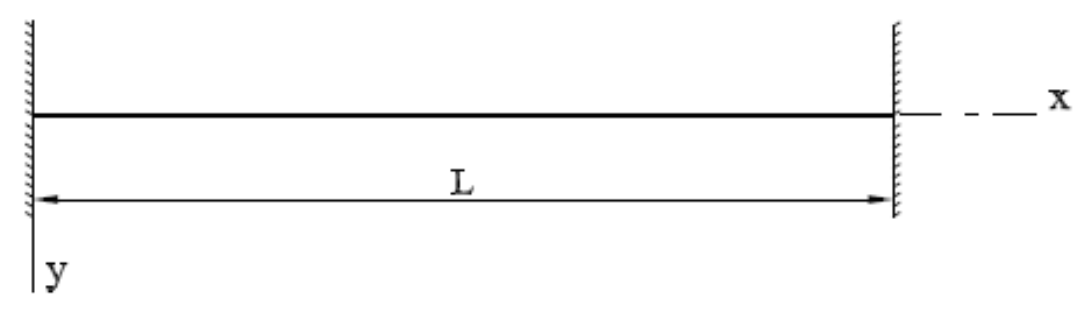

Figura C.12 - Viga biengastada (Hetnarski e Eslami, 2009).

$$
\sigma_{x x}=E \alpha\left[\frac{q}{2 k} y^{2}+\frac{T_{1}-T_{2}}{L_{2}} y+\frac{T_{1}+T_{2}}{2}-\frac{q}{8 k} L_{2}^{2}\right]
$$

Os resultados obtidos com o ANSYS podem ser vistos na Figura C.13 e a comparação com os pontos centrais de $x$ é mostrada na Figura C.14. Nota-se uma boa correlação dos dados.

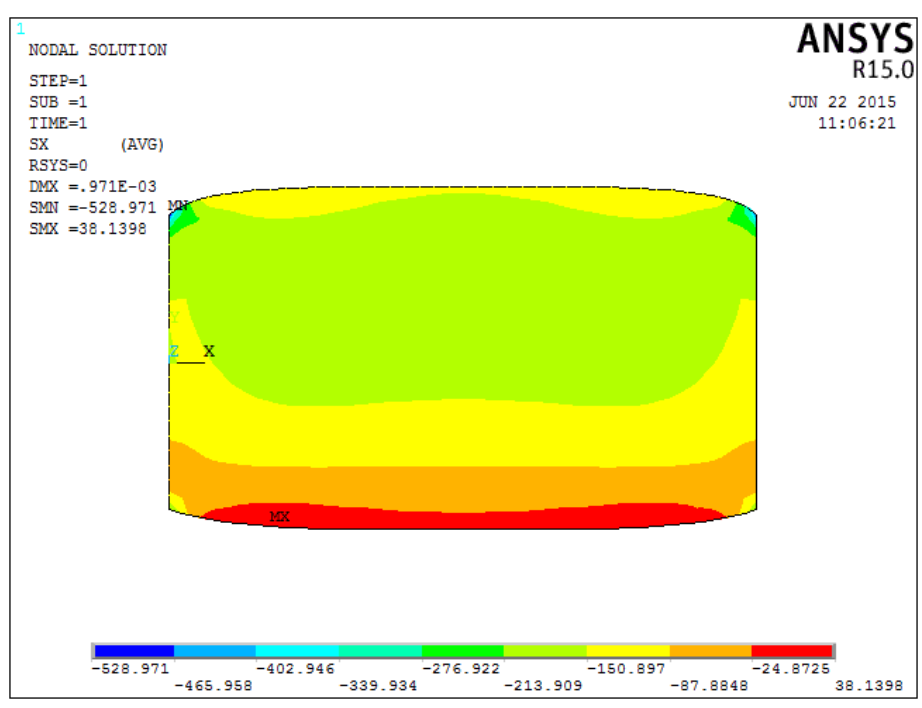

Figura C.13 - Análise pelo MEF (ANSYS) dos resultados termomecânicos para a viga biengastada. 


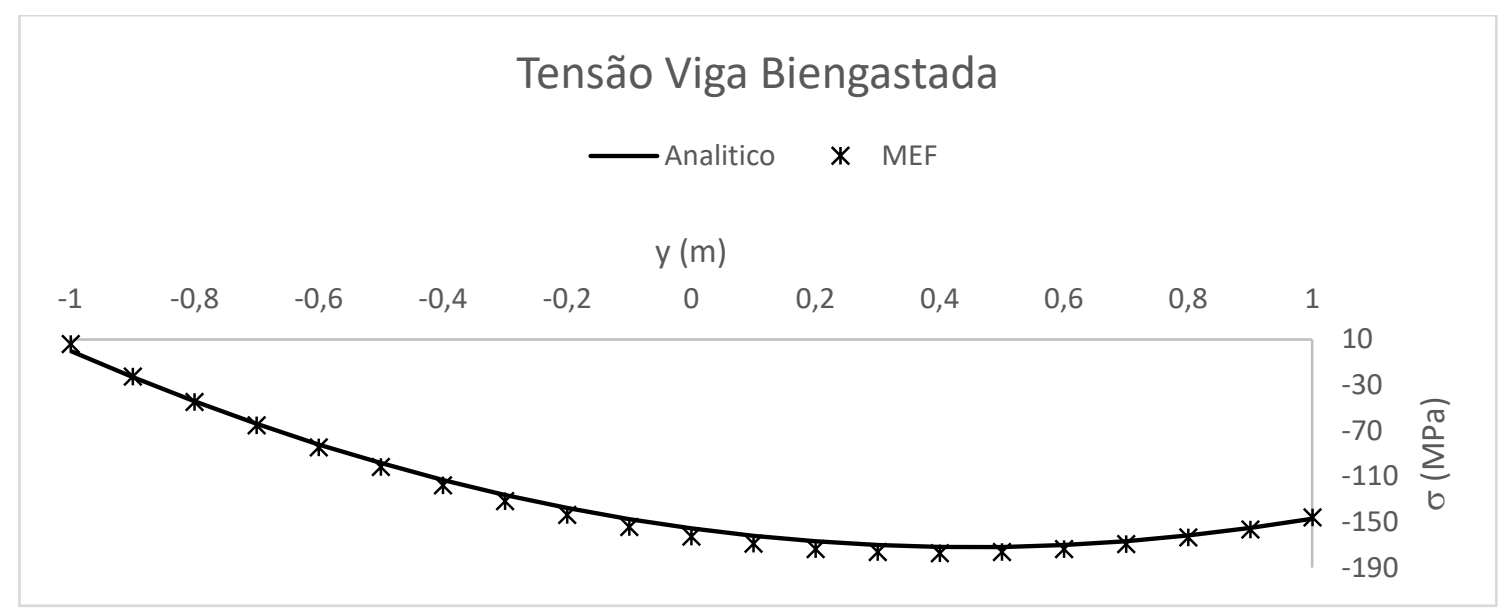

Figura C.14 - Comparação dos resultados mecânicos para a viga biengastada.

O último caso, refere-se a viga engastada e livre nas extremidades, Figura C.15, com a formulação que a representa evidenciada na Equação C.12.

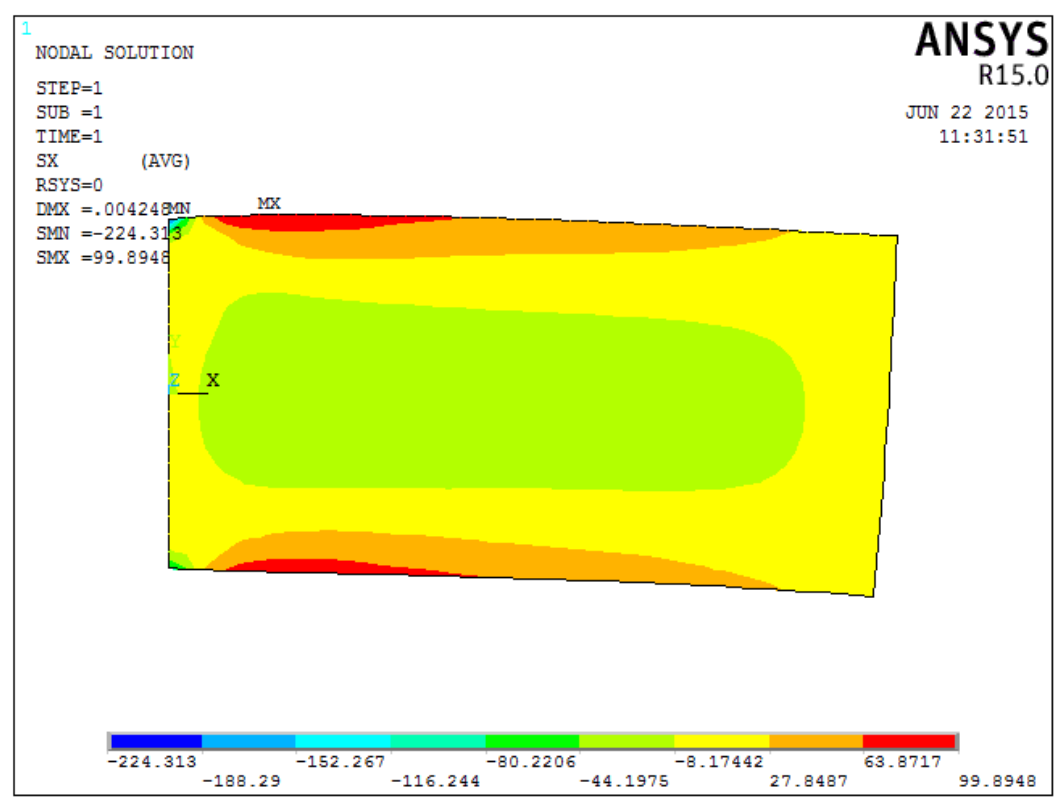

Figura C.15 - Análise pelo MEF (ANSYS) dos resultados termomecânicos para a viga engastada.

$$
\sigma_{x x}=E \alpha \frac{q}{8 k} L_{2}^{2}\left[\left(\frac{2 y}{L_{2}}\right)^{2}-\frac{1}{3}\right]
$$

A Figura C.16 compara os resultados analíticos e numéricos para a viga nos pontos centrais de $x$. 


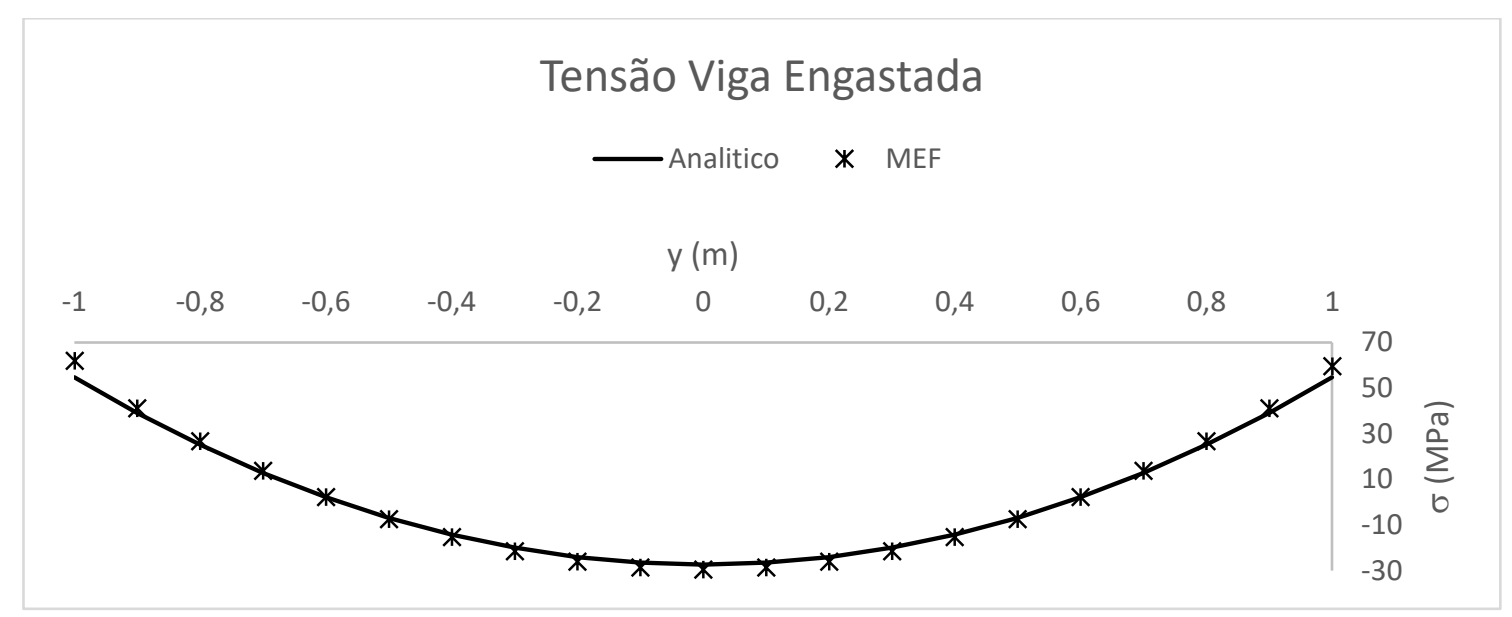

Figura C.16 - Comparação dos resultados mecânicos para a viga biengastada.

Diante de todos os resultados obtidos, evidencia-se boas respostas do programa utilizado em comparação com modelos analíticos, mostrando que o mesmo pode ser utilizado para análises termomecânicas simples e elásticas. A maioria dos problemas de engenharia são mais complexos, de difícil solução analítica. Porém, com o domínio sobre a ferramenta demonstrado, é possível fazer aplicações para conjunturas mais complicadas, pois, considera-se que havendo bons resultados nas situações mais simples, haverá também para as mais complicadas.

\section{C.3 Placa retangular}

Neste caso, foi considerada uma placa retangular com CC fixas sujeita a uma variação de calor não uniforme $\Delta \mathrm{T}$ conforme a Figura C.17, proposta por Szilard (2004).

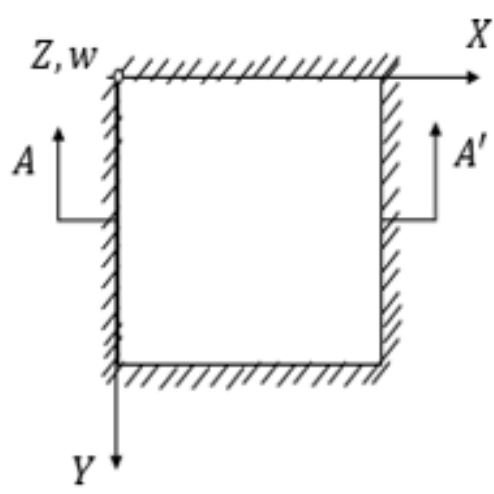

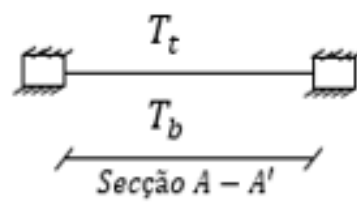

Caso A

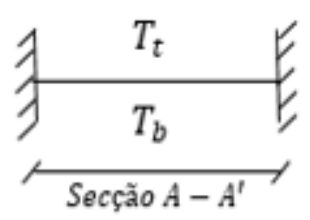

Caso B

$$
T_{t}>T_{b}
$$

Figura C.17 - Comparação dos resultados mecânicos para a viga biengastada.

Primeiro será considerado que as bordas da placa são livres para deslizar, mas restringida contra rotação, caso A. Em tal caso, temos uma condição similar à de flexão pura da placa 
por momentos distribuídos uniformemente. Neste caso, o momento na placa é dado pela Equação C.13.

$$
M=-\frac{D \alpha(\Delta T)}{h}(1+v)
$$

Sendo:

- $\quad M=$ Momento devido ao gradiente de temperatura $(\Delta T)$;

- $\quad D=\frac{E h^{3}}{12\left(1-v^{2}\right)}=$ Rigidez à flexão da placa;

- $E=$ Módulo de elasticidade;

- $\alpha=$ Coeficiente de expansão térmica;

- $h=$ Espessura da placa;

- $\quad v=$ Coeficiente de Poisson.

A máxima tensão correspondente $\left(\sigma_{\max , b}\right)$ é dada pela Equação C.14:

$$
\sigma_{\max , b}= \pm \frac{6 M}{h^{2}}
$$

Considerando no ANSYS Workbench um corpo de dimensões $(\mathrm{x}, \mathrm{y}, \mathrm{z})=(0.5,0.5,0.1)$, Figura C.17. Foram aplicadas as temperaturas $\mathrm{T}=0^{\circ} \mathrm{C} \mathrm{em} \mathrm{z}=0.0 \mathrm{~m} \mathrm{e} \mathrm{T}=100^{\circ} \mathrm{C} \mathrm{em} \mathrm{z}=0.1 \mathrm{~m}$. As isotermas de temperatura para o problema são mostradas na Figura C.18. Observa-se que as máximas temperaturas são dadas nos contornos, havendo uma distribuição uniforme.

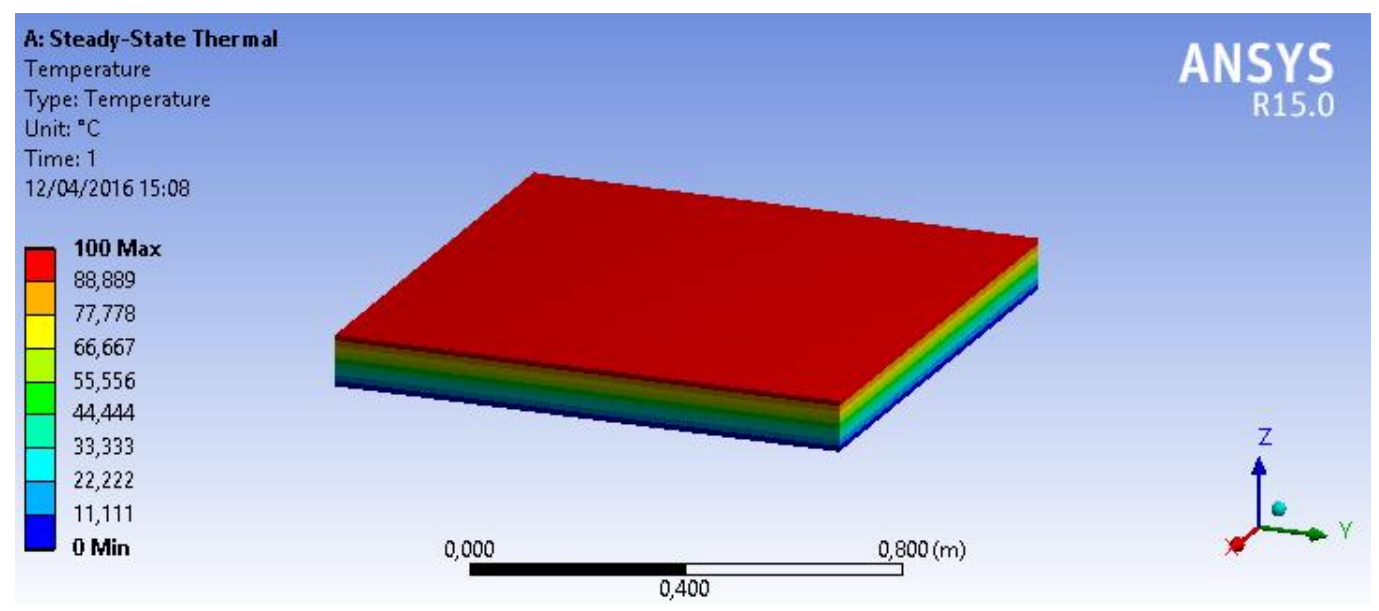

Figura C.18 - Resultados mecânicos para a viga biengastada. 
Havendo apenas a restrição de deslocamento em z, as máximas e mínimas tensões encontradas nos pontos centrais do corpo são \pm 9,4303E7 Pa. Utilizando as Equações C.13 e C.14, as tensões máximas são \pm 8,57E7 Pa, diferindo apenas em 9,0\%. O gráfico da Figura C.19, apresenta a distribuição das tensões (em Pa), eixo das abscissas, pela espessura (em m), eixo das ordenadas. A curva 'tensão calculada' representa as máximas tensões encontradas analiticamente, 'Tensão $X$ ' representa as tensões encontradas pelo programa ao longo da espessura e 'Tensão Z' as tensões na direção da espessura, estando livre para rotacionar, as tensões nesse eixo são nulas. Entretanto, as máximas tensões pelos métodos utilizados estão bem próximas.

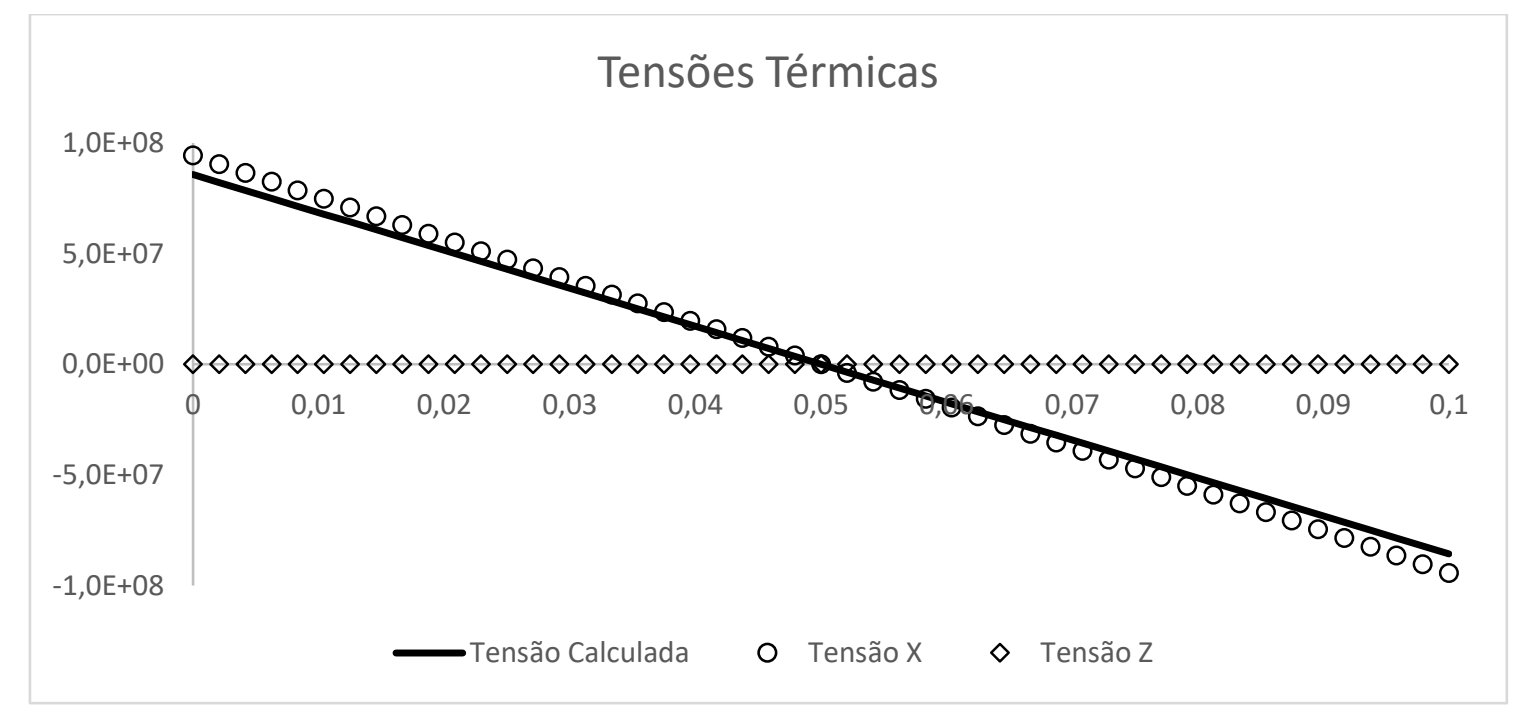

Figura C.19 - Comparação dos resultados mecânicos para a placa, Caso A.

Se as bordas também são impedidas de movimentos no plano, Caso B, as tensões produzidas nos planos X e Y, $\sigma_{x}$ e $\sigma_{y}$, são dadas pelas Equações C.15 e C.16.

$$
\begin{gathered}
\sigma_{x}=\frac{1}{h}\left(n_{r, x}-\frac{n_{T}}{1-v}\right)-\frac{\alpha E(\Delta T)}{1-v} \\
\sigma_{y}=\frac{1}{h}\left(n_{r, y}-\frac{n_{T}}{1-v}\right)-\frac{\alpha E(\Delta T)}{1-v}
\end{gathered}
$$

Em que:

$$
\begin{aligned}
& \text { - } n_{r, x}=-\frac{\partial n_{T, x}}{\partial x} ; n_{r, y}=-\frac{\partial n_{T, y}}{\partial y}=\text { Restrição de expansão da placa nas direções x e y; } \\
& \text { - } n_{T, x}=n_{T, y}=-\int_{-\frac{h}{2}}^{+\frac{h}{2}} \frac{\alpha E(\Delta T)}{1-v} d z=\text { Tensão térmica; }
\end{aligned}
$$


- $n_{T}=-\alpha E \int_{-\frac{h}{2}}^{+\frac{h}{2}} \Delta T d z=$ Resultante da tensão térmica.

Fazendo a simulação numérica para este caso, restringindo os movimentos nas três direções nas bordas da placa apresentada na Figura C.17, as tensões obtidas em $\mathrm{X}$ podem ser visualizadas na Figura C.20.

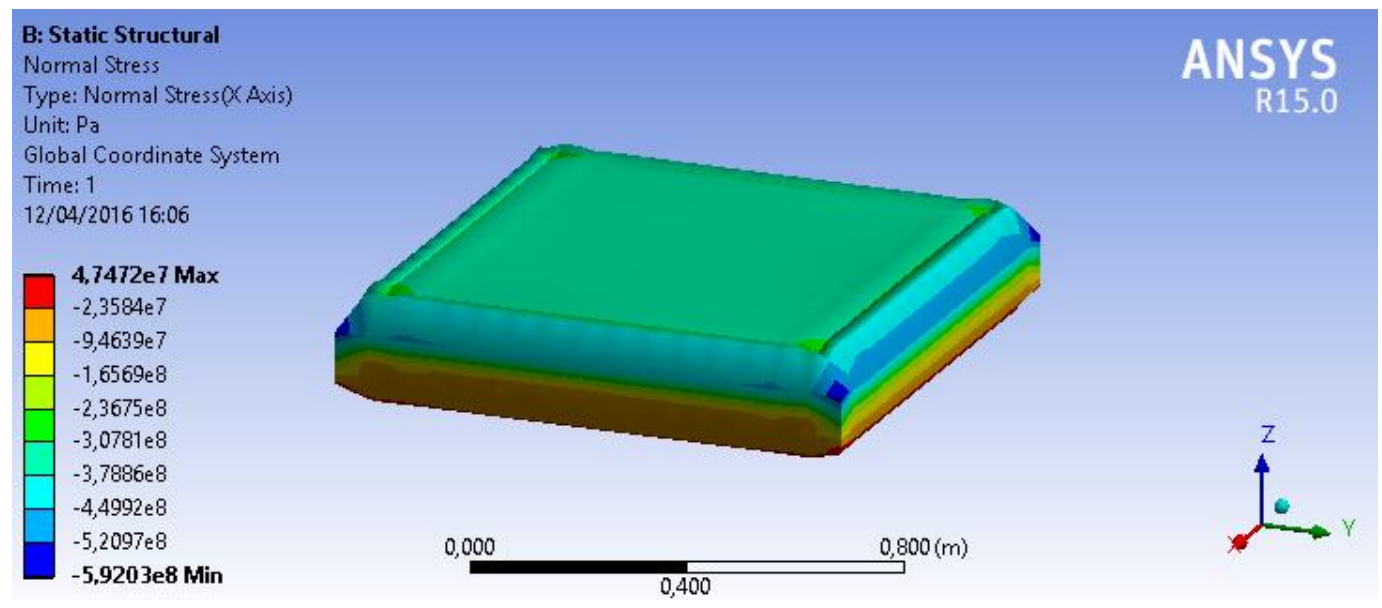

Figura C.20 - Resultados mecânicos para a placa engastada.

Comparando os resultados obtidos nos pontos centrais do plano com as Equações C.15 e C.16, esboçou-se o gráfico da Figura C.21. Tendo as tensões em Pa no eixo das abscissas e a espessura em m nas ordenadas, observa-se que em z a placa está livre, logo as tensões são nulas. Para x e y, há simetria nas restrições, então, os resultados são coincidentes, assim como também coincidem com os valores obtidos analiticamente.

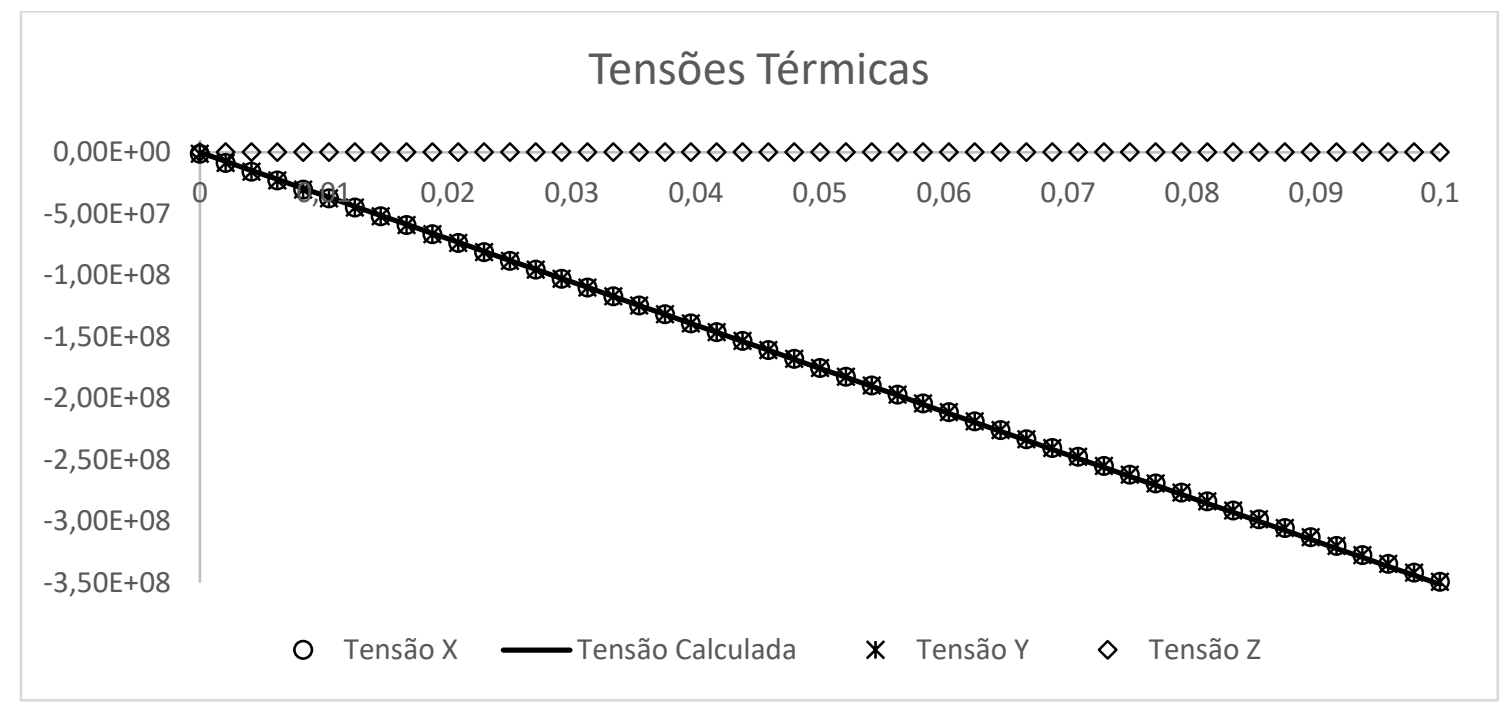

Figura C.21 - Comparação dos resultados mecânicos para a placa engastada, Caso B. 


\section{C.4 Placa retangular com módulo de elasticidade variando com a temperatura}

Para o exemplo mostrado no item 5.6.2, proposto por Bofang (2014), o módulo de elasticidade foi colocado em função da temperatura, de acordo com a Equação C.17:

$$
E(T)=E_{0}\left[1-\exp \left(-0,40 T^{0,34}\right)\right]
$$

Considerando-se $E_{0}=2 \times 10^{11} \mathrm{~Pa}$, e todas as outras propriedades iguais às demais utilizadas.

Assim, fazendo-se a comparação entre os resultados analíticos e numéricos das tensões nas direções de X, Y e Z, eixo das ordenadas, em função do tempo, eixo das abscissas, Figura C.22, observa-se uma boa compatibilidade dos resultados, mostrando o acerto na utilização do programa para problemas elásticos.

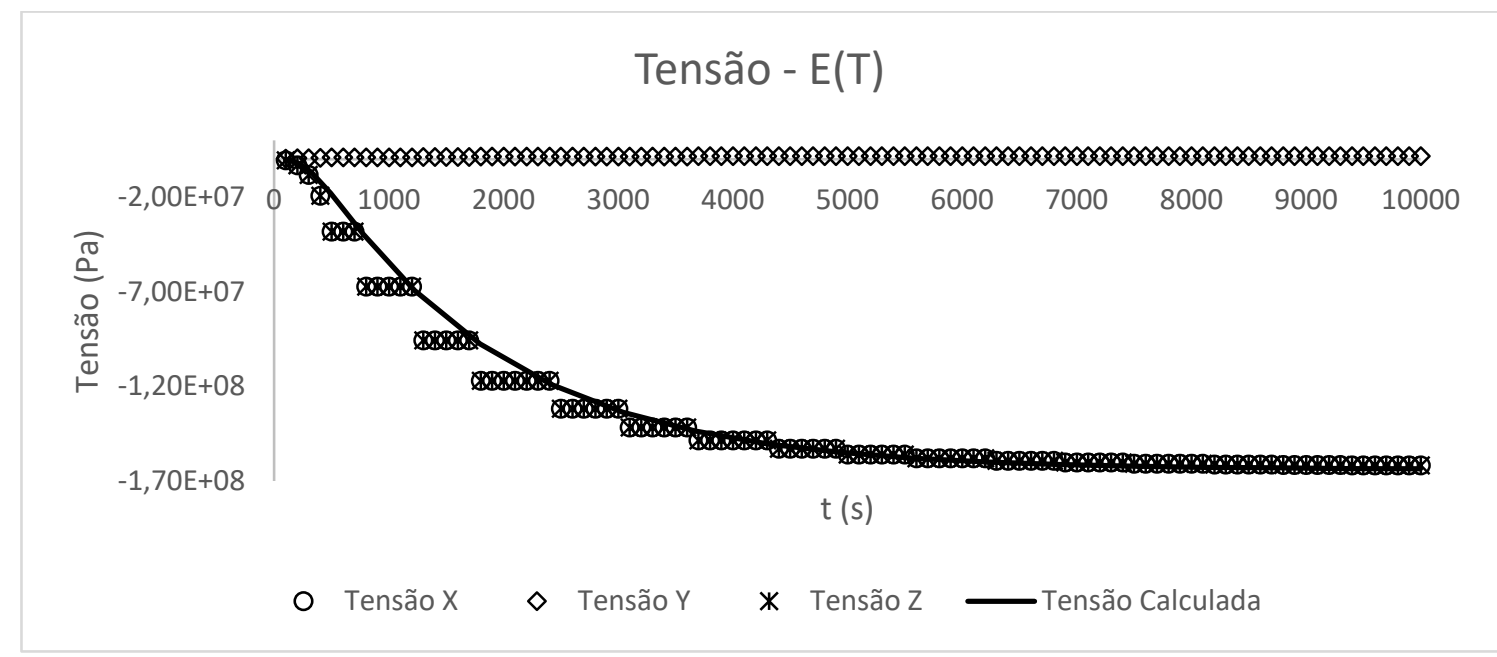

Figura C.22 - Comparação dos resultados mecânicos para a viga biengastada. 


\section{APÊNDICE D - COEFICIENTE DE RESTRIÇÃO}

Foi mostrado no item 2.3.1.1 uma formulação para o coeficiente de restrição. Porém, como exposto, as equações não condizem com os ábacos presentes no ACI 207-2r (2007) e USBR (1981). Com isso, através de um estudo empírico, sugere-se que para cada relação de L/H haja uma equação diferente, conforme mostrado na Tabela D.1.

Tabela D.1 - Equações para $\underline{k}_{r}$ com diferentes valores de L/H.

\begin{tabular}{|c|c|}
\hline $\mathrm{L} / \mathrm{H}$ & $K_{r}$ \\
\hline 20 & $\left(\frac{\frac{L}{H}-2,50}{\frac{L}{H}+1,00}\right)^{\prime}$ \\
\hline 10 & $\left(\frac{\frac{L}{H}-1,85}{\frac{L}{H}+1,00}\right)^{\prime}$ \\
\hline 8 & $\left(\frac{\frac{L}{H}-1,90}{\frac{L}{H}+1,00}\right)$ \\
\hline 6 & $\left(\frac{\frac{L}{H}-1,99}{\frac{L}{H}+1,00}\right)$ \\
\hline 5 & $\left(\frac{\frac{L}{H}-2,04}{\frac{L}{H}+1,00}\right)$ \\
\hline 4 & $\left(\frac{\frac{L}{H}-2,05}{\frac{L}{H}+1,00}\right)$ \\
\hline 3 & $\left(\frac{\frac{L}{H}-2,20}{\frac{L}{H}+1,00}\right)^{\prime}$ \\
\hline 2 & $\left(\frac{\frac{L}{H}-0,75}{\frac{L}{H}+10,00}\right)$ \\
\hline 1 & $\left(\frac{\frac{L}{H}-0,95}{\frac{L}{H}+10,00}\right)$ \\
\hline
\end{tabular}

Com as equações mostradas na Tabela D.1, foram elaborados os gráficos, curvas contínuas, e comparados com o ábaco do ACI 207-2R (2007), representado pelas curvas tracejadas na 
Figura D.1. Observa-se uma aproximação entre as curvas, entretanto, são necessários estudos mais embasados cientificamente para se chegar a exatidão das curvas utilizadas nas normas citadas.
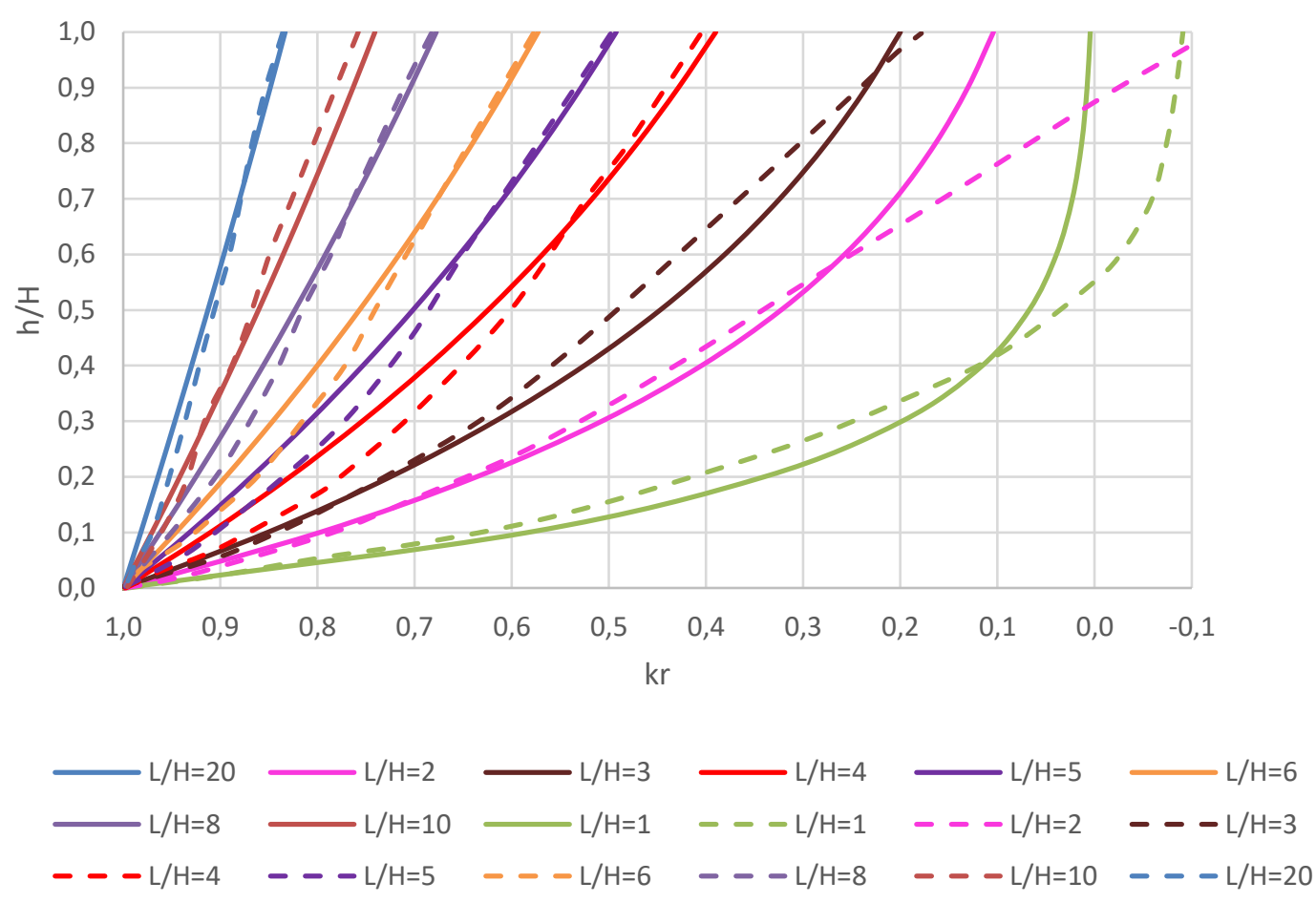

Figura D.1 - Comparação dos resultados mecânicos para a viga biengastada. 


\section{APÊNDICE E - INFLUÊNCIA DO PESO PRÓPRIO NO CÁLCULO DE TENSÕES}

Como mostrado no item 4.4, os cálculos das tensões expostas neste trabalho, desconsideram o efeito do peso próprio das estruturas. No entanto, este apêndice tem a finalidade de mostrar qual seria a contrição dos efeitos gravitacionais nas tensões de uma estrutura de concreto massa. O estudo mostrado aqui refere-se ao caso do muro de 3,0 m de altura, construído em três camadas, sendo cada uma de 1,0 m de altura, com intervalo de lançamento entre as camadas de $24 \mathrm{~h}$.

Para um elemento no interior do volume do corpo as tensões nas direções $\mathrm{x}, \mathrm{y} \mathrm{e} \mathrm{z}$, denominadas $\sigma_{\mathrm{x}}, \sigma_{\mathrm{y}}, \sigma_{\mathrm{z}}$ são representadas na Figura E.1.

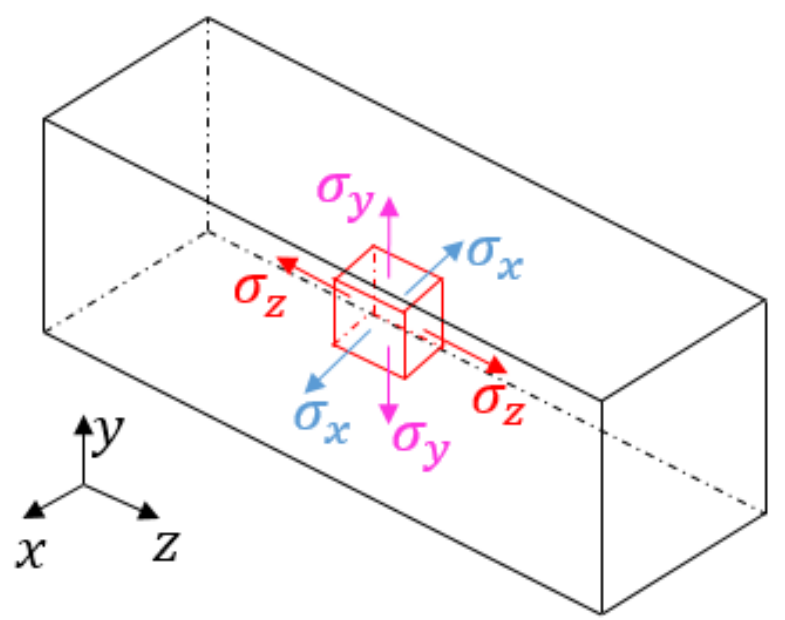

Figura E.1 - Tensões nas direções x, y e z para um elemento no interior de um volume.

De acordo com Beer et al (2009), as tensões multiaxiais, mostradas na Figura E.1, podem ser encontradas em função das deformações, $\varepsilon$, em suas respectivas direções com as Equações E.1, E.2 e E.3.

$$
\begin{aligned}
& \varepsilon_{x}=+\frac{\sigma_{x}}{E}-\frac{v \sigma_{y}}{E}-\frac{v \sigma_{z}}{E} \\
& \varepsilon_{y}=-\frac{v \sigma_{x}}{E}+\frac{\sigma_{y}}{E}-\frac{v \sigma_{z}}{E} \\
& \varepsilon_{z}=-\frac{v \sigma_{x}}{E}-\frac{v \sigma_{y}}{E}+\frac{\sigma_{z}}{E}
\end{aligned}
$$


Sendo:

- $\varepsilon_{x}, \varepsilon_{y}, \varepsilon_{z}=$ deformações nas direções, $\mathrm{x}, \mathrm{y}$ e $\mathrm{z}$;

- $\sigma_{x}, \sigma_{y}, \sigma_{z}=$ tensões nas direções, x, y e z;

- $\quad v=$ coeficiente de Poisson;

- $E=$ módulo de elasticidade.

Sabendo-se também que $\sigma=\varepsilon E$, e multiplicando as equações E.1, E.2 e E.3 por $E$, tem-se as equações E.4, E.5 e E.6.

$$
\begin{aligned}
& \sigma_{x}{ }^{*}=+\sigma_{x}-v \sigma_{y}-v \sigma_{z} \\
& \sigma_{y}{ }^{*}=-v \sigma_{x}+\sigma_{y}-v \sigma_{z} \\
& {\sigma_{z}}^{*}=-v \sigma_{x}-v \sigma_{y}+\sigma_{z}
\end{aligned}
$$

No caso em estudo, $\sigma^{*}$ representa as tensões totais. Sendo as tensões encontradas representadas longitudinalmente por z, Equação E.6, $\sigma_{z}{ }^{*}$ fornece as tensões longitudinais totais, $\sigma_{z}$, representa as tensões térmicas, $v \sigma_{y}$, representa a parcela do peso próprio na direção z, e $v \sigma_{x}$ será nulo, visto que não há nenhuma tensão aplicada nesta direção. Assim, a formulação de interesse é dada pela Equação E.7:

$$
\sigma_{z}^{*}=-v \sigma_{y}+\sigma_{z}
$$

A tensão em y, que considera o peso próprio, em um elemento unitário, é dada pela massa específica multiplicada pela dimensão que sobrepõe o ponto em estudo. Para o muro em camadas, conforme a Figura E.2, foram analisados os pontos PC1, PC2 e PC3, situados no ponto central de cada camada. 


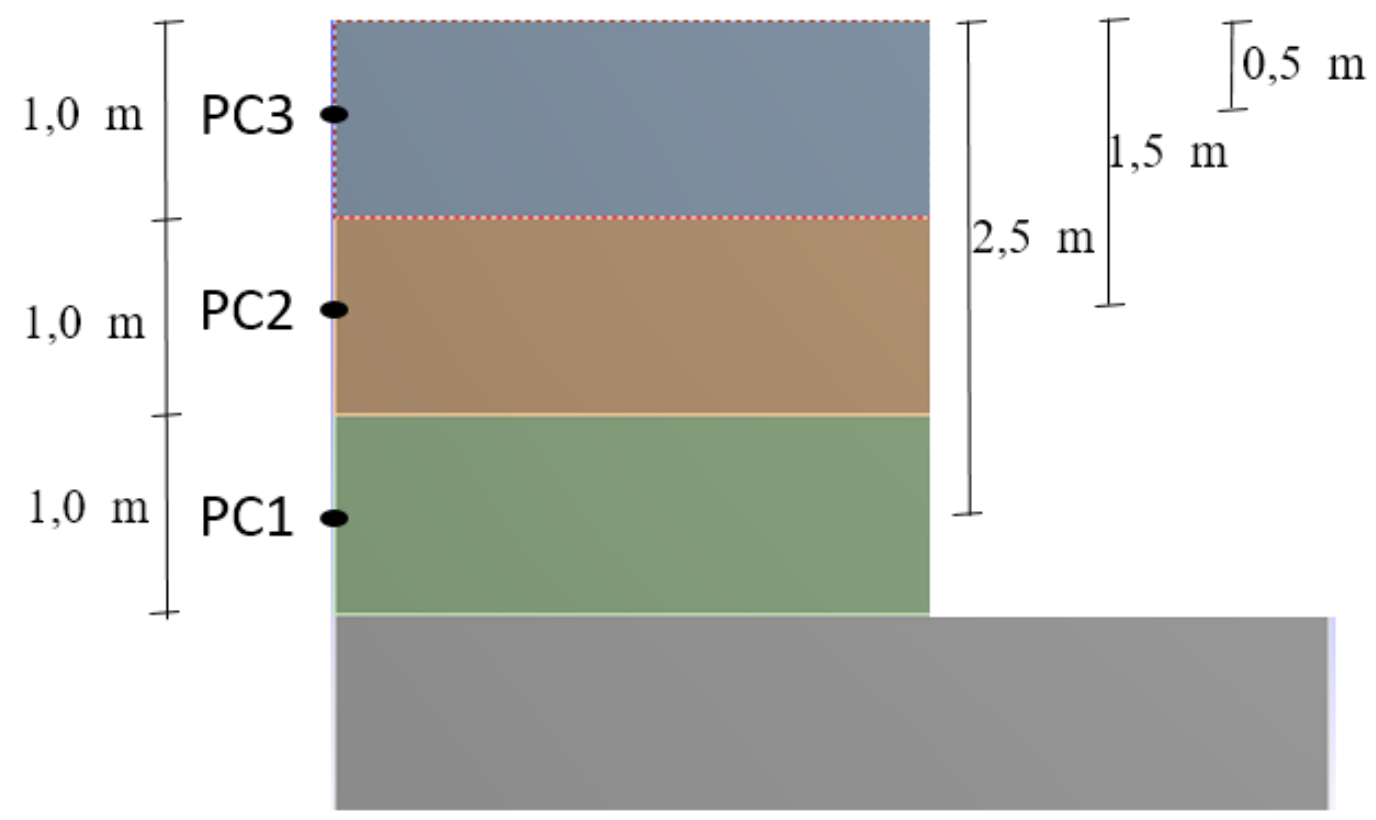

Figura E.2 - Estrutura e pontos analisados.

Sabendo-se que a massa específica do concreto utilizado foi de $2393 \mathrm{~kg} / \mathrm{m}^{3}$, fazendo a conversão de unidades para Pascal e multiplicando pelas alturas dos volumes acima dos pontos estudados, tem-se as tensões em PC1, PC2 e PC3, dadas pelas Equações E.8, E.9 e E.10.

$$
\begin{aligned}
& P C 1: \sigma_{y}=2393 \cdot 10 \cdot 2,5=59825 \mathrm{~Pa}=-0,06 \mathrm{MPa} \\
& P C 2: \sigma_{y}=2393 \cdot 10 \cdot 1,5=35895 \mathrm{~Pa}=-0,04 \mathrm{MPa} \\
& P C 3: \sigma_{y}=2393 \cdot 10 \cdot 0,5=11965 \mathrm{~Pa}=-0,01 \mathrm{MPa}
\end{aligned}
$$

Considerando-se o coeficiente de Poisson igual a 0,15, suas correspondentes tensões na direção z, são dadas conforme as Equações E.11, E.12 e E.13.

$$
\begin{aligned}
& P C 1: v \sigma_{y}=0,15 \cdot 0,06=-0,009 M p a \\
& P C 2: v \sigma_{y}=0,15 \cdot 0,04=-0,006 M p a \\
& P C 3: v \sigma_{y}=0,15 \cdot 0,01=-0,002 M p a
\end{aligned}
$$


O gráfico da Figura E.3 mostra as curvas da temperatura em função do tempo para os pontos PC1, PC2 e PC3, denominados TPC1, TPC2 e TPC3.

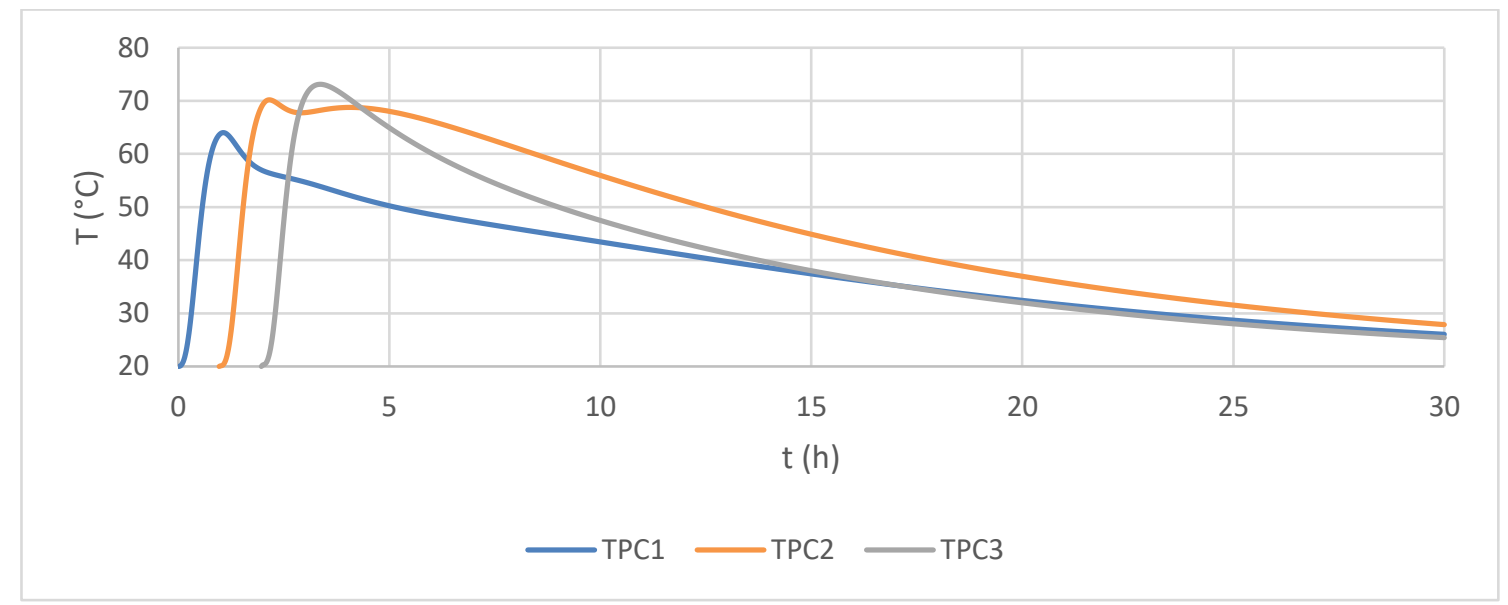

Figura E.3 - Temperaturas para os pontos PC1, PC2 e PC3.

Assim, pode-se calcular as tensões térmicas para os referidos pontos conforme o item 4.4, mostradas no gráfico da Figura E.4 como SPC1, SPC2 e SPC3. Aplicando-se os valores obtidos nas Equações E.11, E.12 e E.13 na Equação E.7, obtêm-se as curvas de tensões com a influência do peso próprio para os pontos em estudo, apresentados no gráfico da Figura E. 4 como SPC1*, SPC2* e SPC 3*. Nota-se que não há distinção entre as curvas de tensões com e sem o incremento do peso próprio para os mesmos pontos, isso pode ser explicado pelos baixos valores de tensões na direção longitudinal devido à gravidade. Dessa forma, afirma-se que a ação do peso próprio para as tensões longitudinais é desprezível em relação às tensões térmicas, portanto não há necessidade de acrescentá-las nos cálculos.

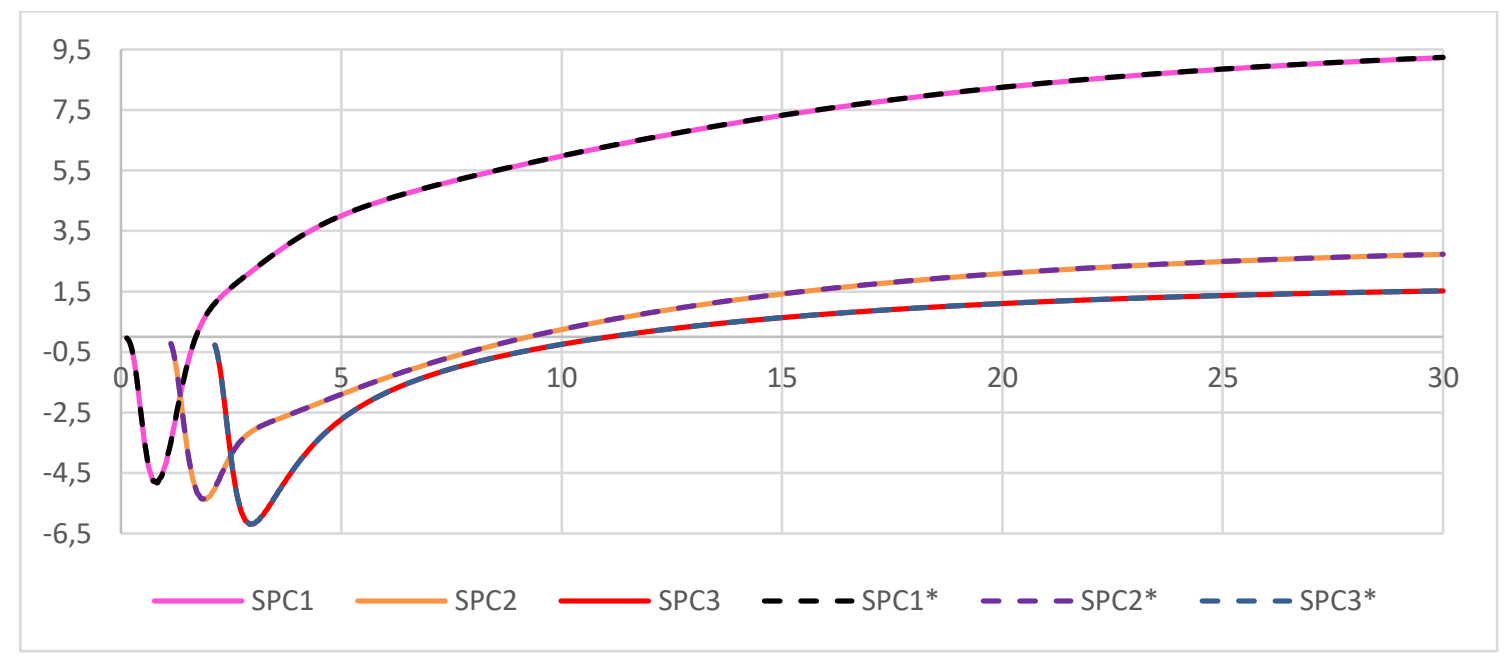

Figura E.4 - Tesões para os pontos PC1, PC2 e PC3. 